Portland State University

PDXScholar

$1-1-2011$

\title{
Governance in the United States Columbia River Basin: An Historical Analysis
}

Eric Thomas Mogren

Portland State University

Follow this and additional works at: https://pdxscholar.library.pdx.edu/open_access_etds Let us know how access to this document benefits you.

\section{Recommended Citation}

Mogren, Eric Thomas, "Governance in the United States Columbia River Basin: An Historical Analysis" (2011). Dissertations and Theses. Paper 48.

https://doi.org/10.15760/etd.48

This Dissertation is brought to you for free and open access. It has been accepted for inclusion in Dissertations and Theses by an authorized administrator of PDXScholar. Please contact us if we can make this document more accessible: pdxscholar@pdx.edu. 
Governance in the United States Columbia River Basin:

An Historical Analysis

by

Eric Thomas Mogren

A dissertation submitted in partial fulfillment of the requirements for the degree of

\author{
Doctor of Philosophy \\ in
}

Public Affairs and Policy

\author{
Dissertation Committee: \\ Craig W. Shinn, Chair \\ Veronica Dujon \\ Henry D. Kass \\ Douglas F.Morgan \\ Craig E.Wollner
}

Portland State University

(C)2011 


\begin{abstract}
Political and institutional leaders in the Pacific Northwest have struggled over how best to manage Columbia River Basin development and the implications of that development since the early 1900s. Their efforts present a seeming paradox: whereas prominent political and institutional leaders believed some form of regional governance system was necessary, those same leaders refused to establish systems with the decision-making authority necessary to resolve the issues that led them to create the systems in the first place. This study examines the historical record at the institutional level to determine why.

This study found twenty-six governance systems proposed since 1933 of which eleven were enacted. Prior to then, a private market oriented system dominated, assisted by supportive federal agencies with jurisdictional authority over individual resource domains. Since 1934, the Basin has experienced an unbroken succession of one governance system or another, at times with multiple systems operating in parallel. This study categorized each system under one of four governance models, distinguished by the locus of decision-making.

Transitions from one system to another came about through evolutionary processes or the emergence of circumstances that allowed for dramatic shifts between models. Evolutionary change within models resulted in collapse due to internal structural weaknesses or shifts to improved systems through mutual agreement. Dramatic change between models occurred when a "critical situation" appeared that called existing governance systems into question and allowed new systems to rise in
\end{abstract}


their place. Four such critical situations occurred between 1929 and 1999. These were the onset of the Depression, the end of World War II, the hydro-thermal crisis of the mid 1970s, and the first ESA listings of salmon in 1991.

This study concluded that the conflicting interests of powerful institutions only partially explain the Basin's governance paradox. Differing worldviews and senses of institutional culture, identity, and values aggravated the conflict over competing interests by shaping the perspectives each party held over the goals and motivations of the others. This study recommends further research to determine how institutional values translate into individual level decision-making. It offers a theoretical framework under which such research might proceed. 


\section{DEDICATION}

Dedicated to Craig Wollner 


\section{TABLE OF CONTENTS}

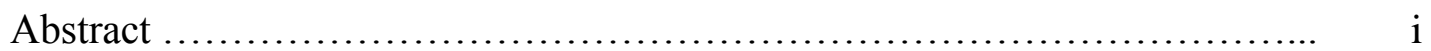

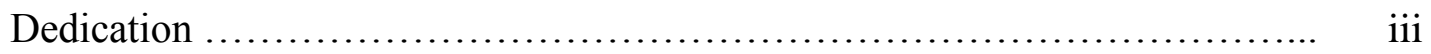

List of Tables ....................................................... vii

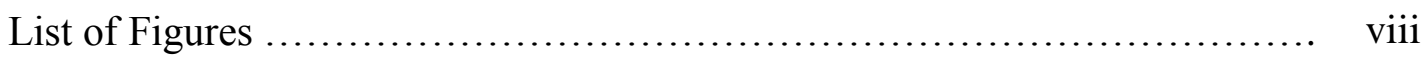

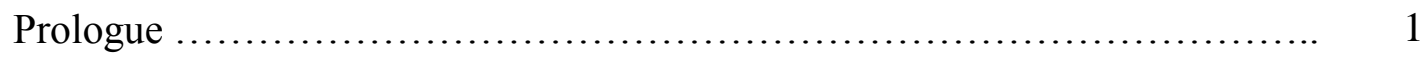

Chapter 1: Introduction to Basin Governance: The Rise and Collapse of the

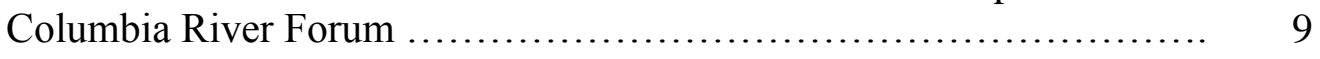

A Paradox in Governance? .......................................... 9

Institutional Background ..................................... 12

Establishment of the Columbia River Basin Forum ................... 20

The Memorandum of Agreement ............................... 26

The CRBF in Action .............................................. 31

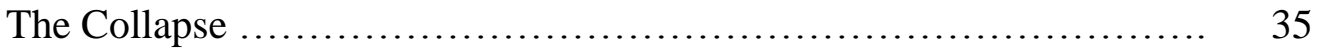

Challenges to Governance in the Columbia River Basin .............. 45

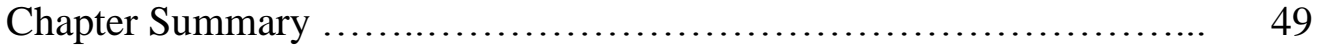

Chapter 2: Analytical Framework .................................... 53

Research Question, Purpose, and Relevance ......................... 53

Scope .......................................................... 58

Methodology .................................................... 59

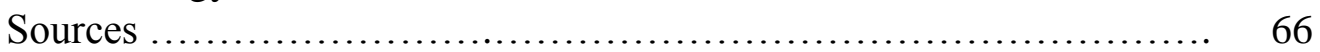

Literature Review ............................................. 70

Summary of Findings and Conclusions ......................... 79

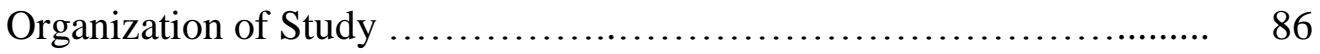

Chapter 3: Setting the Stage: The Columbia Basin Prior to 1929 ............... 89

Introduction .................................................. 89

Native Social Structures and the Tribal Worldview.................... 90

European Exploration and Anglo-American Settlement .................... 97

Regional Economic Development and the Anglo-American Worldview. 101

Regional Institutional Development ............................. 104

Early Signs of Stress on Northwest Resources ....................... 124

The Progressive Conservation Movement ............................ 126

Regional Governance Systems up to 1929 .......................... 130

Chapter Summary .............................................. 134 


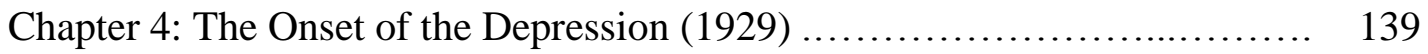

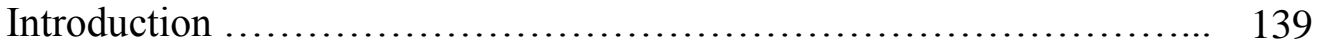

Social and Political Context ....................................... 141

Salient Issues in the Pacific Northwest ............................. 145

Resulting Governance Systems .............................................. 155

Chapter Summary ........................................... 170

Chapter 5: The End of World War II (1945) ................................ 175

Introduction ................................................. 175

Social and Political Context ................................... 178

Salient Issues in the Pacific Northwest .............................. 181

Resulting Governance Systems ............................................... 195

Chapter Summary .............................................. 216

Chapter 6: The Hydro-Thermal Crisis (1976) .................................. 220

Introduction ................................................ 220

Social and Political Context ...................................... 222

Salient Issues in the Pacific Northwest ............................ 232

Resulting Governance Systems ................................................ 251

Chapter Summary .............................................. 254

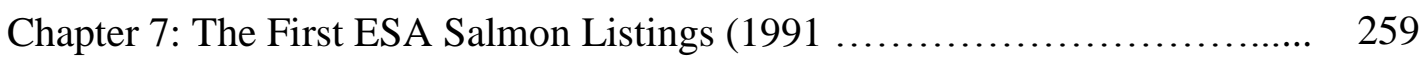

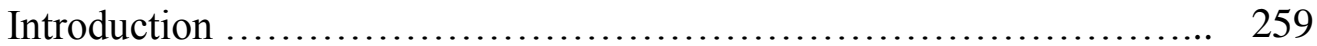

Social and Political Context .......................................... 264

Salient Issues in the Pacific Northwest ............................... 266

Resulting Governance Systems ............................................... 276

Chapter Summary .............................................. 290

Chapter 8: Findings, Analysis, and Conclusions ........................... 293

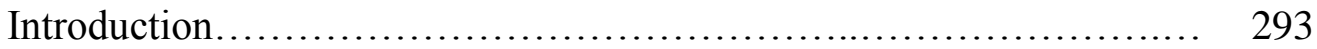

The Complexities of FCRPS Governance ........................... 295

The Role of Law and Legal Structure ............................... 311

Columbia Basin Governance Systems and Models .................... 319

Patterns of Change between Systems and Models ..................... 346

The Preference for Collaboration-Oriented Governance Systems ........ 357

Conclusions ..................................................... 364

Limitations of the Institutional Approach .......................... 377

Framework for Future Research .................................. 380

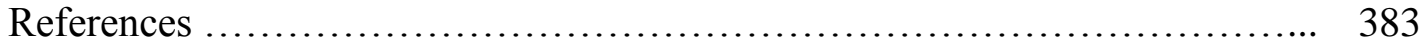


Appendices:

Appendix A: Expanded Literature Review ........................ 399

Appendix B: Theoretical Framework for Future Research ............. 457 


\section{LIST OF TABLES}

Number Title

8-1 Governance Systems under the Market Model.................. 324

8-2 Governance Systems under the Iron Triangle Model ........... 327

8-3 Governance Systems under the Valley Authority Model ......... 331

8-4 Governance Systems under the Federal Cooperation Model ..... 337

8-5 Governance Systems under the State Cooperation Model ....... 341

8-6 Governance Systems under the Three Sovereigns Model ........ 345 


\section{LIST OF FIGURES}

Number Title

P-1 Oregon Territory 1848 (Showing Current State Boundaries) ..... 3

P-2 Columbia River Basin (Showing Location of Major Dams) ..... 5

8-1 Governance Models, Systems, and Critical Situations .......... 352

8-2 Critical Situations, Context, Issues, Participants, and Systems ... 353

8-3 Traditional Lines of Tension in Columbia Basin Governance .... 354

8-4 The Historical Pattern of Basin Governance System

Establishment ..................................... 356

8-5 Generalized Model of Governance System Establishment ....... 376 


\section{PROLOGUE}

The Columbia River is international and interstate in geographic scope. It is over 1200 miles long, drawing its water from two countries, five states, and the reservation lands of thirteen Native American tribes. It drains a 258,000 square mile area encompassing parts of Oregon, Washington, Idaho, Montana, Wyoming, and Canada. It moves at an average stream flow of 265,000 cubic feet per second. It drops 2,650 feet in elevation from its source to mouth. The combination of elevation and flow provides the energy from which the hydropower system's electricity is drawn and constitutes a third of the nation's hydropower potential. It serves as a major transportation corridor, moving timber and agricultural products for distribution to west coast and Pacific Rim markets. Its water irrigates the farms of the arid areas between the Cascade and Rocky Mountain ranges (Ogden, 1949; White, 1995; DeLuna, 1997; Brigham, 1998; Pope, 2008).

Lang (1999) notes that two competing images of the Columbia River have existed since the first Euro Americans arrived. The first is the view of "the river as a spiritual force," the second as a "cornucopian provider of economic value" (p. 147). In more recent years, the conflicts between these two visions have been framed as a clash between regional icons: the Columbia Basin's sophisticated and technologically integrated system of multipurpose dams and its historic runs of wild salmon and steelhead. Within this debate, each icon serves as a metaphorical representative of broader economic, moral, aesthetic, and, in some cases, spiritual values regarding the 
social role of the river in particular and natural resources in general within the Northwest (White, 1995; Williams, 2006; Vogel, 2007).

Disagreements over the river's use have existed since the river's development was first envisioned. The United States side of the Columbia Basin spans multiple jurisdictions of federal, state, tribal, and local agencies. No single entity (other than the courts) has ever had a scope of authority sufficient to resolve disputes spanning multiple jurisdictions. The desire for a rational process to manage (if not resolve) differences over river use, planning, development, and operation led to the region's continuous experiments with various governance systems and structures. The framing of those disagreements evolved over the years as circumstances changed and new institutional actors, often with competing values and worldviews, gained access to the debate through accumulation of financial resources and political power.

The Pacific Northwest region of today generally corresponds to the area bounded by the Northwest Territory of 1848, shown in Figure P-1. However, the Northwest has always had a tenuous relationship with the concept of itself as a unified region. A single territorial government administered the region until 1853. At that point, the increase in population in settlements north of the Columbia (especially in the Puget Sound area), their distance from the seat of government in the Willamette valley, and difficulties in communication led to a successful petition for establishment of what became the Washington Territory (Schafer, 1943/1918). 
Figure P-1.

Oregon Territory $1848^{1}$

(Showing Current State Boundaries)

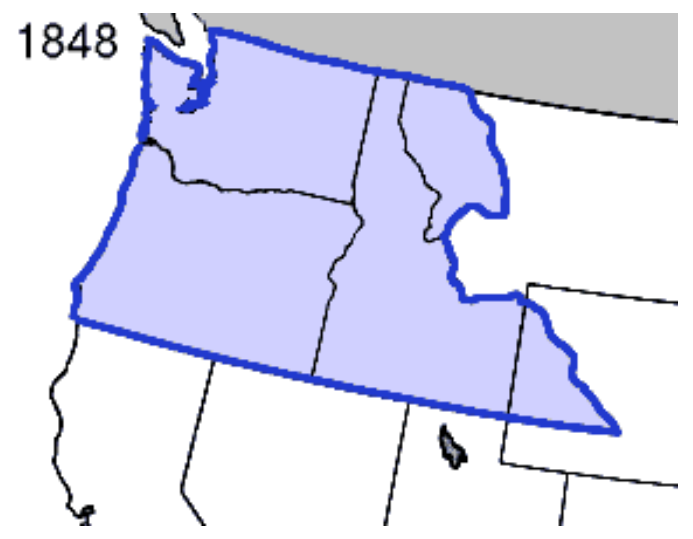

Although Oregon achieved statehood in 1859 the communities of the new state, like those in the Washington Territory and the rest of the nation, consisted of relatively isolated "island communities" prior to the expansion of railroad and communications technology (Wiebe, 1967). These technologies did not reach the inland areas of the Northwest until the latter 1800s. Within the Northwest, disparate communities exploited resources of furs, fish, water, timber, minerals and crops for their own local interests and purposes in relative independence. The idea of the region as a unified political, social, or economic entity did not begin to emerge until the 1920s (Ogden, 1949; Vogel, 2007).

The concept of the region as a potentially unified entity took shape as planners looked to develop the Columbia for purposes of irrigation, navigation, and -

\footnotetext{
${ }^{1}$ Map source: Wikipedia at http://en.wikipedia.org/wiki/Oregon_Territory.

${ }^{2}$ Map source: Northwest Region, National Marine Fisheries Service at http://www.nwr.noaa.gov/SalmonHydropower/Columbia-Snake-Basin. 3

${ }^{3}$ Vogel (2007) provides a great deal of information and insight regarding the establishment and
} 
eventually - hydropower (Ogden, 1949; White, 1995; Vogel, 2007). White (1995) argues that the developed river gives the Northwest a unique unifying identity. The Columbia's current developed state is a sophisticated blend of engineering skill and institutional organization. The map provided in Figure P-2 displays the location of the Basin's multipurpose dams illustrating this “organic machine” (White, 1995). These dams are managed and operated to serve as "the Northwest's primary power plant, central navigation channel, biggest irrigation ditch, and storage facility for flood waters" (Volkman, 1997, p. 10). Other purposes include domestic, municipal, and industrial water supply, outdoor recreation, fish and wildlife restoration, and water quality.

No single entity holds jurisdictional oversight over the entire system. Instead, jurisdiction is fragmented among federal, state, local, and tribal government agencies with benefits accruing to a variety of public and private entities (Volkman, 1997). Although management of the Columbia as a system has been predominately a federal responsibility (Ogden, 1997; Williams, 2006), the interests and prerogatives of these other jurisdictional entities and their competing values and worldviews efforts often confounded governance efforts. Consequently, since the 1920s Northwest leaders have struggled with how to come to a common vision regarding system planning, development, and operation of what was to become the Federal Columbia River Power System (FCRPS). 
There is an abundance of material addressing the historic settlement of the

American Northwest in general (Schafer, 1943/1918; Lyman, 1963/1917; Johansen,

1967; Dodds, 1986; and Robbins, 1997 and 2004) and Columbia River development in

Figure P-2.

Columbia River Basin ${ }^{2}$

(Showing Location of Major Dams)

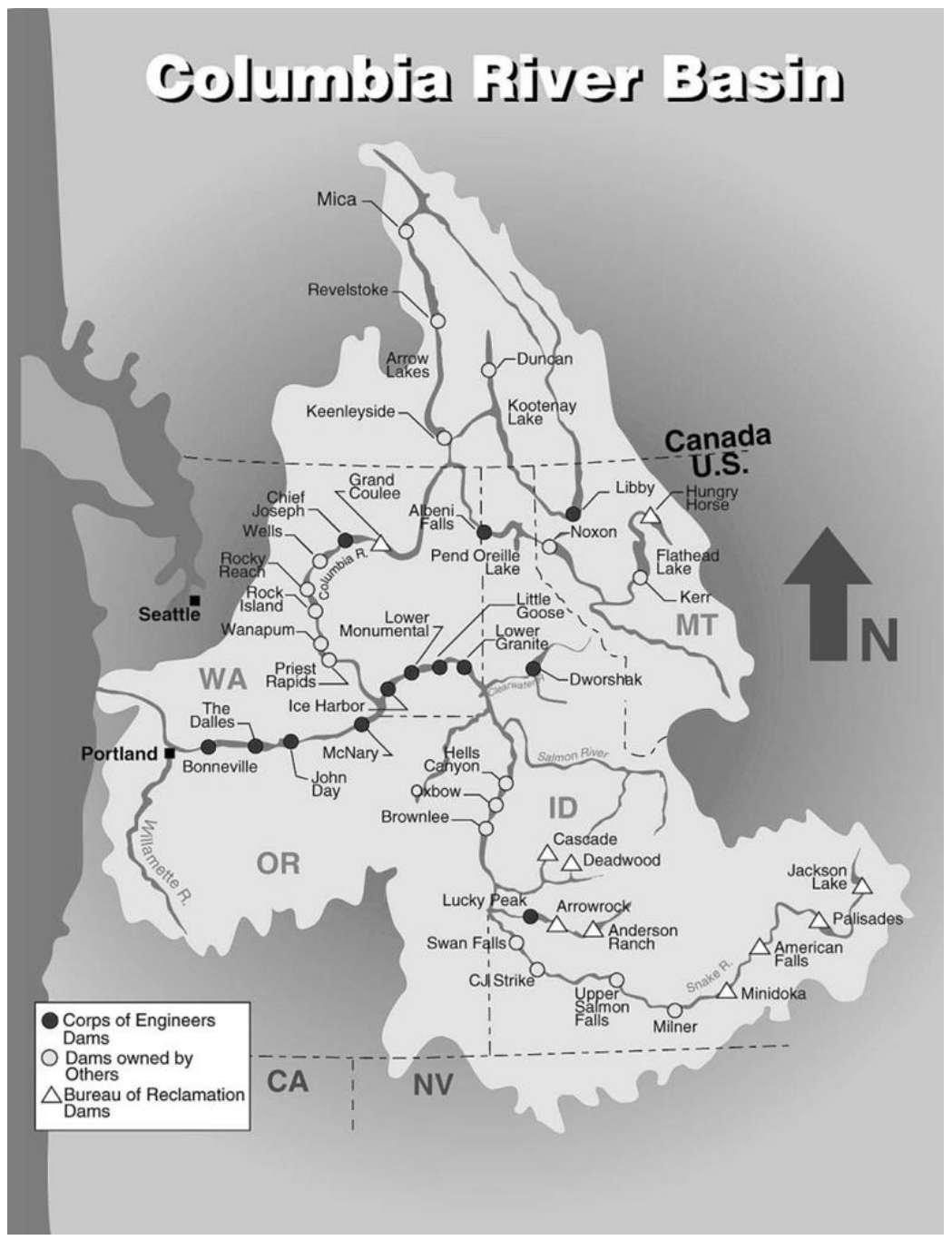

\footnotetext{
${ }^{2}$ Map source: Northwest Region, National Marine Fisheries Service at http://www.nwr.noaa.gov/SalmonHydropower/Columbia-Snake-Basin.
} 
particular (Ogden, 1949; McKinley, 1952; Bessey, 1963; DeLuna, 1997; Brigham, 1998; Vogel, 2007; Pope, 2008). Each illustrates or emphasizes different aspects of the region's settlement and development. Although many mention the regional governance systems relevant to the story the authors wish to tell, only Roy Scheufele's (c. 1970) insightful analysis of the Columbia Basin Inter-Agency Committee and Hemingway's (1983) discussion of the Northwest Power Planning and Conservation Council focused exclusively on Columbia Basin governance systems in the United States as the central subject. ${ }^{3}$ No one has yet written a history devoted to Basin governance.

The intent of this paper is to do so. The author was inspired to undertake this work based on his observations of and experience with the Columbia River Basin Forum (CRBF or the Forum), a short-lived governance effort initiated in 1997 that ended in 2000. When first proposed the idea of a new governance effort enjoyed widespread support from regional governors, tribal leaders, and members of the region's congressional delegation. Nevertheless, despite this support the resulting system collapsed after only a little over a year of operation. The author undertook this research effort to understand why and to determine if the experience of the CRBF was unique or representative of past governance efforts.

This study provides an institutional level analysis of the governance history in the United States portion of the Columbia River Basin., introduced through the CRBF

\footnotetext{
${ }^{3}$ Vogel (2007) provides a great deal of information and insight regarding the establishment and operation of the Pacific Northwest Regional Planning Commission. Her focus, however, is on the role of the Commission in creating the northwest's regional identity rather than the Commission itself.
} 
experience. Whereas this institutional approach established the events, circumstances, institutional actors, interests, and outcomes of regional debates over governance form, it could not reach the motivations within individuals that led them to their stated positions or drove their actions. Differing worldviews and senses of institutional culture, identity, and values aggravated conflicts over interests by shaping the perspectives each participant held over the goals and motivations of the others. Determining how institutional values translated into individual level decision-making regarding governance choices requires further research.

This research effort found that state and federal agency and political leaders debated twenty-six multi-jurisdictional governance systems between 1933 and 1999. Of these, they enacted eleven. This study presents and analyzes the history of these twenty-six systems. The goal was to use a framework inspired by the CRBF experience to understand why regional and national leaders adopted some types of systems and rejected others and determine lessons as may be applicable to future governance efforts. Chapter 2 presents the methodology through which this framework was applied. Chapters 3 through 7 provide the history, with the study's findings and conclusions presented in Chapter 8 .

This study report begins by documenting the rise and collapse of the Columbia River Basin Forum. The richness of primary material regarding the CRBF's inception, operation, and demise offers a fairly complete introduction to the institutional actors, issues, and challenges that governance efforts faced in the recent past and will likely face in the future. From it can be gleaned insights into the interests and positions of 
the entities involved, the types of issues institutional leaders expect such systems to address, and the types of challenges faced. It also suggests a research framework by which a study of past systems can be undertaken. The CRBF experience thus provides an informative case study introduction to this overall research report. 


\section{CHAPTER 1 \\ INTRODUCTION TO BASIN GOVERNANCE: \\ THE RISE AND COLLAPSE OF THE COLUMBIA RIVER BASIN FORUM}

\section{A Paradox in Governance?}

The Columbia River Basin Forum (CRBF or the Forum) had its origins in a “Three Sovereigns” governance structure proposed by Oregon's then-governor John Kitzhaber in October 1997. As the name implies, this process would be comprised of the region's three sovereign entities: federal, state, and tribal governments. Navigation, public power, and irrigation interests met this original proposal with aggressive resistance over concerns about the exclusivity of the new organization's decision-making processes. States, tribes, and federal agencies expressed concerns regarding potential impacts on their jurisdictional prerogatives. All became involved in the drafting of a memorandum of agreement (MOA) that would serve as a guiding charter. Governmental representatives engaged directly while non-governmental actors participated either directly or indirectly through elected congressional representatives. The result was the evolution of the original "Three Sovereigns" concept into the more inclusive "Columbia River Basin Forum." The non-government entity participation in the MOA's drafting ensured that any CRBF related meetings were to be open to non-governmental participants.

An enormous amount of institutional energy and effort went into bringing the CRBF into being. State, tribal, federal, and non-governmental representatives met over a sixteen-month period to craft an agreement under which they would operate. 
State parties to the agreement were Oregon, Idaho, Washington, and Montana. There were thirteen tribal governmental parties. Four were from the Lower Columbia River, collectively referred to as the lower river tribes. These were the Confederated Tribes and Bands of the Yakama Indian Nation, the Confederated Tribes of the Umatilla Indian Reservation, the Confederated Tribes of the Warm Springs Reservation, and the Nez Perce Tribe. Six were from the Upper Columbia River, collectively referred to as the upper river tribes. These were the Coeur D'Alene Tribe, the Confederated Salish and Kootenai Tribes of the Flathead Reservation, the Kalispel Indian Community, the Kootenai Tribe of Idaho, the Confederated Tribes of the Colville Reservation, and the Spokane Tribe of Indians. Three were from the Snake River basin, collectively referred to as the Snake River tribes. These were the Burns Paiute Indian Tribe, the Shoshone-Bannock Tribes of the Fort Hall Reservation, and the Shoshone-Paiute Tribes of the Duck Valley Reservation. Federal parties consisted of the four departments and ten agencies with jurisdictional responsibilities in the Columbia Basin. These were the Department of Commerce (National Marine Fisheries Service), Department of the Army (U.S. Army Corps of Engineers), Department of the Interior (Bureau of Reclamation, Fish and Wildlife Service, Bureau of Land Management, and Bureau of Indian Affairs), Department of Energy (Bonneville Power Administration), and Department of Agriculture (U.S. Forest Service and Natural Resources Conservation Service) and the Environmental Protection Agency (MOA, 1999, p. 1). Each of these entities entered into the CRBF negotiations with their own set of interests and prerogatives. Differing worldviews and senses of institutional culture, 
identity, and values aggravated the conflict over competing interests and shaped the perspectives each party held over the goals and motivations of the others.

Most of the parties signed the MOA in January 1999. Others signed later and some not at all. Regardless, the CRBF went ahead and held its first meeting the following March with high participant expectations. However, in eleven meetings held over sixteen months ${ }^{4}$ members argued almost exclusively over issues of goals, procedure and format. Frustration over lack of progress on substantive issues resulted in key participants either quitting or threatening to quit the process at several points. Despite the well-meaning efforts by CRBF proponents, participation trailed off amid an increasing sense of pointlessness. The CRBF held its last meeting on April 28, 2000.

The experience of the CRBF presents a seeming paradox. Whereas many prominent northwest political and institutional leaders strongly believed some form of regional $^{5}$ governance system necessary, those same leaders failed to grant the CRBF the decision-making authority necessary to resolve the issues that lead them to think that such a system was needed in the first place. Why?

\footnotetext{
${ }^{4}$ Meeting notes or references to meetings exist for each month from March through October 1999 and February through April 2000.

5 "Regional" in this context refers to the jurisdictional space between state and national levels of government. Geographically, for the purposes of this study, it means the states affected by FCRPS related activities within Columbia River Basin: Oregon, Washington, Idaho, and Montana and the Native American tribes residing therein. Jurisdictionally, it means the state and federal agencies and tribal governments with operational, regulatory, and/or tribal trust and treaty responsibilities over these activities. "FCRPS activities" refers to the purposes for which the FCRPS was developed (hydropower, irrigation, river-borne navigation, flood control, and water supply) and the impact those activities have on the Basin's natural resources in general and its salmon and steelhead runs in particular.
} 
The remainder of this chapter chronicles the inception, operation, and ultimate disintegration of the CRBF. It provides the institutional background from which the CRBF emerged. It then presents the arguments made by political leaders in support of a new regional governance system as cited in conferences, publications, and the media. It chronicles the creation of the CRBF's guiding memorandum of agreement (MOA) and analyzes the structural weaknesses that contributed to the Forum's ultimate failure. It then discusses the arc of the CRBF's existence from inception to eventual collapse. It concludes with a summary of key points and an examination of the challenges to regional governance as illustrated by the CRBF experience, thus setting the stage for this study report's research questions and methodology.

\section{$\underline{\text { Institutional Background }}$}

In his history of the Northwest salmon crisis, Taylor (1999) argued that “centrifugal forces of competing interests" (p. 247) constantly undermined solutions to challenges to policy and governance. He criticized all major Northwest resource users, including the institutions and industries of timber harvest, logging, grazing, mining, fisheries, "urban environmentalists," development, and dam building and public bureaucracies who all "artfully converted self-interest into principle" (p. 241).

Although Taylor (1999) focused on the history of the regional salmon fishery, this study extends his argument to issues of Columbia River Basin governance. This study organizes the "centrifugal forces" under three broad institutional categories. These are salmon harvesters, those dependent on the commercial benefits and 
economic development provided by the multi-purpose dams, and environmental interests.

The first two focused their attention on Pacific Northwest's two most enduring icons: the once massive runs of pacific salmon and the large multi-purpose dams located on the mainstems of the Columbia River and its major tributaries. To commercial and sports fishery advocates the salmon harvest was symbolic of a critical regional economic and cultural resource and way of life that was rapidly collapsing. Tribal fishermen, while sharing a commercial interest in fish harvest, were equally if not more concerned with the depleted fish runs' impacts on their culture and the roles played by salmon in their sense of identity and way of life. Although often bitterly opposed to the goals and objectives of each other (Taylor, 1999) and often litigation adversaries (Pevar, 2002), this three-way community of commercial, sport, and tribal fisheries were generally united in their claim that the dams were the primary reason for declining fish numbers (Taylor, 1999; Robbins, 2004).

To those dependent on the commercial benefits provided by hydropower, irrigation, and navigation the dams were a symbol of the region's economic health as well as a guarantor of public safety through flood control. The electricity produced by the dams provided inexpensive power to fuel the region's economy; the irrigation system supported the region's agricultural community; and waterborne navigation provided an inexpensive means to move timber and agricultural products to market (McKinley, 1952; Bessey, 1963). To them, the moralistic arguments of the fishery community were a self-serving and disingenuous attempt to subsidize commercial and 
sport fishing interests under pressure from natural changes in ocean conditions, rising global competition, and an inability to curb their own historic excesses. There were deep disagreements among members of the community of dam proponents as there were within members of the fishery community. Nevertheless, they shared a belief in the economic importance of the dams and related to them as symbolic indicators of the region's economic development and growth potential. The constituent interests of the fishery and commercial development communities have been in conflict at least since the Army Corps of Engineers began its review in the early 1940s of the 1932 " 308 Report” (Ogden, 1949; White, 1995; Lichatowich, 1999; Taylor, 1999; Wilkinson, 2005).

The third category, American environmentalism, is more recent. Concurrent with the Nation's rising environmental consciousness, strong support for the value of restoring sustainable populations of wild fish for their own sake emerged. National and state environmental protection statutes in general and the Endangered Species Act in particular embody this value (Dunlap, 1992; Taylor, 1999; Rosenbaum, 2005).

The geographic breadth and socio-political complexity of this three-way conflict illustrated the inadequacy of the region's governance systems, as they existed in the mid to late 1990s. One party or another filed multiple lawsuits looking to the courts to resolve the issues and, as Taylor (1999) argued, validate the legitimacy of their values and beliefs.

The first listings of salmon and steelhead by the National Marine Fisheries Service (NMFS) in 1991 and 1992 and the establishment by NMFS of the federally led 
Regional Implementation Forum (Regional Forum) ${ }^{6}$ in 1995 shifted the locus of

governance away from the Northwest Power and Conservation Council (NPPC or

Council) to the federal agencies, especially NMFS. ${ }^{7}$ Other listings followed. By

1997, regional concerns over the listings and their potential impacts were coupled

with:

- Uncertainty over a pending new NMFS biological opinion (BiOp) regarding the effect of hydropower operations on listed salmon species, ${ }^{8}$

- A related study by the U.S. Army Corps of Engineers on the impact of the four lower Snake River dams on salmon survival and the study's potential to lead to the breaching of those dams,

\footnotetext{
${ }^{6}$ The Regional Forum is not to be confused with the Columbia River Basin Forum. The Regional Forum was established as a provision of a biological opinion issued by the National Marine Fisheries Service on the FCRPS in 1995. It consisted of state, federal, and tribal institutional representatives. The Executive Committee was comprised of the state Governors or their designated representatives, tribal government leaders, and regional federal agency executives.

${ }^{7}$ The Pacific Northwest Electric Power and Conservation Planning Council was created under the Pacific Northwest Electric Power Planning and Conservation of Act of 1980 to balance hydropower planning with fish and wildlife needs. Chapter 6 discusses the origins of the Council in greater detail. The Council's name was officially changed to the Northwest Power and Conservation Council in 2003 in order to emphasize the fish and wildlife aspects of its mission. In the 1980 Power Act, the word "Conservation" in the Council's name specifically referred to energy conservation. The name change was intended to convey the equal status of enhancing and protecting fish and wildlife resources affected by the dams with energy planning in the Council's programs (NPPC, 2007). To minimize confusion, this report uses the Council's most recent name throughout.

${ }^{8}$ If an agency proposes an action that will take place in an area in which listed species reside, then the Endangered Species Act requires the agency to consult with the regulatory authority over the species affected. Jurisdiction over salmon resides with the National Marine Fisheries Service. Upon reviewing the proposed action, the regulatory agency issues a written opinion (referred to as a "biological opinion" or "BiOp") as to whether the action is likely to jeopardize the continued existence of the listed species or result in the destruction or adverse modification to the listed species' critical habitat. See ESA sections $7(a) 2$ and $7(a) 3$.
} 
- Concern over the nationalization of the dam removal debate by fishery and environmental activists,

- Uncertainty over the impacts of new policies regarding energy deregulation on the region's federally operated hydropower system,

- The collapse of the Executive Committee of the Regional Forum, and

- Frustration with the region's complex and often contradictory patchwork of treaties, statutes, regulations, policies, agency decisions and court determinations regarding salmon.

Regional leaders presented three arguments in favor of a Columbia River Basin governance system. First was the desire to better manage and organize the sheer complexity of Columbia Basin issues. Regional leaders argued in favor of some form of system to eliminate duplication, confusion and conflict in regional decision-making then being carried out through multiple processes. Second, and related to the first, was the desire for greater inclusiveness in the decision-making process. Third was concern over periodic threats to the benefits derived from the Columbia - the most recent of which were outlined above - and the degree to which external forces could assume control over the system and divert those benefits out of region (Crampton, October 16, 1998; Batt, Kitzhaber, Racicot, and Locke, July 15, 1998).

A Government Accounting Office (GAO) report, released in June 2004, clearly portrays the complexity of Columbia River issues. The states of Washington, Oregon, Idaho, and Montana share a geographic and jurisdictional footprint with the thirteen 
sovereign Indian tribes with rights within the Basin and ten federal agencies. ${ }^{9}$ The report characterized federal responsibilities as "a multilayered collection of laws, treaties, executive orders, and court decisions." It identified two Canadian and six Indian treaties; thirty-one nationwide statutes; six basin-specific statutes; fourteen mission-specific statutes applying to individual federal agencies; seven federal executive orders and memoranda applying to all agencies; and seventeen court decisions that defined and guided agency responsibilities for mission authority and operations, fish and wildlife mitigation, and tribal relationships. These in turn spawned thirty-eight supporting plans and programs involving a varying array of federal, state, and tribal involvement (GAO, 2004). This array of rules, regulations, and programs constitute a structure of regional governance absent the benefit of a unifying system to mediate their often-inconsistent goals and requirements. ${ }^{10}$

As complicated as it made the situation out to be, this GAO report was in fact somewhat simplistic in that it only addressed federal activity. It did not discuss additional layers of regulation and bureaucracy resulting from state, tribal, and local levels of responsibility. These other levels of government hold jurisdiction over

\footnotetext{
${ }^{9}$ The agencies identified in the GAO report are the Bonneville Power Administration, U.S. Army Corps of Engineers, Bureau of Reclamation, U.S. Forest Service, Bureau of Land Management, U.S. Fish and Wildlife Service, Bureau of Indian Affairs, National Marine Fisheries Service, Environmental Protection Agency, Natural Resources Conservation Service, and U.S. Geological Survey.

${ }^{10}$ This research report on Basin governance uses the terms "system" and "structure" in the sense offered by Giddens (1984) and Sztompka (1991). Social systems are relationships between and practices of human agents patterned to the point where they form recognizable entities. These entities manifest as organizations, institutions, or other social groupings. Structures are the formal and normative rules and resources by which established systems operate. To use the CRBF as an example, the organization of institutional participants into an arrangement called the Columbia River Basin Forum constitutes a system. The CRBF's memorandum of agreement, facilitation and note-taking support, and internal operating procedures represents its structure.
} 
nonfederal Basin policy domains such as water rights, permitting, fishery harvest levels, recreational facilities, and hunting and fishing regulation and add additional levels of complexity to issues of resource management. No single entity has the authority to integrate areas of jurisdictional overlap or resolve disputes.

Further compounding the issue were nongovernmental private interests active in the Basin and dependent on the missions and programs of federal and state agencies. To use the federal agencies as examples, the U.S. Army Corps of Engineers traditionally draws its support from navigation interests; the Bureau of Reclamation from irrigation interests; the Bonneville Power Administration (BPA) from public utility districts and direct service industries; the NMFS with commercial fishing interests; and the U.S. Fish and Wildlife Service with sports fishermen, hunters, and state fish and game agencies (Clarke and McCool, 1996; Ogden, 1997). Rightly or wrongly, these private interests were frequently perceived to bias agency decisionmaking either through direct lobbying or by acting through their congressional representatives to ensure that agencies paid proper attention to their concerns.

Such a dizzying array of requirements, activity, and competing interests all but guaranteed interpretative disagreement and jurisdictional dispute. Writing to the CRBF following their June 24, 1999 meeting, attorney James Buchal argued for adoption of a clear salmon recovery goal. In doing so, he underscored several of the arguments in favor of developing a coherent governance framework. Buchal argued that unless the CRBF exercised leadership in "tempering and balancing them [fish and wildlife goals] with other relevant goals, the region's fishery managers will continue to 
work at cross purposes." He noted that at several times during the meeting, members asserted the establishment in law of their relative positions to support their arguments. He argued that "the laws are vague and contradictory" and that "Columbia Basin salmon recovery is not progressing because of a lack of coordination among the relevant agencies to strike reasonable accommodations among these statutory goals." "Only when some entity succeeds in taking charge of the recovery program, and giving meaningful guidance to those charged to implement it, can we obtain genuine progress" (emphasis added). ${ }^{11}$

The case for Northwest regional governance, based on the desire for greater efficiency, the desire for more inclusive decision making, the need to reconcile competing statutory and regulatory demands, and protection of regional benefits led many to conclude that existing governance systems were not adequate to the task. For example, former Senator and Oregon Governor Mark Hatfield recommended that Congress expand the membership and authority of the Northwest Power and Conservation Council through legislative action (Collette, 1997). Then-Governor John Kitzhaber stated that the Council "lacks the proper mission, proper representation, and the proper authority" to manage the Columbia River benefits (Crampton, October 16, 1998) and eventually recommended replacement of the Council altogether (O'Bryant, September 24, 1999). Collectively, these issues convinced regional leaders that a new

\footnotetext{
${ }^{11}$ Quoted from a Murphy and Buchal, LLP, memorandum to Columbia Basin Forum Committee Members concerning Columbia Basin fish and wildlife goals. The memorandum is dated June 29, 1999. The original document is on file with Columbia River Basin Forum meeting notes held in the offices of the Northwest Power and Conservation Council and DS Consulting, Portland, Oregon.
} 
system of decision-making was necessary to replace the Regional Forum's Executive Committee and to address weaknesses in the scope and authorities of the Council.

\section{Establishment of the Columbia River Basin Forum}

Seeking to offset the growing federal role in Basin decision-making generated by the salmon listings with increased state and tribal input, Oregon Governor Kitzhaber hosted a regional conference in October 1997 at which he promoted creation of a "Three Sovereigns" process. The stated goal was to manage Columbia River basin issues in a more integrated, accountable, and responsive manner. This was to be done through establishment of a collaborative decision-making process that would develop consensus recommendations for regional decision-making authorities (Crampton, October 16, 1998). Kitzhaber was successful in convincing his fellow governors that some such effort was worthwhile. In a memo issued on July 15, 1998 the four governors presented a statement of joint intent to bring the region together on a "common position" and not let the issues be "determined solely at the national level" (Batt, Kitzhaber, Racicot, and Locke, July 15, 1998).

Governor Kitzhaber, supported by the regional governors, envisioned the Three Sovereigns operating through a "high-level policy forum" consisting of one representative each from the federal government, the four Northwest states, and the thirteen Columbia River Basin tribes. The members of this forum would "address, collaborate on and coordinate basin-level policy, planning, decision-making, and implementation issues." A senior staff-level committee of four state, four federal, and 
four tribal representatives would constitute this forum. Recognizing the difficulty of reaching decisions on the Basin's conflicting issues through consensus, the governors suggested that, "a river governance framework may need to be legislated by the U.S. Congress... a process that could take several years." They then initiated a parallel initiative to determine whether a new statutory structure could be achieved (Batt, Kitzhaber, Racicot, and Locke, July 15, 1998).

The governors also proposed that a memorandum of agreement (MOA) institutionalizing the Three Sovereigns Process be developed and signed by November 1998. However, not all felt that the "Three Sovereigns" process was the "right solution to the right problem." Upriver agricultural and timber interests dependent on the river's commercial uses of irrigation and navigation and hydropower users were deeply concerned over a body so heavily represented by tribal and downriver fishery and environmental advocates. They questioned whether any form of regional governance would be part of a "sensible solution" (Tansey, March 17, 1998; Senate Hearing Focuses on Three Sovereigns, 1998).

This group found a receptive audience among some members of the regional congressional delegation. In a joint letter to Kitzhaber, Representatives Bob Smith (ROR), Doc Hastings (R-WA), Michael Crapo (R-ID), and Rick Hill (R-MT) expressed their concern over the "scope and intent" of the Three Sovereigns proposal and the suggested one-per-government voting scheme. They called for a greater representation of non-governmental interests and more non-governmental participation (Congressmen Rap Three Sovereigns Process, 1998). Senator Slade Gorton (R-WA) 
openly questioned whether the "problem" was a "lack of coordination or the inherent tension of federal agencies having to make decisions in the face of conflicting federal laws and the strong voices of diametrically opposed interests" and whether the Three Sovereigns was the proper response (Senate Hearing Focuses on Three Sovereigns Process, July 13, 1998). Going a step further, Senator Gordon Smith (R-OR) introduced Senate Bill S-214 that would require a non-governmental advisory group for whatever system eventually chosen (Three Sovereigns Develops New Twist, June 9, 1998; Senate Hearing Focuses on Three Sovereigns Process, July 13, 1998; Espenson, August 28, 1998). ${ }^{12}$

The governors' memorandum of July 15 offered four governance options in addition to the original Three Sovereigns proposal. ${ }^{13}$ A regional discussion ensued from which emerged a compromise. The compromise called for more inclusive involvement by non-governmental parties and a renaming of the resultant governance system as the "Columbia River Basin Forum" in order to distance it from the governments-only connotation of the Three Sovereigns label. Commercial interests thus received assurances that CRBF-related meetings would be open to nongovernmental participants. ${ }^{14}$

\footnotetext{
${ }^{12}$ The state legislatures also voiced concern that more stringent recovery efforts may have to be funded from state resources. They created the Legislative Council on River Governance (LCRG) to stay abreast of developments in the Three Sovereigns process.

${ }^{13}$ The governance alternatives offered in the July 15 memo are discussed in detail in Chapter 7.

${ }^{14}$ Ironically, there is no indication in any of the CRBF records or meeting notes that any nongovernmental participant ever attended a formal CRBF meeting. When asked about this, a public power participant to the process replied that once the MOA was signed, his organization realized that the CRBF would be unable to make any significant changes to the system, and therefore posed no threat to
} 
Some saw the CRBF as an interim solution that allowed time for trust and relationship building and greater coordination. Concurrently the parties - particularly the states - could explore whether enough common ground existed for a more formal arrangement with true decision-making authority empowered by statute (Crampton, October 16, 1998; Espenson, October 23, 1998). Others held great hope and faith in the CRBF's own intrinsic potential, although from different perspectives. The federal agencies in general voiced support for a process that would bring the regional parties together and result in greater input to and support for federal decisions. NMFS in particular sought regional input and ultimate buy-in to whatever decisions the biological opinion - due by the end of 1999 - would ultimately make. Many of the tribes were eager to get on with substantive discussions as governing equals. Spokane tribal representative Howard Funke captured tribal feeling when he argued that "the idea of governments sitting down and talking about fish, wildlife, and the habitat... and in their ecosystem...is the right thing to do" (Crampton, October 16, 1998; Espenson, February 5, 1999).

The compromise did not satisfy everyone. Although supportive of regional governance in the abstract, the governors of Idaho and Montana expressed concern over how potential outcomes would affect the agricultural and recreational interests of their respective states. Idaho particularly was leery of even the appearance of ceding authority over water use to some regional authority made up of parties suspected of designs on Idaho water and supportive of the breaching of the four lower Snake River

their interests. Consequently, they stopped investing any time into its workings (Personal communication with participant.) 
dams. Both states threatened to withhold support for the CRBF unless these concerns were addressed (Montana, Idaho won’t Sign on to Northwest Salmon Plan, 1999).

The Nez Perce, distrustful of excessive state influence in the process, felt that their time would more be effectively spent in dealing directly with federal agencies through consultation and, when necessary, litigation. They also, more than other basin tribes, believed that the CRBF was not an appropriate forum for their tribal leaders. In their view, government-to-government negotiations between the Nez Perce and the federal government should not occur through federal agency heads but rather through direct involvement by the White House. They staunchly opposed the notion of representative involvement, stating that they would not allow anyone other than tribal leaders to represent tribal interests and insisting on direct tribal participation at each level of the process (Espenson, Feb 5, 1999; Espenson, Mar 12, 1999). The Nez Perce never signed the MOA.

Divisions existed among the Umatilla board of directors. Like the Nez Perce, they harbored deep distrust of state motives, especially Oregon. Citing previous efforts by the state attorney general to limit tribal fishing rights, many board members did not believe that collaborating with a body historically hostile to fundamental tribal interests was possible. Others on the board believed that the benefits of participation outweighed the risk. It is not clear whether the Umatilla ultimately signed the MOA. ${ }^{15}$

\footnotetext{
${ }^{15}$ Frankly, it is not entirely clear which of the lower Columbia tribes did or did not eventually sign the MOA. The original MOA signature sheet was not filed among the records reviewed for this study. The information presented as to signatories is derived from media accounts and recollection of process participants.
} 
After two postponements ${ }^{16}$ generated by concerns over state decision-making prerogatives, tribal concerns, funding, and extensive review by the federal agencies, a CRBF signing ceremony finally occurred on January 29, 1999. Fourteen regional sovereign entities signed. Six others were supportive and signed a short while later, including Montana. Governor Kempthorne of Idaho signed the following March, although in doing so he made it clear that the state of Idaho would not support any recommendation that included either removal of the Snake River dams or additional water flows out of Idaho (Espenson, Feb 5 and Mar 12, 1999).

The signing ceremony in January of 1999 culminated almost two years of debate and negotiations over roles, responsibilities, representation, and institutional authority. The discussion identified both a general interest in addressing the issue of regional governance and the myriad differences among regional interests that made structuring a governance framework so difficult. Thus, it underscored the paradox of the effort. Almost all parties agreed that a regional governance system could allow for more efficient decision-making, be more inclusive, and help protect regional resources. However, the discussion also revealed a deep unwillingness to concede to the CRBF the decision-making authority that could make it a successful resolver of disputes. A large reservoir of skepticism remained among regional parties as to each other's intent and motives. This skepticism and the lack of agreement over formal decision authority led several to believe that a statutorily constituted body would

\footnotetext{
${ }^{16}$ The draft MOA was released for regional comment in August 1998 and originally scheduled for signing in the following November. The signing date was postponed until mid December and again until January 1999.
} 
ultimately be needed. Nevertheless, signatories agreed to allow participation by nonsignatory entities in the interest of moving forward and with the hope that those parties who had not yet signed would eventually come around.

The document that emerged from this process reflects the concerns and interests of the debate that created it. Its structure and language played a significant role in the ultimate operation of the CRBF. It embodies the rules and procedures of the CRBF's establishment through negotiation by regional agents. It is therefore useful at this point to review its key elements.

\section{The Memorandum of Agreement}

The fifteen pages comprising the MOA signed in January 1999 contain detailed language laying out the Forum's purposes, organization, processes, guidelines for public involvement, and rules for financial management. An appendix outlined five substantive issues intended to receive immediate attention.

Section II of the MOA (1999) identified the Forum's purpose. Its overarching purpose was "to provide a high-level policy forum in which federal, state and tribal governments, working with interested members of the public, will address, collaborate on and coordinate basin-level policy, planning, decision-making and implementation issues that effect [sic] the Columbia River Basin fish and wildlife and related habitat. The parties recognize the need to prioritize their efforts, focusing on the most pressing issues with the greatest opportunity to improve the effectiveness of regional efforts." 
Specific purposes included ensuring coordination among governmental parties and addressing all factors that affect anadromous fish in the Basin, such as hydropower operations, harvest, habitat, and hatcheries. Other purposes were to "harmonize actions and shape initiatives," "simplify current processes by eliminating duplicative efforts and consolidating or eliminating existing committees or bodies," provide for dispute resolution; improve financial management; ensure effective and independent scientific and economic review mechanisms; and "ensure a structured process of public information and involvement" (MOA, 1999, pp. 3-4).

For funding, the MOA (1999) called on the parties to "commit to investigate the full range of funding alternatives." The parties agreed that "funding obligations are to be shared among the parties on an equitable basis," subject to the availability of appropriated funds. The Committee identified an initial budget of $\$ 119,000$ to $\$ 189,000$ and appended this budget to the agreement (MOA, 1999, p. 6 and Appendix B.)

The MOA (1999) defined a two-tiered organizational structure almost identical to that prescribed under Governor Kitzhaber's Three Sovereigns concept. At the upper policy level was the Columbia River Basin Forum Board (the Board). The Board consisted of the governors of Oregon, Idaho, Washington, and Montana; the leaders of the thirteen Basin Indian tribes; and a "representative of the federal Administration." The key functions of the Board were to provide policy guidance with regard to MOA implementation, review priorities and tasks, provide oversight for the Forum Committee. The Board was also empowered to make determinations and 
recommendations on matters upon which it reached consensus (MOA, 1999, pp. 4-5).

There was no formal connection between the Board and the Northwest Power and Conservation Council or with the remnants of the NMFS' Regional Forum, both of which continued to function.

The MOA delegated implementation to the Columbia River Basin Forum Committee (Forum Committee). The Forum Committee consisted of twelve members. One each was to be appointed from the four Northwest states; four collectively representing the twelve tribes; ${ }^{17}$ and one each representing the federal Departments of Commerce, Defense, Interior, and Energy. Committee members were to elect a chair to serve a one-year term. Functions of the Committee included carrying out the purposes of the Forum; development of annual internal operating budgets; implementation of the MOA's public involvement and outreach provisions; monitoring implementation of agreed-upon actions; and preparing issues of such policy significance as would require referral to the Board (MOA, 1999, pp. 5-6).

The MOA carefully defined the processes for getting an issue before the Forum Committee and for the Committee to issue a recommendation. Although any Committee member could propose an issue for consideration, three separate voting processes were required before the Forum Committee could issue a formal recommendation. First, the Committee put the issue to a vote to determine whether to

\footnotetext{
${ }^{17}$ Two represented the upriver tribes and two the lower river tribes. The tribes could also designate up to four alternate representatives from those tribes whose programs were directly affected by an issue before the Forum Committee. (As noted earlier, the Nez Perce did not delegate to anyone the right to represent Nez Perce tribal interests.)
} 
consider it. Nine $(75 \%)$ of the twelve Committee members had to concur before an item could be taken up. If an issue passed this step, it was designated a "Forum Issue." Forum Issues were eligible for further discussion, analysis, and the development of alternative resolutions. Although not clear from the language of the MOA (1999), it appears that the Forum Committee could provide this level of analysis to relevant decision-makers without further action and without making a formal Forum Committee recommendation. If, however, the Committee desired a formal recommendation or believed additional discussion needed then it would call for a second vote. Putting a Forum Issue into the collaborative process required the consensus of the Forum Committee. The Committee member with jurisdiction over the issue in discussion could limit or terminate the process at any time. Once the collaborative process was completed, the Forum Committee could make its recommendation after a third consensus vote. The MOA defined "consensus" as a recorded vote of all twelve Forum Committee members, with no votes in opposition. Members who did not register a vote within two weeks of an issue being called or who chose to abstain did not count against the consensus (MOA, 1999, pp. 6-7).

In addition to spelling out what the Forum could do and how it would do it and perhaps more importantly - the MOA (1999) included a list of twelve exclusions specifying what the Forum could not do. Among these were prohibitions on limiting the otherwise lawful decision-making discretion of any of the parties; prohibitions on requiring parties to limit their use of Basin resources; prohibitions on addressing "local issues that do not have basin-wide effects;" prohibitions on any affect to private 
property and water rights; and a prohibition on requiring any party to expend funds in support of the agreement (pp. 9-10).

The language and procedures embodied in the MOA (1999) are reflective of both the hope and suspicion that underscored the debate and discussion leading up to its signing. The hope was that the Basin's collective interests would outweigh more localized interests and render the restrictive provisions of the MOA unnecessary. Yet this hope was undermined by the parties' deep seated (and, as this study report will show, long standing) opposition to centralized authority in any regional governance system. The states, tribes, and federal agencies would not support a decision process that could challenge state or tribal sovereignty or federal agency prerogatives. The MOA underscored this principle through the requirement for a super-majority to get issues even considered by the Committee; the requirement for consensus voting; the long list of exclusions; and the provision that allowed any party to terminate collaboration of any issue that fell under its jurisdiction. These provisions are the heart of the paradox. ${ }^{18}$ The result was a document crafted on the optimism that consensus on substantive issues would emerge while denying the $\mathrm{CRBF}$, as an institution, any mechanism for resolving issues for which consensus proved impossible.

\footnotetext{
${ }^{18}$ The predictable problems with this sort of arrangement caused some regional leaders to champion a permanent legislative solution to alter the institutional prerogatives that the MOA's provisions were designed to protect. The CRBF debate illustrates how difficult it will ever be to get the political process to produce such legislation absent a regional crisis of such magnitude that it dwarfs parochial concerns. It is difficult to see how the MOA signers - all of whom represent sovereign entities that could have voluntarily surrendered some sovereignty to further region wide interests - would support creation of a statute leading to the same end. As this study will show, they never have.
} 


\section{The CRBF in Action}

The Forum Committee ${ }^{19}$ met thirteen times between March 1999 and April

2000. The first two meetings, both in March 1999, understandably focused on internal organizational issues. The Forum Committee appointed two ad hoc subcommittees, one to address budget and funding and the other to develop an agenda and logistical arrangements for a proposed Forum Board meeting. It unanimously elected Eric Bloch, an Oregon representative to the Council and Oregon's representative to the Forum Committee, as chair. It agreed that discussions of substantive issues would take place within the Forum Committee as a whole rather than developing an overly bureaucratic system of multiple subcommittees. The Committee agreed that each representative should produce credentials from their respective agency head or government formally appointing him or her as their parent body's official spokesperson. ${ }^{20}$ The Committee agreed to hire a coordinator to manage its internal business and assigned a subcommittee to develop a work plan for meeting its MOA responsibilities (Meeting Minutes, March 10 and March 30 1999). In short, the first meetings were used to "sort out the membership and begin formulating a plan for

\footnotetext{
${ }^{19}$ The Forum's tribal representatives were John Platt, Chad Colter, Howard Funke, and Brian Lipscomb. State representatives were Eric Bloch (Oregon) who also served as the Forum Committee Chair, Bob Nichols (Washington), Mike Field (Idaho), and Stan Grace (Montana). Federal representatives were Doug Arndt (U.S. Army Corps of Engineers, for the Department of Defense), Karen Hunt (Bonneville Power Administration, for the Department of Energy), Anne Badgley (U.S. Fish and Wildlife Service, for the Department of Interior), and Danny Constenstein (National Marine Fisheries Service, for the Department of Commerce).

${ }^{20}$ By insisting on credentialing, the group hoped to avoid a problem that plagued the Regional Forum: different people claiming to represent the same governmental entity or non-government interest but advocating different policy positions (Meeting Minutes, March 10 1999).
} 
addressing the tasks outlined in the MOA" (Espenson, March 12, 1999). Subsequent meetings resulted in development of a work plan and agreement on a guiding goal statement (Meeting Minutes, April 29 and September 7, 1999).

The tone of discussions as recorded in meeting minutes and reported in press coverage of meeting proceedings is civil, respectful, and conveys the sense of importance that all participants attached to Forum Committee business. However, over time, the meeting notes also document the growing frustration with the group's inability to come to grips with issues of substance.

Federal agencies and the Northwest Power and Conservation Council had six major, interrelated processes underway in the Columbia Basin at the time of the CRBF's formation. These were:

- The U.S. Army Corps of Engineers environmental impact statement (EIS) concerning juvenile fish passage through the Snake River dams. ${ }^{21}$ The most controversial option under consideration in the EIS was potential removal of the earthen portion of four dams on the lower Snake River. Selection of this option would eliminate commercial navigation into Idaho and hydropower production.

- The National Marine Fisheries Service biological opinion on the Federal Columbia Basin Power System (FCRPS). This opinion and the Corps EIS

\footnotetext{
${ }^{21}$ The National Environmental Policy Act (NEPA) requires federal agencies integrate environmental values into their decision making processes. To meet NEPA requirements, federal agencies must consult with any other federal agency holding jurisdiction by law or special expertise with respect to a potential environmental impact of a proposed action. The agency then prepares a detailed statement known as an environmental impact statement. See NEPA, 1970, section 102 (C).
} 
comprised the core elements informing a much-anticipated decision expected by 1999 on the future of the FCRPS.

- The Federal Caucus' Basinwide Salmon Recovery Strategy. ${ }^{22}$ The federal agencies producing this document intended it to serve as a roadmap to salmon recovery. It addressed all of the "Hs" believed to affect the salmon life cycle: habitat, harvest, hatcheries, and the hydropower system. ${ }^{23}$

- Then Northwest Power and Conservation Council's "Multispecies Framework." The Council undertook this initiative to look holistically at opportunities to improve environmental conditions for all Basin fish species.

- Bonneville Power Administration's (BPA) 2001 - 2006 rate case. The Bonneville Project Act of 1937 requires the BPA administrator to sell electricity generated from federal hydropower projects in the Columbia River to preference customers at cost. Cost includes the cost of energy acquisition, conservation, and transmission and includes routine operations and maintenance and the amortization of capital projects. The rates at the time of the CRBF went into effect in 1996 for the five-year rate period from

\footnotetext{
${ }^{22}$ At this point, the Federal Caucus was a loose consortium of the federal agencies involved with NFMS' Regional Forum. The Federal Caucus would meet to coordinate federal agency positions in preparation for discussions within the Regional Forum and CRBF. The CRBF envisioned three such caucuses; the Federal Caucus, a state caucus, and a tribal caucus. The Federal Caucus was formally codified under a Memorandum of Understanding signed in 2000 (personal experience of author).

${ }^{23}$ The Basinwide Salmon Recovery Strategy was initially referred to as the "4-H Paper." This colloquialism was changed to the "All-H Paper" upon receipt of a letter of complaint sent by the 4-H Club organization (personal experience of author). The original document can be found at http://www.salmonrecovery.gov/BiologicalOpinions/FCRPS/2000Biop/AllHStrategy.aspx.
} 
October 1996 through September 2001 (BPA, 1996). BPA was undergoing its rate setting process for rate period October 2001 through September 2006. The federal government was deregulating and restructuring the energy industry in order to improve competition and reduce prices. Deregulation was especially complex in the Pacific Northwest due to the dominant position in the energy market occupied by BPA, a federal agency under the U.S. Department of Energy. ${ }^{24}$ The impact of deregulation on BPA in general and highly volatile swings in west coast energy prices during the summer of 2000 raised anxiety in the minds of many over the future of the region's cherished low energy prices (BPA, 2001).

- The U.S. Forest Service, U.S. Fish and Wildlife Service, and Bureau of Land Management's Interior Columbia Basin Ecosystem Management Project (ICBEMP). Created through a 1993 directive from President Clinton, ICBEMP's purpose was to develop a "scientifically sound, ecosystem based strategy for management of 64 million acres of lands administered by the Forest Service and the Bureau of Land Management within the Columbia River Basin, and portions of the Klamath and Great basins in Oregon." Concerns over forest and rangeland health, wildland fires, and threats to fish and wildlife species inspired this effort. ICBEMP released a final environmental impact statement and proposed decision in December 2000 (ICBEMP, undated). The release initiated a period of

\footnotetext{
${ }^{24}$ At the time, BPA provided on average about $40 \%$ of the electrical power sold in the region and controlled more than $50 \%$ of the region's transmission lines (BPA, 2001).
} 
protest and recriminations as communities grounded in resource extraction industries such as timber, mining, and ranching reacted to perceived threats to their ways of life.

These six processes were each addressing substantive and far-reaching issues. The resolution of those issues had the potential to disrupt the status quo of regional economic and commercial arrangements. Each participant in the CRBF, as well as numerous non-governmental organizations and institutions, had a substantial stake in the outcome of these other processes and the potential impact of one process on the others. Despite this, as pointed out by the facilitator during the October meeting, even after four or five sessions, the time still being spent on discussing process to the exclusion of substantive matters (Meeting Minutes, October 11, 1999).

It was the importance of the potential policy outcomes of these parallel processes that led to the creation of the CRBF. Ironically, that importance was equally the reason that regional agents ensured, through the MOA's provisions, that the CRBF was impotent to substantively resolve differences over the underlying issues. The resulting sense of frustration led to members eventually losing confidence in the Forum Committee's ability to achieve anything significant.

\section{The Collapse}

The group grew increasingly frustrated over (1) the uncertain role of the CRBF in relation to other regional processes addressing many of the same issues, (2) 
questions by some participants over the actual level of commitment to the CRBF by member governments, (3) funding, and (4) the requirement for consensus decisions.

Recall that the overlapping nature of multiple complex processes and the lack of any comprehensive coordinating mechanism was one of the motivations behind creation of the CRBF. However, the lack of clarity in the MOA (1999) as to precisely what the Forum Committee was expected to do carried into the Forum Committee discussions. Recall also that the purpose written in the MOA (1999) called on the CRBF to serve as "a high-level policy forum in which federal, state and tribal governments... will address, collaborate on and coordinate basin-level policy, planning, decision-making and implementation issues that effect [sic] the Columbia River Basin fish and wildlife and related habitat" (p. 3-4). The parties interpreted this differently. The representatives from Washington, the upriver tribes, and the Corps of Engineers felt the Forum Committee should be developing a basin-wide strategic plan to guide the other ongoing processes. ${ }^{25}$ Others (Montana, Idaho, and lower tribal representatives) ${ }^{26}$ felt that such an overarching plan would be redundant to the other processes and instead looked to the Forum Committee to resolve specific issues (Meeting Minutes, April 29, May 27, June 24, September 7, 1999).

\footnotetext{
${ }^{25}$ Interestingly, this planning function was similar to that performed by The Pacific Northwest Regional Planning Commission (1933-1943), the Columbia Basin Inter-agency Committee (1946-1967), and the Pacific Northwest River Basins Commission (1967-1981). Efforts at multi-domain, region wide planning essentially ended with the 1981 termination of the Pacific Northwest River Basins Commission. These other governance systems will be discussed later in this report.

${ }^{26}$ It is not exactly clear what Oregon's position was on the need for an overarching plan. The July meeting minutes record the Oregon representative as stating that a desired goal of the group was a "plan that will lead to fish and wildlife recovery." In September, however, the meeting minutes state that he believed that, with other processes underway, it would not be appropriate for the Forum to develop another plan.
} 
By July, group frustration over the lack of agreement over its role grew more pronounced. Fundamental differences in policy objectives held by the parties exacerbated the situation. For example, representatives from the Salish Kootenai and lower river tribal representatives argued for restoration of a "natural cycle" to the river, which could mean partial removal of the Snake River dams and/or additional flows out of the reservoirs in Montana and Idaho - actions that Montana, Idaho, and other upper river tribes vehemently opposed. Other controversial issues included the role of hatcheries to supplement conservation objectives, the practice of barging of fish past the dams during the late summer, and a definition of the appropriate balance between "fish and people". Representatives from Idaho, Washington, and the upriver tribes were eager to move on with substantive discussions on these issues. Meanwhile, Oregon and the representative from the lower river tribes believed the group needed to agree to specific objectives before such substantive discussions could be meaningful (Meeting Minutes, July 21 1999; Espenson, July 30, 1999).

Although the Committee adopted an overarching goal statement in September (Meeting Minutes, September 7, 1999), the group was never able to agree to objectives that were more specific or engage on substantive issues. Governor Kitzhaber, concerned over the lack of progress, noted in September that the region was at "grave risk" of losing its two most prized assets: salmon and the "reliable low cost supply of power produced for the Northwest by the federal dams on the Columbia River." Noting once again that neither the Columbia River Basin Forum nor the Northwest Power and Conservation Council could authoritatively address the region's issues, he 
renewed the call for congressional legislative action to replace both. Governor Kitzhaber likened the situation to the Balkans of Europe, noting that regional parties have "no requirement for coordinated action and no way to resolve conflicts between themselves" (O’Bryant, September 24, 1999).

The second general source of member frustration was deep suspicion over the level of genuine commitment the other participating governments had to the process. Both the state and tribal representatives questioned the degree to which federal agencies were willing to accept CRBF recommendations on pending NMFS' biological opinions, the Corps's environmental impact statement on the effects of the Snake River dams on salmon survival, and elements of the Federal Caucus' Basinwide Salmon Recovery Strategy. The continuation of federal-only meetings on those subjects formed the basis of state and tribal skepticism. The states also noted a decreased participation by federal agencies in the Council's Framework process. NMFS, responding for all the agencies, stated that while input from the region was welcome, the federal government alone was statutorily responsible and legally accountable for the responsibilities charged to it under the ESA (Meeting Minutes, March 10 and March 30, 1999). It could not risk failing in these duties should the $\mathrm{CRBF}$ be unable to come up with useful recommendations. Adding to the suspicion over federal intent was the fact that, although the federal government had filled its four positions on the Forum Committee, it never formally put a name to its one position on 
the Forum Board (Meeting Minutes, May 27, June 24, and October 1999). ${ }^{27}$ Federal Forum Committee representatives contended that this was a function of bureaucratic inertia rather than lack of support for the Forum (Meeting Minutes, May 27 1999). The lack of an administration-level representative symbolically reinforced the sense among states and tribal representatives that the federal government was not as committed to the spirit of the CRBF as had been hoped.

Tribal commitment was internally mixed and externally perplexing. Tribal leaders were among the most critical of the $\mathrm{NPPC}^{28}$ and Regional Forum as governance systems due to the lack of tribal membership in those bodies. Tribal leaders had long called for greater input into regional processes and the inclusion of tribal governments in regional decision-making was a central and important purpose of the Three Sovereign's process and CRBF (Crampton, December 5, 1997).

The Snake River and upper Columbia tribes all signed the MOA, and their representative was among the most vocal urging the Forum Committee to begin work on substantive issues. However, a history of court battles over fishing rights had made the four lower river tribes skeptical of state motives. ${ }^{29}$ The lower river tribes

\footnotetext{
${ }^{27}$ From the beginning, the Forum Committee struggled to identify a meeting date for the Forum Board. Although the federal government never formally appointed a representative to the Board, the Chair of the President's Council on Environmental Quality agreed to attend the Board meeting should it ever be held. It never was.

${ }^{28}$ It should be noted that the Council's Multispecies Framework process had the active support and participation of the tribes, and that the 1980 Power Act specifically required consultation with tribal fish managers on the Council's fish and wildlife program.

${ }^{29}$ These comments are based on the author's personal experience in listening to tribal elders and leaders concerns regarding regional governance systems. See also Taylor (1999), Pevar (2002), and Dompier (2005).
} 
consistently made the point that their treaties are with the federal government and are leery of any process that may open an opportunity for state interests to encroach on the rights ensconced in the treaties. Additionally, the Forum Committee's representative structure ran counter to tribal political culture of direct democracy (as underscored by the Nez Perce position). ${ }^{30}$

The lower river tribal governments that were unable to resolve the question of whether to sign the MOA presented a frustrating conundrum to the Forum Committee. These tribes justified their reluctance to sign as by arguing that it was not yet clear if the CRBF process would prove worth their time. Yet, as the Forum Committee chair noted, their official input was essential in the design of what that process would turn out to be (Meeting Minutes, July 21, 1999). In effect, the lower river tribes refused to engage in the process to design the structure that would make their formal participation worthwhile.

Federal and state CRBF members were rankled by the lack of formal involvement and sometimes participation by all of the Basin's tribes. The Idaho representative voiced this frustration when he noted that other participants had signed on to the CRBF process with the understanding that formal tribal participation (the lack of which was noted as a "huge void" in the Regional Forum process) would be forthcoming. If their participation did not occur, he argued that the group should "reassess" what the Forum was doing (Meeting Minutes, June 24 1999). Ultimately, a

\footnotetext{
${ }^{30}$ It was a significant concession on the part of those tribal governments that did sign the MOA to have their interests represented by people not directly associated with their respective tribe.
} 
substantial part of the lower river tribal commitment problem was one of the Forum Committee's own making. By agreeing early on to allow non-signatories to participate in CRBF business, they removed a major incentive for those tribes who had not already done so to sign on to formal membership.

State commitment to participation in the CRBF process was very strong, which is not surprising given that the CRBF was the product of an initiative by the four regional governors. However, the amount of authority carried by each state's representative to truly collaborate and compromise on substantive issues was limited. The governor of Idaho delayed signing the MOA and made it clear when he did so that the issue of dam removal was not up for discussion, a position also maintained by the Washington representative. Idaho and Montana also opposed additional flow augmentation or increases to spill (Meeting Minutes, June 24 1999). What emerges from the meeting minutes is the sense that the states were willing to talk about a great number of things, but would not negotiate or compromise on any action or recommendation from the Forum Committee contrary to core state interests. An unwillingness to compromise or negotiate on key issues led a Yakama tribal council member to chide the group as a whole for "competing and jockeying for position rather than joining forces to improve the resource" [referring to salmon] and noted that "each participating party is unbending in representing its own interests" (Espenson, July 30, 1999).

The third source of frustration related to the second in that questions regarding participant commitment brought attention to participant funding. The MOA (1999) 
required each participating government share an "equitable" distribution of costs.

Unfortunately, the MOA failed to define "equitable."

The initial budget called for $\$ 119,000$ - \$189,000 for federal fiscal year 1999 .

The delay in signing the MOA and establishing the Forum Committee meant that the

Committee did not need entire amount. A revised estimate put direct costs for 1999 at

$\$ 70,000$. The Council agreed to provide about $\$ 28,000$ of in-kind services. ${ }^{31}$ Funding

was not secured until the following July, and then only for $\$ 50,000$. Of this, the

Northwest Power and Planning Council provided $\$ 40,000$ but agreed to pay no more

than $1 / 3$ of direct costs for subsequent years. ${ }^{32}$ The four states represented the Council

contribution as their share. BPA provided an additional $\$ 10,000$. Contributions from

the other entities represented on the Forum Committee consisted of in-kind support

provided by member participation (Meeting Minutes, April 29 1999; Fazio, July 2,

1999).

The Bureau of Indian Affairs initially agreed to fund \$3,000 per tribe for travel (Meeting Minutes, July 21, 1999) although they had trouble actually coming up with all of the money. Despite MOA language calling for "equitable" sharing of costs, neither the tribes nor states contributed any of their general fund moneys to the CRBF. Other than BIA and BPA, no federal agency provided cash contributions. In effect, the Bonneville Power Administration financed the lion's share of the CRBF, either

${ }^{31} \mathrm{CRBF}$ funding followed the federal fiscal year of October 1 through September 30 . The $\$ 70,000$ noted here would fund the Forum Committee through September 1999. The budget for fiscal year 2000 was estimated at $\$ 75,000$. BPA contributed $\$ 10,000$ and NPPC $\$ 25,000$ consistent with its previous 1/3 commitment. No other entity offered funds. As it turned out, additional funds were not needed.

${ }^{32}$ BPA provides all funding for The Northwest Power and Planning Council and its programs in accordance with the Pacific Northwest Electric Power Planning and Conservation Act of 1980. 
directly or through the Council's program (Meeting Minutes, April 29 and October 11, 1999).

The fourth area of frustration was the MOA's requirement for consensus decision-making. Even the seemingly simplest decisions could become difficult. For example, scheduling the first Forum Board meeting was a frequent subject of discussion. The Forum Board never held its meeting, partly due to scheduling but mostly due to disagreement as to the meeting's purpose. Oregon, the tribes, and the federal agencies felt that the first such meeting would be ceremonial in nature, representing a statement of commitment by each participating government. Washington, on the other hand, opposed a Forum Board meeting unless the Forum Committee provided substantive issues or accomplishments for Board member discussion.

The Forum Committee chair summed up the problem of consensus based decision making at the October meeting. He stated, "people think they can come and go, and any time they're not here, then they have a bye that month, and nothing that is accomplished or agreed to is in any way binding on them" (Meeting Minutes, October 11, 1999). The inability to schedule a meeting of the Board meant that the disputes within the Forum Committee could never be elevated, let alone resolved.

The inability to come to agreement over the role of the Forum Committee; lingering suspicion over participants' true level of commitment; funding; and the inability to resolve the challenges of consensus decision making came to a head in January 2000. The Montana representative stated he would no longer attend Forum 
Committee meetings. "I yet see little opportunity for this body to be effective in resolving solutions to the problems they address," he said. "Most of the issues are being debated in other forum arenas that we [Montana] have access to. In those arenas the decision-making bodies have traction in bringing resolution to the issues and implementing those decisions." Also citing the lack of commitment and participation by other parties, he noted that Montana would reengage if the Forum Committee could agree to "changes and commitments" (O’Bryant, January 14, 2000).

Coupled with the withdrawal of Montana was the growing perception that the perceived threats enumerated by Governor Kitzhaber were not as severe as first thought. For example, over time, regional utilities adapted to energy deregulation without major disruption to the region. The Corps study of the Snake River Dams and the NMFS BiOp did not make the dramatic calls for dam removal that some feared. The collective sense of threat posed by the suite of issues facing the region dissipated as other venues worked through them. In effect, the issues that caused so much concern in the beginning failed to rise to a level of criticality sufficient to justify the $\mathrm{CRBF}$ as an enduring governance system.

The withdrawal of Montana signaled the end of the CRBF. The Forum Committee held its last meeting on April 29, 2000 after which effectively dissolved. What could pass as its epitaph is captured in the last line of a document about the CRBF posted on the Northwest Power and Conservation Council's website: "The Forum conducted its deliberations for slightly more than one year before collapsing through diminished participation of the Forum membership" (NPPC, undated). 


\section{Challenges to Governance in the Columbia River Basin}

Why is it that, even with agreement on the common goals of better decisionmaking, a more inclusive process, and preservation of common regional interests, the CRBF failed? Is regional governance intrinsically paradoxical? The circumstances surrounding the CRBF illustrate several inherent challenges to establishing workable governances systems. These are the difficulty of resolving deep-seated conflicts over resource use among resource users, especially when exacerbated by differing values; and structural issues of common vision, commitment to the governance body's goals and objectives, funding, and processes for substantive decision-making.

Competing interests, aspirations, and values.

Inter-institutional conflict can occur over conflicting interests and/or when parties perceive that their aspirations are incompatible with the aspirations of others and when mutually satisfactory alternatives are not available (Pruitt and Kim, 2004). For example, within the Columbia Basin, the interests and aspirations of those dependent on the commercial benefits of the dams were incompatible with those of advocates for dam removal in the interest of improved fish runs. Another example is the incompatibility of the aspirations of those favoring market mechanisms for the pricing of electricity with those favoring cost-based rates. Similar examples could be found of other perennially controversial issues in the region, such as flow augmentation (pitting aspirations of fish advocates against the aspirations of irrigation and recreation advocates) or levels of tribal harvest (pitting the aspirations of tribes against those of recreational and commercial fishermen). No argument, however well 
crafted, regarding dam removal, dam retention, or a significant modification to dam operations can ever completely satisfy all parties.

What leads parties to become so intransigent in defending their aspirations and interests? Pruitt and Kim (2004) identified four conditions that can cause aspirations to become rigid to the point of precluding any opportunity for compromise. These are (1) the importance of the underlying interests, (2) the degree to which strongly held principles are believed to be at stake, (3) the degree to which available options are perceived to be of the either-or variety, and (4) the degree to which parties see their aspirations as being legitimate or just (Pruitt and Kim, 2004). All four conditions are present in the Northwest. A few examples: The preservation of inexpensive hydroelectric power is of vital economic interest to the region as a whole. The low cost of waterborne navigation is of vital importance to agricultural and wood products businesses in Idaho, Montana, and eastern Oregon and Washington. The salmon fishery is of fundamental cultural and economic importance to the tribes and the economic mainstay of communities in the lower Columbia River and along the coast.

Then there is water. Many of the farmers and ranchers in the region are descended from original settlers lured to the region by the promises of free land supported by irrigation water (Smith, 1950; Dodds, 1986; Pisani, 2002). To them preserving their water rights is the central priority, even to the extent of discouraging neighbors from voluntarily trading or selling their water rights for environmental purposes. 
The disputes among regional parties are often perceived as zero-sum options that leave little room for compromise. All parties claim legitimacy grounded in either law or tradition (Taylor, 1999). Examples include tribal rights to fish as protected by treaties and federal trust responsibilities; the defense of long-established water rights by inland farmers and ranchers; and commercial fishermen struggling to maintain a way of life began by their grandfathers and great-grandfathers.

All of this creates an enormous challenge for regional leaders. Their constituents perceive any predilection of an elected or politically appointed official to compromise for the sake of a greater good as a betrayal. One cannot simply attribute this lack of a basis for compromise as a rational defense of tangible institutional interests. Many Columbia Basin resource advocates genuinely and honestly believe in the moral righteousness of their respective positions. These positions are thus reflective of deeply held values and beliefs.

Structural issues: Shared vision, commitment, funding, and decision-making. In addition to conflict over values, four significant structural problems crippled the CRBF. The first was a lack of a common vision over what the CRBF was intended to do, especially given that other processes were underway in the region addressing many of the issues the CRBF was established to address (Meeting Minutes, April 29, May 27, June 24, July 21, and September 7, 1999; Espenson, July 30, 1999).

The second was a perceived lack of commitment on the part of all participants. From the beginning, participants approached the CRBF with varying degrees of enthusiasm. All voiced commitment to the process, but the lack of support to address 
key issues, the failure for all parties to sign the MOA, and the failure to appoint individuals to all positions served to aggravate existing senses of distrust over other parties' motives (Espenson, Feb 5 and Mar 12, 1999; Meeting Minutes, May 27, June 24, and October 1999).

The third contributing factor to the demise of the CRBF was funding. Whereas the MOA (1999) called for each participant to contribute an equitable amount of funds for CRBF operations, only the Bonneville Power Administration (BPA) and, to a lesser degree, the Bureau of Indian Affairs (BIA) did so. Holding participants to the funding terms of the MOA could have potentially accomplished several things. It would have signaled the commitment of each participating government to the process, would contribute to the sense that the deliberations of the group were "real" to its participants, and would have likely sustained attention of the region's elected leadership. None of these occurred since BPA managed ratepayer dollars predominantly funded the CRBF. Consequently, none of the participants other than BPA had a financial stake in ensuring process efficiency (Meeting Minutes, April 29, July 21 and October 11, 1999; Fazio, July 2, 1999).

Fourth and perhaps most importantly was the cumbersome and ineffectual decision-making process called for in the MOA. The process required almost complete agreement before the Forum Committee could even discuss and issue, let alone resolve it. The results of this decision-making process were not binding, even if strong majority agreement existed, in that anyone disagreeing with an outcome could 
simply veto it (MOA, 1999; Meeting Minutes, April 29, May 27, June 24, July 21, and September 7, 1999; Espenson, July 30, 1999).

\section{Chapter Summary:}

Following are the key points drawn from the CRBF history:

- Regional leaders sought to establish a new governance system that would provide a reasoned and rational basis to resolve regional differences.

- Pending significant decisions on energy deregulation, dams, and salmon occurring within processes from which many felt excluded motivated regional leaders to explore a new decision process. These issues held the potential to exert considerable impact on the regional economy, environment, and individual livelihoods.

- The CRBF was comprised of institutional actors with long standing attachments to regional resources and established worldviews and values regarding those resources. These actors included federal and state agencies, regional Indian tribes, commercial firms and trade associations, and non-governmental organizations. Each institution had rights, authorities, interests, and/or prerogatives they wished to protect.

- Regional institutional leaders established the CRBF to address critical regional issues while paradoxically refusing it the authority needed to do so. 
- Some signatories to the Forum MOA made their signature contingent on precluding discussion of key issues. As a result, the Forum was unable to address many of the issues for which it was formed.

- Regional political leaders who recognized this potential weakness from the beginning believed a more effective and authoritative system should be established through federal legislation. However, this legislative effort was either not seriously attempted or eventually abandoned. ${ }^{33}$

- Refusal of all parties to sign the CRBF MOA (1999) exacerbated the MOA's structural problems. The Forum Committee decision to allow nonsignatories to participate in its discussions and decisions added to the dysfunction. Representatives of non-signatory parties were thus free to engage in extended debates without being bound by whatever agreements or decision the group as a whole eventually reached.

- Despite the time spent in negotiating the MOA, serious disagreement remained among Forum Committee members over the Forum's purpose and authorized scope of activity. The Forum Committee spent most of its time debating process as opposed to debating and resolving substantive issues.

- Serious distrust existed as to the commitment and motivation of other Forum Committee members to meet the spirit of the MOA.

\footnotetext{
${ }^{33}$ The records reviewed for this study are not clear on this point.
} 
- Frustration with the inability of the Forum Committee to address issues of substance led Montana to withdraw. The Forum collapsed soon thereafter.

- The CRBF faced challenges of constitutional structure, competing interests and values, and structural design.

The Columbia River Basin Forum had set for itself the purpose of simplifying processes by, "eliminating duplicative efforts and consolidating or eliminating existing committees or bodies" (MOA, January 1999, p. 4). By denying itself any capability for definitive decision-making and lacking commitment from a significant number of participants, the CRBF had no basis for replacing other ongoing processes at the time, almost all of which focused on some substantive goal, however limited that goal may be. In limiting its role to only discussion of the issues, the Forum Committee ended up replicating debates taking place within these other processes. With no real ability to influence outcomes, the CRBF ironically positioned itself to be another one of the "duplicative efforts" it had hoped to eliminate.

In designing the CRBF MOA, institutional negotiators deliberately created a consensus-based process based on the hope that, if reasonable leaders from regional institutional stakeholders could meet to rationally discuss the issues at hand, reasonable compromises would be reached. However, they hedged their bets by ensuring that every representative reserved veto authority over any collective position not in accord with the interests of their respective constituency. As a result, parties to the CRBF gave themselves no ability to address substantive issues. 
As observed by Russell Linden (2002) in his book on collaboration, "the forces that pull people apart are very strong, some of them wired into the very DNA of organizations, and it takes far more than good intentions and kind-hearted people to make collaboration work" (Linden, 2002, p. 36). This study researched the historical record to determine why Linden's assertion seems so applicable to the Columbia. It adopted the apparent paradox of the Columbia River Basin Forum as its research question. The next chapter explains the method through which this question was addressed. 


\section{CHAPTER 2 \\ ANALYTICAL FRAMEWORK}

\section{$\underline{\text { Research Question, Purpose, and Relevance }}$}

The paradox suggested by the Columbia River Basin Forum experience presents a fundamental question. Whereas many prominent northwest political and institutional leaders strongly believed some form of regional governance system was necessary, why did those same leaders fail to empower the system with the authority necessary to resolve the issues that led them to create it the first place?

This study is the first step in a larger research project to address this question. It presents an institutional level case history of Basin governance that identifies the various governance systems proposed and enacted since 1934 and categorizes them into models according to their locus of decision-making as defined by their dominant institutional participants. Its purpose is to analyze the Basin's multi-jurisdictional governance experience for trends both in the types of systems enacted and those rejected. The goal, in effect, is to understand and explain how the region chose the governance systems it established.

This study identified twenty-six governance systems proposed during the period of study of which eleven were established. It presents the history of those systems using an analytical framework suggested by the circumstances surrounding

the rise and collapse of the Columbia River Basin Forum. Chapters are organized by the catalytic, critical situations whose occurrences allowed existing systems and structures to be challenged or overturned and new ones formed in their place - an 
approach inspired by Bessey (1963) in his history of northwest regional planning. Other elements of the framework include each system's dominant participants, the other institutional actors involved, the social and political context from which each system emerged, and the salient issues that they were intended to address or influenced their establishment.

Why does any of this matter?

Giddens' (1976, 1979, and 1984) theory of structuration and Sztompka's (1991) theory of social becoming argue that no social system springs anew. All social systems evolve from those that came before and serve to shape those that follow. The findings of this study support those arguments. Each governance system identified, whether merely proposed and debated or actually enacted, demonstrably had roots in earlier systems and structures. Each new system either evolved noncontroversially or resulted from some catalytic event that allowed excluded parties to challenge existing system(s) as they vied for influence over regional resources and institutional prerogatives. Each was either a modification or an outright replacement of an earlier system and in turn formed the basis for those that came after.

This point is relevant because efforts to establish new Basinwide governance systems did not end with the Columbia River Basin Forum. For example, in 2004 staff from the Northwest Power and Conservation Council presented a proposal to reconfigure the National Marine Fisheries Service’s Regional Implementation Forum 
and establish a new Executive Committee under the auspices of the Council $^{34}$ (Council to Look, May 7, 2004). More recently, sovereign parties in litigation over the impacts of the FCRPS on salmonid species listed under the Endangered Species Act established a Regional Implementation Oversight Group to oversee the measures called for in the National Marine Fisheries' 2008 FCRPS biological opinion (personal experience of author). Understanding the historical connections to past governance systems can inform these and future governance efforts.

The author found no history centered on Columbia Basin governance systems as a whole in researching this report. Of the materials reviewed for this study, only two (Scheufele, c.1970 and Hemmingway, 1983) wrote to objectively analyze a particular governance system. Scheufele (c.1970) analyzed the Columbia Basin InterAgency Committee and Hemmingway (1983) the Northwest Power Planning and Conservation Council. All other accounts were written to either address other aspects of the region's history (for examples, see Ogden (1949), McKinley (1952), Bessey (1963), White, (1995), DeLuna (1997), Brigham (1998), Vogel (2007), Pope (2008) and others) or promote a particular system (see McKinley, 1952 and Ogden, 1997). Consequently, their discussion of any particular governance system was usually limited to those elements relevant to the story they wished to tell.

\footnotetext{
${ }^{34}$ This proposal is fully laid out in two NPCC staff memos. The first, dated June 1, 2004 and authored by Doug Marker, is entitled Discussion of Implementation of Mainstem Amendment Measure Concerning Council Sponsorship of Federal Hydrosystem Decision Making Structure. The second, authored by John Shurts, John Ogan and Doug Marker, subject: Proposal for revision to mainstem implementation forum consistent with fish and wildlife program amendments, is dated July 6, 2004. The July 6 memo is available at the Northwest Power and Conservation Council's web site at http://www.nwppc.org/news/2004_08/aug04_13.pdf. A May 4 draft of the June 1 memo can be found at http://www.nwppc.org/news/2004_05/ fw2.pdf.
} 
In addition to providing a history, this study offers diagnostic, predictive, and normative contributions to the general understanding of the Northwest's governance experience. The study provides its diagnostic contribution through its exploration of the social and political contexts and issues from which various governance systems emerged. As such, it provides an in-depth look at how Basin governance evolved with the region's history and in response to the motives and interests of institutional participants. It thus helps explain why things are the way they are and provides a partial explanation as to why getting to accord over governance of the region's natural resource issues has often proven so difficult.

The study provides predictive contribution through its identification of two sources of system change. The first is noncontroversial evolutionary change from within existing systems. The second is conflict-based change that involves a sequence of activities that appears to repeat itself each time certain conditions are present. In essence, this conflict change pattern showed that regional governance arrangements maintained themselves in relative stability until faced with a critical situation (Giddens, 1984). ${ }^{35}$ These critical situations allowed existing arrangements to be called into question and opened the door for introduction of new governance systems by previously excluded parties. The region then goes through a period of adjustment as these previously excluded entities attempt to gain influence while the included entities seek to retain and/or expand the influence they have. Certain procedural events

\footnotetext{
${ }^{35}$ Giddens (1984) defines critical situations as those that result in changes to social systems and structure. By this definition, if no change occurs then circumstances were not sufficiently "critical." Consequently, the occurrence of such a situation can only be confirmed in hindsight.
} 
follow, with regional institutional leaders calling for public meetings, engaging in negotiations, and eventually deciding to either reach agreement on new systems and structures or modify those already in place. Assuming the situations that inspired the effort prove sufficiently critical, the region adopts new systems that eventually settle into a condition of stability pending arrival of the next critical situation. What the next critical situation will be, or when it will arrive, cannot be predicted with any precision. What is predictable is that, once institutional leaders perceive such a situation to have arrived or be imminent, they will likely initiate the change pattern. By understanding this dynamic, those seeking to change (or preserve) the status quo of governance arrangements can plan accordingly for the day when such circumstances appear.

The study provides its normative contribution in part through its identification of the patterns of change noted above and through its proposal for additional research into the role of values in governance related decision-making. The pattern of system development can lead to expectations over how things are supposed to be and how individual institutional members should behave when critical situations present (Schein, 1984; Giddens, 1984). Consequently, such circumstances can serve to shape the behavior of individuals as similar conditions present themselves in the future. The history reviewed for this study alone did not completely answer the paradox question. It did, however, suggest that a more complete answer might be found through additional research into the role that values associated with institutional worldviews, cultures, and identities play in individual decision-making during periods of 
negotiation. Such research may offer further prescriptions to increase the likelihood of success in future governance efforts.

\section{$\underline{\text { Scope }}$}

The geographic scope of this study is that portion of the Columbia River Basin lying within the United States Pacific Northwest, including its major tributaries, as illustrated in Figure P-2. This corresponds to the geographic scope of the CRBF and most of the other multi-jurisdictional governance systems with which the region has experimented over time. ${ }^{36}$ The study focused only on governance systems involved with the planning, development, and/or operation of what became the Federal Columbia River Power System and the impact that FCRPS operations had on the commercial and sports fishery, natural regional salmon runs, Indian treaty rights, and the region's economic and social development.

The study did not address international issues of governance, such as the 1964 treaty with Canada that governs flood control and power benefit allocations between the two countries. Nor did it examine other natural resource governance systems and structures involving other natural resources issues, such as the Regional Interagency Executive Committee organized under the Northwest Forest Plan or the Pacific Fishery Management Council established under the Magnuson Fishery Conservation and Management Act of 1976.

\footnotetext{
${ }^{36}$ All systems identified in this study encompassed the Columbia River Basin. Some, such as the Pacific Northwest Regional Planning Commission encompassed the entire Northwest.
} 


\section{Methodology}

Whereas this study presents a case history, it does not follow a traditional case study methodology. With the exception of the discussion of the Columbia River Basin Forum, it uses an historical method, relying on secondary sources to research governance systems at the institutional level. This section describes this method. It discusses the methodological sources upon which the study design relies, the methodological approach, and the study's potential limitations and weaknesses.

\section{Method.}

The methodological approach used generally followed those offered by Neustadt and May (1988) in Thinking in Time: The Uses of History for Decision $\underline{\text { Makers and Ritchie and Spencer (2002) Qualitative Data Analysis for Applied Policy }}$ $\underline{\text { Research. }}$. Neustadt and May's (1988) Thinking in Time is based on the authors' Use of History course offered through the Kennedy School of Government. The authors intended their book for senior policy makers as a manual for staff work regarding the use of history to inform decision-making. Using a case study approach, the authors advocate a reflective and systemic process for analyzing history to inform policy choices. They offer a seven-step process that focuses on storytelling to make the links between what is known to what the researcher wishes to find. Ritchie and Spencer's (2002) Qualitative Data Analysis, although intended for use in analyzing original data, offers useful advice for the review of secondary sources as well. Their framework involves a systematic process for sifting and sorting material according to key issues and themes. 
This study's unit of analysis was the institutions involved in Basin governance systems. These institutions included those Indian tribes, federal and state agencies, and private enterprises involved with land and water use, river infrastructure development, and the salmon fishery within the boundaries of the Columbia River Basin (Figure P-2). This study emphasizes the federal agencies in the interest of space and since the operation of the Columbia River is essentially a federal responsibility (Ogden, 1997, Williams, 2006).

Research proceeded through three steps. The first step documented the history of events leading to the rise, activity, and collapse of the CRBF. This step analyzed the issues and challenges faced by the CRBF as presented in Chapter 1. This study used the results of that analysis to develop a framework around which to construct a history of Basin governance systems. The components of that framework were:

- The catalytic events or circumstances that created the opportunity for conflict-based change to existing systems and structures. This study frames the narratives of Chapters 3 through 7 using these critical situation events.

- The governance systems proposed or enacted in response to the perceived changes in circumstances.

- The dominant institutions that would form or formed the locus of decision making for each governance system proposed or enacted. This study used this criterion to define the six models subsequently identified.

- The political and social context surrounding the points in time at which change occurred. 
- The salient issues in the Pacific Northwest for which new governance systems were proposed or enacted to address.

- The institutional participants and their interests.

- The worldviews held by the institutional participants.

- Additional information as available. Such information included the duration of enacted systems, types of products produced, effectiveness, and any other material as may be relevant to the research question.

The second step reviewed regional histories in the method recommended by Neustadt and May (1988) and Ritchie and Spencer (2002) and used the framework to develop an institution-oriented historical overview of past governance efforts.

The third step inductively analyzed the historical record, identifying key themes and lessons as may explain the CRBF's institutional genealogy and provide insights that may inform future governance efforts.

Potential problems and limitations.

This study identified four categories of potential problems and limitations. These were source reliability, source completeness, the risk that the historical record alone would prove insufficient to fully explain the paradox of governance, and the author's proximity to the circumstances surrounding the CRBF.

Source reliability

This study used both primary and secondary sources. The history of the Columbia River Basin Forum presented in Chapter 1 relied exclusively on primary source material. These included press reports from print and electronic media, CRBF 
meeting notes taken by a contracted note taker, and notes taken by the CRBF's contracted facilitator. All of these materials represented firsthand accounts by witnesses to the events being recorded. They are, however, potentially subject to the biases, misinterpretations, and/or lapses of attention of those who prepared them.

This study partially mitigated this potential weakness by cross checking, where possible, the accounts of one against the accounts of the others for the same events. As an additional step, the author allowed several of the direct participants to the CRBF process to review early drafts of Chapter 1 . None offered substantive corrections. As such, the author is confident that the events portrayed occurred essentially as presented.

The history of governance presented in Chapters 3 through 7 relied predominantly on secondary sources. This study pieces together fragmentary discussions of governance found in a wide array of historic accounts. As such, there is some risk of misinterpretation regarding the details of each system's purpose, organization, and membership. This author attempted to mitigate that risk by cross checking significant events and facts among multiple sources. As a matter of protocol, this study notes disagreements either in the text or in an accompanying footnote. If research found sufficient information to resolve the difference, the resolution was so explained.

The following example illustrates the risk and approach to mitigate possible misinterpretation. Both McKinley (1952) and Bessey (1963) mention state participation in the Columbia Basin Inter-agency Committee. McKinley (1952) 
claimed that the states participated only as observers, while Bessey (1963) reported that they participated as full voting members. Scheufele (c.1970) resolved the difference. The CBIAC existed from 1946 into 1967. During that time, the nature of state participation fluctuated between passive observation and active participation. Thus, both McKinley (1952) and Bessey (1963) were accurate as of the time they wrote. However, having relied only on one or the other would have resulted in a misrepresentation as to what actually occurred. This study used a general approach of crosschecking multiple sources within each domain throughout to present as accurate a portrayal as possible.

\section{Source completeness}

Even if the primary and secondary sources used were completely accurate in the information they contained, there was still risk that they did not tell the complete story. And there are, in fact, gaps in the narrative. For example, as detailed as was the reporting on the events leading up to the signing of the CRBF memorandum of agreement (MOA), there were no records found by this author describing the specifics of the MOA negotiations. Presumably, if they exist, they would be in the form of the personal notes kept by the negotiators. The CRBF story would benefit from additional interviews to see if these additional sources exist in addition to exploring the motivations and institutional objectives as understood by the participants.

This risk also applied to the history of governance as inferred from the secondary sources used. In some cases, secondary source authors provided a great deal of information for some systems. For example, there was a wealth of published 
material regarding the Northwest Power and Conservation Council, the Regional Forum, the Columbia Basin Inter-Agency Committee, and the Pacific Northwest Regional Planning Commission. Alternatively, the sources reviewed contained only passing references to the Northwest States Development Association, the Committee on Fish Operations, and the Fish Operations Executive Council. Consequently, the sources reviewed did not contain all of the information sought for each governance system identified. However, they did provide sufficient information to warrant the findings and conclusions presented in Chapters 8.

\section{Risk of insufficient material in the historic record to resolve the paradox}

There was a risk that the historical record alone, including both primary and secondary sources, would not present sufficient information to answer the research questions or offer a satisfactory resolution to the paradox of regional governance. That proved to be the case. Most accounts of the Columbia Basin's development spoke to events and the related economic and political interests and issues. Examples included McKinley (1952), Bessey (1963), Scheufele (c.1970), DeLuna (1997), Brigham (1998), Pope (2008), and others. It is a fundamental conclusion of this study that events, politics, economics and disagreements over tangible party interests offered only a partial answer to the question of the paradox. Relatively few spoke to the social issues of worldview, institutional culture and identity, and values that drove individuals to so passionately believe in one position or viewpoint. Examples of those that did were Hays (1957 and 1999/1959), Wiebe (1967) and Taylor (1999). Particularly good at describing the role that worldview (or conceptual framework) 
plays in policy decisions and social structure are Lichatowich (1999), Dunlap (2004), and Williams (2006). However, none directly linked how those values actually affected regional governance or policy choices. The understanding of the CRBF's history in particular and the study of regional governance in general would be greatly improved by in-depth interviews with participants to better explore the role that worldview, social identity, and individual values played in negotiations over the MOA and the CRBF's operations.

\section{Author's proximity to the events under study}

Maxwell (2002) argues that good qualitative work must be transparent in its articulation of author background, potential biases, and selected methodology. The author of this study was closely associated with the events that led to the Columbia River Basin Forum's creation. He served as the Deputy Commander and Chief of Staff of the U.S. Army Corp of Engineer's Northwestern Division, headquartered in Portland, Oregon. He held that position from 1997 to 2001. He held supervisory authority over and appointed the Corps's CRBF representative. He exercised executive coordination with other federal agencies regarding the Corps's environmental impact statement on salmon survival through the lower Snake River dams, one of the major issues in which the CRBF members took interest. He presided over four regional public meetings regarding that study and on several times testified to Congressional committees regarding the study and related biological opinions on 
the operation of the Columbia Basin dams. ${ }^{37}$ Consequently, he was familiar with many of the issues and events discussed.

To mitigate the effects of any bias, points supported only by the personal experience and observations of the author were kept to a minimum and offered only when no other source could be found or to amplify a point made by others. To the maximum degree possible, this study presents information found in already published accounts, the public record, and other sources accessible to the public.

The author is currently on contract as facilitator and program coordinator for the Columbia Basin Federal Caucus. In that capacity, he is required to maintain a confidentiality agreement regarding information presented in meetings, discussions, or documents to which he is available. The events discussed in this study predate this confidentiality agreement and concern events outside of the confidentiality agreement's scope. There are no instances in which information was withheld due to constraints or conditions from the author's past or current professional duties.

\section{$\underline{\text { Sources }}$}

\section{Primary sources.}

Primary material for the rise and collapse of the Columbia River Basin Forum presented in Chapter 1 included meeting minutes, facilitator notes, and other CRBF related documents and committee reports. The Northwest Power and Conservation

\footnotetext{
${ }^{37}$ A transcript of one such testimony as presented to the House Committee on Environment and Public Works, Subcommittee on Fisheries, Wildlife, and Water Works, can be found at http://bluefish.org/mogren.htm.
} 
Council in Portland, Oregon, maintains one set of files of these documents. The other set of files is located with DS Consulting, a firm also located in Portland. ${ }^{38}$ To the author's knowledge, these are the only existing collections of CRBF records. Both the Council and DS Consulting were very gracious in allowing the author full access to their files to research this paper. This was fortunate in that some records were included in one file but not the other. It may be that additional records exist in the private hands of CRBF participants. However, the effort to contact those individuals was beyond the limit of this research project. Consequently, the material reviewed bounded the CRBF history presented in Chapter 1.

In addition to official CRBF related documents, the files contained notes prepared by two sources. The Northwest Power and Conservation Council hired a contractor (Mr. Jeff Kuechle) to prepare CRBF meeting minutes. Although not verbatim transcripts, these minutes provide a relatively detailed summary of meeting discussions. Copies of minutes are on file in both the Council and DS Consulting collections for meetings conducted on March 10 and 30, April 29, May 27, June 24, July 21, September 7, and October 11 1999. The files did not contain minutes for any of the meetings held in 2000. Apparently, Mr. Kuechle was not replaced when his contract expired. Chapter 1 cites information from Mr. Kuechle's notes as "meeting minutes."

\footnotetext{
${ }^{38}$ DS Consulting specializes in public health, natural resource, organizational, and health care issues. Services include facilitation, mediation, conflict-needs assessment, systems design, negotiated rulemaking, collaborative problem solving, and consensus building. Additional information is available from the company websites at http://www.mediate.com/dsconsulting/index.cfm and http://www.mediate.com/DS/index.cfm.
} 
The second source of notes was DS Consulting, contracted to provide mediation and facilitation support for meetings beginning on May 27, 1999. In addition to the meeting minutes recorded by Mr. Kuechle, Ms. Donna Silverberg, meeting facilitator, and/or members of her staff, took abbreviated outline notes. These notes are on file with DS Consulting for the meetings held on July 21, 1999, and February 25, March 10, April 21, and April 28, 2000. Chapter 1 cites information from these documents as "facilitator notes." An attendance sheet and references in media reports indicate a meeting also held on January 19, 2000 although the files contained no record of what transpired at that meeting. Subcommittee memos, budget reports, meeting agendas, and the memorandum of agreement developed to guide CRBF activities provided additional information.

In addition to the meeting notes and $\mathrm{CRBF}$ records, regional news outlets carried a running account of the CRBF's formation, operation, and collapse. The author screened online websites of regional news sources for "Three Sovereigns" and CRBF related articles. This study used almost every news article thus found; the few not used were rejected solely because they were superficially redundant of coverage found elsewhere. The articles and editorials used appeared in the Oregonian and the online NW Fishletter and Columbia Basin Fish and Wildlife News Bulletin. Energy NewsData produces the Fishletter. Founded in 1982, Energy NewsData provides reports of interest to the electric and utility industry. The NW Fishletter is found online at http://www.newsdata.com/fishletter/index.html, with specific locations of the articles used identified in the list of references following Chapter 8. 
Although the Oregonian and Fishletter articles were helpful, this study drew the preponderance of its news account related information from reporters Barry Espenson and Mike O'Bryant from the Columbia Basin Fish and Wildlife News $\underline{\text { Bulletin. Intermountain Communications of Bend, Oregon publishes the Bulletin. }}$ The Northwest Power and Conservation Council's Fish and Wildlife Program funds the Bulletin, a program funded by the Bonneville Power Administration. The Bulletin is found online at www.cbbulletin.com. In addition to meticulously following the establishment of the CRBF, either Espenson or O'Bryant attended and reported on each CRBF meeting. Their reporting thus greatly supplements the CRBF meeting minutes and facilitator notes. The list of references following Chapter 8 identifies the specific online location for each Bulletin article cited.

\section{Secondary sources.}

Secondary sources provided the preponderance of of information for the governance history discussed in Chapters 3 through 7 . There were several reasons for this. First, delving into the archives for primary material on each of the twenty-six proposed systems identified in this study was time prohibitive. Second, this study found the body of material in each literature domain to be substantial and well developed. Third, although this account would undoubtedly benefit from additional analysis of primary documents, the published material reviewed provided sufficient information to support the findings and conclusions presented herein.

This study constructed its historical narrative from references to governance systems and contextual trends in works generally intended to address other issues or 
present other arguments. The study reviewed published material selected from the following topical domains:

- Regional Native American tribes and tribal perspectives,

- Euro-American exploration and settlement of the Pacific Northwest,

- Columbia River Basin commercial development,

- The impact of Basin development on regional salmon runs, and

- The American environmental movement.

The discussion below reviews the material considered essential to this study's argument. Appendix A presents an expanded review of this literature. This study used additional sources to cross check information and to add or supplement details to specific incidents or issues. The reference list that follows Chapter 8 identifies these other sources.

\section{Literature Review}

This section summarizes the literature used to write the history of Basin governance, organized by domain. Works categorized under more than one domain are listed under each that applies.

\section{Domain: Regional Native American tribes and tribal perspectives.}

The research into regional Indian tribes (1800s through 2000) focused on a general background of Northwest tribes, their interactions with white settlers, the worldviews and perspectives around which tribal society was organized and how these views shaped later debates over Columbia Basin issues. 
Trosper (1995), Pevar (2002), and Wilkinson (2005) provided information on tribal social values. Trosper (1995) summarized Indian cultural precepts based on his study of native peoples. Pevar (2002) focused on the legal and political evolution of tribal rights. Wilkinson (2005) traced the history of the tribal sovereignty movement. Lichatowich (1999), Taylor (1999), and Williams (2006) provide additional tribal social context. These works offered insights into the connection between worldview and tribal social organization and behavior. They also provided a comparison of tribal worldviews and with those of early Euro-American explorers and settlers and discussed the impact of shift from one to the other on the region's natural resources.

Three other books provided regional context oriented from the tribal perspective. In two books, Ruby and Brown (1981 and 1992) provide an encyclopedialike overview of the tribes and bands of the Pacific Northwest. Clark (1953) transcribed traditional Northwest Tribal stories that provided Indian interpretations of the creation and man's relationship with nature. Collectively, this body of work provided a sufficient array of historical context, facts and circumstances relevant to the tribal role in the region.

Domain: Euro-American exploration and settlement of the Pacific Northwest.

Research of regional exploration and settlement focused on the worldviews of the new arrivals, the impact of those worldviews and white expansion on native tribes, and the impact settlement had in setting the region's social trends. This study reviewed material for facts, dates, and circumstances; the early roots of regional institutions; and the context from which later efforts at planning and governance emerged. 
In their essay promoting a new conceptual framework to guide regional salmon management, Lichatowich, McConnaha, Liss, Stanford, and Williams (2006) argued that conceptual foundations (or worldviews) have a profound effect on social organization and behavior. Taylor (1999) and Lichatowich's (1999) critique of regional fishery management also argued the power of worldviews on social structure. They further argued that the replacement of the tribal foundation of unity with nature with the Euro-American concept of nature as a warehouse of marketable resource commodities directly resulted in the depletion of those resources - some, like salmon, almost to the point of extinction.

Four authors captured the origins and nature of the worldviews brought by settlers to the Pacific Northwest. These were Max Weber (2002/1920), Henry Nash Smith (1950), Jenks Cameron (1928 and 1929) and Dodds (1986). That worldview believed in the moral rightness of the creation of personal wealth (Weber, 2002/1920). It embraced the right of property ownership, especially land, as a guarantor of individual liberty and republican virtue (Smith, 1950), a belief in the west as an Edenic garden of opportunity (Smith, 1950), a belief in the inexhaustibility of the resources the west offered (Cameron, 1928 and 1929). It also carried a belief in the doctrine of Manifest Destiny. The doctrine of Manifest Destiny held that some combination of God, nature, and/or fate ordained an American empire from coast to coast (Dodds, 1986).

Dodds (1986) further argued that the institutions of the Northwest evolved under circumstances of relative complacency. This was because white settlers the 
region predominantly emigrated from the upper Midwest of the United States.

Consequently, they already shared a common belief in American values and how those values were to be applied in social, political, and economic settings. As the region filled with people all operating within the same conceptual framework, the institutions they chose to establish faced little crucial review or challenge (Dodds, 1986).

This study relied upon the following sources to document the Northwest settlement up to the early 1900s. Robert Wiebe (1967) and Samuel Hays (1957) wrote from national perspectives, discussing broad trends that shaped American settlement and development in the $19^{\text {th }}$ century and thus provided context for the settlement of the Pacific Northwest. Research into the history of Northwest exploration and settlement examined the work of Lyman (1963/1917), Johansen (1967), Schafer (1943/1918), Dodds (1986), and Robbins (1997 and 2004). Lyman (1963/1917), Johansen (1967), and Dodds (1986) concentrated on key personalities and the region's economic, social, and political development. Robbins (1997 and 2004) wrote from an environmental perspective, focusing on the impact of regional development on the regional ecology. All provided at least some additional insight into the worldview carried by the white settlers to the region and the influence of that worldview on Indian culture and development of the region's Anglo-American political and social institutions.

\section{Domain: Columbia River Basin commercial development.}

This study found that almost all references to Columbia Basin governance systems were contained in histories of the river's commercial development. Johansen 
(1967), White (1995), DeLuna (1997) and Brigham (1998) provided contextual background regarding the impact of Progressive and New Deal philosophies in general and the public-power debate in particular on Columbia River development. Ogden's 1949 doctoral dissertation traced the economic and social reasons behind the river's development and the political environment in which that development took place. White (1995) argued the social impact of converting the Columbia from a natural ecologic system into an "organic machine" producing multiple commercial benefits is what makes the Northwest a true region of common interest. Vogel's 2007 doctoral dissertation took White's (1995) argument a step further. She concluded that the concept of the Northwest as a unified region centered on the provision of inexpensive hydroelectricity and socially institutionalized through the Pacific Northwest Regional Planning Commission (PNWRPC). Vogel (2007) based her argument on review of primary materials in PNWRPC archives. Although not focused on the PNWRPC as a governance system per se, her work provided a great deal of insight into PNWRPC origins and operation.

McKinley (1952), Bessey (1963), Scheufele (c.1970), and Norwood (c.1981) provide firsthand accounts written by men with active roles in regional developmental policy and governance in the 1950s and '60s. McKinley (1952) provided an overview of federal responsibilities in the region, analyzed the voluntary nature of interagency governance, and argued for establishment of a more authoritative Columbia Valley Authority to plan and manage Basin resources. Bessey (1963) traced the region's efforts at regional planning. Scheufele (c.1970) provided an insightful analysis of the 
Columbia Basin Inter-Agency Committee and in so doing provided an applicable critique to collaborative governances systems in general. Norwood (c.1981) traced the history of the policies of the Bonneville Power Administration.

Histories of more recent events included Pope's (2008) account of the hydrothermal crisis of the 1970s; Blumm's (1982) discussion of the background of the 1980 Pacific Northwest Electric Power Planning and Conservation Act; Hemmingway's (1983) analysis of the Northwest Power Planning and Conservation Council; and Crampton and Espenson's (2009) synopsis of salmon litigation between 1991 and 2009. This study effort researched these works with the goal of identifying the key issues facing the Pacific Northwest at the time, and the governance systems proposed or enacted in order to address those issues. Also researched were the key arguments for or against the various governance systems and the positions of regional institutional actors as those debates played out.

Domain: The impact of Basin development on regional salmon runs.

All Columbia Basin efforts at collaborative governance were initiated to guide planning and management of the Basin's resources and/or to provide a forum where differences among regional institutional actors could be resolved. Many of the most dominant differences have involved conflicts among commercial, sport, and tribal fishery interests and the collective opposition of fishery interests to the construction and operation of mainstem dams. This issue was central in the formation of the Columbia River Basin Forum and has been at least a component issue of every governance system proposed or enacted since the 1940s. Its importance intensified 
once NMFS began listing Columbia basin salmonid species as threatened or endangered under the Endangered Species Act in 1991. Fish management and conservation will likely continue as a central governance issue into the future.

Literature on the Northwest salmon situation proved a mix of objective analysis and issue advocacy. Research focused on basic facts, dates, and circumstances; institutional context with regard to governance; insights into various advocates' interests and worldviews; and the role the issue played in governance choices. The National Research Council (1996) provided an objective and comprehensive general overview of the salmon crisis and interrelated causes of salmon declines. Cone and Ridlington (1996) provided excerpts from statutes, policy statements, Indian treaties, speeches, and technical reports considered central to policy decisions and editorial comments on each from regional salmon scientists and activists. Lichatowich (1999), Taylor (1999), and Williams (2006) provide holistic critiques of the causes of salmon decline and the impacts of cultural perspectives on salmon policy.

This study researched advocacy books and articles for basic facts, dates, and circumstances and insights into how worldviews of the parties on whose behalf the authors were writing influenced perspectives on causes and solutions. Buchal (1998), writing from the perspective of those dependent on the commercial benefits of the developed river, tends to dismiss the impact of dams and primarily attributes the salmon decline to overfishing, mismanaged hatchery practices, and ulterior political motives of federal regulatory agencies. Alternatively, Blumm et al. (1998) placed primary blame on the existence and operation of Columbia and Snake River dams. 
Lichatowich (1991) critically focused on hatchery policy, arguing that it was an application of industrial-scale fish production through hatcheries that created a misguided belief that the region could continue to have harvestable fish runs and commercial development - all of which came at the expense of natural salmon runs.

Notwithstanding the enormous cultural importance of salmon to tribal culture, much of the salmon debate in the first half of the $20^{\text {th }}$ century consisted of a contest among competing economic interests framed within the market-capitalist worldview. In the 1960s and 70s a new worldview emerged that emphasized environmental values. Arguably, one of the underlying reasons that the salmon crisis seems so irreconcilable is the view by some parties of salmon as an economic commodity to be exploited and by others as an ecological treasure to be preserved. The environmental worldview has gained significant traction in the Northwest with adherents insisting that resource managers consider ecological concerns. Understanding that worldview is therefore important to understanding the Basin's more recent governance history.

\section{Domain: The American environmental movement.}

This study effort researched literature on the United States environmental movement primarily for its contextual roots and the role environmentalism played in recent American political life.

Many environmental historians generally credit George Perkins Marsh as providing the intellectual foundation of the American environmental movement. Marsh (1965/1864) provided an intellectual framework for the conservation movement. Marsh (1965/1864) promoted a responsible stewardship approach to 
natural resource use grounded in the American capitalist and protestant traditions. Kline (2000) and Thomas Dunlap (2004), while giving Marsh his due, traced the historical trajectory of environmental philosophy from the Middle Ages up through the 1990s. Both are self-described environmentalists who provided critiques of the impact of the market-capitalist worldview on natural resources.

Hays (1999/1959), Riley Dunlap and Mertig (1992a), and Rosenbaum (2005) collectively presented a history of the movement's political and institutional development. Hays (1999/1959) argued that to most environmental historians, the significance of the progressive conservation movement lay in the substance of progressive policies concerning sustained yield forestry, multiple use river development, and efficient public land management. He argued that the movement was much more than that. It was nothing short of a major realignment of American political power away from private corporations and into the hands of government administrative agencies in the moral interest of promoting the public good. Dunlap and Mertig (1992a) argued that despite predictions to the contrary, the American environmental movement has not had the short life span of most social movements and has embedded itself in American political life as a core value. Rosenbaum (2005) offered an accounting of the nation's progress toward environmentalism, how much lost, and how much gained. He chronicled changes in national policy due to changes in presidential administrations and congressional makeup. He discussed the shift from single-issue policies for protection of individual elements of the environment such as water, air, and discrete species to more holistic concerns over ecological impacts. He 
addressed the uncertainty of science and the political difficulty of justifying costs for environmental consequences that fall to individual consumers whereas the benefits are spread over the population.

Although no piece of the environmental literature reviewed directly addressed the Pacific Northwest, they provided a context for the environmental worldview that in recent years played an increasingly significant role in Northwest natural resource issues.

\section{$\underline{\text { Summary of Findings and Conclusions }}$}

\section{Findings.}

This study produced five primary findings, outlined here and discussed more fully in Chapter 8. First is the sheer complexity of the governance task. This complexity is due to several factors. The first is the sheer scope of the operational issues to be addressed, especially in balancing the commercial purposes of the river's operation with mitigation for impacts on fish and wildlife. The second is the legacy effects of localism, institutional power, and perspectives over resource use dating to the region's early settlement. Third is the challenge of structure, or coming to agreement on a common vision of purpose and the internal rules and procedures to guide routine business and decision-making. The complications of scope, institutional legacy, and structure are further exacerbated by the different worldviews institutional participants bring to debates over substantive issues. 
The second general finding concerns the role of law and legal structure. The U.S. constitutional framework and federal and state laws establish legal standing for state and federal agencies to carry out assigned tasks. They also define relationships among institutional parties, delegate decision-making, and mandate tasks and objectives to be achieved. Consequently, the legal structure both enables and constrains efforts at multi-jurisdictional governance.

The third general finding is that, despite these complexities and legal framework, the Basin managed to employ some form of inter-jurisdictional governance system since establishment of the Pacific Northwest Regional Planning Commission in 1934. The Basin has not been without at least one governance system in place since. Between 1934 and 2000, twenty-six different governance systems were proposed. Eleven were established. This study found that either each system identified was an evolutionary progression from an existing system or a new system specifically established to displace another. This study categorized each identified system as either decision oriented or collaboration oriented. As the names imply, decision oriented systems favored efficient, authoritative decisions regarding resource management and use at the expense of inclusiveness. Conversely, collaborative systems favored broad inclusion at the expense of efficient decision-making.

This study further subdivided these two broad characterizations into six governance models as determined by the dominant institutional actors in each system. The study identified three decision oriented and three collaboration oriented models. This study termed the decision-oriented models as the Market Model, the Iron 
Triangle Model, and the Valley Authority Model. Private enterprises led decisionmaking under Market Model systems. Three-way arrangements among federal agencies, their congressional oversight committees, and private interests controlled individual resource policy domains under the Iron Triangle Model. In contrast to the decentralized decision-making nature of the Market and Iron Triangle Model, Valley Authority Model systems centralized federal decision-making under one administrative structure.

This study categorized collaborative systems under models termed the Federal Cooperation Model, the State Cooperation Model, and the Three Sovereigns Model. Under the Federal Cooperation Model, federal agencies coordinated their discretionary decision-making and programs. State Cooperation systems were led by state entities, usually representatives from the governors' offices. Three Sovereigns systems envisioned federal, state, and tribal representatives working as co-equal management partners. Chapter 8 discusses the models in more detail and identifies the systems assigned to each.

The fourth general finding concerned patterns of system change. Change came about either through evolutionary processes within models or the emergence of circumstances that allowed for dramatic shifts between models. Evolutionary changes occurred through collapse due to internal structural weaknesses for which participants lacked a compelling reason to resolve or mutual agreement to improve and replace extant systems. Conflict-based system change occurred through emergence of a critical situation that called existing governance systems into question and allowed a 
new set of participants to achieve dominance. This study found four such critical situations to have occurred between 1929 and 1999. These were the onset of the Great Depression in 1929, events surrounding the end of World War II circa 1945, the issuance of a notice of insufficiency by the Bonneville Power Administration in 1976, and the first listings of regional salmon under the Endangered Species Act in 1991. Events and circumstances that precipitated the Columbia Basin Inter-Agency Committee (the end of World War II), the Northwest Power Planning and Conservation Council (the BPA notice of insufficiency in 1976), and the Columbia River Basin Forum (potential threat of deregulation and loss of regional benefits from the FCRPS) suggest a patterned response to perceived pending critical situations. Chapter 8 explains this pattern and illustrates it in Figures 8-4 and 8-5. The events that led to formulation of the CRBF did not rise to the level of criticality that would justify replacement of other extant forums and regimes. This circumstance undermined any incentive for participants to invest in CRBF success, rendered it duplicative of these other forums, and thus contributed to its collapse.

Fifth is the regional preference for collaboration-oriented governance systems. Between 1934 and 2000, the region repeatedly rejected decision-oriented models in favor of collaboration-oriented models. All eleven systems enacted were collaboration oriented under one model or another; no decision-oriented system has yet been chosen. This is in spite of a mixed record of success. Some collaborative systems, such as the Pacific Northwest Regional Planning Commission, the Columbia Basin Inter-Agency Committee, and the Northwest Power Planning and Conservation Council, existed for 
decades and delivered substantive and credible programs, plans, products and services. Others, such as the Pacific Northwest Governors' Power Planning Committee, Regional Forum Executive Committee, and Columbia River Basin Forum collapsed after a relatively short period, accomplishing little. The systems that succeeded appear to have achieved a shared sense of purpose and identity among their members that transcended individual participant institutional interests. Those that failed apparently did not.

\section{Conclusions.}

The study's findings led to the following six conclusions, introduced below and discussed more fully in Chapter 8. First, regional leaders are likely to continue to support some form of multijurisdictional governance system. The reason for that support is the continuing desire to establish a rational process for resolving (or precluding) problems of competition and disagreement over resource uses that transcend individual federal agency, state and tribal government jurisdiction.

Second, the apparent paradox of Basin governance is inherent in the Basin's consistent preference for collaboration-based governance systems. The challenge of reaching consensus among multiple parties with deeply held interests, strong institutional cultures, and differing worldviews seems one the region is consistently willing to tackle. This elusive - if not unattainable - goal seems an institutionalized characteristic of the Northwest's approach to natural resource management within the Columbia River Basin. It is not likely to change. The region derived value and benefit from collaboration-oriented systems established under the Federal 
Cooperation, State Cooperation, and Three Sovereign models. Despite recurring frustration over the inability of such systems to solve the region's more intractable problems, regional leaders find that living with that frustration is preferable to the outcomes that may be produced by more decision-oriented alternatives.

Third, statutory support for collaboration-oriented governance systems is neither a necessary nor a sufficient condition to ensure system success. This study found examples of successful collaborative systems that were not established through law and examples of not-so-successful systems that were. The reason is that the effectiveness of the collaborative systems identified in this study was more dependent on the relationships among the institutional leaders involved than any external mandates.

Conversely, statutory support is a necessary condition and may be a sufficient condition for any decision-oriented system that the region may desire to establish. The authorities and prerogatives of state, federal, and tribal governments and agencies and, to some degree, the relationships among them are all established in law. Any system with the authority to direct agency priorities and prerogatives must therefore have statutory authority to do so. The degree to which the relationships and decision hierarchy of participating entities are defined in some new authorizing statute will determine the degree to which effectiveness will depend on voluntary compliance with system decisions.

Fourth, the region is highly unlikely to ever support an authoritative decisionoriented governance system. Even if the region were able to overcome the 
constitutional, statutory, and institutional challenges at the state and federal levels, institutional leaders have historically rejected such systems. The regional preference for collaborative systems does not reflect an avoidance of tough choices. Rather it reflects a strong desire to obtain as much agreement on choices made as possible even though getting to those choices frequently involves a contentious mix of negotiation, legislation, and/or litigation. It may be possible that, at some point in the future, a critical situation of such magnitude occurs that allows establishment of a more authoritative system. However, the history shows that the Great Depression, the end of a World War, a major regional financial crisis represented by BPA's notice of insufficiency in 1976, and the listing of regional salmon under the Endangered Species Act were not of sufficient criticality to allow enactment of such a system. At this point, it is difficult to imagine one that would.

Fifth, regardless of the level of unity achieved within any one system, there will likely always be parties who believe that the system(s) in place do not properly serve their interests. These parties will look for opportunities to challenge existing structures when presented with critical situations. As was shown in the CRBF experience, the perception of a pending critical situation is not sufficient to institutionalize a new system or overturn existing ones. When such situations do arise, the region's experience with past governance system changes suggests the behavioral model explained in Chapter 8 and illustrated in Figure 8-4 will likely be followed.

The sixth and final conclusion concerns limitations to the institutional methodology as used in this study to fully explain the governance paradox. The 
history recounted provided only partial answers to the study's research question. This study findings suggest that worldview belief patterns embedded in institutional identity and culture, (Tajfel and Turner, 1979/2004; Albert and Whetten, 1985; Hogg and Terry, 2001; Schein, 2004) inculcated in individual institutional members as the correct way to think, perceive, and feel (Schein, 2004) and manifest through individual decision making processes (Beach, 1998) condition the agents of those institutions as to what constitutes acceptable policies and systems. The experience of the Columbia River Basin Forum offers an opportunity to investigate this question in greater depth. Appendix B presents a framework for such a study.

\section{Organization of Study}

This study used an organizing framework inspired by Bessey (1963) and drawn from Giddens' (1984) argument regarding critical situations. According to Giddens (1984), when social systems become established, they remain in place until a significant event occurs that upsets the status quo and allows new or previously suppressed alternatives to become viable. Giddens (1984) terms such occurrences "critical situations" and defines them as those situations where the "established modes of accustomed life are drastically undermined or shattered" and "circumstances of radical disjuncture of an unpredictable kind which affect substantial numbers of individuals, situations that threaten or destroy the certitudes of institutionalized routines" (Giddens, 1984, p. 60-61). Writing in 1963, Roy Bessey presented changing economic factors alone as the primary catalysts 
for this sort of dramatic change within the Columbia Basin. ${ }^{39}$ This study takes advantage of the additional context offered by the forty-plus years since Bessey published his work expands his argument to include the catalytic effect of events other than economic drivers of change.

This study found major events that marked a turn in public interest for or against various regional governance systems from the 1920s to the present. The first two are in accord with Bessey (1963): the onset of the Great Depression and the end of World War II. The second two are the Columbia River power system's hydro-thermal crisis of the 1970s and the first listing of Columbia basin salmon under the Endangered Species Act in 1991. These events frame Chapters 3 through 7.

Chapter 3 summarizes the region's history up to the first of these critical situations, the onset of the Great Depression in 1929. It presents the region's early exploration and settlement by Euro-Americans and their impact on Native Indian people. It explains the Indian and white settler worldviews and how those worldviews influenced their respective social organizations. It identifies the key institutions that would come to be significant actors in regional governance debates. It also summarizes the political and social context leading up to the Depression. It concludes by explaining the market and agency-oriented governance systems that managed regional natural resources at the time.

\footnotetext{
${ }^{39}$ Giddens' (1984) theoretical construct and Bessey's (1963) empirical work reflect Gersick's (1991) theory of "punctuated equilibrium." Gersick argues that social activity tends to follow status quo behaviors until disrupted by a threat or changed condition that calls those routine behaviors into question and sets the conditions under which new policies and behaviors can be brought into being.
} 
Chapter 4 focuses on the onset of the Depression in 1929 and the changes the policies enacted in response to the nation's economic crisis caused in regional governance systems. The chapter outlines the national political and social context of the time, the salient regional issues that directly or indirectly affected Basin governance and the governance systems proposed in response. Chapters 5, 6, and 7 do the same for the three other critical situations found in this study to have created the circumstances that led to Basin governance changes. These are the end of World War II in 1945, the region's hydro-thermal crisis and resultant BPA notice of insufficiency (NOS) in 1976; and the first listings of regional salmon under the Endangered Species Act in 1991, respectively.

Chapter 8 summarizes and analyzes the findings of Chapters 3 through 7 and presents the study conclusions. It categorizes the twenty-six governance systems proposed or enacted under the six governance models introduced above. It also presents a pattern of governance development that in which the region appears to engage each time a perceived critical situation presents. A complete reference list follows Chapter 8. Appendix A provides the detailed literature review; Appendix B a theoretical framework to guide future research. 


\section{CHAPTER 3 \\ SETTING THE STAGE: \\ THE COLUMBIA BASIN PRIOR TO 1929}

\section{$\underline{\text { Introduction }}$}

This chapter establishes the point of departure for the discussion of Columbia Basin governance systems in the chapters that follow. It documents the legacy effects of regional settlement that would influence future governance debates. It begins with a discussion of the worldview of the Native tribes in the region and a comparison of those views with those of the first European explorers. The chapter ends with a discussion of the impact of the Great Depression in 1929, an event that dramatically altered the market-based, decentralized systems of regional governance in place up to that time.

This chapter also introduces the major regional institutions that would come to shape future governance systems. These institutions include the Indian tribes, federal and state agencies, and private enterprises that were established around the Columbia Basin's fisheries, land and water use (agriculture, grazing, and timber harvest), and river development (irrigation, navigation, flood control, and - eventually hydropower). Since the Columbia as currently developed is a primarily a federal responsibility, emphasis is placed on federal agencies with jurisdictional responsibilities over the Basin's land, water, fish, wildlife, and timber.

The chapter is divided into the following eight sections:

- The social structure and worldview of the region's Indian tribes. 
- Early European exploration and Anglo-American settlement.

- The region's economic development and its underlying worldview.

- Regional institutional development, focusing on the institutions established around land use, western water law, early federal Columbia River development projects, the salmon fishery, and the rivers hydropower potential.

- The earliest indications that the philosophies that guided initial settlement and development may carry serious consequences.

- The Progressive conservation movement and the implications of that movement for the Northwest.

- The governance systems by which the Basin's resources were being managed as of 1929.A short chapter summary.

\section{Native Social Structure and the Tribal Worldview}

The Columbia region's temperate climate, abundance of water, and plentiful food sources resulted in a large variety of early native tribal bands and cultures in the Pacific Northwest. Ruby and Brown (1992) identified fifteen "language families" comprised of 115 native Indian tribes that lived in the present states of Oregon, Washington, Idaho, and Montana by the early 1800s. Of these, five language families dispersed among thirty-eight tribes lived in the Columbia and Snake River basins. ${ }^{40}$

\footnotetext{
${ }^{40}$ Information on the number of historic tribes and language families is taken from the maps in Ruby and Brown (1992), pages 116-124. The authors note that this information is based on the best available information, but may not be complete. They also do not identify the time periods over which the tribes
} 
Indian social systems were clan based. Social mores varied. Coastal peoples were highly individualistic, materialistic, and competitive with a limited concept of "tribe"" loyalties belonged to the family and village. Inland people were less materialistic and more likely to identify with tribal allegiances (Johansen, 1967). Indian economies were dependent on the wildlife and plants of the surrounding countryside for food and materials for tools, weapons, and building materials. Wealth accumulated at the clan level; Indians sought wealth for the power and security of the clan (as opposed to individuals) and depended on the clan to sustain them through hard times. Marriage and trade brought wealth to the clan while gift giving circulated it within the clan. In addition to the practical effect of distributing food and other items throughout the community, gift giving enhanced individual prestige and influence (Johansen, 1967; Lichatowich, 1999; Taylor, 1999; Lichatowich, McConnaha, Liss, Stanford, and Williams, 2006).

Underlying all of the various tribes was a shared worldview grounded in cultural values of respect and commitment to the community, connectedness with the natural world, humility, and the need to consider the impact of one's actions today on those that will live seven generations hence (Trosper, 1995; Taylor, 1999;

Lichatowich, McConnaha, Liss, Stanford, and Williams, 2006). This worldview led to complex social and ethical arrangements that prescribed how humans should interact with the world around them. Tribal culture grounded natural resource use in a

they identify existed, and the assertion that the number of tribes identified was as of the early 1800 s is based on the authors' reference citations. The authors note that many of the tribes they identify no longer exist and it is unknown how many others disappeared and whose histories are lost. 
spiritual basis that recognized the "inexorable linkage between salmon, humans, and the world" (Lichatowich, McConnaha, Liss, Stanford, and Williams, 2006, p. 32). Tribal stories and legends in which landforms, fish, and animals routinely interact with Indian peoples and occasionally change from one form to another illustrate this "inexorable linkage" (Clark, 1953). Within this general conceptual framework, each tribe prided itself on its own distinct traditions and orally passed them from generation to generation (Clark, 1953; Wilkinson, 2005).

Central to Northwest tribal economies was the concept of reciprocal exchange as practiced through the potlatch - although its practice varied between coastal and inland tribes (Johansen, 1967). The potlatch was a gift giving and barter event that distributed the clan's collective wealth among individuals. It modeled what the Indians observed in the processes of nature: soil gave seeds the opportunity to produce plants; plants fed the animals; animals fed other animals; and, in death, the animals fed the soil. It was a natural cycle in which no element was dominant, not even humans, and in which each element depended on the others. The etiquette of reciprocal exchange called for a return in equal or greater measure for gifts received (Trosper, 1995; Lichatowich, 1999).

None of this precluded the use of technology to manage nature's resources to improve tribal life. Indians used fire throughout the Northwest to enhance root gathering and hunting and weirs, gillnets, seines, dip nets, and spears to enhance the harvest of fish (White, 1995; Robbins, 1997; Hays, 2000; Taylor, 1999). Salmon was the "largest single source of protein" (Taylor, 1999, p. 13) for Northwest tribes and 
preservation through drying, smoking, and pemmican-making allowed food to be stored for winter and transported over extended distances for trade or gift giving.

These technologies, coupled with the stable and healthy populations of tribal people, posed potentially significant threats to fish runs. Natural calamities caused periodic food shortages, but tribal tradition and custom provided normative restraints that prevented human over-use. "Restraint flowed from the concepts and practices of Oregon country Indians, who filled their world with spirits that demanded respect. The way they understood this relationship resulted in a series of activities dedicated to propitiating salmon, and although conservation was not the stated purpose, moderation of harvests was the effective result" (Taylor, 1999, p. 27). The result was a regime of natural resource management that sustained tribal society for centuries (Taylor, 1999; Lichatowich, McConnaha, Liss, Stanford, and Williams, 2006).

Spanish explorers first arrived along the Northwest coast in the early $1540 \mathrm{~s}^{41}$ They sought new sources of wealth to supplement the treasure taken from the Aztecs and Incas of Central America (Dodds, 1986). Lyman (1963/1917) and Dodds (1986) argue that the Spanish maps of the Northwest coast, unlike those drawn of other parts of the North American coastline, were wildly inaccurate implying little or no inland exploration. In an oft-repeated story, ${ }^{42}$ William Lyman (1963/1917) records a legend

\footnotetext{
${ }^{41}$ Dodds (1986) says the first Spanish ships arrived in 1542; Lyman (1963/1917) says 1543. Schafer (1943/1918) and Johansen (1967) do not specify.

${ }^{42}$ This story appears in Clark (1953), Indian Legends of the Pacific Northwest and Judson (1916), Early Days in Old Oregon. Both cite Lyman (albeit from different editions of his book) and others. Judson states that a Chinook version of the story was recorded in 1896. Judson and Lyman also relate a story from a book by Gabriel Franchere, an early settler in Astoria. Franchere tells of meeting an old man in
} 
told him by an old Clatsop woman. According to Clatsop tribal lore, two white sailors of unrecorded origin, perhaps shipwrecked or marooned, landed in a small sail boat about two miles south of the Columbia's mouth. One or two local tribes, depending on the version, either adopted or enslaved them, again depending on the version. One was apparently a blacksmith, providing the tribes a new and invaluable technology for tool making and jewelry. Using this story, coupled with other circumstantial evidence and a healthy dose of speculation, Lyman (1963/1917) concludes that the landing of the two sailors could have occurred as early as $1725 .{ }^{43}$ Lyman also argued that this explains why, as recorded in the journals of Captain James Cook in 1778, the Indians showed no surprise at Cook's weapons or other iron implements. ${ }^{44}$ Later explorers $^{4}$ engaged in trade with the tribes and, occasionally, violence (Lyman, 1963/1917; Schafer, 1943/1918; Johansen, 1967). Thus, Northwest Indians may have had up to 250 years of sporadic contact with whites before arrival of the Lewis and Clark expedition in 1805 .

Prior to 1828 , the official policy of the American government toward the tribes was one of "agreements between equals" (Pevar, 2002, p. 6). Congress passed laws

1811 near the Cascades who claimed that his father, a Spaniard, had been wrecked at the river's mouth many years before.

${ }^{43}$ Judson (1953) and Lyman relate a story from a book by Gabriel Franchere, an early settler in Astoria. Franchere tells of meeting an old man in 1811 near the Cascades who claimed that his father, a Spaniard, had been wrecked at the river's mouth many years before. Lyman suggests that the father of the old man was one of the two found by the Clatsops and uses this in support of his 1725 date of the landing.

${ }^{44}$ Presumably they could have been made aware of European metalwork through contact with earlier Spanish explorers as well. 
restricting access by whites onto tribal lands, regulated white-Indian trade relations to ensure fairness to the tribes, and exempted tribes from state trade laws. Although well intentioned, the states and settlers in general did not respect these laws and they proved virtually impossible to enforce. Besides, they also stood in direct conflict with the growing nation's westward expansion (Pevar, 2002).

Official policy changed with the election of President Andrew Jackson in 1828. Under Jackson's administration, continuing through 1887, removal and relocation to make way for white settlement became the dominant federal policy (Pevar, 2002). The General Allotment Act, passed in 1887, further reduced tribal land holdings. The Act was motivated both by well-meaning reformers who believed tribal interests were best served by turning Indians into farmers and by white developers and speculators who coveted Indian land. The Act, applied to about three-fourths of the nation's tribes, provided every member of a reservation tribe a personal allotment of 160 acres (80 acres on some reservations), with reservation land in excess of that amount declared "surplus" and put up for sale to non-Indians. By the time Congress repealed the Act in 1934, federal policy had relegated Indians to a state of "coerced dependency" on the federal government (Pevar, 2002, p. 7).

The beginning of settlement in the Northwest in the early 1800s held dire consequences for regional tribes. Initially, white dependence on Indians to provide fish and furs for trade moderated consumption. As the number of white settlers grew through the mid- to late-1800s, the demand for land and resources increased exponentially. Concurrently, disease decimated tribal populations. Taylor (1999) 
cites estimates of Oregon Indian populations declining by 95\% from 1840 to 1900 as non-Indians increased from less than 800 in 1840 to over 1.1 million in the same period. Robbins (1997) relates similar numbers.

Tribal society was under assault from Anglo-American influences other than disease. Fur trappers introduced alcohol to Northwest tribes in the 1820s and 30s with devastating results. Burgeoning pride in American nationhood, coupled with Protestant missionary zeal in the late 1700 s, led to national Indian policies intended to "civilize" Indian tribes and assimilate their people into mainstream American society. For many, "'civilize' quickly became a near synonym for "Christianize” (Pevar, 2002; Wilkinson, 2005, p. 33). The goal of the missionaries, often with the best of intentions and believed in the best interest of the Indians, was in effect to eradicate the tribal cultural worldview and replace it with white values regarding private property, agriculture, and religion. Less altruistic trappers and settlers simply took what they wanted. Violence was sporadic until the Cayuse war of 1847 . Unable to effectively compete militarily with encroaching white settlement, Northwest tribes signed a series of treaties between 1854 and 1863 . These treaties relegated the tribes to designated reservations, most of which were beyond areas in which white settlers were initially interested. War erupted again with the Modocs in 1873, the Nez Perce in 1877, and the Bannacks in 1878 . Organized tribal resistance ended by 1880 . From then on, the tribes had little choice but to accept life on the reservations (Lyman, 1963/1917; Johansen, 1967; Dodds, 1986; Ruby and Brown, 1981; Wilkinson, 2005). 
Although the treaties and subsequent legislation resulted in the loss of most Indian lands and relocated the tribes to remote reservations, the Northwest tribes retained important rights to hunt and fish at their usual and accustomed locations (Wilkinson, 2005). These treaty rights would come under repeated assault over the following years by whites seeking additional land and by fishery interests.

Nevertheless, federal courts upheld the treaty promised rights. These court cases would come to play a significant role in the governance debates in the decades to come. ${ }^{45}$ But by 1929 , and despite having been formally recognized as United States Citizens in 1924, the tribes lost virtually all influence over the management of Columbian Basin resources - influence they would not begin to regain until the 1970 s (Ruby and Brown, 1981; Pevar, 2002).

\section{European Exploration and Anglo-American Settlement}

Whereas early Spanish interest in the Northwest centered on gold to replace that taken from South and Central America, it was the abundance of furs that sparked initial settlement (Lyman, 1963/1917; Schafer, 1943/1918; Dodds, 1986). The potential value of the Northwest fur trade was in effect discovered by accident. According to Schafer (1943/1918), the sailors of James Cook's 1778 voyage exchanged "baubles as the sailors cared to part with" with natives for sea otter and

\footnotetext{
${ }^{45}$ The treaty tribes have consistently prevailed in federal court in defending their treaty fishing rights, and the judicial history of the Pacific Northwest contains numerous milestones in the development of Indian law. The National Research Council (2004) identifies United States v. Winan (198 U.S. 371), decided by the U.S. Supreme Court in 1905, as the foundational legal case regarding treaty reserved fishing rights. Others are discussed later in this report.
} 
other furs to supplement their clothing and bedding and improve shipboard comfort. Upon arrival in Canton, China, they were beset by merchants willing to pay "a hundred dollars" for "[s]kins that did not cost the purchaser sixpence sterling" (Schafer, 1943/1918, p. 15). As word spread, Spain, France, Holland, Portugal, Russia, Great Britain, and the United States all sought or claimed rights to the Pacific Northwest. A growing demand for fur pelts in China and East India and long-standing interest in finding a northern waterway linking the North American east and west coasts fueled this international interest.

United States and Great Britain held the strongest claims; those of the others eventually fell away or were otherwise resolved (Schafer, 1943/1918; Lyman, 1963/1917 $7^{46}$ ). The United States based its claim on Robert Gray's exploration of the mouth of the Columbia in 1792 (which gave the river its current name ${ }^{47}$ ) and the Lewis and Clark expedition of 1804-1806. Great Britain rested its claim on the seabased discoveries of Francis Drake, James Cook and George Vancouver and Alexander Mackenzie's overland expedition in 1793. A treaty in 1846, establishing the current border between the United States and Canada, settled British claim (Lyman, 1963/1917; Schafer, 1943/1918; Dodds, 1986).

"Mountain Men" operating as independent trappers (mostly from Kentucky and Virginia) or as employees of large fur companies followed in the wake of the

\footnotetext{
${ }^{46}$ See Lyman, 163/1917, pp. 157-162 for discussion as to how these various claims were resolved.

${ }^{47}$ Gray named the river after his ship, the Columbia Rediviva. See Schafer (1943/1918), Lyman (1963/1917), Dodds (1986), and just about everyone else who has ever written about the Northwest.
} 
Mackenzie and Lewis and Clark expeditions. These companies included the British Hudson's Bay Company, first chartered in 1670; the Canadian Northwest Fur Company, established in 1783; and the American Pacific Fur Company founded by John J. Astor in 1810. These companies did more than just pursue their business interests. Their posts and forts established the first systems of white governance in the region, providing social organizations for defense, trade, food production, administration of justice, and other regulations over day-to-day life (Lyman, 1963/1917; Schafer, 1943/1918; Dodds, 1986; Robbins, 1997).

In the 1820s, the Hudson's Bay Company (the Company) merged with the Northwest Fur Company and bought out the American Pacific Fur Company. The fact that the the Hudson's Bay Company almost derailed establishment of a provisional government in the Oregon Territory demonstrates the Company's regional political power. The policy of the British as implemented through the Company was to "keep the country a wilderness, to maintain amicable relations with the Indians, and to depend mainly on the fur trade for the great profits of their enterprise" (Lyman, 1963/1917, p. 162). American interests, in contrast, lie in regional settlement and development.

The Northwest established its first provisional territorial government in May 1843 when local leaders called a meeting of American and French Canadian settlers to create a framework of laws and elect officers. The Hudson's Bay Company ordered their employees, which accounted for about half of the delegates selected, to vote against any such plan. Nevertheless, the proposal to form a provisional government 
passed albeit by a narrow margin. The new government laid the basis for American settlement and eventual establishment of the Oregon Territory in 1848 (Schafer, 1943/1918; Lyman, 1963/1917; Johansen, 1967). ${ }^{48}$

The Oregon Territory of 1848 (see map at Figure P-1) consisted of the current states of Oregon, Washington, and Idaho and portions of Wyoming and Montana. In 1853 settlements north of the Columbia, located around Puget Sound and along the Cowlitz River, petitioned Congress to form a new Territory from within the boundaries of the Oregon Territory. Noting that the current Oregon Territory was too large to form a single state and stating their frustration at the distance between their communities and the Territorial capital in Oregon City, proponents argued that division was inevitable anyway. Presciently identifying the governance conflicts that were to follow, their petition stated that the residents north and south of the Columbia "would always rival each other in commercial advantages..." The petitioners predicted the communities around Puget Sound and those within the Willamette Valley would always "as they are now and always have been, be actuated by a spirit of opposition" (Johansen, 1967, p. 248). The bill creating the Washington Territory passed in 1853 with little opposition. Similar arguments led to further dividing the Washington Territory to create the Idaho Territory in 1863, followed by the Montana Territory in 1864 and Wyoming Territory in 1868. Statehood came for Oregon in

\footnotetext{
${ }^{48}$ See Lyman, 1963/1917, pp, 162-169 for a detailed and dramatic account of the proceedings leading up to this vote and description of the newly formed provisional government. He claims the measure passed by two votes from over a hundred cast. The veracity of his telling may be suspect, however, given that he mistakenly reports the year of the provisional government's formation as 1841 apparently confused it with a different meeting that occurred in that earlier year. Johansen (1967) questions the closeness of the vote.
} 
1859, Washington and Montana in 1889, and Idaho in 1890 (Johansen, 1967; Dodds, 1986). With formal government structures in place and treaties signed with the Indians, migration to the Northwest began in earnest.

\section{$\underline{\text { Regional Economic Development and the Anglo-American Worldview }}$}

White economic and social development flourished just as tribal societies disintegrated. The economy of the Pacific Northwest developed along five lines of extractive industries between the late eighteenth and late nineteenth centuries. These were the fur trading, fishing, mining, forestry, and agriculture (to include farming and ranching) and their supporting social and institutional infrastructure (Norwood, c.1981; Robbins, 1997; Taylor, 1999).

Trapping died out as a major commercial enterprise by the 1840 s. Fueled by the trappers' stories, promises of free land, and discovery of gold in California in 1848 and in Oregon in 1850, the population quickly grew. The rapid influx of settlers and prospectors created demands for food, land, and timber. The market for increased food supported development of an extensive salmon fishery in the lower Columbia River and farms and ranches throughout the region. Canning technology provided the means to preserve food economically transport it over long distances supported the growth in food production. Farm land in the water-rich area west of the Cascades, particularly in the fertile Willamette Valley, was developed first and was fully claimed by the 1850 s. Timber harvest from the forests of the Northwest and northern California, made efficient through the use of the steam engine, fed the need for 
building material for mines, and towns (especially San Francisco) (Smith, 1950; Johansen, 1967; Dodds, 1986).

The railroads arrived in the 1870 s, connecting the resources of the Northwest to growing demand from the nation in general and the meteoric growth and development in California in particular. With the arrival of the railroads, the period 1870 - 1914 saw an expansion of cattle and sheep ranching and the growth of dry land farming east of the Cascades in Oregon and Washington and in southern Idaho.

A belief in market capitalism and divine support for the American political system grounded the general social values of the Euro-American settlers. These values held nature as a warehouse of natural goods provided by Providence for human enrichment (Taylor, 1999; Lichatowich, McConnaha, Liss, Stanford, and Williams, 2006). These values epitomized the Judeo-Christian belief in human dominance over nature (Kline, 2000) and the accumulation of individual wealth as a divinely endorsed moral good (Weber, 2002/1920). They were coupled with uniquely American concepts of private property in general and land ownership in particular as guarantors of social equity, individual wealth creation, and democratic government. These concepts were combined with a belief that divine providence preordained an American empire from coast to coast (Smith, 1950).

In addition, those arriving in the Pacific Northwest, having survived the arduous cross-country journey, brought with them an enormous sense of selfconfidence. New settlers poured into the region, especially following the Indian treaties. Most came from the Midwest, descended from British stock and already 
American by several generations. They were conservative, ambitious, and strongly believed in the west as a mythical garden awaiting the plow and settlement. They saw the land of the West as an opportunity for a better life and for the growth of American republican virtue. Thus, they added to an already American value of economic prosperity through capitalist enterprise and the belief that settlement of the west was part of God's divine plan (Smith, 1950; Dodds, 1986).

These philosophical predispositions were coupled with the seemingly limitless natural resources of the North American continent. Writing with regard to timber, Jenks Cameron (1928) argues that a "legend of inexhaustibility" evolved beginning with the earliest reports from European New World explorers. The perception of inexhaustibility applied to fisheries (Weber, 2002; Cart, 2004) and game (Cameron, $1929)$ as well. Estimates of annual salmon and steelhead returns to the Columbia River Estuary are as high as 16 million (National Research Council, 2004). With regard to game, Cameron (1929) wrote that the abundance of birds and wildlife ...bred in the early American settler a fixed idea and a trait. The fixed idea was a conviction that any such thing as the extermination of game was impossible. The trait was a prodigal disregard for not merely game but wildlife of all sorts comparable to the solicitude which the boy with a stick in his hands feels for the weeds by the wayside. And both the trait and the idea were transmitted to the early settler's children and to his children's children. And along with them were transmitted the fierce conviction that a free-born American had the right to bear arms, and to 'gun' pretty much where, when, and how he pleased (Cameron, 1929, p. 5).

The national belief in markets and individual liberty, an assumption of resource inexhaustibility, and dubious assumptions about water availability led to federal policies on western settlement, agriculture, mining, grazing, water, and timber 
intended to encourage passage of western public lands into private hands with little regard for consequences (Wilkinson, 1992; Reisner, 1993). As settlement progressed, the newcomers began to call for the institutional infrastructure needed support their ambitions.

\section{$\underline{\text { Regional Institutional Development }}$}

America as a whole in the late 1800 s was largely a country of "island communities" - small towns separated by miles of rural land. Most people's concept of the nation was limited to their immediate and surrounding communities (Wiebe, 1967). Drawn by the region's abundance and the land and wealth promised by national policy, people and business enterprises established isolated, independent, and relatively self-contained communities built around mining, farming, ranching, fishing, and timber throughout the Northwest (Robbins, 1997, Vogel, 2007). Seattle, Washington (timber); Bend, Oregon (timber); Astoria, Oregon (initially a fur-trading outpost; later fishing); Wenatchee, Washington (initially a fur-trading outpost; later agriculture) and Kellogg, Idaho (mining) provide examples of these early communities and the resources around which they were built.

Isolation and independence also occurred in the administrative framework for oversight of federal and state statutes and policies. Responsibility for policy oversight and implementation was assigned to specific government agencies, such as the Corps of Engineers for waterway navigation and flood control; the Bureau of Reclamation for irrigation; the U.S. Forest Service and General Land Office for timber harvest, 
grazing, and mining on and/or distribution of public lands; the Department of Agriculture for farming; the state fish and wildlife agencies and federal Fish and Fisheries Commission (later the Fish and Wildlife Service and National Marine Fisheries Service) for fishery management (Conover, 1923; Holt, 1923; McKinley, 1952, Steen, 1976; Shallat, 1994; Cart, 2004; Pisani, 2002; Rowley, 2006 ).

Thus, local communities, private enterprises, and state and federal agencies evolved together around the region's fisheries, water resources, land, farms, ranches, and timber. The approach and attitudes of the federal agencies were functions of their origins. The earliest agencies, such as the Army Corps of Engineers (established 1802), the General Land Office (established 1812), and the Department (later Bureau) of Indian Affairs (established 1824) had organizational roots and traditions dating back to the nation's colonial period. Congress expected the Corps, GLO, and the Department of Agriculture (established 1868) to work with private interests to support and promote development of the nation's economy. Later arrivals, such as the Reclamation Service (later Bureau of Reclamation) (established 1902) and U.S. Forest Service (established 1905), while grounded in Progressive values of scientific management, efficiency, and management of public resources for the greatest public good, were also development oriented albeit with the twin goal of sustainability over the long term. Each developed close working relationships with the private constituencies that came to depend on them (Conover, 1923; Holt, 1923; Steen, 1976; Shallat, 1994; Pisani, 2002; Rowley, 2006). 
The upshot was that by 1929 the Northwest economy and social system rested almost entirely upon extraction and development of the region's rich natural resources. Although frequently in conflict over markets and other tangible interests, regional institutions met with little challenge during their formative years (Dodds, 1986). Later attempts to provide a more holistic management system, regardless of how well intentioned, would often be seen as threats to established ways-of-life, entrenched interests, and agency prerogatives and thus met with deep suspicion. (Ogden, 1949; Smith, 1950; Bessey, 1963; Norwood, c.1981; Dodds, 1986; Wilkinson, 1992; White, 1995; Robbins, 1997; Lichatowich, 1999; Taylor, 1999). The remainder of this section introduces the major institutional actors that would come to play significant roles in future debates over the Basin's governance systems. In addition to the already-discussed Indian tribes, these include the federal and state agencies and private enterprises developed around regional land development, water law, river development, fisheries, and hydroelectric power.

Land use: farming, ranching, and timber. ${ }^{49}$

Eighteenth and early $19^{\text {th }}$ century policies focused on the sale of public land to help fund the federal government (Conover, 1923). By the mid $19^{\text {th }}$ century, federal policies offered both free land ownership to encourage an agricultural life style for average Americans and generous access for resource extraction to support settlement and economic development. The Homestead Act of 1862 promised 160 acres to

\footnotetext{
${ }^{49}$ Mining was also a major land use activity and a significant factor in regional settlement. However, the research for this study revealed no involvement by mining interests in any of the proposed or enacted governance systems identified. Consequently, discussion of mining is limited to its interconnection with other agencies and land uses.
} 
anyone willing to claim and work the land; the Hardrock Mining Law of 1872 allowed free access to public land for extraction of minerals; and state grazing laws permitted private use of public land free of charge. The stated goal of these policies was to build a society of small, "yeoman" farmers in the Jeffersonian tradition to avoid the European practice of an aristocracy of major landowners. The west's abundance of natural resources could support regional settlement, enhance the national economy, assist in establishing the United States' place in international commerce, and offer a relief valve for potential crowding and social unrest in the east (Smith, 1950; Wilkinson, 1992; Cortner and Moote, 1999).

The strategy for implementing settlement policy was simple and straightforward. Adopting laissez faire policies at the state and federal levels, the government would essentially "open the gates to western public lands, step back, and allow American ingenuity to take over" (Wilkinson, 1992, p. 18). Federal policy encouraged the exploitation of resources on public land; federal and state laws provided incentives for people to move west and codified the practices of those already there. The two federal agencies charged with implementing these policies were the General Land Office (GLO) and, later, the Forest Service.

Originally organized under the Department of the Treasury, GLO was moved to the newly created Department of the Interior in 1849. In effect, GLO served as the nation's real estate agent (Conover, 1923). GLO opened its first office in the Pacific Northwest in the Oregon Territorial capital, Oregon City, in 1855. Field offices later opened in Olympia, Seattle, Walla Walla, Yakima, and Spokane in what is now 
Washington and Burns, Lakeview, Roseburg, The Dalles, and Vale in the future state of Oregon.

GLO's already large workload increased with the issuance of railroad grants between 1851 and 1872, the mission of managing public timber in 1855 , the $\underline{\text { Homestead Act, }}$ and the Hardrock Mining Act. These laws intended settlement to proceed in an orderly fashion guided by careful surveys. The additional responsibilities imposed on GLO by these laws did not bring with them new staff, and the agency felt constantly besieged by more work than it could handle (Conover, 1923). Complaints over the slow processing of claim and requests by the agency mounted, and settlers, developers, and business interests often moved ahead with their development plans without formal approval.

The agency compensated for its staff shortages by depending on grant applicants to provide their own surveys. This often led to fraud, especially with regard to timber and minerals. Reports to Congress requesting additional funds, larger staffs, better regulation, and greater authority went largely unheeded (Steen, 1976). ${ }^{50}$

Much of the abuse on public land involved timber poaching. Progressive reformers, motivated by the efforts of Franklin Hough, repeatedly tried to establish a professional forest service to combat the wasteful and damaging practices by timber companies on public land. Congressman Mark Dunnell of Minnesota tried unsuccessfully to get such a bill through the Public Lands Committee in the mid 1870s. Private timber interests and their supporters on the committee opposed the bill.

\footnotetext{
${ }^{50}$ For an example, see the report to Congress from the Commissioner of the General Land Office, 1888).
} 
In frustration, Dunnell slipped a rider for a "forest study" under seed distribution provision in the Department of Agriculture appropriations bill. Conducted by Hough, the report proved highly influential. Congress appropriated funds for additional reports on a case-by-case basis until establishment of a formal Division of Forestry in Agriculture in 1881 with Hough as its chief. Upon its establishment in 1905 under the leadership of Gifford Pinchot, the U.S. Forest Service assumed full responsibility for public forest management (Steen, 1976). Six local district offices (later regions) were established the same year. District (region) 6 was headquartered in Portland, Oregon.

The federal government owns a large percentage of land within the Northwest, land now managed by the Bureau of Land Management and Forest Service. ${ }^{51}$ The agencies developed close working relationships with local cattlemen's associations, farm bureaus, and timber companies interested in leasing access for grazing, farming, and timber harvest on lands under agency management (Conover, 1923; Steen, 1976). This close relationship with local interests coupled with the shear amount of land under their control destined both agencies to become significant actors in future governance activities.

Western water law: the doctrine of prior appropriation.

Prior to the early 1800 's, east coast states based access to water on a doctrine of riparian rights and reasonable use. Those holding streamside lands had a right to draw water for use as long as the use was "reasonable" in relation to other stream

\footnotetext{
${ }^{51}$ As of 2007, USFS and BLM owned land constituted $60 \%$ of Idaho, $46 \%$ of Oregon, $27 \%$ of Montana, and $23 \%$ of Washington. Data obtained from http://www.wildlandfire.com/docs/2007/western-statesdata-public-land.htm.
} 
users. Although this began to change in the 1820's with industrialization in New England, in general private individuals could own the land along lakes and riverbanks while the water itself was considered a public resource (Steinberg, 1991; Wilkinson, 1992).

This concept of water use was carried west by the early settlers. It began to change with the use of water in hydraulic gold mining in California in 1848. The demands for water at mining sites located far from any water supply resulted in construction of elaborate systems of canals throughout western mining states. Predating written law and court decisions, miners developed their own water rules which paralleled the rules they developed for mineral extraction. The rule was simple: "first in time, first in right" or "prior appropriation." Influenced by the role of gold mining in the newly admitted state, the Supreme Court of California upheld this doctrine in 1855 (Wilkinson, 1992).

Newly arriving ranchers and farmers adopted the doctrine of prior appropriation and incorporated it into state constitutions and statutes throughout the west. Later developments clarified that, in order to maintain a water right, the user had to put the water to "beneficial use." The water had to be diverted from its natural bed and consumed for specified purposes such as mining, agriculture, municipal or domestic supply, livestock, or hydropower. Not included were in-stream uses such as recreational boating, swimming, or fish and wildlife protection. Although some states 
eventually adopted exceptions, ${ }^{52}$ by 1929 prior appropriations doctrine governed almost all water use in the West (Wilkinson, 1992).

Prior appropriation doctrine was embedded in the Reclamation Act of 1902, which - while claiming a water right for the federal government on water on public lands not already appropriated - prohibited the federal government from interfering with State and Territorial laws governing control, use, appropriation or distribution of water (Rowley, 2006). Jurisdiction over water use and allocation was vested in the state, and not federal, governments. The Northwest states would jealously guard their prerogatives over water in future governance debates. Local parties quickly contested any hint of encroachment on local water by federal or other regional entities.

State water law provides rules for water use. Other than the provisions respecting the doctrine of prior appropriation found in the 1902 Reclamation Act, state law does not govern the development of water infrastructure. That responsibility would ultimately fall to the Army Corps of Engineers and Bureau of Reclamation.

\section{Early federal development of the Columbia River.}

Given the centrality of hydropower to the region's economy today, it is worth noting that electricity was not the first commercial purpose envisioned for the river. Irrigation water for farms and river transportation to move agricultural and timber products to market were more pressing needs for early settlers (Ogden, 1949, Norwood, c.1981).

\footnotetext{
${ }^{52}$ For example, Oregon exempted from appropriation several of its scenic waterfalls in 1915 (Wilkinson, 1992).
} 
Whereas farms in rain-rich areas west of the Cascades did well, most of the $19^{\text {th }}$ and early $20^{\text {th }}$ century farming efforts east of the mountains failed due to limited rainfall. The lack of rain, coupled with ever-increasing demand, prompted residents and political leaders to look to the region's major river systems as sources of largescale irrigation. Additionally, monopolistic pricing practices by the railroads caused inland farmers, organized through the Grange, to promote development of the rivers as means of cheaper transportation (Ogden, 1949, Norwood, c.1981).

The demand for irrigation and inland navigation were the two primary motivators for the series of dams and reservoirs that exist today. Private investors or other local resources developed smaller tributaries and rivers, such as found in the Klamath and Umatilla basins. However, major projects on the mainstem of the Columbia River were far too complex and expensive for local developers or the states (Robbins, 1997) and the cost of mainstem dam construction could not be economically justified based on irrigation and navigation benefits alone. Eventually, projected revenue from hydroelectricity provided the economic justification for large-scale dams that irrigation and navigation improvements alone could not (Ogden, 1949; Norwood, c.1981).

Early visionaries foresaw a system of dams providing efficient and inexpensive navigation and irrigation, the cost of which would be subsidized by the sale of hydroelectricity. Consistent with the Progressive emphasis on the instrumental use and scientific management of natural resources, proponents of river development sought to harness the water being "wasted" by allowing it to run to the sea and transfer 
it to equally "wasted" open land lying unused for want of moisture (Robbins, 1997).

Their plan was to turn the unpredictable Columbia into a machine serving commercial and developmental purposes (White, 1995).

Federal responsibility for irrigation and navigation rested with the U.S.

Reclamation Service (later the U.S. Bureau of Reclamation) and the U.S. Army Corps of Engineers, respectively. The Reclamation Act of 1902 established the Reclamation Service. Whereas the older Corps of Engineers drew its members from the U.S. Military Academy at West Point, the Reclamation Service was initially staffed from the U.S. Geological Survey, self taught engineers, and graduates of the many engineering colleges opening around the country. Progressive values of competence and scientific management grounded the Reclamation Service. It based career advancement on merit and demonstrated achievement. By 1926, the government had authorized twenty-nine federal irrigation projects. Northwest projects included Minidoka, Idaho (1904), Boise, Idaho (1905), Klamath and Umatilla, Oregon (1905), Okanogan and Yakima, Washington (1905), King Hill, Idaho (1917), and Owyhee and Vale, Oregon (1926) (Rowley, 2006). Eventually, the Boise office would be designated the headquarters for the Service's Pacific Northwest Region. Reclamation project offices established close working relationships with local Grange offices, irrigation districts, irrigation associations, and other agricultural interests and entities.

The Minidoka project, located on the Snake River, was the first federally constructed hydroelectric facility built by the Reclamation Service. The Minidoka project came on line in 1909 (Pisani, 2002; FCRPS, 2003). The 1902 Reclamation 
Act authorized dams to be outfitted with turbines to generate hydroelectricity in order to power the pumps that would move reservoir and groundwater to farms. Later, the Town Sites and Power Development Act of 1906 authorized the Bureau to lease surplus power with a preference to municipal purposes (Bureau of Reclamation, 2006). Later Bureau irrigation-hydropower dams came on line in the Snake Basin at the Boise River Diversion project in 1912 and Black Canyon in 1925. The Federal Columbia Basin Power System All would eventually come to encompass all of these projects (FCRPS, 2003).

These first dams were single-purpose in that they were oriented primarily on irrigation; the hydropower plants provided the electricity needed to pump water from the projects' reservoirs to higher elevations. Proposals for multi-purpose water development were beginning to be made in 1908 but did not gain widespread support until the broader push for development and promotion of hydroelectric power began around 1918. The multi-purpose approach ultimately reinforced the notion that the federal government needed to take the lead on river development due to the complexity of the issues and the multiple jurisdictions that spanned major watersheds (Billington et al., 2005).

Federal civil engineering expertise also resided in The U.S. Army Corps of Engineers (the Corps). Congress provided for the first American military engineers in 1775 on the day before the Battle of Bunker Hill. The Continental Army was heavily dependent on French trained engineers, as there were few technically trained Americans. The Military Peace Establishment Act of 1802 formally established what 
the Corps of Engineers. This act also established a military academy focused on the teaching of civil engineering at West Point, New York (Holt, 1923; Shallat, 1994; U.S. Army Corps of Engineers, 1998).

The Corps civil works mission dates to the River and Harbors Act of 1824 . Supporters of the act hoped to create an interconnected series of improved waterways, canals, and roads to facilitate national defense and promote the commercial development of the interior. ${ }^{53}$ However, Congress never fully supported this nationwide vision, electing instead to fund projects on a piecemeal basis in keeping with local needs and interests (Holt, 1923; Shallat, 1994; U.S. Army Corps of Engineers, 1998).

In the early 1900s, the Corps officially opposed multi-purpose river development. ${ }^{54}$ The Corps position was that development of waterways for navigation purposes, both to enhance national defense and to facilitate internal growth and development, was justified under the "general welfare" and "promotion of commerce" clauses in the Constitution. The constitutional support for other proposed purposes was, in the Corps's view, suspect. Hydropower - even if constitutionally supportable - was untested in the open market and investing in large dams risked a significant

\footnotetext{
${ }^{53}$ The United States had been invaded by Great Britain from Canada, the eastern seaboard (which resulted in the burning of Washington, DC), and the south at New Orleans during the War of 1812. Improving inland transportation infrastructure would improve the ability to move troops and military supplies within the country. See U.S. Army Corps of Engineers, 1998, pp. 37-39.

${ }^{54}$ The Corps's "official" position on any given issue at any particular point in time can be hard to determine. The Corps traditionally operated in a decentralized decision making structure. Thus, despite "official" positions being often declared by Corps or administration officials, actual practices in local district offices could be far different. See Shallat (1994), Maas (1974/1951), and/or Ferejohn (1974) for further discussion.
} 
waste of public funds should the expected demand never materialize. Furthermore, river transportation was facing stiff competition from the railroads and diluting river purposes among other functions could weaken the effort to promote and enhance navigation. Critics claimed that the Corps's arguments had more to do with protecting the agency's dominance over the nation's waterways than concern over broader national interests. Regardless, the Corps found support in the members of their Congressional oversight committees who did not want their influence eroded or shared with other committees and agencies holding jurisdiction over other water purposes (Hays, 1999/1959; Billington et al., 2005; Rowley, 2006; Pope, 2008).

The Corps would hold to its single-purpose perspective until forced to incorporate flood control due to a series of devastating floods in the early 1900s and the abject failure of its policy of relying on levees for protection during floods on the Lower Mississippi in 1927. The final shift away from its single-use philosophy occurred when the 1925 and 1927 River and Harbors Acts called on the Corps to study opportunities for multiple uses, to include flood control and hydropower development, on the nation's major rivers (Billington, et al. 2006).

The Corps's first improvements in the Columbia River began in 1868. It opened an office in Portland (later the Portland District headquarters) in 1871 and another in Seattle in 1896. These offices were organized under the North Pacific Division established in 1901, originally located in San Francisco. The division headquarters office would alternate between San Francisco and Portland until finally settling in Portland in 1931 (Scheufele, 1969). 
Like the General Land Office, Forest Service, and Bureau of Reclamation the Corps established close ties with the local business and trade associations built around their activities. Steam ship companies and coastal fishing communities depended on navigation improvements in order to carry out their business. Given their respective places in the regional economy and their jurisdictional responsibilities on the Columbia, both the Bureau of Reclamation and Corps would become major players in future governance debates. Their projects would be at the center of the future controversy between river development and the region's salmon fishery.

The Columbia River salmon and steelhead fisheries.

The seemingly limitless bounty of Pacific Northwest fish attracted a robust fishing industry, especially with the advent of canning technology. The tribes, of course, had fished the river and its tributaries for centuries. Tribal fishers also provided all of the settlers' fish needs until a few white entrepreneurs began fishing commercially in 1850. In 1861, the Territory of Washington granted two white men exclusive gill net fishing rights in the lower Columbia. This seemingly simple act symbolized the beginning of conflict among tribal and state fishery managers and a profound transition from a fishery focused on regional subsistence to an integral part of a capitalism-driven market. Industrial-scale fishing arrived in 1866 along with the first cannery. By 1887, 39 canneries packed 42 million pounds of salmon per year (Taylor, 1999).

The first hatchery was built in 1877 and was soon followed by others. However, hatchery production could not keep pace with the loss of habitat upriver due 
to mining, timber, agriculture, and other development and ever-increasing harvest levels by an essentially unregulated fishery. The fish also suffered severe natural setbacks between the early 1860s and late 1890s from periodic redds-scouring floods and stream-drying drought. The combination of upriver habitat degradation, over harvest, and natural occurrences caused Columbia salmon runs to crash in the 1890s with some predicting imminent extinction. The decline in the numbers of fish and subsequent consolidation of the market drove many commercial fishermen out of the market and closed a number of canneries. Control of the market soon shifted from the Columbia to Alaska. The Columbia market rebounded briefly with an increased military demand for food in the mid 1910s during World War I, largely met with increased hatchery production, but it declined again soon after the War's end. It eventually stabilized, largely dependent on hatchery-produced fish. An entire institution evolved around the science of artificial propagation of fish for the purposes of food production. Despite the hatchery effort, the fishery never regained the size it enjoyed in its early heyday (Lichatowich, 1999; Taylor, 1999).

The formation of a federal fisheries service was almost single handedly accomplished by Spencer Fullerton Baird. Baird sent a letter to Congress laying out his proposal for a federal fish commission. He recommended, “...careful, scientific research be entered upon, for the purpose of determining what should really be done." The federal fish commissioner's duties included conducting such investigations and “...perhaps, after conferences with the Fish Commissioners of the several states, advise what action, if any, should be taken by the General Government alone or in 
conjunction with the states..." (Baird, quoted in Cart, 2004, p. 4). Congress forwarded a joint resolution establishing the U.S. Fish and Fisheries Commission to President Ulysses Grant who signed it on February 9, 1871. Grant appointed Baird as Commissioner. The Fish Commission, located under the Department of Treasury, had three duties:

- Research oriented to preserving the commercial fishery.

- Research into fish culture and artificial propagation.

- Compilation of statistics and evaluation of the efficacy of fishing methods.

The goal of Fish Commission research was production of fish as a marketable commodity. Consequently, close ties developed between Baird and his subordinates and promoters of hatcheries intended to increase sport and commercial harvest. The stated goal of the fish culture research was to "make fish so abundant that they can be caught without restriction" (Cart, 2004, p. 6.).

Although it opened investigations into the Alaska salmon fishery around 1890, the Fish Commission's presence in the Northwest was initially limited. In 1903, the Fish Commission lost its status as an independent agency when it was transferred to the Department of Commerce and Labor and renamed the Bureau of Fisheries. The Bureau opened a small office in Seattle in 1914 as the center for the Bureau of Fisheries Pacific operations. In 1921, at the request of and in conjunction with the Oregon Fish Commission, it initiated a study on Columbia River salmon. Although it would push for regulation when needed, particularly with regard to salmon 
exploitation in Alaska, the Bureau of Fisheries in general cultivated close working relationships with state fishery and hatchery managers (Cart, 2004).

Already stressed by overfishing and habitat loss, the Columbia salmon runs now faced a new threat - the construction of dams in the Columbia mainstem. Hydropower: the public - private power debate.

No issue of the early 1900s arguably held greater implications for the future of the Columbia River than the debate over whether electrical generation and transmission should be a public or private enterprise. Nationally, a backlash to the electricity monopoly exercised by major trust and holding companies grew along with the public's increasing concern over corporate power and other social inequities.

Private utilities and holding companies viewed electricity as a commodity whose price and availability should be determined by the open market. Critics contended that the electrical market was hardly "open.” By 1912, ten holding companies owned $60 \%$ of the nation's hydropower with local monopolies setting rates with limited, if any, competition or regulation. Private power interests dominated the policy arena in the 1920s, supported by Republican majorities in Congress and an administration generally hostile to public utility ownership and anti-monopoly policies. As a result, there were few regulatory constraints and low permitting fees. As a result, private waterpower development boomed until passage of the Water Power Act in 1920 (Blumm, 1982).

Electricity became a political issue due to the growing recognition of its potential to affect peoples' lives. Despite arguments that large companies would 
ensure low rates through economies of scale, greed and questionable business practices often resulted in the opposite. Technology advances in communications and transportation at the turn of the $20^{\text {th }}$ century resulted in a nationwide transformation of American business from predominately small, locally owned enterprises to nationwide, multi-unit corporations. The complicated ownership structure of holding companies that spanned multiple jurisdictions often rendered local regulation meaningless. Frequently, company executives either bribed or ignored local regulators. Monopoly power allowed companies to set prices without fear of competition and to avoid expanding electrical service to areas deemed unprofitable, such as rural communities (Ogden, 1949; Blumm, 1982; Brigham, 1998).

Private power advocates argued it inappropriate for the the government to be involved in power production, transmission, or distribution. They pointed out that the very existence of electrical power was the product of entrepreneurial experimentation and innovation by private inventors such as Thomas Edison. In the late 1800s and early 1900s, private power supporters heralded such individual examples as classic success stories of American capitalism. They viewed public ownership as "socialistic" and equated it to the confiscation of private property in order to place it under "political management" (Brigham, 1998, pp. 108-109). Private power supporters defended the consolidation of locally owned utilities into large holding companies and interlocking corporations as an essential evolution necessary to ensure economies of scale and low rates. As pressure for public ownership grew, privately owned businesses and utilities reluctantly agreed to support locally regulated 
monopolies in order to protect investments and guarantee some level of return (Ogden, 1949; Brigham, 1998).

Conversely, Progressives and public power advocates viewed electricity as a powerful social force that could raise the standard of living for everyone if made affordable. They did not, however, speak with one voice. Those advocating outright government ownership and operation of energy facilities and those who sought a balance between the extremes of unconstrained markets and socialism split the movement. Moderate Progressives argued less for government ownership and more for regulation of private utilities, the use of cost-based pricing as a "yardstick" against which to measure private rates, and "postage stamp" pricing that guaranteed customers of similar service would pay the same rate regardless of location (Ogden, 1949; McKinley, 1952; Brigham, 1998).

Public power had numerous successes at the local level, with municipally owned utilities emerging in urban areas and energy cooperatives in rural areas, especially in Washington. State measures were passed in California in 1913; Arizona, Nebraska, and Montana in 1915; and several other western states between 1927 and 1930 (Ogden, 1949; McKinley, 1952; Brigham, 1998). However, success at the local and state levels did not translate into similar success at the federal level. The Federal Water Power Act of 1920 affirmed federal jurisdiction over water power sites on navigable rivers, limited licenses of private facilities to 50 years, affirmed the right of the federal government to charge for private licenses, established public preference for the power generated from federal projects, and authorized federal construction of 
hydroelectric projects as recommended by the Federal Power Commission. But congressional support for federal licensing of hydropower projects was limited to concern that uncontrolled dam building would impede navigation, and did not equate to support for outright public project ownership (DeLuna, 1997). Although the 1920 Act established a uniform process for licensing private hydroelectric projects, it did not provide any funds for planning those projects (National Research Council, 1999). Furthermore, the small government and pro-market/pro-business administrations of Warren Harding (1921-1923), Calvin Coolidge (1923-1929), and Herbert Hoover (1929-1933) preferred that actual development be left in private hands. In their view, the federal government role was to provide technical support and studies to inform private entity development (DeLuna, 1997; Blumm, 1982).

The River and Harbor Act of 1925 directed the Corps of Engineers and Federal Power Commission to estimate the cost for a comprehensive survey to study multiple use development of the Nation's navigable streams, to include hydropower, flood control, navigation, and irrigation. The Corps replied in 1926 with what became House Document No. 308. The report identified 180 rivers for study, including the Columbia. Congress responded with the River and Harbor Act of 1927, authorizing the Corps to undertake comprehensive surveys and formulate general plans for water resources development in the nation's major watersheds. The Corps responded in turn with its 308 Report in March 1932. The 308 Report represented the nation's first basin-wide development plan (Ogden, 1949 and 1997; Billington, et al., 2005; National Research Council, 1999). 
The Hoover administration intended the 308 Report to guide private investment in water resource development. It was not to turn out that way. The onset of the Depression and the election of President Franklin Roosevelt shifted the publicprivate power debate decisively in favor of public power advocates. The next chapter presents the impact of that shift for the Columbia.

\section{Section summary.}

By 1929, a large number of the institutional actors that would participate in future governance activities were well established in the Northwest. These institutions include the federal and state agencies, private businesses and trade associations, and political supporters involved with land use, water use, river development, fisheries, and early hydropower production. Each operated in a relatively autonomous manner within their respective jurisdictions and often competed with each other for federal funding, increased jurisdiction, and expanded missions (McKinley, 1952; Clarke and McCool, 1996). Although their organizational roots originated in different eras of American history, they all shared a common worldview grounded in market capitalism.

\section{Early Signs of Stress on Northwest Resources}

By the late 1920s, the Pacific Northwest comprised about $9 \%$ of the United States land mass but held only $2.5 \%$ of its population. Planners estimated it to hold $40 \%$ of the nation's timber and $40 \%$ of its hydropower potential. The region's mines were leading national producers of copper, silver, lead, and zinc (Bessey, 1963). 
Fertile soil and plentiful water beckoned farmers to the Willamette Valley, and the promise of irrigation made agriculture and farming viable in the dry areas east of the Cascades (Bessey, 1963; Taylor, 1999). Pre-development salmon runs have been estimated by some at between 6.2 and 12 million fish per year (Taylor, 1999; Williams, 2006) with some estimates as high as 16 million (National Research Council, 1996). Commercial fishermen harvested 20 to 40 million pounds of salmon between 1875 and the 1920s (Taylor, 1999; Williams, 2006). Given this "unlimited" bounty, it was extremely difficult to make a compelling case for restraint and regulation.

Despite the relatively sparse population, negative impacts were beginning to be felt as early as the late 1800 s. The hard winter of 1886-1887 caused a massive die-off of cattle from starvation. The overstocking of cattle, coupled with several subsequent years of drought, devastated public grasslands (Wilkinson, 1992). The salmon fisheries, while strong, were beginning a serious decline due to over harvest and the destruction of habitat due to mining, timber practices, and the construction of dams in Columbia tributaries (Bessey, 1963; Taylor, 1999). These declines caused Livingston Stone, an agent of the U.S. Fish Commission in the Northwest, to call for a national salmon park in 1892 to protect declining wild runs from the impacts of development (Cone and Ridlington, 1996, pp. 332-334).

The effects of over grazing and fishery declines were the first indicators that the region's rapid and virtually unconstrained economic development could have significant long-term consequences. New political and social forces were emerging 
that would challenge the underlying premises upon which the region's institutional arrangements were based.

\section{$\underline{\text { The Progressive Conservation Movement }}$}

Unlike the east, where the Progressive movement carried strong support from the population, Progressive reforms in the Northwest were more the work of legislatures, political parties, and party leaders. More interested in visibility at the national level, regional leaders enacted reforms for which the population often seemed ambivalent, at best. Progressive reformers constantly struggled against the more conservative strain of the Northwest population (Johansen, 1967).

More relevant to the Northwest was the Progressive Movement's strong resource conservationist members. There were motivated by disgust at over-harvest of timber, over-grazing of grassland, soil depletion through poor agricultural practices, degradation of public lands due to mining, and water pollution due to factory waste. For the public as a whole, the concern was less about environmental degradation than the unfair advantage and heavy-handed tactics exercised by large businesses (Wiebe, 1967; Cortner \& Moote 1999).

Viewing natural resources as an interconnected ecosystem was in its earliest stages in the latter 1800s. John Perkins Marsh, largely credited with being the first to record the impacts of development on natural processes, first published his observations in 1864 (Marsh, 1965/1864; Dunlap, 2004). Two philosophical conservation perspectives emerged to challenge the prevailing view of nature as an 
inexhaustible warehouse of marketable commodities, both of which had their origins in the observations of Marsh. The "conservation" perspective was personified by Gifford Pinchot for public land, C. Hart Merriam for wildlife, and Spencer Fullerton Baird for marine fisheries. "Conservation," as used in the context of the time, called for management of natural resources in a way that ensured their long-term availability for utilization. Under this view, failure to develop and use existing resources was considered as wasteful as depleting them to a point where they could not be recovered.

A letter from James Wilson, Secretary of Agriculture, provided initial guidance to Gifford Pinchot, Chief Forester of the just-established Forest Service, and concisely captured the Progressive conservation philosophy regarding natural resources.

Although written specifically for the newly established Forest Service (and written by Pinchot for Wilson's signature ${ }^{55}$ ), the letter articulates the Progressive philosophy. Public land was to be "devoted to its most productive use" for "the permanent good of the whole people" as opposed to individuals or private companies. Water, wood, and forage are to be "conserved and wisely used" to ensure "permanent and accessible supply" in support the "continued prosperity of agricultural, lumbering, mining, and livestock interests." The letter directed that the new agency professionally manage its assigned resources under "businesslike regulations" "under the eye of thoroughly trained and competent inspectors" (Wilson, 1905).

As such, Progressive philosophy did not repudiate the concepts of private markets and commercial utilization of natural resources. Instead, it introduced a new

\footnotetext{
${ }^{55}$ For detailed discussion of the origin, significance, and far-ranging influence of the "Pinchot Letter," see Wilkinson (1992) pp. 127-130 and Steen (1976) p. 75.
} 
role for government. Professionally trained, apolitical civil servants would apply scientific management principles to regulate against the excesses of the market. New federal agencies established in part to curb the power and excesses of corporations on public land through competent government stewardship (Wilson, February 1, 1905; Wiebe, 1967; Steen, 1976; Wilkinson, 1992; Billington, et al., 2005).

The second perspective that emerged to challenge the market model placed an inherent aesthetic value on natural resources independent from their economic value. John Muir personified this "preservationist" perspective. Muir argued that the wilderness had an intrinsic worth all its own that was worth preserving in its natural state. Both the conservation and preservation movements established initial beachheads into corporate and private exploitation of public land due in no small part to the passion and energies of Pinchot, Merriam, Baird, and Muir and their support by President Theodore Roosevelt.

The conservation perspective found expression through laws and policies governing the use of wildlife, fisheries, forests and water under federal jurisdiction and institutionalized through establishment of federal agencies such as the Bureau of Biological Survey, U.S. Fish and Fisheries Commission, Forest Service, and Bureau of Reclamation. Establishment of the state and national park systems, starting with Yosemite and Yellowstone, and creation of the National Park Service implemented the preservation perspective (Cameron, 1929; Steen, 1976; Cortner \& Moote, 1992; Clarke and McCool, 1996; Cart, 2004; Dunlap, 2004). All of these agencies or their successors would come to play dominant roles in future Basin governance systems. 
Opposition to the Progressive conservation and preservation movements came mostly from westerners opposed to eastern-based interference with their prerogatives. They saw hypocrisy from those preaching conservation principles that were too late to implement in the already largely developed east (Steen, 1976) and a complete lack of understanding by easterners of the challenges and hardships of settling the often brutal conditions in the west (Wilkinson, 1992). Corporate interests used to all but unrestricted access to the resources on public land were equally opposed to both movements (Hays, 1999/1959; Wilkinson, 1992).

Despite the opposition from the west and large corporate interests, the administration of Theodore Roosevelt and the Progressive conservationists in government and in Congress successfully led and shaped the formal government conservation and preservation policies of the era. The American public generally supported these efforts, but not because of any affinity for environmental protection. The direct experience of many nineteenth century Americans with nature presented personal challenges and outright threats, especially in the west. Struggling against harsh weather, floods, drought, predators, insects, and rodents they carved an oftenprecarious livelihood on small farms, ranches, mills, and homesteads (Cameron, 1929; Wiebe, 1967; Wilkinson, 1992; Robbins, 1997). Often the actions and practices of legions of individual homesteaders, prospectors, and ranchers resulted in environmental consequences as severe as those of the industrialized giants (Hays, 1999/1959). Given the prevailing "legend of inexhaustibility," many simply would 
not have believed that any restrictions on the pursuit of personal economic advancement were necessary.

Attitudes shaped by a strong protestant ethic of individual work and distrustful of the apparently unearned wealth, power, and corruption of large corporate entities underscored public support for the Progressive cause. Values and lifestyles developed in isolated small-towns and centered on natural resource extraction, agriculture, and local factory working conditions left most Americans wary of monopolies, rising waves of immigration, land speculators, and wealthy land-grabbers (Wiebe, 1967). Progressive conservationism thus found public traction not because of any deep-seated public belief in environmental values, but because of deep-seated skepticism over the motives of moneyed interests (Cortner and Moote, 1992). The result was a partial but significant shift in power from large corporate trusts and the market to the federal government as exercised through public agencies over public resources (Hays, 1999/1959).

\section{$\underline{\text { Regional Governance Systems up to 1929: }}$}

Regional natural resource governance up through the 1920s consisted of private enterprises working in concert with supportive and relatively autonomous federal agencies responsible for specific resource domains, constrained only by the authorities and funds provided by Congress. Laissez faire policies left development to the market and individual ingenuity and many in the Northwest felt that minimum or no government equated to good governance. In addition, many had little patience with 
anyone, government or otherwise, interfering with their affairs or their rights to resources (Dodds, 1986; Wilkinson, 1992). For example, Gifford Pinchot, then head of the U.S. Forest Service, imposed a modest grazing fee on ranchers in 1906 to attempt some control over the overstocking that led to the cattle disaster in the late 1880s. His effort outraged ranchers who had grown used to free grazing on public land with no government oversight or controls. They pilloried him in the western press as a "dictator and carpet bagger" (Wilkinson, 1992).

Progressives made some inroads in the laissez faire environment of the day by establishing federal agencies charged with the responsibility to better manage public resources. These agencies included the Reclamation Service, the Forest Service, the National Parks Service, and the U.S. Fish and Fisheries Commission (later the Bureau of Fisheries). These new agencies joined those previously established, most notably for this study, the Corps of Engineers, the General Land Office, the Office of Indian Affairs, and the Department of Agriculture. Legacy effects from the nation's earlier expansionist period and that era's policy emphasis on localism, support for commercial development, and the transfer of public lands into private hands established the traditions and cultures of the earlier agencies. Some of these agencies, like the General Land Office and Office of Indian Affairs, had roots dating back to the nation's colonial period (Conover, 1923; Holt, 1923; McKinley, 1952; Shallat, 1994; U.S. Army Corps of Engineers, 1998; Pisani, 2002). Regardless of origin, all agencies developed close ties with regional interests dependent on their respective programs and services and for whom they had originally been largely established to support. 
Authorizing statutes and assigned jurisdictional oversight of specific policy domains governed each agency. Agencies exercised decision-making in keeping with their respective missions and authorizing statutes and regulations. Just as American society was segmented into island communities at the end of the $19^{\text {th }}$ century (Wiebe, 1967) so too were federal agencies segmented into island communities of policy and program jurisdiction. Each agency was focused on a constituency that was dependent on the agency's authorities and expertise and supported by constituency-centered Congressional authorizing and appropriating committees. Political scientists variously characterize these powerful triads of agency expertise, Congressional support, and local constituencies as "subgovernments," "policy whirlpools," or "iron triangles" due to their autonomy, strength, and resistance to reform (Cater, 1954; Griffith, 1961; Heclo, 1978). But a dramatic alternative to functional-management-by-individualagency was evolving in the East on the Tennessee River.

Muscle Shoals is approximately the midpoint of the 600-mile long Tennessee River. At this point, the river drops 134 feet over 37 miles creating a series of rapids and waterfalls that long impeded the use of the river for navigation. The sharp drop in elevation offered the opportunity for hydropower development and attracted the attention of private corporations. President Theodore Roosevelt vetoed a bill to allow the site to be privately developed in 1903. The National Defense Act of 1916 authorized the Corps to construct a dam, nitrate plant, and related temporary steam generating plant near the site to support the production of munitions for World War I and eliminate about 15 miles of rapids. The War ended before construction was 
completed, and project funding subsequently slowed. The Corps ultimately completed the plant and Wilson Dam in 1925 (Norwood, c.1981; Conklin 1983). ${ }^{56}$

To thwart further private interest in taking over the site, Progressives introduced a bill in 1922 to create a government corporation to run the nitrate plant (ultimately retrofitted to produce fertilizer) and to be responsible for future development. The bill failed. Although the public-private power debate was part of the Muscle Shoals controversy since 1897 (Conklin, 1983), the 1922 bill made Muscle Shoals a national focal point. Both President Coolidge in 1928 and President Hoover in 1931 vetoed subsequent similar bills passed by Congress. The election of President Franklin Roosevelt removed White House objections. Roosevelt signed the Tennessee Valley Authority Act into law in 1933 (Norwood, c.1981; Conklin 1983).

The Tennessee Valley Authority (TVA) was destined to provide an inspiring governance model for Northwest Progressives. However, as of 1929, management of resources in the Columbia Basin meant governance through private corporations operating independently on private land or in concert with supportive federal and state agencies. Private companies and individual federal and state agencies exercised decision-making in keeping with their individual objectives and priorities. This combination of the laissez faire doctrine toward private businesses, weak government regulation, and public agencies exercising "iron triangle"-type functional jurisdiction over discreet policy domains characterized a market-oriented governance preference. All involved, whether in the private or public sectors, shared a common worldview

\footnotetext{
${ }^{56}$ Wheeler Dam was subsequently constructed to solve remaining Muscle Shoals navigation issues.
} 
regarding natural resources. There simply were no voices challenging the "rightness" of whether the various programs and projects underway or under consideration should be undertaken.

The sharing of a common worldview did not automatically translate to cooperation. The division of federal agencies among four cabinet level departments, the exercise of Congressional prerogatives by oversight committees, and strong support from agency constituencies often drove agencies to compete rather than cooperate (McKinley, 1952; Clarke and McCool, 1996). As the government grew in size and complexity, a growing realization emerged among the major actors that better coordination and control arrangements were necessary.

\section{Chapter Summary}

The situation in the Pacific Northwest stood as follows by 1929:

- The earliest regional governance structures consisted of clan-based tribal societies located on traditional tribal lands (Ruby and Brown, 1992). The rules and regulations of large fur trading companies governed the earliest white communities in the late 1700s and early 1800s. These in turn gave way to provisional governments, followed by establishment of the Oregon in 1848 , later subdivided into the Territories of Oregon, Washington (1853), Idaho (1864), and Montana (1868). County and municipal governments were first established under the Territorial governments. The states of Oregon, Washington, Montana, and Idaho Montana were admitted 
to the Union in $1859,1889,1889$, and 1890 respectively (Schafer, 1943/1918; Lyman, 1963/1917; Johansen, 1967; Dodds, 1986).

- The role of Native American tribes in the development of policy in the Northwest was dramatically mercurial. The role began with dominance in the early 1800s but declined to a point of all-but-extinction from the mid 1800 s to the mid 1900s. In essence, the tribes were simply not a relevant voice in the early 1900s (Taylor, 1999; Pevar, 2002; Wilkinson, 2005).

- The West experienced a major demographic shift with the decline of Indian populations and increase of Anglo-American settlers. The territorial population was distributed among a few large cities and numerous small towns. Isolated, "island" communities developed with economies centered on agriculture, ranching, or resource extraction (Lyman, 1963/1917;

Wiebe, 1967; Dodds, 1986; Wilkinson, 1992; Taylor, 1999).

- National policy up to the 1860 s was focused on helping fund the federal government through sale of public lands to private individuals or interests; thereafter the policy shifted to the transfer of public lands and resources to private control through sale, grants, or patents (Conover, 1923; Wilkinson, 1992).

- The Protestant-market-capitalism worldview dominated, modified in the Pacific Northwest by unique attitudes toward western land and a selfconfidence bred by surviving the move westward. Disease, efforts to civilize their culture, and displacement to reservations all but erased the 
tribal worldview (Cameron, 1928 and 1929; Smith, 1950; Dodds, 1986;

Robbins, 1997; Taylor, 1999; Hays, 1999/1959; Kline, 2000; Weber, 2002/1920; Wilkinson, 2005; Lichatowich, McConnaha, Liss, Stanford, and Williams, 2006).

- The environmentalist worldview was in its infancy and expressed through the tenets of Progressive conservatism (Kline, 2000; Dunlap, 2004; Rosenbaum, 2005).

- This dominant worldview held by policy makers and administrators fostered localized decision-making. Communities, private businesses, and federal agencies exercised a great deal of autonomy in determining what they were going to do and how they were going to do it. Corporate interests working alone or in partnership with federal agencies and appropriate congressional committees provided the governance framework for natural resource management (Cater, 1954; Griffith, 1961; Wilkinson, 1992).

- The Northwest was a region rich in natural resources, with a large potential for timber, agriculture, ranching, fisheries, mineral, irrigation, and hydropower development. Exploitation of these resources was driven by a "legend of inexhaustibility," the lack of effective regulation, and the opportunities for creation of private wealth. Natural resource development was largely in the hands of large corporations and holding companies, such as timber, railroads, and mining interests, supported by federal agencies 
(Cameron, 1928 and 1929; Lyman, 1963/1917; Dodds, 1986; Wilkinson, 1992; Robbins, 1997; Taylor, 1999; Lichatowich, McConnaha, Liss, Stanford, and Williams, 2006).

- Federal agencies developed as policy autonomous "island communities" with little cross-agency coordination or planning and frequent conflict over turf and congressional attention (Cameron, 1928; McKinley, 1952; Steen, 1976; Shallat, 1994; Clarke and McCool, 1996; Pisani, 2002).

- Progressive era ideals of sustainable use and conservation-oriented public management of public resources for the public good were very much part of the political debate, but failed to overturn the prevailing belief in private markets and the laissez faire doctrine of minimum government involvement in private business activities. The Progressive goal was a better life for average Americans through planning, scientific management of natural resources, and provision of electricity through public ownership or strict regulation of power production (Hays, 1957; Hays, 1990/1959; McKinley, 1952; Steen, 1976; Norwood, c.1981; Cortner and Moote 1999; Billington et al., 2005).

- Commercial fishing on the Columbia began in 1850, growing to industrial scale in 1866 . The first hatchery was built in 1877 . By 1887 the river housed 39 canneries. Overfishing, habitat degradation, and a series of naturally occurring floods and drought crashed salmon runs in the $1890 \mathrm{~s}$ 
(Cone and Ridlington, 1996; National Research Council, 1996; Taylor, 1999).

- Any debate over natural resource development was a debate over who should own, control, or operate natural resource exploitation. There was no question among the relevant parties as to the rightness of such exploitation (Cortner and Moote 1999; Pisani, 2002; Billington et al., 2005; Lichatowich, McConnaha, Liss, Stanford, and Williams, 2006).

- The Corps, acceding to the demand for multiple use waterway

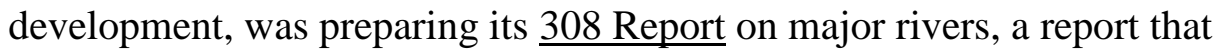
would assess the feasibility for hydropower, navigation, and irrigation on a scale not yet seen in the United States (Ogden, 1949; McKinley, 1952; Norwood, c.1981).

Such was the situation as of 1929. On October 29 of that year the stock market crashed and dramatically "punctuated the equilibrium" (Gersick, 1991) of private market dominance through laissez faire and symbolically marked the onset of the Great Depression. The Depression proved "a major turning point in American history. It changed the Nation's economic beliefs and attitude toward business. It revised American politics and the Government's role. The laissez faire doctrine gave way to public demands for government action to battle the depression [sic], and the policies and special interests that contributed to its onset" (Norwood, c.1981, p. 34). 


\section{CHAPTER 4 \\ THE ONSET OF THE DEPRESSION (1929)}

\section{$\underline{\text { Introduction }}$}

The onset of the Great Depression presented the first critical situation that induced changes to prevailing Basin governance systems. It created the conditions for a dramatic shift away from a model of governance based on private market enterprises working in concert with supportive federal agencies. Rejecting calls for consolidation of federal agency missions under an authoritative valley authority, the region adopted a new model characterized by state-led centralized planning. The onset of the Depression also resulted in the creation of a model for Basin operations that was characterized by cooperation among federal agencies.

The catastrophic economic collapse of the Great Depression ushered in a decade of "persistent, continuing unemployment and unrelenting, grinding poverty" (Norwood, c.1981, p. 30). Its wide effects significantly undercut the prevailing laissez faire attitude toward unconstrained free markets and challenged the relatively autonomous "iron triangle" arrangements among local interests, federal agencies, and their congressional supporters. It created the conditions under which prevailing market and agency-centric governance systems could be changed as the public looked to government to restore the national economy. The changes in governance did not eliminate the market role in the economy or fundamentally alter federal agency missions. What changed was the autonomy under which these long-standing institutions previously operated. Private corporations were subject to greater 
government regulation. Federal agencies in the Columbia Basin were required to be more collaborative and inclusive in their discretionary decision-making.

In addition to Progressives who believed in a more activist role for government was an influential group of advocates who embraced the concept of "regionalism." Regionalists critically looked at state and federal government structures seeking criteria other than private markets or jurisdictional boundaries to suggest logical administrative arrangements. ${ }^{57}$ The Tennessee Valley Authority exemplified this thinking. TVA admirers saw the watershed of the Tennessee River as a more efficient organizational concept than the political boundaries of the states, the market boundaries of privately incorporated businesses, or the jurisdictional boundaries of individual federal agencies (White, 1995; Vogel, 2007).

The concept of multi-state regions presented, among other challenges, two fundamental questions. The first was the structure under which long-range planning of regional resources was to take place. Regionalists and Progressives believed planning to be the answer to the resource waste and inefficiency they saw as inherent in the fractured decision-making processes for land, soil, water, timber, fish, and timber development as practiced through unrestrained markets and uncoordinated agencies (Bessey, 1963; McKinley, 1952). The second question focused on operational issues. The desires for rational region-scale planning to guide river development and other resource use meant determining how responsibilities for design, construction, and operations of resulting activities that crossed traditional

\footnotetext{
${ }^{57}$ Ogden (1949 and 1997), McKinley (1952), Bessey (1963), and Norwood (c.1981) all wrote from a regionalist perspective.
} 
agency jurisdictional boundaries were to be allocated (McKinley, 1952; White, 1995; DeLuna, 1997; Brigham, 1998).

This chapter identifies the Northwest governance systems proposed and enacted to address these functional questions in the 1930s. It documents the social and political context from which governance proposals emerged and the key issues in the Northwest that influenced those proposals. The following four governance proposals emerged in this period of which two were enacted:

- The Pacific Northwest Regional Planning Commission (PNWRPC or Commission), established in 1934 under the National Planning Board to perform the planning function.

- Proposals in 1935 to assign full responsibility for all purposes of the dams, to include marketing and transmission of electricity, to either the Corps of Engineers or Bureau of Reclamation (not enacted).

- Proposals made later in 1935 for a Columbia Valley Authority modeled after the Tennessee Valley Authority (not enacted).

- Establishment of the five-agency Bonneville Advisory Board under the Bonneville Project Act of 1937.

\section{$\underline{\text { Social and Political Context }}$}

Franklin Roosevelt achieved a landslide electoral victory in 1932, winning 472 electoral votes to Hoover's 59. Democratic majorities were swept into Congress. Democrats won $70 \%$ of seats in the House of Representatives and commanded a $22-$ 
seat majority in the Senate (Norwood, c.1981). The Depression provided a catalytic opportunity for a more robust government role in the economy, marking "the final, inevitable collapse of an economy that had been beset for at least fifty years by overproduction and an excess of competition” (Kennedy, 2009, p. 261).

The Depression presented a critical situation that opened opportunities for change beyond regional governance systems. It also enabled responses to other demands that had gained momentum in American society (Norwood, c. 1981). The 1932 election was a clear public mandate to get the economy back on track. It was also a mandate that was far more sensitive to Progressive ideals than its predecessor and far more activist in pushing for both regulation and, in some limited cases, direct government involvement in areas previously relegated to private markets (Norwood, c.1981; Kennedy, 2009). Kennedy (2009) argued that the New Deal crowded more social and institutional change into American society than at any comparable period of time in its history, addressing issues such as social security for the elderly, the financial desperation of small farmers (especially in the Midwest), health, and housing. ${ }^{58}$ Although many of Roosevelt's specific organizational experiments did not last long, the New Deal succeeded in creating a set of institutional arrangements establishing unprecedented economic security for average citizens.

\footnotetext{
${ }^{58}$ One could argue that the periods of the Civil War and subsequent Reconstruction brought far greater change given the abolition of slavery, the economic destruction and eventual recovery of the South, the growth in power assumed by the federal government at the expense of the states, the emergence of transportation and communications technologies, and the beginnings of national industrialization, all of which presented major challenges to the traditional foundations of American society. See Hays 1957; Wiebe, 1967; and Hays, 1999/1959.
} 
The New Deal brought dramatic reversals to private power interests. Building on previous success at the state and local levels, public power advocates effectively swept the national policy field in the early 1930s. With the support of President Roosevelt and the congressional Democratic majorities, they were able to enact legislation strongly regulating corporately owned activities and played a strong role in passage of the Bonneville Project Act in 1937 (Hays, 1959/1999; Bessey, 1963; Norwood, c.1981; Kennedy, 2009).

The New Deal created the belief in the minds of the American public that the government had a major responsibility to ensure national economic health and citizen welfare. This represented a major shift away from the laissez faire period that preceded it. This shift notwithstanding, the New Deal did not challenge the fundamental tenant of capitalism - the private ownership of production - and left the nation's dominant market-capitalist worldview intact, if badly tarnished (Kennedy (2009).

Kennedy additionally claimed that, excepting the Tennessee Valley Authority, "no significant state-owned enterprises emerged in New Deal America" (Kennedy, 2009 , p. 253). Whereas this generalization may be true on the national scale, it overlooks the significant regional impacts that the New Deal had on the Northwest. These impacts include the conceptualization of the Northwest as an administrative entity oriented on the Columbia River (White, 1995; Vogel, 2007), establishment of the Bonneville Power Administration, and expansion of the roles that the Corps of 
Engineers and Bureau of Reclamation were to play in the Columbia Basin following federal dam construction (McKinley, 1952; Norwood, c.1980).

The period also opened opportunities for major changes within the federal bureaucracy. New agencies were created, such as the Public Works Administration and its associated national planning committee, ${ }^{59}$ the Soil Erosion Service (later the Soil Conservation Service), and the U.S. Grazing Service. Others were reorganized. Secretary of the Interior Harold Ickes, pursuing his vision of consolidating all natural resource agencies into the Department of Interior, successfully acquired the Bureau of Biological Survey from the Department of Agriculture and the Bureau of Fisheries from the Department of Commerce in 1939. These were subsequently combined to create the Fish and Wildlife Service in 1940 (Clarke and McCool, 1996; Weber, 2002). Ickes also tried to acquire the U.S. Forest Service and the civil works function of the Corps of Engineers. He failed in both due to those agencies' strong support from their respective Congressional oversight committees and local constituents (McKinley, 1952; Clarke and McCool, 1996) demonstrating that "iron triangle" type arrangements were still very much in play with some agencies. ${ }^{60,61}$

\footnotetext{
${ }^{59}$ This "central planning committee" underwent several organizational changes between 1933 and 1943. It operated as the National Planning Board from 1933-1934; the National Resources Board from 1934-1935; the National Resources Committee from 1935-1939, and the National Resources Planning Board from 1939-1943. See Bessey, 1963, pp. 48-52. This report uses the generic phrase "central planning committee" to minimize confusion.

${ }^{60}$ Ickes frustration at being unable to overcome the bureaucratic and political power of the Corps and Forest Service resulted in frequent invective against both agencies, invectives that were subsequently cited in periodic calls for agency reform. For the Corps, see Ickes' introduction to Arthur Maas (1974/1951) Muddy Waters, in which he describes the Corps as "lawless and irresponsible" and Reisner's subsequent reference to those comments in Cadillac Desert (1993). For the Forest Service, see Fromes's The Forest Service (1971) where he quotes Ickes as characterizing the Service as a "bureaucracy run wild."
} 


\section{$\underline{\text { Salient Issues in the Pacific Northwest }}$}

Two overriding policy issues influenced Pacific Northwest governance during this period. The top national and regional priority, up until the United States' entry into World War II in 1941, was economic restoration. New Deal programs addressed the economic challenge through tighter regulation of markets, central planning, and public works projects. Complementing the belief in planning and public works were completion of the Corps 308 Report in 1932 and construction of the massive Bonneville and Grand Coulee dams across the Columbia. The emphasis on economic restoration provided the backdrop for the governance proposals put forth during this period. Following the attack on Pearl Harbor in 1941, the emphasis shifted to winning World War II, an emphasis that finally achieved the economic recovery sought under the New Deal. ${ }^{62}$ The need for electrical power to support the Northwest industries engaged in the production of war materials forced an unprecedented level of operational cooperation among the newly created Bonneville Power Administration, Corps of Engineers, and Bureau of Reclamation and tested the collaborative governance arrangement between them called for in the 1937 Bonneville Project Act.

Economic development through centralized planning.

Bessey (1963) traces the roots of the Northwest's regional planning to the watershed management philosophy of John Wesley Powell in the late $19^{\text {th }}$ century and

\footnotetext{
${ }^{61}$ See McKinley, 1952, pp. 411- 423.

${ }^{62}$ Kennedy (2009) argued that it took the mobilization for World War II to create a context that permitted levels of deficit spending that finally restored the economy. He further argued that such deficit levels were "intellectually inconceivable" and politically impossible in the 1930s despite the widespread unemployment and economic misery.
} 
the progressive conservation philosophy of the Theodore Roosevelt administration in the early $20^{\text {th }}$ century. Progressive goals were to be achieved through integrated planning on a watershed scale to optimize use of all natural resources, especially water. Advocates called for nationally coordinated planning commissions to design a "rational distribution" of goods and services that would not be "hamstrung" by interstate differences (Mumford, 1939). In the Northwest, the states of Oregon, Washington, Idaho, and Montana were interested in finding ways to leverage federal dollars for river development projects too expensive for state funding alone (Vogel, 2007).

Prior to the Depression, critics of government led planning undercut public support by successfully associating it with rising totalitarian regimes in Japan, Italy, and Germany following the First World War and the centralized five-year plans of the communist Union of Soviet Socialist Republics (Bessey, 1963; Norwood, c.1981). The onset of the Depression pushed those fears aside. The public demand for economic relief engendered support for federal leadership and planning that, while stopping short of the scope of the regimes rising in Europe and Asia, were far more extensive than previously undertaken. The National Industrial Recovery Act put forth a national blueprint for recovery in 1933. The Act created the Public Works Administration (PWA), which in turn established its central planning committee. Private sector advisors dominated this committee, supported by federally funded staff. The central planning committee shared the belief that successful planning rested on local and state initiative and that effective planning at those levels was essential to the 
national planning program. Consequently, the committee established and supported state and local planning boards with technical assistance and funding. Oregon, Washington, Idaho, and Montana organized state planning boards between 1933 and 1934. County, area, and city planning boards were established as well (Bessey, 1963; McKinley, 1952; Norwood, c.1981).

In addition to the state-level boards, the committee identified a need for two interstate regional planning commissions, one in New England and the other in the Pacific Northwest. The Pacific Northwest Regional Planning Commission (PNWRPC or Commission) was subsequently established in 1934. The Commission would come to play a major role in shaping both the form and nature of future regional governance systems (McKinley, 1952; Bessey, 1963; Norwood, c.1981; Vogel, 2007). It also solidified the concept of the Northwest as a unified region defined by the Columbia River (Vogel, 2007).

The 308 Report.

The Corps produced its long awaited 308 Report for the Columbia River and its tributaries in 1932. Elwood Mead, Commissioner of the Bureau of Reclamation and the Army's Chief of Engineers Major General Lytle Brown jointly endorsed the report. In a letter of transmittal ${ }^{63}$ forwarding the report to the Secretary of War on March 29, Mead and Brown identified ten locations in the Columbia Basin

\footnotetext{
${ }^{63}$ The Corps provided the Bureau of Reclamation the opportunity to review and comment on the final report. Commissioner Mead provided General Brown with a letter generally concurring with the report, the only exception being its treatment of irrigation as discussed below. General Brown incorporated Commissioner Mead's letter into his own when forwarding the report to the Secretary of War.

Consequently, the two letters are referenced here as one.
} 
recommended by the Board of Engineers for Rivers and Harbors as the most promising for waterpower facilities and, more important, provided economic justification for their construction. The report characterized the Columbia River and its tributaries as "susceptible of being developed into the greatest system for water power anywhere in the United States." The envisioned series of dams would provide an estimated eight million kilowatts of installed hydro electricity. The report warned, however, that power development should be done "in such increments as not to outrun the demands of the market" and called for "close coordination of the entire power industry in the region" to guard against over production (Mead and Brown, 1932, March 29). The Government Printing Office subsequently published the Columbia River portion of the report in 1934 under the title Columbia River and Minor Tributaries (Ogden, 1997).

The report offered the opportunity for long sought after low-cost, high-volume barge navigation from Bonneville Dam to the mouth of the Snake River. It claimed that the "potential navigation on the middle section is of such value" as to "warrant the assumption by the Federal Government of the entire cost of the necessary locks and channel enlargement" provided they be constructed as an integrated part of each hydropower project. By integrating a series of locks at the hydroelectric dams, the report estimated a total of 600,000 tons of freight at a savings of over one million dollars per year (Mead and Brown, 1932, March 29).

The report noted the problem of flooding in the lower Columbia and stated that the projects may be able to provide some incidental flood protection. Consistent with 
the still-lingering attitude within the Corps that flood control was a local or state

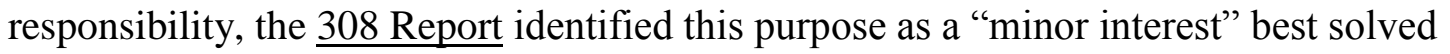
"by local interests whenever the economics of the situation justify the building of better levees" ${ }^{64}$ (Mead and Brown, 1932, March 29; Ogden, 1949).

The 308 Report's recommendations on irrigation were somewhat ambivalent. General Brown's portion of the transmittal letter noted that there were about two million acres along the United States' portion of the Columbia that were susceptible to irrigation. But the Corps questioned the economic feasibility of irrigating this much farmland, citing cost and noting concerns by agricultural authorities that such additional farmland would compete with "other lands already under cultivation." The Corps concluded that irrigation was "not an economical proposition at this time and should await the future." In any case, the cost of irrigation could only be justified in conjunction with hydropower development. The Bureau of Reclamation's Commissioner Mead concurred with the Corps that the cost of irrigation could only be justified if subsidized by the revenues from power and that there was no current demand for additional farms or crops. But he recommended irrigation development begin anyway at Grand Coulee, arguing that the project would take at least ten years

\footnotetext{
${ }^{64}$ The Corps's position on flood protection methods varied over time. It adopted a policy of protection through levees only in the 1860 s, dismissing a visionary 1852 report recommending the use dams and reservoirs in tributaries to prevent or manage floods on the Mississippi. Although dams for flood control in the Sacramento River were supported by the Corps and included in the 1917 Flood Control Act, in general the Corps opposed large federal investments in flood control. This attitude gradually changed within the Corps in light of severe flood damage experienced in the lower Mississippi River in the late 1920s and the demonstrated inadequacy of flood protection dependent solely on levees. Flood control was subsequently included as an authorized purpose for those dams capable of large scale water storage in the Columbia. For discussions of early Corps flood control policies, see Shallat (1994), pp. 174-176; Billington et al., (2005), pp. 314-315, and The Corps's official history (1998) pp. 47-51.
} 
for construction and another ten or fifteen after that for the region to absorb the resulting electrical power. By then, Mead believed, projected population increases would provide the needed market (Mead and Brown, 1932, March 29; White, 1995; Rowley, 2006; Pisani, 2002).

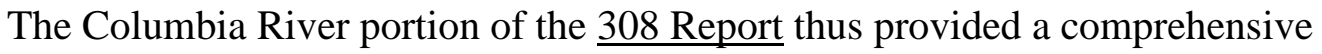
plan for a series of multipurpose dams on the Columbia. It was, by design, purely a technical product, leaving open the questions of who should build, own, and operate the completed projects (although Brown recommended in the transmittal letter that hydropower development that local government or private investment should take on the responsibility for hydropower development) ${ }^{65}$ Although expressly calling for coordination with the power industry for hydroelectric development, it did not offer any suggestions as to how or if the completed projects were to be managed in a systematic way. In short, it was a blueprint for turning the naturally flowing Columbia into a mechanism for commercial purposes. It did not - nor was it asked to - address the complex social network inherently created with the system's completion, a network of interests bound by common dependence on the Columbia's water and the products and services that the use of that water would ultimately produce (White, 1995).

${ }^{65}$ For their part, private power companies balked at the capital investments needed for provision of electricity to rural areas, especially if forced to sell the subsequent power at flat rates, and were skeptical that a market demand for power from large projects would ever materialize (Pope, 2008). 


\section{Construction of the first Columbia River mainstem dams.}

On a campaign stop in Portland Oregon in 1932, Franklin Roosevelt had promised to build the next large dam on the Columbia. To New Dealers such as Roosevelt dam construction represented much more than just job relief. It was a visible statement of the government's commitment to equitable distribution of national resource wealth to the public as a whole and to improving the quality of life and standards of living for millions of Americans. Central planning would ensure efficiency and provide the maximum benefit to the people of the region (Ogden, 1949; Bessey, 1963; Norwood, c.1981).

True to Roosevelt's campaign promise, the government initiated construction on Grand Coulee and Bonneville Dams in 1933 (FCRPS, 2003). The Bureau of Reclamation held authority for construction of Grand Coulee due to the project's irrigation purposes and the fact that the dam would not have a navigation function. Conversely, the Corps of Engineers designed and constructed Bonneville due to the primacy of its navigation purpose. Both would provide hydropower, with Grand Coulee also offering storage for flood control purposes (Billington, et al., 2006). ${ }^{66}$ Bonneville Dam was ready for power generation in 1938, with its first electricity flowing over federal transmission lines to Cascade Locks and Portland in 1939. Grand Coulee began generating power in 1942 (FCRPS, 2003).

\footnotetext{
${ }^{66}$ Bonneville Dam, like most of the dams built on the mainstem Columbia and Lower Snake Rivers, was designed as a "run of the river" project. This means that water flowing into the reservoir flows out through the dam's turbines or over its spillway.
} 


\section{World War II in the Pacific Northwest.}

The mobilization for the Second World War had a major impact on FCRPS development with effects that extended into the post-war years. The war's production effort would depend heavily on energy. Ships, planes, and land vehicles needed oil for fuel. Defense industries needed electricity for war production (Norwood, c.1981).

The strategic role of electricity in modern war production first became apparent during World War I. German submarine warfare had cut the supply of nitrates from Chile upon which the United States depended for ammunition production. This prompted the 1916 National Defense Act that authorized federal construction of a nitrate plant and supporting electricity generation facilities at Muscle Shoals on the Tennessee River. Military planners recognized the national energy shortage with regard to munitions production and the implication of that shortage for a sustained war effort. World War I ended before their fears could be realized, but they captured the issue in a report presented in 1921 (Norwood, c.1981).

Norwood (c.1981) suggested that Franklin Roosevelt's support for public power in the 1930s might have in part been due to the strategic near miss in the First World War and a premonition of pending war due to rising tensions in Europe, although he acknowledges that there is no evidence to support this. ${ }^{67}$ Regardless of Roosevelt's level of foresight, his support of public power in the early 1930s proved fortuitous. He used his successes in the public power debates to help build American

\footnotetext{
${ }^{67}$ See Norwood, (c.1981), p. 120 for further discussion.
} 
production capacity as Japan's aggression in Asia and Germany and Italy's aggression in Europe increased between 1936 and 1938 (Norwood, c.1981).

In the Northwest, the expansion of industrial capacity in the late 1930s translated into demand for expansion of federal hydropower capability. The Bonneville Power Administration (BPA), established under the 1937 Bonneville Project Act to market the power produced at federal dams, often functioned, in effect, as a "regional chamber of commerce" (Norwood, c.1981, p. 125) conducting industrial site and economic surveys. This pre-war promotion resulted in new war-related electrometal and electrochemical plants being quickly located in the region. The electrical needs of mobilization "telescoped more than 10 years of normal growth into a brief 5 years" (Norwood, c.1981, p. 123) in the Northwest. The federal transmission system grew from zero to 2500 circuit miles between 1939 and 1944, with generation capacity increasing from less than 100,000 kilowatts to over 1.3 million in the same period. This growth in capability provided inexpensive electricity to the Pacific Northwest's military installations, defense production industries, and, beginning in 1943, to the highly classified plutonium production facility at Hanford, Washington. About $92 \%$ of federally produced hydropower went to support war production industrial loads, of which up to $80 \%$ (prior to the Hanford project) went to aluminum production in support of aircraft manufacturing (Norwood, c.1981; FCRPS, 2003). Ogden (1949) argues that low electrical rates enabled by federal hydropower so lowered the cost of aluminum production that the federal government saved the "entire cost of the two dams in reduced aluminum prices alone" compared to what it would 
have spent had the aluminum industry been forced to purchase power from private utilities (Ogden, 1949, p. 422). ${ }^{68}$

The Corps accelerated its schedule for generator installation at Bonneville Dam, ensuring that by war's end all ten planned generators were on line (McKinley, 1952). The Bureau of Reclamation made similar efforts at Grand Coulee. BPA constructed a transmission line between Grand Coulee and Bonneville between 1938 and 1940. This transmission line provided the infrastructure to move power to where it was needed as well as enabling the expansion of the federal system that was to come later. An executive order directed BPA to begin marketing Grand Coulee power upon the transmission line's completion (Norwood, c.1981). ${ }^{69}$

Although the war would not end until 1945, Allied victory was apparent by 1944. The Allies won in significant part through the United States superior production capacity. This capacity remained intact even as war in Europe and the Pacific destroyed the production capacities of the Axis nations and seriously damaged those of America's European and Asian Allies. Planning ahead, BPA began promoting Northwest hydropower resources as key to regional post-war development. The agency published a prospectus report entitled Pacific Northwest Opportunities that outlined the industries needed in the Northwest and how they could benefit from the region's low cost power (Norwood, c.1981).

\footnotetext{
${ }^{68}$ Ogden cites the U.S. Congress, House, Interior Department Appropriations bill for 1948, p. 354, in making this claim.

${ }^{69}$ Executive Order 8526, dated August 26 ${ }^{\text {th }}, 1940$.
} 


\section{$\underline{\text { Resulting Governance Systems }}$}

The Roosevelt Administration used the $\underline{308 \text { Report to justify federal }}$ construction of the Bonneville and Grand Coulee Dams (Ogden, 1997). However, construction of the two dams was well underway before any sort of system-wide operational arrangement had been decided. With the pending completion of both projects, the management issue had to be addressed.

Progressives and public power advocates envisioned and promoted a Columbia Valley Authority (CVA) to plan and operate the system along the lines of the Tennessee Valley Authority (Conklin, 1983; Lowitt, 1983). Others still believed in free markets as the best arbiter of where, how, and by whom natural resources should be developed. However, the jolt of the Depression and the political landslide enjoyed by Roosevelt and his supporters swept aside the former dominance of private market advocates in the policy arena (Kennedy, 2009).

The influence of individual agencies over their respective resource jurisdictions, however, was relatively unaffected by the nation's economic situation and proved far more resistant to reform. Consequently, the debate over Basin governance centered on whether hydroelectric generation, transmission, and marketing should be divided among existing agencies or assigned to new ones.

There was little debate that the planning function would be carried out by the Pacific Northwest Regional Planning Commission (PNWRPC). The management issue was far more contentious. The two alternatives under early consideration were the marketing of power by the existing dam-operating agencies (The Army's Corps of 
Engineers and the Bureau of Reclamation) or establishment of a valley authority into which some or all individual agency functions would be absorbed or at least supervised. The PNWRPC produced a report offering several other governance alternatives intended to resolve this debate. Given the urgency of coming to at least a temporary solution before the two dams came on line, the parties to the debated agreed to a compromise solution modeled after the PNWRPC recommendation. The Commission, although favoring the valley authority idea, realized the political impossibility of getting such a structure established in time. Instead, the Commission recommended retention of project operation by the Corps of Engineers and Bureau of Reclamation and establishment of a new agency to market power. The compromise also resulted in the region's first experiment with a governance system based on federal agency collaboration, the Bonneville Advisory Board.

The Pacific Northwest Regional Planning Commission.

Echoing White's (1995) later assertion that it was the FCRPS that united the Northwest as a region, Bessey (1963) argued that "the Columbia River System [not

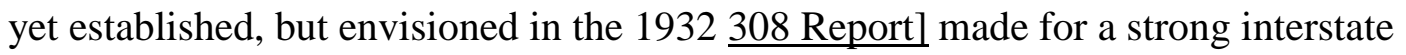
community of interest in development" (p. 46). ${ }^{70}$ The PNWRPC provided the institutional infrastructure to coordinate the efforts of that "community of interest."

\footnotetext{
${ }^{70}$ McKinley also refers to this "community of interest" in his introductory chapter (McKinley, 1952, p. 2). Although not defined as such by either Bessey (1963) or McKinley (1952), their context is clearly a community of economic and development interests as neither tribal nor fishery interests were substantially addressed. Fishery proponent protests against dam construction beginning in the 1940s demonstrated that this community of interests had its limits. Bessey and McKinley did not address environmental interests either, understandable since both were writing before the environmental movement had gained much traction in the public mind.
} 
The immediate need was to provide relief for unemployment and adjustments to agricultural policy in order to address the acute economic distress in urban and rural communities (McKinley, 1952). ${ }^{71}$ Bessey (1963) reports McKinley as believing that "lasting success...would depend upon the degree to which interagency coordination in this work can be secured" (Bessey, 1963, p. 49, emphasis added). The Commission would conduct its planning effort based on the Corps's 308 Report (Ogden, 1949; Bessey, 1963).

The PNWRPC was, by design, state-centric. Its membership consisted of the chairs from each of the four state planning boards, a full-time executive director, and staff (McKinley, 1952; Bessey, 1963; Vogel, 2007). The part-time district chairman of the national planning committee (like all national planning committee members, a private citizen) served as Commission chair. Federal agencies were not Commission members, although they supported the Commission and state board's technical teams with staff and information (McKinley, 1952). The Commission's purpose was "to advise and assist...in the development of comprehensive plans for public works, as contemplated by the Recovery Act, for the regional area" (Bessey, 1963, p. 21). Its functions were investigational and advisory, not operational. The Corps of Engineers, Bureau of Reclamation, and other agencies retained operational decision authority for their respective programs. Consistent with its Progressive roots, the Commission made clear that its intent was to improve the regional economy through the best use of

\footnotetext{
${ }^{71}$ McKinley (1952) also states that the Commission chair believed in participation by "private civic groups" in addition to state, regional, and local entities. Nongovernmental participation is not mentioned by Bessey. See McKinley, 1952, p. 460.
} 
resources (Bessey, 1963). In effect, this arrangement relegated federal agencies to the role of technical advisors and the executors of plans and priorities as established by others.

Vesting supervision of the national planning effort under Secretary of Interior Harold Ickes caused interagency cooperation at the departmental level to suffer. Agencies not under the Department of Interior cooperated reluctantly at best. Disputes were most prominent in Washington, DC but were reflected in the actions of regional agency offices as well. The non-Interior departments and agencies were simply not inclined to support the efforts of someone they considered a rival who had previously campaigned to take over their programs. This problem was eventually resolved by moving the planning function under the executive office of the President (McKinley, 1952).

Proposals for management by existing agencies.

While the Commission was getting its planning function organized, others were calling the question as to how hydroelectricity from the soon-to-be-completed Bonneville and Grand Coulee dams was to be marketed and transmitted. In January 1935, Washington Representative Knute Hill introduced a bill in Congress that would transfer Bonneville Dam to the Bureau of Reclamation upon its completion and assign the Bureau full responsibility for Columbia River development and power marketing. The Corps of Engineers, not surprisingly opposed this proposal (Norwood, c.1981).

Secretary of the Interior Harold Ickes sent a letter requesting the PNWRPC provide recommendations on several issues, including a regional organizational 
system. Presumably with the intent of preempting whatever the Commission might recommend, on July 29 Oregon Senators Charles McNary and Frederick Steiwer and Washington Representative Martin Smith introduced bills in their respective houses of Congress that would have the Corps of Engineers operate Bonneville Dam and market its power. The bill also called for the Corps to build local transmission lines to serve the Portland and Vancouver urban areas. The Corps's service area would be limited to the lower Columbia River. The bill assigned rate-setting authority to the Federal Power Commission. It specified the use of "railroad rates" which varied dependent on distance from the point of generation. Proponents of this proposal included Oregon, private power advocates, and local business owners (McKinley, 1952; Norwood, c.1981). On its part, the Corps believed that the Northwest electricity market was limited, and thus argued for building short transmission lines to service the Portland urban area and industries near the river as the best use of public funds (Pope, 2008).

Opponents included public power advocates in general and much of the public sentiment in the states of Oregon and Washington. Many still recoiled from memories of the role that business leadership in public affairs had played in bringing about the Depression. Washington's delegation in particular was comprised mostly of New Dealers opposed to the McNary proposal and its tilt to private power interests (McKinley, 1952). Because of this opposition, neither the Senate nor the House bill went to hearings. However, they did help frame the debate between advocates of single-agency management of the Columbia (by either the Corps of Engineers or the 
Bureau of Reclamation) and advocates of the proposed Columbia Valley Authority (Norwood, c.1981).

\section{Proposals for a Columbia Valley Authority.}

For Progressives in the 1930s, the Tennessee Valley Authority represented the epitome of government planning and service provision for the greater public good, successfully protecting government resources from the clutches of rapacious corporate interests. It thus served as an inspiration and guiding model for many in the ensuing governance discussions in the Columbia (McKinley, 1952; Norwood, c.1981; Conklin, 1983, quote from p. 4; DeLuna, 1997).

Later in January 1935, after submittal of the Hill Bill favoring Bureau of Reclamation management of the system, Senator James Pope of Idaho introduced a bill in the Senate, with Washington's Hill agreeing to introduce an identical bill in the House, to establish a Columbia Valley Authority modeled after the TVA. The CVA would take over operation of Bonneville and Grand Coulee Dams and administer future development over the Basin (McKinley, 1952; Norwood, c.1981).

Proponents of the Columbia Valley Authority proposal included Progressives and New Deal liberals throughout government and public power advocates (Norwood, c.1981; White, 1995; DeLuna, 1997). Norwood (c.1981) adds the states of Idaho and Washington as supporters, and DeLuna (1997) notes qualified support from the Departments of Commerce ${ }^{72}$ and Interior. ${ }^{73}$ Opponents included the Corps, ${ }^{74}$ private

\footnotetext{
${ }^{72}$ According to DeLuna (1997), the Department of Commerce favored a CVA but one bureaucratically weaker than the TVA. Commerce supported a central authority for dam planning and building in order
} 
utilities, and a number of local chambers of commerce throughout the region,

including Portland's (Norwood, c.1981; Goodwin, 1983; White, 1995; DeLuna, 1997).

Goodwin (1983), DeLuna (1997) and White (1995) state that the Bureau of

Reclamation was also opposed, with White stating that its opposition was muted in

order to not offend the Secretary of the Interior. Goodwin (1983) and DeLuna (1997)

also note opposition from the Department Agriculture due to concerns over potential

threats to the Department's land management authorities in the Forest Service and its

agricultural programs. In general, a belief in market forces, a more opportunistic

approach to development, and opposition to the general power such an organization

would wield regionally philosophically drove non-federal CVA opponents. For their

part, ever since the early 1900s, private power companies had been skeptical that a

market demand for power from large projects would ever materialize - a skepticism

shared by the Corps of Engineers. Federal agencies, especially the Corps, Bureau of

to provide cheap electricity in support of economic development. But it was wary of a central bureaucracy with authority over a potentially broader array of policy arenas.

${ }^{73}$ Disagreement existed within the Department of Interior over whether valley authorities in general should be under the supervision of DOI, the position favored by Secretary Ickes, or independent (DeLuna, 1997).

74 A general Corps of Engineers' policy position on valley authorities is hard to gauge. White (1995) states that "the Tennessee Valley had no equivalents to the Bureau of Reclamation and Army Corps of Engineers, large bureaucratic players, on the river who [sic] could not be easily replaced" (White, 1995, p. 65). White is correct insofar as the Bureau of Reclamation is concerned since the 1902 Reclamation Act limited the Bureau's jurisdiction to the states west of the Mississippi. But his statement regarding the Corps implies that, had the Corps been a stronger presence in the Tennessee Basin, the TVA may not have been developed. But Conklin (1983) presents a relatively cooperative relationship between the Corps and TVA promoters, with the Corps primarily interested in preserving its navigational prerogatives through partnership. McKinley (1952, pp. 521-525) notes some tension in the dual jurisdictional arrangement on the Tennessee but that the two agencies eventually developed protocols and worked through it. With regard to the CVA proposal, it is not clear if Corps opposition represented an institutional change of heart after the TVA experience, differing perspectives between the different local Corps offices, or some other reason. Regardless, the Corps was staunchly opposed to establishing a valley authority in the Columbia. 
Reclamation, and Department of Agriculture (led by the Forest and Soil Conservation Services) were fearful of the potential for impingement on agency prerogatives (McKinley, 1952; Norwood, c.1981; Goodwin, 1983; White, 1995; DeLuna, 1997; Pope, 2008).

Compromise: the Bonneville Power Administration and Bonneville Advisory

Board.

In the spring of 1935, after the Hill and Pope Bills had been submitted, the chair and the executive director of the PNWRPC and Senator Pope met with the President to determine his preference for a Columbia Basin organizational system (Norwood, c.1981). Roosevelt, though supportive of the TVA, "was not precommitted to any particular plan or type" for the Columbia (Bessey, 1963, p. 25). Roosevelt urged the three to study the problem with an open mind, cautioning that a region's characteristics may make a valley authority approach unsuitable (Norwood, c.1981).

Because of that meeting, Secretary of the Interior Harold Ickes sent a letter on July 9, 1935, that requested the PNWRPC to develop a report on the future of the Columbia Basin regarding planning, construction, and operation of public works in the area. The study was to provide a holistic look at power generation and transmission in the Northwest, as well as potential organizational systems (Bessey, 1963; Norwood, c.1981). 
The Commission held seven meetings to collect regional views the following September (Bessey, 1963; Norwood, c.1981). ${ }^{75}$ Bessey (1963) stated that views were collected from "official, commercial, industrial, utility, agriculture, forest, and transportation interests." He further stated that the resulting study confirmed the "broad homogeneity and coherent regionality of the Pacific Northwest" (p. 30). Neither Bessey (1963) nor Norwood (c.1981) mentions any participation by regional Indian tribes or fishing interests. In fact, Norwood (c.1981, p. 57) states, "Chamber of Commerce witnesses dominated the meetings." Neither Bessey (1963) nor Norwood's (c.1981) accounts clarify whether the region's Indian tribes and fishery interests were not invited or chose not to attend. Regardless, the views of regional fishermen and tribes, as future events were to demonstrate, were distinctly at odds with the views of those who did participate.

Each of the four state Commission members, the Chair, and the executive director signed the Commission's report (Bessey, 1963) and submitted it to the National Resources Committee on December 28, 1935. The Committee wrote a strong letter endorsement and published the report for public consumption in May 1936 under the title Regional Planning Part 1 - Pacific Northwest (Norwood, c.1981). However, the Committee's endorsement did not carry the signature of the Secretary of War, reflecting continuing opposition by the Corps of Engineers and its supporters who opposed any recommendation that would take the construction of transmission lines from Bonneville Dam and the marketing of power away from the Corps

\footnotetext{
${ }^{75}$ These meetings were held in Helena, MT; Seattle and Spokane, WA; Portland and Pendleton, OR: and Boise and Pocatello, ID. See Norwood, c.1981, p. 57.
} 
(McKinley, 1952). Two of the PNWRPC report findings of interest to this study were its recommendations regarding the regional transmission grid and its analysis and recommendations regarding regional organization.

The report proposed a "high-voltage, high-capacity, synchronized, constantvoltage network of lines, and switching and transformer stations" (quoted in Bessey, 1963). Initially, transmission lines were to run from the Puget Sound in western Washington through Grand Coulee to Spokane; from Puget Sound south to the Willamette Valley in Oregon; and from Grand Coulee through Bonneville Dam to Portland. Future extensions would connect Spokane to western Montana and through the Snake River Basin to southeastern Idaho and from Portland and The Dalles southward through western Oregon (Bessey, 1963).

Organizationally, the report evaluated five alternatives:

- Project operation and power marketing by both Corps and Bureau of Reclamation for their respective projects,

- Selection of either the Corps or Bureau to assume control of power generation, transmission, and marketing for all or part of the Basin,

- Creation of a new public agency to generate, transmit, and market power,

- Establishment of a Columbia Valley Authority, or

- Establishment of a new federal corporation to generate and market power. The Commission favored creation of a regional valley authority of some kind or a power agency paralleled by a regional planning and program-coordinating agency. They chose the latter in recognition of significant opposition to the former. The 
Commission recommended creation of a federal corporation, and included multiple staff studies as annexes in support of its analysis and recommendations. The voluminous report and its annexes thus provided the administration a "carefully evaluated proposal and supporting arguments" (Norwood, c.1981, p. 58) ${ }^{76}$.

The new corporation was to be overseen by a three-person board of directors selected by the president and approved by the Senate, one of whom would also serve as PNWRPC chair. The proposal allowed the Corps and/or Bureau to add a fourth and/or fifth board member on temporary terms (Ogden, 1949). The Corps, Bureau of Reclamation, Forest Service, and Resettlement Administration provided staff to collect and analyze data and help prepare the report's recommendations (McKinley, 1952). The Commission's recommendation for a statutorily constituted regional planning and program coordination entity (presumably to be itself) was not acted upon (Bessey, 1963). ${ }^{77}$ Had it been, and assuming these functions were assigned to the PNWRPC, the mission of the PNWRPC would have expanded from one of just planning into operational oversight.

Norwood (c.1981) reports on the April 1937 testimony of Oregon Governor Martin who complained of thirty-eight bills submitted in Congress on the Columbia

\footnotetext{
${ }^{76}$ It is not clear if fishery interests felt threatened by the pending river development at this early date; McKinley (1952), Bessey (1963), and Norwood (c.1981) do not mention them one way or the other.

${ }^{77}$ The recommendation for a statutorily supported regional planning entity was eventually implemented upon passage of the Water Resources Planning Act in 1965 and establishment of the Pacific Northwest River Basins Commission in 1967. These events occurred after publication of Bessey's work and are discussed further in the next chapter.
} 
issue since $1935 .^{78}$ At the end of the day, the debate resulted in a bill that, with the exception of the planning and coordination entity, largely followed the recommendations of the PNWRPC report. The bill called for establishment of a government corporation to sell the power produced by the Corps and Bureau and develop a transmission system to connect generation with markets. It was supported by the Corps, provided the Corps retained operational control over the projects it constructed. Oregon, Washington, and Idaho Congressional delegations and the administration also supported it. The PNWRPC recommendation thus became the basis for the 1937 Bonneville Project Act that established the "Bonneville Project" under the Department of Interior (Norwood, c.1981; Blumm, 1982; White, 1995; Pope, 2008).

Those engaged in the debate viewed the Bonneville Project Act as an interim measure, driven by the Corps's construction schedule for Bonneville Dam and the belief by public power advocates that an ultimate CVA-like system was inevitable (Pope, 2008). In its initial form, it applied only to Bonneville Dam. The Act stated that "the form of administration herein established for the Bonneville project is intended to be provisional pending establishment of a permanent administration for Bonneville and other projects in the Columbia River Basin (Bonneville Project Act, 1937, Section 2 (a)) (emphasis added). ${ }^{79}$ The Act also called for preference of sales to

\footnotetext{
${ }^{78}$ Norwood (c.1981) details these various proposals and the political debate around them in pp. 56-62.

${ }^{79}$ The provisional nature is further illustrated in that the Act did not name the new agency thus created. Consequently, a lot of confusion was generated in the minds of the public as to the role of the new Bonneville Project Administrator with regard to the role of the Corps in completing, operating and
} 
public utilities and required the power thus sold to be at uniform "postage stamp" rates. It addressed transmission, but did not specify which agency was to actually build and operate transmission lines (Bonneville Project Act, 1937; Norwood, c.1981). It made clear that construction, operation, and future maintenance of Bonneville Dam was to be the responsibility of the Corps subject to the Act's provisions regarding the authority of the administrator (see Section 1). President Roosevelt signed the Bonneville Project Act into law on August 20, 1937.

Long-standing public power advocate James D. (“J.D.”) Ross was appointed as Administrator of the "Bonneville Project" the following October. Described by Norwood (c.1981) as a "one-man whirlwind" (p. 66), Ross successfully pushed for a policy of postage stamp rates to govern sale of federal power and strongly promoted early construction of a transmission intertie between Bonneville and Grand Coulee Dams. His premature death in March 1939 cut short his tenure. Paul J. Raver succeeded to the administrator's chair the following September. Raver was to serve until 1954. Just as Pinchot's drive and personality shaped the values and culture of the Forest Service, so to would Raver's come to shape the values and culture of BPA (Norwood, c.1981).

The Bonneville Project Act illustrates just how provisional the new agency was intended to be in that it did not give it a name. The Act's title of Bonneville Project Administrator generated confusion in the minds of the public as to the role of the new

maintaining the actual dam. This was finally resolved in 1940 when the agency was made permanent and the Secretary of the Interior approved "Bonneville Power Administration" as the agency's name. See Norwood, c.1981, pp. 68 and 124. 
agency with regard to the role of the Corps in completing, operating and maintaining the actual dam. This was finally resolved in 1940 with amendment of the Bonneville Project Act to make the new agency permanent and assign it authority to build and operate transmission lines. Raver recommended, and the Secretary of the Interior approved, the "Bonneville Power Administration" as the agency's name (BPA) (Norwood, c.1981; DeLuna, 1997).

The Bonneville Project Act (1937) also established the first governance system based on federal agency cooperation. It required that the administrator " ... act in consultation with an advisory board" to be named the Bonneville Advisory Board (the Board). The Act specified the Board's membership, calling for representatives designated by the Secretaries of the Army, Interior, and Agriculture and by the Federal Power Commission (Bonneville, Project Act, 1937, Section 2 (a)). ${ }^{80}$ General Theron Weaver of the Corps of Engineers represented the Army; Reclamation's Robert Newell represented Interior; the Forest Service's Robert Putman represented Agriculture; and Lester Wing represented the Federal Power Commission (Bessey, 1963).

\footnotetext{
${ }^{80}$ The Bonneville Power Administration would come to establish other advisory groups, such as the Bonneville Regional Advisory Committee, established 1944 - 1978, and the Pacific Northwest Utilities Conference Committee, established 1946 - present. These were set up as advisory and/or sounding boards to assist BPA in rate setting and other policy issues. Although federal agency members were invited to sit in on the meetings, the organizations were not intended to implement policy or otherwise directly participate in system management (Bessey, 1963; Norwood, c.1981). Additionally, the Department of Interior instituted its Pacific Northwest Field Committee in 1946 as part of a Department-wide effort to better coordinate regional Interior agency activities. BPA participated (Bessey, 1963). These groups are not discussed in detail as they did not exercise Basin "governance" in the sense used in this study.
} 
The Board's first meeting occurred on November 30, 1937. It held 11 more between 1939 and 1946, meeting four times in 1943 to coordinate War requirements (Norwood, c.1981). McKinley (1952) reports that the board's sessions were usually held in Washington, DC, with Washington-level officers usually in attendance. Issues addressed by the board included the rates to be charged by Bonneville Dam, funding for transmission line construction, and plans for additional generators during the War years. Eventually, the board came to agreement that there should be only a single marketing agency for the electricity produced by Bonneville and Grand Coulee Dams, and recommended BPA be designated that responsibility through executive order. President Roosevelt signed such an order in 1940 (McKinley, 1952).

Board participation dropped off after 1943 as war-related generation and transmission construction efforts ended. In 1946, the Columbia Basin Inter-Agency Committee assumed its regional coordination functions (McKinley, 1952; Bessey, 1963; Norwood, c.1981).

The governance debates of the 1930s resulted in a rejection of the decentralized, decision-oriented governance by the private market and iron triangle arrangements that dominated the region prior to the Depression's onset. The debates also resulted in a rejection of a more centralized valley authority type decision-making system. Instead, the region agreed to two collaboration-based systems. The first was the PNWRPC, a state led entity intended to provide centralized planning to guide resource development in the Columbia River Basin. The second was the Bonneville Advisory Board, a federal-agency collaborative body intended to inform the 
Bonneville Power Administrator in the performance of his duties and coordinate operations. Establishment of both the PNWRPC and Bonneville Advisory Board introduced a regional preference for collaborative versus decision-oriented governance systems. Although specific governance systems would change in the years to come, this preference for collaboration-based systems would prove enduring.

\section{Chapter Summary:}

The events and circumstances related to the Basin governance systems of the period 1929 - 1945 can be summarized as follows:

- The onset of the Great Depression ushered in sweeping Democratic majorities in Congress enabling the New Deal Program of the Roosevelt Administration. Economic restoration was the most visible priority during the 1930s. The public expected the federal government to undertake a direct role in economic recovery efforts. In response, new federal agencies were created and existing agencies reorganized (Hays, 1959/1999; Bessey, 1963; Norwood, c.1981; White, 1995; Billington, et al., 2006; Kennedy, 2009).

- Two precepts of the New Deal were centralized planning and regionalism. The National Industrial Recovery Act authorized creation of the Public Works Administration (PWA) and establishment of subordinate organizations under the PWA. Its subordinate national planning committee believed that successful planning for economic growth and resource 
development depended on regional, state and local participation. Accordingly, the committee established regional, state, and local planning boards (McKinley, 1952; Bessey, 1963; Norwood, c.1981, Vogel, 2007).

- Oregon, Washington, Idaho, and Montana established state planning boards between 1933 and 1934. The national planning committee established the Pacific Northwest Regional Planning Commission in 1934 to provide governance over regional planning. Although chaired by a part-time representative of the national planning committee, it was a state-centric system, comprised of members from the four Northwest states' planning boards. Federal agency participation was relegated to provision of technical advice and expected execution of Commission plans (McKinley, 1952; Bessey, 1963; Norwood, c.1981).

- The Corps's 308 Report, released in 1932, provided a blueprint for future development of the Columbia Basin. It presented technical and economic analyses of multipurpose dam development but left unanswered management questions regarding future design, construction, and

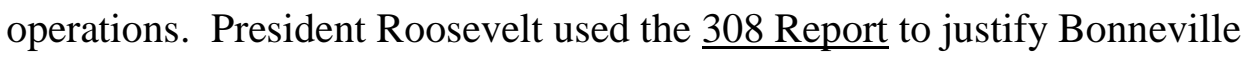
and Grand Coulee Dams the construction of which began in 1933 by the Corps of Engineers and Bureau of Reclamation, respectively (Ogden, 1949; Bessey, 1963; McKinley, 1952; Norwood, c.1981; White, 1995).

- Congressional bills that would keep management of hydropower generation, transmission, and marketing in the hands of either the Corps of 
Engineers or Bureau of Reclamation were introduced in 1935 (Norwood, c.1981; White, 1995; DeLuna, 1997; Pope, 2008).

- In the minds of many Progressives, the ideal governance system for river development was the Tennessee Valley Authority. Proponents in the Northwest promoted a similar valley authority for the Columbia.

Congressional bills to this effect were also submitted in 1935 (Ogden, 1949; Bessey, 1963; McKinley, 1953; DeLuna, 1997; Billington, et al., 2006; Pope, 2008)

- The Pacific Northwest Regional Planning Commission proposed a compromise, eventually codified in the 1937 Bonneville Project Act. The Act created the ambiguously named Bonneville Project as a government corporation to market public power at cost to preferred public customers. It also created the Bonneville Advisory Board to advise the Bonneville Project administrator in the execution of his duties. Responsibility for project operation would reside with the constructing agency. An amendment to the Bonneville Project Act made the agency permanent and renamed it as the Bonneville Power Administration in 1940 (Ogden, 1949; Norwood, c.1981; White, 1995; DeLuna, 1997; Pope, 2008).

- The region's potential for low-cost hydropower, coupled with aggressive promotion by BPA in the mobilization for the War, attracted aluminum and other electricity-dependent defense industries to the Northwest (Ogden, 1949; Norwood, c.1981; White, 1995; DeLuna, 1997; Pope, 2008). 
- Just as the PNWRPC was the region's first effort at multi-jurisdictional planning, so to was the Bonneville Advisory Board its first effort at collaborative governance to coordinate operations. Board members included the regional executives of BPA, the Corps, the Bureau of Reclamation, the Forest Service, and the Federal Power Commission. The Board did not possess a decision-making mechanism to resolve differences among the agencies. This was not a major issue in the early 1940s due to common interest in successful prosecution of the War effort. However, once construction of the war-related transmission lines and project generation facilities were completed and Allied victory imminent, interest in Board participation fell off (McKinley, 1952; Bessey, 1963; Norwood, c.1981).

The onset of the Depression thus created the opportunity for change to the market and iron triangle governance systems that dominated up to the early 1930s. The conceptual framing of Columbia Basin governance in the Northwest shifted from one of isolated communities to a region unified by the potential of a developed Columbia River (White, 1995; Vogel, 2007). New Deal policies asserted federal authority to regulate private power, opened the door for federal ownership and operation of power facilities, and encouraged cooperative arrangements between federal agencies and with private industry (DeLuna, 1997).

By 1946 major Columbia River dams were under federal construction or already online, and the region was struggling with how to manage the necessary 
cooperation between the federal agencies responsible for project purposes, private and public utilities, and others impacted by project activities. Progressives and public power advocates viewed the voluntary structure of the Bonneville Advisory Board as a short-term situation, inherently unworkable and destined to ultimately collapse. They continued to hold out and advocate for a Columbia Valley Authority arrangement to direct, manage, and balance the production of electricity and other river purposes (McKinley, 1952; Norwood, c.1981; White, 1995; DeLuna, 1997).

The return of national prosperity following the end of World War II caused a loss of support for expensive government-led programs, valley authority-type systems, and centralized planning. A renewed confidence in private markets began to emerge (Bessey, 1963; DeLuna, 1997). The end of the War provided the region's second catalytic opportunity to change its governance arrangements. 


\section{CHAPTER 5 \\ THE END OF WORLD WAR II (1945)}

\section{$\underline{\text { Introduction }}$}

The end of World War II presented the region's second critical situation that resulted in a shift between Basin governance models. The model of state dominance in planning gave way to a return to systems of federal agency cooperation.

Meanwhile, the region again rejected renewed calls for governance under a centralized valley authority.

The War ended for the United States in 1945. Three events occurred around that time that collectively created the circumstances for change in Columbia Basin governance systems. The first was the decision by Congress to cease funding for national level planning in 1943 (Bessey, 1963). The second event was the surprise reelection of Harry Truman as president in 1948 and a return of Democrat majorities in both houses of Congress, majorities they had lost to the Republicans in 1946 (DeLuna, 1997). The third event was the end of the Depression. The buildup to World War II, the War's prosecution, and the prosperity that followed in the War's aftermath ended the nation's economic hardships. Prosperity brought a lessening of support for the central role of government in the economy and a return to faith in private markets (McKinley, 1952; Bessey, 1963; Norwood, c.1981; DeLuna, 1997).

Regional issues events played out against this national backdrop. Key regional issues affecting governance decisions included the rise in regional influence of the Bonneville Power Administration, jockeying by the state governors to maintain a 
strong voice in Basin development, the rise of opposition by fishery interests to river development, severe floods in the late 1940s, and the continued construction of dams (McKinley, 1952; Bessey, 1963; Norwood, c.1981).

These changes brought an abrupt end to the Pacific Northwest Regional Planning Commission and eventual disintegration of the Bonneville Advisory Board. Whereas the Bonneville Advisory Board continued to exist, the completion of efforts to expand hydropower generation and transmission coupled with growing confidence that the Allies would win the War reduced the sense of immediacy regarding the Board's purpose. Consequently, the Board operated in a rather desultory fashion until 1946 (McKinley, 1952; Bessey, 1963; Scheufele, c.1970, Norwood, c.1981).

Congress, federal departments, and the states collectively originated eleven governance system proposals during this period. Five systems were enacted, although only three operated for any extended period. These proposed and enacted systems are summarized below:

- State led system proposals. Northwest states made three efforts to maintain the state-centric nature of the PNWRPC in regional development. The first was the Northwest States Development Association, established in 1943 upon the demise of the PNWRPC. It disbanded in either late 1943 or early 1944. ${ }^{81}$ The second was the Pacific Northwest Governors' Power Policy Committee. It was ostensibly set up in 1953 as a committee under the CBIAC to implement the Eisenhower administration's partnership

\footnotetext{
${ }^{81}$ The record on this point is not clear. The Association produced a report in December, 1943 and disbanded "shortly thereafter." See McKinley(1952), Bessey (1963), and Scheufele (c.1970).
} 
program. It disbanded in 1958. The third was an attempt at an interstate compact. Negotiations began in 1949 but the proposal failed when state legislatures refused to ratify the resulting proposal.

- Valley authority proposals. Congress introduced five bills to again attempt to establish some form of a Columbia Valley Authority. One was introduced in 1945 and four others between 1947 and 1949. None was enacted.

- The Columbia Basin Inter-Agency Committee (CBIAC). A regional association of federal agencies, with invited state participation, established in 1946. The federal agencies instituted the CBIAC based on a recognized need for effective interagency coordination in Basin planning and operations and as a counter to the renewed called for some form of Columbia Valley Authority. It effectively assumed the planning function of the PNWRPC and operational coordination function of the Bonneville Advisory Board. It was replaced by the Pacific Northwest River Basins Commission in 1967.

- The Committee on Fish Operations (COFO). Established in the 1960s to better address the impact of Basin development on regional fish runs.

- The Pacific Northwest River Basins Commission (PNWRBC). Federalagency centric successor to the CBIAC. Authorized by the Water Resources Planning Act of 1965 and established by executive order in 1967. 
The remainder of this chapter discusses the social and political context outlined above and the key issues and events in the Northwest that influenced the debates over the various governance forms. It then describes the nature and structure of each of the proposed or enacted governance systems.

\section{$\underline{\text { Social and Political Context }}$}

The main national level developments that affected Columbia Basin governance systems were the ending of funding for New Deal planning structures, the reelection of Truman in 1948, and the return of national prosperity which brought with it a resurgence of influence by private power interests.

The War, which ended for the United States with the Japanese surrender on August 15, 1945 and subsequent signing of the surrender terms on September 2, had destroyed or seriously damaged the economies of the major European and Asian nations. Of the War's major participants, only the United States and Canada retained functioning economic systems. The worldwide demand for post-war goods and commodities for rebuilding greatly expanded the American economy and ushered in a period of renewed national prosperity (McKinley, 1952; Bessey, 1963; Norwood, c.1981).

Prosperity brought a renewed confidence in private markets and a decline in support for many New Deal bureaucracies and programs. Congress, despite its Democratic majority, ceased funding for the National Resources Planning Board (the latest incarnation of the national planning committee) in 1943. This in turn led to the 
disbanding of state and regional planning commissions, including the PNWRPC

(McKinley, 1953; Bessey, 1963).

Executive Branch interagency planning and coordination may have lost favor with Congress, but the affected agencies still believed in a need for some collaborative mechanism to coordinate river basin operations and development. Northwest agencies were also concerned about the greatly diminished but still simmering interest on the part of public power advocates and New Dealers to install a valley authority in the Columbia. Federal departments, reacting to the defunding of the National Resources Planning Board, established the Federal Inter-Agency River Basin Committee (FIARBC, known colloquially as "Firebrick") in1943. ${ }^{82}$ FIARBC resulted from a voluntary agreement between the Chief of Engineers, the Commissioner of the Bureau of Reclamation (on behalf of the Secretary of the Interior), the Secretary of Agriculture, and the chair of the Federal Power Commission. The Secretary of Commerce was added in $1947 .{ }^{83}$ Its purpose was to better coordinate the preparation of reports dealing with multipurpose water projects, and the signatories agreed to ensure their respective field offices would "communicate and confer" (McKinley, 1952, p. 90) regarding data and to avoid duplication of effort (McKinley, 1952; Scheufele, c.1970).

\footnotetext{
82 The accounts of Bessey (1963) and Scheufele's (c. 1970) differ as to the date of the FIARBC's establishment. Bessey claimed it was 1943. Scheufele stated it was established in 1939, although he mistakenly referred to it as a "commission" instead of "committee." McKinley (1952) did not give a date. The National Archives supported Bessey's account, so the 1943 date is used here. See http://www.archives.gov/research/guide-fed-records/groups/315.html\#315.2.

${ }^{83}$ The Departments of Labor and Health, Education, and Welfare were apparently added later as well, although not mentioned by McKinley (1952) or Bessey (1963). See the National Archives web site at http://www.archives.gov/research/guide-fed-records/groups/315.html\#315.2.
} 
The Eisenhower administration reorganized FIARBC as the Inter-Agency Committee on Water Resources (ICEWATER) in 1954 (Bessey, 1963; Scheufele, c.1970). ICEWATER continued the planning role of FIARBC but shifted from an emphasis on federal leadership in centralized planning under Truman to a more limited federal role under Eisenhower (Bessey, 1963; Scheufele, c.1970).

Despite the national trending toward a lessening of government role in the economy, there were still progressives and New Deal supporters that held little faith in the efficacy of voluntary cooperation among federal agencies. They continued to believe that valley authority type entities best served the public's interests in regional resource development. Valley authority advocates in Congress submitted bills to establish some form of Columbia Valley Authority in 1945 and 1947. However, the retirement of many New Deal senators and congressional representatives in the election of 1946 and the increase in Republicans doomed those particular efforts. The 1948 reelection of Truman, who in part championed valley authorities during his campaign, reenergized valley authority supporters (DeLuna, 1997).

Despite Democrats maintaining modest majorities in both Houses of Congress in 1948 and retaining them in 1950, the post-War economic boom and the election of the Republican Eisenhower administration in 1952 generated a resurgence of influence by private power. Private power advocates worked with the administration to block further efforts at public ownership and operation of electricity generation.

The Eisenhower administration's energy policy revolved around "partnerships" between federal and private power entities. This policy, endorsed by private power 
interests as a way to undo pubic power advances in the 1930s, resulted in a variety of relationships and arrangements. Few depended on federal funding, federal construction, or federal operation of facilities. If private utilities were willing to make the investments, they were free to develop new hydropower sites at locations previously envisioned for federal projects (Scheufele, c.1970; Norwood, c.1981; Pope, 2008). However, the administration in general and Eisenhower in particular provided little direct support to the partnership program. Democratic majorities in Congress and the lukewarm support from the administration caused the partnership concept to “sputter to a halt" during Eisenhower's second term (Scheufele, c.1970; Pope, 2008).

The ending of Congressional funding for New Deal planning structures, the reelection of Truman, and the return of prosperity following the end of World War II thus presented a wave of conditions that would lead to Columbia Basin governance system changes. Within this national context were circumstances unfolding in the Northwest.

\section{$\underline{\text { Salient Issues in the Pacific Northwest }}$}

This study identified five activities during this period that significantly affected perceptions of governance needs within the region in the mid to late 1940s. These were (1) the emergence of the Bonneville Power Administration as a major regional institution; (2) state interest in maintaining their centrality in regional planning and development following the dissolution of the PNWRPC, (3) the development of opposition from fishery interests to further river development; (4) severe flooding in 
the lower Columbia River in 1949; and (5) continued construction of dams in the Columbia and its tributaries. Each is discussed in turn.

Emergence of BPA as a regional institutional leader.

Paul Raver assumed the role of Administrator of the Bonneville Project in 1939 and served until 1954. His tenure would instill in BPA a set of values and operating traditions that continue to this day. These values included the New Deal ideals of rural electrification; cost-based rates for public power; the use of public power as a yardstick against which to gage private pricing; and the use of "postage stamp" rates ${ }^{84}$ to set federal prices. Under his leadership, BPA would rise to become a major institutional actor in matters of regional development and energy (Norwood, c.1981).

Upon assuming the job in 1939, Raver immediately set out to strengthen the agency's administrative structure. He was instrumental in drafting the 1940 amendments that made the agency permanent and recommended the agency's name. Organizationally, he opened field offices around the region to ensure close ties to regional parties and interests. He led the effort to give BPA the authority to construct and operate transmission lines and orchestrated the wartime expansion of generation capacity at Bonneville and Grand Coulee Dams. Over the course of his tenure he met

\footnotetext{
${ }^{84}$ The term "postage stamp" rates refers to the policy of charging the same rate for the same unit of electricity, regardless of where in the service area the end-user resided. The term comes from the postage rates for mail delivery as practiced by the U.S. Postal Service. The alternative, favored by private utilities, were "railroad rates" which would be determined by the marginal cost of delivery. Under a railroad rate policy, electricity sold to rural areas would cost significantly more than delivery in urban areas due to the need to distribute the infrastructure and operating costs of generation, transmission, and distribution over long distances among a relatively small population.
} 
continuously with electricity customers and public and private utilities throughout the Northwest, building relationships and promoting BPA's regional role. Valuing their input and support, he invited them to participate in numerous advisory bodies he formed to help inform BPA decisions in response to regional circumstances. ${ }^{85} \mathrm{He}$ worked closely with the region's Congressional delegation and encouraged BPA staff to think of the delegation as the agency's board of directors. He strengthened BPA's office in Washington, DC to better keep Congressional members informed of regional events and coordinate legislative initiatives. He also worked hard to establish close working relationships with his fellow regional agency executives (Norwood, c.1981). Regional public power advocates under Raver's leadership largely outmaneuvered private power efforts to limit federal project development in the Northwest. An example is BPA's response to the impact of the decline in regional power demand at the end of World War II. Once the War ended, the region faced huge layoffs as defense plants, airplane factories, and shipyards curtailed production. Reduced demand for aircraft forced aluminum plants to lay off hundreds of workers and created a corresponding reduction in electrical demand. The unrest generated by the layoffs provided an opportunity for private utilities to reassert themselves. Four private utilities issued a joint memorandum in January 1946 and later testified to Congress that the region faced a power surplus of about a million kilowatts. Consequently, in their view, there was no need for additional federal hydropower

\footnotetext{
${ }^{85}$ An example is the Bonneville Regional Advisory Council established in 1944 to advise BPA on regional policy.
} 
dams (Norwood, c.1981). In effect, the private utilities hoped for a return to the preDepression market dominated governance model.

In response to the utility memorandum, Raver formed the Tacoma Conference, later renamed the Pacific Northwest Utilities Conference Committee. This group assembled the load forecasts of individual regional utilities and consolidated them into a regional forecast. Rather than showing a surplus of capacity as alleged in the utility memorandum, the consolidated report displayed a shortfall. Raver presented the report in testimony to Congress (Norwood, c.1981). ${ }^{86}$ As they had in the 1930s, the public power advocates won and additional multi-purpose federal dams began coming on line in 1952. This effort was indicative of Raver's style throughout his time as BPA Administrator.

Raver was also instrumental in laying the groundwork that finally resolved the Northwest public-power debate. Pope (2008) argues that the Eisenhower administration's “partnership" policy contained within it a fundamental paradox for the Northwest. The envisioned partnerships implied decentralized operations within a competitive market. But development at the major hydropower sites was too complicated and expensive for all but the largest utilities to finance. Utilities therefore had to work together in order to raise capital and develop markets by promoting demand. Raver recognized this and worked to establish he institutional arrangements

\footnotetext{
${ }^{86}$ The Tacoma Conference's load forecasting effort was fortuitously assisted by an increase in worldwide aluminum demand that began in 1947 and extended through the Korean War (Norwood, c.1981); severe regional flooding in 1948 and the coincidentally released joint report of the Corps and Bureau regarding Columbia River development (McKinley, 1952); and by record Northwest cold in the winter of 1948/1949 (Ogden, 1949).
} 
that would eventually guide cooperation between private and public utilities. The ultimate result was a more closely coordinated and centrally planned system than a purely competitive market model would anticipate (Pope, 2008).

The upshot was that the structures and processes initiated by Raver largely muted the public-private power debate by the end of the 1960s. The Corps, Bureau of Reclamation, BPA, and regional utilities signed the Pacific Northwest Coordination Agreement in 1964. At about the same time the United States signed a treaty with Canada that doubled flood storage protection capacity to the United States in exchange for hydropower benefits (Blumm, 1982; Ogden, 1997; Pope, 2008). The coordination agreement and Canadian treaty codified Raver's vision of regional energy producers operating together (Norwood, c.1981; Pope, 2008).

The foregoing illustrates Raver's belief in and efforts to establish structures and relationships at the national and regional levels to improve coordination among the multiple parties engaged in Northwest energy and development issues. It thus explains his continued support for the otherwise dysfunctional Bonneville Advisory Board and its more successful replacement, the Columbia Basin Inter-Agency Committee. Following in the tradition established by Raver, BPA would continue to be a major participant in and shaper of the Basin's future governance systems.

\section{$\underline{\text { State efforts at Basin governance. }}$}

The Northwest states strongly supported the purpose, functions, and state-led nature of the Pacific Northwest Regional Planning Commission. Although nominally a federal entity, it was designed to give maximum voice to its representatives from 
each of the state planning commissions. The federal coordinator at the time, like the other members of the National Resources Planning Board, was not a federal employees but a part time advisor engaged in his own business enterprises. This arrangement, coupled with the relatively subordinate relationship of the federal agencies to the Commission, meant that the states could guide plans that would leverage federal funding and expertise in development that would benefit state economies (Vogel, 2007).

This arrangement collapsed when Congress stopped appropriating federal funds for the National Resources Planning Board and state and regional planning commissions in 1943. The demise of the PNWRPC left the federal-agency-only Bonneville Advisory Board as the sole multi-jurisdictional coordinator of Columbia Basin development and operations. The states were not included as Board members (McKinley, 1952; Bessey, 1963; Norwood, c.1981).

In 1943, the Bonneville Advisory Board began considering ways to increase upriver storage in order to better regulate streamflow and allow for greater power generation. One option was to increase the level of Flathead Lake in western Montana by seventeen feet. This was not a new proposal as it had been a provision of the 1932 308 Report. However, the federal agencies did not vet the proposal local interests who generated a storm of protest over the impact of changes in water level on those living and working around the lake. The states reacted to the ending of the PNWRPC and the Flathead Lake controversy by establishing the Northwest States Development Association to ensure local and state interests were properly consulted in future 
development proposals (McKinley, 1952; Bessey, 1963; Scheufele, c.1970; Norwood, c.1981).

This was the first of three state-led efforts to assert a prominent state role in Basin governance. Despite the support of state governors, all state-led systems faced serious challenges in overcoming parochial state interests in favor of regional priorities, obtaining funding and appropriate authorities from multiple state legislatures, and the tendency of the bodies to serve as veto mechanisms over actions perceived as contrary to the interests of state or local interests (McKinley, 1952; Bessey, 1963). The experience of these efforts underscores the challenge to governance presented by the tension among the states themselves and between the states and federal agencies over who gets to decide regional priorities.

Fishing interest opposition to continued Columbia system development.

In 1943, the Senate Commerce Committee directed the Corps to extend and revise the 308 Reports and prepare a plan for further development of the Columbia. The Committee directed the Corps to complete the report by October 1948 (McKinley, 1952).

In 1944, the U.S. Fish and Wildlife requested that the Corps, as part of its review, conduct a comprehensive investigation of the effects of federal dams on Columbia River juvenile salmon. The Corps and Bureau of Reclamation agreed, dedicated funds to this purpose, and launched an "elaborate research program" (McKinley, 1952, p. 110). 
As the Corps study progressed, regional opposition to further large dam construction arose despite fish passage facilities having been installed at Bonneville dam and included in designs for proposed new projects (Arndt, Stroud, and Mogren, 2004). Sports and commercial fishers, Indian tribes, conservation groups objected to the potential impacts on fisheries and natural character of the Columbia and Snake Rivers. These groups forced a series of formal and informal hearings. The first, held in The Dalles in 1945, provided a forum for fishery interests to protest plans for a dam that would ultimately inundate Celilo Falls and destroy a tribal fishery that had existed for centuries. Other hearings were conducted from 1946 through 1947, largely pitting fisheries associations and tribes against regional development promoters (Robbins, 2004).

The objections voiced by the Fish and Wildlife Service to the Corps were not resolved to the satisfaction of the Fish and Wildlife Service. In October 1946, the agency, with the later support of the Office of Indian Affairs, protested in a memo to the Secretary of the Interior the proposed construction of four dams planned for the lower Snake River and the two Columbia mainstem dams proposed below the confluence of the Snake and Columbia (McKinley, 1952). The agency recommended, among other things, a ten-year moratorium on further dam construction on the Columbia and lower Snake Rivers to study and better understand the impacts of the dams on the rivers' fisheries (Robbins, 2004).

The Secretary of Interior invited both BPA and the Bureau of Reclamation to comment and asked the Interior Department's Pacific Northwest Coordination 
Committee ${ }^{87}$ to address the question as well. The Committee submitted a report, ${ }^{88}$ backed by substantial technical analysis, detailing the conflicting interests at stake. It established the threat to salmon runs of the existing Columbia dams and by the new dams under consideration for the Columbia and Snake Rivers. It also pointed out the pending loss of tribal fishing grounds, particularly at Celilo Falls, a fact that the Office of Indian Affairs protested as a violation of 1855 treaty obligations. The National Park Service joined the protest due to probable damage to sports fishing on the tributaries of the Snake and Columbia. BPA, on its part in defending the new development, noted the projected power demand increases for the region in support of the proposed dams. Reclamation did the same with respect to projected irrigation needs. Eventually the regional Interior agencies reached accord, producing a consensus report that adopted the Fish and Wildlife Service's proposed ten-year moratorium to give time to resolve the salmon and tribal issues, with additional funds requested to do so. Interior's assistant secretary endorsed the report on March 6, 1947, essentially presented a Department-wide critique of key provisions of the pending Corps report (McKinley, 1952).

\footnotetext{
${ }^{87}$ The Pacific Northwest Coordination Committee was part of a Department of Interior effort to better coordinate its programs and to provide Interior's representative to the Bonneville Advisory Board and the later Columbia Basin Inter-Agency Committee. It was formally established by departmental order in September, 1946 and consisted of the regional office chiefs from the BPA, Bureau of Reclamation, Fish and Wildlife Service, National Park Service, and newly created Bureau of Land Management. It also included staff representatives from the U.S. Geological Survey, Bureau of Mines, and Office of Indian Affairs. The executive director was Roy Bessey. A similar intradepartmental coordination body had previously been established in the Department of Agriculture during the War years. Since the purpose of these groups was intradepartmental coordination and to provide departmental positions to the aforementioned interdepartmental structures, they are not considered as "regional governance structures" for the purposes of this study. See McKinley (1952), pp. 411-479 and Bessey (1963), p. 65.

${ }^{88}$ The formal name of this report, if it had one, is not given by McKinley (1952), Bessey (1963), or Norwood (c.1981). It has not been determined as of this writing.
} 
News of the Department's position leaked and aroused immediate regional opposition, especially from river navigation interests. The Fish and Wildlife Service, the Office of Indian Affairs, and the National Park Service asked the Department to release the full coordination committee report in order to get the committee's detailed assembly of facts and analysis in front of the public. They wanted to preclude regional condemnation before the facts of the conservation and tribal issues could be made known. Instead, the Department referred the report to the interdepartmental Columbia Basin Inter-Agency Committee ${ }^{89}$ for resolution, only later releasing the full report to the public (McKinley, 1952).

The CBIAC held hearings in Walla Walla, Washington, in June of 1947. Hydropower, irrigation, inland-navigation, and urban development advocates testified in strong opposition to the Interior position, especially the proposed ten-year delay in further dam construction in the interests of fish impact studies. They questioned the evidence as to whether the dams would do the harm that opponents argued, and, regardless, hatcheries could make up any losses in fish numbers. Fishery advocates testified in favor of the moratorium, arguing the economic value of the salmon fishery to the region would be lost to regional electrical needs. They predicted extinction of the salmon and ruination of one of the richest fisheries in the nation (Robbins, 2004). Of interest to this study is the fact that these two generalized arguments, made by a numerous pro-dam and anti-dam organizations and individuals, shared the world-

\footnotetext{
${ }^{89}$ The CBIAC is discussed in greater detail below.
} 
view of natural resources as market commodities. The argument was essentially over which resource should take precedence in the name of economic development.

Testifying from an entirely different perspective was Tommy Thompson of the Wyam Indian band, who said "I don't know how I would live if you put up a dam which will flood my fishing places" (Robbins, 2004, p. 62). Although speaking specifically about the fish as his only dependable food source, the context of Thompson's comments spoke to the profound place salmon occupied in tribal society.

The CBIAC did not support the recommendation for a moratorium. Tellingly, the two Interior Department members of the CBIAC (BPA and Reclamation) did not support their department's position in discussions within the CBIAC despite the supposed agreement reached by Interior agencies within the Coordination Committee (McKinley, 1952). The CBIAC did, however, recommend protection of all fishery interests below The Dalles. The CBIAC forwarded its recommendation to the Federal Inter-Agency River Basins Committee, which provided its support in 1947 (Robbins, 2004).

Scheufele (c.1970) described the salmon issue as among the most contentious faced by the CBIAC. Although it did not affect the debate over governance systems following the end of World War II, the fish issue did result in the formation of the Committee on Fish Operations to focus on the design of facilities to improve fish passage at the dams. The overall frustration of fishery interests and continued declines of Columbia salmon continued to mount. Although dissatisfied with the way the 
CBIAC addressed fishery issues, fishery interests had no choice but to wait until an opportunity to establish a more sympathetic governance system presented itself.

\section{The Memorial Day Flood of 1949.}

With the salmon debate seemingly settled, at least in the mind of the Corps of Engineers, the Corps completed its draft report in October 1948. The Corps made substantial revisions in the months just prior completing its final report due to devastating flooding that occurred in late May and early June 1949. The so-called Memorial Day Flood destroyed the city of Vanport, located on the lower Columbia River between Portland and Vancouver, Washington, along with other communities along the lower Columbia. The impact of the flood on the Corps report was to induce a new basis for economic justification of flood protection and a completely revamped plan for flood control. The report called for immediate Congressional authorization for an integrated system of seven storage dams, ${ }^{90}$ a levee construction and renovation program, and navigation improvements up into Idaho. It addressed some of the issues raised by the Fish and Wildlife Service. For example, it called for salmon passage improvements at new dams below Grand Coulee and fish restoration efforts in the lower Columbia tributaries. It also called for irrigation and sub-basin development in the lower Columbia and new transmission lines. The lower Snake River dams and the dam at The Dalles remained over the objections of the tribes and fishery interests. The

\footnotetext{
${ }^{90}$ These dams were to be located at Libby, Albeni Falls, Priest Rapids, Hells Canyon, John Day, The Dalles, and at Glacier View in Glacier National Park. With the exception of Glacier View, which was dropped due to objections from the National Park Service, all of these dams were eventually completed although the Priest Rapids and Hells Canyon projects were built by public utility and private utility interests respectively. See McKinley, 1952, pp. $636-643$.
} 
estimated cost for the full program was $\$ 3$ billion (McKinley, 1952). The flood thus effectively washed away, along with the city of Vanport, any hopes by opponents for a construction moratorium on the proposed projects.

\section{Continued system development.}

Concurrent with the Corps's flood study was the Bureau of Reclamation's Report on the Columbia River Power System, completed in $1947 .{ }^{91}$ At the height of the 1948 flooding, before the Corps report was finished, the President requested the Department of Interior to review and comment on existing long-range plans for the Columbia in light of the flooding. Presumably, this meant review of the pending Corps's revision to the 308 Report and the Bureau's report, although McKinley (1952) does not specifically state this. The regional field offices of the Corps and Reclamation entered into discussions to "harmonize the two separate comprehensive reports for the river system" (McKinley, 1952, p. 638). They reached agreement in early December a few days before DOI formally released its report, causing some consternation within Interior as the offices had entered into negotiations before the Department had agreed on a position (McKinley, 1952). Subsequent "harmonization" discussions took place at the Washington DC level resulting in a joint letter signed by the Secretary of the Interior, Secretary of the Army, the Chief of the Corps of Engineers, and the Commission of the Bureau of Reclamation on April 11, 1949. The agreement included provisions on policy, project features, construction

\footnotetext{
${ }^{91}$ Ogden (1949) reported that the Bureau of Reclamation completed a comprehensive study in 1947 (see p. 425) as did Bessey (1963). McKinley (1952) did not give a date, ambiguously stating only that the report was "recently prepared and about to be published" (p. 436) when speaking of events occurring around 1947 and 1948.
} 
responsibilities, and construction scheduling. The Northwest now had a revised, comprehensive planning document addressing the areas noted above plus watershed protection, soil conservation, water supply, recreation, and pollution. It did not, however, resolve the tribal treaty issues or fully address salmon conservation needs (McKinley, 1952). Regional commercial development needs of electricity, navigation, irrigation, and flood protection had sidelined tribal and salmon fishery issues.

In accordance with the agreed to plan, The Corps of Engineers and Bureau of Reclamation built major dams on the mainstems and /or tributaries of the Columbia, Willamette, Yakima and Snake River Basins. Joining Bonneville and Grand Coulee Dams on the Columbia main stem were McNary Dam (in service 1952), ${ }^{92}$ Albeni Falls (1955), The Dalles (1957), Chief Joseph (1958), and John Day (1971). The Flathead and Kootenai and Flathead tributaries to the upper Columbia saw completion of Hungry Horse (1953) and Libby (1975) respectively. Dams built on Willamette ${ }^{93,94}$ tributaries were Big Cliff, Detroit, and Lookout Point (1953); Dexter (1954), Green Springs (1960), Hills Creek (1962), Cougar (1963), and Foster and Green Peter (1967). Chandler and Roza Dams came in service on the Yakima in 1956 and 1958,

\footnotetext{
${ }^{92}$ McNary dam completion was delayed by the DOI - Corps negotiations over the two plans (McKinley, 1952).

${ }^{93}$ Whether the Willamette projects are actually a formal part of the FCRPS is a point of some confusion. For purposes of the ongoing salmon litigation, the federal government has tended to not count them as they are outside of the "action area" as defined by the action agencies and evaluated by NMFS in their biological opinions. The same is true for projects in the Yakima and Snake River above Hells Canyon. However, the dams on all of these tributaries are included in the joint BPA-CorpsReclamation brochure (2003) entitled the Federal Columbia River Power System. Consequently, they are included here.

${ }^{94}$ No federal dams were constructed on the mainstem of the Willamette River.
} 
respectively. In the Snake Basin, Anderson Ranch (1950) and Palisades (1958) were completed in the upper tributaries and Ice Harbor (1962), Lower Monumental (1969), Little Goose (1970), and Lower Granite (1975). Dworshak Dam, on the Clearwater River tributary to the lower Snake, came into service in 1973 (FCRPS, 2003). ${ }^{95}$ Lost Creek on the Willamette was soon to follow, coming into service in 1977. Twenty-six major dams were completed for hydropower, navigation, flood control, and other purposes over twenty-five years. These, plus the five completed prior to 1946 , brought the FCRPS to 31 projects ultimately leading to a total federal hydropower generating capacity of over 22,000 megawatts. All were constructed, operated, and maintained by either the Corps or Bureau, with BPA marketing the electricity generated (FCRPS, 2003). With the exception of Grand Coulee Dam, The Corps and Bureau included fish passage facilities at all federal projects on the Columbia River mainstem and lower Snake River (Arndt, Stroud, and Mogren, 2004).

\section{$\underline{\text { Resulting Governance Systems }}$}

The abolishment of the national central planning committee and PNWRPC in 1943 and the weakness of the Bonneville Advisory Board at War end highlighted the need for continued coordination and collaboration on Columbia development issues. The states, reacting to the loss of the PNWRPC and the Flathead Lake controversy, implemented the Northwest States Development Association in 1943. This state-only effort collapsed in early 1944.

\footnotetext{
95 All dates shown are the dates the projects came on line for hydroelectricity generation. These may vary from the dates of construction or when other purposes became available.
} 
The vacuum in Basin governance highlighted in others the need for a more robust governance entity. In 1945, new bills were introduced in the Senate and House to resurrect and establish some form of Columbia valley authority. These bills failed, but in response to them and in recognition of the need for more effective planning and operational coordination, the regional federal agencies recommended establishment of the Columbia Basin Inter-Agency Committee in 1946. The CBIAC was formed as a subcommittee of the national FIARBC. The CBIAC assumed the functions of both the PNWRPC and the now replaced Bonneville Advisory Board (McKinley, 1952; Scheufele, c.1970).

Continued concerns over the voluntary nature of CBIAC participation and the lack of a decision making structure to overcome agency differences resulted in other governance systems being proposed. There were several revised efforts between 1947 and 1949 to establish some form of valley authority for the Columbia. These efforts failed due to a general nationwide collapse in support for powerful centralized government entities in general, loss of public and political support for valley authorities in particular (Goodwin, 1983), and lackluster support from the Truman administration (DeLuna, 1997). The Northwest states made another effort to establish a state-led system by initiating negotiations for a Columbia River Basin Interstate Compact in 1949. This state effort was also inspired in part by the resurrection of the valley authority idea and in part by the desire of the states to play a significant if not dominant role in regional development (Bessey, 1963). While these negotiations were underway, the states established a Pacific Northwest Governors' Power Policy 
Committee in 1953. This committee, ostensibly created within the framework of the CBIAC for purposes of coordinating regional implementation of the Eisenhower's partnership policy, was in reality an attempt by the states to assert a more influential voice in regional development. When the partnership policy ended so too did this committee.

Events surrounding the end of the War inspired these governance proposals. Evolutionary changes within existing systems led to two other governance systems being enacted that were not directly due to events occurring around the time of the War's conclusion. Both were evolutionary improvements among existing systems. One of these was the Committee on Fish Operations established in the 1960s in response to growing agency concerns over the impact of the dams on regional salmon runs. The other was the result of a proposal from the Truman administration's Water Policy Commission to abolish the voluntary inter-agency committees and replace them with congressionally authorized and statutorily supported river basin commissions. Congress responded with the Water Resources Planning Act of 1965 authorizing the recommended commissions. The Pacific Northwest River Basins Commission was established in 1967 to replace the CBIAC. The states and federal CBIAC members strongly supported the PNWRBC as a significant improvement over the CBIAC.

Further discussion of each of these eleven systems follows.

The Northwest States Development Association.

Following the dissolution of the national planning board and the PNWRPC in July of 1943, five of the Pacific Northwest governors agreed to establish the 
Northwest States Development Association. Complaints by Montana over the Bonneville Advisory Board's failure to consult with the state in its proposal to raise Flathead Lake water levels prompted them to do so. The loss of the central role held upon the PNWRPC's termination also motivated the governors. The Association's purpose was to coordinate and correlate the plans of member states with regard to interstate developmental issues. Its priorities were development of irrigation, power, and flood control. The group produced one report on Basin development in December 1943, and then became inactive. It disappeared shortly thereafter due to conflicts over state interests and priorities, changes in governors, and a general lack of public and political interest (Bessey, 1960; Scheufele, c.1970).

\section{Columbia Valley Authority: redux I.}

The shortcomings of the Bonneville Advisory Board's cooperative structure, including its lack of a decision-making mechanism and inability to manage interagency rivalry became apparent once the war-related construction effort ended. These limitations, coupled with the lack of access by non-federal interests, led to a renewed effort to implement a Columbia Valley Authority (McKinley, 1952). Senator Hugh Mitchell of Washington introduced a bill to that effect in 1945. His proposal would transfer the Bonneville and Grand Coulee dams and all future Basin development responsibilities to a new public corporation, managed under a threeperson board of directors and under the supervision of the Secretary of the Interior. It would also establish an advisory council of regional governors. Although the CVA 
was to conduct its operations in cooperation with other agencies, McKinley considered this limitation "hortatory, rather than legally enforceable" (McKinley, 1952, p. 551).

That same year Congressman Walt Horan introduced a bill promoting a Columbia Valley Cooperative Authority. This proposal was a modification of the original valley authority idea. It limited the authority's duties to planning, development, and management of a single resource - water. Other than that, its structure and provisions were similar to Mitchell's Senate bill, to include the transfer of BPA to the new authority. A significant difference was its provisions for a presidentially appointed corporate oversight board of which at least one member would be from one of the regional states as recommended by that state's governor. The proposal also called for an advisory council comprised of the state governors and supported by a staff-level commission that would review all proposals for water resource utilization. Like Mitchell's bill in the Senate, Horan's bill went nowhere, especially in light of the Republican victories in 1946 (McKinley, 1952).

The Grange, ${ }^{96}$ labor, and public power leaders seeking more integrated river management strongly supported the idea of a valley authority. However, even these proponents disagreed with the centralized nature of Mitchell's proposal and demanded greater local involvement in decision-making. The Grange, for example, opposed the

\footnotetext{
96 The Grange was founded by Oliver Hudson Kelley. A farmer himself, Kelley was appalled by the way carpetbaggers from the north were taking advantage of the plight of southern farmers in the aftermath of the Civil War. Kelley joined with six others to form the Order of the Patrons of Husbandry, the National Grange on December 4, 1867. The Grange's stated purpose was to unite private citizens in improving the economic and social position of the nation's farm population. In the Northwest, it proved an instrumental voice in the development of the Columbia for irrigation and navigation purposes (Ogden, 1949; Gilliam, 1999).
} 
apparent surrender of state water law to federal authority and proposed alternatives to Mitchell's provisions on irrigation and water rights (McKinley, 1952). Mitchell submitted a second bill later in the year that contained "elaborate appointment requirements and advisory council review" provisions (Ogden, 1949, p. 358). Organized labor and farmers, the Washington governor, and public power advocates supported these provisions, but others felt them to be too awkward for efficient administration. Opposition to the new CVA proposal appeared almost immediately, led by private power and reclamation associations such as the Northwest Development Association, an influential lobbying group formed in 1945 to promote private-federal agency partnerships and oppose CVA establishment. ${ }^{97}$ The CVA effort ultimately failed with the temporary loss of Democrat majorities in Congress and Mitchell's retirement in 1946 (Ogden, 1949; McKinley, 1952; Scheufele, c.1970; Robbins, 2004).

The Columbia Basin Inter-Agency Committee.

The Federal Inter-Agency River Basin Committee charter allowed creation of regional "subcommittees." FIARBC established the Columbia Basin Inter-Agency Committee as one such subcommittee in 1946 (McKinley, 1952; Bessey, 1963; Scheufele, c.1970; DeLuna, 1997). The CBIAC was the second regional subcommittee so established, the other being in the Missouri River Basin (McKinley, 1952; Scheufele, c.1970). The CBIAC came at the urging of the heads of the regional federal agency offices, based on the need for interagency cooperation after the

\footnotetext{
${ }^{97}$ Not to be confused with the by-then disbanded Northwest States Development Association, discussed earlier.
} 
dissolution of the PNWRPC and in response to renewed proposals for establishment of a Columbia Valley Authority-like agency (Scheufele, c.1970; Ogden, 1997).

FIARBC intended the CBIAC as a forum for regional field representatives of federal agencies to exchange information and effectively coordinate their activities. At the urging of BPA Administrator Raver, CBIAC federal membership was established as the same as the former Bonneville Advisory Board. CBIAC members thus included the Commander of the Corps's North Pacific Division, the Northwest regional director of the Bureau of Reclamation, a representative from the Federal Power Commission, a special field representative from the Department of Agriculture, and the Administrator of the Bonneville Power Administration (Scheufele, c.1970). The Department of Commerce was added in 1947 (McKinley, 1952) as was the Department of Labor (Bessey, 1963).

Of interest was that Interior representation was limited to the Department's two development-oriented agencies: BPA and the Bureau of Reclamation. The conservation-oriented Fish and Wildlife Service, the preservationist-oriented National Park Service, and the tribal-oriented Office of Indian Affairs were not members and had to route their issues through the Departmental representative from the Bureau of Reclamation. Passage of the Fish and Wildlife Coordination Act changed this in 1956, at which time the Fish and Wildlife Service became Interior's third CBIAC member (Ogden, 1997).

The states were not included as members in the original resolution, but the governors of Oregon, Idaho, Montana, Washington, Wyoming, Utah, and Nevada 
were later invited to participate by jointly designating five representatives. The intent for these representatives was to participate in regular meetings and advise the CBIAC on state interests. The states never formally designated their five representatives. However, from the outset, as a practical matter once they began meeting, the CBIAC considered all seven state governors (or their designated representatives) as bonafide members allowed to cast votes along with the federal agency representatives. Initially, all but Washington accepted the opportunity to formally participate. ${ }^{98}$ Despite this formal declination, once the CBIAC began to meet, Washington would participate in an "observer" status at each meeting. It finally accepted formal membership in 1949 (McKinley, 1952; Scheufele, c.1970).

State contributions varied throughout the life of the CBIAC, however. To some members, it appeared that the individual state representatives were more interested in protecting state and local interests than contributing to region-wide planning vision. The status of the states with respect to the federal members and state interest in participating varied over time (Scheufele, c.1970).

The CBIAC chair rotated on an annual basis among the federal members. Meetings were conducted at cities throughout the region in order to stay in touch with local concerns, with part of each meeting was open to the public. There was no dedicated funding for supporting staff; the Chair's agency provided any needed staff

\footnotetext{
${ }^{98}$ According to McKinley (1952), the Washington governor's stated reason for declining was that Washington had a predominate interest in the Columbia Basin and should not be considered an equal with states of lesser interest. McKinley (1952) opined that the real reason was suspicion on the part of Washington that the CBIAC was just a substitute for a CVA, to which the state was philosophically opposed.
} 
support (McKinley, 1952; Bessey, 1963; Scheufele, c.1970). ${ }^{99}$ The CBIAC

established several technical committees and produced numerous technical studies in areas such as hydrologic data, power planning, stream flow, recreation, demographic trends, noxious weeds, and fisheries. ${ }^{100}$

FIARBC intended their regional subcommittees to function as a coordination forum between the federal agencies and participating states (McKinley, 1952; Bessey, 1963; Scheufele, c.1970). Bessey (1963) and Scheufele (c.1970) argued that the CBIAC performed the coordination function quite well and served admirably as a vehicle for keeping the Committee's members in touch with local regional needs and the public informed of Committee activities. Oregon governor Mark Hatfield echoed this feeling, declaring at a 1959 meeting, "In my opinion, the Columbia Basin InterAgency Committee has completely justified its existence under its present charter. It has provided a forum for discussion and dissemination to the public of facts and group thinking on various basin problems...It has, through its subcommittees and task forces, developed much basic data of vital importance in planning activities" (Quoted in Bessey, 1963, p. 111).

Nevertheless, the CBIAC was roundly criticized as well, mostly by valley authority proponents. From the beginning, "will of its membership, always precarious

\footnotetext{
99 McKinley (1952) claimed that this format did not work particularly well, arguing that "coordination in the usual administrative sense of the term cannot be effectively practiced in the atmosphere of a public hearing" (p. 471). Bessey (1963) was more supportive, claiming that the public hearing aspect helped keep the region informed and the CBIAC in touch with local concerns.

${ }^{100}$ Many of these reports can be found online through a web search for "Columbia Basin Inter-Agency Committee."
} 
and by the laws, policies, and practices of member agencies" (Scheufele, c.1970, p. 1) could limit movement on any issue. The CBIAC was thus "notoriously silent on many controversial issues, partly because one Federal [sic] agency hesitates to criticize publicly the views and determinations of another such agency and partly because the state and federal members are reluctant to take positions on which there is not unanimity" (Mark Hatfield, as quoted by Bessey, 1963, p. 111). Hatfield's ultimate point was the need for one, single comprehensive plan for water resource development and utilization that all of the basin's entities would use to guide their respective projects and programs. Such unified agreement apparently eluded the CBIAC even after the Corps-Reclamation 1949 report was completed. Portland's Oregonian editorially criticized the CBIAC as a "paper tiger" that was unable to arrive at a comprehensive plan as long as it could not make decisions to resolve interagency disagreements (Bessey, 1963, p. 111). Others criticized the CBIAC's cooperative structure to call for its replacement by "a single agency not charged with the primary responsibility of any one use of water" (Bessey, 1963, p. 112) - in effect, a valley authority.

In his 1952 argument for a Columbia Valley Authority, McKinley cites the failure of the CBIAC to adopt the Interior proposal regarding the dam construction moratorium in 1946 as an example of the failure of the CBIAC process. ${ }^{101}$ McKinley also notes "sharp conflict" (McKinley, 1952, p. 110) between the development-

\footnotetext{
${ }^{101}$ It's not clear if McKinley (1952) was critiquing the process in general or the outcome of this particular decision.
} 
oriented CBIAC and conservation-oriented Fish and Wildlife Service (and presumably the Office of Indian Affairs) as well among CBIAC members in general. For example, the CBIAC was unable to resolve a conflict between BPA and the Bureau of Reclamation when the former wanted to extend its transmission system into southern Idaho in 1946 (McKinley, 1952). ${ }^{102}$ Neither the CBIAC nor its parent FIARBC had an authoritative decision mechanism to resolve such differences (McKinley, 1952). Scheufele (c.1970) was more forgiving, noting that the harshest critics tended to base their criticism on what they thought the CBIAC ought to do, rather than evaluating it against the reasons for which it was actually established. When assessed from the perspective of its originating resolution, Scheufele (c.1970) declared the CBIAC remarkably successful.

Despite its weaknesses, the CBIAC functioned for a little over twenty years. During that time, it was the only intergovernmental regional entity active in resource planning and development (Bessey, 1963). It held its last meeting in 1967 at which point it amiably transferred its responsibilities to the Pacific Northwest River Basins Commission (Scheufele, c. 1970). ${ }^{103}$

\section{Columbia River Basin Interstate Compact.}

In 1949, regional governors asked the governor of Washington to lead an effort to establish an interstate compact for Pacific Northwest states. Each interested state

\footnotetext{
${ }^{102}$ See McKinley, 1952, pp. 210-224 for further discussion of the southern Idaho issue.

${ }^{103}$ Norwood (c.1981) stated that the last meeting occurred in 1966. Ogden (1997) agreed with Scheufele (c. 1970) that the date of the last CBIAC meeting was in 1967. As Scheufele (c.1970) based his report upon review of CBIAC records, it is his 1967 date that is used here.
} 
was to name a delegate to participate in a commission to negotiate an interstate compact. Delegates from Washington, Oregon, Idaho, Montana and Wyoming met in 1950. Utah and Nevada would later join for the first formal meeting of the Columbia Interstate Compact Commission in 1952 (Bessey, 1963).

This was the second state effort (after the Northwest States Development Association) intended to carve out a larger regional planning role for the states (Bessey, 1963) and to provide a forum for resolving upper and lower Columbia Basin water allocation issues (National Research Council, 2004). Myriad other motives energized promoters both for and against the effort in the region (Bessey, 1963). The governors opposed establishment of a federal-centric valley authority, although opinions on this point varied sharply among their respective state officials and legislatures (Bessey, 1963). Much of the compact negotiations focused on publicprivate hydropower issues with arguments among the states with a history of private power development and those with a history of public power (National Research Council, 2004). Ogden (1997) says that negotiations collapsed in the late 1950s due to opposition by public power advocates and the state of Washington, who came to see the effort as an attack on the federal hydropower system. Bessey (1963) noted the effort as still alive though unresolved at the time of his writing. The National Research Council (2004) says negotiations continued up to 1968, at which point the state compact commissioners finally signed a Columbia River Basin Compact. Congress approved the Compact the same year. The effort collapsed, however, when 
the legislatures of Washington and Oregon refused to ratify it (National Research Council, 2004).

\section{$\underline{\text { Pacific Northwest Governors’ Power Policy Committee. }}$}

The third state effort at regaining a central role in development planning came in 1953. President Eisenhower's partnership program anticipated replacing reliance on the federal bureaucracy for natural resource planning and management with joint venture type arrangements among federal agencies, state and local governments, and private interests (Scheufele, c.1970). In response, the Northwest governors proposed at the September CBIAC meeting that a subcommittee be formed to implement this new policy direction. At least one governor saw this subcommittee as an interim measure pending ratification of the Columbia River interstate compact then under negotiation among the states. Federal members saw it as a veiled attempt to wrest control over regional resources - especially the hydrosystem - away from the federal agencies and transfer it to state or private entities. In time, this committee all but took over the role of the full CBIAC, operating as an independent group led by the governors. As a result, participation in CBIAC meetings dwindled to just about the point of collapse (Scheufele, c.1970).

The Governors' group produced seven technical reports before disbanding by mutual consent in 1958. The group suffered from the same interstate conflicts that had doomed the Northwest States Development Association. It did not help that the administration's “partnership” policy was poorly defined, never well received politically, and enjoyed little support from the administration especially in the latter 
half of Eisenhower's second term. The partnership policy died around 1958 taking the Pacific Northwest Governors' Power Policy Committee with it. With the demise of the governors' committee, members renewed their participation in the CBIAC (Bessey, 1963; Norwood, c.1981).

\section{Columbia Valley Authority: redux II.}

The Columbia Valley Authority idea was resurrected in three variants between 1947 and 1949. The first, introduced in the House 1947 and entitled the Columbia Interstate Commission, was essentially a resubmitted version of Horan's 1945 Columbia Valley Cooperative Authority. It envisioned a public corporation similar to the CVA but with its jurisdiction limited to water resources and hydroelectricity. The second was a reintroduction the CVA along the lines of the revised 1945 Mitchell bill submitted to the Senate in 1947 and House in 1948. The third was a proposal for a Columbia Valley Administration, backed by the administration to the degree that it eventually completely eclipsed discussion of the other proposals (McKinley, 1952).

The election of 1946 "retired" a number of New Deal congressional representatives and senators, including many in the pro-public power state of Washington. In their place were elected Republicans that were more conservative. As a result, the "political stock of the CVA movement took a drastic tumble" (McKinley, 1952, pp. 561-562). The banner of CVA leadership thus passed from the now-retired Senator Mitchell of Washington to Congressman Walt Horan of Washington and Senator Glen Taylor of Idaho. 
In 1947, Horan revised his 1945 Columbia Valley Cooperative Authority proposal in deference to the pro-business sympathies of the Republicans. He introduced a House bill calling for establishment of a Columbia Interstate Commission. This agency would be the same as contemplated in his earlier bill but limited water resource development to only those activities not suitable for private development and restricted transmission and sale of electrical energy to wholesale markets only (McKinley, 1952). It too failed.

Taylor of Idaho introduced his Columbia Valley Authority bill to the Senate later in 1947. It retained the major components of the second 1945 Mitchell bill. A significant modification was a joint federal-state-private interest advisory structure to review unified plans and major policy proposals and advise as to which programs were suitable for private development. "Though there was little serious hope" that the $80^{\text {th }}$ Congress would pass this bill, it served "to keep the [CVA] idea alive in the region" pending the return of a more supportive political environment (McKinley, 1952, p. 564).

The surprise reelection of the Truman administration in 1948 brought new hope to Columbia Valley Authority proponents (DeLuna, 1997). Congressman Henry "Scoop" Jackson took the opportunity rendered by the election results to reintroduce the second Mitchell CVA bill in the House in 1948, supporting Taylor's effort in the Senate the year before. President Truman sent a special message to Congress in April 1949 in support, urging establishment of a CVA (McKinley, 1952). 
Shortly thereafter, the administration established a team under one of the president's personal aides to create a legislative plan for the Columbia. Senator Warren Magnuson of Washington introduced the resulting bill in April 1949. Debate over this bill took "center stage" in the valley authority discussions, essentially sidelining the previous Jackson and Taylor proposals (McKinley, 1952).

The newly proposed agency was entitled the Columbia Valley Administration (CVAd). Like the Horan proposals, it limited operating responsibilities to water resources, power generation, and power transmission. Unlike other CVA proposals, it would not transfer land management functions of the Department of Agriculture or the lands, minerals, and wildlife functions of the Department of Interior unless Congress otherwise appropriated funds especially for that purpose. In effect, the CVAd would take over the regional water resource responsibilities of the Bureau of Reclamation, BPA, and the Corps of Engineers, eliminating the first two from the Pacific Northwest and limiting the Corps civil functions to the coastal tributaries and operation of the Columbia navigation system (McKinley, 1952).

As originally proposed, the CVAd would be a government corporation with a general manager appointed by a board of directors. This board was to be comprised of the regional agency leaders and the governors of the Northwest states. The board was to develop unified plans and programs for the President to submit for approval to Congress. Proponents within the Administration claimed that this granted no new authorities to the federal government, just "relocated" the decision-making power 
from old agencies to this new entity that was answerable to a board with substantial regional representation (McKinley, 1952; DeLuna, 1997).

In addition to the New Dealers, supporters included the state agency staff and most legislators from Washington and Oregon, farmers, public utilities, and the Department of the Interior. Opponents saw this as a thinly disguised version of the CVA. In contrast to their agency staffs, the governors of Oregon and Washington opposed the measure, as did governors from Utah, Idaho, and Nevada. Their reasons were the same as their opposition to the CVA - relinquishment of local control over natural resources, especially water, to a central federal decision-maker. Additional opponents included the Corps of Engineers, Bureau of Reclamation, private power advocates, and many local towns and jurisdictions. The Department of Agriculture voiced neutrality (DeLuna, 1997).

The CVAd represented the final attempt by New Dealers to impose a stronger decision-making system over Northwest resource development. Its purpose was to serve as a balance between the decision-by-consensus model of the CBIAC and the authoritative CVA. It failed due to tepid support from the Truman administration coupled with strong opposition from federal agencies and regional governors. Its demise effectively ended serious efforts to establish a central federal authority to oversee federal natural resource programs in the Northwest (DeLuna, 1997).

\section{Committee on Fish Operations.}

The Committee on Fish Operations was established in the 1960s to find ways to operate the FCRPS in order to address the impact of the system on fish and 
wildlife. ${ }^{104} \mathrm{COFO}$ consisted of state fish and wildlife managers and federal operators and regulators. It apparently evolved into a committee of apparently narrower focus entitled the Water Budget Implementation Work Group under some association with the Northwest Power and Conservation Council soon after passage of the 1980 Power Act (Mainstem Operations Work Group Revised Draft, 1996). COFO coexisted alongside the CBIAC and the Pacific Northwest River Basins Commission. It is not clear at the time of this writing if COFO was a component of one or the other or established independently of these other two systems.

Pacific Northwest River Basins Commission.

In 1950, the presidentially appointed Water Resources Policy Commission issued a report on water resources development. Although the commission believed that empowering a single federal agency to oversee water development was the preferred alternative, it realized after the defeat of the administration's CVAd effort that Congress would not support such an approach. Instead, they proposed that FIARBC's regional subcommittees be reconstituted as congressionally created "commissions." The commissions were to consist of the federal agencies involved in the given river basin. The President would appoint an independent chairman answerable only to him. A board of review established within the executive branch

${ }^{104}$ The only reference to COFO found in the course of this study was a brief mention in the Mainstem Operations Work Group Revised Draft dated 1996 and found on the Northwest Power and Planning Council's website. It is not clear whether COFO was established as a committee under the CBIAC (Scheufele, c.1970, does not mention it). It does not appear in any of the other sources reviewed for this study. Its exact dates of origin and termination and its exact membership were not identified. It is also not clear if its "fish and wildlife managers" membership included tribal representation or was limited to state and federal agencies. There are several COFO participants still active in regional fish and hydropower issues, however. Further information could likely be obtained through interviews with them. 
would provide oversight. States would be consulted but would not be formal commission members. The board recommended changing the congressional authorization and appropriation's processes for each individual agency to be supportive of the commission concept. Unresolved was the issue of whether commission chairs would be empowered to authoritatively resolve agency disputes (DeLuna, 1997).

Congress acted on this proposal through passage of the Water Resources Planning Act in 1965. ${ }^{105}$ The Act established a Water Resources Council to be comprised of cabinet level representatives from the Departments of Interior, Army, Agriculture, Commerce, Housing and Urban Development, Transportation, and the Federal Power Commission (later the Department of Energy). It further authorized establishment of river basin commissions upon recommendation from a state governor or from the Council. In a major departure from the inter-agency committees, it also authorized federal funding for regional basin commission staff, supplies, and office space (Water Resources Planning Act, 1965; Ogden, 1997).

Executive Order 11331 subsequently established the Pacific Northwest River Basins Commission on March 6, 1967 (National Archives, undated). Consistent with the recommendation of the 1950 commission report, the PNWRBC chair was a federal

\footnotetext{
105 The circumstances surrounding passage of this Act in 1965 could arguably serve as another critical situation in governance paradigms for this paper. However, the lack of published secondary information and analysis regarding the formulation of this act and the resulting river basin commissions made such a division hard to define. Additionally, in practice, the PNWRBC does not seem to present a significant departure from the purpose and function of the CBIAC. Its formation was supported by most if not all CBIAC participants and its membership was identical to that of the CBIAC (Bessey, 1963; Scheufele, c.1970). Consequently, for the purposes of this study, its passage is considered an evolutionary improvement to the CBIAC rather than a forced change under a critical situation.
} 
appointee. Federal members included the Corps of Engineers; Department of Agriculture agencies Soil Conservation Service, Forest Service, and Economic Research Service; Department of Interior agencies Bureau of Reclamation, Bureau of Sports Fisheries and Wildlife, Bureau of Commercial Fisheries, ${ }^{106}$ and Water Pollution Control Administration; the Federal Power Commission; the Department of Housing and Urban Development; and the Bonneville Power Administration acting as a separate agency (Ogden, 1997). Later, some agencies were replaced due to reorganizations and other, newly created, agencies added. The Department of Energy replaced the Federal Power Commission. The Department of Commerce absorbed the Bureau of Commercial Fisheries and reorganized it to the National Marine Fisheries Service, which in turn joined the Commission. The Environmental Protection Agency joined upon its establishment under the National Environmental Policy Act of 1969 (Ogden, 1997).

In contrast to the 1950 recommendation, there were no adjustments made to congressional authorizations or appropriations. Established congressional authorizing and appropriating committees would continue to oversee the agencies charged with implementing the statutes under committee jurisdiction. Furthermore, the 1965 Act specifically retained each agency's decision-making prerogatives. Participants were to make a "reasonable endeavor" (Water Resources Planning Act, 1965, section 203 (d))

\footnotetext{
${ }^{106}$ Weber (2002) stated that the bureaus of Sports Fisheries and Wildlife and Commercial Fisheries were created in 1956 as subordinate bureaus of the U.S. Fish and Wildlife Service. Clarke and McCool (1996) stated that they functioned more as independent entities. The fact that Ogden (1997) identified them separately implies they acted in their own right with regard to PNWRBC business.
} 
to reach consensus, and, failing consensus, dissenting views were to be included in Commission reports (Water Resources Planning Act, 1965).

Washington, Oregon, Idaho, Montana, Wyoming, and Nevada were eligible to send representatives although, in practice, Nevada was not an active participant. The states could choose the Commission's vice-chair from among their representatives (Ogden, 1997). The PNWRBC was authorized its own staff, funded under Water Resources Council appropriations. It had responsibility for comprehensive planning for water and related land resources planning. During its time, it completed a comprehensive report on the Columbia River Basin and several studies on individual subbasins (Ogden, 1997). Similar to the CBIAC, it produced numerous technical reports covering fish, power, nuclear energy development, the Columbia River estuary, and water requirements, among others. ${ }^{107}$

There was no indication in the material reviewed for this study as to who supported or opposed the river basins commission concept. Apparently, no one has yet written general history of the 1965 Water Resources Planning Act or the PNWRBC. Regardless, on September 30, 1981 President Ronald Reagan terminated the PNWRBC by Executive Order 12319. Congress never repealed the statutory authorization, however and, theoretically, the President could reestablish the commissions by executive order (Ogden, 1997; National Archives, undated).

107 These topics were derived from the titles of multiple reports, published under the name of the PNWRBC or its committees, obtained through a web search for material related to the PNWRBC. 


\section{Chapter Summary}

The events surrounding the end of World War II and their impact on regional governance can be summarized as follows:

- The return of economic prosperity following the end of World War II resulted in a lessening of support for large governmental bureaucracies and a return of confidence in private markets. As a result, the National Resources Planning Board lost its congressional funding and the Pacific Northwest Regional Planning Commission and associated state planning commissions were disbanded (McKinley, 1952; Bessey, 1963; Goodwin, 1983).

- Eleven proposals to establish governance systems were made to replace the PNWRPC and address the weaknesses of the Bonneville Advisory Board. Five were enacted, of which three lasted for any length of time. Those three were the Columbia Basin Inter-Agency Committee (1946 - 1967), its successor the Pacific Northwest River Basins Commission (1967-1981), and the Committee of Fish Operations (1960s - early 1980s) (McKinley, 1952; Bessey, 1963; Scheufele, c.1970; Norwood, c.1981; DeLuna, 1997; Ogden, 1997).

- Northwest states made three efforts to reestablish the central role they lost with the demise of the PNWRPC. Two (the Northwest States Development Association and the Pacific Northwest Governors' Power Policy Committee) were enacted but short lived. State legislatures did not 
ratify the third, an initiative to establish an interstate compact even though agreed to by the governors and supported by Congress. These efforts succumbed to interstate rivalries, lack of funding, and diminished public and political interest (McKinley, 1952; Bessey, 1963; Norwood, c.1981; DeLuna, 1997; Ogden, 1997).

- Congressional proponents of a Columbia Valley Authority renewed their efforts in 1945 and 1947. The surprise reelection of Harry Truman in 1948 reenergized them, leading a series of valley authority bills up through 1949 . All failed to pass as public and political support for the valley authority idea dwindled ((McKinley, 1952; Bessey, 1963; Goodwin, 1983; Ogden, 1997; DeLuna, 1997).

- In the Northwest, the Bonneville Power Administration developed as a major regional institutional actor under the leadership of Administrator Paul Raver. Raver's aggressive promotion of close collaboration with regional utilities, fellow federal agencies, and the regional congressional delegation strengthened the agency's position in the region and established a tradition within BPA that exists to this day (Norwood, c.1981, Blumm, 1982; DeLuna, 1997; Pope, 2008).

- Opposition to planned construction of mainstem dams by commercial, sport, and tribal fishery interests appeared in the mid 1940s, represented by the U.S. Fish and Wildlife Service and Office of Indian Affairs. Efforts to impose a moratorium on dam construction pending more research on the 
effects of the dams on fish failed (McKinley, 1952; Bessey, 1963;

Scheufele, c.1970; Norwood, c.1981; Robbins, 1997).

Although the Northwest salmon issue made its way onto the governance agenda beginning in the mid 1940s, the efforts of the governance systems in place comprised almost exclusively of development-oriented agencies - failed to satisfy the concerns of fishery managers. However, pressure for change was building. A tribal sovereignty movement emerged in the 1950 s to restore tribal culture and promote tribal interests. Backed by major court victories in the 1970s, the tribes sought to obtain a greater voice in regional decision-making. In addition to the emergence of the tribes as regional actors, the nascent American environmental movement was gaining traction beginning in the 1960s. Environmentalists voiced concerns about the impact of development on Northwest resources but, like the tribes, could not find traction in the region's governance systems.

The development-oriented institutions controlling Basin policy decisions continued to see management of Columbia Basin issues through the lens of commercial benefit. The agencies perceived the governance challenge to be a balancing of federal agency prerogatives with the interests of the states and nongovernmental trade associations dependent upon the system's commercial uses of navigation, power, irrigation, water supply, recreation, land, timber, and fish harvest. The competing interests of a relatively limited set of participants all of whom shared the same general commercial market-oriented worldview thus effectively guided 
governance decisions. As of 1976, tribal members and environmentalists holding different worldviews had not yet obtained a seat at the regional governance table.

The opportunity for them to do so came with the region's hydro-thermal crisis of the 1970s. A mixture of miscalculations and overconfidence by energy planners led to a major financial crisis in the 1970s and presented the region with its third critical situation. It resulted in a governance system that offered those holding worldviews based on tribal culture and environmental values their first foothold in regional decision making. 


\section{CHAPTER 6 \\ THE HYDRO-THERMAL CRISIS (1976)}

\section{$\underline{\text { Introduction }}$}

The region's hydro-thermal crisis, symbolized by the notice of insufficiency issued by the Bonneville Power Administration in 1976, provided the catalyst for the Basin's third major change between governance models. The resulting Pacific Northwest Electric Power Planning and Conservation Act of 1980 (Power Act) created the Pacific Northwest Electric Power and Conservation Planning Council (NPPC or Council) that shifted the locus of Basin developmental decision-making away from the federal cooperation model back to a state-centric model. The pressure for change this had been building over the previous thirty years.

Several national trends set the social and political context for events in the Northwest. A tribal sovereignty movement began in the 1950 s in response to a new national policy to terminate Indian treaties, end the tribal trust relationship with the federal government, and assimilate Indian people into mainstream American culture. This movement resulted in improvements in tribal capacity for self-government, a renewed confidence in asserting their rights, and a partial return to traditional tribal culture and beliefs (Pevar, 2002; Wilkinson, 2005). In addition to the tribal movement was the American environmental movement. Events such as publication of Rachel Carson's Silent Spring, the 1969 Cuyahoga River fire in Ohio, and the first Earth Day in 1970 propelled environmentalism into the national consciousness (Dunlap and Mertig, 1992a; Kline, 2000; Rosenbaum, 2005). Finally, the election of Ronald 
Reagan to the presidency in 1980 brought with it a philosophy of smaller government and an emphasis of the prerogatives of local government and private enterprise.

Four regional developments converged with national trends and led to the governance provisions of the Power Act. The first was the region's hydro-thermal program and resulting financial crisis provided the proximate cause for the Power Act's passage (Pope, 2008). The second was the continuing decline in regional salmon runs. The decline continued the opposition to the dams by fishery interests that began in the 1940s. It also led to a coalition of commercial, sport, and tribal fishery managers with environmental activists. Although operating from three dramatically different worldviews, the impact that dams were having on regional fish united them in opposition to existing management systems and structures (Lichatowich, 1999; Taylor, 1999). The third regional development was two major court victories won by regional tribes regarding their trust and treaty rights to fish (Wilkinson, 2005). The fourth, related to the third, was the decision by the tribes of the Confederated Tribes of the Warm Springs Indian Reservation, the Confederated Tribes of the Umatilla Indian Reservation, the Confederated Tribes and Bands of the Yakama Nation, and the Nez Perce tribe to unite in a coalition to promote tribal fishing rights and manage intertribal fisheries (CRITFC, 2010).

Absent the the regional salmon decline, the common opposition to dams by environmentalists and regional fishery interests, and the growth in tribal influence, the 1980 Power Act would likely have only addressed regional electric power issues in response to the hydro-thermal financial crisis. Instead, it established a new 
governance system oriented on resource conservation as well as power production and insisted that the Basin's fish and wildlife receive equal consideration with the region's electricity needs (Blumm, 1982; Hemmingway, 1983; Bodi, 1995).

Coincident with the establishment of the Council was the disbanding of the Pacific Northwest River Basins Commission, along with almost all of the other river basin commissions, by executive order in 1981. The termination of the PNWRBC had more to do with the philosophical leanings of the Reagan administration than specific issues in the Northwest. Its disestablishment and the apparent dissolution of the Committee on Fish Operations at around the same time left the state-led Council as the Basin's governance system for the next several years. No other governance systems were proposed at this time.

The remainder of this chapter discusses the national social and political trends and the regional issues and events outlined above that led to the Council's creation. It also describes the Power Act's provisions regarding the Council and the Council's organization and operation.

\section{$\underline{\text { Social and Political Context }}$}

Two national trends that would come to effect regional governance included the rise of the tribal sovereignty movement and the rise of the American environmental movement. In the case of the tribes, the renewed interest in traditional Indian culture meant a reestablishment of the tribal worldview toward resources. The environmental movement generated a third worldview. It provided a critique of the 
dominant market-oriented capitalist system and called for greater stewardship of resources. Each would prove influential in the writing of the 1980 Power Act.

The rise of the tribal sovereignty movement and reestablishment of the Indian worldview.

By the early 1900s tribal society had descended into what Wilkinson (2005) describes as an "abyss." The Bureau of Indian Affairs, assigned to manage federal trust and treaty obligations to the tribes, pressured tribes to abandon their traditional ways. Unemployment far exceeded the national average. A program to educate Indian children in white public schools began to systematically erase tribal culture and promote Indian integration into white society. A traditional economy built on hunting, fishing, gathering, and gift giving was transformed through federal programs to one built on farming (Wilkinson, 2005).

Despite treaties with the federal government, northwest state governments imposed restrictions on tribal fishing practices in the name of conservation. The public generally supported the states' actions, believing that non-Indian sport and commercial fisheries were important to the economy. There was also an underlying resentment felt toward the tribes holding "special privileges" (Wilkinson, 2005, p. $151)$.

However bad conditions were locally, policy at the national changed abruptly in the early 1930s in a direction interests that were more sensitive to tribal. There were several reasons for this shift. The Depression all but eliminated demands for further confiscation of Indian land due to the general lack of financing for 
development. Additionally, publication of the Brookings Institution's influential Meriam Report in 1928 made the public aware of the abysmal conditions of life on tribal reservations through. This study documented the "extreme poverty, devastating epidemics, inadequate food, and inadequate education" resulting from previous federal policy (Pevar, 2002, p. 10).

Roosevelt responded by appointing a new Commissioner of Indian Affairs more sympathetic to the tribes. At the new Commissioner's urging, Congress in 1934 passed the Indian Reorganization Act designed to "rehabilitate the Indian's economic life and to give him a chance to develop the initiative destroyed by a century of oppression and paternalism" (Pevar, 2002, p. 10). The Act prohibited further allotment of tribal land, encouraged tribal constitutions for purposes of selfgovernment, gave Indians preferential hiring within the Bureau of Indian Affairs, and established a revolving credit fund to provide tribal loans (Pevar, 2002). However welcome these changes may have been to reservation life, traditional tribal culture was barely on life support. Missionary and government efforts to erase Indian culture coupled with the reservations' poor conditions took their toll, sapping confidence and hope. In their weakened state, the tribes had little voice to challenge the extensive changes taking place within the Columbia Basin in the 1930s, 40s, and 50s.

Federal policy toward the nation's Indian tribes did two about-faces between 1949 and the 1960s. The compassionate attitude toward tribal culture reflected in the 1934 Indian Reorganization Act was relatively short lived. The Hoover Commission Report, issued in 1949, recommended the integration of Indians into white society, 
asserting once again that assimilation was in the best interests of tribal peoples. It further argued that the federal government could save money by ending Indian programs. When the Eisenhower administration came to power in 1953, federal policy took the Hoover recommendations to heart, changing official policy from promoting tribal self-government to the outright termination of the tribal trust relationship with the United States (Pevar, 2002; Wilkinson, 2005).

Termination meant ending the federal trust relationship along with federal benefits and support services. It also meant dissolution of tribal governments and the closing of reservations. For tribal governments so terminated, tribal land and property was to be distributed among tribal members or to a tribal corporation. The states were to acquire full jurisdiction over terminated reservation land. Between 1954 and 1966, Congress terminated 109 tribes, most of them in Oregon and California. Public Law 83-280 further extended state jurisdiction over reservations in Alaska, California, Minnesota, Nebraska, Oregon, and Wisconsin by subjecting reservation residents to state criminal law (Pevar, 2002). Nationwide, "termination affected at least 1.3 million acres and 11,000 people, diminishing tribal trust lands by 2.5 percent and cutting off federal services to 3 percent of all federally recognized Indians." As a result, "every terminated tribe floundered" (Wilkinson, 2005, p. 81).

Whereas the $19^{\text {th }}$ century relocation from traditional homelands to reservations had been brutal, and the Indian Reorganization Act programs less successful than hoped for in relieving reservation misery, the termination policy meant cultural extinction. Termination served as a tribal rallying cry, although the organizational 
challenges were substantial. Tribal society possessed little tradition in intertribal cooperation, and, in several cases, the federal government had deliberately collocated tribes with histories of conflict on the same reservation. Wilkinson (2005) credits a handful of leaders and writers with providing the intellectual energy for the tribal sovereignty movement and inspiring others to regain long-promised rights.

The Johnson administration supported the tribal efforts. It shifted federal policy once again, repudiating the previous administration's termination policies. The Nixon administration followed suit, with the president stating in 1970 that, "[t]his, then, must be the goal of any new national policy toward the Indian people: to strengthen the Indian sense of autonomy without threatening his sense of community." Congress subsequently promoted tribal sovereignty and autonomy through legislation and programs directed toward enhancing the capacity for tribal self-rule and economic development. Examples include the prohibition to states from acquiring any new authorities over Indian reservations in 1968; development of the Indian Business Development Fund; and passage of the Indian Financing Act and Native American Programs Act to create and provide financing for commercial opportunities. Particularly important from the cultural perspective was the Indian Self-Determination and Education Assistance Act of 1975, allowing tribes to administer health, law enforcement, education, and social service programs on the reservation (Pevar, 2002, quote from p. 12). These efforts did not solve all tribal social problems, but they did begin to reverse previous efforts to eradicate the tribal worldview and provided a 
tribally run social infrastructure within which traditional Indian culture could at least be partially reestablished. ${ }^{108}$

The rise of the American environmental movement and worldview.

The worldview of environmentalism has a seemingly paradoxical parentage, with deep roots in Western Judeo-Christian biblical teachings, Progressive Conservatism, and market capitalism (Cortner and Moote, 1999; Kline, 2000; Rosenbaum, 2005). It emerged as a powerful critique of the market capitalist worldview in the late 1960s and early 1970s. Motivated by Euro American aesthetic values regarding natural beauty, the impacts of pollution on human health, and concerns over challenges to ecological stability that many came to think threatened the continued existence of the human race (Hays, 2000), environmentalists faced a monumental challenge in reversing the market worldview. Thomas Dunlap (2004) captures the essence of this challenge. Echoing - but not citing - Max Weber's (2002/1920) theory about the connection between religious belief and protestantmarket-capitalism Dunlap states,

...defenders of the [market oriented] status quo gaze in rapture on the goodness of the market and the gross domestic product, which distributes benefits to all who strive - for they are the virtuous. They look on the market as the Hand of God, endless economic growth as the path to the Earthly Paradise, and the conquest of nature, human destiny ... Because society accepts these propositions as self-evident truths and rational descriptions of the universe, other views - ecological interdependence as the Hand of God, a sustainable economy as the path to the Earthly Paradise, and living as citizens of the biotic community

\footnotetext{
${ }^{108}$ The spiritual aspect of the traditional tribal worldview did not recover to pre-contact levels within Indian society. Almost a century of white efforts to move Indian peoples away from their traditional beliefs had achieved many of its objectives. Current tribal religious affiliations among reservation residents present a mix of various Christian denominations and traditional beliefs.
} 
as human destiny - look like emotional arguments, unworthy of consideration (Dunlap, 2004, p. 165).

It would take time for the concept of a "biotic community" to crystallize. Similar to Progressives' treatment of water, timber, and wildlife as independent entities, early environmental protection focused on protection of individual components of the environment, such as air, water, and soil. It evolved to a belief in the interconnectedness among nature's components (Dunlap and Mertig, 1992a; Hays, 2000; Dunlap, 2004). In this, it was similar to the tribal worldview with an important distinction. Rosenbaum (2005) states that environmentalism "assumes that humanity is part of the created order, ethically responsible for the preservation of the world's ecological integrity" (p. 39). Thus humankind, while part of the greater whole, is the senior partner within the whole. It is in control of, capable of, and responsible for managing its actions to minimize negative impacts and making improvements as it can. The tribal worldview, in a subtle but important contrast, held humans as integral and equal components within nature. Although a vocal minority - termed "deep ecologists" (Rosenbaum, 2005) - adopted a view of man as an integral and equal member of the natural order, the mainstream environmental movement viewed humans as being above the rest of nature with a responsibility to minimize their impact on the environment and mitigate for damage already done.

In 1962, Rachel Carson's Silent Spring put forward the dangers posed by modern technology on human health and welfare in clear, non-technical language. Inspired by Carson's book, environmental interest groups like the Sierra Club and 
National Wildlife Federation initiated campaigns for public education and awareness. Highly publicized events such as the Cuyahoga River fire near Cleveland in 1969 punctuated their message. The upshot was that by Earth Day 1970 there was within the country a growing consensus that the concept of conserving resources for sustainable development alone was not enough. A national view of environmentalism emerged which focused on the interrelationships and interdependencies between man and nature. Environmentalism thus became the dominant natural resource policy paradigm (Dunlap \& Mertig, 1992b).

The mainstream leadership of organized environmentalism was concentrated in a small number of nationally recognized organizations. Referred to by some as "The Group of Ten" ${ }^{\prime 109}$ (Rosenbaum, 2005; Mitchell, et al, 1992), this group represented some of the oldest and best-established lobbying organizations in America. The three oldest date back to the Progressive Era and followed the preservationist philosophy of John Muir. These were the Sierra Club, the National Audubon Society, and the National Parks and Conservation Association founded in 1892, 1905, and 1919 respectively. Groups that are more recent include those formed during a widespread expansion in the number of interest groups that occurred in the 1960s and 1970s. Examples are the Environmental Defense fund established in 1967, the Natural Resources Defense Council in 1970, and the Environmental Policy Institute in 1972 (Dunlap and Mertig, 1992b).

\footnotetext{
${ }^{109}$ The "Group of Ten" included the Sierra Club, the National Wildlife Federation, the National Audubon Society, the Wilderness Society, Friends of the Earth, the Environmental Defense Fund, the National Parks and Conservation Association, the Izaak Walton League, the Natural Resources Defense Council, and the Environmental Policy Institute.
} 
The wide range of environmentally oriented groups resulted in emergences of a variety of perspectives as to goals, methods, and priorities. Most sought to work within the framework of the American political and legal systems (Rosenbaum, 2005). Some believed that American democratic capitalism was not up to resolving the environmental crisis facing humankind and called for a complete restructuring of the American political system (Ophuls and Boyan, 1992). Others believed tighter government regulation and control unnecessary and that the environmental movement was nothing more than a hoax intended to extend government control over private property. In this view, society could depend on market mechanisms alone to preclude resource extinction (Simon, 1999).

The late 1960s and early 1970s saw an unprecedented array of environmental legislation. Most of the legislation focused on discrete classes of resources. The $\underline{\text { Endangered Species Act (ESA) (enacted 1966; revised 1973), the Clean Air Act }}$ (1970), the Clean Water Act (CWA) (1972), the Pesticides Control Act (1972), the Marine Mammal Protection Act (1972), and the Surface Mining Control and

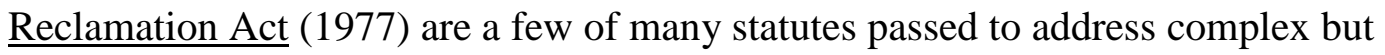
relatively distinct environmental problems. These laws replaced earlier, largely ineffective attempts that relied on partnerships between the federal government and often hostile or disinterested states that tried to treat pollution issues as local problems. Broader in nature was the National Environmental Policy Act (NEPA), passed by Congress in 1969 and signed into law in 1970. NEPA imposed public involvement and the requirement to address environmental impacts on agency decision-making 
(Cortner and Moote, 1999; Rosenbaum, 2005). The result were strong, enforceable policies that produced measurable results in cleaning up the nation's air and water, identified and protected endangered species, and fundamentally changed behaviors in federal resource agencies.

The environmental worldview brought about significant changes in the formal institutions of federal government. These changes included the creation of new agencies, such as the Environmental Protection Agency created under NEPA in 1970. Established agencies received new environmental responsibilities. For example, the Endangered Species Act assigned regulatory jurisdiction over listed species to the Fish and Wildlife Service and National Marine Fisheries Service - both of whose origins lay in promoting sport and commercial fishing. All agencies were required under NEPA to consider the impact of new programs and activities on the environment and publish the results in publicly reviewable environmental impact statements. Agencies not in compliance with the provisions of these environmental statutes were subject to suit. Consequently, environmental legislation had a profound effect on the process and substance of agency decision-making (Cortner and Moote, 1999; Rosenbaum, 2005).

Once labeled a fad that would run its course by the mid 1970s, the environmental movement grew to enjoy broad public support. It successfully deflected efforts by the Reagan Administration in the 1980s to overturn or undermine the laws noted above, despite Reagan's personal popularity (Dunlap and Mertig, 
1992b). By the 1970s, environmentalism was institutionalized as a core value of American society and an influential force in American politics (Rosenbaum, 2005).

That influence of both the tribal sovereignty and environmental movements would be felt in negotiations over the 1980 Power Act.

\section{$\underline{\text { Salient Issues in the Pacific Northwest }}$}

Anticipations of regional growth coupled with rising demand for electrical energy led to a plan to integrate the Northwest's hydropower dams with the construction of new nuclear plants. Misjudgments by the Bonneville Power Administration and Northwest energy utilities in the program's planning and execution resulted in a regional financial crisis that began in 1973. In 1976, events forced BPA to issue a notice that it might not be able to meet its statutory obligations. This crisis occurred coincident with a worldwide energy crisis, stagflation, and a growing movement away from nuclear power (Pope, 2008).

Champions of greater involvement in regional power decisions by tribal, fishery, and environmental interests seized the opportunity presented by the crisis. They sought to ensure that the resulting policy not only created a mechanism for public involvement and oversight of future electrical load and capacity projections but also a fish and wildlife program to mitigate for the environmental effects of the dams in the Columbia. Thus, the hydro-thermal crisis provided the catalyst for fishery, environmental, and tribal voices to finally gain influence in Basin governance. The 
result was the Northwest Electrical Power Planning and Conservation Act of 1980 that created the Council (Blumm, 1982; Hemmingway, 1983).

Three regional events directly affected regional governance. The first was termination of the Pacific Northwest Regional River Basins Commission by executive order in 1981. The second was the apparent dissolution of the Committee on Fish Operations at around the same time. Both have already been discussed to the degree relevant to this study and nothing further will be added here. The third and most significant issue was region's hydro-thermal program and resulting financial crisis that led to passage of the 1980 Power Act. Strongly related were the continued declines in regional fish runs; significant tribal court victories regarding tribal fishing rights; an increase in capacity for self-governance by regional tribes; and the negotiations leading up to the Power Act.

The hydro-thermal program.

Never supportive of public power, the Eisenhower administration slowed construction of federal hydropower dams in the Northwest prompting public and investor owned utilities to build their own facilities in the face of the expected demand increases. In 1956, the administration sought to sell the Tennessee Valley Authority. The State of Washington and regional public utilities feared the administration might also try to sell BPA's transmission grid (Pope, 2008).

The Washington Public Power Supply System (WPPSS) was formed in part to present a joint operating agency of public utilities that could pool resources to purchase the transmission lines should that become necessary. A secondary purpose 
was to provide the capacity to build new generating plants. WPPSS was state approved as a joint operating agency in 1957. The Washington governor appointed the WPPSS leadership. PUD representatives made up the members of an oversight board. As such, WPPSS had no direct accountability to or oversight from voters or ratepayers. In essence, WPPSS represented an organization grounded in the democratic ideals of the Progressive era but that lacked any public accountability (Pope, 2008).

A belief in supply side, construction-oriented policies by the Northwest energy community marked the period from the 1950s through the 1970s. A 1958 update by

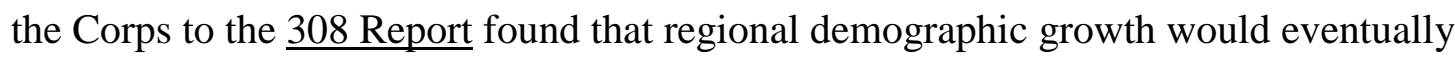
exceed the supply provided by the hydropower system. The report implied that, if the region provided additional energy supply, then regional development and economic growth would follow. In effect, BPA, WPPSS, and private utilities would promote regional growth in the interest of increasing the demand for power. Planners would then use the estimates of projected growth to justify additional generation capability through new plants. This somewhat circular logic led to adoption and publication of the hydro-thermal program in 1969 (Blumm, 1982; Pope, 2008).

There were no effective mechanisms for those outside the power planning interests to challenge this logic. National oversight waned with the demise of the national planning apparatus in 1943 and was limited to annual testimony to congressional appropriations committees. Furthermore, BPA enjoyed exemption from the Administrative Procedures Act. Consequently, policy and program development 
plans and the non-federal utilities and related trade associations were not subject to the same level of public scrutiny and review applied to other federal agency decisions. This included review by the utility customers and bondholders who would eventually be responsible for the costs incurred by BPA and WPPSS decisions. This lack of oversight, coupled with power promotion through industrial use, led to the impending crisis (Blumm, 1982).

The resulting Ten Year Hydro-Thermal Power Program for the Pacific Northwest (the hydro-thermal program) envisioned a twenty-year program, projecting that by 1990 the region would need the equivalent of the power produced from twenty nuclear plants of 1000 megawatt capacity each, plus one coal fired plant of 1400 megawatts. The nuclear and coal thermal projects would provide the region's base load, with the federal hydropower dams meeting peaking needs. The federal contribution consisted of completion of those hydropower projects underway, planning for new projects, and expansion of the regional transmission grid. The hydro-thermal program anticipated a tripling of electrical output within the Pacific Northwest from all sources between 1970 and 1990. Interestingly enough, environmental groups (most notably the Sierra Club) who believed nuclear power to be less environmentally destructive than large dams and less polluting than fossil-fuel plants initially applauded the program (Norwood, c.1981; Pope, 2008).

The initial plan was to build three nuclear plants (projects 1, 2, and 3) at the federal nuclear site at Hanford, Washington. The Hanford site had originally been built to produce the uranium that went into the atomic bombs that ended World War 
II. BPA financially guaranteed the projects, planning to finance them through a process termed "net billing" (Pope, 2008).

Prior to 1974, the law precluded BPA from owning generation capability or buying power from non-federal power plants. Net billing involved a complicated process to bypass this restriction. ${ }^{110}$ In essence, BPA combined the high cost of nuclear plant construction with the low cost of hydropower production and set "net" rates based on a blending of the two. In effect, regional hydropower customers subsidized the construction costs of the WPPSS utilities engaged in nuclear power development. This ensured that the high nuclear plant costs were not directly billed to WPPSS utilities' customers. If those costs had been directly billed during construction, the utilities would have to impose significantly higher rates until the new plants came on line and began generating revenue. The theory was that once the new plants came on line, rates would significantly drop throughout the region and everyone would benefit (Pope, 2008).

The legality of net billing was never really tested. Its legal justification rested on advisory opinions from the DOI solicitor's office and the GAO office of counsel and a letter from the chair of the congressional subcommittee overseeing BPA. It never received formal legislative approval or subjected to public scrutiny (Pope, 2008).

The risks were substantial, if not fully understood at the time. The utilities priced power from net-billed projects well below its marginal cost of production,

\footnotetext{
${ }^{110}$ See Pope (2008) for a detailed explanation of the net billing mechanics.
} 
encouraging consumption. The arrangement ignored or dismissed any elasticity of demand for electricity. It also ignored the risk that if a net-billed nuclear plant failed, then BPA would still have to distribute the costs of the failed plant to ratepayers without any revenue in return. In effect, BPA assumed the risk of construction nonperformance on behalf of the utilities nuclear program (Blumm, 1982; Pope, 2008). Net billing ended in 1973 when it became apparent that delays to the nuclear plant construction schedule and increases in cost would render the process under the current rate structure insolvent by 1981. If this were to occur, the result would be a dramatic increase in regional rates - the exact circumstance that net billing was created to avoid (Pope, 2008).

Ever-increasing estimates of demand led WPPSS to determine that two additional plants (projects 4 and 5) were needed. However, Bonneville would not provide the same financial guarantees for these plants they had for projects 1,2 , and 3 . Instead, BPA encouraged WPPSS to issue bonds to cover construction costs of the two newly proposed projects, threatening that the agency would be forced to issue a "notice of insufficiency" if they did not do so. An NOS is a statement whereby Bonneville declares an inability to meet demand from its public preference customers, ${ }^{111}$ thus requiring rationing of federal hydropower and forcing public utilities to purchase the difference on the open market (Pope, 2008).

The utilities were slow to react, and BPA issued its NOS in June of 1976. Later that year, 88 public utilities signed a participants' agreement that resulted in

${ }^{111}$ The Bonneville Act of 1937 requires BPA to give preference to public utilities in its sale of power and sell that power at cost. 
issuance of $\$ 2.25$ billion in bonds to fund projects 4 and 5. Eventually, the entire financial structure collapsed. The utilities defaulted on the bonds, costs soared, schedules expanded, and the actual market demand for power fell far short of predictions (Pope, 2008).

Pope (2008) diagnosed the causes of the financial fiasco as self-delusion, misdiagnosis, mismanagement, and over-optimism over demand forecasting. Additionally, he described BPA as an agency not historically oriented to open collaboration. However, Pope's assessment regarding BPA's collaborative history is at odds with BPA's history with the Bonneville Advisory Board and other collaborative forums initiated to inform agency decision making. McKinley (1952) probably offers a more accurate albeit inadvertent assessment when he defended BPA's decision to keep those not in agreement with BPA's basic mission from participation in the Bonneville Regional Advisory Council, designed to serve as a sounding board for BPA policy. Regardless, Pope (2008) accurately claimed that BPA and WPPSS throughout the process tended to dismiss concerns expressed by ratepayers and environmentalists.

At the time, the WPPSS bond default was the largest in United States history. The default, BPA's 1976 NOS, the worldwide oil shortage brought about by an embargo by countries in the Middle East, and economic stagflation set the stage for a new national energy policy (Blumm, 1982; Pope, 2008) This opened the door for those heretofore excluded from direct participation in governance decision making to claim a seat at the governance table. Among those were regional fishery interests. 
The continued decline in salmon runs.

The commercial salmon fishery continued to suffer from the legacy effects of over-fishing and habitat degradation due to mining, timber harvest, and agriculture. To these were added new threats from development as the region's population expanded and with the completion of the federal hydropower system dams (National Research Council, 1996). As predicted during the hearings of the 1940s and by Interior's Pacific Northwest Coordination Committee, salmon returns continued to decreased as new dams were completed. As measured by fish harvest, the average annual salmon fishery yield dropped from 24 million pounds in the 1940s to 11 million pounds in the 1950s. By the early 1980s, the average yield dropped to 1.2 million per year (National Research Council, 2004). Not reflected in these numbers is the impact on naturally spawning fish. Since the late 1800 s, an ever-increasing share of the commercial fishery came from hatcheries. However, regional hatcheries were failing to live up to their earlier promises of being able to sustain virtually unlimited levels of harvest despite other economic development (Taylor, 1999; Lichatowich, 1999).

The decline in numbers of fish underscored a long simmering conflict among sports, commercial and tribal fishery institutions. Recreational fishing was largely a pastime for middle and upper income Americans. They looked to nature as a source of solace and renewal and reveled in the personal scale of catching fish one at a time. In contrast, commercial fishermen were part of a large-scale industrial effort to collect food. The work was manual and often dangerous. Tribal fishing represented more 
than food collection; it was a fundamental social and religious component of tribal life. As fish numbers dwindled, each institution looked at the other as competition to their respective interests. Conflict was common over allocations of catch among the groups and each often criticized the fish-catching technologies of the others as wasteful and unfair (Taylor, 1999).

The newly developed river of the 1930s held additional consequences for the region's iconic salmon runs. Although private, state, and federal entities constructed dams in Columbia tributaries since the late 1800s, none would have the impact on fish of the mainstem dams. The dams modified the ecological organization of the Columbia at the expense of naturally spawned fish. Fishery interests argued to moderate the damage, but "their combined numbers and strongest arguments paled before the bureaucratic might, popular appeal, and Progressive ideology" (Taylor, 1999, p. 226) that drove the dam construction projects of the Bureau of Reclamation and Corps of Engineers. The cold fact was that most regional institutional leaders perceived the salmon fishery as less valuable than the combined potential benefits of hydropower, navigation, irrigation, and flood control (White, 1995; Taylor, 1999).

Fishery interests proved unable to mount any effective opposition to early river development. Nor, for the most part, were they sufficiently motivated or organized to do so. Some tried. For example, Miller Freeman continually criticized the impacts of dams and the reliance on hatcheries in the Pacific Fisherman, a publication he founded in 1902 and remained associated with it until his death in 1955 (Cone and Ridlington, 1996). But a 1937 report on the salmon impacts of Bonneville Dam prepared by the 
U.S. Commissioner of Fisheries better illustrated the general tone. The report dutifully noted the many problems salmon were experiencing but concluded that further study and technological improvements would in all likelihood resolve those problems (Cone and Ridlington, 1996; Lichatowich, 1999; Lichatowich, McConnaha, Liss, Stanford, and Williams, 2006). ${ }^{112}$

Taylor (1999) suggested two reasons for the early lackluster involvement of fishery managers in governance. First, the legacy of commercial development (timber, mining, settlement, agriculture, and dams) may have been perceived as unstoppable, especially since the role of the federal government, based on past practice, was to facilitate and support such development. Second, and perhaps more importantly, prior to the later enactment of federal environmental statutes, the states had sole jurisdiction over fisheries in state waters and controlled most hatchery production. Therefore, the policy focus of white fishing interests centered more on state, not on federal, activities and decisions.

Additionally fishermen, like everyone else in the region, operated on the widespread belief that hatcheries and other technical measures could and would make up for lost habitat (White, 1995; Lichatowich, 1999; Taylor, 1999; McConnaha, Williams, and Lichatowich, 2006). Consistent with the 1937 Fish Commission report, and in response to the decline in naturally spawning salmon, Congress passed the Mitchell Act in 1938. The act intended to provide for conservation (in the Progressive sense of the term) of the salmon and steelhead fishery resources of the Columbia River

\footnotetext{
${ }^{112}$ See Cone and Ridlington (1996) pp. 100-105 for further discussion.
} 
to serve tribal, recreational, and commercial needs. It authorized the construction of hatcheries, fish ladders, screens for irrigation intakes, restoration and mitigation projects, and studies. Ultimately, the program would come to fund 25 hatcheries and produce over 100 million juvenile fish before Endangered Species Act concerns caused it to be scaled back (Cone and Ridlington, 1996; NMFS, 2009b).

\section{Tribal court victories.}

U.S. federal courts consistently upheld tribal treaty rights since the early 1900s. US v. Winans (1905) and US v. Winters (1908) form the legal foundation for tribal fishing and water rights Winans upheld the tribes' rights to take fish at their usual and accustomed places, even if those places were now privately owned or surrounded by privately non-Indian owned land. Winters recognized tribal water rights as reserved on reservation land (National Research Council, 2004; Wilkinson, 2005). Despite Winans and Winters, northwest state governments routinely ignored treaty provisions and imposed restrictions on tribal resource gathering in general and fishing in particular.

The states asserted that state fish and game laws applied to Indian fishermen whether on or off the reservation, especially during the termination years, despite federal court decisions to the contrary. In the 1960s, tribal fishermen faced dozens of prosecutions in county and state courts in Oregon and Washington. Juries seldom convicted, but state departments of fish and game continued to prosecute on the belief that tribal fishing methods were wasteful and contrary to state conservation laws. 
Commercial and sports fishing organizations often prompted these prosecutions to minimize competition (Wilkinson, 2005).

The dispute moved to federal court in 1968 when the U.S. Department of Justice filed a lawsuit on behalf of David Sohappy, a Yakama tribal member, in the Federal Court of the District of Oregon. Washington arrested and jailed Sohappy for three days for violation of state fishing law. Sohappy believed the treaties protected him from state prosecution. The Yakama, Umatilla, Warm Springs, and Nez Perce tribes joined as interveners. ${ }^{113}$ The court consolidated several similar cases, rendering the states of Oregon and Washington as joint defendants. Ruling in 1969, Belloni held tribal treaty provisions as valid; that state regulations did not apply to treaty tribes; and that the tribes had a legal right to a share of the fishery. In this, he broke new ground. He did not specify what that share might be, expecting the states to negotiate an allocation with the tribal governments. The decision caused an immediate and angry response from sports and commercial fishing interests concerned that dedicating a percentage of harvest to the tribes would potentially put many of them out of business (Wilkinson, 2005).

A suit filed in 1970 on behalf of seven tribes in the District Court of Washington followed the Belloni decision. Ruling in 1974, Judge Boldt took Belloni's decision a step further by finding that the tribes were entitled to a 50-50 share of fish that moved through recognized tribal fishing grounds in the state of

\footnotetext{
113 Initially, the Yakama tribal government refused to support Sohappy as he tended to be equally dismissive of tribal fishing regulations. See Wilkinson (2005), pp. 164-166.
} 
Washington. Like the US v. Oregon decision, the Boldt ruling set off an angry and prolonged reaction among non-Indian fishermen. Many openly defied Boldt, fishing on tribal land and refusing to recognize the court's decision. The Washington Supreme Court further complicated matters by ruling that the state fish and game agencies could not legally enforce the provisions of Judge Boldt's decision. The U.S. Supreme Court finally settled the matter in 1979, ruling to uphold Boldt. The court's key findings were that the tribes were entitled to fish in their usual and accustomed places; that the states had the right to set harvest limits within state waters in the interests of conservation and sustainability; that all fish caught by Indians counted against the tribal share; that all fish caught by non-Indians counted against the nonIndian share; and that Indians had exclusive use of fishing sites on their reservations (National Research Council, 2004: Wilkinson, 2005).

The Belloni and Boldt decisions engendered increasing confidence on the part of tribes to assert their rights in federal court, especially in the wake of federal termination efforts. The decisions also created a new governance system made up of representatives from the state, tribal, and federal governments, under continued court supervision, to manage the fishery (Wilkinson, 2005; personal knowledge and experience of author). ${ }^{114}$ Success in court motivated the tribes to a new assertiveness in reminding federal agency members of federal trust and treaty responsibilities and looking for opportunities to more proactively engage in the regional decisions that

\footnotetext{
${ }^{114}$ This system, known as the U.S. v. Oregon Process, is oriented solely on setting and overseeing fishery allocations and related hatchery issues. Consequently, it is outside the scope of this study. 
could affect them. They improved their capacity for interacting with federal agencies by establishing intertribal coalitions to promote their collective interests.

\section{Establishment of multi-tribal governance coalitions.}

For generations, the tribes had relied on traditional social arrangements and tribal authority to manage tribal fisheries (Johansen, 1967; Taylor, 1999; CRITFC, 2010). One such authority was the "Celilo Fish Committee." This committee regulated fishing practices to ensure that the salmon resource would flourish and always exist (CRITFC, 2010). These traditional practices proved successful in sustainably managing tribal harvest (Taylor, 1999; CRITFC, 2010).

Traditional management could not work, however, in the face of removal to the reservations and the construction of dams and other obstacles to salmon migration. In 1977, the tribes of the Warm Springs, Yakama, and Umatilla reservations and the Nez Perce tribe, all holding treaties with the United States, joined together to renew their authority in fisheries management. The tribes established a coordinating and technical organization to support their joint and individual exercise of sovereign authority. Entitled the Columbia River Inter-Tribal Fish Commission (CRITFC), this organization served as an intertribal representation body for purpose of regional planning, policy, and decision-making (CRITFC, 2010) and greatly increased the visibility and influence of lower Columbia tribal perspectives within the Basin (personal experience and observation of the author).

Concerned and inspired by the influence that CRITFC was beginning to 
exert on fishery policy issues, particularly over water releases from reservoirs serving upper river fisheries (personal knowledge of author), the upper Columbia River tribes soon mimicked the strategy of the lower river tribes by forming their own coalition to protect their interests. The Coeur d'Alene Tribe, Kalispel Tribe of Indians, Kootenai Tribe of Idaho and the Spokane Tribe of Indians joined to establish the Upper Columbia United Tribes (UCUT) in 1982. The Confederated Tribes of the Colville Reservation joined in the mid 1990s (UCUT, undated). ${ }^{115}$

Commercial and sport fishery, environmental groups, and the tribes each had their own goals and objectives and operated within their own worldview. This led to conflicts among them. For example, recreational, commercial, and tribal fishermen had long disputed each other's fishing methods and the allocation of catch among them (Taylor, 1999). The tribes and environmentalists were at odds over hatchery policy, specifically the marking of hatchery fish for selective fishing, a dispute that continues as of this writing (personal knowledge of author) and different factions within the environmental movement differed over priorities and policy approaches (Rosenbaum, 2005). Upriver and downriver tribes often split over legal standing, water issues, and fish catch allocations. Those tribes with treaties with the United States argued that the federal government should accord their concerns greater deference than the concerns of non-treaty tribes. But what united this disparate group was their common opposition to the impact of major dams on the river's fish

\footnotetext{
115 Tribes living in the Snake River Basin (Shoshone Paiute, Burns Paiute, and Shoshone Bannock) formed a similar coalition through compact in 2006 creating the Upper Snake River Tribes (USRT). Since that event occurred outside the period covered by this history, it will not be further discussed.
} 
runs (McKinley, 1952; Taylor, 1999; Robbins, 2004; Crampton and Espenson, 2009). The hydro-thermal crisis and Congressional efforts to forge a new Northwest energy policy provided the opportunity for tribal and environmental group concerns over dam impacts addressed in a new governance system.

The 1980 Power Act.

BPA's exemption to the public review procedures of the Administrative Procedures Act (APA) insulated the agency from critical public examination of its policy and program development. Its method of operation, in concert with public and private utilities, was to develop a unified front over a particular course of action and present an essentially completed product for pro forma comment by the public. As such, BPA had no institutional capacity to deal with critical public review of its actions (Hemmingway, 1983; Pope, 2008).

BPA issued its notice of insufficiency in 1976. In 1977, the agency was transferred from the Department of the Interior to the newly created Department of Energy. The agency was now subject to the rule-making procedures of the federal

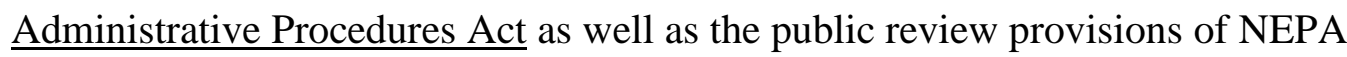
(Hemmingway, 1983; Pope, 2008). A lawsuit filed under NEPA enjoined BPA from pursuing the hydro-thermal construction program until it completed an environmental impact statement (EIS). Hemmingway (1983) argues that BPA's lack of experience in dealing with true public involvement extended the time needed to complete its EIS. 
Meanwhile, private utility rates rose sharply upward. In response, the Oregon state legislature created the Oregon Domestic and Rural Supply Authority in 1977. Always more dependent on private power than the state of Washington, Oregon planned to create a public power entity in order to lay claim, under the 1937 Bonneville Project Act's preference clause, to a share of electricity from the federal hydrosystem. This would create additional demand that the system was not prepared to meet, especially with the supply contracts BPA had signed with local aluminum and other industrial customers for its "excess" power. Oregon's demand for cheap federal hydropower threatened to spark a regional "civil war" over power allocations (Blumm, 1982).

The completion of the dams under the Canadian treaty doubled the Columbia Basin's reservoir storage capacity, providing flood protection to the lower river (especially Portland). It also disrupted the natural flow of the river, depriving downstream fish of much of the natural spring freshet juvenile salmon depended on to flush them to sea. The hydro-thermal program's plan to shift the hydropower system from meeting relatively steady base loads to peak loads would further disrupt the natural flow of water. Fishery interests believed that this would lead to even further declines in fish returns. They argued that fish and wildlife losses caused by hydrosystem operations were in effect subsidizing power production (Blumm, 1982).

Regional power interests first attempted to rewrite the 1937 Bonneville Project Act in the 1950s. Their objective was to get BPA self-financed through 
power sales as opposed to being subject to the unpredictable nature of Congressional appropriation funding. Those efforts failed, but growing concerns over the budding hydro-thermal crisis led to a renewal of effort. The Pacific Northwest Utilities Conference Committee (PNUCC) took the lead in coordinating and drafting a new legislative proposal. After several failures, PNUCC completed an acceptable draft in 1977. Washington Senator Jackson subsequently introduced it as a bill in the House (Blumm, 1982). ${ }^{116}$ Meanwhile, prompted by environmental interests, the National Marine Fisheries Service and U.S. Fish and Wildlife Service initiated a process in 1978 to review the biological status of upper Columbia salmon and steelhead and determine whether the fish warranted listing under the Endangered Species Act (Bodi, 1979).

Fishery interests found a champion for their cause in Congressman John Dingell of Michigan. Dingell chaired the House Commerce Committee. Upon receiving the Jackson bill, Dingell's committee staff, working with an ad hoc committee ${ }^{117}$ of utility, industry, fishery, and tribal representatives, wrote into it extensive fish protection and public involvement measures. Responding to tribal and fishery manager concerns, Dingell's provisions would require public input with

\footnotetext{
${ }^{116}$ Jackson, who was first elected to Congress in 1940 and had introduced a CVA bill upon Truman's election in 1948, left the House upon election to the Senate in 1952.

${ }^{117}$ The ad hoc Pacific Northwest Power and Fisheries Committee was formed from the regional confluence of power and fishery interests. The committee was a compromise worked out between the Columbia River Fisheries Council, representing state and tribal federal fishery managers, and the Public Power Council. The Public Power Council represented utility concerns that fish mitigation language being considered in the new legislation could present an "open checkbook" from regional ratepayers. See Crampton and Espenson, 2009, pp. 29-30.
} 
respect to regional energy planning and fish and wildlife mitigation efforts.

Although opposed by power interests, Dingell's seniority and strong position in the House ensured that a new bill would not pass without addressing the impacts of the dams on regional salmon and other wildlife (Hemmingway, 1983; Bodi, 1995).

President Jimmy Carter signed the resulting Power Act into law on December 5, 1980. Among its purposes was to provide for conservation and energy efficiency and "provide for participation and consultation of the Pacific Northwest states, local governments, consumers, customers, users of the Columbia River System." These users specifically included federal and state fish and wildlife agencies, Indian tribes, and the public at large (Power Act, 1980, section 2.(3)).

Several converging interests brought the Power Act about. NMFS and the Fish and Wildlife Service were considering ESA protection for Basin salmon, an action that would place the fish stocks so listed under the primary jurisdiction of federal regulatory agencies (Bodi, 1979; Blumm and Simrin, 1991), a situation the region very much wished to avoid. Bonneville customers sought a legislative solution to allow better access to agency decision-making. Oregon's threat to create an unsupportable demand on the federal hydrosystem aligned with the corresponding interest of BPA and utilities to allow BPA to buy power on the open market to meet load. In addition, tribal and fishery interests sought a way to address the impacts of the dams on regional fisheries. The Power Act passed because it benefited all affected parties. It minimized rate disparities by giving private utilities access to 
federal power. Although overall rates increased, the Power Act gave industrial users long-term contracts to protect them from future rate fluctuations. Bonneville received its long sought market purchase authority. Fish and wildlife advocates gained access to decision-making and the guarantee that federal hydrosystem revenues internalized into regional electrical rates would pay the cost of mitigation efforts. In addition, the region was given a new governance system designed to ensure the Power Act's purposes and provisions were met (Blumm, 1982).

Confidence in the Act was so high that NMFS terminated its ESA review process (Blumm and Simrin, 1991; Wright, 1995; Bodi, 1995).

\section{$\underline{\text { Resulting Governance Systems }}$}

Based on a recommendation by the Water Resources Council, and in accordance with the provisions of the Water Resources Planning Act, President Reagan disbanded the Pacific Northwest River Basins Commission along with five similar commissions by executive order on September 9, 1981 (Executive Order 12319, 1981). The Committee on Fish Operations appears to have become inactive at about the same time, perhaps in response to the passage of the Power Act. ${ }^{118}$ With the loss of the PNWRBC, responsibility for Basin governance transferred to the Pacific

\footnotetext{
${ }^{118}$ The sole reference found regarding COFO does not explain why the group ceased to function.
} 
Northwest Electric Power Planning and Conservation Council upon its establishment in 1981. No other systems were proposed or enacted at this time. ${ }^{119}$

\section{$\underline{\text { Pacific Northwest Electric Power Planning and Conservation Council }}$}

The Power Act defined the Council as to be comprised of two members each from Oregon, Washington, Montana, and Idaho appointed by their respective governor. The Council was authorized an executive director and staff. The Power Act assigned the Council two broad responsibilities. The first was to develop a regional energy plan to guide electrical planning. The second was to establish a program to "protect, mitigate, and enhance" fish and wildlife impacted by the hydrosystem (Power Act, 1980, section 4.(h)(1)(A)). Experts hired to the Council's staff would develop the energy plan. The Fish and Wildlife program, in contrast, was to solicit the active involvement of the public and regional interests (Power Act, 1980).

The Power Act required that proceeds of the sale of federal electricity by BPA pay Council expenses. Decisions were to be made by majority vote "of members present and voting" (Power Act, 1980, section 4.(c)(2)) with a majority of members constituting a quorum. This potentially precluded the inability of the previous CBIAC and PNWRBC to reach decisions due to their dependence on full consensus. There were exceptions to this general majority vote rule, however. The regional energy plan and amendments to the fish and wildlife program required a majority plus a vote from

\footnotetext{
${ }^{119}$ As far as the author can determine, the timing of President Reagan's executive order and enactment of the Power Act were purely coincidental. Had the Power Act not been enacted, or it had been delayed for any period of time, the region may have been without any form of interjurisdictional governance structure in the Basin for the first time since 1934. However, the history of the region suggests that some form of federal cooperation system would likely have formed, similar to the manner in which the CBIAC formed following the disbanding of the Pacific Northwest Regional Planning Commission.
} 
at least one member of each state or agreement by at least six members of the eight members (Power Act, 1980).

The Act did not change the missions or authorities of federal agencies, states, or local governments (Hemmingway, 1983). It did, however, require federal agencies to exercise their responsibilities "consistent with the purposes of this Act and other applicable laws" with regard to fish and wildlife impacts (Power Act, 1980, section 4.(h)(11)(A)(i)). It further required federal agencies to "take into account...to the fullest extent practicable" (Power Act, 1980, section 4.(h)(11)(A)(ii)) the Council's program when exercising discretionary decision-making. ${ }^{120}$ Due to the multi-state nature of the Council's area of jurisdiction, lawsuits against the Bonneville Power Administration were to bypass federal district courts and be filed directly with the federal $9^{\text {th }}$ Circuit Court of Appeals (Power Act, 1980, section 9.(e)(5)).

The Council has had its critics. Utility rate payers and BPA staff complained that, rather than produce a coherent strategy for fish mitigation, the Council more frequently "buys off" regional interests by paying for poorly thought out actions and

\footnotetext{
${ }^{120}$ Council members frequently complained that federal agencies, especially the Corps and Reclamation, did not take this provision seriously and essentially ignored the Council's fish and wildlife program provisions in making agency decisions. The Council recommended repeatedly that the language of the Power Act be strengthened. See, for example, NPPC, 1996, p. 5, and option 3 in the attachment to Batt, Racicot, Kitzhaber, and Locke, 1998. For their part, the agencies argued that the language in Power Act section 10. (h) specifically stated that the provisions of the Power Act were not to "affect the rights or jurisdictions of the United States" or other entities over waters of any river or stream. They further argued that, regardless, the sovereignty clause of the Constitution precluded the states from dictating actions to federal agencies. The issue was settled in court by Federal Magistrate Leif Erickson in 1999. Erickson, in a case involving water releases from dams in Montana designed to help downriver fish, ruled that the Power Act's requirements for agencies to take fish and wildlife provisions into account at each relevant stage of decision making did not contravene federal law. In effect, Erickson ruled that the Power Act required that Corps and Reclamation operational decisions should comport to the Council program unless there were reasons not to and that, if such reasons existed, they be documented and justified. See NPPC, 1999.
} 
exercising little or no oversight of project quality (personal experience of author). Ogden (1997) notes that the Power Act's singular focus on the water resources for fish and wildlife does not allow for integration of those issues with other regional resource planning needs such as land use, irrigation, fishery harvest, and recreation. Furthermore, its scope of authority is limited to the geographic boundaries of the Columbia River basin. Hemmingway (1983) notes the limited authority over the actions of federal agencies. The Army Corps of Engineers, The Bureau of Reclamation, the Federal Energy Regulatory Commission, and BPA, while required to consider Council plans, are not necessarily required to follow them. Despite these shortcomings, no alternative governance proposals were forthcoming until the ESA listings of 1991.

\section{Chapter Summary}

Events leading up to the region's hydro-thermal crisis, the resulting passage of the 1980 Power Act, and establishment of the Pacific Northwest Electric Power and Conservation Planning Council can be summarized as follows:

- Nationally, the tribal sovereignty movement gave new confidence to Indian tribes in asserting their rights in the policy arena and in court. It resulted in a renewed tribal interest in traditional Indian culture and beliefs and expansion of tribal governance capacity (Pevar, 2002; Wilkinson, 2005).

- The American environmental movement transitioned from its roots in Progressive era conservationism to an ecological based worldview toward 
natural resources. The movement resulted in multiple environmental statutes and regulations promulgated in the late 1960s and early 1970s. It brought the impacts of unrestrained resource development and pollution into the public consciousness and institutionalized itself as a core national value (Hays, 1999/1959; Dunlap and Mertig, 1992a; Dunlap, 1992;

Rosenbaum, 2005).

- BPA and utility estimates concluded that the federal hydropower system alone could not meet projected regional demand growth. The hydrothermal program was developed and designed to integrate the regional hydropower system with new coal and nuclear generation plants (Hemmingway, 1983; Luce, 1996; Pope, 2008).

- Faulty predictions, mismanagement, program cost overruns, delays due to environmental lawsuits, and the fact that the anticipated electrical demand did not materialize in the time predicted caused Bonneville to at first threaten and then issue a notice of insufficiency on June 24, 1976. The NOS declared an inability to meet the demand of its preference customers and perhaps its Treasury payments. The region needed a new energy policy to address the causes of this problem (Hemmingway, 1983; Luce, 1996; Pope, 2008).

- The resulting financial crisis provided the catalyst for long-excluded fishery interests to gain access to regional decision-making (Blumm, 1982; Hemmingway, 1983; Pope, 2008). 
- Regional salmon runs, already stressed by overfishing, the legacy effects of mining, timber harvest, and agricultural practices continued their decline due to the construction and operation of additional mainstem dams in the in the 1950s, 1960s, and 1970s. Fishery and tribal advocates protested the river's development but to no avail (McKinley, 1952; Taylor, 1999; Robbins, 2004; Lichatowich, McConnaha, Liss, Stanford, and Williams, 2006).

- The need for a new Northwest energy policy to deal with the hydro-thermal crisis, coupled with pressure from fishery and tribal interests, resulted in passage of the 1980 Power Act and creation of the Pacific Northwest Electric Power Planning and Conservation Council. The Council, comprised of appointees from the four states governors, was responsible for development of an energy plan and fish and wildlife mitigation program (Power Act, 1980, Blumm, 1982, Hemmingway, 1983).

- NMFS first considered listing Columbia and Snake River salmon and steelhead in the late 1970s. They terminated this effort in the belief that the fish and wildlife provisions of the Power Act would lead to fish restoration (Bodi, 1979 and 1995; Blumm and Simrin, 1991).

The Power Act represented a turning point in Basin governance and planning. For the first time, tribes and fishery interests were in a position to influence the actions of federal system managers (Harden, 1996). It was also the first time that the impacts to fish and wildlife by the dams were to be given equal footing with hydropower with 
substantial revenues generated by electricity sales directed to fund mitigation efforts (Hemmingway, 1983; Volkman, 1997). In addition, the Act precluded, at least temporarily, ESA listing of Basin salmon in the belief that the Power Act's provisions would result in meaningful recovery plans (Blumm and Simrin, 1991; Bodi, 1995).

The Council developed its first fish and wildlife program in 1982. Initially, fish runs rebounded although that was more likely due to a period of favorable ocean conditions than any results from the embryonic restoration efforts. Mid Columbia stocks improved from about 12,000 fish in 1980 to over 100,000 a few years later, and Snake River spring fall chinook jumped from 9-10,000 to about 50,000 over the same period $^{121}$ (Wright, 1995). The period 1982-1991 was one of great hope for fish interests. The state-centric Council's program led many to believe that the region had finally found an effective counterweight to the influence of the electrical power and commercial river user communities on federal agency decision-making (Bodi, 1995).

Despite the Council's program, fish returns crashed in the late 1980s. Wild Snake River spring and fall chinook fell to less than 10,000 by 1990 and Snake River fall chinook numbered just 78 wild fish in 1990 and 318 in 1991 (Crampton and Espenson, 2009). NMFS subsequently reopened its status review process under the ESA in 1990 and listed Snake River Sockeye in 1991, the very action regional interests had hoped the Power Act would preclude. Listings of Snake River

\footnotetext{
${ }^{121}$ In a conversation with the author regarding the early period of the Council and the early apparent improvement in fish returns, Angus Duncan, Oregon Council representative from November 1994 October 1995, quipped, "It looked like this [fish and wildlife restoration] was going to be a lot easier than we thought." Angus' father, Robert, was among the Council's first appointees (NPPC, 2007).
} 
spring/summer and fall chinook followed in 1992. These actions by NMFS prompted an "elaborate series of discussions" seeking revised strategies for averting ESA listings (Blumm and Simrin, 1991, quote from p. 660) the most notable of which was Senator Mark Hatfield's "Salmon Summit" of state, federal, and tribal fish managers in 1990 (Cone and Ridlington, 1996).

These ESA listings would present the region with it fourth critical situation and once again shift the prevailing governance model. The governance dominance of the states enjoyed through the Council would shift back to a federal cooperative model led by the National Marine Fisheries Service. The ESA listing and resulting governance changes are the subjects of the next chapter. 


\section{CHAPTER 7 \\ THE FIRST ESA SALMON LISTINGS (1991)}

\section{$\underline{\text { Introduction }}$}

The National Marine Fisheries Service (NMFS) halted their review of Columbia Basin salmon stocks in the belief that the Council's Fish and Wildlife Program would render listing under the Endangered Species Act (ESA) unnecessary (Bodi, 1979 and 1995; Blumm and Simrin, 1991). However, Basin salmon and steelhead numbers continued their decline and confidence in the Council's program waned. In 1990, the Shoshone-Bannock Tribes of the Fort Hall Reservation petitioned NMFS to list Snake River sockeye salmon. NMFS subsequently listed Sockeye as endangered in November 1991. ${ }^{122}$ Additional listings of Snake River chinook salmon and steelhead soon followed. The ESA listings starkly highlighted the need for an even greater governance emphasis on fish. They reopened the debate over regional governance systems, resulting in the greatest variety of alternative governance proposals since the debates of the 1930s and 40s as federal agencies and the Council tussled over which would lead salmon restoration efforts. The federal nature of the ESA all but preordained a federally coordinated effort. As a result, the locus of Basin governance-decision making shifted away from the state led Northwest Power and Conservation Council and back to regional federal agencies - most notably the National Marine Fisheries Service.

\footnotetext{
${ }^{122}$ Under the Endangered Species Act, an "endangered" species is one that is at risk of extinction throughout all or a significant portion of its range. A "threatened" species is one that is likely to become endangered in the foreseeable future. See ESA sections 3(6) and 3(20).
} 
The listings highlighted another important shift as well. Beginning with 1930s era planning efforts, the focus for FCRPS construction and operation was on harnessing commercial benefit from the Columbia River (White, 1995; Harden, 1996). As fish issues evolved from the first protests in the 1940s up through the ESA listings in the 1990s, the priority for dam operations gradually shifted from a sole focus on commercial benefit to an ever-increasing emphasis on mitigation for environmental impacts. The Basin's governance systems slowly began to respond, beginning with the CBIAC (Scheufele, c.1970). Whereas the Bonneville Power Administration had led the federal agency collaboration during the years of the FCRPS' initial development, the ESA listings caused the federal leadership role to shift from BPA to the National Marine Fisheries Service. Additionally, an ever increasing share of revenue generated by hydropower sales would eventually fund fish mitigation measures such as hatcheries, habitat restoration, predation reduction, and improved juvenile and adult fish passage facilities and programs at the dams costing hundreds of millions of dollars per year (Vogel, 2007; FCRPS, 2010). Not surprisingly, the Basin's governance debate became ever more focused on fish related issues as well.

The election of William Clinton as president in 1992 and his subsequent reelection in 1996 shaped the national political context. Clinton ran in part on a platform friendly to environmental goals in stark contrast to the policies of the Reagan and George H.W. Bush administrations that preceded it (Rosenbaum, 2005). Although the Clinton administration maintained an active interest in the Northwest salmon issue and established an interdepartmental-level oversight team led by the 
Chair of the Council on Environmental Quality (CEQ), it delegated much of the leadership on the issue to its appointee to the regional NMFS office.

The biggest regional issue was the ESA salmon listings. NMFS followed those listings with biological opinions regarding FCRPS operations. The biological opinions in turn initiated what became a long-running sequence of litigation.

Additional regional issues were the structural weaknesses of the Council as exposed by the salmon crisis, the Council's efforts to retain control of the salmon issue, and Oregon Governor Kitzhaber's call for a new regional governance process.

Nine governance systems were proposed during the period between the first salmon listings in 1991 and the establishment of the Columbia River Basin Forum in 1999. The Council proposed most of them, recommending ways to amend the Council and/or the 1980 Power Act in order to strengthen Council authority over the salmon issue. Of these nine proposals, three were enacted. The proposed and enacted systems were the:

- Fish Operations Executive Committee. Formed as provision of the Council's 1992 Fish and Wildlife Program. Brought fishery managers (to include the Fish and Wildlife Service and National Marine Fisheries Service) into a Council committee to advise on salmon issues. Apparently assumed the membership and functions of COFO. Merged into the Regional Forum in 1995.

- Regional Implementation Forum (Regional Forum). Created as provision of NMFS' 1995 biological opinion on FCRPS operations. Included 
executives and staffs from the states, Basin Indian tribes, and federal agencies. Absorbed the members and functions of the Fish Operations Executive Committee. Introduced a new governance model in which the Basin's sovereign entities would engage as partners, albeit within the context of the federal Endangered Species Act.

- Columbia River Administration. Essentially, a revised Columbia River Valley Authority that would consolidate federal resource management agencies into one department. Recommended in 1997 by Dan Ogden. Not enacted.

- Three Sovereigns Process. Proposed by Governor John Kitzhaber in 1997. Developed further by the Council in 1998. It was included among five options presented to the region in a memo signed by the governors of Oregon, Washington, Idaho, and Montana. Called for a full partnership of Basin federal, state, and tribal sovereigns to address a wide array of Basin issues. Not enacted.

- Expansion of Northwest Power and Conservation Council. Option to expand the Council membership to include tribes. Proposed by the Council in 1998 as an alternative to the Three Sovereigns and included as one of five options in a memo signed by the four governors to the region. Not enacted. 
- Regional Resources Council. Proposed by the Council in 1998 as an alternative to the Three Sovereigns and included as one of five options in a memo signed by the four governors to the region. Not enacted.

- Northwest Rivers Commission. Proposed by the Council in 1998 as an alternative to the Three Sovereigns and included as one of five options in a memo signed by the four governors to the region. Like the Council, this commission would consist of two members appointed from each state plus tribal representatives. Would be legislatively empowered with jurisdiction over regional Endangered Species Act issues. Not enacted.

- Comprehensive River Agency. Proposed by the Council in 1998 as an alternative to the Three Sovereigns and included as one of five options in a memo signed by the four governors to the region. A river basin commission modeled after the Delaware River Basin Commission. Not enacted.

- Columbia Basin River Forum. Established in 1999 as an outgrowth of the debate over the five proposals identified in the governors' memo. Collapsed in 2000.

The remainder of this chapter discusses the national context outlined above and the key issues and events in the Northwest that influenced the debates over the various governance forms. It then describes the nature and structure of each of the proposed or enacted governance systems. 


\section{$\underline{\text { Social and Political Context }}$}

The Clinton administration's approach to the salmon crisis and the goals of the ESA set the context for this period immediately following the salmon listings. In passing the ESA, Congress found and declared that "various species of fish, wildlife, and plants in the United States have been rendered extinct as a consequence of economic growth and development untempered by adequate concern and conservation" and that "these species of fish, wildlife, and plants are of esthetic, ecological, educational, historic, recreational, and scientific value to the Nation and its people." The purposes of the ESA are thus to "provide a means whereby the ecosystems upon which endangered species and threatened species depend may be conserved, to provide a program for the conservation of such endangered species and threatened species" and to meet the provisions of international conservation-related treaties and agreements (Endangered Species Act, 1973, section 2). The ESA carried strong, legally enforceable mandates to ensure federal actions would not cause further harm to species already on the brink of extinction.

Bill Clinton campaigned in part on an environmental platform, aggressively promoted by vice presidential nominee $\mathrm{Al}$ Gore. Election of the Clinton-Gore administration in 1992 raised the hopes of the nation's environmental community for a reversal of the anti-environmental agenda of the Reagan administration and the lackluster environmental record of the George H.W. Bush administration. However, the Clinton administration never quite lived up to environmentalist expectations. Faced by Republican majorities in Congress and Clinton's personal attention being 
drawn to other issues, the hoped for renaissance of new environmental policies and legislation never materialized (Rosenbaum, 2005).

Environmental groups did enjoy far greater access to the Clinton administration than they had their predecessors (Rosenbaum, 2005). Once litigation commenced over the Northwest ESA salmon listings, environmental groups initiated a coordinated campaign to nationalize the issue seeking to exercise influence over the government's position in court and regional agency decision-making. The intent was to generate political pressure on Congress and the administration to achieve salmon policy objectives through the Endangered Species Act and legislative action. The most dramatic of these objectives was partial removal of four federal dams on the lower Snake River in order to restore that portion of the river to a more natural condition. $^{123}$

The administration assigned responsibility for coordinating federal salmon policy to the president's Council on Environmental Policy. The CEQ was established under NEPA. Among its assigned responsibilities were to develop and promote policies to improve environmental quality. CEQ's influence on presidential policy enjoyed its zenith under the Carter administration and then suffered a dramatic decline in influence during the Reagan and Bush administrations. Rosenbaum (2005) argues that the election of the Clinton administration did not greatly increase CEQ's influence on policy, despite the hopes of the environmental community. Rosenbaum writes, "[t]he CEQ remains, but it has long ceased to be a major player in White House

\footnotetext{
${ }^{123}$ These dams were Little Goose, Monumental, Lower Granite, and Ice Harbor, all operated by the Corps of Engineers.
} 
Politics" (2005, p. 89). Whereas Rosenbaum's argument may be true from a broad national perspective, the CEQ came to play an influential role in the Northwest salmon issue.

$\underline{\text { Salient Issues in the Pacific Northwest }}$

On April 2, 1990, the Shoshone-Bannock tribe petitioned for the listing of Snake River sockeye salmon under the Endangered Species Act. Environmental groups soon followed suit, filing petitions for listing of Snake River spring-summer and fall runs of chinook salmon and lower Columbia River coho salmon (National Research Council, 1996). Responding to the Shoshone-Bannock petition, NMFS listed Snake River sockeye salmon as endangered on November 20, 1991. More listings followed, with NMFS listing Snake River fall and spring-summer chinook as threatened on May 22, 1992 (Crampton and Espenson, 2009).

The listings resulted in the National Marine Fisheries Service assuming a dominant role in federal salmon efforts, eventually eclipsing the state-led NPPC effort with each additional listing (Crampton and Espenson, 2009). The ESA listings also provided greater advantage for the environmental community and tribes through the Act's enabling of "citizen suits" by third parties who believed that provisions of the ESA were being violated or not carried out. ${ }^{124}$

The listings thus created conditions that resulted in a series of proposals for new governance systems. Several regional events and circumstances influenced the

\footnotetext{
${ }^{124}$ See Endangered Species Act, 1973, section 11 (g).
} 
debate over the choice of a new governance system. The biological opinions by NMFS regarding the effect of FCRPS operations on listed fish and the lawsuits that followed the salmon listings were most prominent. Additional issues included the manner in which the Clinton administration chose to address the salmon issue and efforts by the Council to address its weaknesses and retain control over the salmon problem. Each of these issues is discussed in turn.

The ESA biological opinions and lawsuits.

NMFS listed fourteen additional species of salmon in the Pacific Northwest and along the California Coast following the 1991 Snake River sockeye listing (NMFS, 2009a). The listings were a major disappointment to regional state and federal fishery managers. Up until that point, it was believed that the NPPC fish and wildlife program would preclude such an outcome (Blumm and Simrin, 1991; Bodi, 1995; Wright, 1995).

In a biological opinion issued in 1992, NMFS determined that the operation of the FCRPS would not jeopardize the survival and recovery of the listed salmon. In May 1992, a coalition of environmental, tribes, and fishing groups led by the Sierra Club Legal Defense Fund, sent a 60-day notice of intent to sue under the ESA to federal dam operating agencies (Buchal, 1998). Plaintiffs filed their lawsuit federal District Court on August 4, 1992. Plaintiffs contended that the primary cause of the decline of listed salmon was the construction and operation of the region's dams. The suit ignited a "legal free-for-all" (Crampton and Espenson, 2009, p. 9) with suits, claims, and cross-claims filed by power users, irrigation interests, navigation interests, 
tribes, sports fishers, commercial fishers, and environmental groups joining the case as plaintiffs, plaintiff-interveners, or defendant-interveners. Litigation proceeded through several phases and a series of biological opinions (Crampton and Espenson, 2009). NMFS followed its 1992 biological opinion with another in 1993: the court found both deficient remanded them back to NMFS. NMFS voluntarily withdrew its third opinion in 1994 in order to reinitiate consultation and revise it. NMFS issued its revised opinion in 1995, which the district and appeals courts upheld (Crampton and Espenson, 2009).

Litigation continues as of this writing. It is not the intent to capture the full history of the litigation here. What is of interest here is the juxtaposition of interests and worldviews and the seemingly incongruous coalitions that formed within the litigation crossfire.

The listings unleashed what Taylor (1999) labels the region's “centrifugal forces," forces that had been building for decades. It is to these forces that Oregon Governor Kitzhaber referred when noting the balkanization of the Northwest over the salmon issue in his call for a new governance system (O'Bryant, September 24, 1999).

This study groups those forces under three general categories. These were salmon harvesters; the power, irrigation, and navigation interests that commercially benefited from the presence of the dams; and environmental interests.

The region's commercial and sports fishery advocates represented salmon harvest as an important region's history and culture and a rapidly disappearing foundation of the economy, although they often clashed over harvest allocations 
(Taylor, 1999). Lower river Indian tribes, while sharing a commercial interest in harvest, were more concerned with the depleted fish runs' impacts on their culture and the roles played by salmon in their sense of identity and ways of life. Although often bitterly opposed to the goals and objectives of each other (Taylor, 1999) and often litigation adversaries (Pevar, 2002), this three-way harvest community were united in their blame of the impacts of the dams as a primary reason for declining fish numbers (Taylor, 1999; Robbins, 2004).

To those dependent on the dam's commercial benefits, the dams were symbolic of the region's economic health and a guarantor of public safety through flood control. The electricity produced by the dams provided inexpensive power to fuel the region's economy; the irrigation system supported the region's agricultural community; and waterborne navigation provided an inexpensive means to move timber and agricultural products to market (McKinley, 1952; Bessey, 1963). To them, the moralistic arguments of the fishery community were a self-serving and disingenuous attempt to subsidize an anachronistic fishing industry under pressure from natural changes in ocean conditions, rising global competition, and an inability to curb their own historic excesses. As with the members of the fishery community, there were deep disagreements among members of the economic development community. Nevertheless, they all shared a belief in the economic and symbolic importance of the dams and related to them as a sign of the region's historic economic development and growth potential (Ogden, 1949; White, 1995; Lichatowich, 1999; Taylor, 1999; Wilkinson, 2005). 
The third category was the growing interest in restoring naturally viable populations of wild fish for their own sake. This value is embodied in national and state environmental protection statutes in general and the Endangered Species Act in particular (Dunlap, 1992; Taylor, 1999; Rosenbaum, 2005). Environmental organizations interested in raising national political interest in the case further promoted this value. The ESA's emphasis on "esthetic" and "ecological" values is consistent with the worldview of the environmental movement. However, up until the 1992 lawsuit, ecological values were rarely, if ever, invoked in the regional debate. ${ }^{125}$ Rather, the debate had previously centered on the commercial interests of those whose livelihoods depended upon the dams and those whose livelihoods depended upon the fishery harvest. It was essentially a debate that occurred among adherents to a worldview embracing commercial markets and resource commoditization. Dam defenders blamed overfishing, poor hatchery practices, and natural conditions over which humans had little control (Buchal, 1998). Fishery, tribes, and environmental groups blamed the existence and operation of the dams (Blumm, et al., 1998). Taylor (1999) cogently summarizes the situation by stating, “...each perspective sees the [salmon] problem lying elsewhere" (p. 247).

\section{The Clinton administration's response.}

The environmental community's efforts to nationalize the salmon debate captured the attention of the Clinton administration. The administration delegated the coordination of the federal response to the Council on Environmental Quality. The

\footnotetext{
${ }^{125}$ Ecological restoration, when called for, was advocated in the interest of a means of increasing the fishery for purposes of harvest, seldom as a value in its own right.
} 
CEQ chair organized a team of departmental assistant- and under-secretary level officials from the Department of Army, Department of Interior, Department of Agriculture, and Department of Commerce. Also included were the Environmental Protection Agency, Office of Management and Budget, and attorneys from the Department of Justice. This group would eventually be designated the Salmon Policy Team (personal knowledge of author).

Although the Salmon Policy Team would pay close attention to events in the Northwest, the administration delegated the lead in devising a solution to the crisis to its newly appointed regional administrator for the NMFS's Northwest Region, William W. Stelle, Jr. Appointed in 1994, Stelle arrived in the northwest with administration backing to preside over development of a revised salmon policy and coordinate the actions of the other regional federal agencies. Whereas during the era of the FCRPS's development the BPA administrator exerted a leadership role among federal agencies, Stelle assumed that role as the agencies struggled to get the FCRPS into compliance with the Endangered Species Act (personal knowledge of author). Although the biological opinions issued under Stelle stopped short of requiring dam breaching, they squarely raised that once unthinkable possibility should other mitigation efforts fail to reverse the salmon decline.

Under Stelle, NMFS issued a new Biological Opinion in 1995 that declared jeopardy on listed salmon due to FCRPS operations and called for a series of actions and studies under a "spread the risk" strategy. The intent was to issue a revised opinion in 1999 that would address the system's most serious issues. Crampton and 
Espenson (2009) characterized the period 1995 to 1999 as the "interim" and "sound science years" as fisheries scientists, economists, and bureaucrats conducted research and compiled information to inform the decisions expected in 1999. They also represent a period where the region reengaged the debate on governance systems in order to keep regional decision making out of the courts and within the region (Batt, Kitzhaber, Racicot, and Locke, 1998).

NPPC efforts to regain control of the salmon issue.

The NPPC continued to function, although its role as salmon restoration leader would gradually be eclipsed by the federal government efforts led by NMFS. In 1995, Congress requested, through language in its energy and water appropriations legislation, that the Council prepare a report outlining options for more effective management of regional salmon conservation efforts. The Council provided the requested report on May 15, 1996. Upon conclusion of a process that occurred between November 1995 and April 1996, involving "extensive discussion" (NPPC, 1996, p. 4) within the region, the Council reported "widespread agreement" on the need for a single fish and wildlife plan as opposed to the multiple plans then in existence. It further called for a responsible, accountable, and transparent decisionmaking system for implementation; independent scientific input into decision-making; and a watershed-up versus top-down decision-making approach (NPPC, 1996).

The report offered three general recommendations. The first called for federal, state and tribal fish and wildlife efforts to be consistent with each other. The report 
notes improved and constructive collaboration to this effect. ${ }^{126}$ But it goes on to say that, if this cooperative effort should fail, either legislation or an executive order directing federal implementation of the Council's program may be needed (emphasis added). The second recommendation was that, if such legislation was needed, the Corps, Bureau of Reclamation, Federal Energy Regulatory Commission, NMFS, and the Fish and Wildlife Service be required to act consistently with the 1980 Power

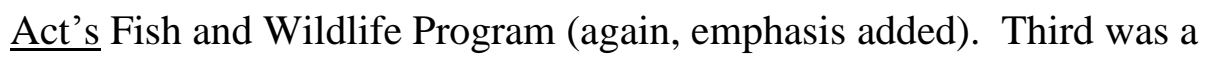
recommendation for direct funding by BPA to a monitor and evaluate programs to better determine the results of actions undertaken (NPPC, 1996).

The report also offered a concise and astute summary of the institutional challenges that led to so much conflict over governance in the Basin's far and recent history. This section of the report opens as follows:

"The fact that the salmon declines resumed even after passage of the Northwest Power Act, the Magnuson Act, the Salmon and Steelhead Conservation Act and the U. S. - Canada Salmon Treaty inevitably raises questions about the efficacy of these remedial measures. For purposes of this review, it is important to focus specifically on institutional questions that arise in fish and wildlife governance on the river" (NPPC, 1996, p. 7, emphasis added).

The institutional questions dealt with the limitations on effective planning posed by the Council's lack of authority over river uses other than power and fish and wildlife, the nature of Council membership, the diffusion of responsibility for policy

\footnotetext{
${ }^{126}$ The structure under which this improved cooperation was occurring was not specified in the report. Note that the Regional Forum, discussed below, was only just being established.
} 
formulation and implementation among multiple regional entities, and the inability to balance Council program needs with those of other agency programs. ${ }^{127}$

The report goes on to highlight important differences between the requirements of the Endangered Species Act and the Power Act. These include the federal-only, internal decision making structure of the ESA versus the open public process of the Power Act; the lack of attention to non-listed species under the ESA; the lack of ESA consideration for economic and community impacts; and the lack of explicit protection of tribal treaty rights in the language of the ESA. According to the report, these issues lead to one of three conclusions:

"Some conclude that the Endangered Species Act and the Northwest Power Act can complement each other, each shoring up the other's weak points. From this perspective, the question is not whether one law should be implemented at the expense of the other but how to make the two work better together.

Others conclude that the Endangered Species Act listings have knocked things out of balance. They argue that regardless of whether the two laws could work together in principle, in fact the Endangered Species Act dominates decisions on the river and leads to decisions that insufficiently reflect the region's values and concerns. These voices do not necessarily argue for changes in the Endangered Species Act, but they do suggest that the region play a more prominent role in Endangered Species Act decisions.

Yet a third possibility is that neither the Endangered Species Act nor the Northwest Power Act strikes the right balance among species, ecosystems and economic development. They should be replaced by a single law that properly accounts for these interests" (NPPC, 1996, p. 9, emphasis added).

${ }^{127}$ See NPPC, 1996, pp. 7-8 for a complete list and discussion. 
This analysis implicitly underscored Council and others' concern over the potential shift in regional decision making from the Council to the federal government resulting from the ESA listings.

The report is relatively modest in its identification of new governance systems. It presents five alternative approaches to Basin decision making. Two specifically address governance arrangements; two suggest potential revisions to the Power Act and/or ESA; and one suggests merely reinterpreting existing law. Of the systemoriented approaches, one called for an inter-agency federal agreement to implement the Council's program or explain why not. The other called for replacement of the Council with a new entity comprised of state, tribal, and federal representatives (NPPC, 1996, Table 1, p. 28). These recommendations were to find a more definitive form in the governance alternatives prepared for the governors' memo released to the region in 1998.

Instead of pushing immediately for new systems and structures, the Council's report outlines recently adopted processes and procedures and asks that they be given time to mature. Among the recently adopted measures identified in the report was creation of a revised charter in 1994 for the Independent Science Group, first established in 1992. Another was the implementation in 1995 of a prioritization process to align proposed fish and wildlife projects within a prescribed budget. Yet another was the recent creation of the Regional Forum (NPPC, 1996). In substance and tone, the Report presented a thoughtful, insightful, and guardedly optimistic status 
of the governance and salmon recovery situations. Current institutional arrangements should thus be allowed to continue pending evidence of failure.

\section{$\underline{\text { Resulting Governance Systems }}$}

The optimism of the Council's 1996 Report did not last long. The collaborative framework hoped for in the NPPC report and embodied in the NMFS' Regional Forum collapsed in 1997. Frustration over the lack of progress led to Oregon Governor Kitzhaber's call for a new governance system later that year, the call that sparked establishment of the Columbia River Basin Forum as recounted in

Chapter 1. The Council offered a leadership role in the development and dissemination of alternative governance structures for consideration by the public, albeit by ignoring the institutional questions they so carefully presented in 1996 and focusing instead on legislative proposals to expand the scope of the 1980 Power Act (NPPC, 1996).

The limitations of the NPPC (Hemmingway, 1983; Ogden, 1997; Blumm and Simrin, 1991) and ESA inspired lawsuits and listings caused many to rethink the options for regional governance. Industrial groups and political leaders felt the economic benefits enjoyed by the region's inexpensive hydropower were seriously at risk and sought ways to prevent its loss. Multiple proposals were put forward, with new efforts at joint federal-state-tribal decision making enacted.

The nine Governance systems proposed following the salmon listings included creation of a committee of federal and state fishery managers under the auspices of the 
Council, a Regional Implementation Forum called for in NMFS' 1995 biological opinion, a new call for a valley authority, Governor Kitzhaber's proposed "Three Sovereigns" process, various proposals to revise and expand the Council, and the Columbia River Basin Forum.

Fish Operations Executive Committee.

Following NFMS’ 1991 and 1992 ESA listings of Snake River fish, the Council released its 1992 Fish and Wildlife Program. Section 3 of that program called for creation of a Fish Operations Executive Committee (FOEC) to be comprised of "senior management representatives of the Council, as well as power and fishery interests." In practice, the FOEC seems to have adopted the membership and functions of the previous COFO (Mainstem Operations Work Group Revised Draft, 1996). ${ }^{128}$ The Council's 1994 program carried forward the language of section 3. Under both plans, the FOEC was to produce a detailed implementation plan for and resolve conflicts concerning such issues as flow, spill, juvenile fish transportation, fish passage, and other "mainstem passage matters" as found in various regional plans and programs (NPPC, 1992 and 1994/95). FOEC was a creation of the Council, and, therefore, viewed by the Council as subordinate to it. This changed with NMFS' 1995 Biological Opinion and establishment of the Regional Implementation Forum.

\footnotetext{
${ }^{128}$ The Mainstem Operations Work Group Revised Draft, 1996, also mentions a "Water Budget Implementation Work Group" that succeeded COFO. Other than this passing reference, even less information on this Work Group was found in the sources reviewed for this study than was found for COFO. Consequently, it is not included as a governance system.
} 


\section{The Regional Implementation Forum (Regional Forum).}

In his 1994 court ruling, Judge Malcolm Marsh struck down NMFS’ 1993 biological opinion, declaring that "the process is seriously flawed, significantly flawed" in that it favored the status quo of river operations through small incremental actions and that "The situation literally cries out for a major overhaul" (Marsh, quoted in Crampton and Espenson, 2009, p. 110). In response, NMFS issued a revised BiOp in March 1995. In addition to its enhanced biological provisions and spread-the-risk strategy, the new BiOp called for an adaptive management structure involving states, tribes, and federal agencies (NMFS, 1995; Crampton and Espenson, 2009).

This system envisioned an "Executive Committee" consisting of top policy makers from the regional federal agencies, state governors' offices, and tribal governments. Unlike the FOEC, which was organized under the Power and Conservation Council, NMFS regional administrator Will Stelle chaired this committee. The Executive Committee introduced a new model of governance to the Columbia Basin. Previous governance system membership was limited to federal agencies and representatives from the state governors' offices. The Regional Forum was the first system to seat the tribes, states, and federal governments as co-managing equals, albeit with a limited focus on implementation of the 1995 biological opinion.

Under the Executive Committee was an "Implementation Team" comprised of senior managers and policy advisors from the same entities as represented on the Executive Committee. The Implementation Team subsumed the membership of the FOEC (Mainstem Operations Work Group Revised Draft, 1996). Although the 
membership was unchanged, this revised organization was now answerable to the federal agencies under the auspices of the Endangered Species Act as opposed to the Council under the authorities of the 1980 Power Act.

Under the Implementation Team were three technical teams. The Technical Management Team (TMT), comprised of staff from participating entities, served to advise the dam operators on day-to-day operations. TMT members could submit systems operating requests to the action agencies, which could be negotiated or taken under advisement. If the TMT members could not agree on the operation, they referred the issue up to the Implementation Team. Disagreements within the Implementation team were in turn referred to the Executive Committee. The other two technical teams consisted of a Systems Configuration Team to recommend and assist in prioritizing physical changes to the dams and a Water Quality Team to address dam-related issues of water temperature and dissolved gas (Interim Procedures, 1997; Crampton and Espenson, 2009).

Participation for all parties was voluntary, and the Regional Forum did not impose any obligations on individual agency decision-making beyond the provisions of the 1995 BiOp. As such, it had no decision-making authority beyond items upon which the parties could agree (Crampton and Espenson, 2009).

The lack of authority was a source of friction among some parties. Others criticized the Forum for its lack of clear guidelines, its lack of participation by the public, the erratic attendance by participants, its lack of a dispute resolution 
mechanism, and, finally, the little or no explanation offered regarding resulting decisions (Crampton and Espenson, 2009). ${ }^{129}$

Judge Marsh ruled in favor of the $1995 \mathrm{BiOp}$ in 1997, albeit with a large degree of pessimism over whether it would work. ${ }^{130}$ This ruling in effect shifted the locus of salmon recovery planning away from the Council's Fish and Wildlife Program and to NMFS's BiOp provisions and the implementation-oriented Regional Forum (Crampton and Espenson, 2009).

The Regional Forum's executive structure did not last. Suspicious of Oregon, NMFS, and tribal designs on water from upriver reservoirs and lacking the confidence in NMFS' Regional Forum to “integrate the needs of Snake River salmon with other resource needs," Montana withdrew from the Executive Committee shortly after Marsh issued his ruling. Montana held that the Power and Conservation Planning Council was the more appropriate forum with which to address resource management issues. A month later the lower river tribes (Nez Perce, Yakama Nation, Confederated Tribes of the Umatilla Indian Reservation, and Confederated Tribes of the Warm Springs Indian Reservation) followed Montana, stating that the NMFS process was flawed in that it failed to properly recognize tribal sovereignty and treaty rights. The tribes also objected to the use of technical committees to resolve operating issues instead of the government-to-government consultations they felt were obligated by the

\footnotetext{
${ }^{129}$ Criticism over procedures, transparency, and dispute resolution would be partially answered in a set of interim operating procedures produced in 1997 and a revised set of guidelines agreed to in 2002.

${ }^{130}$ American Rivers and other plaintiffs appealed Marsh's ruling to the $9^{\text {th }}$ Circuit U.S. Court of Appeals in January, 1999. The Appeals Court issued its opinion later that year, upholding Marsh. See Crampton and Espenson, 2009, pp. 34-35.
} 
treaties. Despite the collapse of the Executive Committee, the Implementation Team and technical teams continued to meet and advise on day-to-day operations and policy issues (Crampton and Espenson, 2009). ${ }^{131}$ The federal members of the Executive Committee continued to meet occasionally, however, to resolve disputes elevated from the Implementation Team and to discuss interagency issues related to $\mathrm{BiOp}$ implementation (personal experience of author).

The Regional Forum was a significant departure from past governance systems in that it invited direct participation by tribal leaders in discussions with state and federal leaders over Basin decisions. The context of those discussions was the Endangered Species Act listings, with NMFS retaining final jurisdictional decision authority over ESA related issues. Despite its short tenure, the state-tribal-federal structure of Executive Committee would inspire further attempts at joint sovereign decision-making. The departure of Montana and the tribes from the Forum's Executive Committee was the proximate cause of Governor Kitzhaber's call for a new, “Three Sovereigns" process. While that proposal gained momentum, other governance models were being proposed as well.

\section{Columbia River Administration (CVA III).}

In 1997, Dan Ogden presented a paper calling for a new structure capable of comprehensive river basin planning and authoritative governance. His proposal was

\footnotetext{
${ }^{131}$ These teams continued to meet up until 2009, at which time the Implementation Team was abolished and the technical teams subsumed into the Regional Implementation Oversight Group (RIOG). As the RIOG was established after the period covered in this report it will not be further discussed here (personal knowledge of author).
} 
sweeping in its scope, offering a nationwide framework for restructuring national resource management. ${ }^{132}$ Consistent with the Hoover Commission's recommendation in 1948 and McKinley's in 1952, Ogden recommended consolidation of federal resource management agencies into one department. This consolidation would include all bureaus within the Department of Interior, the civil works function of the Corps of Engineers, the Department of Energy, the Forest Service, the Small Watershed program of the National Resources Conservation Service, the Environmental Protection Agency, the National Oceanographic and Atmospheric Administration (including NMFS), elements of the Coast Guard, and the Tennessee Valley Authority. They would be combined into a newly created Department of Natural Resources.

The new department would be internally organized along functional lines at the departmental level. Subordinate field bureaus would be organized on a watershed basis, with an "Administration" for each major river basin. He specifically proposed a Columbia River Administration, encompassing both the drainage area of the Columbia plus Northwest coastal streams and rivers. The chief of the Administration would be a career civil servant with responsibility to "plan and manage the river, and also smaller basins, for all purpose in a carefully balanced, multiple purpose manner" (p. 16). States, tribes, organized interest groups and other interested parties were to participate through a permanently established advisory council. He called upon Congress to reorganize its committee structure accordingly.

\footnotetext{
${ }^{132}$ It is not clear if Ogden prepared this paper with knowledge of the Congressional request to the Council for new governance proposals or whether it was prepared in response to the Council's 1996 report.
} 
Ogden's proposal was, in effect, a resurrection of the valley authority concept the region consistently in years past. Although Ogden presented his proposal at several public forums at which he was respectfully received (personal experience of author), his idea garnered apparently even less support than had previous valley authority efforts. It is not clear whether the Council formally considered his recommendation when they pulled together their 1998 governance alternatives in response to Governor Kitzhaber's 1997 Three Sovereigns proposal. Regardless, neither Ogden's Columbia River Administration nor any other valley authority proposal was included among the Council's proposed governance alternatives. ${ }^{133}$ Ironically, his proposal did an arguably better job of addressing the seven institutional questions identified in the Council's 1996 report to Congress, although perhaps inadvertently, than most of the Council's own proposals.

\section{The Three Sovereigns Process and Columbia Basin River Forum.}

As recounted in Chapter 1, Governor Kitzhaber proposed his Three Sovereigns process in October 1997 (Crampton, 1998, October 16). Chapter 1 of this study covered the ensuing process, culminating in the signing of the Columbia River Basin Forum Memorandum of Agreement in January 1999, in detail.

Recall from Chapter 1 that, as the draft CRBF MOA was about to be released for public comment, power, agriculture, and other river user interests criticized the Three Sovereigns process as being poorly defined and lacking in non-governmental participation. In response to these criticisms, the Council developed and presented

\footnotetext{
${ }^{133}$ Not surprising, given the regional governors' historic opposition to any valley authority system.
} 283 
five alternatives for governance reform. A letter "to interested parties" jointly released by the governors of Oregon, Washington, Idaho, and Montana on July 15, 1998 forwarded the alternatives for regional consideration and discussion. The five options were entitled (1) The Three Sovereigns, (2) an expansion of Council membership to include the tribes, (3) a Regional Resource Council, (4) a Northwest Rivers Commission, and (5) a Comprehensive River Agency (Batt, Racicot, Kitzhaber, and Locke, 1998). ${ }^{134}$ Three of the proposals were sketchy at best. None, as written, addressed all of the very profound governance challenges within the region outlined in the Council's 1996 report. ${ }^{135}$ All emphasize a greatly increased state and modestly increased tribal role in decision-making. In effect, the proposals represented an effort by the Council and regional fishery managers to move decision-making away from the federally centric ESA BiOp related process, represented by the now federal-agency heavy Regional Forum, and back to either a statutorily enhanced Council or a muscled-up replacement.

\section{Council alternative 1: the Three Sovereigns.}

The intent of this system was to establish a "principal-level forum" consisting of four states, thirteen tribes, and one federal representative. ${ }^{136}$ A senior staff level

\footnotetext{
134 The paper Models for Columbia River Governance was distributed under the governors' letter dated July $15^{\text {th }}, 1998$ but is archived separately on the NPPC website. The letter is found at http://www.nwppc.org/fw/3sov; the Models attachment at http://www.nwcouncil.org/fw/3sov/ models.htm.

${ }^{135}$ This statement refers to the proposals as written. Presumably, the authors of those documents would disagree with this characterization. This could be confirmed through interviews with those authors.

${ }^{136}$ Presumably, these principals were envisioned to be the four governors, the chairs of the tribal governments, and a DC level federal member, perhaps the Chair of the President's Council on
} 
committee consisting of four state, four tribal, and four federal representatives would support the principals group. This system required no change in existing law and was to be established by memorandum of agreement signed by participating sovereigns. The proposal envisions "collaborative decision-making" plus "different approaches for different issues and processes" without specifying what those approaches might be. In making its decisions, the sovereigns recognize the ultimate "decision-makers' legal obligations" inferring that the principal forum could not require federal agencies to do anything contrary to their federal statutory obligations (Batt, Racicot, Kitzhaber, and Locke, 1998, quotes from p. 3 of the Models attachment). This model is essentially the same as "Approach 1" identified in the Council's 1996 report to Congress (NPPC, 1996, table 1, p. 28).

This proposal addressed the problems for which the Regional Forum's Executive Committee was first envisioned. It called for participants to unify the multiple fish and wildlife recovery plans then vying for attention, including a salmon recovery plan produced by CRITFC entitled the Spirit of the Salmon, the NMFS draft 1994 recovery plan for Snake River fish stocks, and the Council's 1994 Fish and Wildlife Program. Somewhat naively, given the recent experience of the Regional Forum, this proposal was based on the that the assumption "that shared information, process and commitment to finding solutions will foster consensus....If the Three Sovereigns agree on a recommendation, the recommendation will continue to carry significant weight” (Batt, Racicot, Kitzhaber, and Locke, 1998, quotation from Models

Environmental Quality. The proposal, however, did not specify. See Batt, Racicot, Kitzhaber, and Locke, 1998, model option 1. 
attachment, p. 4). As discussed in Chapter 1, the CRBF MOA incorporated this general approach. The Council's Three Sovereigns option required no legislative changes, implying that ultimate decision-making, in the absence of consensus, would remain with the agency or entity holding jurisdiction over the issue at hand (Batt, Racicot, Kitzhaber, and Locke, 1998, Models option 1).

Council alternative 2: expansion of Council membership to Indian tribes.

This option called for the governors to appoint tribal members to the Council. This alternative proposed no changes to the Council's state makeup as specified under the 1980 Power Act. Rather, the proposal expanded Council membership to include appointments made "from the ranks of the region's tribes" (Batt, Racicot, Kitzhaber, and Locke, 1998, quote from Models attachment, p. 5).

This proposal explicitly assumed that the primary problem with the existing Council was its lack of participation by the tribes. It called for no changes to the

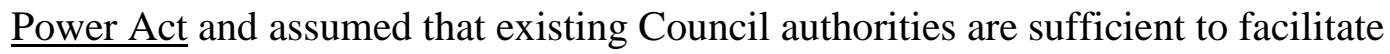
collaborative efforts. It made no provision for federal participation, and was silent as to how including tribal participation would address issues with federal agency discretionary decision-making. In this, it ignored several of the profound governance issues identified in its 1996 report to Congress (Batt, Racicot, Kitzhaber, and Locke, 1998, Models option 2).

Council alternative 3: the Regional Resources Council.

The Regional Resources Council alternative envisioned a "more broadly representative and authoritative new council" that would replace the Power and 
Conservation Council. This proposal is very similar to the Council's "Approach 3" alternative in its 1996 report excepting the new Council's role under the ESA. The 1996 report stated that an "expanded council" would exercise unspecified "Endangered Species Act and Northwest Power Act responsibilities" (NPPC, 1996, table 1, p. 28). Under the 1998 proposal, this new council would "participate in federal agency consultations under the Endangered Species Act, not supplanting existing federal agency authorities, but ensuring the council an opportunity to assert a system-wide perspective in hydropower operations" (Batt, Racicot, Kitzhaber, and Locke, 1998, quote from Models attachment, p. 7).

This new council would be authorized by revisions to federal statue and/or a congressionally approved interstate compact to develop "an integrated resource plan to offset the effects of the hydropower facilities on anadromous fish, resident fish and wildlife in the Columbia River Basin." The council would "integrate fish and wildlife obligations, power system operations, energy conservation and resource needs" (Batt, Racicot, Kitzhaber, and Locke, 1998, quote from Models attachment, p. 5). Unstated was whether the council would also influence other federal water resource issues such as harvest, hatcheries, flood control, irrigation, navigation, and water supply.

Membership would consist of "some number of state and tribal representatives" with a super-majority vote required for major decisions. Federal agencies, though not members, would be required to "act in a manner consistent with the resource council's integrated resource plan, as Bonneville is now obliged to do under the Northwest Power Act." The proposal stated that this authority would be 
limited, however, due to the need to comply with federal law, with no federal agency required to contravene its legal authorities. In this, the proposal addressed the criticism that federal agencies frequently ignored the NPPC Fish and Wildlife program provisions (Blumm and Simrin, 1991). The council would be an entity unto itself, developing its own program based on its own analysis as opposed to the current Council's requirement to develop its program based on recommendations from fish and wildlife agencies and tribes. The Regional Resource Council would fund its program by overseeing federal funds from whatever source (both appropriated and ratepayer generated) and federal project expenditures were to be consistent with the overall plan (Batt, Racicot, Kitzhaber, and Locke, 1998, Models option 3).

\section{Council alternative 4: the Northwest Rivers Commission.}

This proposal called for a ten-person Northwest Rivers Commission comprised of two governor appointed members from each state and two tribal members appointed by the Secretary of the Interior. An advisory council would assist through establishment of subcommittees oriented on river operations, fish resources and facilities (presumably hatcheries), fish harvest, agriculture and irrigation, and public lands management.

This commission would assume most Endangered Species Act functions, to include making jeopardy determinations, developing recovery plans, approving incidental take permits, and developing habitat conservation plans. It is not clear from the proposal if this Commission would replace the Power and Conservation Council or operate alongside of it. It is also not clear if the commission would assume the 
responsibilities of the Power Act. ${ }^{137}$ It sees the primary problem facing the region as the manner in which federal agencies implement the ESA, and suggests that a joint state-tribal entity could do better.

The proposal did not explain why four states should be given eight representatives to the commission while the thirteen basin tribes are limited to only two. Nor does it explain how ESA responsibilities would be transferred from NMFS and the Fish and Wildlife Service to the commission. It does not provide a role for federal agencies; presumably, they would participate in the advisory and technical subcommittees and, in effect, become implementers of decisions rendered by the commission (Batt, Racicot, Kitzhaber, and Locke, 1998, Models option 4).

Council alternative 5: a Comprehensive River Agency. Although entitled "A Comprehensive Agency," this proposal was in effect a modified river basin commission, patterned after the Delaware River Basin Commission. Unlike the more expansive Pacific Northwest River Basins Commission, participation would be limited to the states of Oregon, Idaho, Washington, and Montana and "one or more" presidentially appointed federal representatives. The tribes would be afforded membership, although the allocation of tribal seats was not specified. This new river agency would prepare long range and annual plans recognizing the "hydrologically and ecologically integrated" nature of the river system (Batt, Racicot, Kitzhaber, and Locke, 1998, Models attachment, p. 9).

\footnotetext{
137 The proposal somewhat ambiguously states that "it is possible that the Northwest Power Planning Council could comprise the eight state members of the commission" (Batt, Racicot, Kitzhaber, and Locke, 1998, quote from Models attachment, p. 9).
} 
Federal law would apply to the river agency as if it were a federal agency. This represented a substantial change from the 1980 Power Act that specifically described the Council as not being a federal entity. Unlike the other models, this one focuses on "broad and evolving" interests in the river and would not focus solely on fish and wildlife issues. The alternative did not specify the role of the federal agencies, again implying that they act to implement the river agency's plans and decisions (Batt, Racicot, Kitzhaber, and Locke, 1998, Models option 5).

\section{Chapter Summary}

Events surrounding the first ESA listings and the impacts on Basin governance can be summarized as follows:

- The initial salmon listings under the ESA precipitated a bevy of legal and administrative actions, including four biological opinions from NMFS and five court challenges. They also resulted in an institutional tug of war over whether regional decision-making would reside in systems designed around the federally centric ESA or state centric Power Act (Crampton and Espenson, 2009).

- The limitations of the NPPC and the ESA inspired listings and lawsuits caused a rethinking of options for regional governance (Hemmingway, 1983; Ogden, 1997; Blumm and Simrin, 1991).

- Under its 1995 BiOp, NMFS established a "Regional Forum" to oversee the implementation of BiOp provisions. This Forum consisted of an Executive 
Committee comprised of leaders from federal agencies and regional state and tribal governments. It was supported by a policy level Implementation Team and three technical teams. Although the Executive Committee dissolved with the departure of Montana and the four lower river tribes in 1997, the rest of the system continued to operate into 2009 (NMFS, 1995a; Interim Procedures, 1997; Crampton and Espenson, 2009).

- In 1995, Congress requested a review of regional governance systems by the Power and Conservation Council. The Council's ensuing report identified seven "institutional questions" upon which any governance proposal would need to focus. Rather than call for immediate changes to existing arrangements, the Council's report highlighted recent advances in regional cooperation and recommended that the new tools and processes be given a chance to work. If success was not achieved, changes to legislation and structure may become necessary (NPPC, 1996).

- In response to the collapse of the Regional Forum Executive Committee, Governor Kitzhaber proposed a "Three Sovereigns" process for regional decision-making (Crampton, 1998, October 16).

- Opposition to the government-only nature of the original Three Sovereigns proposal by river users prompted a regional discussion, led by the Power and Conservation Council, to identify governance alternatives. The Council identified five, forwarded to the region under a letter signed by the governors of Oregon, Idaho, Montana, and Washington in July 1998. All of the 
Council's proposals were state centric, with varying degrees of federal and tribal involvement. As a result, none fully addressed the seven "institutional questions" the Council identified in its 1996 report to Congress. Several called for legislative changes to the 1980 Power Act and/or the Endangered Species Act (Batt, Racicot, Kitzhaber, and Locke, 1998).

- In 1997, Dan Ogden prepared a proposal for a Columbia River Administration, essentially resurrecting the valley authority concept last promoted in 1949 (Ogden, 1997). The Council and governors' 1998 letter to the region did not include this proposal (Batt, Racicot, Kitzhaber, and Locke, 1998). Instead of uniting regional decision-making under one structure, the turmoil caused by the lawsuits and sequence of biological opinions resulted in three coexisting systems. These were the continuation of the Northwest Power and Conservation Council as first envisioned under the 1980 Power Act, the establishment and continuation of the Regional Forum minus its originally envisioned Executive Committee, and the fledgling Columbia River Basin Forum. 


\section{CHAPTER 8 \\ FINDINGS, ANALYSIS, AND CONCLUSIONS}

\section{$\underline{\text { Introduction }}$}

This study report began by introducing the following seeming paradox in Columbia Basin governance as illustrated by the Columbia River Basin Forum (CRBF) experience: whereas prominent northwest political and institutional leaders believed some form of regional governance system necessary, those same leaders failed to enact systems with the decision-making authority necessary to resolve the issues that led them to think such systems were needed in the first place. The study study sought to determine why this phenomenon seemed to repeatedly occur.

This study investigated this paradox using an historical approach. It used the institutions involved in the development and implementation of Basin governance systems as its unit of analysis. The institutions examined included Basin Indian tribes, federal and state agencies, and private enterprises involved with land and water use, river infrastructure development, and the salmon fishery within the geographic area of the Columbia River Basin. The report emphasized the role of federal agencies in the interest of time and given the scope of federal responsibility for management of Basin resources.

Research proceeded through three steps. The first step documented the history of the rise, operation, and collapse of the CRBF. Chapter 1 presented the results of that effort. From this came a research framework around which a history of Basin governance was constructed. The components of that framework were the events or 
circumstances that created the opportunity for change to existing systems and structures; the governance systems proposed or enacted in response to the perceived changes in circumstance; the locus of decision making for each governance system proposed or enacted; the political and social context surrounding the points in time at which change occurred; salient Northwest issues; the institutional participants; and the positions, interests, agendas and general worldviews held by the institutional participants.

The second step used that framework develop an institution-level historical overview of past Basin governance efforts primarily relying on previously published work. Chapters 3 through 7 provided the results.

The third step inductively analyzed the findings from the historical record to identify the themes and conclusions as may be relevant in explaining the Basin's past approaches to governance and inform future governance decisions. This chapter presents those findings and conclusions.

The subsequent five sections present the study's findings organized under the following headings:

- The complexities of Columbia Basin governance.

- The role of law and legal structure.

- Columbia Basin governance systems and models.

- Patterns of change between systems and models.

- The regional preference for collaboration-oriented systems. 
The study's conclusions follow the findings. A closing section introduces a theoretical framework to address the limitations of the institutional approach and guide further research.

The Complexities of Columbia Basin Governance

Each enacted system had to address a wide array of substantive and structural issues, issues that rendered any effort at governance an enormously complex undertaking. The success and longevity of each enacted system was to a large degree dependent on how they chose to address these issues. These issues are summarized below under the following headings:

- The scope of substantive issues to be addressed.

- The legacy effects of the region's settlement and development.

- Structural issues.

- The impact of differing worldviews.

The scope of Columbia Basin management issues.

In one sense, the scope of Basin governance grew easier over the years. The primary focus of the Basin's first governance system was planning. The original purpose of the Pacific Northwest Regional Planning Commission (PNWRPC, established 1934) was to create comprehensive long-range plans for development and management of all basin resources to foster economic growth. The array of issues addressed by the PNWRPC included hydropower development, agriculture, ranching, water use, mining, land use, navigation, flood control, and recreation (Bessey, 1963; 
Vogel, 2007). Consequently, the scope of planning potentially touched the interests of just about every institution in the Basin.

This vision of multipurpose planning continued with establishment of the Columbia Basin Inter-Agency Committee (CBIAC) and Pacific Northwest River Basins Commission (PNWRBC). However, this broad-scope approach to planning came to an abrupt end with the termination of the PNWRBC by executive order in 1981 (Bessey, 1963; Scheufele, c.1970). In its place came the state led Pacific Northwest Electrical Power Planning and Conservation Council (NPPC) and later the federally led Regional Forum. The Council's mandate under the 1980 Power Act was limited to power planning and development of a fish and wildlife program (Power Act, 1980; Blumm, 1982; Hemmingway, 1983; NPPC, 1996) whereas the Regional Forum concentrated on the effects of the hydropower system on salmon and steelhead listed under the Endangered Species Act (NMFS, 1995; NPPC, 1996). In effect, holistic regional planning became "easier" because the region simply stopped doing it.

Multijurisdictional governance entities took up planning for discrete resource domains such as fish and power only to the degree mandated under law. ${ }^{138}$ Planning for those domains not so mandated (agriculture, grazing, mining, recreation, hunting, timber, water) were left to the discretion of those state, federal, tribal or private institutions under whose control they lay.

\footnotetext{
${ }^{138}$ Other examples include the management of timber under the Northwest Forest Plan due to the ESA listing of spotted owls and the management of state-tribal harvest under the US v. Oregon process. Both of these examples, however, are outside the scope of this study.
} 
As the scope of Basinwide planning decreased the scope of Basin operations became much more complicated. The 1990s saw a culmination of a long-building and profound shift in the focus of FCRPS operations. Planning for and construction of the dams in the 1930s focused primarily on the commercial benefits of electrical power, irrigation, flood control, and navigation. However, over time, operations to mitigate the dams' impact on fish and wildlife gradually assumed an ever-increasing share of budget, time, and staff from FCRPS management agencies. It also gradually assumed an ever-increasing dominance on the governance agenda (Bessey, 1963; Scheufele, c.1970).

Meanwhile, the region's demographic and economic growth resulted in increased demands for electrical power, water, recreation, and transportation. National and global growth increased demand for regional timber and minerals. Absent a mechanism for holistic long-range resource planning to guide development, the challenge of balancing competing demands was left to operational managers. The challenge of operational governance over the conflict between the commercial benefits provided by Basin dams and their impact on fish became one of the region's most pronounced.

The Fish and Wildlife Service, Office of Indian Affairs, commercial fishermen, and tribes first raised concerns over the impact of dams on salmon in the 1940s. Requests from Department of Interior and fishery and tribal interests for a moratorium on dam construction until the impacts on salmon runs could be further studied were denied. These initial efforts by fishery and tribal interests failed to halt or delay plans 
for further dam construction, especially following the devastation of the May Day flood in 1946 (McKinley, 1952; Robbins, 2004).

Early river development agencies anticipated (although badly underestimated) the impact that the envisioned system of dams would have on fish runs. The Corps of Engineers included adult and juvenile passage facilities as part of the initial design for Bonneville and subsequent dams on the Columbia and its tributaries (Arndt, Stroud, and Mogren, 2004). ${ }^{139}$ The Corps and other development interests believed these technical adaptations, coupled with agreements to improve habitat in the lower Columbia River and the construction of hatcheries, to be enough (McKinley, 1952; Lichatowich, 1999; Taylor, 1999).

As the years progressed and the toll that dams and other Basin commercial development enacted on fish became clearer, the Corps, BPA, and other agencies made additional investments in mitigation. They improved fish bypass facilities, barged juvenile fish around the dams, restored habitat, constructed hatcheries, reduced predation, adjusted flow and spill, and took other actions at the expense of hydropower production. By the late 1990s, Council and agency programs were spending millions of dollars each year in to mitigate the effects of the dams. Frustration mounted, however, as these investments failed to reverse the downward spiral in numbers of

\footnotetext{
${ }^{139}$ Fish passage facilities were ultimately included in all federal and nonfederal mainstem dams in the Columbia and Snake Rivers except Grand Coulee and Hells Canyon. The early efforts were rudimentary and often not particularly effective - especially for juvenile fish passage. However, as studies were made and the lessons learned applied to each succeeding generation of projects, salmon survival improved. See Arndt, Stroud, and Mogren, 2004.
} 
returning fish (Buchal, 1998; Taylor, 1999; Arndt, Stroud, and Mogren, 2004;

Williams 2006).

Furthermore, the bevy of environmental legislation enacted in the 1960s and 1970s meant FCRPS operators had to contend with a slew of new environmentally oriented regulations and requirements affecting more than just fish. The 1996 report to Congress prepared by the Northwest Power and Conservation Council and the 2004 Government Accounting Office report illustrated just how complex operations had become. Both reports delineated the region's federal, state, and tribal institutional actors and myriad laws, treaties, executive orders, court decisions, and operating plans and programs that defined and guided agency responsibilities (NPPC, 1996; GAO, 2004).

Adding to this complexity is the fact that dealing with standing and new governance challenges is more than an intellectual exercise in rational analysis of objective data to solve the current problem of the day. The multiple institutions charged with managing the Basin's resources and the constituencies dependent upon them have interests and perspectives shaped by their respective histories. The legacy effects of the region's settlement hold strong influence over the way current issues and problems are perceived, rationalized, and addressed.

The legacy effects of regional settlement and development.

Settlers arriving in the Northwest in the mid to late 1800s almost exclusively immigrated from the American Midwest. Many carried with them a belief in the American political system as divinely ordained. They saw the resources of the land as 
a gift given presented by Providence to secure individual liberty through the generation of individual wealth and to promote social virtue through hard work and self-reliance. National policy further enabled this belief through its focus on on putting public land and natural resources into private hands for beneficial use (Conover, 1923; Cameron, 1929; Smith, 1950; Dodds, 1986).

The settlers that flowed into the Northwest in the $19^{\text {th }}$ century dispersed throughout the region, creating a few large cities and numerous small towns. Isolated, "island" communities developed with early economies centered on agriculture, ranching, or resource extraction (Lyman, 1963/1917; Wiebe, 1967; Dodds, 1986; Vogel, 2007). A Protestant-market-capitalist worldview dominated, modified by unique attitudes toward western land and resources and a self-confidence bred by surviving the arduous move westward (Cameron, 1928 and 1929; Smith, 1950; Dodds, 1986; Robbins, 1997; Taylor, 1999; Hays, 1999/1959; Kline, 2000; Weber, 2002/1920; Wilkinson, 2005; Lichatowich, McConnaha, Liss, Stanford, and Williams, 2006).

This worldview coupled with the dispersed nature of the settlements fostered a localist approach to decision-making. Communities and private businesses exercised a great deal of autonomy in determining what they were going to do and how they were going to do it. This sense of localism pervaded the region and became well entrenched. The key point for the purpose of this study is that the dispersed nature of regional communities, the self-confidence of the population, the belief in resource development as a means to foster social virtue, and a tradition of localism combined to 
breed a suspicion of and resistance to strong centralized government, centralized planning, and centralized decision-making ${ }^{140}$ (Smith, 1950; Dodds, 1986; Wilkinson, 1992; Vogel, 2007).

The historic pattern of regional settlement affected the legacies of government agencies as well. The new arrivals found the Northwest to be rich in natural resources. They saw opportunities to make their fortunes through timber, agriculture, ranching, fisheries, or mining. Exploitation of these resources was driven by a "legend of inexhaustibility," the lack a perceived need for effective regulation, moral attitudes regarding the role of development in promoting social virtue, and simple greed. The federal and state governments established agencies to support national, regional, and state economic development (Cameron, 1928 and 1929; Lyman, 1963/1917; Dodds, 1986; Wilkinson, 1992; Robbins, 1997; Taylor, 1999; Lichatowich, McConnaha, Liss, Stanford, and Williams, 2006). Local interests and private corporations working alone or in partnership with state and federal agencies and appropriate congressional committees emerged as "iron triangle"-type governance structures for natural resource management (Cater, 1954; Griffith, 1961; Clarke and McCool, 1996). These clusters of relationships among agencies, local interests, and congressional committees developed into relatively autonomous island communities of policy with little crossagency coordination or planning and frequent conflict over turf and congressional

\footnotetext{
140 The structure of the state governments reflects this regional aversion to strong centralized authority. Many Northwest state agencies and institutions, rather than reporting directly to the governor, either report to an appointed board of citizens or are elected in their own right. Consequently, Northwest governors hold limited direct authority over many state agencies.
} 
attention (Cameron, 1928; McKinley, 1952; Steen, 1976; Shallat, 1994; Clarke and McCool, 1996; Pisani, 2002).

The physical isolation of communities, the nation's laissez fare attitude toward private business, and the political insularity of federal policy and agency establishment resulted in Northwest institutions putting down strong roots and achieving a large measure of economic and political strength. Powerful private and public institutions developed around water, land use, fisheries, agriculture, ranching, timber, river navigation, irrigation, and - eventually - hydropower. Whereas national Progressive era ideals of sustainable use and management of public resources for the public good were very much part of the national political debate, these ideals made relatively few inroads against the prevailing belief in private markets and laissez faire in the Northwest until the early 1930s (Hays, 1957; Hays, 1990/1959; McKinley, 1952; Johansen, 1967; Steen, 1976; Norwood, c.1981; Cortner and Moote 1999; Billington et al., 2005).

As a result, the region's institutions were well entrenched when proposals for multi-domain governance entities with more holistic planning and operational responsibilities and authorities were first made. Many eventually recognized the value of working together to further common purposes or to preclude imposition of a stronger governance form that may work against institutional prerogatives (McKinley, 1952; Bessey, 1963; Scheufele, c.1970). Examples include the alignment of private and public electrical utilities in signing the Pacific Northwest Cooperation Agreement under the single utility concept (Pope, 2008) and the creation of the Columbia Basin 
Inter-Agency Committee to better coordinate federal responsibilities (Scheufele, c.1970). The recognized need for institutional cooperation grew as institutional interests and issues expanded and intertwined.

However, this growing recognition of the value of institutional cooperation did not extend to surrendering institutional prerogatives in the interest of more efficient decision-making. The conflictual desires for better coordination and retention of institutional decision authority greatly complicated the design of governance system structures.

The challenges of structure.

Giddens (1984) refers to the formal and normative rules that govern the internal operation of any social system as system structure. This study found four significant issues of system structure in its examination of the Columbia River Basin Forum (CRBF) experience. As the CRBF was the only governance system whose internal structure was examined in any depth in this study, the findings from the CRBF are used here. The challenges identified from the CRBF experience were the difficulty of agreeing to a common purpose, generating institutional commitment to that purpose, funding, and decision-making.

Competing institutional interests, perspectives as to priorities and the nature of the problems to be addressed, and lack of trust confounded the CRBF's initial simplesounding task of defining a common vision and sense of purpose. Even when CRBF parties finally agreed on language defining the group's vision and purpose, disagreements still arose over what the language meant and how it applied to given 
issues("Montana, Idaho won't Sign on to Northwest Salmon Plan,” 1999; Espenson, Feb 5, 1999; Espenson, Mar 12, 1999). Reaching agreement over any system's goal and purpose is a fundamental step for system effectiveness.

Related is the difference between agreeing to a statement of purpose and obtaining true commitment to that purpose. From the beginning, participants approached the CRBF with varying degrees of enthusiasm. All voiced commitment to the process, but the lack of support to address key issues, the failure for all parties to sign the MOA, and the failure to appoint individuals to all positions served to aggravate existing senses of distrust over other parties' motives (Espenson, Feb 5 and Mar 12, 1999; Meeting Minutes, May 27, June 24, and October 1999).

Whereas the MOA (1999) called for each participant to contribute an equitable amount of funds for CRBF operations, only the Bonneville Power Administration (BPA) and, to a lesser degree, the Bureau of Indian Affairs (BIA) did so. Holding participants to the funding terms of the MOA could have potentially accomplished several things. It would have signaled the commitment of each participating government to the process, would contribute to the sense that the deliberations of the group were "real" to its participants, and would have likely sustained attention of the region's elected leadership. None of these occurred since BPA managed ratepayer dollars predominantly funded the CRBF. Consequently, none of the participants other than BPA had a financial stake in ensuring process efficiency (Meeting Minutes, April 29, July 21 and October 11, 1999; Fazio, July 2, 1999). 
Finally and perhaps most importantly was the cumbersome and ineffectual decision-making process called for in the CRBF's MOA. The process required almost complete agreement before the Forum Committee could even discuss and issue, let alone resolve it. The results of this decision-making process were not binding, even if strong majority agreement existed, in that anyone disagreeing with an outcome could simply veto it (MOA, 1999; Meeting Minutes, April 29, May 27, June 24, July 21, and September 7, 1999; Espenson, July 30, 1999).

Every governance system established with the Basin faced the governance challenges posed by the scope of planning and operational issues within the Basin, the legacy effects of regional settlement, and the need to agree to acceptable rules and operating procedures. However, only recently did systems need to account for an additional confounding layer of complexity posed by the differing worldviews of governance participants.

The impact of differing worldviews.

A number of the sources reviewed for this study (Harden, 1996; White, 1996; Taylor, 1999; Lichatowich, 1999; Lichatowich, McConnaha, Liss, Stanford, and Williams, 2006) argue the profound impact worldviews have on the way people interpret the world around them, structure social systems, and define acceptable behavior. For example, many accounts of Columbia River development either begin with or eventually refer to early descriptions of the river as it existed at the time of 
early Anglo-American arrival. ${ }^{141}$ Such descriptions cited the journals of the Lewis and Clark expedition, letters and journals of early white settlers, and/or traditional Indian accounts. These accounts portrayed a river of awesome power that supported an abundance of fish and wildlife. Wild rapids, waterfalls, and dramatic and unpredictable changes in flow volumes characterized the river. To the original tribal inhabitants, these conditions were statement of a natural order within which humans were spiritually entwined. To the initial white settlers, they represented either problems to be conquered (flooding, dangerous and erratic river navigation, agricultural aridity) or opportunities for commercial exploitation (mining, commercial fish harvest, navigation, irrigation, recreation, hydropower). To Progressive conservationalists and preservationists and the more recent environmentalists these conditions constituted a natural treasure at risk and in need of government regulation, management, and protection. Regardless, the worldviews held by members of the region's dominant institutions shaped the region's governance history as those institutions debated, enacted, or rejected various governance systems.

This study identified three worldviews relevant to Columbia Basin governance choices. The first and oldest is the worldview of Native American tribes and their beliefs regarding man's place in the natural order (Trosper, 1995; Lichatowich, 1999; Taylor, 1999; Lichatowich et al,, 2006). The second is Euro American market capitalism (Weber, 2002/1920; Lichatowich, 1999; Taylor, 1999; Kline, 2000; Lichatowich et al., 2006) as leavened by Northwestern attitudes toward natural

\footnotetext{
${ }^{141}$ For example, see Norwood (c. 1981) pages 9-10, Wilkinson (1992) pages 175-187, Harden (1996) pages 15 and 59-64, Robbins (1997) pages 50-54, and Lichatowich (1999) page 44.
} 
resources (Cameron, 1928 and 1929) and the virtues of American republicanism (Lyman, 1963/1917; Smith, 1950; Dodds, 1986). The third and newest is American environmentalism as injected into issues of governance (Dunlap and Mertig, 1992a; Hays2000; Dunlap, 2004; Rosenbaum, 2005).

From the mid-1800s up to the 1970s, adherents to the market-capitalist worldview dominated Northwest resource development. The tribal sovereignty movement, coupled with tribal court victories and an increase in governance capacity, reintroduced the tribal perspective - albeit modified by years of effort to Christianize the Indians, erase tribal culture, and assimilate tribal people into mainstream American society (Pevar, 2002; Wilkinson, 2005). Passage of the National Environmental Protection Act, Endangered Species Act, and other environmentally oriented legislation injected the environmental perspective into regional decision-making. The addition of these differing worldviews added an additional layer of complication to those of issue scope, developmental legacy, and governance system structure. No longer were debates limited to how best to manage the system or distribute developmental benefits. Rather, adherents to the tribal and environmental worldviews challenged previously taken for granted assumptions over whether the dams and associated commercial infrastructure of the Columbia should ever have been built, let alone allowed to operate as they had in the past.

In recent years, environmental perspectives became well entrenched in major population centers such as Portland and Seattle and held significant sway in the regional policy discourse. Both states cite with pride their signature environmental 
legislation, such as Oregon's so-called bottle bill regarding recycling and Washington's establishment of salmon recovery boards. However, rural parts of the region often derided the environmental worldview as elitist and more interested in preserving natural conditions for their own recreational interests at the expense of rural community economic health (Harden, 1996; Taylor, 1999).

Both the environmental and tribal worldviews gained some measures of influence over governance through court victory. The environmentalist perspective won a major victory over timber interests in obtaining through the courts the ESA listing of the Northern spotted owl and significantly altering timber practices on federal lands (Swedlow, 2003) and in litigation over salmon (Crampton and Espenson, 2009). In a similar vein, the tribal worldview made major inroads in governance decisions regarding fishery management through litigation success in the USv. Washington and US v. Oregon lawsuits. Tribal voices are now major players in decision making through the court supervised US v. Oregon governance process (Pevar, 2002; personal observations of author). However, environmental and tribal perspectives have been far less successful until recently in gaining direct participation in FCRPS related governance systems.

Both the spotted owl and tribal fishery cases, however bitterly fought, involved a relatively limited number of regional interests. In both cases, the plaintiff complaints represented very strong legal positions. In the spotted owl situation, the defendant market worldview (represented by timber interests) went up against an environmental worldview armed with the rigorous regulatory provisions of the 
Endangered Species Act. In the tribal fishery cases, defendant commercial and sports fishery interests, backed by state fishery agencies, went up against the treaty provisions guaranteed by the federal government. In both instances proponents of the market worldview lost.

In contrast, the commercial benefits of the FCRPS take in a large number of regional institutional interests and affect far greater numbers of people. Utility and energy proponents often describe be the federal electricity generation and transmission system as the backbone of the regional economy. To them and other commercial beneficiaries the dams represent as much a regional icon as do the historic salmon runs. The river navigation system moves petroleum, timber, and agricultural cargo between Lewiston Idaho, the farthest inland seaport in the country, and the Pacific Ocean. Water from system reservoirs supports regional agriculture and provides domestic and municipal water supply. As a result, decision-making processes for the FCRPS attract a greater variety of divergent interests than did either the spotted owl or fishery issues.

The worldview of tribal and state fishery managers obtained a measure of influence over hydropower operations through passage of the 1980 Power Act and its provisions regarding the process by which the Northwest Power and Conservation Council is to develop its Fish and Wildlife Program (Power Act, 1980). However, decisions rendered by the Council under the 1980 Power Act are not necessarily binding on federal agencies and, in any event, only address power, fish, and wildlife. The Power Act claims no jurisdiction over navigation, flood control, recreation, 
irrigation, water supply, hatcheries, or fishery management (Power Act, 1980; NPPC, 1996). Federal agencies govern these areas under their discretion as authorized by federal law. Consequently, although the Power Act requires input from regional salmon managers in the development of the Council's fish and wildlife program, fishery voices hold less influence over these other river uses.

The environmental worldview exerted even less influence with regard to the FCRPS. Environmental interests were successful in forcing listings of Columbia Basin salmon and steelhead under the ESA and ensuring fish and wildlife concerns were included in the 1980 Power Act. But environmentalists have been markedly less successful to date in getting the courts to significantly alter the system to the degree many believe is necessary to restore the Columbia's ecological health (Crampton and Espenson, 2009). As a result, debates over governance systems for the FCRPS have more often than not taken place within the conceptual framework of the capitalist market worldview (Lichatowich, McConnaha, Liss, Stanford, and Williams, 2006), characterized by fishery interests' opposition to the initial construction and later operation of Columbia dams. Prior to the ESA listings, the debate was framed characterizing the fish as a market commodity instead of a critical component of the region's ecology and thus reduced to comparison of economic value relative to other commercial river uses (Lichatowich, 1999; Taylor, 1999; Lichatowich, McConnaha, Liss, Stanford, and Williams, 2006). There was little or no success with arguments made in favor of fish restoration strictly for the purposes of ecological health. 
The scope of issues to be addressed, the legacy effects of early regional settlement and resultant strength of regional institutions, the established lines of conflict among those institutions, the scope of issues to be addressed, the challenges of system structure, and the differing worldviews held by governance participants frame the complexities that every enacted governance system had to face. The success of any chosen system was therefore dependent on the manner in which the system dealt with those complexities. But regardless of whatever structure was ultimately agreed to, each system had to operate within the confines of federal and state law, a legal framework that added yet an additional layer of complexity and has both hindered and enabled Basin governance efforts.

\section{The Role of Law and Legal Structure}

The Government Accounting Office report released in June 2004 highlighted the legal structure within which regional institutions operate. It noted the oftenoverlapping jurisdictional boundaries of the Northwest states, Indian tribes, and federal agencies engaged with Basin issues. The report identified the "multilayered" collection of laws, treaties, executive orders, and court decisions that defined and guided federal agency responsibilities for mission authority and operations, fish and wildlife mitigation, and tribal relationships (U.S. Government Accounting Office, 2004). Consequently, a central challenge of any governance system is the mediation of the often-inconsistent goals and requirements imposed by these myriad directives and statutes. 
The provisions of these legal mandates can be roughly divided into two categories. The first constitutes mandates that federal and state agencies are required to meet. Examples from this group include Congressional and state authorizations and appropriations for agency programs; mandates imposed on agency programs by federal or state environmental statutes; water allocations per state water law; and fishery allocations per the treaties with Canada and the Indian tribes. In essence, these provisions define what agencies are supposed to do. This category will not be further discussed.

The second category defines or informs the manner in which federal, state, and tribal agencies interact with each other. Examples include the U.S. Constitution's provisions regarding the relationships among the federal, state, and tribal governments; the consultation requirements of the Endangered Species Act; the federal trust responsibility to Indian tribes; and the degree of discretionary decisionmaking allowed by each agency's authorizing statutes and regulations. These examples illustrate the importance of the law in creating the standing of government agencies to act within their scope of authority within the various governance systems and with its member partners. Consequently, the remainder of this section addresses this process-centered (authorizing) legal category.

$\underline{\text { Regional governance under the U.S. constitutional framework. }}$

The U.S. Constitution sets up a federal system of government whereby the people of the Nation delegate certain rights and powers to the national government. The states or the people reserve any power not so delegated (U.S. Constitution, $10^{\text {th }}$ 
Amendment). In addition to this vertical dispersion of power, the Constitution shares power laterally among the executive, judicial, and legislative functions of government. The concept of a regional governance system sandwiched between the national, state, and tribal governments, although not expressly prohibited, does not easily fit within this paradigm.

The Constitution also defines the relationships among the federal government, states, and tribes. Article I section 10, Article IV, and Article VI establish the supremacy of the Constitution, federal law, and treaties over the states. Within this framework of federal sovereignty, Amendment $\mathrm{X}$ recognizes state sovereignty by reserving those powers not delegated to the United States to the states. The relationship between the federal government and Indian tribes is defined by section 6 of Article I, which Congress the power to regulate commerce with the tribes; section 10 of Article I, which prohibits the states from forming their own treaties, and Article 6, which establishes the supremacy of treaties established by the federal government. Although the interpretation and enforcement of these provisions by the federal government has varied dramatically over time (Pevar, 2002), and, despite past efforts by the states to encroach on tribal rights with regard to fishing, hunting, and taxation (Pevar, 2002; Wilkinson, 2005), the courts have affirmed the federal responsibility regarding tribal treaty rights and federal government trust obligations. They have also affirmed state limitations regarding tribal resources.

The constitutional framework thus severely constrains establishment of a state or tribal led decision-oriented governance system, defined as governance system in 
which one agency has the authority and power to direct the actions of others.

However, constitutional constraints alone cannot explain the success or failure of the various governance systems dependent on voluntary collaboration among parties that the Basin has employed. ${ }^{142}$ A number of systems identified in this study established in the face of these same challenges functioned relatively successfully for extended periods. Examples include the Pacific Northwest Regional Planning Commission (nine years), the Columbia Basin Inter-Agency Committee (twenty-one years), the Regional Forum (less the executive committee) (fourteen years) and the Northwest Power and Conservation Council (thirty years and running). Alternatively, several collaboration-oriented systems collapsed after relatively short periods. Examples include the the Northwest States Development Association (less than a year), the Regional Forum executive committee (less than a year), and the Columbia River Basin Forum (thirteen months). In each of the long-term cases, participants agreed to an initial framework of rules and procedures, modified them through experience and institutionalized them over time. Consequently, the creation a workable governance framework is not solely a function of the Constitution's framework.

\section{Legal standing of federal and state agencies.}

Federal and state statutes authorize the legal existence of most federal and state agencies, respectively. For example, the Military Peace Establishment Act of 1802 established the Corps of Engineers; the Reclamation Act of 1902 established the Bureau of Reclamation; and the Bonneville Project Act of 1937 the Bonneville Power

\footnotetext{
${ }^{142}$ A further discussion of decision and collaboration-oriented governance systems is provided later in this chapter.
} 
Administration. In some cases, federal agencies were established by executive order, as was the Environmental Protection Agency in 1970. Similar laws or orders established all state and federal agencies, granting them the legitimacy and authority to carry out the duties and programs for which they were created. In many cases, original agency authorities were expanded by subsequent legislation. For example, the originally authorized duties of the Corps of Engineers were to "constitute a military academy" at West Point and to "do duty in such places, and on such service, as the President of the United States shall direct" (Military Peace Establishment Act of 1802, Section 27). This mission was initially construed as the teaching of engineering at the Military Academy, construction of military coastal fortifications, and the surveying of roads and canals (Shallat, 1994; U.S. Army Corps of Engineers, 1998). Examples of added missions include navigation improvements in the Ohio and Mississippi Rivers in 1824, management of the Washington DC water supply in 1853 , flood control in 1936, and regulation of dredging and dumping in U.S. waters in 1972, and many others (U.S. Army Corps of Engineers, 1998). All federal and state agencies in the Columbia Basin operate under similar law granting them authority for prescribed sets of activities within their respective domains of responsibility.

Statutes themselves provide but the broadest framework within which a field office of a given agency must operate. Agency rules and regulations supplement the statutes and govern internal operations. They also can define, to some degree, the discretionary authority delegated to each field office. It is beyond the scope of this paper to describe the details of each law and regulation governing Northwest agencies. 
Rather, the point here is that the combination of law and regulation establishes boundaries within which agencies must operate and the degree of discretionary decision-making delegated to regional office leaders and managers.

\section{Statutory support for Basin governance systems.}

Each of the decision-oriented governance system proposals identified in this study included recommended legislative proposals to either grant broad decision authority to an existing agency or transfer authority to a new agency. In 1935, Representative Hill introduced a bill in Congress that would transfer Bonneville Dam to the Bureau of Reclamation upon its completion and grant the Bureau authority to manage future federal Columbia River development and power marketing. Later that year, Senators McNary and Steiwer and Representative Smith introduced bills in their respective houses of Congress that would expand Corps of Engineers authority to include the marketing of power construction of transmission lines in the lower Columbia. Subsequent multiple proposals for a valley authority-type system also carried legislative proposals to define decision authorities and reorder agency relationships (McKinley, 1952; Norwood, c.1981). While none of these proposals was enacted, they underscored the necessity of legally reordering agency authorities and reporting relationships if an effective decision-oriented governance system model were to be established.

Several of the collaboration-oriented systems enacted enjoyed statutory support. The Bonneville Project Act of 1937 created the Bonneville Advisory Board consisting of the administrator of the Bonneville Project (later the Bonneville Power 
Administration), the Corps of Engineers, the Bureau of Reclamation, the U.S. Forest Service, and the Federal Power Commission. The 1965 Water Resources Planning Act authorized creation of the Pacific Northwest River Basins Commission (PNWRBC), established by executive order in 1967. The 1980 Power Act established the Northwest Power and Conservation Council (the Council). Collaborative systems supported by statutes enjoyed marked benefits, such as a dedicated stream of funding for internal operations and staff and a defined relational framework. For example, the 1965 Water Resources Planning Act authorized appropriated funds for an inter-agency executive director and staff for the PNWRBC. The 1980 Power Act directed that the Council staff be funded by funds generated through the sale of federal hydropower as collected by the Bonneville Power Administration (Power Act, 1980, section 4(h)(10)(A)). In some cases, these statutes helped define the relationships among regional institutions, such as the provision in the 1980 Power Act that requires managers of federal hydropower operations to take the Council's Fish and Wildlife mitigation program into account in rendering decisions (Power Act, 1980, section $4(\mathrm{~h})(11)(\mathrm{A}))$.

However, federal statutory support for collaborative systems is no guarantor of system effectiveness or even establishment. The effectiveness of the Bonneville Advisory Board, although mandated by the 1937 Bonneville Project Act, dissipated upon completion of the generation and transmission projects needed to support World War II industrial production due to a lack of purpose and personality conflicts (Norwood, c.1981). After almost twenty years of interstate negotiations, Congress 
authorized creation of an interstate Columbia River Basin Compact in 1968. The effort subsequently failed, however, when the Oregon and Washington legislatures refused to ratify the agreement their appointed commissioners so carefully negotiated (Bessey, 1963; National Research Council, 2004). The limited jurisdiction afforded the Northwest Power and Conservation Council under the 1980 Power Act is frequently critiqued for its inability to address impacts on fish and wildlife other than those imposed by the hydropower system (Blumm, 1981; Bodi, 1995; NPPC, 1996; Crampton and Espenson, 2009). Statutory support does thus not necessarily guarantee governance success.

Conversely, two collaborative systems enjoyed both effectiveness and longevity absent any statutory support. The Columbia Basin Interagency Committee (CBIAC), established in 1946, existed until its transition to the PNWRBC in 1967. The CBIAC and its parent the Federal Interagency River Basin Committee were created through the exercise of agency discretionary decision-making and interagency agreement. Although criticized for its inability to resolve tough interagency disputes (McKinley, 1952), it generally met the purposes for which it was established (Bessey, 1963; Scheufele, c.1970). Although the federal-state-tribal Executive Committee of the Regional Forum collapsed shortly after being established in 1995, the Regional Forum's policy-level Implementation Team and technical-level System Configuration, Technical Management, and Water Quality teams went on to function through the 
period of this study ${ }^{143}$ Although called for in NMFS' 1995 biological opinion on the hydropower system, the Regional Forum and its subordinate teams functioned entirely on the basis of interagency and inter-institutional coordination and cooperation.

In summary, the nation's legal framework both enabled and constrained the agencies involved in Basin governance. Agency existence, mission, and authority are grounded in statute. Discretionary authority is shaped by both statue and regulation. Interagency relationships can be defined by both statute and agency discretion.

Responsibility over resource domains is relegated to specific agencies based on legal authorizations, and agency decision authority is granted to them within the boundaries of those domains. The law imposes constraints on institutions wishing to encroach on a single agency domain or on the sovereign prerogatives of the federal government, states, or tribes. Consequently, governance system effectiveness is dependent on both the degree of latitude perceived in the law (Constitution, statute, executive order, rule, court opinion, etc.) and the personal proclivities of and relationships among institutional leaders.

\section{Columbia Basin Governance Systems and Models}

Prior to 1929, a private market-oriented governance system dominated, with natural resource decisions essentially rendered by private enterprises often assisted by supportive agencies with jurisdictional authority over individual resource domains. Examples include the relationships among commercial and sport fishermen and state

\footnotetext{
${ }^{143}$ The Implementation Team and three technical teams were absorbed into the Regional Implementation Oversight Group (RIOG) in 2009.
} 
fish and wildlife agencies, timber harvesters with the U.S. Forest Service, the navigation community with the Corps of Engineers, and agricultural interests with the Bureau of Reclamation and Department of Agriculture agencies.

Among the many New Deal programs initiated in response to the Depression was a national planning board to oversee regional planning commissions. The Pacific Northwest Regional Planning Commission was subsequently established in 1934 (Vogel, 2007). Between then and 1999, this study found twenty-six governance systems that were proposed for the Basin of which eleven were enacted.

This study characterized each proposed and enacted systems as either decision oriented or collaboration oriented. As the names imply, decision oriented systems were structured to make decisions while collaboration oriented systems are structured for the inclusion of the greatest number of relevant parties. There is an inherent tension between the two. Decision-making becomes more difficult with larger numbers of participants due to the increased number of interests and worldviews to be taken into account. Decision-oriented systems favored efficient, authoritative decisions at the expense of inclusiveness. Collaborative systems favored inclusion at the expense of authoritative decision-making. This study characterized nine of the twenty-six governance proposals identified as decision-oriented in nature. None of the decision-oriented systems was enacted. There were seventeen collaboration-oriented proposals. All eleven enacted systems were drawn or negotiated from these seventeen collaborative proposals. 
This study further categorized the decision-oriented and collaboration-oriented systems under different models distinguished by the entity or entities holding control over each system. This study identified three models for the decision-oriented systems and three for the collaboration-oriented systems. The decision-oriented models were termed the Market Model, the Iron Triangle Model, and the Valley Authority Model. The study categorized collaborative systems under models termed the Federal Cooperation Model, the State Cooperation Model, and the Three Sovereigns Model. The following sections discuss each of these models in turn and tabulate the systems categorized under each. Each table presents the name of each system, a short description, system institutional supporters and proponents (when identified) and a short discussion of the system's outcome. ${ }^{144}$

\section{The Market Model.}

Governance systems under the Market Model vested natural resource decisionmaking to private firms. The fur companies that arrived in the Pacific Northwest beginning in the late 1700s represent the earliest and extreme forms of this model. The British Hudson's Bay Company, Canadian North-west Fur Company, and American Pacific American Fur Company all exercised the functions of government in

\footnotetext{
${ }^{144}$ There is a seventh potential model as well: governance through court supervision. Such a model has been used elsewhere in the region. For example, a "Court Supervision" system resulted from the United States v. Oregon litigation and now guides Basin fishery allocations between the states and tribes. State and national political leaders and the federal agencies have generally (Oregon being an occasional exception) been as opposed to the application of a "Court Supervision Model" for the FCRPS as they have been to proposals for a valley authority. In the past, the threat of system operation under court oversight has prompted better coordination between regional parties. This is evidenced by the regional reaction to the first ESA salmon listing in 1991, the support for the Regional Forum implemented under NMFS' 1995 biological opinion, and reaction to more recent court directions.
} 
addition to pursuing their business objectives (Lyman, 1963/1917; Johansen, 1967; Dodds, 1986). The the strength of the early fur company position is evidenced by Hudson's Bay Company actively campaign that almost blocked formation of the first provisional government in the Northwest Territory in the belief such a government could eventually hamper company discretion and autonomy (Lyman, 1963/1917; Shafer, 1943/1918; Johansen, 1967; Dodds, 1986).

The advent of American industrialization in the 1860s saw creation of large corporate trusts that owned companies of finance, railroad, timber, electrical utility, and mining. Each corporation operated the governance system over its respective resource domain, often operating in cooperation with supportive federal and state agencies. Examples include the railroads and land developers cooperation with the General Land Office, navigation interests working with the Corps of Engineers, and organized agricultural interests working with agencies of the Department of Agriculture. The nation's belief in private markets and the doctrine of laissez fare conferred legitimacy to market resulting decisions (Conover, 1923; Hays, 1957; Hays, 1999/1959; Wiebe, 1967; Wilkinson, 1992; Shallat, 1994; Pisani, 2002).

The influence of these corporate giants reached its zenith in the late $1800 \mathrm{~s}$ under a governmental doctrine of laissez faire. The Depression of 1873 presented the first challenge to this all-but unfettered influence and in part inspired the Progressive movement. The primary relevance to Northwest governance is the impact on governance of the private-public power debates of the 1920s and 30s. The onset of the Depression in 1929 and imposition of New Deal legislation and programs caused the 
collapse of this model as the Northwest's dominant resource governance system (Ogden, 1949; McKinley, 1952; Wiebe, 1967; Norwood, c.1981; White, 1995; Robbins, 2004).

The Market Model never regained the dominance it enjoyed in the $19^{\text {th }}$ and early $20^{\text {th }}$ centuries although its precepts have enjoyed periodic resurgence, usually under Republican administrations. Corporations and trade associations trade associations continued to play a role in mustering political support for or against particular governance systems or policies. Examples include the halt to federal hydropower construction under the Eisenhower administration, the transfer of the Hells Canyon dams from federal to private purview, and efforts at environmental deregulation and government downsizing supported by the Reagan and Bush administrations. In recent years, calls for the privatization of the FCRPS or the sale of federally produced hydropower at market rates echo the Market Model (Ogden, 1949; McKinley, 1952; Wiebe, 1967; Norwood, c.1981; White, 1995; Munson, 2001; Robbins, 2004).

Table 8-1 summarizes Northwest governance systems under the Market Model. In the interests of space, and because the purposes of this study would not be served by listing each regional corporation over history, individual corporations are not shown. 
Table 8-1.

Governance Systems under the Market Model

\begin{tabular}{|c|c|c|c|c|}
\hline $\begin{array}{l}\text { Governance } \\
\text { System }\end{array}$ & Description & Supporters & Opponents & Outcome \\
\hline $\begin{array}{l}\text { The Hudson's } \\
\text { Bay Company, } \\
\text { the North-west } \\
\text { Fur Company, } \\
\text { and the } \\
\text { American } \\
\text { Pacific Fur } \\
\text { Company all } \\
\text { vied for } \\
\text { dominance } \\
\text { over the } \\
\text { regional fur } \\
\text { trade. }\end{array}$ & $\begin{array}{l}\text { Private corporations whose networks } \\
\text { of posts and forts established the } \\
\text { first systems of white governance in } \\
\text { the Northwest, providing social } \\
\text { organizations for defense, trade, food } \\
\text { production, administration of justice, } \\
\text { and other regulations over day to day } \\
\text { life. }\end{array}$ & $\begin{array}{l}\text { British, Canadian, and } \\
\text { American governments and } \\
\text { associated business } \\
\text { partners. }\end{array}$ & $\begin{array}{l}\text { Opposition came from the } \\
\text { competition among firms } \\
\text { for dominance of the fur } \\
\text { trade and by the } \\
\text { governments supporting } \\
\text { their respective } \\
\text { companies. Later opposed } \\
\text { by settlers that favored a } \\
\text { more pro-settlement } \\
\text { provisional government } \\
\text { modeled after the } \\
\text { American governmental } \\
\text { system. }\end{array}$ & $\begin{array}{l}\text { The Hudson's Bay } \\
\text { Company bought out the } \\
\text { North-west Fur Company } \\
\text { in } 1821 \text {. American Pacific } \\
\text { Fur went out of business } \\
\text { following the War of } 1812 \\
\text { when in Northwest } \\
\text { holdings were seized. Fur } \\
\text { company influence } \\
\text { gradually declined with } \\
\text { the collapse of the fur } \\
\text { trade and creation of the } \\
\text { region's first provisional } \\
\text { government in } 1841 \text {. }\end{array}$ \\
\hline $\begin{array}{l}\text { Laissez faire } \\
\text { doctrine; } \\
\text { primacy of } \\
\text { relatively } \\
\text { unregulated } \\
\text { commercial } \\
\text { markets in } \\
\text { resourced } \\
\text { development. }\end{array}$ & $\begin{array}{l}\text { Federal policy in early-late } 1800 \mathrm{~s} \\
\text { was to transfer public lands into } \\
\text { private ownership. Goal was to turn } \\
\text { western land over to individual } \\
\text { farmers and entrepreneurs. But the } \\
\text { enormity of the task and fraud } \\
\text { resulted in large tracts of land going } \\
\text { to large corporate trusts such as } \\
\text { railroads, private power, timber } \\
\text { corporations, and mining interests. } \\
\text { State regulation proved largely } \\
\text { ineffective. }\end{array}$ & $\begin{array}{l}\text { Individual settlers, private } \\
\text { trusts and developers. }\end{array}$ & $\begin{array}{l}\text { Progressive reformers } \\
\text { concerned about extensive } \\
\text { degradation on public land } \\
\text { by large scale industrial } \\
\text { exploitation. }\end{array}$ & $\begin{array}{l}\text { Stock market crash of } \\
1873 \text { undermined public } \\
\text { trust in large corporations; } \\
\text { Progressive era agencies } \\
\text { imposed government } \\
\text { control over resources on } \\
\text { public land; } 1929 \text { crash set } \\
\text { stage for stronger } \\
\text { government role in the } \\
\text { economy. Echoes of the } \\
\text { market model are heard in } \\
\text { calls for privatization of } \\
\text { BPA and for sale of } \\
\text { federal hydropower at } \\
\text { market rates. }\end{array}$ \\
\hline
\end{tabular}




\section{The Iron Triangle Model.}

Coincident with the rise of the Market Model was the rise of the Iron Triangle Model. Although some agencies, notably the Corps of Engineers and General Land Office, were first established in the early 1800s, a large number of state and federal agencies came into being in the late 1800s and early 1900s during the Progressive era. Progressives intended many of these agencies to counter the severe impact the Market Model was having on public lands and resources. The states and Congress created state and federal agencies to research and apply scientific management practices to fisheries, wildlife, forests, waterways, agriculture, and public lands. Few of these agencies were regulatory in nature beyond their assigned jurisdictions. Each often developed close working relationships with the private entities engaged in their respective policy domain and with the congressional committees overseeing their authorities and appropriations (Conover, 1923; Cameron, 1929; Steen, 1976; Wilkinson, 1992; Shallet, 1994; Clarke and McCool, 1996; Weber, 2002; Cart, 2004). These co-called "iron triangles" exercised almost exclusive decision-making within their respective domains and gained strong institutional and political support from their supported constituencies. The locus of decision-making under this model rested with the individual agencies, working in cooperation with local constituencies and the agency's congressional oversight committees. Examples include relationships among commercial fishermen, state fishery agencies, and the federal Bureau of Fisheries; timber companies and the Forest Service; and water resource developers and the Corps of Engineers and Bureau of Reclamation. Garnering the support of 
legislative committees and meeting local needs conveyed legitimacy to the decisions made (Cater, 1954; Griffith, 1961; Steen, 1976; Heclo, 1978; Shallat, 1994; Weber, 2002; Pisani, 2002).

"Iron triangle" relationships existed in just about every resource domain in the Northwest. However, as in the case with the individual corporations of the Market Model, listing each iron triangle relationship that existed prior to the 1930s would not contribute to the purposes of this study. There are, however, two examples that directly affected the earliest debates over Basin governance. In the 1930s, in response to proposals for creation of a Tennessee Valley Authority-type agency in the Northwest, congressional proponents of agency prerogatives introduced bills in Congress that would delegate the oversight of Basin hydrosystem operations to either the Corps of Engineers or Bureau of Reclamation. The debate between proponents of iron triangle and valley authority governance led to the compromise that created the Bonneville Power Administration and Bonneville Advisory Board (Ogden, 1949; McKinley, 1952; Norwood, c.1981).

Table 8-2 summarizes the systems promoted under this model. 
Table 8-2.

Governance Systems under the Iron Triangle Model

\begin{tabular}{|c|c|c|c|c|}
\hline $\begin{array}{c}\text { Governance } \\
\text { System } \\
\end{array}$ & Description & Supporters & Opponents & Outcome \\
\hline $\begin{array}{l}\text { "Iron Triangle" } \\
\text { oversight by } \\
\text { federal } \\
\text { agencies over } \\
\text { individual } \\
\text { resource } \\
\text { domains }\end{array}$ & $\begin{array}{l}\text { Relatively autonomous arrangements among } \\
\text { federal agency, congressional committees, and } \\
\text { local interests. Earliest example is Corps of } \\
\text { Engineers, established 1802, and its relationship } \\
\text { with navigators and ports. Other examples } \\
\text { include USFS and timber interests, USBR and } \\
\text { irrigators, Bureau of Mines and miners, Bureau } \\
\text { of Fisheries and commercial fishing interests, and } \\
\text { USFWS and recreational fishers and hunters. }\end{array}$ & $\begin{array}{l}\text { Progressives and } \\
\text { agencies. } \\
\text { Private industry } \\
\text { supported those } \\
\text { agencies designed to } \\
\text { provide technical } \\
\text { assistance and } \\
\text { planning. }\end{array}$ & $\begin{array}{l}\text { Private industry } \\
\text { whose felt interests } \\
\text { being challenged. } \\
\text { Initial opposition } \\
\text { often overcome } \\
\text { through outreach } \\
\text { (example: USFS and } \\
\text { timber). } \\
\text { Environmentalists and } \\
\text { others by mid 1960s. }\end{array}$ & $\begin{array}{l}\text { These arrangements } \\
\text { still exist although } \\
\text { much less powerful } \\
\text { than in the past due to } \\
\text { the the New Deal and } \\
\text { the later rise of issue } \\
\text { networks, } \\
\text { environmental statutes, } \\
\text { and other government } \\
\text { reforms. }\end{array}$ \\
\hline $\begin{array}{l}\text { System } \\
\text { operation by } \\
\text { Bureau of } \\
\text { Reclamation }\end{array}$ & $\begin{array}{l}\text { Proposed in } 1935 \text { House bill (Hill). Bill called } \\
\text { for transfer of Bonneville Dam to the Bureau of } \\
\text { Reclamation upon completion and assigned the } \\
\text { Bureau full responsibility for Columbia River } \\
\text { development and power marketing. }\end{array}$ & $\begin{array}{ll}- & \text { Bureau of } \\
& \text { Reclamation } \\
\text { - } & \text { Private power } \\
\text { - } & \text { Valley authority } \\
& \text { opponents }\end{array}$ & $\begin{array}{ll}\text { - } & \text { Corps } \\
\text { - } & \text { Portland area } \\
& \text { businesses } \\
\text { - } & \text { Public power } \\
& \text { advocates } \\
\text { - } & \text { Valley authority } \\
& \text { proponents }\end{array}$ & Not enacted. \\
\hline $\begin{array}{l}\text { Power sales, } \\
\text { transmission, } \\
\text { and operations } \\
\text { by Corps of } \\
\text { Engineers }\end{array}$ & $\begin{array}{l}\text { Proposed in } 1935 \text { (McNary, Steiwer, and Smith). } \\
\text { Bills would have the Corps operate Bonneville } \\
\text { Dam, build local transmission lines to serve the } \\
\text { Portland and Vancouver urban areas and } \\
\text { industries along the river, and charge "railroad } \\
\text { rates" in a service area limited to the lower } \\
\text { Columbia. The Corps would market power with } \\
\text { rates set by the Federal Power Commission. }\end{array}$ & $\begin{array}{ll}\text { - } & \text { Corps of Engineers } \\
\text { - } & \text { State of Oregon } \\
\text { Private power } \\
\text { advocates } \\
\text { - Portland-Vancouver } \\
\text { chambers of } \\
\text { commerce and } \\
\text { business owners }\end{array}$ & $\begin{array}{ll}\text { - } & \text { Public power } \\
\text { advocates } \\
\text { - } & \text { State of Washington } \\
\text { - } & \text { Public sentiment in } \\
\text { Oregon and } \\
\text { Washington }\end{array}$ & $\begin{array}{l}\text { Not enacted. } \\
\text { Succeeded, along with } \\
\text { the Bureau bill, in } \\
\text { framing the debate as a } \\
\text { choice of structures } \\
\text { between a valley } \\
\text { authority and existing } \\
\text { agency. This framing } \\
\text { led to the } 1937 \\
\text { compromise and } \\
\text { creation of Bonneville } \\
\text { Power Administration. }\end{array}$ \\
\hline
\end{tabular}




\section{The Valley Authority Model.}

The Valley Authority Model is the third decision-oriented governance model identified by this study. Whereas Market and Iron Triangle Model systems exercised decision-making on a decentralized basis, proposals for Valley Authority systems called for consolidation of individual agency functions into one agency or subordination of individual agency decisions to a supervising administrative structure (McKinley, 1952).

Many Progressives were wary of the power of iron triangle relationships and the close relationship exercised between agencies and private entities and staunchly opposed to the resulting corruption and abuses of public resources. Progressives were supportive of centralized planning as the best means to ensure the greatest public good from regional resources. In keeping with this belief, they favored creation of a new regional agency for the Northwest with broad planning and operational authority. This agency would assume the resource management functions of existing agencies, although exactly which agencies affected varied between proposals. In general, these proposals were modeled after the Tennessee Valley Authority. However, proposals varied with regard to scope of responsibility, degree of participation by state and nongovernmental entities, and whether the proposed systems would supplant or supervise existing agencies. The common thread of all valley authority proposals was that new statutes would vest decision-making authority in the new agency. Despite the model's apparent success in the east, Northwest institutions that did not want their previously enjoyed prerogatives encroached upon vigorously opposed them. Consequently, the 
Northwest as a whole never supported any version of this model (Ogden, 1949;

McKinley, 1952; Norwood, c.1981; Conklin, 1983). Calls in recent years to establish a "salmon czar" with undefined authority to direct the actions of regional federal agencies with respect to the hydrosystem and fish restoration efforts echo the Valley Authority Model. ${ }^{145}$

This study found seven varieties of valley authority proposals made during the period covered by this study, none of which were enacted. ${ }^{146}$ These were:

- A Columbia Valley Authority, patterned after the Tennessee Valley Authority, jointly introduced in the Senate by Pope and in the House by Hill in 1935.

- A modified version of the 1935 proposal introduced in the Senate by Mitchell in 1945.

- A revised version of Mitchell's 1945 bill, submitted by Mitchell later in 1945. Taylor introduced this same proposal in the Senate (with some revisions) in 1947; Jackson did likewise in the House in 1948.

- A proposal for a Columbia Valley Cooperative Authority introduced in the House by Horan in 1945.

\footnotetext{
${ }^{145}$ Suggestions for appointment of a "salmon czar" to direct federal agencies toward more salmonfriendly operational decisions emerged under the Clinton administration in the 1990s. To the author's knowledge, the idea was never fleshed out as a formal proposal. Consequently, it is not included as a governance system in this study.

${ }^{146}$ McKinley’s 1952 book Uncle Sam in the Pacific Northwest presents an argument strongly supportive of some form of centralized decision authority over natural resource development in the Pacific Northwest. However, the author clearly states that his intent is not "to outline a complete plan for rationalizing the national executive organization" (p. 573). As such, his book is taken by the author to offer general support for any valley authority-type proposal and is not therefore considered a separate proposal in its own right.
} 
- A proposal for a Columbia Interstate Commission introduced in the House by Horan in 1947. This bill offered a revision of Horan's 1945 proposal.

- A proposal for a Columbia Valley Administration proposed by the Truman administration in 1949.

- A proposal for a Columbia River Administration proposed by Dan Ogden in 1997.

Table 8-3 summarizes proposals made under the Valley Authority Model. 
Table 8-3.

Governance Systems under the Valley Authority Model

\begin{tabular}{|c|c|c|c|c|}
\hline $\begin{array}{c}\text { Governance } \\
\text { System } \\
\end{array}$ & Description & Supporters ${ }^{147}$ & Opponents ${ }^{143}$ & Outcome \\
\hline $\begin{array}{l}\text { Columbia } \\
\text { Valley } \\
\text { Authority } 1\end{array}$ & $\begin{array}{l}\text { Modeled after the TVA. Submitted in } 1935 \\
\text { following bills to assign future development to } \\
\text { either the Corps or Bureau. Introduced in the } \\
\text { Senate by Pope and House by Hill. The CVA } \\
\text { would take over operation of Bonneville and } \\
\text { Grand Coulee Dams and administer future } \\
\text { development over the Basin. Would centralize } \\
\text { Columbia decision-making on river system } \\
\text { planning, construction, operations, and, in some } \\
\text { cases, land management under one administrative } \\
\text { structure. }\end{array}$ & $\begin{array}{ll}- & \text { Grange (with } \\
& \text { reservations) } \\
\text { - } & \text { Labor groups } \\
\text { - } & \text { Public power } \\
& \text { advocates } \\
\text { - } & \text { Progressives/New } \\
& \text { Dealers among some } \\
& \text { state agencies } \\
\text { - } & \text { ID and WA } \\
\text { - } & \text { DOI (if new agency } \\
& \text { assigned under DOI) }\end{array}$ & $\begin{array}{ll} & \text { Federal agencies, } \\
\text { (Corps, Department } \\
\text { of Ag, UFSF, SCS, } \\
\text { and (quietly) USBR) } \\
\text { - } \quad \text { State governors } \\
\text { - } \quad \text { Reclamation } \\
\text { - } \quad \text { Nassociations } \\
\text { - } \quad \text { Private utilities } \\
\text { - } & \text { Railroads } \\
\text { - } & \text { TVA } \\
\text { - } & \text { Chambers of } \\
& \text { commerce }\end{array}$ & $\begin{array}{l}\text { Not enacted. } \\
\text { Resulted in } \\
1937 \\
\text { compromise } \\
\text { creating the } \\
\text { Bonneville } \\
\text { Power } \\
\text { Administration. }\end{array}$ \\
\hline $\begin{array}{l}\text { Columbia } \\
\text { Valley } \\
\text { Authority } 2\end{array}$ & $\begin{array}{l}\text { Introduced in the Senate by Mitchell in } 1945 . \\
\text { Modified the } 1935 \text { proposal. Would transfer the } \\
\text { Bonneville and Grand Coulee dams and all future } \\
\text { Basin development responsibilities to a new } \\
\text { public corporation, managed under a three- } \\
\text { person board of directors and under the } \\
\text { supervision of the Secretary of the Interior. } \\
\text { Would also establish an advisory council of } \\
\text { regional governors. Included unenforceable } \\
\text { provisions calling for the new agency to conduct } \\
\text { its operations in cooperation with other agencies. }\end{array}$ & $\begin{array}{l}\text { Same, except Grange, } \\
\text { labor, and public } \\
\text { power opposed } \\
\text { centralized nature of } \\
\text { decision-making. }\end{array}$ & - $\quad$ Same & $\begin{array}{l}\text { Not enacted due } \\
\text { to Republican } \\
\text { majority in '46 } \\
\text { and Grange, } \\
\text { labor, and } \\
\text { public power } \\
\text { concerns. }\end{array}$ \\
\hline
\end{tabular}

\footnotetext{
${ }^{147}$ The full array of local, regional, and national supporters and opponents of each valley authority proposal is too complex to be provided in a simple table.
} See McKinley (1952), pp. 556-566 for a more in-depth discussion. 
Table 8-3. (Continued)

Governance Systems under the Valley Authority Model

\begin{tabular}{|c|c|c|c|c|}
\hline $\begin{array}{l}\text { Governance } \\
\text { System }\end{array}$ & Description & Supporters & Opponents & Outcome \\
\hline $\begin{array}{l}\text { Columbia } \\
\text { Valley } \\
\text { Authority } 3\end{array}$ & $\begin{array}{l}\text { Second Mitchell bill introduced } 1945 \text {. Revised } \\
\text { earlier bill to include elaborate appointment } \\
\text { requirements and advisory council review } \\
\text { provisions requested by labor, the Grange, and } \\
\text { public power advocates. } \\
\text { The second Mitchell proposal was reintroduced } \\
\text { in the Senate by Taylor in } 1947 \text { and House by } \\
\text { Jackson in 1948. Both retained the major } \\
\text { components of the second } 1945 \text { Mitchell bill. A } \\
\text { significant modification in Taylor's version was } \\
\text { a joint federal agency - state - private interest } \\
\text { advisory structure to review unified plans and } \\
\text { major policy proposals. Thus, existing agencies } \\
\text { would still have a role even though their river } \\
\text { development management responsibilities were } \\
\text { transferred to the new agency. }\end{array}$ & $\begin{array}{l}\text { Same; Grange, labor, } \\
\text { and public power } \\
\text { supported revisions. }\end{array}$ & - $\quad$ Same. & $\begin{array}{l}\text { Not enacted due } \\
\text { to opposition } \\
\text { from } \\
\text { Republicans. }\end{array}$ \\
\hline $\begin{array}{l}\text { Columbia } \\
\text { Valley } \\
\text { Cooperative } \\
\text { Authority }\end{array}$ & $\begin{array}{l}\text { Introduced in } 1945 \text { (Horan). Modified the valley } \\
\text { authority idea in that it limited the authority's } \\
\text { duties to planning, development, and } \\
\text { management of a single resource - water. Other } \\
\text { than that, its structure and provisions were } \\
\text { similar to Mitchell's } 1945 \text { CVA bill. A } \\
\text { significant difference was its provisions for a } \\
\text { presidentially appointed corporate oversight } \\
\text { board of which at least one member would be } \\
\text { from one of the regional states as recommended } \\
\text { by that state's governor. An advisory council } \\
\text { comprised of the state governors and supported } \\
\text { by a staff-level commission that would review all } \\
\text { proposals for water resource utilization. }\end{array}$ & $\begin{array}{l}\text { Not identified. } \\
\text { Presumably similar to } \\
\text { supporters for the CVA. }\end{array}$ & $\begin{array}{l}\text { Not identified. } \\
\text { Presumably similar to } \\
\text { opponents of the CVA. }\end{array}$ & $\begin{array}{l}\text { Not enacted due } \\
\text { to Republican } \\
\text { congressional } \\
\text { victories in } \\
1946 .\end{array}$ \\
\hline
\end{tabular}


Table 8-3. (Continued)

Governance Systems under the Valley Authority Model

\begin{tabular}{|c|c|c|c|c|}
\hline $\begin{array}{l}\text { Governance } \\
\text { System }\end{array}$ & Description & Supporters & Opponents & Outcome \\
\hline $\begin{array}{l}\text { Columbia } \\
\text { Interstate } \\
\text { Commission }\end{array}$ & $\begin{array}{l}\text { Introduced in } 1947 \text { (Horan). Essentially a } \\
\text { revised, more pro-business version of the } 1945 \\
\text { Columbia Valley Cooperative Authority. This } \\
\text { agency would be the same as contemplated in his } \\
\text { earlier bill, but limited water resource } \\
\text { development to only those activities not suitable } \\
\text { for private development and restricted } \\
\text { transmission and sale of electrical energy to } \\
\text { wholesale markets only. }\end{array}$ & $\begin{array}{l}\text { Not identified. } \\
\text { Presumably similar to } \\
\text { supporters for the CVA } \\
\text { plus business and private } \\
\text { developers. }\end{array}$ & $\begin{array}{l}\text { Not identified. } \\
\text { Presumably similar to } \\
\text { opponents of the CVA. }\end{array}$ & $\begin{array}{l}\text { Not enacted. } \\
\text { Overcome by } \\
\text { the unexpected } \\
\text { reelection of } \\
\text { President } \\
\text { Truman in } 1948 \\
\text { and renewed } \\
\text { calls for a more } \\
\text { robust valley } \\
\text { authority. }\end{array}$ \\
\hline $\begin{array}{l}\text { Columbia } \\
\text { Valley } \\
\text { Administration } \\
\text { (CVAd) }\end{array}$ & $\begin{array}{l}\text { Proposed by the Truman administration in } 1949 \\
\text { to respond to concerns over CVA. Introduce in } \\
\text { the Senate by Magnuson. Promoted as improved } \\
\text { organization for federal programs, and not as an } \\
\text { extension of federal power. Would limit } \\
\text { operating responsibilities to water resources, } \\
\text { power generation, and power transmission. Did } \\
\text { not transfer land management functions of } \\
\text { Agriculture or the lands, minerals, and wildlife } \\
\text { functions of Interior. In effect, the CVAd would } \\
\text { take over the regional water resource } \\
\text { responsibilities of Reclamation, BPA, and the } \\
\text { Corps. Envisioned as a government corporation } \\
\text { with a general manager to be appointed by a } \\
\text { board of directors. The board was to be } \\
\text { comprised of the regional agency leaders and the } \\
\text { governors of the Northwest states. Responsible } \\
\text { for developing unified plans and programs to be } \\
\text { recommended to the President and submitted for } \\
\text { approval to Congress. }\end{array}$ & $\begin{array}{l}\text { Progressives and New } \\
\text { Dealers; similar support as } \\
\text { for CVA. }\end{array}$ & $\begin{array}{l}\text { States, private utilities, } \\
\text { manufacturing interests, } \\
\text { Corps, Bureau of } \\
\text { Reclamation, BPA, and } \\
\text { irrigators opposed it as } \\
\text { thinly veiled CVA. }\end{array}$ & $\begin{array}{l}\text { Died in } \\
\text { committee; } \\
\text { never enacted. } \\
\text { Echoed in late } \\
\text { 1990s and early } \\
\text { 2000s with calls } \\
\text { for a regional } \\
\text { "salmon czar." }\end{array}$ \\
\hline
\end{tabular}


Table 8-3. (Continued)

Governance Systems under the Valley Authority Model

\begin{tabular}{|c|c|c|c|c|}
\hline $\begin{array}{c}\text { Governance } \\
\text { System }\end{array}$ & Description & Supporters & Opponents & Outcome \\
\hline $\begin{array}{l}\text { Columbia } \\
\text { River } \\
\text { Administration } \\
\text { (CVAd) }\end{array}$ & $\begin{array}{l}\text { Proposal by Daniel Ogden in } 1997 \text { in response to } \\
\text { regional governance debates following ESA } \\
\text { salmon listings. } \\
\text { Proposal called for single agency capable of } \\
\text { comprehensive river basin planning and } \\
\text { authoritative governance. Recommended } \\
\text { consolidation of federal resource management } \\
\text { agencies into one department. They would be } \\
\text { combined into a newly created Department of } \\
\text { Natural Resources. } \\
\text { The new department would be internally } \\
\text { organized along functional lines at the } \\
\text { departmental level. Subordinate field bureaus } \\
\text { would be organized on a watershed basis, with an } \\
\text { "Administration" for each major river basin. He } \\
\text { specifically proposed a Columbia River } \\
\text { Administration, encompassing both the drainage } \\
\text { area of the Columbia plus Northwest coastal } \\
\text { streams and rivers. Other interested parties were } \\
\text { to participate through a permanently established } \\
\text { advisory council. Recommended that Congress } \\
\text { to reorganize its committee structure accordingly. }\end{array}$ & Unknown & Unknown & $\begin{array}{l}\text { Not enacted. } \\
\text { Was not } \\
\text { included in the } \\
\text { array of } \\
\text { governance } \\
\text { proposals } \\
\text { presented to the } \\
\text { Northwest by } \\
\text { four governors } \\
\text { in } 1998 \text {. }\end{array}$ \\
\hline
\end{tabular}




\section{The Federal Cooperation Model.}

The Federal Cooperation Model is one of three collaboration-oriented models identified in this study. The Federal Cooperation Model emerged from the debate between advocates for system management by individual agencies and the 1935 proponents of a Columbia Valley Authority. The 1937 Bonneville Project Act created what became the Bonneville Power Administration as a temporary compromise to market power from the federal dams at Bonneville and Grand Coulee and to construct transmission lines from federal projects to local energy markets. The Act also required establishment of an advisory board to assist the new agency's administrator in carrying out his duties. This board, called the Bonneville Advisory Board, was comprised of the Administrator of the Bonneville Project, the Corps of Engineers, the Bureau of Reclamation, the U.S. Forrest Service, and the Federal Power Commission (Bonneville Project Act, 1937; Norwood, c.1981). The provisions of the 1937 Bonneville Project Act thus ensured that collaboration would be hard-wired into FCRPS decision making. The Bonneville Advisory Board was the Basin's first experience in cooperative decision making among federal agencies.

Under the Federal Cooperation Model, each agency retains its decision authorities but agrees to coordinate its discretionary decision making with other agencies and to take their concerns and issues into account. These cooperative systems were thus essentially strategies adopted by the federal agencies to both better manage the Basin as well as to ward off imposition of a more authoritarian valley authority-type system (Scheufele, c.1970). 
At times Federal Cooperation systems opened participation to other Basin entities. For example, the Columbia Basin Inter-Agency Committee (1946 - 1966) and the Pacific Northwest River Basins Commission (1967 - 1981) expanded participation to include the states, and the Regional Implementation Forum (1996 2009) included state and tribal participants.

This study categorized six governance systems as belonging under this model, all of which were enacted. These were:

- The Bonneville Advisory Board, 1937 - 1946.

- The Columbia Basin Inter-Agency Committee, 1946 - 1967.

- The Pacific Northwest River Basins Commission, 1967 - 1981.

- The Committee on Fish Operations, c.1960s - c.1980s.

- $\quad$ The Fish Operation Executive Committee, 1992 - 1996.

- Regional Implementation Forum, 1996 - 2009 (Executive Committee disbanded in 1997).

Federal Cooperation governance systems are summarized in Table 8-4. 
Table 8-4.

Governance Systems under the Federal Cooperation Model

\begin{tabular}{|c|c|c|c|c|}
\hline $\begin{array}{c}\text { Governance } \\
\text { System } \\
\end{array}$ & Description & Supporters & Opponents & Outcome \\
\hline $\begin{array}{l}\text { Bonneville } \\
\text { Advisory } \\
\text { Board }\end{array}$ & $\begin{array}{l}\text { Called for in the } 1937 \text { Bonneville Project Act that } \\
\text { "temporarily" established Bonneville Power } \\
\text { Administration. Members were BPA, Corps } \\
\text { (representing Department of Army), Bureau of } \\
\text { Reclamation (representing Interior), USFS } \\
\text { (representing Agriculture) and Federal Power } \\
\text { Commission. Preserved individual agency } \\
\text { authorities and prerogatives. Required cooperation } \\
\text { among federal agencies; no one agency has } \\
\text { directive authority over another. }\end{array}$ & \multicolumn{2}{|c|}{$\begin{array}{l}\text { Compromise between supporters of } \\
\text { single-agency and valley authority } \\
\text { proposals. }\end{array}$} & $\begin{array}{l}\text { Held } 12 \text { meetings } \\
\text { between } 1937 \text { and } 1946 . \\
\text { Participation waned as } \\
\text { War effort wound down. } \\
\text { Suffered from lack of a } \\
\text { decision-making } \\
\text { structure and agency } \\
\text { disagreements. } \\
\text { Replaced in } 1946 \text { by } \\
\text { CBIAC. }\end{array}$ \\
\hline $\begin{array}{l}\text { Columbia } \\
\text { Basin Inter- } \\
\text { Agency } \\
\text { Committee } \\
\text { (CBIAC) }\end{array}$ & $\begin{array}{l}\text { Prompted by renewed calls for a valley authority in } \\
1945 \text { and a recognized need for agency cooperation. } \\
\text { Served as forum for coordination among federal } \\
\text { agencies and states. Rotating federal chair. } \\
\text { Participants included Corps, Department of Interior, } \\
\text { Department of Agriculture, Federal Power } \\
\text { Commission, and Bonneville Power } \\
\text { Administration. Commerce and Labor added in } \\
\text { 1947; USFWS in 1956. Governors of OR, WA, ID, } \\
\text { MT, WY, UT, and NV were invited to attend. } \\
\text { Meetings open to public. No separate funding; } \\
\text { activities donated by participating agencies. }\end{array}$ & $\begin{array}{ll}\text { - } & \text { Valley } \\
\text { authority } \\
\text { opponents } \\
\text { - } & \text { Federal } \\
\text { agencies at } \\
\text { regional and } \\
\text { departmental } \\
\text { levels } \\
\text { - States }\end{array}$ & $\begin{array}{l}\text { Not } \\
\text { identified; } \\
\text { presumably, } \\
\text { valley } \\
\text { authority } \\
\text { proponents }\end{array}$ & $\begin{array}{l}\text { Operational 1946-1967. } \\
\text { Criticized for inability to } \\
\text { resolve disagreements, } \\
\text { address tough issues, and } \\
\text { produce a } \\
\text { comprehensive river } \\
\text { plan. } \\
\text { Held } 138 \text { meetings until } \\
\text { replaced by the Pacific } \\
\text { Northwest River Basin } \\
\text { Commission in } 1967 .\end{array}$ \\
\hline $\begin{array}{l}\text { Pacific } \\
\text { Northwest } \\
\text { River Basins } \\
\text { Commission } \\
\text { (PNWRBC) }\end{array}$ & $\begin{array}{l}\text { Authorized by Water Resources Planning Act and } \\
\text { constituted by executive order in } 1967 \text {. Chaired by } \\
\text { federal appointee. Consisted of same } \\
\text { representatives as CBIAC, less UT. Appropriation } \\
\text { funded. Function was regional water resource } \\
\text { planning. No operational authority over agency } \\
\text { projects or decision-making. }\end{array}$ & Not identified & Not identified & $\begin{array}{l}\text { Operational } 1967 \text { to } \\
1981 . \text { Terminated by } \\
\text { executive order. Its } \\
\text { congressional authority } \\
\text { to exist, however, was } \\
\text { never withdrawn. }\end{array}$ \\
\hline
\end{tabular}


Table 8-4. (Continued)

Governance Systems under the Federal Cooperation Model

\begin{tabular}{|c|c|c|c|c|}
\hline $\begin{array}{c}\text { Governance } \\
\text { System } \\
\end{array}$ & Description & Supporters & Opponents & Outcome \\
\hline $\begin{array}{l}\text { Committee on } \\
\text { Fish } \\
\text { Operations } \\
\text { (COFO) }\end{array}$ & $\begin{array}{l}\text { Established in the 1960s to find ways to operate the } \\
\text { FCRPS to better address the impact of the system } \\
\text { on fish and wildlife. Consisted of fish and wildlife } \\
\text { managers and federal operators and regulators, } \\
\text { although exactly who is not clear. Apparently co- } \\
\text { existed with the CBIAC and the later Pacific } \\
\text { Northwest River Basin Commission. It is not clear } \\
\text { if COFO was established as part of one of these } \\
\text { other systems or existed independently. }\end{array}$ & $\begin{array}{ll}- & \text { FCRPS } \\
\text { agencies } \\
\text { - } & \text { Fish and } \\
\text { wildlife } \\
\text { managers. }\end{array}$ & Not identified & $\begin{array}{l}\text { Established in the } 1960 \mathrm{~s} \text {, } \\
\text { although exact date is not } \\
\text { clear. Apparently } \\
\text { became the Water Budget } \\
\text { Implementation Work } \\
\text { Group under the NPPC } \\
\text { sometime after passage } \\
\text { of the } 1980 \text { Power Act. }\end{array}$ \\
\hline $\begin{array}{l}\text { Fish Operation } \\
\text { Executive } \\
\text { Committee } \\
\text { (FOEC) }\end{array}$ & $\begin{array}{l}\text { Called for under the NPPC } 1992 \text { Fish and Wildlife } \\
\text { Program. Comprised of "senior management } \\
\text { representatives of the Council, as well as power and } \\
\text { fishery interests." The policy level committee } \\
\text { consisted of federal agency executives, regional } \\
\text { Indian tribal leaders, and appointed Council } \\
\text { members. The purpose was to coordinate federal } \\
\text { obligations following ESA listings of salmon }\end{array}$ & Not identified & Not identified & $\begin{array}{l}\text { Established in } 1992 \text { upon } \\
\text { request by the NPPC. } \\
\text { Ceased to exist upon } \\
\text { establishment of } \\
\text { Regional Implementation } \\
\text { Forum. }\end{array}$ \\
\hline $\begin{array}{l}\text { Regional } \\
\text { Implementation } \\
\text { Forum } \\
\text { (Regional } \\
\text { Forum) }\end{array}$ & $\begin{array}{l}\text { Created by National Marine Fisheries } 1995 \text { FCRPS } \\
\text { Biological Opinion. Constituted } 1996 \text {. Purpose } \\
\text { was to ensure a unified approach to recovery of } \\
\text { ESA listed stocks. Essentially replaced the NPPC } \\
\text { Fish Operation Executive Committee. Multi- } \\
\text { government in nature, with Executive Committee } \\
\text { consisting of regional agency executives, governor } \\
\text { representatives, and regional tribal leaders. } \\
\text { Established policy level implementing team (IT) } \\
\text { and three technical subcommittees for technical } \\
\text { coordination of system operations. }\end{array}$ & $\begin{array}{l}\text { Initially supported } \\
\text { by states, federal } \\
\text { agencies, and upper } \\
\text { and lower river } \\
\text { tribes. }\end{array}$ & $\begin{array}{l}\text { Montana left } \\
\text { group over } \\
\text { disagreements } \\
\text { regarding upper } \\
\text { Columbia water. } \\
\text { Lower river tribes } \\
\text { soon followed. }\end{array}$ & $\begin{array}{l}\text { Operational } 1996-2009 . \\
\text { Difficulty in reaching } \\
\text { consensus among states } \\
\text { and tribal interests as to a } \\
\text { regional recovery plan. } \\
\text { Executive Committee } \\
\text { ceased to exist in } 1997 . \\
\text { IT and technical teams } \\
\text { continued until functions } \\
\text { assumed under a new } \\
\text { system in } 2009 \text {. }\end{array}$ \\
\hline
\end{tabular}




\section{The State Cooperation Model.}

The State Cooperation Model encompasses systems structured either under agreements among Northwest states or federal statute in which the states have the lead in planning, development, and - under some system proposals - operational decisions. State Cooperation systems sought to leverage federal agency resources to meet regional needs as defined by the participating states and to ensure federal agency decision-making reflected state interests.

This study found nine State Cooperation Model systems proposed over the period covered by this study, of which four were enacted:

- Pacific Northwest Regional Planning Commission, 1934-1943.

- Northwest States Development Association, 1943-1944.

- Columbia Basin Interstate Compact, negotiations initiated in 1949, not enacted.

- Pacific Northwest Governors' Power Planning Committee, 1953-1958.

- Pacific Northwest Electric Power and Conservation Planning Council (later the Northwest Power and Conservation Planning Council), 1981-present.

- Alternative governance system proposed by the the Council developed in 1998 to expand NPPC membership to include tribal representatives. Not enacted.

- Regional Resource Council, an alternative governance system proposed by the the Council developed in 1998. Not enacted. 
- Northwest Rivers Commission, an alternative governance system proposed by the the Council developed in 1998. Not enacted.

- Comprehensive River Agency, an alternative governance system proposed by the the Council developed in 1998. Not enacted.

These nine systems are summarized in Table 8-5. 
Table 8-5.

Governance Systems under the State Cooperation Model

\begin{tabular}{|c|c|c|c|c|}
\hline $\begin{array}{c}\text { Governance } \\
\text { System }\end{array}$ & Description & Supporters & Opponents & Outcome \\
\hline $\begin{array}{l}\text { Pacific } \\
\text { Northwest } \\
\text { Regional } \\
\text { Planning } \\
\text { Commission } \\
\text { (PNWRPC) }\end{array}$ & $\begin{array}{l}\text { First attempt at regional governance; outgrowth of } \\
\text { New Deal efforts to use public works to invigorate } \\
\text { the national economy in response to the Depression } \\
\text { and develop plans to implement National Recovery } \\
\text { Act. Comprised of four state planning board chairs, } \\
\text { with part time federal chair who reported to DC level } \\
\text { planning board. Federal agencies not included at } \\
\text { regional level due board member interest in } \\
\text { protecting state prerogatives; agencies effectively } \\
\text { relegated to technical support role. Functions were } \\
\text { investigational and advisory, not operational. }\end{array}$ & $\begin{array}{l}\text { Not identified; } \\
\text { presumably New } \\
\text { Deal and public } \\
\text { power advocates }\end{array}$ & $\begin{array}{l}\text { Not identified; } \\
\text { presumably New } \\
\text { Deal opponents } \\
\text { and private power } \\
\text { interests }\end{array}$ & $\begin{array}{l}\text { Established } 1934-1943 . \\
\text { Terminated in } 1943 \\
\text { when the Republicans } \\
\text { won the majority in } \\
\text { Congress and ended } \\
\text { funding for numerous } \\
\text { New Deal programs, } \\
\text { including national and } \\
\text { regional planning. }\end{array}$ \\
\hline $\begin{array}{l}\text { Northwest } \\
\text { States } \\
\text { Development } \\
\text { Association }\end{array}$ & $\begin{array}{l}\text { Established by the governors of the Northwest states } \\
\text { (not clear exactly which states were involved) as a } \\
\text { replacement of the PNWRPC to coordinate interstate } \\
\text { issues. }\end{array}$ & $\begin{array}{l}\text { - } \\
\text { states; others not } \\
\text { identified }\end{array}$ & - $\quad$ Not identified & $\begin{array}{l}\text { Operational from July } \\
1943 \text { - early } 1944 . \\
\text { Disbanded after } \\
\text { production of one report. }\end{array}$ \\
\hline $\begin{array}{l}\text { Pacific } \\
\text { Northwest } \\
\text { Governors' } \\
\text { Power } \\
\text { Planning } \\
\text { Committee } \\
\text { (PNWGPPC) }\end{array}$ & $\begin{array}{l}\text { Initially organized in } 1953 \text { as a subcommittee of the } \\
\text { federal centric Columbia Basin Inter-Agency } \\
\text { Committee. Ostensibly formed to assist in } \\
\text { implementing the Eisenhower administration's } \\
\text { partnership program. Led by state governors. } \\
\text { Consisted of public and private power interests, } \\
\text { federal agencies, and others. }\end{array}$ & $\begin{array}{ll}\text { - } & \text { Governors' } \\
\text { offices } \\
\text { - } & \text { Electrical power } \\
\text { utilities and } \\
\text { interests }\end{array}$ & - $\quad$ Not identified & $\begin{array}{l}\text { Established } 1953 . \\
\text { Almost supplanted the } \\
\text { CBIAC. Produced at } \\
\text { least seven influential } \\
\text { technical reports. } \\
\text { Interest waned, and } \\
\text { members agreed to } \\
\text { disband in } 1958 .\end{array}$ \\
\hline $\begin{array}{l}\text { Columbia } \\
\text { Basin Interstate } \\
\text { Compact }\end{array}$ & $\begin{array}{l}\text { Effort initiated in } 1949 \text {. Intent was to provide a } \\
\text { larger role for the states in regional planning, } \\
\text { partially motivated by renewed calls for a valley } \\
\text { authority and partially by weaknesses in CBIAC. } \\
\text { Planning commission comprised of representatives } \\
\text { from Oregon, Montana, Idaho, and Washington was } \\
\text { organized to promote the effort. Utah and Nevada } \\
\text { joined in } 1952 \text {. }\end{array}$ & $\begin{array}{ll}\text { - } & \text { Governors' } \\
\text { offices } \\
\text { - } \quad \text { Valley authority } \\
\text { opponents }\end{array}$ & $\begin{array}{ll}\text { - } & \text { Public power } \\
\text { advocates } \\
\text { - } \\
\text { Washington } \\
\text { and Oregon } \\
\text { legislatures }\end{array}$ & $\begin{array}{l}\text { Effort failed when } \\
\text { Washington withdrew its } \\
\text { support over public } \\
\text { power concerns } \\
\text { regarding threats to } \\
\text { federal hydropower and } \\
\text { the Oregon legislature } \\
\text { refused to ratify. }\end{array}$ \\
\hline
\end{tabular}


Table 8-5. (Continued)

Governance Systems under the State Cooperation Model

\begin{tabular}{|c|c|c|c|c|}
\hline $\begin{array}{c}\text { Governance } \\
\text { System }\end{array}$ & Description & Supporters & Opponents & Outcome \\
\hline $\begin{array}{l}\text { Pacific } \\
\text { Northwest } \\
\text { Electric Power } \\
\text { and } \\
\text { Conservation } \\
\text { Planning } \\
\text { Council } \\
\text { (NPPC) }\end{array}$ & $\begin{array}{l}\text { Product of } 1980 \text { Pacific Northwest Electric Power } \\
\text { Planning and Conservation Act. Council comprised } \\
\text { of two representatives from each of the four } \\
\text { northwest states. Charged with developing regional } \\
\text { power plan and a fish and wildlife program to } \\
\text { balance needs of energy and fish. Agencies must } \\
\text { consider Council programs in making decisions but } \\
\text { are not bound by them. Name subsequently changed } \\
\text { to Northwest Power and Conservation Council } \\
\text { (NPPC). }\end{array}$ & \multicolumn{2}{|c|}{$\begin{array}{l}\text { Power Act was a compromise between } \\
\text { regional power customers and utilities } \\
\text { seeking legislative response to the } \\
\text { region's hydro-thermal crisis and } \\
\text { fisheries advocates. }\end{array}$} & $\begin{array}{l}\text { Operational } 1981 \text { to } \\
\text { present. } \\
\text { Influence in broader } \\
\text { governance issues } \\
\text { somewhat marginalized } \\
\text { by the Council's } \\
\text { relatively limited scope } \\
\text { and upon the first salmon } \\
\text { ESA listings in 1991. }\end{array}$ \\
\hline $\begin{array}{l}\text { Tribal } \\
\text { members on } \\
\text { Power and } \\
\text { Conservation } \\
\text { Council }\end{array}$ & $\begin{array}{l}\text { Option presented in the PNW governors' } 1998 \text { letter } \\
\text { to the region. Called for the governors to allocate } \\
\text { some of the seats on the Power and Conservation } \\
\text { Council to tribal members. Proposal called for no } \\
\text { changes to the Power Act. No federal members. }\end{array}$ & Not identified. & Not identified. & Not enacted. \\
\hline $\begin{array}{l}\text { Regional } \\
\text { Resources } \\
\text { Council }\end{array}$ & $\begin{array}{l}\text { Option presented in the PNW governors' } 1998 \text { letter } \\
\text { to the region. Would replace the Power and } \\
\text { Conservation Council, exercising ESA and Power } \\
\text { Act responsibilities. Membership of state and tribal } \\
\text { representatives with no federal members. Federal } \\
\text { agencies would be required to act consistent with } \\
\text { council plans. }\end{array}$ & Not identified. & Not identified. & Not enacted. \\
\hline
\end{tabular}


Table 8-5. (Continued)

Governance Systems under the State Cooperation Model

\begin{tabular}{|c|c|c|c|c|}
\hline $\begin{array}{l}\text { Governance } \\
\text { System }\end{array}$ & Description & Supporters & Opponents & Outcome \\
\hline $\begin{array}{l}\text { Northwest } \\
\text { Rivers } \\
\text { Commission }\end{array}$ & $\begin{array}{l}\text { Option presented in the PNW governors' } 1998 \text { letter } \\
\text { to the region. Called for a ten-person commission } \\
\text { comprised of two governor-appointed members from } \\
\text { each state and two tribal members appointed by the } \\
\text { Secretary of the Interior. An advisory council would } \\
\text { assist in river operations, fish resources and facilities } \\
\text { (presumably hatcheries), fish harvest, agriculture and } \\
\text { irrigation, and public lands management. Not clear } \\
\text { if this Commission would replace the Power and } \\
\text { Conservation Council or operate alongside of it. }\end{array}$ & Not identified. & Not identified. & Not enacted. \\
\hline $\begin{array}{l}\text { Comprehensive } \\
\text { River Agency }\end{array}$ & $\begin{array}{l}\text { Proposed in the PNW governors' } 1998 \text { letter to the } \\
\text { region. Patterned after the Delaware River Basin } \\
\text { Commission. Participation would be limited to four } \\
\text { PNW states and one or more presidentially appointed } \\
\text { federal representatives. Membership would include } \\
\text { tribes, although the allocation of tribal seats was not } \\
\text { specified. Purpose to prepare long range and annual } \\
\text { plans recognizing the integrated nature of the river } \\
\text { system. Role of the federal agencies was not } \\
\text { specified, implying that they act to implement the } \\
\text { river agency's plans and decisions. }\end{array}$ & Not identified. & Not identified. & Not enacted. \\
\hline
\end{tabular}




\section{The Three Sovereigns Model.}

The Three Sovereigns Model was a direct outgrowth of the growing awareness of the wide-ranging impacts of that ESA salmon listings in the 1990s were going to have throughout the basin. The model name is borrowed Governor Kitzhaber's 1997 suggestion to implement a "Three Sovereigns" process of state, federal, and tribal leaders to oversee policy and development of the Columbia Basin. What separates this model from the others was the inclusion of regional Indian tribes as co-equal management partners.

Arguably, the Regional Implementation Forum established under NMFS' 1995 biological opinion represented the first system under this model. The Regional Forum envisioned an Executive Committee of state, federal, and tribal leaders to oversee the biological opinion's implementation. However, the scope of the Regional Forum's structure was more oriented to implementation of federal agency actions than oversight of Basin policy in general. Consequently, this study considered the Forum under the Federal Cooperation Model.

This study categorized two proposals under this model, one of which was enacted. These are listed below and summarized in Table 8-6:

- The Three Sovereigns Process proposed by Governor Kitzhaber in 1997 and included in the Council's list of governance alternatives in 1998. Not enacted.

- The Columbia Basin River Forum, established 1999-2000. 
Table 8-6.

Governance Systems under the Three Sovereigns Model

\begin{tabular}{|c|c|c|c|c|}
\hline $\begin{array}{c}\text { Governance } \\
\text { System }\end{array}$ & Description & Supporters & Opponents & Outcome \\
\hline $\begin{array}{l}\text { Three } \\
\text { Sovereigns }\end{array}$ & $\begin{array}{l}\text { Proposed by Governor Kitzhaber in } 1997 \text { and } \\
\text { fleshed out as a governance proposal by the NPPC } \\
\text { in } 1998 \text {. Envisioned as a "principal-level forum" } \\
\text { consisting of representatives from the four PNW } \\
\text { states, thirteen tribes, and one federal } \\
\text { representative. Principal group to be supported by } \\
\text { a senior staff-level committee with four seats each } \\
\text { allocated to the states (one per state), federal } \\
\text { agencies, and thirteen tribes. No change required in } \\
\text { existing law; would be established by memorandum } \\
\text { of agreement among participating sovereigns. In } \\
\text { effect, proposal mirrored the purpose and structure } \\
\text { of the Regional Forum Executive Committee but } \\
\text { broadened its scope of activities. }\end{array}$ & $\begin{array}{l}\text { Governors and } \\
\text { regional } \\
\text { congressional } \\
\text { delegation generally } \\
\text { supportive of new } \\
\text { governance system. } \\
\text { Supported "Three } \\
\text { Sovereigns" as } \\
\text { starting point for } \\
\text { discussion. }\end{array}$ & $\begin{array}{l}\text { Non- } \\
\text { governmental } \\
\text { river users such as } \\
\text { irrigation } \\
\text { associations, } \\
\text { navigation } \\
\text { interests, and } \\
\text { utilities. }\end{array}$ & $\begin{array}{l}\text { Not enacted; modified to } \\
\text { in response to river user } \\
\text { concerns; became the } \\
\text { CRBF. }\end{array}$ \\
\hline $\begin{array}{l}\text { Columbia } \\
\text { River Basin } \\
\text { Forum (CRBF) }\end{array}$ & $\begin{array}{l}\text { Established in response to the Oregon governor's } \\
\text { "Three Sovereigns Process." Established under a } \\
\text { memorandum of agreement signed in 1999. Intent } \\
\text { was to establish consensus-based collaborative } \\
\text { decision-making process pending legislative action } \\
\text { on a new governance system (which never } \\
\text { materialized). Existed alongside the Regional } \\
\text { Forum and Northwest Power and Conservation } \\
\text { Council. }\end{array}$ & \multicolumn{2}{|c|}{$\begin{array}{l}\text { Compromise between federal agencies } \\
\text { and proponents of governance models } \\
\text { favoring stronger state control over } \\
\text { FCRPS operations and fish restoration } \\
\text { efforts. }\end{array}$} & $\begin{array}{l}\text { Effectively ceased to } \\
\text { exist in } 2000 \text { due to } \\
\text { inability to reach } \\
\text { consensus, funding } \\
\text { issues, and loss of } \\
\text { interest by participants. }\end{array}$ \\
\hline
\end{tabular}


In addition to identifying the specific systems and models debated and adopted within the Basin, this study also analyzed them for patterns. The purpose of this analysis was to determine if such patterns existed that could inform both this study's research question on the apparent paradox of governance and future regional governance efforts. As it turned out, this study found two such patterns to exist.

\section{$\underline{\text { Patterns of Change between Systems and Models }}$}

This study characterized changes in governance systems under two general patterns. The first pattern concerned changes in systems within a given governance model. This category included instances where system participants recognized structural weaknesses within the system and voluntarily acted to improve upon them. Examples included the non-conflictual rolling of the Bonneville Advisory Board into the Columbia Inter-Agency Committee. Weaknesses in decision-making and the lack of a statutory basis for dependable CBIAC funding led in turn to creation of the Pacific Northwest River Basins Commission (DeLuna, 1997; Ogden, 1997).

This category also included situations where structural weaknesses within a system were recognized but for which participants lacked compelling reason to change, resulting in system termination. Examples included the non-controversial dissolution of the Northwest States Development Committee in 1944, the disbanding of the Pacific Northwest Governors' Power Planning Committee in 1958, and the collapse of the Columbia River Basin Forum in 2000 (McKinley, 1952; Bessey, 1963; 
Norwood, c.1981). This pattern is not further discussed here as it did not offer much insight into this study's primary research question.

The more interesting and informative is the pattern identified for changes between models. These changes were most often conflictual in nature as institutional actors who believed their interests and aspirations were not being adequately addressed under existing system(s) sought opportunities to challenge the status quo. In each case, the opportunities for change presented themselves through situations of such critical significance to challenge existing governance arrangements and establish new ones established in their place.

This section examines this second pattern in some depth. It begins by identifying the critical situations that allowed dramatic change between governance models to occur. It then maps the evolution of the systems and models identified in the previous section in relation to the critical situations experienced. It concludes by presenting a model of governance system selection as determined from the findings of this study.

The catalytic role of critical situations.

Giddens (1984) defines critical situations as those situations where the “established modes of accustomed life are drastically undermined or shattered" and “circumstances of radical disjuncture of an unpredictable kind which affect substantial numbers of individuals, situations that threaten or destroy the certitudes of institutionalized routines” (Giddens, 1984, p. 60-61). Under Giddens' construct, critical situations are identified by their practical effect and are therefore only apparent 
in hindsight. This point is important in understanding the failure of the CRBF in particular and the nature of Basin governance change in general.

Recall that the reasons given for the need for the CRBF included concerns over the pending NMFS biological opinion, collapse of the Regional Forum Executive Committee, the potential for Snake River dam removal, and energy industry deregulation coalesced in the period 1996-1997. Regional leaders saw any or all of these as risking a loss of regional control over decisions regarding salmon and all or part of the FCRPS and its attendant benefits. Consequently, regional leaders deemed them critical enough to warrant a new decision-making governance system.

However, the perceived threat never materialized to the degree necessary to inspire significant change. All either proved to be less threatening than originally feared or were resolved through process other than the CRBF. Consequently, by definition, those circumstances did not pose a critical situation in the sense used by Giddens (1984). The CRBF thus failed in part due to lack of a sufficient crisis that would cause its members to structure it in a way to ensure its continuation over the long term.

This study identified four critical situations that challenged the status quo to the point where opportunities for change opened not just between existing governance systems but also between models. The onset of the Great Depression (as symbolized by the stock market crash of 1929), the end of World War II, the issuance of BPA's notice of insufficiency (symbolizing the hydro-thermal financial crisis), and the first listing of Snake River salmon under the Endangered Species Act provided those 
opportunities. These situations framed the narrative presented in Chapters 4 through 7. This study found that changes between models could be either conflictual or nonconflictual in nature.

In three cases, the transition between governance models was decidedly conflictual. The onset of the Depression resulted in a bitter debate among Market Model, Iron Triangle, and Valley Authority model proponents that resulted in the compromise that created the Bonneville Power Administration and introduced the Federal Cooperation model through the Bonneville Advisory Board. The hydrothermal crisis of the 1970s provided an opening for fishery, tribal, and environmental interests to challenge the federal-centric Pacific Northwest River Basins Commission and establish the state-led Pacific Northwest Electric Power and Conservation Planning Council (McKinley, 1952; Bessey, 1963; Bodi, 1979 and 1995; Norwood, c. 1981; Blumm, 1982; Hemmingway, 1983; DeLuna, 1997; Pope, 2008; Crampton and Espenson, 2009). The ESA salmon listings in 1991 reopened tensions between proponents for state-led and federal-led efforts and resulted in reestablishment of a federal lead in governance initially through the Fish Operation Executive Committee and later the Regional Forum.

Governance changes brought about by critical situations did necessarily involve conflict. Whereas events around the end of World War II precipitated significant changes in Columbia Basin governance systems, those changes were relatively conflict free. Congress eliminated funding for New Deal programs that resulted in the termination of the Pacific Northwest Regional Planning Commission in 
1943. This was a Congress still holding slender Democrat majorities in both houses, indicating a joint recognition between both parties that the need for expensive New Deal programs and agencies was nearing its end. Shortly after abolishment of the PNWRPC, the federal agency participants agreed to establish the CBIAC and invited the continued participation by the states that had been PNWRPC members. A recognized need for interagency cooperation in managing the hydropower system, coupled with the weaknesses of the Bonneville Advisory Board and the nascent threat of some form of valley authority system imposed by Congress, led the Board's federal members to create interagency committees at the federal (Federal Inter-agency River Basin Committee) and regional (Columbia Basin Inter-agency Committee) levels in (McKinley, 1952; Bessey, 1963; Norwood, c. 1981; DeLuna, 1997). This change from a State Cooperation based system (PNWRPC) to a Federal Cooperation based system (CBIAC) appears to have occurred without major controversy.

The genealogy of Columbia Basin governance systems.

Figure 8-1 illustrates the trajectory of the Basin's governance history and the causal relationships between critical situations and governance systems and models. The figure maps the evolution of the various governance systems and models identified in this study and maps them in the general chronological order in which they were proposed or enacted. Critical situations are shown in the vertical scale on the left. Solid line arrows indicate where direct evolutionary linkages were found between systems. The figure demonstrates two important findings. First is the fact that the Basin has continuously employed some form of inter-jurisdictional governance system 
since establishment of the Pacific Northwest Regional Planning Commission was in 1934. The second is the connection between each system enacted with its predecessors. In effect, Figure 8-1 presents the CRBF's institutional family tree.

Figure 8-2 illustrates the relationship among the social and political context of the the periods leading up to each critical situation, regional issues, and relevant participants to the governance systems enacted. The figure summarizes the key issues and participants that influenced governance system debates and selection as discussed above.

The trajectory of governance system evolution discussed above and illustrated in Figures 8-1 and 8-2 suggests a recurring pattern that the region seems to follow. The pattern of Columbia Basin governance structuration.

The six governance models reflect a long-running four-way struggle among proponents for the prerogatives and authorities of individual federal agencies, valley authority proponents, advocates for state control over regional resources; and commercial interests advocating market mechanisms as to which system provides the best allocator of resource values and optimum economic development. Historically, the commercial interests have generally allied with state and federal agencies holding jurisdiction over their resource area of interest (such as navigation interests and the Corps; irrigation interests and the Bureau of Reclamation; public power interests and the Bonneville Power Administration; fishing interests and state departments of fish and game) in favor of Market or Iron Triangle Model systems. 
Figure 8-1.

Governance Models, Systems, and Critical Situations

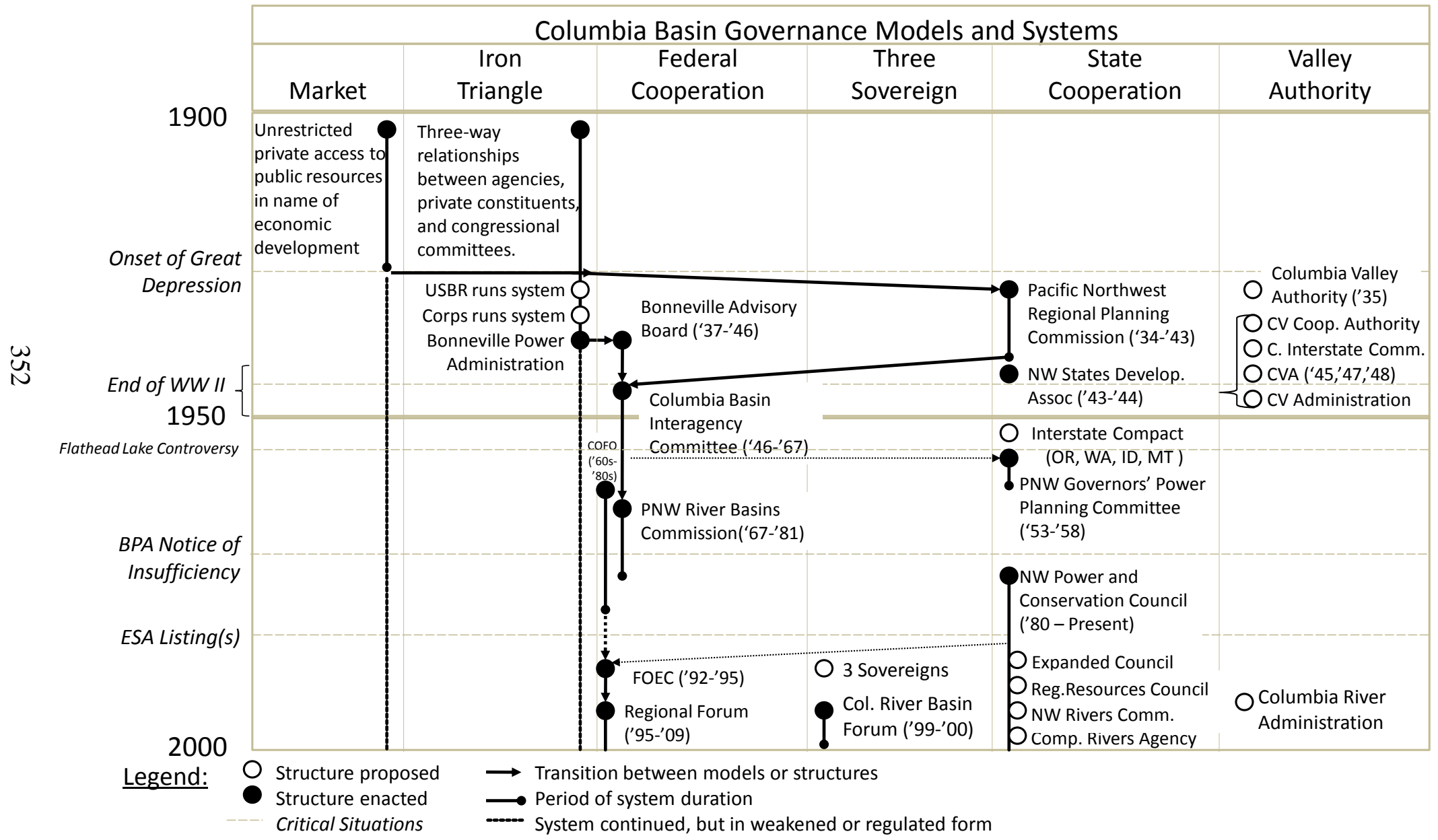


Figure 8-2.

Critical situations, Context, Issues, Participants, and Systems

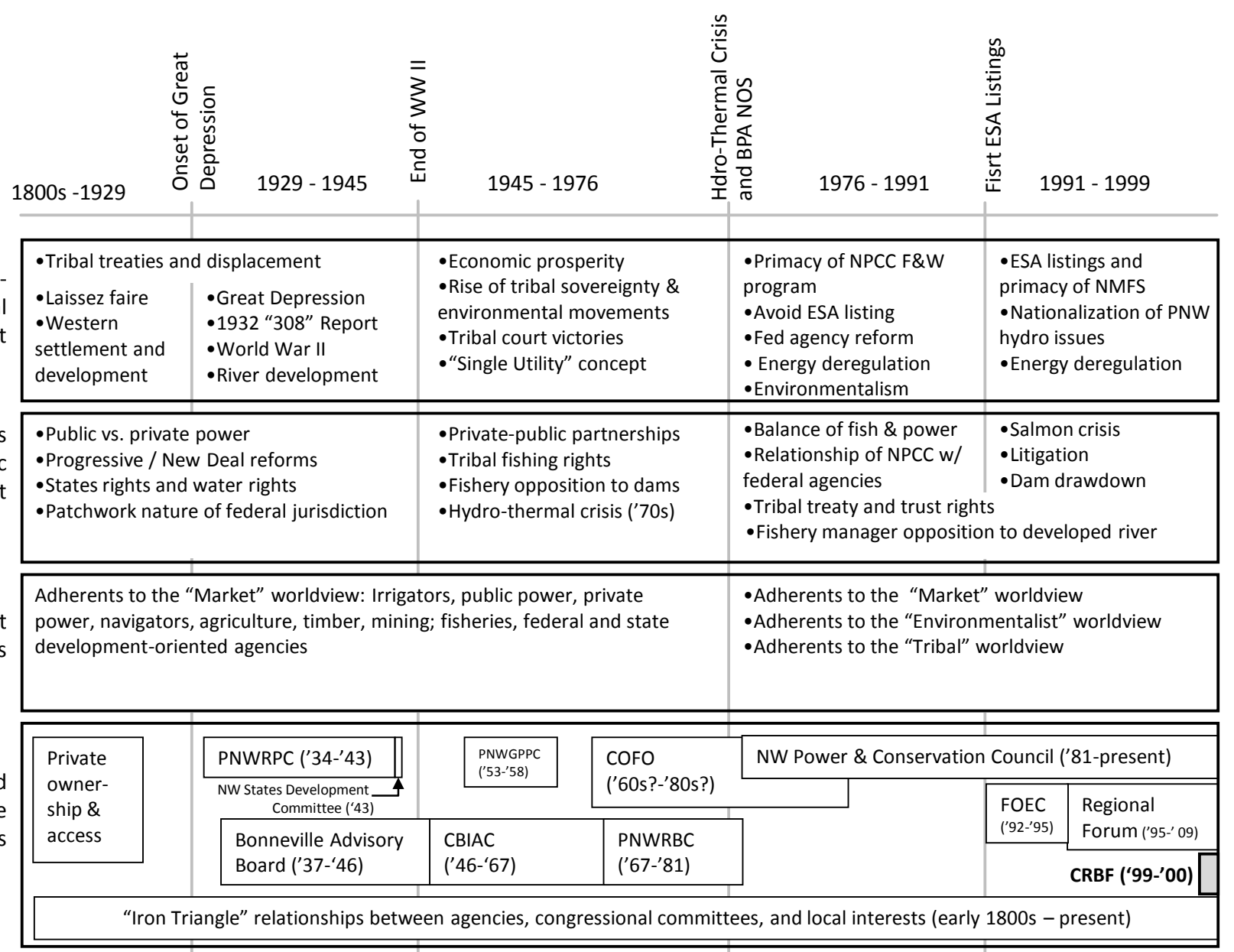


Figure 8-3 illustrates these historic lines of tension. Historically, commercial interests resisted the creation of a centralized valley-authority system that could impinge on their plans for economic development or encroach on the prerogatives of supportive individual agencies. Proponents of state control sought greater influence in regional decision-making, often proposing systems that would require federal agencies to operate consistent with state plans and programs. Proponents of strong, central federal authority cited the exploitation of natural resources by market forces, the inefficiencies of resource management by individual agencies, the lack of coherent central planning, and the lack of alignment between the political boundaries of the states and ecological boundaries of watersheds. The systems enacted at any given point in time (displayed in Figures 6-1 and 6-2 above) were more often than not compromise solutions among these competing perspectives.

Figure 8-3.

Traditional Lines of Tension in Columbia Basin Governance

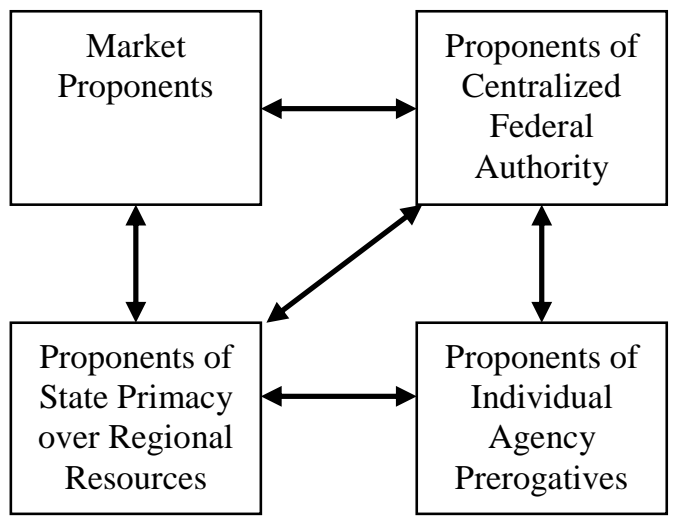


The historic record in general and the CRBF experience in particular reveal a pattern to governance structuration as illustrated in Figure 8-4. The box on the left indicates the traditional participants in Columbia Basin issues as identified in this study. It portrays status quo governance systems and the relationships and lines of conflict among regional institutions, thus further elaborating on the lines of conflict introduced in Figure 8-3. These relationships and systems existed in some form of stability until faced one of the four critical situations identified earlier.

The emergence of a critical situation may or may not result in conflict. If it does, it reopens the standing lines of regional conflict among the Basin's major institutional actors. Regional political and/or institutional leaders then initiate a series of steps that have been repeated to the point of ritual in the Northwest. Institutional leaders and representatives engage in calls for rational processes to resolve the crisis, convene meetings, initiate negotiations, and sometimes litigate. Over time, they reach agreement on one or more new system. These new systems eventually become stabilized pending emergence of the next critical situation.

This concludes this study's findings regarding the pattern that regional leaders seem to follow when confronted with challenges to existing governance systems. Of particular interest is the tendency of this process to yield relatively consistent results. Regional leaders have consistently settled on one of the collaboration-oriented models and have historically rejected models with authority to render final decisions. The next section presents the study's findings with regard to this phenomenon. 
Figure 8-4.

The Historical Pattern of Basin Governance System Establishment

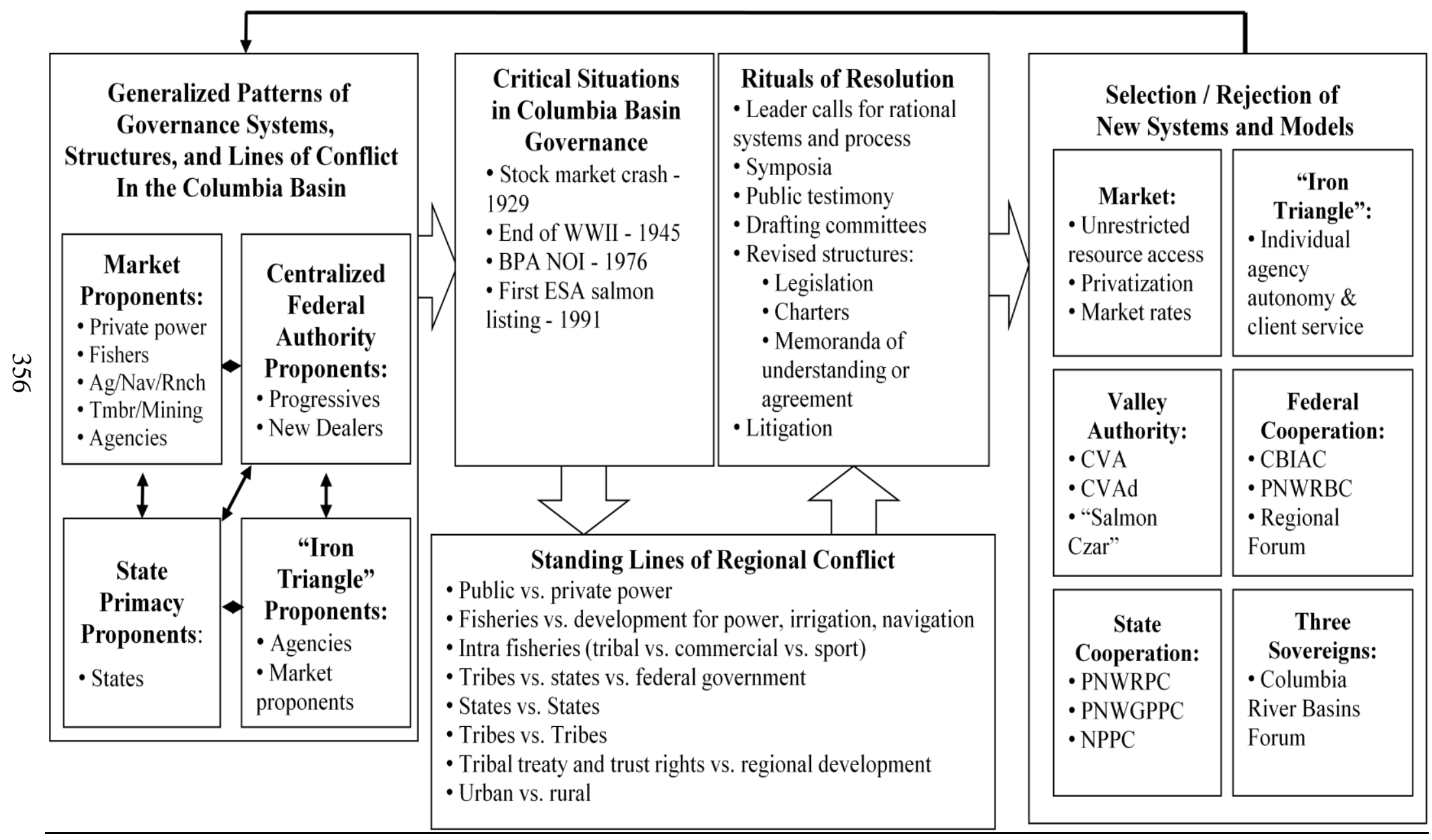




\section{The Preference for Collaboration-Oriented Governance Systems}

McKinley (1952) described that in 1944, BPA Administrator Paul Raver invited twenty select community leaders to discuss with him the impact of the BPA program on the life of the region. This call was the beginning of the Bonneville Regional Advisory Council, ${ }^{148}$ designed to provide a two-way communication between the Administrator and regional leaders regarding system policies and for those leaders to provide recommendations on system operations. Council participation was by invitation only, with Administrator Raver limiting admittance to those holding "a friendly acceptance of the basic policies established by Congress for the BPA. In choosing the council members, the administration has regarded such acceptance as an essential common denominator in obtaining useful advice. Consequently, this advisory group excludes any person who has actively opposed the Bonneville program.” (McKinley, 1952, p. 200). McKinley (1952) goes on to justify this exclusionary practice by stating, "After all, an administrator could hardly expect to obtain useful advice from people in basic disagreement with his job" (p. 200, emphasis added). McKinley (1952) underscores a fundamental truism: it is far easier to reach agreement on complex issues if you limit the discussion to those sharing a common worldview and value set with regard to the issue in question.

It also underscores the centrality of worldview and values as held by participants in the governance discussions. Up until the establishment of the

\footnotetext{
${ }^{148}$ This committee is not to be confused with the Bonneville Advisory Board mandated in the 1937 Bonneville Project Act. This committee was advisory only and did not execute governance functions as defined for this project. It was not, therefore, identified as a governance system for the purposes of this study.
} 
environmental and tribal sovereignty movements as viable forces in the Northwest, meaningful participation in decision-making was limited to those holding the "market" worldview. As previously discussed, adherents to the tribal and environmental worldviews, although scoring victories in some areas were historically unable to affect FCRPS decision making to the degree that they wished.

In establishing governance systems, the region has had to face the tension between establishing decision-oriented systems with a capacity for problem solving and those that would allow greater inclusion of regional worldviews and values. The historic trend has been to select systems from that favor inclusion over decisionmaking. Of the eleven systems enacted, six were formed under the Federal Cooperation Model, four under the State Cooperation Model, and one under the Three Sovereigns Model. None was enacted from the decision-oriented systems offered under the Market, Iron Triangle, and Valley Authority models. Why? The historical record and $\mathrm{CRBF}$ experience suggest the following reasons.

First is the sheer number of competing interests directly or indirectly involved with the FCRPS. In contrast, as bitter and hard-fought as they were, the debates between timber interests and environmentalists over the spotted owl and between state and tribal fishery managers over salmon harvest involved a relatively small number of affected players. Conversely, the scope of interests affected by the hydrosystem system includes almost every major social entity in the Pacific Northwest. Efforts to establish governance systems over the system unveiled fault lines of conflict among fishery and energy interests; fishery and development interests; the states; states and 
tribes; individual tribes; federal agencies; urban and rural communities; upriver and downriver interests; public and private power advocates; and others. These groups were represented by hundreds of interest based organizations and associations of organizations. These groups have been disinclined to give up some aspect of their core interests to benefit another. Regional parties agreed to the collaborative systems selected because they pose the least threat to established interests, practices, and arrangements.

Second, and related to the first, is the role of worldviews. Prior to the hydrothermal crisis of the 1970s, the dominant voices in the region controlling governance processes were members of the commercial market worldview. These entities were comprised of interests that benefit from commercial development of river resources, such as manufacturers, irrigators, navigators, hydropower proponents and sports and recreational fisheries managers. Debates within this group primarily involved disputes over goals and interests. These debates all took place within the paradigm that the commercial exploitation of the river was acceptable, inevitable, and morally supportable based on economic growth. It was not until the late 1960s and early 1970s with the regional hydro-thermal crisis, the increase in environmental legislation (especially NEPA and the ESA), and the rise of the tribal sovereignty movement that parties with a different value set began to challenge the premises under which the river had originally been developed. These other parties emphasized respect for tribal treaty rights and argued for operational adjustments and/or dam removal in the interests of improving fish harvest and for the intrinsic ecological value of a 
natural river system. Entities not sharing the same market-oriented worldview sorely tested the Basin's traditional approach to development, such as when the tribes were included in the Regional Forum and Columbia River Basin Forum. Holders of one worldview have proven reluctant to submit to a regional governance system dominated by adherents to another.

Third is the fact that the FCRPS is a federally owned and operated system. The sovereignty and appointments clauses of the United States Constitution State frequently confounded state and tribal efforts to assert greater control. The language of the 1980 Power Act this reflects this reality with its provision that, should a court hold the Council to be unconstitutional, it be reformed as a federal agency with Council members to be appointed by the Secretary of Interior. Absent supporting federal legislation that realigns existing agency authority and prerogatives, establishing a decision-oriented system would prove constitutionally problematic.

Fourth is the federal agencies' historical experience that cooperation and coordination provide their best defense against external imposition of a more robust valley authority type arrangement. The region's states and commercial interests have generally shared agency interest in avoiding a robust decision-oriented system. Regional institutions held different reasons for supporting such an approach:

- Federal agencies: Federal agency goals were to protect discretionary authority and preclude oversight over core functions by a valley authoritytype structure (Bessey, 1963; Scheufele, c.1970) and to provide for coordination for more efficient operation of the FCRPS (Scheufele, 
c.1970). This is not to say interagency competition did not exist

(McKinley, 1952; Reisner, 1993; Clarke and McCool, 1996; Pisani, 2002)

but that regional federal leaders frequently rose above parochial disputes in the interest of better coordination of the hydropower system and its related purposes.

- Northwest States: The states based their support for governance on protecting state interests affected by the operation of what is in fact a federal system (Ogden, 1997). Prominent among these interests was ensuring that the benefits of the hydropower system and its multiple purposes remain in the Northwest and maintaining access to federal programs and resources to advance state interests (Vogel, 2007).

- Regional Indian Tribes: This study found mixed tribal motivations regarding regional governance. Some tribes like the Nez Perce, insisted on the paramount nature of their treaties and argue that the only appropriate governance relationship for treaty tribes is with the federal government as trustee of Indian resources. Others, such as the Spokane, argue that the only way the region can address its natural resource issues is through joint decision-making forums of the federal government, states, and tribes meeting as co-equals. Confounding tribal participation is a history that undermined trust due to fluctuations in federal Indian policy (Pevar, 2002), fishery disputes with the states (Taylor, 1999; Dompier, 2005, and longstanding disputes with other tribes over land and resource access. 
- Non-governmental entities: Representatives of private commercial interests and non-profit organizations (such as environmental groups) varied widely regarding governance model preferences. In general, they tend to support systems that minimize encroachment into the discretionary or mandated decision-making by supportive agencies and constrain the actions of agencies whose missions do not align with organization goals. As a result, regional institutions have tended to see collaboration-oriented governance systems as more in keeping with their core interests than more decision-oriented systems.

Fifth is recognition of the practical need by the federal hydropower agencies to coordinate their various programs with regard to the Columbia. This started shakily with the Bonneville Advisory Board in 1937 then progressed and improved with establishment of the CBIAC, PNWRBC, and later Regional Forum.

The 1937 Bonneville Project Act in effect construed what became the FCRPS as a shared operation by BPA, the Corps of Engineers, Bureau of Reclamation, Federal Power Commission, and Forest Service. The subsequent level of agency involvement and cooperation has varied. The Bonneville Advisory Board and Committee on Fish Operations enjoyed participation from a relatively small number of the Basin's federal agencies, whereas the PNWRPC, PNWRBC and CBIAC saw support from almost all of them. The broad plans produced by the PNWRPC, PNWRBC, and CBIAC were endorsed by all member agencies. ${ }^{149}$ In time, the

\footnotetext{
${ }^{149}$ It is not clear from the sources used in this report as to the degree to which single regional plans developed by the PNWRPB, CBIAC, and PNWRBC influenced individual agency programs. In other
} 
agencies came to see some degree of cooperation as being in their collective best interest.

Sixth is the consistent reluctance of the federal government to reorganize itself along lines more conducive to efficient resource management. Such realignments have been proposed in the pass, most dramatically illustrated by calls to consolidate resource agencies under a Department of Natural Resources with subordinate field offices organized around watersheds (Ogden, 1997). Related to this is the historic reluctance of Congress to change its authorization and appropriation procedures to be more supportive of regional institutional arrangements, despite at least two formal reports recommending they do so.

As a result, collaboration-based systems are the historically preferred alternatives for the Northwest. They provide a framework for institutional dialogue and have a history of some achievement. They also do not threaten institutional interests with the authority to make decisions contrary to in institutional goals and programs. The preference for collaboration-oriented models thus partially explains the paradox of Northwest governance.

This concludes discussion of the findings regarding the regional preference for collaborative governance systems. This study's conclusions, drawn from the previously discussed findings, are presented below.

words, not clear that projects agency constituents promoted, but were either not included or received low priority in favor of more regionally advantageous projects. This is an area of further inquiry in order to determine the efficacy of centralized planning absent a supportive congressional authorization and funding process. 


\section{Conclusions}

The findings presented above lead to six general conclusions. These are listed below and discussed in further detail in the sections that follow:

- Regional leaders will continue to support multijurisdictional governance systems.

- The apparent paradox of Basin governance is inherent in the Basin's preference for a collaborative approach to governance.

- Third, statutory support for collaboration-oriented governance systems is neither a necessary nor a sufficient condition to ensure system success. Conversely, statutory support is a necessary condition and may be a sufficient condition for any decision-oriented system that the region may desire to establish.

- The region is highly unlikely to ever support an authoritative decision-oriented governance system.

- Critical situations will continue to emerge and provide catalytic opportunities for change between models and systems.

- The institutional analysis used in this study proved inadequate to fully understand the paradox of Basin governance.

$\underline{\text { Regional leaders will continue to support multijurisdictional governance systems. }}$ On the surface, establishment of a multi-jurisdictional governance system may seem a superfluous waste of time and money. The region has multiple federal, tribal, and state agencies assigned to manage regional resources and staffed with competent, 
skilled public servants. These agencies are generally well supported with sufficient funding by their respective legislatures. All are well established. Meanwhile, other regions of the country seem to get by without the myriad sorts of governance systems found in the Columbia River Basin.

Yet the region clearly perceives a need for some form of multijurisdictional governance system. The Columbia River Basin has had at least one system continuously in place since establishment of the Pacific Northwest Regional Planning Commission under the New Deal in 1934. Many of these systems enjoyed the support of regional leaders and existed successfully for many years. Examples include the Pacific Northwest Regional Planning Commission (ten years), the Columbia Basin Inter-Agency Committee (twenty years), the Pacific Northwest River Basins Commission (fourteen years), The Northwest Power and Conservation Planning Council (thirty years and counting) and the Regional Forum (fourteen years, less Executive Committee). This fact is by itself evidence of a perceived regional need on the part of institutional leaders.

Records and accounts available for the Columbia Basin Inter-Agency Committee (Scheufele, c.1970), Northwest Power and Conservation Council (NPPC, 2007) and the Columbia River Basin Forum (press accounts, meeting notes, and facilitator notes) provide reasons for this broad institutional support. From these accounts can be concluded the following:

- Regional leaders seek multijurisdictional governance systems that transcend individual federal and state agency and tribal jurisdiction in order 
to objectively resolve (or preclude) problems of competing interests among regional institutions.

- The intent of regional leaders is to reach joint decisions through rational discussions inclusive of all relevant regional parties.

The apparent paradox of Basin governance is inherent in the Basin's consistent choice of a collaborative approach to governance.

The historic regional preference for collaboration-oriented governance systems is not likely to change. There is an inherent tension between the desire for inclusiveness and the desire for decision-making. The greater the degree of inclusiveness, the greater the likelihood of conflict among participant interests and/or their respective worldviews. In essence, the desire for better decisions through inclusiveness works against the intent to resolve or preclude problems.

Prior to the 1930s, regional natural resource-related decisions were made either through uncoordinated commercial enterprises responding to market supply and demand (the Market Model) or by individual federal agencies often working in concert with constituencies and Congress but independently of each other (the Iron Triangle Model). These were decision-oriented systems, with decisions made to meet the goals and objectives of those who made them. Progressive and New Deal proponents sought to curb the cumulative waste and excesses of those models through more rigorous government regulation and greater governmental involvement in regional resource planning. The interest in centralized planning resulted in creation of the state-centric PNWRPC in 1934, the region's first experiment with the State Cooperation Model. 
The interest in greater central control of resource decisions resulted in Progressive and New Deal proposals for a Columbia Valley Authority patterned after the Tennessee Valley Authority. The Valley Authority Model represents a third decision-oriented model that the regional historically rejected. The compromise between valley authority proponents and proponents of decision by individual agency resulted in the Bonneville Project Act of 1937, creation of the Bonneville Power Administration, and establishment of the Bonneville Advisory Board - marking the first experiment the Federal Cooperation Model. Thus, the collaboration-oriented approach was hard-wired into the Basin's first two governance systems.

Ever since the region has relied on systems oriented toward the inclusion of multiple parties. Up until the 1970s, "inclusiveness" was largely limited to parties sharing the commercial-market worldview of natural resource development. Since the 1970s, parties holding dramatically different worldviews gained access to governance decisions due to due to the tribal sovereignty and environmental movements. Whereas earlier debates over basin resource development were based on economic priorities and allocation of benefits, these new worldviews questioned whether such development should be allowed at all.

From this discussion the following suite of conclusions may be drawn:

- The region derives value and benefit from collaboration-oriented systems established under the Federal Cooperation, State Cooperation, and Three Sovereign models. Despite recurring frustration over the inability of such systems to solve the region's more intractable problems, regional leaders 
find that living with those weaknesses is preferable to the risks to core institutional interests posed by decision-oriented model alternatives.

- The concept of "relevant parties" has evolved over time. Originally including only development-oriented agencies and state governors' offices, it has grown to include fishery interests, be more sensitive to environmental concerns, and to a willingness to include regional tribal leaders as co-equal management partners.

- The region will likely continue its tradition of establishing new governance systems from the Federal Cooperation, State Cooperation, and Three Sovereign models. The emergence of the tribes as a recognized relevant party will likely mean a preference for finding a workable Three Sovereigns system.

- The success of collaboration-based systems in solving difficult problems will be limited.

- Frustrations over the inability of collaboration based systems to resolve significant issues will likely result in future system and model changes as participants take advantage of critical situations to emplace systems more to their liking.

The necessity and sufficiency of system statutory support.

Of the eleven collaboration-based governance systems enacted in the Columbia Basin between 1934 and 2000, three - The Bonneville Advisory Board, The Pacific Northwest River Basins Commission, and the Northwest Power and Conservation 
Council - were established in law as detailed above. One system - the Northwest Interstate Compact - was authorized in federal law but never established. A fifth system - the Pacific Northwest Regional Planning Commission - enjoyed indirect statutory support through the National Industrial Recovery Act of 1933, which created the Public Works Administration (PWA). It authorized the PWA to establish additional planning agencies, among which was the central planning committee (a committee that underwent numerous name changes during the course of its existence). This committee went on to establish state and regional planning boards, of which the PNWRPC was one. Thus, although authorized by law, it was not specifically established in law as were the Bonneville Advisory Board or Northwest Power and Conservation Council. The remaining seven enjoyed no statutory support but were established instead through voluntary agreement among participants.

There is some correlation between system effectiveness and system support in law, if one judges effectiveness as the accomplishment of the goals specified for a given organizational entity. . The PNWRPC, PNWRBC, and NPPC all existed for extended periods of time and produced reports and plans enjoying broad institutional support (Bessey, 1963; Norwood, c.1980; Vogel, 2007). Alternatively, the Bonneville Advisory Board essentially ceased to function upon completion of its World War II related tasks, although it nominally existed until replaced by the CBIAC in 1946. The Northwest Interstate Compact, although negotiated over a span of almost twenty years and authorized in law by Congress, failed to win ratification in the state legislatures 
(McKinley, 1952; Bessey, 1963; Norwood, c.1980). Consequently, support in law does not guarantee collaborative system success.

Systems established through voluntary agreements among participants enjoyed similarly mixed records of achievement. The Columbia Basin Interagency Committee and the Committee on Fish Operations, which later became the Fish Operations Executive Committee and later yet the Regional Forum, all enjoyed extended periods of cooperative existence and were successful within the parameters of their formation. Conversely, the Northwest States Development Association, Pacific Northwest Governors' Power Planning Committee, and Columbia River Basins Forum existed for only short periods of time and produced little of consequence (Bessey, 1963; Scheufele, c. 1970; Norwood, c.1980).

Thus, the absence of statutory support does not preordain collaborative system failure. Instead, almost by definition, collaborative systems are dependent on the good will of participants, the support of their parent institutions, the degree of rapport among members, and their willingness to compromise within the bounds of their statutory authority. They require voluntary cooperation to resolve differences in agency interests and mediate differences in institutional values.

In contrast to collaboration-oriented governance systems, statutory support is necessary for adoption of a decision-oriented governance system. This is because of the fragmented nature of Basin institutions and the myriad laws, regulations, and directives guiding regional institutional activities (NPPC, 1996; GAO, 2004). 
All of the decision-oriented system proposals found in this study carried with them recommendations to substantively reorder existing institutional relationships. For example, the bill by Washington Representative Knute Hill in 1935 transferred responsibility for Columbia River development exclusively to the Bureau of Reclamation, assigning to the Bureau responsibilities previously authorized to the Corps of Engineers. Bills by Senators Charles McNary and Frederick Steiwer and Representative Martin Smith submitted the same year would expand Corps of Engineers' authority to include power marketing and transmission in the Lower Columbia. The bill by Senator James Pope and Representative Hill, also submitted in 1935, proposed to establish a Columbia Valley Authority that would transfer the authorities and responsibilities from multiple Basin federal agencies to the jurisdiction of an entirely new agency. The bill submitted by Senator Warren Magnuson in 1949 would subordinate Columbia Basin federal functions of water resources, power generation, and transmission under the supervisory structure of a Columbia Valley Administration. Daniel Ogden offered a more sweeping proposal in 1997, calling for reordering of not just regional agency offices, but a restructuring of the national departments and congressional committee structure as well. The key point is that any system intended to render final decisions must be empowered with the authority to reconcile and, if necessary, override the interests and proclivities of individual regional institutions. Such a system would also require support at the national level either voluntarily provided or enacted through statute - to preclude departmental or congressional actions that may undermine the system's goals and priorities 
(McKinley, 1952; Ogden, 1997). Historically, regional institutional leaders, state political leaders, congressional representatives, and federal agency heads have never collectively supported such a step.

The foregoing discussion leads to the following conclusions:

- Statutory support for collaboration-oriented governance systems is neither a necessary nor a sufficient condition to ensure system effectiveness. Rather, collaborative systems by their nature are dependent on the relationships among institutional participants.

- Conversely, statutory support is a necessary condition and may be a sufficient condition for establishment of a decision-oriented governance system. The authorities and prerogatives of state, federal, and tribal governments and agencies and, to some degree, the relationships among them are all established in law. Any system with the authority to direct agency priorities and prerogatives must therefore have statutory authority to do so. The degree to which institutional relationships among regional agencies, federal departments, and the congressional committee structure are defined in any new authorizing statute will determine the degree of voluntary cooperation that may still be needed.

An institutional reordering of the magnitude needed for an effective decisionoriented system would invest that system with enormous power and influence over the Basin's residents and institutions. Under what conditions could such a reordering be supported? How likely is it to occur? 
The region is highly unlikely to ever support an authoritative decision-oriented governance system.

Calls for greater centralized decision-oriented systems have consistently been made since the 1930s. Recent examples include the suggestions for a "Salmon Czar" to oversee Basin salmon recovery efforts during the Clinton administration and Dan Ogden's 1997 proposal for a Columbia River Administration. ${ }^{150}$ Calls for greater market control have come in the form of proposals to privatize the federal hydropower system or sell it electrical power at market rates (see Munson, 2001). Regional Institutional and political leaders have consistently rejected all of these decisionoriented proposals.

Even if regional leaders were to agree to a valley authority system, they would have to overcome significant structural challenges if such a system were to be effective. Political leaders would have to address the constitutional provisions regarding the sovereignty of federal agencies. They would have to address respective agency authorizing statutes at the federal and state levels. Congress would need to revise their fractured oversight of federal agencies by multiple committees in both houses. Absent any of these steps, the resulting body would default to a collaborativesystem in that it could only advise and not direct federal action.

Consequently, only a governance body that is empowered through legislation, executive order, court order, and/or a binding compact among the states and tribes

\footnotetext{
${ }^{150}$ The "Salmon Czar" suggestion, though frequently made, was never to the knowledge of the author developed into a coherent governance proposal. Consequently, it was not considered in this study.
} 
with the legal authority to override parochial opposition will be able to render decisions or come to compromise on significant differences.

From this discussion come the following conclusions:

- Based on the region's history, institutional leaders are not likely to enact a robust, authoritative system unless a threat emerges of such magnitude that sovereign political leaders and their constituents are convinced that such a system better serves their interests than otherwise.

- An event of such magnitude is highly unlikely. None of the region's previous critical situations - the Great Depression, the end of a world war, the hydro-thermal crisis, or the 1991 ESA salmon listings - was sufficient to put a more decision-oriented system into place. It is hard to imagine one of greater criticality that would.

- Imposition of such a system from outside the region, say by legislative action or Executive order, is equally unlikely given the democratic nature of American decision making, likely state opposition, and the entrenched nature of regional interests and institutions.

Critical situations will continue to emerge and provide catalytic opportunities for change between models and systems.

Regardless of how inclusive and collaborative future governance systems prove to be, parties excluded from the process or who believe the extant system is not meeting their needs will likely take advantage of future critical situations to force change. Future governance model and system changes will likely follow the historic pattern illustrated 
in Figure 8-4 and generalized below in Figure 8-5. Opportunity for change may occur through a critical situation that either reopens traditional lines of conflict as institutions vie for influence or causes leaders to meet on a less conflictual basis. Regardless, there will likely be calls for public meetings, negotiations, testimony to state and/or federal legislators, representatives to meet in negotiation, and other ritualistic exercises intended to arrive at a new system. If successful, these newly adopted systems will eventually institutionalize as the new status quo pending appearance of the next critical situation.

This study bases its conclusion regarding the likelihood of future conflictual changes in governance systems the complexities of the region's issues, the large number of institutional interests affected by activities within the Basin, and the region's governance history. ${ }^{151}$

${ }^{151}$ A possible candidate for the next critical situation is the pending decision by Judge James Redden regarding the litigation over the NMFS 2008 Biological Opinion and operation of the FCRPS. Should Judge Redden rule against the government and order future operations under court supervision, it would (1) introduce a new model of governance for the FCRPS (a Court Supervision model, perhaps similar to tht operating under the Unites States v. Oregon process for basin fisheries) and (2) initiate thresolution" rituals to determine what the form and structures of the new system will be. 
Figure 8-5.

Generalized Model of Basin Governance System Establishment

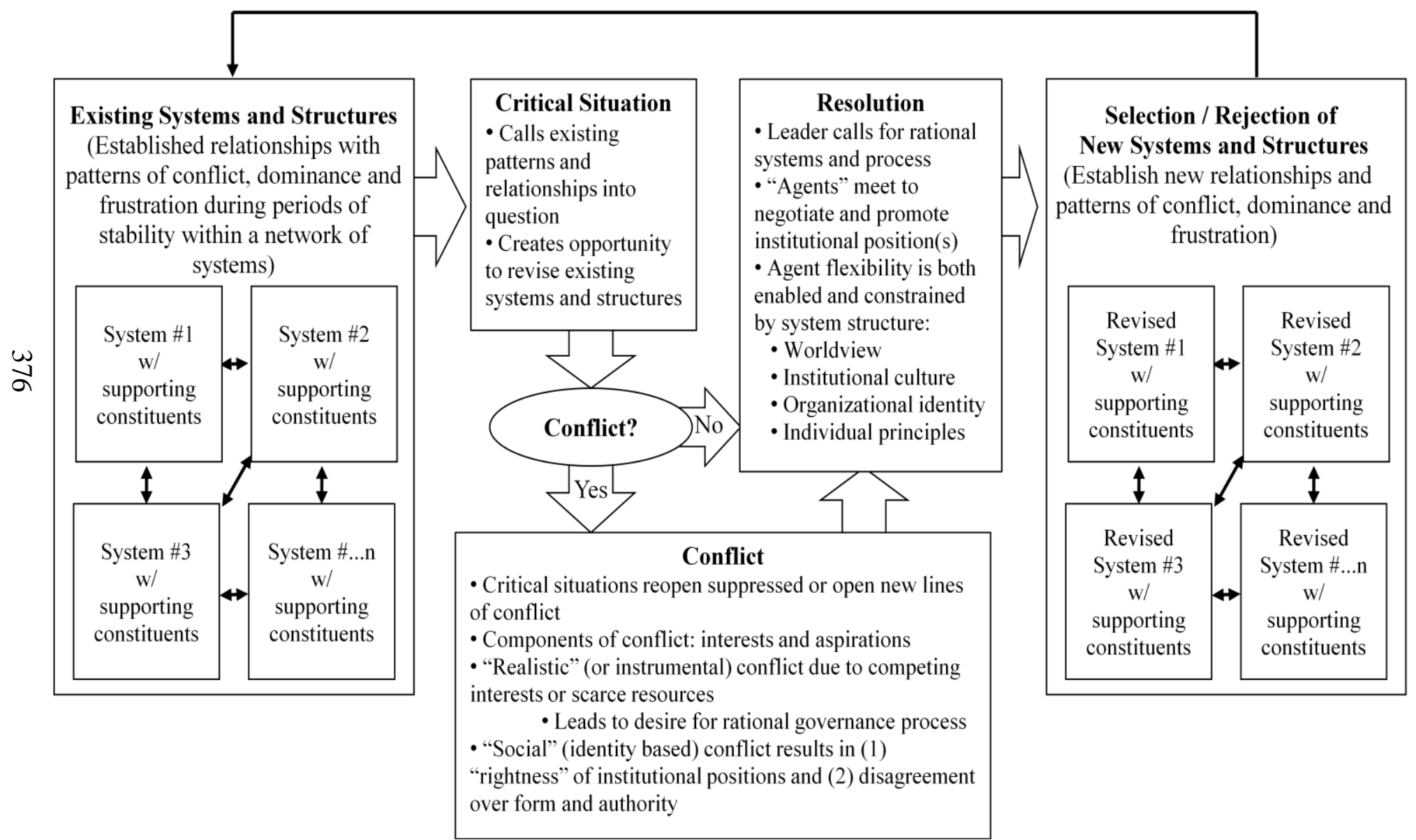




\section{Limitations of the Institutional Approach}

Using an institutional level of analysis provided a workable methodology for exploring the history of regional governance. It offered insights into institutional interests over time, the social and political context and issues that shaped governance choices, and the governance systems and models that subsequently emerged. It also provided a basis for establishing governance and trends, allowing for development of the models provided in Figures 8-1 through 8-5.

The institutional approach only partially explained the region's governance paradox. It did not provide for full explanation as to why some systems failed and others succeeded, even when faced with a relatively similar array of issues and challenges. For example, both the Columbia River Inter-Agency Committee and Columbia River Basin Forum were collaboration-oriented systems created by voluntary participants. Both faced participant conflict over fish and hydropower system priorities. Arguably, the CBIAC faced the more difficult challenge in that it faced a broader scope of activities, such as public land use planning for timber, mining, and grazing. Furthermore, funding for the CBIAC came solely from participant contributions, while the CRBF received additional funds for facilitation and staff support and tribal participation from BPA and the Bureau of Indian Affairs. Yet the CBIAC operated relatively successfully for fourteen years while the CRBF collapsed in a little over one.

Moreover, while the institutional approach was able to identify institutional interests, it could not explain the passion that regional participants attached to those 
interests. It could not explain the close identity that individuals felt toward organizational purposes, goals, and objectives. Nor could it explain why different participants interpreted established facts so differently. To get to a more complete answer requires research in areas not available in the historic record.

This study identified three worldviews operative in the Pacific Northwest. It concluded, based on the material reviewed, that differences over the values that underlay those worldviews may be as important in regional resource conflicts as tangible competition over resource use. It has alluded to the influences of organizational culture (Schein, 2004) and organizational and social identity (Tajfel and Turner, 2004/1979; Albert and Whetten, 1985; Hogg and Terry, 2001). However, it has done so in the abstract, not providing any empirical link between the values of any given institution and the decisions and actions of that institution's representative agent(s) in governance forums.

The theoretical concept of "agency" (Giddens, 1984; Sztompka, 1991) suggests the importance of such a link. Agency represents the capacity to make things to happen. Agents are knowledgeable individuals acting alone or as a group to defend, modify, or replace existing systems and structures. Individuals exercise agency. Agency manifests through individual decisions and action and it is through agency that social organization occurs. As Sztompka explained it:

"If we think of any empirical event or phenomenon in a society, anything that is actually happening, is it not always, without exception, a fusion of structures and agents, of operation and action? Show me an agent who is not enmeshed in some structure. Show me a structure which exists apart from individuals. Show me an action which does not participate in societal operation. Show me societal operation not resolving in to action. 
There are neither structureless agents nor agentless structures" (Sztompka, 1991, p. 92).

A greater understanding of agency and the ways in which institutional values and personal principles influence the decisions of institutional representatives may provide greater insight into the workings of collaboration-based models. Furthermore, empirically supported findings that organizational identity is malleable (Gioia and Thomas, 1996; Albert, Ashforth, and Dutton, 2000) suggest that conflict over values may not be as intractable as they so often appear. An understanding of the influences that motivate individual agents and the degree to which institutional values contribute to those motivations would complete the understanding as to why more robust regional governance systems have not been brought about. It could also suggests strategies to develop systems and structures that instill their own sense of identity in participants, potentially transcending competing attachments to parent groups and offering a more sophisticated approach to regional conflict resolution.

A situation that to a stronger system does not even register in the organizational consciousness may pose an existential threat to systems with weak senses of identity and culture, weak affinity between organizational values and individual principles, weak alliances with external stakeholders, and/or weak psychological bonds between the system and its participants. The implication for governance is that establishing senses of organizational identity and creating psychological bonds between individual members and system principles enhances the potential for system success. The circumstances of the negotiations over the CRBF MOA provide a unique opportunity for this sort of research. 


\section{$\underline{\text { Framework for Additional Research }}$}

The Columbia River Basin Forum adopted a collaborative process based on the belief that, if reasonable leaders from the region's key stakeholders could rationally discuss the issues at hand they would reach reasonable compromises. This approach underestimated the deep differences in values within the region. By ensuring that every representative reserved veto authority over any collective position not in accord with the interests of their respective constituency, participants in the CRBF had no institutional incentive to address substantive issues. As observed by Russell Linden (2002) in his book on collaboration, "the forces that pull people apart are very strong, some of them wired into the very DNA of organizations, and it takes far more than good intentions and kind-hearted people to make collaboration work" (Linden, 2002, p. 36).

Theory states that belief patterns embedded in institutional identity and culture condition the members of those institutions as to how to perceived and interpret events around them (Albert and Whetten, 1985; Ashforth and Mael, 1989; Schein, 2004). The tendency for institutions to evolve into groups of like-valued individuals exacerbates this phenomenon (Tajfel and Turner, 2004; Ashforth and Mael, 1989). In the case of the CRBF, those influences resulted in the adoption of the MOA designed to preclude any real decision making.

The operative question is "why?" Determining the processes by which agents internalized institutional values, what those values were, and how they played in the negotiation of the CRBF MOA and the CRBF's subsequent activities a research 
framework beyond the review of historical literature and primary sources presented heretofore. However, the historical record discussed in Chapters 3 through 7 and the analysis in Chapter 8 suggests the following set of hypotheses to guide development of such a framework:

- The organizations and institutions participating in the development of the CRBF MOA and subsequent CRBF activities held interests and aspirations (both stated and unstated) they wished to defend and/or pursue. Theses institutional interests and aspirations were functions of the institution's tangible goals and objectives as well as its worldview, organizational culture and sense of social identity.

- Representative agents from each participating institution each held their own set of personal principles, goals, and plans. These principles, goals and plans were functions of the individual's upbringing and reflective of the institutional values with which the agent most closely identified.

- The "macro" influences of worldview, culture, and identity coupled with individual principles shaped the way agents construed information, perceived the issues at hand, and interpreted the motivations of other participants to the process.

- Agents selected to represent organizations in negotiations and CRBF activities were expected to either win a governance system that would further parent institutional interests and validate parent institutional values or, at a minimum, prevent the adoption of a system that could threaten those interests and values. 
Consequently, organizations selected representatives who identified with and believed in the inherent "rightness" of institutional interests, values, and positions.

- The circumstances that drove regional leaders to believe that $\mathrm{t}$ new system of regional governance was necessary turned out to be of insufficient magnitude to either transcend individual principles and beliefs or threaten institutional interests or existence.

- The lack of an overwhelming threat coupled with deeply held principles and the expectation to defend institutional goals and objectives translated into position taking that limited opportunities for compromise and rendered achievement of the rational decision making system sought by regional leaders extremely difficult to achieve. A general lack of trust between parties and a lack of common purpose was hard-wired into the CRBF MOA, thus preordaining its failure.

Appendix B presents a theoretical framework under which these hypotheses may be tested. 


\section{REFERENCES}

The sources used for this study are listed below and organized as follows in:

- Books. Published and accessible book-length treatments.

- Journal articles and essays. Published and accessible material appearing in professional journals or books. Web links are given for those cases in which articles were downloaded from electronic sources.

- Unpublished doctoral dissertations and research reports. Dissertations and reports prepared for a specific audience that may not be generally accessible. Web links are given for those cases in which articles were downloaded from electronic sources.

- Official documents, reports, publications, and press releases. Material prepared for public release by official government sources. Sources include federal agencies, the Northwest Power and Conservation Council, and tribal coalitions. Web links are given for those cases in which material was downloaded from electronic sources.

- Federal statutes.

- Primary sources. Firsthand accounts and notes, stored on file but not generally available to the public.

- Press accounts. Web links are given for those cases in which material was downloaded from electronic sources.

- Methodological approaches.

References for the future research framework are listed at the end of Appendix B. 
$\underline{\text { Books }}$

Billington, D.P., Jackson, D.C., \& Melosi, M.V. (2005). The history of large federal dams: planning, design, and construction. Denver, CO: U.S. Department of the Interior, Bureau of Reclamation.

Brigham, J.L. (1998). Empowering the west: electrical politics before FDR. Lawrence, KS: University of Kansas Press.

Buchal, J.L. (1998). The great salmon hoax: an eyewitness account of the collapse of science and law and the triumphs of politics in salmon recovery. Aurora, OR: Iconoclast Publishing Company.

Cameron, J. (1928). The development of governmental forest control in the United States. Baltimore, MD: Johns Hopkins Press.

Cameron, J. (1929). The bureau of biological survey: its history, activities and organization. Service monographs of the U.S. Government \#54, Brookings Institution, Institute for Government Research. Baltimore, MD: John Hopkins Press.

Cater, D. (1954). Power in Washington: a critical look at today's struggle to govern in the nation's capital. New York: Random House.

Clark, E.E. (1953). Indian legends of the Pacific Northwest. Berkeley, CA: University of California Press.

Clarke, J.N. \& McCool, D.C. (1996). Staking out the terrain: power and performance among natural resource agencies. Albany, NY: State University of New York Press.

Cone, J.C. \& Ridlington, S. (Eds.) (1996). The Northwest salmon crisis: a documentary history. Corvallis, OR: Oregon State University Press.

Conover, M. (1923). The general land office: its history, activities, and organization. Service monographs of the U.S. Government \#13, Brookings Institution, Institute for Government Research. Baltimore, MD: Johns Hopkins Press.

Cortner, H.J. \& Moote, M.A. (1999). The politics of ecosystem management. Washington, DC: Island Press.

DeLuna, P.K. (1997). Public vs. private power during the Truman administration: a study of fair deal liberalism. New York: Peter Lang Publishing, Inc. 
Dodds, G.B. (1986). The American Northwest: a history of Oregon and Washington. Arlington Heights, IL: The Forum Press, Inc.

Dompier, D.W. (2005). The fight of the salmon people: blending tribal tradition with modern science to save sacred fish. Online Publisher: Xilbris Corporation. [Website indicates corporate headquarters in Bloomington, Indiana. See http://www2.xlibris.com/contactus.html.]

Dunlap, R.E. \& Mertig, A.G. (Eds.). (1992a). American environmentalism: the U.S. environmental movement, 1970 - 1990. New York: Taylor \& Francis.

Dunlap, T.R. (2004). Faith in nature: environmentalism as religious quest. Seattle, WA: University of Washington Press.

Ferejohn, J.A. (1974). Pork barrel politics: rivers and harbors legislation, 1947-1968. Stanford, CA: Stanford University Press.

Frome, M. (1971). The forest service. New York: Praeger Publishers.

Griffith, E. (1961). Congress: its contemporary role. New York: New York University Press.

Harden, B. (1996). A river lost: the life and death of the Columbia. New York: W.W. Norton and Company.

Hays, S.P. (1957). The response to industrialism, 1885 - 1914. Chicago: University of Chicago Press.

Hays, S.P. (1999). Conservation and the gospel of efficiency: the progressive conservation movement, 1890-1920. Pittsburgh, PA: University of Pittsburgh Press. (Originally published in 1959).

Hays, S.P. (2000). A history of environmental politics since 1945. Pittsburgh, PA: University of Pittsburgh Press.

Holt, W.S. (1923). The office of the chief of engineers of the army: its non-military history, activities and organization. Service monographs of the U.S. Government \#27, Brookings Institution, Institute for Government Research. Baltimore, MD: John Hopkins Press.

Johansen, D.O. (1967). Empire of the Columbia: a history of the Pacific Northwest $\left(2^{\text {nd }}\right.$ Ed.). New York: Harper and Row, Publishers.

Judson, K.B. (1916). Early days in old Oregon. Chicago, IL: A.C. McClurg and Company. 
Kline, B. (2000). First along the river: a brief history of the U.S. environmental movement (2 $2^{\text {nd }}$ Ed.). Lanham, MD: Acada Books.

Lichatowich, J.A. (1999). Salmon without rivers: a history of the Pacific salmon crisis. Washington, DC: Island Press.

Linden, R.M. (2002). Working across boundaries: making collaboration work in government and nonprofit organizations. Jossey Bass: San Francisco, CA.

Lyman, W.D. (1963). The Columbia River: its history, its myths, its scenery, its commerce $\left(4^{\text {th }}\right.$ Ed.). Portland, OR: Binfords \& Mort, Publishers. [First edition published 1909. Lyman, who died in 1920, produced his book's second and third editions in 1911 and 1917 respectively. "L. K. P.," whose full name is not disclosed, apparently edited and updated Lyman's 1917 edition to contrast the pristine conditions eloquently chronicled by Lyman with the river's subsequent development.]

Maas, A. (1974). Muddy waters: the Army engineers and the nation's rivers. New York: Da Capo Press. (Originally printed by Harvard University Press in 1951).

Marsh, G.P. (1965). Man and nature; or, physical geography as modified by human action. (D. Lowenthal, Ed.). Cambridge, MA: Belknap Press. (Original work published 1864).

McKinley, C. (1952). Uncle Sam in the Pacific Northwest: federal management of natural resources in the Columbia River valley. Berkley, CA: University of California Press.

National Research Council (1996). Upstream: salmon and society in the Pacific Northwest. Washington, DC: National Academies Press.

National Research Council (1999). New directions in water resources planning for the U.S. Army Corps of Engineers. Washington, DC: National Academies Press.

National Research Council (2004). Managing the Columbia River: instream flows, water withdrawals, and salmon survival. Washington, DC: National Academies Press.

Norwood, G. (c. 1981). Columbia River power for the people: a history of the policies of the Bonneville Power Administration. Portland, OR: U.S. Department of Energy, Bonneville Power Administration. 
Ophuls, W. \& Boyan, A.S. (1992). Ecology and the politics of scarcity revisited: the unraveling of the American dream. San Francisco: W.H. Freeman \& Co.

Pevar, S.L. (2002). The rights of Indians and tribes: the authoritative ACLU guide to Indian and tribal rights $\left(3^{\text {rd }}\right.$ Ed.). Carbondale, IL: Southern Illinois University Press.

Pisani, D.J. (2002). Water and American government: the reclamation bureau, national water policy, and the west, 1902-1935. Berkley, CA: University of California Press.

Pope, D. (2008). Nuclear implosions: the rise and fall of the Washington public power supply system. New York: Cambridge University Press.

Reisner, M. (1993). Cadillac desert: the American west and its disappearing waters. New York: Penguin Books.

Robbins, W.G. (1997). Landscapes of promise: the Oregon story 1800-1940. Seattle, WA: University of Washington Press.

Robbins, W.G. (2004). Landscapes of conflict: the Oregon story, 1940 - 2000. Seattle, WA: University of Washington Press.

Rosenbaum, W.A. (2005). Environmental Politics and Policy $\left(6^{\text {th }}\right.$ Ed.). Washington, DC: CQ Press.

Rowley, W.D. (2006). Reclamation: managing water in the west: The bureau of reclamation: origins and growth to 1945. Volume 1. Washington, DC: U.S. Government Printing Office.

Ruby, R.H. \& Brown, J.A. (1981). Indians of the Pacific Northwest: a history. Norman, OK: University of Oklahoma Press.

Ruby, R.H. \& Brown, J.A. (1992). A guide to the Indian tribes of the Pacific Northwest (Revised edition). Norman, OK: University of Oklahoma Press.

Schafer, J. (1943). A history of the Pacific Northwest. New York: The Macmillan Company. A reprint of a work originally completed in 1905 that was updated and rewritten in 1918.

Scheufele, R.W. (1969). The history of the North Pacific Division. U.S. Army Corps of Engineers. Portland, OR: NPD-USACE. 
Scheufele, R.W. (c. 1970). History of the Columbia Basin inter-agency committee: the story. A joint publication of the Department of Agriculture, Department of the Army, Bonneville Power Administration, Federal Power Commission, Department of Health, Education, and Welfare, and Department of Labor. Portland, OR: Pacific Northwest River Basins Commission.

Shallet, T. (1994). Structures in the stream: water, science, and the rise of the U.S. Army Corps of Engineers. Austin, TX: University of Austin Press.

Simon, J.L. (1999). Hoodwinking the nation. New Brunswick, NJ: Transaction Publishers.

Smith, H.N. (1950). Virgin land: the American west in symbol and myth. New York: Vintage Books.

Steen, H.K. (1976). The U.S. forest service: a history. Seattle, WA: University of Washington Press.

Steinberg, T. (1991). Nature incorporated: industrialization and the waters of New England. Amherst, MA: University of Massachusetts Press.

Taylor, J.E. (1999). Making salmon: an environmental history of the northwest fisheries crisis. Seattle: University of Washington Press.

Weber, M. (2002). The protestant ethic and the "spirit" of capitalism. (Baehr, P. and Walls, G.C., Trans. and Eds.). New York: Penguin Books. [Original work published 1905 and 1920].

Weber, M.L. (2002). From abundance to scarcity: a history of U.S. marine fisheries policy. Washington, DC: Island Press.

White, R. (1995). The organic machine: the remaking of the Columbia River. New York: Hill and Wang.

Wiebe, R. H. (1967). The search for order 1877 - 1920. New York: Hill and Wang.

Wilkinson, C. (1992). Crossing the next meridian: land, water, and the future of the west. Washington, DC: Island Press.

Wilkinson, C. (2005). Blood struggle: the rise of modern Indian nations. New York: W.W. Norton \& Company.

Williams, R.N. (Ed.). (2006). Return to the river: restoring salmon to the Columbia River. Burlington, MA: Elsevier Academic Press. 


\section{$\underline{\text { Journal Articles and Essays }}$}

Blumm, M.C. (1981). Hydropower vs. salmon: the struggle of the Pacific Northwest's anadromous fish resources for a peaceful coexistence with the federal Columbia River power system. Environmental Law, 11, 211-300.

Blumm, M.C. (1982). The Northwest's hydroelectric heritage: prologue to the Pacific Northwest electric power planning and conservation act. Washington Law Review, 58 (129), 175-244.

Blumm, M.C. \& Simrin, A. (1991). The Northwest power act: point and counterpoint: the unraveling of the parity promise: hydropower, salmon, and endangered species in the Columbia Basin. Environmental Law, 21, 657-744.

Blumm, M.C., Laird, J.L., Miller, D.B., Rohlf, D.J., \& Spain, G.H. (1998). Saving Snake River water and salmon simultaneously: the biological, economic, and legal case for breaching the lower Snake River dams, lowering John Day reservoir, and restoring natural river flows. Environmental Law, 28, 997-1054.

Bodi, F.L. (1979). Protecting Columbia River salmon under the endangered species act. Environmental Law, 10, 349-351.

Bodi, F.L. (1995). Colloquium: who runs the river? The history and legislative background of the Northwest Power Act. Environmental Law, 25, 365-367.

Cannon, B.Q. (2000). Book review: empowering the west: electrical politics before FDR. American Historical Review, 105 (1). American Historical Association. Retrieved July 16, 2008 from the World Wide Web at http://www.historycooperative.org/cgi-bin/printpage.cgi.

Cart, T.W. (2004). The federal fisheries service, 1871-1940: its origins, organization, and accomplishments. Marine Fisheries Review, 66 (4), 1-46. Washington, DC: United States Department of Commerce. Retrieved September 29, 2009 from the World Wide Web at http://spo.nmfs.noaa.gov/mfr664/mfr6641.pdf.

Conklin, P.K. (1983). Intellectual and political roots. In Hargrave, E.C. and Conklin, P.K. (Eds.). TVA: Fifty Years of Grass-roots Bureaucracy (pp. 3 - 34).

Urbana, IL: University of Illinois Press. 
Dunlap, R.E. \& Mertig, A.G. (1992b). The evolution of the U.S. environmental movement from 1970 to 1990: an overview. In R. E. Dunlap \& A. G. Mertig (Eds.), American Environmentalism: The U.S. Environmental Movement, $1970-1990$ (pp. 1 - 10). New York: Taylor \& Francis, Inc.

Dunlap, R.E. (1992c). Trends in public opinion toward environmental issues: 1965 1990. In R. E. Dunlap \& A. G. Mertig (Eds.), American Environmentalism: The U.S. Environmental Movement, 1970 - 1990 (pp. 89 - 116). New York: Taylor \& Francis.

Gersick, C.J.G. (1991). Revolutionary change theories: a multilevel exploration of the punctuated equilibrium paradigm. Academy of Management Review, 16, 1036.

Goodwin, Craufurd D. (1983). The valley authority idea - the fading of a national vision. In E.C. Hargrave and P.K. Conklin (Eds.). TVA: Fifty Years of Grassroots Bureaucracy (pp. 263-296). Urbana, IL: University of Illinois Press.

Heclo, H. (1978). Issue networks and executive establishments. In A. King (Ed.), the new American political system (pp. 87-124). Washington, DC: American Enterprise Institute.

Hemmingway, R. (1983). The Northwest Power Planning Council: its origins and future role. Environmental Law, 13 (673), 637-697.

Kennedy, D.M. (2009, Summer). What the new deal did. Political Science Quarterly, $124(2), 251-268$.

Lang, W.L. (1999). What has happened to the Columbia? A great river's fate in the twentieth century. In W.L. Lang and R.C. Carriker (Eds.). Great Rivers of the West: Essays on the Columbia River, (pp. 144-166). Seattle, WA: University of Washington Press.

Lichatowich, J.A., McConnaha, W.E., Liss, W.J., Stanford, J.A., \& Williams, R.N. (2006). The existing conceptual foundation and the Columbia River Basin fish and wildlife program. In R.N. Williams (Ed.), Return to the River: Restoring Salmon to the Columbia River, (pp. 29-50). Burlington, MA: Elsevier Academic Press.

Lowitt, R. (1983). The TVA, 1933-45. In Hargrave, E.C. and Conklin, P.K. (Eds.). TVA: Fifty Years of Grass-roots Bureaucracy (pp. 35-65). Urbana, IL: University of Illinois Press. 
Luce, J. O. (1996). When the walls come tumbling down: the demise of the Northwest Power Act. Hastings West-Northwest Journal of Environmental Law and Policy, 3 (2), 299-326.

McConnaha, W.E., Williams, R.N., \& Lichatowich, J.A. (2006). Introduction and background of the Columbia River salmon problem. In Williams, R.N. (Ed.). Return to the River: Restoring Salmon to the Columbia River, pp. 1-28. Burlington, MA: Elsevier Academic Press.

Mitchell, R.C., Mertig, A.G., \& Dunlap, R.E. (1992). Twenty years of environmental mobilization: trends among national environmental organizations. In R.E. Dunlap and A.G. Mertig (Eds.), American Environmentalism: The U.S. Environmental Movement, 1970-1990. (pp. 11-26). New York: Taylor \& Francis, Inc.

Mumford, Lewis (January 3, 1939). Regional planning in the Pacific Northwest. Portland, OR: Northwest Regional Council.

Munson, R. (2001). Rethinking Bonneville: why BPA must be reformed. Washington DC: Northeast-Midwest Institute.

Ogden, D.M. (1997, December 11). "Governance" of the Columbia River. Unpublished monograph.

Swedlow, B. (2003). Scientists, judges, and spotted owls: policymakers in the Pacific Northwest. Duke Environmental Law \& Policy Forum 13 (2), 187-278.

Thurber, J. A. (1991). Dynamics of policy subsystems in American politics. In A. J. Cigler \& B. Loomis (Eds.), Interest group politics ( $3^{\text {rd }}$ ed.), (pp. 319-345). Washington, DC: Congressional Quarterly Press.

Trosper, R.L. (1995). Traditional American Indian economic policy. American Indian Culture and Research Journal, 19 (1), 65-95.

Williams, J.C. (2000, July). Book review: empowering the west: electrical politics before FDR. Technology and Culture, 41, 608-610.

Wollner, C. (2001, Summer). Book review: Empowering the west: electrical politics before FDR. The Business History Review, 75 (2), 388-391.

Wright, A. (1995). Colloquium: who runs the river? Should the courts run the river? Environmental Law, 25, 403-405. 
Unpublished Doctoral Dissertations and Research Reports

Arndt, D.P., Stroud, P.L., \& Mogren, E.T. (2004, March 18). The federal Columbia River power system: actions, investments, and lessons learned. Kleinfelder project number 28470. Report prepared for and on file with the Bonneville Power Administration and Kleinfelder, Inc. Beaverton, OR: Kleinfelder, Inc.

Gilliam, C.P. (1999). A short history of the order of the patrons of husbandry: the national grange. Washington, DC: Headquarters, The National Grange. Retrieved October $14^{\text {th }}, 2009$, from the World Wide Web at ${ }_{152}$ http://www.geocities.com/cannongrange/cannon_nationalhistory.html?200914.

National Grange Historic Preservation Committee (2002). 142 years of service to rural America: Grange history - founders - structure. Retrieved October $14^{\text {th }}$, 2009 from the World Wide Web at http://www.nationalgrange.org/templates/ pfv.php.

Ogden, D.M. (1949). Development of federal power policy in the Pacific Northwest. Doctoral dissertation, Portland State University, Portland, Oregon.

Vogel, E. (2007). The Columbia River's regional politics, place, and environment in the Pacific Northwest, 1933-present. Unpublished doctoral dissertation, University of Oregon, Eugene.

Volkman, J.M. (1997, August). A river in common: the Columbia River, the salmon ecosystem, and water policy. Report to the Western Water Policy Review Advisory Commission. Available from the U.S. Department of Commerce National Technical Information Service at http://www.ntis.gov.

Government Documents, Reports, Publications, and Press Releases

Bessey, R.F. (1963). Pacific Northwest regional planning - a review. State of Washington Division of Power Resources Bulletin No. 6. Olympia, WA: Washington State Printing Plant.

BPA (Bonneville Power Administration). (1996, June). 1996 wholesale power and transmission rate proposal: administrator's record of decision. Retrieved on November 7, 2010 from the World Wide Web at http://www.bpa.gov/psp/ final/wp-96-a-02.pdf.

${ }^{152}$ Website subsequently closed. 
BPA (Bonneville Power Administration). (2001, June). 2002 supplemental power rate proposal: administrator's record of decision. Retrieved on November 7, 2010 from the World Wide Web at http://www.bpa.gov/power/psp/rates/ RateCase/sproposal/WP-02-A-09.pdf.

Bureau of Reclamation (2006, April 6). Significant legislation and legal opinions affecting Reclamation's power program. Bureau of Reclamation web site. Retrieved on December 29, 2009 from the World Wide Web at http://www.usbr.gov/power/who/legislat.html.

CRITFC (Columbia Basin Intertribal Fish Commission) (2010). What is CRTIFC. Retrieved July 18, 2010 from the CRITFC website on the World Wide Web at http://www.critfc.org/text/work.html.

Commissioner of the General Land Office (1888). Annual Report. General Land Office, Department of the Interior. Washington DC: Government Printing Office.

Executive Order 12319. (1981, September $\left.9^{\text {th }}\right)$. River basins commissions. Retrieved April $20^{\text {th }}, 2004$ from the World Wide Web at http://www.reagan.utexas.edu/resource/speeches/1981/90981d.htm.

FCRPS (Federal Columbia River Power System) (2003, August). Portland, OR: Jointly published by the U.S. Army Corps of engineers, Bonneville Power Administration, and Bureau of Reclamation. Retrieved from on December $29^{\text {th }}, 2009$ from the World Wide Web at http://www.bpa.gov/power/pg/fcrps_brochure_17x11.pdf.

GAO (Government Accounting Office). (2004). Columbia River basin: a multilayered collection of directives and plans guides federal fish and wildlife activities (Report No. GAO-04-602. Washington, DC: U. S. Government Accounting Office.)

ICBEMP (Interior Columbia Ecosystem Management Project). (Undated). Interior Columbia Basin ecosystem management project. Retrieved November 7, 2010 from the World Wide Web at http://www.icbemp.gov.

Mead, E. \& Brown, L.B. (March 29, 1932). Letter of transmittal: report on the Columbia and minor tributaries. Offices of the Chief of Engineers and the Commissioner, Bureau of Reclamation: Washington DC. Retrieved May 27, 2007 from the World Wide Web at http://www.ccrh.org/comm/umatilla/ primary/308rprt.htm. 
National Archives (undated). 315.3.2 Records of the Pacific Northwest river basins commission. Retrieved January $3^{\text {rd }}, 2010$ from the World Wide Web at http://www.archives.gov/research/guide-fed-records/groups/315.html\#315.3.2.

NMFS (National Marine Fisheries Service). (1995). Endangered species act section 7 biological opinion on the reinitiation of consultation on 1994-1998 operation of the federal Columbia River power system and juvenile transportation program. Seattle, WA: National Marine Fisheries Service Northwest Region.

NMFS (National Marine Fisheries Service). (2009a, March 12). ESA salmon listings. Retrieved December $21^{\text {st }}, 2009$ from the World Wide Web at http://www.nwr.noaa.gov/Esa-Salmon-Listings/.

NMFS (National Marine Fisheries Service), (2009b, March 19). Mitchell Act Program. Retrieved January 23, 2010 from the World Wide Web at http://www.nwr.noaa.gov/Salmon-Harvest-Hatcheries/Hatcheries/MitchellAct-Program.cfm.

NPPC (Northwest Power and Conservation Council) (1992). Columbia River Basin fish and wildlife program - strategy for salmon. Portland, OR: Northwest Power and Conservation Council. Retrieved January 24, 2010 from the World Wide Web at http://www.nwcouncil.org/library/1992/Default.htm.

NPPC (Northwest Power and Conservation Council) (1994/95). 1994/95 Columbia

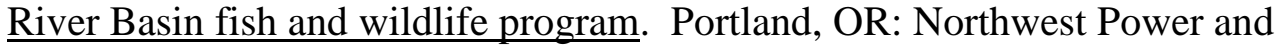
Conservation Council. Retrieved January 24, 2010 from the World Wide Web at http://www.nwcouncil.org/LIBRARY/1994/Default.htm.

NPPC (Northwest Power and Conservation Council) (1996, May 15). Report to congress: Fish and wildlife governance and the Columbia River hydropower system. Portland, OR: Northwest Power and Conservation Council. Retrieved January 14, 2010 from the World Wide Web at http://www.nwcouncil.org/LIBRARY/1996/ 96-10.pdf.

NPPC (Northwest Power and Conservation Council) (1999, January 22). Court orders federal agencies to consult regional fish and wildlife plan in Columbia River operation decisions. Retrieved January 16, 2010 from the World Wide Web at http://www.nwcouncil.org/library/releases/1999/0122.htm.

NPPC (Northwest Power and Conservation Council) (2007, January). Northwest power and conservation council briefing book. Council Document 2007-1. Portland, OR: Northwest Power and Conservation Council. Retrieved January 10, 2010 from the World Wide Web at http://www.nwcouncil.org/library/2007/2007-1.pdf. 
NPPC (Northwest Power and Conservation Council) (Undated). Columbia River basin forum. Retrieved June 2, 2004 from the World Wide Web at http://www.nwcouncil.org/fw/3sov/crbforum.htm.

U.S. Army Corps of Engineers (1998). The history of the U.S. Army Corps of Engineers $\left(2^{\text {nd }}\right.$ Ed.). Alexandria, VA: Office of History, U.S. Army Corps of Engineers.

UCUT (Upper Columbia United Tribes). (Undated). Upper Columbia united tribes: about us. Retrieved on July 18, 2010 from the UCUT website on the World Wide Web at http://www.ucut.org/about_us.ydev.

Wilson, J. (1905, February 1). Letter (untitled) from the Secretary of Agriculture to newly appointed Forester Gifford Pinchot. Retrieved July 19, 2010 from the World Wide Web at http://www.foresthistory.org/ASPNET/policy/ Agency_Organization/Wilson_letter.pdf.

\section{$\underline{\text { Federal Statutes }}$}

Bonneville Project Act, 50 Stat 731, 16 U.S.C. Chapter 12B (1937). Subsequently amended 1940, 1945, 1946, and 1966. [Text of statute available in pamphlet form from the Bonneville Power Administration, Portland, Oregon.]

Endangered Species Act, 87 Stat. 884, 16 U.S.C. 1531 (1973, December 28). Retrieved January $12^{\text {th }}, 2010$ from the World Wide Web at http://epw.senate.gov/esa73.pdf.

NEPA (National Environmental Policy Act). Pub. L. 91-190, 42 U.S.C. 4321-4347, ( 1970, January 1). Retrieved January 1, 2011 from the World Wide Web at http://ceq.hss.doe.gov/nepa/regs/nepa/nepaeqia.htm.

Power Act (Pacific Northwest Electric Power Planning and Conservation Act). 94 Stat. 2697, 16 U.S.C. 839, Public Law 96-501 (1980, December 5). [Text of statute available in pamphlet form from the Bonneville Power Administration, Portland, Oregon.]

Water Resources Planning Act, 42 U.S.C. 1962 nt (1965, July 22). Public law 89-80. Retrieved January 6, 2010 from the World Wide Web at http://www.senate.gov/wrpa.pdf. 


\section{Primary Source Materials}

Columbia River Basin Forum meeting minutes, prepared by contractor Jeff Kuechle. On file with the Pacific Northwest Power and Conservation Council in Portland, Oregon and the office of DS Consulting, Portland, Oregon. Specific meeting minutes are cited in the text.

Columbia River Basin Forum internal reports and memorandums. On file with the Pacific Northwest Power and Conservation Council in Portland, Oregon. Specific documents are cited in the text.

Columbia River Basin Forum facilitator notes, prepared by Donna Silverberg and/or members of her staff. On file in the offices of DS Consulting, Portland, Oregon. Specific notes are cited in the text.

Fazio, J. F. (1999, July 2). Columbia Basin Forum Memorandum to Committee Members, Subject: Budget for fiscal year 1999-2000.

Interim Procedures: Regional Implementation Forum: Executive Committee, Implementation Team, and Technical Teams. (1997, June 5).

Mainstem Operations Work Group Revised Draft. (1996, December 4). Retrieved January $24^{\text {th }}, 1010$ from the World Wide Web at http://www.nwdwc.usace.army.mil/TMT/1996/docs/multi_yr_plan/myip4.htm.

MOA (Memorandum of Agreement for the Columbia Basin Forum), (January 1999).

\section{Press Accounts}

Bakke, B. (1997, October 14). Kitzhaber calls for new salmon forum. NW Fishletter, 45. Retrieved December 6, 2004 from the World Wide Web at http://www.newsdata.com/enernet/fishletter/fishltr45/html\#3.

Batt, P.E., Kitzhaber, J.A., Racicot, M., \& Locke, G. (1998, July 15). Letter to interested parties. Retrieved June 2, 2004 from the World Wide Web at http://www.nwppc.org/fw/3sov. [The letter's attachment entitled Models for Columbia River governance is filed separately at http://www.nwcouncil.org/fw/3sov/models.htm.]

Buchal, J.L. (1999, June 29). Memorandum to the Columbia Basin Forum Committee concerning Columbia Basin fish and wildlife goals. Murphy and Buchal, LLP. 
Collette, C. (1997, Winter). Interview: Oregon senator Mark Hatfield. Northwest Energy News. 3-8.

Congressmen rap three sovereigns process. (1998, March 17). NW Fishletter \#55. Retrieved June 2, 2004 from the World Wide Web at http://newsdata.com/enernet/fishletter/fishltr55.html.

Council to look at possible regional decision making changes (2004, May 7). The Columbia Basin Bulletin. Retrieved June 9, 2004 from the World Wide Web at http://www.cbbuletin.com/archive/05072004/16452.aspx.

Crampton, B. (1997, December 5). Another stab at regional governance: three sovereigns, one table. The Northwest Salmon Recovery Report (1), 15. Intermountain Communications.

Crampton, B. (1998, October 16). Conference tackles river governance. The Columbia Basin Bulletin. Retrieved June 9, 2004 from the World Wide Web at http://www.cbbuletin.archive/10161998/2866.aspx.

Crampton, B. \& Espenson, B. (2009). Salmon and hydro: an account of litigation over federal Columbia River power system biological opinions for salmon and steelhead, 1991-2009. Columbia Basin Bulletin Issue Summary No. 1. Bend, OR: Intermountain Communications.

Espenson, B. (1998, August 28). Three sovereigns gets new name, revised MOA. The Columbia Basin Bulletin. Retrieved June 9, 2004 from the World Wide Web at http://www.cbbulletin.com/archive/08281998/2781.aspx.

Espenson, B. (1998, October 23). Feds, states, tribes mull MOA signing. The Columbia Basin Bulletin. Retrieved June 9, 2004 from the World Wide Web at http://www.cbbulletin.com /archive/10231998/2880.aspx.

Espenson, B. (1999, February 5). Basin forum moves ahead despite holdouts. The Columbia Basin Bulletin. Retrieved June 9, 2004 from the World Wide Web at http://www.cbbulletin.com/archive/02051999/3018.aspx.

Espenson, B. (1999, March 5). Forum's relationships pondered. The Columbia Basin Bulletin. Retrieved June 9, 2004 from the World Wide Web at http://www.cbbulletin.com/archive/03051999/3049.aspx.

Espenson, B. (1999, March 12). Idaho joins basin forum process. The Columbia Basin Bulletin. Retrieved June 9, 2004 from the World Wide Web at http://www.cbbulletin.com/archive/03121999/3065.aspx. 
Espenson, B. (1999, July 30). Basin forum members agree on goal. The Columbia Basin Bulletin. Retrieved June 9, 2004 from the World Wide Web at http://www.cbbulletin.com/archive/07301999/3280.aspx.

Montana, Idaho won't sign on to northwest salmon plan. (1999, January). $\underline{\text { U.S. Water }}$ News Online. Retrieved June 2, 2004 from the World Wide Web at http://uswaternews.com/archives/arcrights/9nonida1.html.

O’Bryant, M. (1999, September 24). Kitzhaber proposes river governance body. The Columbia Basin Bulletin. Retrieved June 0, 2004 from the World Wide Web at http://www.cbbulletin.com/archive/09241999/3353.aspx.

O’Bryant, M. (2000, January 14). Montana temporarily nixes basin forum. The Columbia Basin Bulletin. Retrieved June 9, 2004 from the World Wide Web at http://www.cbbulletin.com/archive/01142000/3504.aspx.

Senate hearing focuses on three sovereigns. (1998, July 13). The Columbia Basin Bulletin. Retrieved June 0, 2004 from the World Wide Web at http://www.cbbulletin.com/archive/07131998/2709.aspx.

Tansey, B. (1998, Mar 17). Congressmen rap three sovereigns process. NW Fishletter, 55. Retrieved June 2, 2004 from the World Wide Web at http://www.newsdata.com/enernet/fishletter/fishltr55.html.

Three sovereigns develops new twist. (1998, June 9). NW Fishletter, 60. Retrieved June 2, 2004 from the World Wide Web at http://www.newsdata.com/enernet/fishletter /fishltr60.html.

Methodological Approaches

Neustadt, R.E. and May, E.R. (1988). Thinking in time: the uses of history for decision-makers. New York: The Free Press, a division of Macmillan, Inc.

Maxwell, J.A. (2002). Understanding and validity in qualitative research. In A. M. Huberman and M. B. Miles (Eds.). The qualitative researcher's companion, (pp. 37-64). Thousand Oaks, CA: Sage Publications.

Ritchie, J. \& Spencer, L. (2002). Qualitative data analysis for applied policy research. In Huberman and Miles (eds.) The Qualitative Researcher's Companion (pp. 305-330). Thousand Oaks, CA: Sage Publications. 


\section{APPENDIX A \\ EXPANDED LITERATURE REVIEW}

\section{$\underline{\text { Introduction }}$}

This study research the history of governance from works in five literature domains. These were:

- Regional Native American tribes and tribal perspectives,

- Euro-American exploration and settlement of the Pacific Northwest,

- Columbia River Basin commercial development,

- The impact of Basin development on regional salmon runs, and

- The American environmental movement.

These domains were reviewed using a content-analysis approach as recommended by Neustadt and May (1988) and Ritchie and Spencer (2002). Specifically researched were insights into the worldviews held by the major regional institutions and for elements of governance suggested by the Columbia River Basin Forum experience in order to construct the history presented in Chapters 3 and 4. Those elements were:

- The name and nature of governance systems proposed or enacted.

- The locus of decision making for each governance system proposed or enacted.

- The critical situations or catalytic events that created the opportunity for change to existing systems and structures. 
- The political and social context of the periods as framed by the dates of the selected critical situations.

- The salient issues in the Pacific Northwest that the proposed or enacted system was intended to address.

- The institutional participants and their positions, interests, and agendas.

- The worldviews held by the institutional actors.

- The governance systems both proposed and enacted within each period and their supporting structural components (to the degree recorded).

- Additional information as available. Such information included the duration of enacted systems, types of products produced, effectiveness, and any other material as may be relevant to the research question.

\section{Domain: Regional Native American Tribes and the Tribal Worldview}

The literature reviewed here was selected for two purposes. The first was to present the events and circumstances of the tribes' and their cultural role in the Northwest from the early 1800s up through the period of the CRBF. The second purpose is to identify the worldviews and perspectives that tribal participants later brought to the governance discussions. Trosper (1995) provides a summary of Indian cultural precepts that he generalizes from his study of native peoples nationwide. Pevar (2002) also takes a nationwide perspective, focusing on the legal and political evolution of tribal rights. Wilkinson (2005) traces the history of the tribal sovereignty movement. Ruby and Brown, in two books, (1981 and 1992) provide an 
encyclopedia-like overview of the tribes and bands of the Pacific Northwest, while Clark (1953) transcribes traditional Northwest Tribal stories that provide Indian interpretations of the creation and man's relationship with nature. Finally, portions of Lichatowich (1999), Williams (2006) and Taylor (1999) present, compare, and contrast the tribal worldview with the worldview of the Northwest's Anglo-American settlers and the regional implications of those differences; the review of these three accounts is provided in the discussion of the regional salmon crisis further below.

Ronald L. Trosper is a researcher and professor at the School of Forestry and Department of Applied Indigenous Studies, Northern Arizona University, Flagstaff, Arizona. He has written numerous articles on tribal economic culture and traditions. His Traditional American Indian Economic Policy was published in 1995. In this paper, Trosper defines and generalizes traditional Indian views and compares them with western societal views for purposes of deriving policy implications. He begins by noting the danger in generalizing about Indian culture since tribal societies vary significantly in time and space, and therefore the elements discussed may not apply to all tribes equally. However, he argues that the four fundamental components he presents are sufficiently present across Indian culture to offer a general philosophical understanding of tribal economic perspectives.

Trosper argues that traditional Indian culture is based on respect for the natural world in which man lives. This notion of respect contains four basic components:

- Community: People are members of a community that includes all beings, living and non-living. Each has its proper role, and each has obligations to 
others. The sacred aspect is that all beings have a spirit. The economic aspect is that reciprocity in exchange must exist; for everything that is taken, something must be given back.

- Connectedness: Whereas community provides a source of obligation and a guide as to how people ought to behave, the concept of connectedness is a description of how things are. All elements of the earth are connected to each other, and one cannot violate the principals of community without having some negative impact on the natural order.

- Seventh Generation: Past human generations left a legacy and people have a duty to pass it on so it will be present seven generations hence.

- Humility: Humanity should be humble in its actions. The natural world is powerful and well able to cause trouble if not treated properly.

These four components result in an Indian economic perspective that is dramatically different from the Anglo-American tradition. For example, "high grading" (taking best first - such as old-growth trees) is not allowed since respect for the $7^{\text {th }}$ generation means leaving enough of the best to be enjoyed by that generation. Connectedness and humility dictate that there is an upper bound on consumption. In addition, the notions of community and connectedness require that ecosystem health be maintained.

Trosper further argues that these components guided development of tribal social institutions. For example, private real property ownership as understood by Anglo-Americans did not exist. People had a right of use of what was on the land but 
not of ownership of the land or its resources. The concept of individual property rights as applied to land, water, and wildlife was all but incomprehensible within the tribal concept of community.

Central to Northwest tribal economies was the practice of what Trosper calls "reciprocal exchange" as practiced through the potlatch. The potlatch was a gift giving and barter event in which collective wealth was shared and redistributed. It modeled what the natives interpreted as the natural process; soil gave seeds the opportunity to produce plants; plants fed the animals; some animals fed other animals; and in death the animals fed the soil. It was a natural cycle in which no element was dominant, not even humans, and in which each element depended on the others. Under the concept of reciprocal exchange, anything received had to be returned in equal or greater measure - to included gifts among individuals.

Not everyone agrees with Trosper's construct. Environmental historian Samuel Hays (2000) notes that “...the Native Americans engaged in practices little different for those of the Europeans who displaced them." After listing examples such as Indian use of fire for land clearing; the use of land for agriculture, hunting, fishing, and edible plant gathering; and irrigation in the Southwest, Hays concludes that "These practices reflect not a people 'in harmony with nature' but a native people who used their immediate environment intensively." (p. 6). Hays attributes the differences in environmental impact of the two cultures to the tribes' relatively small numbers dispersed over an immense landscape in comparison to the all-but unlimited number of Anglo-Americans with their advanced technologies. William Robbins (1997) makes a 
similar point. Pointing to archaeological studies, Robbins states that tribal peoples deliberately manipulated the natural landscape in support of their subsistence activities. Their primary technology was fire, strategically set to stimulate new growth for browsing by wildlife and waterfowl, to enhance development of a variety of plant foods, to assist in hunting, to maintain clearings for travel, and, once horses were acquired, to provide graze.

Stephan Pevar's The Rights of Indians and Tribes: The Authoritative ACLU Guide to Indian and Tribal Rights $\left(3^{\text {rd }}\right.$ edition) (2002) is one of a series of writings published by the American Civil Liberties Union (ACLU) to help inform individuals about their rights under the law. The author is an attorney for the ACLU, lecturer, and former adjunct professor at the University of the Denver School of Law. His purpose is to present the unique nature of federal Indian law.

Pevar (2002) begins with a just-the-facts review of federal Indian policy. He provides an overview of the estimated number of tribal nations prior to European arrival, aspects of their general culture, and the consequences of contact with whites. Pevar characterizes, based on evidence of policy, the fluctuations in official policy positions with regard to American Indians during periods of time as:

- Tribal independence (1492 - 1787).

- Agreements between equals (1787 - 1828)

- Relocation of the Indians (1828 - 1887)

- Allotment and assimilation (1887 - 1934)

- Indian reorganization (1934 - 1953) 
- Termination $(1953-1968)$

- Tribal self-determination (1968 - present)

Pevar (2002) then methodically and objectively lays out the fundamentals of Indian law, beginning with basic definitions and moving from there through the federal trust responsibility, the nature and role of tribal treaties, the relationship between the tribes and states, issues of criminal and civil jurisdiction on tribal reservations, and other aspects. He carefully cites his work back to statute or treaty language or the determinations of relevant litigation. Relevant statutes are included as appendices. The book provides an accessible and straightforward reference for issues regarding the legal status of the tribes and their relationship with the federal and state governments.

Whereas Pevar (2002) concentrates on policy and law, Charles Wilkinson's 2006 book Blood Struggle: the Rise of Modern Indian Nations traces the rise in tribal capacity for self-governance. Wilkinson is a professor of law at the University of Colorado and former attorney for the Native American Rights Fund, specializing in American Indian law. While providing a summary background history of United States policy toward its Indian peoples, he concentrates on the period from the midtwentieth century onward. Writing from a national perspective, he notes the poverty and despair that pervaded Indian reservations in the 1940s and 50s. Government policy toward Indians varied over the nation's history from severe to expansive with regard to native rights and enforcement of treaty provisions. By the 1950s, the mood in Congress was to end federal subsidies to tribal people, sell of tribal land, and more 
aggressively assimilate Indians into mainstream American society. The policy of "termination" was formally announced through House Concurrent Resolution 108.

Passage of this resolution was a catalyst for tribal action. Wilkinson (2005) recounts the tribal efforts at defending their rights and land in the courts. Within the next forty years tribal leaders succeeded to a degree few would have predicted. For this study, Wilkinson (2005) is used for its background on key legislation regarding fishing and land rights, insights into tribal perspectives, and the development of tribal governance.

Two books by Robert Ruby and John Brown provide an archeological overview of regional tribes and their history and interrelationships. Indians of the Pacific Northwest: A History (1981) and A Guide to the Indian Tribes of the Pacific Northwest (1992) together provide an exhaustive (but by the authors admission still incomplete) description of the tribes and bands found in Oregon, Washington, Idaho, and western Montana. The authors provide excellent summary histories of individual tribes, collected through research in older narratives, documents, and tribal oral histories where they could be found. Ruby and Brown do not try to interpret or evaluate the meanings of the tribal practices and social structures they record. As such, they do not provide the cultural insights offered by Trosper (1992), Lichatowich (1999), Taylor (1999), or Williams (2006). What Ruby and Brown do offer is an encyclopedic account of tribal groupings, maps, photographs, outlines of reservation governance, and descriptions of tribal life. They seemingly (there are few citations used) base their 
work on primary source material and their own interviews with tribal leaders and other historians.

Ruby and Brown's (1981 and 1992) sorting of Northwest tribes and artifacts is complemented by the transcription of traditional Northwest tribal stories in Ella Clark's 1953 Indian Legends of the Pacific Northwest, the first of four books she wrote to capture native American traditional stories. Like Ruby and Brown, Clark only recorded the stories she had heard; she offers no attempt at interpretation or sociological insight as to the stories meanings to tribal peoples. Her intent is to "prepare a collection of Pacific Northwest myths and legends that the general reader will enjoy, either as entertainment or as information about an American way of living strange to him" (p. 1). Her sources include accounts "tucked away in obscure" books (p. 1), government documents, reports of anthropologists and folklorists, pioneer manuscripts and journals, and her own discussions with tribal members during visits to fourteen reservations.

The stories Clark (1953) records include tribal traditions regarding the creation, natural phenomena, and origins of tribal people and regional geographic features. She also includes Wasco and Chinook/Clatsop stories regarding the first native encounters with white people and their ships on the Oregon coast. Mindful of Schein's (2004) admonition that such stories should be treated as "artifacts" whose meanings are often not obvious to those outside the culture, this study leaves interpretations to others. Rather, Clark is used to help illustrate the close relationship 
that regional tribal people felt with the natural world as demonstrated by their characters and story lines.

\section{Domain: Euro-American Exploration and Settlement of the Pacific Northwest ${ }^{153}$}

Literature in this domain was research for insights into the worldviews brought to the Pacific Northwest by Euro-American settlers and for facts and circumstances of the region's early white exploration and settlement.

Four authors were reviewed whose works captured the origins and nature of the worldviews brought by settlers to the Pacific Northwest. These were Max Weber (2002/1920), Henry Nash Smith (1950), Jenks Cameron (1929), and Gordon Dodds (1986).

Weber (2002/1920) argued that the growth of western capitalism is directly attributable to and derived from Protestant religious beliefs. The essay was based on Weber's observations and research in Germany in particular and European countries and the United States in general. Weber observed that, in developed capitalist countries, business leaders, the owners of capital, senior factory managers, and the more highly skilled members of the work force were predominately of Protestant religious denominations. He further noted that the percentage of Protestants in positions of leadership far exceeded the percentage in the general population. Furthermore, Protestants tended to pass on larger estates to their heirs and to favor

\footnotetext{
${ }^{153}$ Settlers pushing west over the Alleghenies and into the Ohio, Mississippi, and Missouri River valleys were a mix of several European nationalities. Those who later moved to the Northwest from the Midwest were largely of British descent. See Smith (1950) and Dodds (1986). Consequently, "EuroAmerican" is used when speaking of western settlement in general and "Anglo-American" when speaking of settlement to the Pacific Northwest.
} 
higher education, especially in the sciences, math, and other technical fields. By contrast, Catholics tended to end their education earlier and concentrate in liberal arts fields. In the work force, he noted that even poorer Protestants tended to strive to exceed to a greater degree than their Catholic counterparts, often moving from cottage crafts to city factories in which they moved up in either managerial or skilled labor occupations. Catholics, on the other hand, seemed predisposed to stay at the crafts, at best working up to master craftsman. Weber (2002/1920) believed that these differing occupational choices were due to "distinct mental characteristics which have been instilled into them by the influence on them of the religious atmosphere of their locality and home background" (p. 4, emphasis in original). Weber's (2002/1920) argument challenged the prevailing belief that rejection of the feudal economic model opened the door to challenges to other traditional authorities, such as the Catholic Church. Weber argued the opposite - it was the challenge to Church authority by the Reformation that led to a revolution in the way people perceived the relationship between their worldly existence and the accumulation of individual wealth. Weber attributed Protestant success to "distinct mental characteristics which have been instilled into them and indeed by the influence on them of the religious atmosphere of their locality and home background" (p. 4, emphasis in original). He further notes the distinct "points of view" (p. 9) held by members of the Catholic Church and the various Protestant denominations.

Weber's (2002/1920) argument draws from his study of the formative writings of early and influential leaders of various Protestant sects. He traced the evolution 
from the belief in the Middle Ages that one's place in life and material circumstances was a preordained part of God's plan, through the Protestant Reformation, to the eventual Protestant belief in social progression and wealth creation through hard work and individual effort.

Smith's book Virgin Land: the American West as Symbol and Myth (1950) studied the impact of the vast lands of the western United States on the consciousness of Americans. He traces that impact on the literature and social thought at various periods of American history. Smith notes the change in the way Americans thought about America, offering as evidence the way the west was portrayed in fiction and written accounts. Up through the early 1800 s, America viewed itself as a sea power in the tradition of Europe in general and Great Britain in particular. Under this view, the way to national prosperity was through seaborne trade, initially with Europe and later with Asia. This view created the global (and national) obsession with the long sought for passage to India believed to exist across North America. For the United States, finding that passage meant true independence from England and would symbolize national greatness. But by the late 1800s, American thinking changed. They began to think of the vast expanse of land between the east and west coasts as the basis for an American continental empire. Free land to the west was seen as the way to ensure individual liberty and prosperity, and a vehicle to eliminate poverty.

Smith (1950) further argues that the exploration and settlement of the frontier assumed a romantic conceptualization captured in the feats of fictional heroes, such as James Fenimore Cooper's Leatherstocking and pulp fiction hero Dead Eye Dick and 
the fictionalization of the lives of living frontiersmen, such as Daniel Boone and William Cody. These symbolized and celebrated the values of frontier independence and individualism. He also presents the political implications of western settlement, the organization of regional economies in the Northeast, Southeast, and West, and the impact on the Civil War. He also examines the consequences when idealized notions of the west came up against actual conditions on the frontier. However, for the purposes of this study, it is his capturing of the perspective of the western settler that is of primary interest.

Turn-of-the-century western perspectives on natural resources were captured by Jenks Cameron's introduction to his 1928 The Development of Governmental Forest Control in the United States and his 1929 The Bureau of Biological Survey: Its History, Activities and Organization. In addition to his work on federal forest policy and the Bureau of Biological Survey, he produced the Brookings Institution's service monographs for the National Park Service (1922) and Bureau of Dairy Industry (1929). His book on federal forest policy was apparently highly regarded and is cited in Forest Service histories (see, for example, Steen, 1976).

Cameron's Forest Control traces the origins of federal involvement in U.S. forest policy. Most relevant to this study is his first chapter. It focuses on the worldview held by early explorers and settlers that the resources of the North American continent in general and timber in particular, were inexhaustible. Cameron's (1929) Bureau of Biological Survey was one of a series of monographs on U.S. government agencies prepared in the 1910s and 1920s. The monographs were 
prepared by the Brookings Institution in response to a charge from President William Taft to examine the missions and structures of all the federal agencies of the time in order to create a framework for more an efficient and economical approach to the conduct of government business.

His primary purpose was to present the history of the Bureau of Biological Survey in keeping with Brookings Institution guidelines, which he does. In this work, he also does something much more. As he did in his study of forest policy, he provides in Bureau of Biological Survey a rich cultural and social context within which this Bureau and other agencies emerged during the Progressive era. This is a context he did not provide in his earlier monograph on the National Park Service and is not found in the other Brookings Institution monographs reviewed for this study. Although studiously avoiding any subjective judgments regarding the Bureau, he does offer his impressions of his and the public's thoughts regarding the relationship between the natural order, agriculture, and economics. He seems to celebrate in tone what he sees as the impending eradication of wolves, cougar, bobcat, and lynx. He notes that bears are not predators, per se, but occasionally become "... addicted to a diet of lamb, goat, steer, or colt. Once they do this, they are killers for life and can only be shunted from their evil ways by complete elimination.” (p. 51, emphasis added) and supports rodent control as a means of disease reduction. He decries "sentimentalists" who refuse to see the practical aspects of wildlife management through lethal take. Underscoring Weber (2002/1920) and Kline (2000), he further notes that the history of the Bureau underscores the "inevitability of economics" and 
believes economics to be ".... force that could no more be withstood than the force that pulls the tides." (p. 63). In a departure from the just the facts tone of other monographs (to include his 1922 monograph on the National Park Service), he seems to support the promotion of economics development as guided by principles of scientific conservation. Thus, he writes in the vein of Pinchot and other progressive conservationists. He seems to either ironically miss or disagree with the findings of his own research where he describes the interconnectivity between species, the "harmony" of nature, and the consequences of upsetting the natural balance. ${ }^{154}$ The implications of Weber's (2002/1920), Smith's (1950), and Cameron's (1928 and 1929) arguments and the manner in which the cultural forces they describe influenced settlement in the Northwest is found and amplified in Gordon Dodds' 1986 book The American Northwest: A History of Oregon and Washington. The author's intent was to provide an introductory history to settlement in the Pacific Northwest. Dodds claims that, at the time of writing, it was the "first book to do so in almost twenty years" (p. ix). The author concentrates on major regional economic, social, political, and cultural events. His discussion of regional governance focuses on the establishment of the territorial, state, and, to a limited degree, county government systems; he does not discuss regional governance in the sense used in this study. The book is organized by major periods of time, tracing the arrival of the region's earliest inhabitants in c.15,000 BC, first European contact in 1542, British and AngloAmerican settlement in the $18^{\text {th }}$ and $19^{\text {th }}$ centuries, and subsequent regional

${ }^{154}$ See pp. 5-7 for his discussion of the impact of Euro-American settlement on the balance of nature and pp. 50-63 for his support of the Bureau's work in the reduction in various "noxious" species. 
development up through the mid 1980s. His primary argument is that the region's natural wealth led to a relatively easy life for Northwestern residents - especially whites. Consistent with the agrarian social theory of the early $19^{\text {th }}$ century (Smith, 1950), the region offered lots of room with ample supplies of water (at least in the western part of the region and along the region's rivers), fertile soil, timber, and minerals combined with a temperate climate.

Dodds (1986) is valuable for his careful chronicling of key dates and events, his insights into regional culture and identity, and his careful articulation of the historical social, political, and cultural trend. He also offers the insight that the region's vast resources allowed for institutions to develop and take root absent serious competition, at least initially. When they later came into conflict (such as fisheries versus hydropower development), the by-then well-established institutional senses of identity and culture made agreement difficult. He also adds to the worldview of American settlers to the Northwest. Noting that they for the most part originated in the Midwest, they were already convinced of American exceptionalism. He describes the newcomers to the Northwest as an energetic and conservative people, imbued with the premises of Manifest Destiny that in part proclaimed American democracy as part of God's divine plan for the advancement of humankind. American values of political democracy, economic opportunity, social mobility, and religious freedom were considered self-evident truths the spreading of which justified the establishment of a continent-wide empire. 
Dodds (1986) does not discuss governance other than the establishment of formal political entities such as territories, states, and, to a limited degree, counties. His main argument regarding Northwest "complacency" and ill preparedness for change proved prescient in that the difficulties the regional faced in resolving conflicts between the region's economic dependence on resource extraction and environmental concerns came were just beginning to come to the fore at about the time of publication.

In addition to Smith (1950) and Dodds (1986), Schafer (1943/1918), Lyman (1963/1917), Hays (1957), Wiebe (1967), Johansen (1967), and Meinig (1968) provided the facts and circumstances surrounding white western settlement.

Joseph Schafer published his A History of the Pacific Northwest in 1905 and updated it in 1918. His work was reprinted in 1943, which is the edition reviewed here. His only stated purpose was to update his earlier work. In style and organization, his intent seems to have been to provide a textbook on Northwest history. As such, he presents a factual and straightforward account of Northwest exploration and settlement from the early $16^{\text {th }}$ century up to 1917 . This study used Schafer primarily for information on the region's early settlement and to cross check material presented by Lyman (1963/1917) and Johansen (1967).

Adding color commentary to the Pacific Northwest's history of settlement is William Lyman's (1963/1917) Columbia River: Its History, Its Myths, Its Scenery, Its Commerce, first published in 1909. Lyman, who died in 1920, produced his book's 
second and third editions in 1911 and 1917 respectively. The fourth edition was edited, updated, and expanded by someone only identified by the initials "L. K. P." Lyman's stated intent was to present a history and description of the Columbia River. He wished to convey "a lively sense of the romance, the heroism, and the adventure" of the river's white settlement and development. He further wished to "breathe into the narrative something of the spirit and sentiment which we call 'Western' - a spirit and sentiment more easily recognized than analyzed (Lyman, 1963/1917, p. iii, apparently using the forward from the original 1909 publication). L.K.P. updates Lyman's work with the results of research not then available to Lyman and makes other factual corrections to the text, mostly through footnotes. He also adds a section on development, contrasting the pristine conditions eloquently chronicled by Lyman with the river's subsequent development up through the early 1960s - most notably the construction of the river's mainstem dams.

Lyman (1963/1917) is presented in three sections. The first presents a regional history from early geologic formation up through the late 1910s. The second is a narrative of a journey down the river taken by Lyman. Lyman states that his sources are other books supplemented with his own observations of the river and conversations held with original pioneers, hunters, steamship crewmembers, and tribal members. Unfortunately, the book is absent any bibliography for Lyman's original work. The third section is L.K.P.'s update regarding dam construction and other river development, supported by a bibliography. Of these, only the first section is used 
here, as L.K.P.'s third section has been superseded by additional dam construction and more recent accounts.

What Lyman (1963/1917) adds to Schafer (1943/1918) and Dodds (1986) is a very human component to historical events. For example, he includes tribal legends regarding the first arrival of whites and tribal perspectives on subsequent settlement. Quoting from transcripts of the time, he puts life into the region's historical founders. For example, he details the issues and positions of Oregon founders in his account of the political issues and debate behind the establishment of a provisional government for what became the Oregon Territory in 1848, an account L.K.P. rightfully critiques as being " $4^{\text {th }}$ of Julyish." In fact, there is a strong tone of patriotic and regional pride throughout Lyman's account, a tone counterbalanced by Dodds (1986) more objective presentation.

Hays' 1957 The Response to Industrialism 1885-1914 focuses on the impact of industrialization on the lives of people throughout the United States. His interest is on the transition from a society of "relatively stable, local business affairs" to one of “intense nationwide competition that rendered [the individual's] way of making a living far less secure" (p. i) regardless of whether he was a manufacturer, merchant, laborer, or farmer. He argues that industrialization led to the growth of large cities with an urban culture that slowly encroached into the countryside, replacing traditional networks of personal relationships with more impersonal forces of efficiency and competition. These new forces threatened the familiar order with an indifference to tradition and a community's sense of identity. It also resulted in a large influx of 
foreigners seeking work. Hays' intent is to examine the ways in which the people of the United States responded to these drastic changes in their lives.

Hays (1957) disputes the accepted historical argument that the unifying theme of history between 1885 and 1914 was a populist attack against corporate wealth in which a discontented public sought to curb corporate influence through government action. He sees this argument as simplistic and incomplete. More fundamental, in his view, was the social reaction to industrialization and the multiple ways in which both industrialization and the reaction to it changed American life. In essence, it represented a clash between the values of the price-and-market economy and the values of the intimate, interpersonal community relationships.

Wiebe (1967) provides a social and political context to the American social order in the early 1900s. In The Search for Order 1877-1920, Wiebe outlines a dramatic social transformation of society that began at the end of the post-Civil War reconstruction period. His purpose is to describe the breakdown of informal, ruralagricultural American society and its eventual replacement with a more hierarchical urban-industrial model.

Dorothy Johansen and Charles Gates first published their Empire of the Columbia: A History of the Pacific Northwest in 1957. Johansen produced a second edition in 1967, and it is that edition used here. Her stated intent with the second edition was to put more effort on the flow of events and on the interaction of politics and economics on the first half of the $20^{\text {th }}$ century. Like Schafer (1943/1917), Lyman (1963/1918) and Dodds (1986), Johansen provides a straightforward, textbook-like 
account of Northwest settlement and history. Of particular interest for this study was her work on early settlement and development (which corrected some of the material presented by Lyman) and her discussion of the Progressive movement in the Northwest.

Weber (2002/1920), Smith (1950), Cameron (1928 and 1929), Wiebe (1967), Hays (1957), Dodds (1986), Schafer (1943/1918), Lyman (1963/1917), Johansen (1967) and Meinig (1968) all write solely from the perspective of white Americans. Lyman (1963/1917), although he includes tribal traditions in his narrative, does so in the context of white exploration and settlement. Together they illustrate both the worldview of Anglo-American settlers to the Northwest and the implications of that worldview in shaping events. Equally important to a discussion of regional governance, however, is the worldview held by the region's original inhabitants and its implications.

\section{Domain: Columbia River Basin Commercial Development}

This next body of literature examines the commercial development of the river. The works reviewed are grouped by four general themes. These are memoir accounts of efforts at regional planning and economic development; histories of the Federal Columbia River Power System; legal and political histories; and - given its centrality to the most recent attempts at regional governance - histories of the region's salmon fisheries and attempts at salmon restoration. This literature is central to the purposes of this study as it was the expanding efforts in developing the basin's resources that 
brought various resource users into conflict and gave rise to the need for governance systems and structures.

\section{Memoir accounts of regional planning and development.}

Four works that were reviewed were written by men with active roles in regional developmental policy and governance in the 1950s and '60s. As such, they offer personal perspective, insight, and context.

Charles McKinley served as consultant to the Northwest Regional Planning Commission, the Hoover Commission Task Force on Natural Resources, as a researcher for the President's Water Resources Policy Commission, and a consultant to other various Northwest agencies and commissions. ${ }^{155}$ He also served as a faculty member of Reed College. He authored several papers on New Deal planning (Bessey, 1963). In 1952, while at Reed, he published Uncle Sam in the Pacific Northwest: Federal Management of Natural Resources in the Columbia River Valley. He presents a critical administrative and political history of federal "field agencies" (regional offices) that manage and develop natural resources in the Pacific Northwest. His intent is to describe the relationships between regional federal entities and the impact of those relationships on public administration and policy. In effect, he presents an argument favoring an authoritative Tennessee Valley Authority-like governance structure for the Columbia, citing what he views as the inadequacies of the voluntary collaborative approaches put in place following World War II, particularly the Columbia Basin InterAgency Committee. Although his description of agency missions and inter-agency conflict is dated, (for example, the jurisdictional competition between the Corps of

\footnotetext{
${ }^{155}$ Per fly leaf and preface to McKinley (1952), Uncle Sam in the Pacific Northwest.
} 
Engineers and the Bureau of Reclamation over yet-to-be-built dams) much of his critique of collaborative decision making rings true today.

A contemporary of McKinley was Roy Bessey. Bessey was commissioned by the state of Washington's Department of Conservation to chronicle regional resource planning from 1933 to 1963 . His pamphlet, Pacific Northwest Regional Planning: a

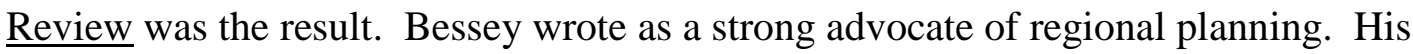
over 50-year career included work with government and private consulting firms in the fields of engineering, resources development, planning, and programming. ${ }^{156} \mathrm{He}$ was active as a consultant during the period covered in his book. As such, and like Ogden and McKinley, Bessey writes with the insights of an insider who had a frontrow seat and was actively involved in the planning activities he documents.

Bessey's intent is to provide a study of the regional experience in resource planning, noting the lack of such literature for the Pacific Northwest (as opposed to the Tennessee Valley Authority). He states his purpose as “...to give a reasonablyconnected narrative account of a regional planning movement from the necessarily limited perspective of a single witness" (p. viii). He does not attempt to provide a comprehensive, detailed, or definitive investigation of the whole PNW planning effort. Rather, he provides “.... a reasonably-connected narrative account of a regional planning movement from the necessarily limited perspective of a single witness" ( $p$. viii).

\footnotetext{
${ }^{156}$ From the forward to Pacific Northwest Regional Planning: a Review, written by Earl Coe, Director, Washington Department of Conservation on September 10, 1963.
} 
Although presented as administrative history, Bessey writes with a strong bias to central government planning. Comparing the Tennessee Valley experience with the Columbia, he argues that, "[t]he parallel Pacific Northwest effort obviously has fallen short of that of the more innovational TVA in a number of respects - notably as to integration of program, impacts upon the region, and world attention and interest engendered" (Bessey, 1963, p. vii).

Bessey provides an excellent source of early efforts at multi-agency cooperation and governance (although the word "governance" does not appear). He organized his book into periods defined by key events that changed the planning paradigm nationally and regionally. The first period is $1933-1943$, marked by the Great Depression at one end and the outbreak of World War II on the other. Bessey characterizes this period by the strong leadership from the national level and support for centralized resource planning from the national to local levels in order to overcome the effects of the Depression. The second period is 1943 - 1953, during which the nation was focused on winning World War II and the Korean War. This period, according to Bessey, is characterized by abolition of the New Deal's National Resources Planning Board that had provided the "heart and life blood" for the planning movement. The result was fragmentation of the New Deal's centralized governmental planning effort and its replacement with voluntary arrangements and compliances. The federal role shifted from central planning to technical analysis, and the pre-Depression policy of laissez-faire begins to reassert itself. Bessey's third period is from 1953 to 1963 , a period of strong economic growth, with 
correspondingly less support for strong government involvement in the economy. Bessey's model of defining historic periods by points of "punctuated equilibrium" (Gersick, 1991) or "critical situations" (Giddens, 1984) is used in this study as the organizational model for Chapter 4. Of direct interest to this study are Bessey's insights into the Pacific Northwest Regional Planning Commission (PNWRPC), with which he personally worked.

Roy Scheufele served as executive assistant to the Commanding General of the U.S. Army Corps of Engineers North Pacific Division, a position from which he retired in 1963. He completed his History of the Columbia Basin Inter-Agency Committee: the Story around 1970 (the work is undated). The history was commissioned by unanimous resolution at the last meeting of the Committee and funded through pooled agency funds.

The Columbia Bain Inter-Agency Committee (CBIAC) was formed through voluntary agreement among the Corps of Engineers, Bureau of Reclamation, Bonneville Power Administration, U.S. Forest Service, and Federal Power Commission in 1946. It was later joined by the Departments of Labor and Health, Education, and Welfare, and functioned until replaced by the Pacific Northwest River Basins Commission in 1967.

Citing primary material drawn from CBIAC meeting files, Scheufele (c. 1970) provides a history and critique of the CBIAC's origins, operation, problems, accomplishments, and failures. He also provides occasional glimpses into other governance systems that came into being around the same time, in some cases being 
the only references to those organizations found during the research for this study. Examples of these other systems include the Northwest States Development Committee and the Pacific Northwest Governors' Power Planning Committee, all discussed in further detail in Chapter 4. Scheufele organizes his work into three sections. The first deals with the genesis of the CBIAC, recounting the region's history in resource planning back into the 1800s. The second is a chronicle of CBIAC meetings. The third is his candid and insightful critique of the Committee's operations, accomplishments, and weaknesses. The value of this critique is its general applicability to subsequent governance systems organizes around the concepts of voluntary cooperation and consensus-based decision-making.

Gus Norwood published his book Columbia River Power for the People: a History of the Policies of the Bonneville Power Administration apparently in 1981, although the work itself is undated. Norwood was the first executive director of the Northwest Public Power Association from 1947-1967. As such, his history is written from a pro-public power point of view. He also offers the perspectives of one personally involved with many of the policies of which he writes. As noted in the forward by Sterling Munro, BPA Administrator at the time the book was published, “...this is not a safe and sanitized bureaucratic exercise. It is written from a perspective and a point of view" (Norwood, c. 1981, p. v.).

Norwood was hired by BPA (who published his book) to review the history of BPA's policies and examine that history's relevance to the agency's future. He presents a history of the policies of the Bonneville Power Administration. His 
guidance from Don Hodel, BPA Administrator at the time the project began and Munro's predecessor, was to (1) "follow the facts wherever they lead, or the history will not have credibility" and (2) "where appropriate and feasible, evaluate the policies for their relevance to the future" (Norwood, c. 1981, p. viii).

Norwood adopted a three-step approach to the project. First, he identified BPA's major policies and, from these, selected those he felt were most significant to the purposes of the study. Second, he traced each policy back to its genesis, many of which had roots that preceded the agency's creation. Third, he described the setting and political context at the time each policy was adopted. Norwood organized his findings into ten parts, arranged chronologically. The first three discuss the national and regional context within which the conservation and public power movements in the Northwest evolved, beginning with the Louisiana Purchase in 1803.

Underlying the entire book are three themes. Most prominent, and captured in the title, is the provision of economic electrical power to the public at large. Policies on federally built and operated transmission facilities, cost-based postage stamp rates, anti-private utility monopolies, public preference for federally produced hydropower, industrial and economic development, and rural electrification underscore the New Deal belief in the social power of electricity to improve people's lives. Second is the regional nature of the transmission system. The nation's largest at the time of Norwood's writing, the grid system opened the door for power management beyond the marketing of federally generated electricity. Third, and of greatest interest to this study of regional governance, is the institutional evolution of BPA as a member of "a 
pluralistic, regional electric system of public, cooperative, and private utilities, and large industrial customers, with major inter-regional and inter-agency relationships" (Norwood, c. 1981, p. ix).

McKinley (1952), Bessey (1963), Scheufele (c.1970), and Norwood (c.1981) all offer first-hand insights into the issues of which they write. They also, albeit inadvertently, exemplify a perspective favoring a worldview of economic development, accepting as a given the dominant use of natural resources for enhancement of the regional economy. Ogden (1949) and McKinley (1952) do not address tribal or environmental issues other than in passing. Scheufele (c.1970) does, but limits his discussion to the conflict between fishery managers and river developers. Scheufele writes from the perspective of salmon as a market commodity, the harvest of which was effected by the construction of dams and other commercial impacts on fish habitat. Bessey (1963) makes passing acknowledgement of the impact on the environment and fish, but makes little mention of tribal concerns. Norwood (c.1981) discusses both, writing at about the time that the Northwest Power Planning and Conservation Act with its mandates for fish and wildlife protection were enacted. However, Norwood can only introduce the topic as he was writing at the time the Council was only just getting organized and before it fully developed its program. Interestingly, although all four were directly involved with the governance systems of their day, only Scheufele's (c.1970) work is specifically devoted to chronicling any given system. McKinley (1952) provides an overview and analysis of the role played by federal agencies in resource development and management and 
argues that the fractured nature of federal management should be replaced with a valley authority-type agency. Bessey (1963) documents the history of regional planning efforts. Norwood's (c.1981) interest is the administrative history of the Bonneville Power Administration. Whereas the experiences of each offer insights into the region's development, other sources are needed to fully establish the social and political contexts from which the region's various governance systems emerged.

\section{The Federal Columbia River Power System.}

The Columbia Basin's commercial development is most vividly exemplified by its integrated system of federal and non-federal hydroelectric dams. The federal dams and related transmission grid are jointly operated by the Corps of Engineers, Bureau of Reclamation, and Bonneville Power Administration. Among the earliest accounts of federal hydroelectric development is the unpublished $\mathrm{PhD}$ dissertation of Daniel Ogden, written in 1949, entitled Development of Federal Power Policy in the

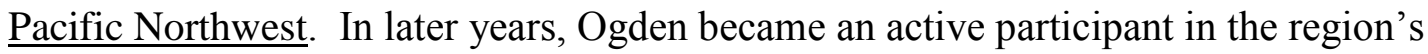
governance systems, serving in multiple administrations and positions and being a frequent lecturer and writer on regional issues. Ogden's intent in his dissertation was to trace the historical basis for federal involvement in Columbia River hydropower. Using primary source documents and interviews with many of the key individuals involved with the development of the Columbia's hydropower system, Ogden presents an in-depth history of that development and the policies and issues that drove it.

Ogden argues that the origin of the system were the twin demands for irrigation in the arid land east of the Cascades and a safe and economical means of river transportation 
through the Columbia's falls and rapids as an alternative to high railroad prices. Neither, by themselves, would justify the necessary expense on the part of the government. Hydropower was added later as a component of the public power movement; as a public works employment program during the Depression; to promote regional economic growth, and to provide inexpensive electricity as a counterweight to high private utility prices, especially to rural areas.

Of interest to this study are (1) the regional context of the period prior to and through the New Deal; (2) the development of what became strong regional support for federal ownership and operation of hydroelectric dams in the Northwest; and (3) his detailed discussion of the policy issues of the day and how they translated into various planning and operational structures. He also discusses in some detail the debate over creation of a Columbia Valley Authority; the option to allow the Corps of Engineers and Bureau of Reclamation to market power from their projects; and the policy issues behind the 1937 Bonneville Project Act.

Whereas Ogden's dissertation presents a detailed litany of events, dates, personalities, and motivations written from largely an economic perspective, Robert White's The Organic Machine: the Remaking of the Columbia River (1995) provides a view of the Basin's development through the lenses of social and environmental history. He argues that it was the Columbia River dams that made the Pacific Northwest a region, connecting the states through a network of hydroelectricity, irrigation, and river navigation. In so doing, the Columbia was remade from a natural ecological system to an industrial- scale machine designed for production of 
commercial and social goods and services. His underlying theme is that this industrialization came at the cost of both the environment and the personal relationship that native tribes and the earliest Euro-American settlers had with their environment.

White (1995) argues that, prior to industrialization man's relationship with nature was measured by his personal labor. Man knew nature through the labor it took to overcome and live with it. It was direct and personal. The impacts of human action on the natural environment were immediately felt and vice versa. Interactions between humans and nature occurred on a very personal scale (examples: farming, tribal fishing, families rafting down rapids of The Dalles to get to Portland, and the predictable seasonal threat of flooding.) While industrialization reduced or eliminated many of the very real threats to personal safety and property inherent in this personal relationship, it did so by turning what had been, in White's eyes, romantic and majestic into a sanitized, tightly managed suite of commodities. But he over does it. White's romanticized description of the pre-development river and his if-only-we'dknown-we-would-never-have-done-it tone seems to dismiss or trivialize the very real threats posed by the natural Columbia to those trying to build communities and livelihoods from the river's resources. It also ignores the worldview assumed by the region's Anglo-American settlers and developers that guided their responses to those threats. Their conceptual framework would simply not allow serious consideration of non-development options. 
Romanticism notwithstanding, the value of White's work for this study is his presentation of the history of the social organizations employed by the Basin's societies at various periods and the impact of technology and culture on those organizational forms. ${ }^{157}$ He helps illustrate the differences between the tribal and Euro-American worldviews. His review of organizing structures includes the Columbia Valley Authority, PNWRPC, and Columbia Basin Inter-Agency Committee and the context from which they emerged. He also provides a concise synopsis of the private-public power debate, the influence of the Progressive era's conservation movement, and the counterintuitive lack of early involvement by salmon harvest managers as issues of governance as the system was being planned and developed.

Eve Vogel presented a study of Northwest regionalism in her 1997 doctoral dissertation, The Columbia River's Region: Politics, Place, and Environment in the Pacific Northwest, 1933-Present. Vogel studied the role of regional institutions in fostering the regionalist ideal in the 1930s. Her thesis is that this ideal was institutionalized in the Pacific Northwest Regional Planning Commission, established in 1934. She argues that the NPWRPC was conceived as a way to avoid political conflict over Basin development by creating an inclusive process to accommodate interests that otherwise were likely to come into conflict. She evokes and extends White's (1995) argument regarding the Columbia River as the basis for Northwest regionalism. In her argument, it was not so much the river as the interest in the low cost hydropower the river could produce and the institutionalization of that low cost power through creation of the Bonneville Power Administration.

${ }^{157}$ In this sense, White (1995) closely follows the logic of Sztompka (1984) and Giddens (1991). 430 
The region's institutional methods for estimating power needs, its efforts to integrate nuclear power with the hydrosystem, and resulting economic catastrophe of the 1970s are the subject's of Daniel Pope's 2008 Nuclear Implosions: the Rise and Fall of the Washington Public Power Supply System. Pope's goal is to explore the recently revived interest in nuclear energy in the U.S. He attributes this interest to rising oil and gas prices and a growing concern about the impacts of carbon emissions on climate. As a result, the author believes that public opinion is shifting in greater favor of nuclear energy. Furthermore, growing numbers of environmentalists are seeing the value of nuclear energy in the face of climate change. The author's objective is to inform this current discussion by using the Northwest experience as a case study to illustrate both the perils and promise of nuclear development. He does this through a detailed chronological historical narrative beginning with the first efforts to harness the river's energy and carrying it through the nuclear era. He writes from an economic perspective. He focuses on the relatively closed set of institutions involved in power planning development and how regional utilities, often led by the Bonneville Power Administration, evolved into hierarchical organizations that emphasized centralized and professionalized long-term planning. Pope's primary thesis is that poor planning, closed circuit thinking, and misjudgments that led to one of the largest public bond defaults in United States History.

\section{Political and legal histories of Basin development.}

Five histories of Columbia Basin political and legal events were reviewed. Each deals with the policies and politics a specific periods. Jay Brigham (1998) and 
Phyliss DeLuna (1997) present academic studies based on historical research. Like Ogden, Norwood, Bessey, and McKinley, and unlike Brigham and DeLuna, Michael Blumm and Roy Hemmingway were both close observers and participants in Columbia Basin power issues and provide firsthand accounts of their observations and resulting insights. Writing from a more detached perspective are reporters Bill Crampton and Barry Espenson who focus almost exclusively on natural resources issues in the Columbia Basin.

In his 1998 book Empowering the west: Electrical politics before FDR, Jay Brigham presents the rise of the public power movement prior to the New Deal. Franklin Roosevelt's election in 1932 represented the culmination of efforts begun in the early 1900s to use government to counter the excesses of private industry. The 1932 election brought people into power with a predilection to use government to solve social problems. The public power movement, which began in the 1920 s, was only one of these social issues.

The author notes that American business was in a state of transition at the turn of the century. Echoing Wiebe (1967) and Hays (1957), Brigham (1998) argues that the nation was moving from small, locally owned economic enterprises to nationwide multi-unit corporations. This consolidation and expansion was made possible by technical advances in communications and transportation, abetted by the doctrine of laissez-faire by the government, enabled large corporations to amass a great deal of power. The excesses of these large corporations resulted in the progressive reform movement. 
Brigham's (1998) work has received mixed reviews. While praised as an "excellent study" that "significantly extends our understanding of electrification" (Cannon, 2000), it has also been criticized for "reductivist tendencies" in that he tends to generalize and categorize various complex issues into two or three conceptual nodes (Wollner, 2001) and for presenting an overly simplistic and incomplete account (Williams, 2000). While these criticisms may be true, they do not detract from the value of Brigham's work to this study. Brigham dispassionately lays out the key arguments of advocates of both private and public power. In doing so, he presents one of the few relatively in-depth renderings of the free market perspective. He centers his argument on three case studies in the search for inexpensive electricity: Seattle, Los Angeles, and eight small-towns across America. Although it may have its flaws, Brigham helps a layperson understand the foundations upon which the public-private power debate rested.

Whereas Brigham (1998) discusses the public power movement prior to Roosevelt, Phyliss DeLuna's (1997) book focuses on the period immediately thereafter. Public vs. Private Power During the Truman Administration: A Study of Fair Deal Liberalism presents the efforts of New Dealers to retain what they saw as the gains of the public power movement that was coming under increasing attack by promarket advocates. DeLuna's stated intent is to contribute to the understanding of the political significance of the Truman years with regard to public power policy, focusing on the period 1949-1952. She offers insights into Fair Deal liberalism with regard to the public-private power debate. Just as Brigham (1998) argues that the debate did not 
begin with Roosevelt's election, DeLuna (1997) argues that it did not end with his death.

The policy position of the Truman administration was that government should be run for the benefit of the public at large versus narrow interests. "Espousing a form of economic democracy, Truman and certain administration officials put themselves forward as defending the country's natural resources against monopolization by special interests and ensuring that they were developed for the good of the whole citizenry" (p. xi). DeLuna (1997) goes on to recount a resurgent effort to install first a Columbia Valley Authority in the Northwest, followed by a more modest Columbia Valley Administration. Neither effort succeeded, as the nation and region were more comfortable with voluntary, collaborative associations, such as the Columbia Basin Inter-Agency Committee, that came into being in the 1940s. DeLuna offers an excellent account of the politics and positions of federal agencies, states, and private interests as this debate played itself out.

Michael Blumm, a professor at Northwestern School of Law and director the law school's Northwest Water Law and Policy Project, has authored numerous books, essays, and articles on Columbia Basin issues. His work is often critical of the impacts of the hydropower system on the environment. The paper reviewed for this study was his 1982 paper The Northwest's Hydroelectric Heritage: Prologue to the

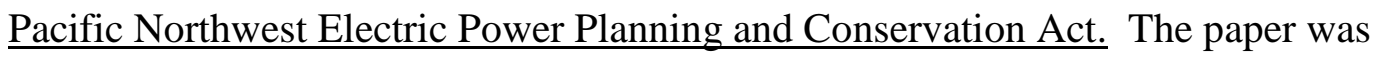
published in 1982, two years after enactment of the Pacific Northwest Electric Power Planning and Conservation Act (1980 Power Act). 
Blumm (1982) argues that current resource conflicts are a legacy of past policies and programs. His intent is to provide historical perspective on Northwest hydropower policies that led to the 1980 Power Act. He provides a thoughtful, chronological discussion of key events leading to enactment of his Act. Somewhat similar to Bessey (1963), he organizes his paper by periods that changed the direction of important power policy. His categories are the pre-New Deal (or progressive period); World War II and the post war years; and the region's hydro-thermal program where it was envisioned that regional energy needs could be best met by adding nuclear generators to the region's hydropower system. In so doing, he provides a factladen history of dates and events that provide context for the creation of the Council.

Roy Hemmingway served as a member of Oregon Governor John Kitzhaber's administration and one of the original appointees to the Northwest Power Planning Council. Hemmingway, an attorney by training, also wrote his essay The Northwest Power Planning Council: Its Origins and Future Role shortly after passage of the 1980 Power Act. Like Blumm (1982), his purpose is to outline the history of the Council and articulate its roles and potential. He begins his 1983 history with the hydrothermal program, preferring to devote more discussion on the potential for the future rather than recounting the past.

Hemmingway (1983) describes the Council as a unique experiment in American federalism. The 1980 Power Act was not a case of surrendering federal jurisdiction or power to the states, but sharing authority among federal agencies and the Northwest states in regional decision making. It did not require federal agencies to 
follow the plans and programs prepared by the Council, but only to consider them when making decisions. As such, Hemmingway envisioned the Council as a check on arbitrary agency decision-making.

What Blumm (1982) and Hemingway (1983) both point out is that, unlike its predecessor structures, the Council was the first in which the region recognized an obligation to balance hydropower with the systems impact on fish and wildlife and to tribal interests. The crisis generated by construction cost overruns in the governmentbacked nuclear power facilities, an inflated projection of regional energy needs, and other issues opened a window in which environmental and tribal interests could obtain a seat at the regional governance table.

Bill Crampton and Barry Espenson have methodically covered Columbia Basin FCRPS issues for years, and their first-hand reports are a primary source of information on the rise and collapse of the CRBF as related in Chapter 1. In 2009, they summarized their reporting in Salmon and Hydro: An Account of the Litigation over Federal Columbia River Power System Biological Opinions for Salmon and Steelhead, 1991 -2009. Bill Crampton is the owner of Intermountain Communications and serves as editor and publisher of both the website and the Columbia Basin Bulletin on-line newsletter. He has worked for 20 years as a newspaper reporter and editor in Alaska and the Northwest. Barry Espenson is a senior writer for the Columbia Basin Bulletin. He has worked for 20 years as a newspaper reporter and editor in the Northwest, often specializing in natural resource and agriculture issues. 


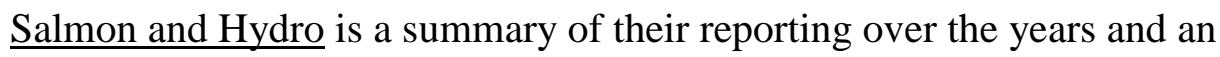
overview of litigation concerning NOAA's series of FCRPS biological opinions on ESA listed salmon and steelhead. It begins with the first listing of Snake River Sockeye on November 20, 1991 and follows through 12 subsequent listings and the issues in front of the court as of the date of publication. The authors' intent is to provide the reader with "a general understanding of the history of biological opinion litigation - how the Northwest moved, in legal terms, from the first salmon listings under the Endangered Species Act to the 2008 Federal Columbia River Power system Biological Opinion - and the major issues involved in case after case” (p. 4). Source material comes from original reporting by the authors as published in the periodic Northwest Salmon Recovery Report, which ran in print from 1997 to 1999, and in the on-line Columbia Basin Bulletin from 1998 to the present. Their central thesis is that the 1995 biological opinion and the court decision on that opinion rendered in 1997 were turning points in regional salmon management and hydropower operations.

The "issue summary" condenses what are likely hundreds, if not thousands of pages of court filings, declarations, motions, and orders into a concise 77 pages. As such, it only offers the broadest outline of the key issues at play in the courts. In their effort to be brief, the authors may confuse readers not intimately familiar with the details of which they are writing. For example, terms like "population," "stock," "evolutionary significant unit (ESU)," and "distinct population segment (DPS)" are not well defined and may appear to the lay reader to be interchangeable when, in fact, each is a term of art with its own specific meaning and application. A second example 
is their discussion of the Regional Forum. The Regional Forum originally consisted of an Executive Committee of sovereign leaders, an Implementation Team of senior managers and policy advisors, and several technical teams. The authors introduce the Executive Committee and technical teams on pages 12 and 13, discuss Oregon's objections to them on page 17 , and the court's ruling on them on page 27 . The term "Regional Forum" is not introduced until page 28. To a reader not familiar with Regional Forum organization and history these may appear to be separate, unrelated entities.

However, these criticisms are minor in comparison to what the authors accomplish. Salmon and Hydro presents a succinct outline, laid out in generally chronological order, of the listing of thirteen species of salmon in the Columbia Basin, the associated biological opinions written by the National Marine Fisheries Service on the Federal Columbia River Power System (FCRPS), and the sequence of litigation that followed. It summarizes the major parties involved, their interests and motivations, the key decisions rendered by the courts, and the impact of those decisions on FCRPS system operations. Consequently, the authors largely achieve that which they set out to do.

The authors also tangentially provide useful insights as to how the Basin's litigation battles over fish affected experiments with different governance systems. These systems include the Northwest Power Planning and Conservation Council, the Regional Forum, the CRBF, the Columbia River Fisheries Council, and the lower river tribes' Columbia River Intertribal Fish Commission, all discussed only to the 
degree they intersect with the litigation narrative. For example, the authors note that it was the region's inability to agree on a coherent salmon recovery strategy that led to the ESA listings and collapse of the Regional Forum's Executive Committee. The resulting frustration motivated the initiation of the Three Sovereigns Process, which eventually resulted in creation of the CRBF. The authors do no more than introduce the CRBF. The (rightful) implication is that the CRBF, although at least partially linked to regional efforts to respond to litigation actions, proved functionally inconsequential to later decision making.

\section{Domain: The Impact of Development on Regional Salmon}

There is no shortage of written material on the status of northwest salmon and related institutions. Much is written to promote various policy positions. For example, James Buchal's 1998 The Great Salmon Hoax attributes the salmon decline to overfishing, mismanaged hatchery practices, and ulterior political motives of federal regulatory agencies while dismissing the impact of Columbia Basin dams. Alternatively, Michael Blumm et al. (1998) place primary blame on the existence and operation of the dams. As Taylor (1999) puts it, "Every interest claimed to speak for citizens and salmon, but their rhetoric revealed that the core dispute was less about salmon than social legitimacy" (p. 165) as they argued so vehemently over who was to blame for the salmon decline.

Basic background facts were obtained primarily from two sources. The National Research Council's Upstream: Salmon and Society in the Pacific Northwest 
(1996) provides a comprehensive general overview of the evolution of the salmon situation and the causes of salmon decline. Rather than focus on any one cause, the Council outlined the threats to traditional salmon runs brought about by changes in salmon habitat, development of the dams and hydropower system, over harvest, hatchery management, and changes in ocean conditions. For this study, Upstream was used for general background information and facts.

Similar use was made of Cone and Ridlington's The Northwest Salmon Crisis: A Documentary History (1996). As Pevar (2002) did with key source documents central to tribal rights, Cone and Ridlington provide excerpts from source documents central to understanding the policy decisions and social structures that underlay the salmon decline. These documents include statutes, policy statements, Indian treaties, text from speeches, and technical reports. Each document is accompanied by editorial comment from a variety of regional salmon experts representing a variety of perspectives and viewpoints. Cone and Ridlington provide an excellent, comprehensive desk-side compendium of key documents with accompanying context.

Lichatowich (1999), Taylor (1999), and Williams (2006) provide holistic treatments of the social aspects of the salmon debate and the impacts of cultural perspectives on salmon policy. All provide a comparison between the tribal and Anglo-American worldviews and the consequences of those worldviews with respect to the environment in general and regional salmon runs in particular. As such, they provide both insights into the social aspects of the salmon situation and add to the understanding of the tribal worldview introduced above. 
In Salmon Without Rivers: A History of the Pacific Salmon Crisis (1999), James Lichatowich argues that the concept of hatcheries to offset the impacts of development on salmon runs created an unrealistic and devastating perception that the Northwest could have it all - salmon plus the benefits of development. Thus, it is not a critique of hatchery management per se, but a critique of an industrial approach to resource management that viewed nature as a warehouse of marketable commodities.

Of particular interest to this study is Lichatowich's (1999) contrast of the traditional Indian gift-based economy with the Western market-based economy. He states that the relationship between man and salmon in the Northwest began to evolve about 9,000 years ago on the Fraser River in Canada and about 7,000 - 8,000 on the Columbia at The Dalles. The technology for preserving salmon through drying and smoking evolved about 3,000 years ago. This allowed salmon to be stored between fishing seasons, thus boosting the region's human carrying capacity and laying the basis for development of complex cultural customs. Fully developed salmon economies appeared in Oregon and Northern California about 1500 years ago.

The author notes that the common perception that Indians lived within the constraints of the natural ecological economy is misleading. The Indians developed a sustainable salmon based on the power of their own world-view, a way of thinking that would not have accommodated modern ecological concepts. "The sustainable relationship between the Pacific salmon and Native Americans derived not from ecology but from an economy based on the age-old concept of the gift and a belief system that treated all parts of the earth - plants, animals, rocks - as equal members of 
a community." (p. 34). The economy was based on gift giving, a way to transfer goods and redistribute wealth. Gift-based economies worked on a cycle of obligatory returns.

Joseph Taylor's 1999) Making Salmon: an Environmental History of the Northwest Fisheries Crisis looks holistically at the historical events leading to the current state of the region's development and its impacts on salmon. His work critically examines the major northwest resources users - logging, grazing, mining, commercial and sport fishing, pre- and post-contact tribal activities, and the effects of development through dam building and the spread of urban areas. Similar to Lichatowich (1999), Taylor provides a cultural and historical context for the evolution of perspectives regarding salmon in the PNW in general and the "Oregon country" in particular.

Taylor (1999) looks at the intersection of culture, economy, and nature to examine the long-running collapse of the salmon fishery in the Pacific Northwest. He notes that the "crisis" has been unfolding in plain sight for over 150 years, with imminent extinction of salmon runs being first prophesied in 1875 . Throughout most of the book, he presents an even-handed and meticulously researched history of the region, offering insights, ironies, and paradoxes. He saves his opinions and conclusions for the end.

Also like Lichatowich (1999), Taylor's (1999) main critique is social rather than technical. Taylor argues that history is story telling and, like any story, the narrator makes decisions about what to include and exclude. He states, 
History is political. Its ability to legitimate or condemn activities of the state, society, and markets make it a force in public debates, which is, in part, why Pacific northwesterners have argued so vehemently about Who is to Blame for the decline of salmon. Every explanation has rested on a rendition of the past, and each version holds profound social, cultural, and environmental consequences...We do not all view the world through a common lens. Identity, culture, and location affect how we understand the present and remember the past (Taylor, 1999, pp. 237-238, emphasis in original). Northwesterners segregated the salmon fisheries by race, ethnicity, class, and geography. Each side claimed themselves to be decent citizens, property owners, and taxpayers while disparaging other groups as greedy, self-serving, and corrupt. "Every interest claimed to speak for citizens and salmon, but their rhetoric revealed that the core dispute was less about salmon than social legitimacy" (Taylor, 1999, p. 165). His key insight is that the salmon decline is not a sudden disaster discrete in time, but the result of a long-running process. "The essence of the salmon crisis is the struggle to define and solve a complicated environmental and social problem, but resolution has been elusive because participants have so little in common." (p. 4). "How people respond depends on who they are, where they live, what they do for a living, and how they think it happened." (p. 4).

Taylor's (1999) summary argument is that once salmon became viewed as an economic commodity rather than an integral part of a natural process, they fell victim to other sectors of industrial development that offered greater financial return. 
"Fishers, managers, and scientists tried to moderate damage, but their combined numbers and strongest arguments paled before the bureaucratic might, popular appeal, and Progressive ideology of the Bureau of Reclamation, Corps of Engineers, and Bonneville Power Administration. "Salmon fishing was simply less profitable than other industries” (Taylor, 1999, pp. 225-226) such as timber, mining, hydroelectricity, and agriculture.

In 1992, the Northwest Power Planning and Conservation Council requested that an independent science group (ISG) to review the Council's 1992 fish and wildlife program. The members of the ISG, which included James Lichatowich, subsequently published their recommendations and the logic behind them in a collection of essays titled in Return to the River: Restoring Salmon to the Columbia River (2006), edited by Richard Williams (also a member of the ISG). The intent of the book is to present a critique of the failure of salmon and steelhead management in the Columbia Basin and suggest a new "conceptual foundation" for salmon management for the $21^{\text {st }}$ century. It also presents a critique of the Council as a suitable governance body to address the salmon issue, arguing that it is captive to the developmental worldview of the federal agencies, fishery managers, and regional electrical power interests.

The authors note the region's well-documented failure to halt the decline in salmon runs. Of interest to this study is their insight on the role of perspective, identity, and culture in that decline - making arguments consistent with Taylor (1999) and, not surprisingly, Lichatowich (1999). "What is [sic] less recognized is the lack of an explicit and scientifically based conceptual foundation and the consequences of this 
on salmon management and recovery actions" (Lichatowich, McConnaha, Liss, Stanford, and Williams, 2006, p. 4).

The authors' (2006) intent is to propose an alternative to the commoditiesbased conceptual foundation with one that holistically stresses the role of natural ecological processes. They characterize the dominant regional market perspective as one that began with a belief in an inexhaustible supply of resources that was later replaced with the belief that technical fixes, through engineering and artificial propagation, could mitigate for the loss of natural processes. ${ }^{158}$ This new conceptual foundation is based less on engineering nature to fit societal needs and more on managing human activities to facilitate natural processes that shape the environment. This "return to the river" concept envisions the Columbia as an ecosystem as opposed to the organic machine described by White (1995).

Williams and his colleagues (2006) write from the perspective of the ecologist. As such, they seem to miss a fundamental implication of their own argument. The authors, in their essays, present a detailed history of the region's development and support their arguments with a large amount of detailed, technical information. In effect, they attempt to use a rational argument to convince the reader of the correctness of the conceptual foundation they propose.

The findings of this study of Columbia Basin governance and history of regional governance calls the "lack of an explicit and scientifically based conceptual foundation" part of their argument into serious question. Arguably, the problem is not the lack of a conceptual foundation but the large number of them, all conflicting in

${ }^{158}$ Again, consistent with Taylor (1999) 
their objectives and all claiming scientific underpinnings and legitimacy. They also miss (or do not acknowledge) the fact that others can look at the same technical data they do and either derive different conclusions or offer counter-data in challenge.

This is because, to use the authors' own language, conceptual foundations are defined as "a body of prior knowledge reflecting training, beliefs, and experience"; a "lens through which we interpret observations and thereby form conclusions"; and a set of "principles and assumptions" (p. 29). "Conceptual foundations are often buried so deep in the culture of management agencies that they are rarely articulated, examined, or evaluated." (p. 36). Their definition is very similar to the "shared basic assumptions" that Schein (2004) uses in his definition of culture. Consequently, an argument to adopt a new framework centered on salmon restoration and preservation as the region's most important value is unlikely to sway the beliefs and values of others based on rational argument, regardless of how well supported.

What this study does confirm is Williams' and his colleagues' (2006) more fundamental point on the power of conceptual foundations (or worldviews) to drive social system and structure. "A conceptual foundation or 'worldview' is fundamental to how we interpret the 'facts' garnered from observation or scientific investigation, and, in turn, to how we manage human interactions with the environment" (p. 4). This point will be tested in the examination of governance structures presented in the chapter to follow.

Lichatowich (1999), Taylor (1999), and Williams (2006), in addition to offering the connections between culture, social organization, and policy decisions all 
provided detailed accounts of the history behind the regional salmon fishery development. As such, they add to (and largely complement) the accounts of dates and events provided by Schafer (1943/1918), Johansen (1967), Dodds (1986) and Lyman (1963/1917); the just-the-facts narratives of the National Research Council (1996) and Cone and Ridlington (1996); and the discussion of basin commercial development provided by Ogden (1949), McKinley (1952), Bessey (1963), Scheufele (c.1970), Norwood (c.1981), Hemmingway (1982), Blumm (1982), White (1995), DeLuna (1997), Brigham (1998), and Pope (2008).

\section{Domain: The American Environmental Movement}

Early roots and philosophic underpinnings.

Although the earliest roots of the American environmental movement can be traced to the Middle Ages and biblical teachings (Cortner and Moote, 1999; Kline, 2000; Dunlap, 2004), environmental historians generally credit George Perkins Marsh as providing the intellectual foundation of the American environmental movement. For example, in 1931 Lewis Mumford credited Marsh as "the fountainhead of the conservation movement" (quoted by Lowenthal in introduction to Marsh, 1965/1864, p. ix) and Dunlap (2004) describes Marsh as providing "the first lengthy discussion of humans as a geological and biological force" (p. 37).

Marsh's (1965/1864) intent, as stated in his introduction was:

“...to indicate the character and, approximately, the extent of the changes produced by human action in the physical conditions of the globe we inhabit; to point out the dangers of imprudence and the necessity of caution in all operations which, on a large scale, interfere with the spontaneous arrangements 
of the organic or the inorganic world; to suggest the possibility and the importance of the restoration of disturbed harmonies and the material improvement of waste and exhausted regions; and, incidentally, to illustrate the doctrine, that man is, in both kind and degree, a power of a higher order than any of the other forms of animated life, which, like him, are nourished at the battle of bounteous nature." (p. 3).

His basic argument was that humankind was destroying the land and water upon which it depended for its existence. As he put it, "man has too long forgotten that the earth was given to him for usufruct alone, not for consumption, still less for profligate waste" (p. 36) and "man...is essentially a destructive power" (p. 36) against which nature cannot respond fast enough.

Man in Nature $(1965 / 1864)$ chronicles Marsh's observations regarding apparent linkages between timber over-harvest and over-grazing to hillside erosion, insect infestations, disease, the drying up of springs, and the destruction of fish spawning beds by the resulting sedimentation.

Benjamin Kline (2000) provides a more holistic history in First along the River: a Brief History of the U.S. Environmental Movement. His intent was to present an introductory study of the history of American environmentalism by discussing the historical foundations of the U.S. environmental movement and introduce the important facts and themes essential to understanding the movement. Kline is, however, an environmental advocate and his book is in essence a critique of the market-capitalist worldview. His presentation of historical events is, however, fairly straight forward.

Of interest to this study is his presentation of the philosophical underpinnings of European society's relationship with the natural world. Kline (2000) argues that 
this relationship is based on the philosophy of the Judeo-Christian tradition, citing the biblical commandment to multiply and subdue the earth. He notes the spread of Christianity across Europe by $500 \mathrm{AD}$ and the corresponding reduction in paganism. Whereas paganism taught that people and the natural world were connected and interdependent, Judaism and Christianity taught that people were placed separate from and above nature by God. It was God's will that man dominate nature in the struggle for sustenance and life, following the bible's examples of Adam and Noah.

Kline (2000), like Weber (2002/1920), provides the philosophic justification for - and perceived inherent rightness of - commercial development of natural resources. Wiebe (1967) and Hays (1957 and 1999/1959) explain how the administrative capacity for a nationwide application of that philosophy developed. Thomas Dunlap (2004) takes an additional step: rather than just limiting himself to an accounting of the development of environmental thought he argues that environmentalists should directly challenge the righteousness of the market philosophy by countering it with environmentalism's own sense of spirituality.

Thomas Dunlap's Faith in Nature: Environmentalism as Religious Quest (2004) was inspired by the reaction of some historians and environmental advocates to an essay delivered by William Cronon entitled The Trouble with Wilderness. ${ }^{159}$ Cronon argued an academic point that the concept of "wilderness" was socially constructed. By this, he meant that certain areas of land were designated "wilderness"

\footnotetext{
${ }^{159}$ Of interest is the similarity between Dunlap's account of his motivation for writing Faith in Nature and the observations by Stuart Albert and David Whetten of colleagues' reaction to relatively minor budget reductions imposed by the Illinois state legislature on the University of Illinois. That observation led to their development of a theory of organizational identity (Albert and Whetten, 1985).
} 
based on historical processes and events and certain characteristics. This in turn shapes the way the public looks at those lands and nature in general. Members of the environmental community were outraged - in their view, wilderness was something real with objective and intrinsic characteristics. Dunlap points out that Cronon made a distinction between "wilderness" - which, as mentioned, Cronon believed to be socially constructed - and "wild nature" or "wild land" which Cronon saw as an objective condition in nature. This distinction was lost on or ignored by Cronon's critics, and they in effect condemned him for an argument that he did not make. In the view of his critics, arguing that wilderness was anything less than an objective reality gave anti-environmentalists a basis to argue against wilderness preservation.

The vehemence of the environmentalist reaction to Cronon's argument seemed to Dunlap (2004) analogous to the reaction of Christian fundamentalists to historical critiques of the Bible. Even if such a critic was a Christian in good standing, suggesting that Scripture was the product of human recorders influenced by the social conditions of their time and not a direct, inherently truthful rendition of God's words brought charges of apostasy. Impressed by the passion of the environmentalists' reaction to Cronon, Dunlap looked more closely at its source.

Dunlap's (2004) adoption of a religion-like perspective is his book's main argument and its greatest weakness. It is weak for two reasons. First, Dunlap's (2004) justification for his argument reads as strained and contrived. Second, the way he makes his argument opens Dunlap to the same situation as befell Cronon - of being attacked for a making a case that he has no intention of making. Dunlap (2004) 
carefully stops short of declaring environmentalism to be its own religion. He does not call for a new paganism or the worship of animals, trees and rocks. Nevertheless, devout religious believers and rationality-oriented capitalists alike could easily make the point that this is exactly what he is doing, and thus completely dismiss Dunlap's work through ridicule.

These weaknesses are unfortunate, because they mask the book's otherwise tremendous strengths. In a concise 172 pages, Dunlap presents a cogent and accessible history of the development of the American environmental movement. In effect - to borrow from Giddens (1985) - Dunlap outlines the structuration of that movement. He identifies agents who most influenced the American movement's evolution beginning with Marsh's Man in Nature and through Aldo Leopold, Ralph Waldo Emerson, Henry David Thoreau, John Muir, Gifford Pinchot, Rachel Carson, and more recent authors Michael Pollan and Sara Stein, among many others. He sets this evolution in historical and cultural context, noting the movement's link with and contradictions over American values such as private property, the role of science, individual choice, and Western instrumental rationality over time. Of greatest interest to this research project are the values and belief systems he notes underlying the movement's current branches.

Marsh (1965/1864) provided an intellectual framework for the conservation movement grounded in the American capitalist and protestant traditions, while Kline (2000) and Thomas Dunlap (2004) trace the historical trajectory of environmental philosophy from the Middle Ages up through the 1990s. What follows next is a 
review of literature charting the history of the movement's institutional development as presented by Hays (1999/1959 and 2000), Riley Dunlap and Mertig (1992a), and Rosenbaum (2005).

Institutional history.

Marsh's arguments in Man in Nature partially inspired the Progressive Conservation movement. Samuel Hays' examined that movement in his Conservation and the Gospel of Efficiency: the Progressive Conservation Movement, 1890-1920 (originally published 1959; edition reviewed published 1999). Hays uses the evolution of policies during the progressive conservation era to study the political structure of the time and the decision-making system that efficiency and conservation represented. He wished to produce a history of the structure of power, not solely an intellectual history of conservation policy development. He sees conservation not as just a public policy, but as an integral part of the evolution of the United States' political structure.

Conservation and the Gospel of Efficiency is, in a sense, a critique of the normal way environmental history is presented. Hays (1999/1959) argues that to most environmental historians, the significance of the conservation movement lies in the substance of progressive policies concerning sustained yield forestry, multiple use river development, and efficient public land management. He wants to look at the period differently, not as a recounting of events and decisions but rather to examine the patterns of social forces that caused the events to occur. To Hays, and reminiscent 
of Giddens (1984) and Sztompka (1991), history is best understood as a "web of human relationships, of patterns of human interaction within the larger society" as opposed to a simple sequence of events (Hays, 1999/1959, p. ix).

Riley Dunlap and Angela Mertig collected and edited a series of essays presented in American Environmentalism: The U.S. Environmental Movement, 1970 $\underline{-1990}$ (1992a). They note that, despite predictions to the contrary, the American environmental movement has not had the short life span of most social movements. It ranks among the relative few that significantly changed society. Their purpose was to describe the evolution of the environmental movement from 1970 - 1990 and to assess its current status. The book provides an overview of environmentalism's major organizations and explores the diversity of the movement.

Although Dunlap and Mertig (1992a) place the roots of American Environmentalism in the Progressive Movement's late $19^{\text {th }}$ century backlash to the reckless exploitation of natural resources, government corruption, and bureaucratic ineptitude (consistent with Marsh (1965/1864), Kline (2000), and T. Dunlap (2004)), they note the catalyst for the modern movement as the first Earth Day in 1970. They then trace the evolution of the movement through three "waves." The first wave occurred in the late 1800s and early 1900s and was primarily grounded in the wise management of natural resources for human use, although they acknowledge the preservationist movement's origins also date to approximately the same time. The second wave occurred during the Franklin Roosevelt administration and addressed the environmental consequences of the dust bowl and massive flooding. The third wave 
began in the 1950s as more Americans gained affluence in the post World War II economic boom, creating an increased demand for preservation of natural areas for public enjoyment. By the 1960s, this third wave had evolved into modern environmentalism.

An even more up to date accounting of institutional environmentalism is Walter Rosenbaum's sixth edition of Environmental politics and policy published in 2005. Rosenbaum notes that in recent times Americans have lost their "ecological innocence." Only a few decades ago the average American never heard of environmentalism, whereas now they debate the wisdom of international treaties on global warming. Environmentalism has thus changed Americans' view of themselves and their place in the natural order. His intent is to offer an accounting of how far the nation has progressed, how far is left to go, what has been lost, and what has been gained. Like Dunlap and Mertig (1992a, whom he cites and, who in turn, cite his earlier editions), he places the catalytic origin of the modern environmental movement to Earth Day 1970. His goal is to speak to the changes from that point forward, emphasizing the political context of environmental issues and the political implications of policy decisions.

Of interest to this study is Rosenbaum's (2005) chronicling of changes in national policy due to changes in presidential administrations and congressional makeup; the shift from single issue policies for protection of individual elements of the environment such as water, air, and discrete species to more holistic concerns over ecological impacts; the uncertainty of science; and the political difficulty of justifying 
costs for environmental consequences that fall to individual consumers whereas the benefits are spread over the population. He argues that environmentalism is a passive consensus issue, by which he means that public support is widespread but not intense unless flamed by specific issue or action. He also notes traditional American resistance to supporting specific actions when inconvenience or personal cost is involved. Although Rosenbaum speaks from a national perspective, his arguments are germane to Northwest natural resources policy in general and salmon restoration in particular. He places the number of organized groups as over 10,000, with organizational membership largely drawn from upper middle class, well educated, whites. Consequently, the movement is frequently criticized for being racist and elitist, especially when confronted with issues of environmental justice, public health, and poverty.

Rosenbaum (2005) also catalogues the basic ideologies of the movement into the following subgroups:

- The "ideological mainstream" of pragmatic reformers. These groups emphasize political action through government. There is a great deal of diversity within the mainstream groups, from preservationism as promoted by the Sierra Club vs. wise use and economic exploitation represented by the NWF or Izaak Walton League.

- The "deep ecologists" who feel man is at best a part of nature, and all life forms have an equal right to exist. Deep ecologists call for fundamental 
changes in national institutions and lifestyles are essential to preserve global ecological integrity.

- The "radical environmentalists" who do not support compromise and favor direct and occasionally violent action.

Rosenbaum's concluding argument is that $21^{\text {st }}$ century environmental degradation is being resolved under $19^{\text {th }}$ century rules and institutions. Checks and balances, federalism, interest group liberalism, and congressional localism were created by the Constitution or were implicit in its philosophy. Administrative politics now play as fundamental a part in environmental policy as any other element of government. The growth of regulation and legislation, coupled with the intransigence of many environmental challenges, has created a permanent new policy domain within federal and state governments. 


\section{APPENDIX B \\ THEORETICAL FRAMEWORK FOR FUTURE RESEARCH}

\section{$\underline{\text { Introduction }}$}

Images of the Columbia River as a "spiritual force" and "cornucopian provider of economic value" (Lang, 1999, p. 147) and as a natural ecological system heavily degraded by manmade structures and operations (Williams, 2006) illustrate profoundly different worldviews of the relationship between the people of the Basin and their place in the natural order. This study identified three worldviews operative in the Pacific Northwest and relevant to the establishment of governance structures and systems. They are characterized as "tribal," "market-commodity," and “environmental."

Within each of these worldviews evolved numerous organizations, institutions, and other societal systems created to carry out specific missions and purposes purposes defined within the context of the worldview held by the original institutional organizers. Examples include native Indian tribes and clans, state and federal agencies, private business corporations, and non-profit interest groups among numerous others. Each of these institutions subsequently evolved with their own cultures, values, and senses of identity consistent with the purposes for which they were created and shaped by organizational members, the constituents they served, the sociological environment in which they operated, and their experiences over time.

The sheer number of institutions operating within a defined geographical space would anticipate disagreements over resource use priorities based on differing 
organizational missions and interests. Rational, interest-based conflict of this nature is termed "realistic" (Coser, 1964; Campbell, 1965; Pruitt and Kim, 2004) or “instrumental” (Tajfel and Turner, 2004/1979). Long standing lines of realistic conflict within the Columbia Basin conflict include debates over public vs. private hydropower development (Ogden, 1949; McKinley, 1952; Bessey, 1963; Norwood, c. 1981; White, 1995; DeLuna, 1997); commercial versus sport and tribal fishers (Taylor, 1999); fishery managers versus hydropower system developers (Robbins, 2004) and others as identified in Chapter 8 . However, if these disagreements were simply over rational allocation of resource use, and if the parties' interests could be served by agreement on an optimum allocation of those resources, one would expect governance systems that successfully address those needs to generate support from the parties concerned and thus enjoy extended periods of stability.

There are examples from outside the scope of this study where this has been the case. The Pacific Northwest Cooperation Agreement and the "single utility" concept essentially resolved the regional debate between public and private power and has been in place since the 1960s (Pope, 2008). An even longer lasting example is the commercial harvest allocation process agreed to between Oregon and Washington under the Columbia River Compact, codified in 1918, that resolved forty-four years of dispute over fishery management (Taylor, 1999).

In sharp contrast to the constancy enjoyed by the Pacific Northwest Cooperation Agreement and the Columbia River Compact is the variety of attempts at a Basin-wide governance system. Interest-based (also called instrumental or realistic) 
conflict theory suggests that this is due to the much broader array of interests affected, thus making stable agreement that much more difficult to attain. This study concluded that the consistent desire for a rational approach to regional decision could be attributed to instrumental (or realistic) conflict theory.

Instrumental conflict theory does not explain the intensity and personal attachment with which parties in the basin hold to various positions. Recognition of this phenomenon in other settings led to the development of "social" conflict under social identity theory. Social conflict is based on findings that merely being a member of a group can lead to feelings of hostility toward other groups even where no realistic competition exists. Social conflict is grounded in group values and the degree to which an individual's identity is linked to the values of the social group(s) in which the individual is a member (Tajfel and Turner, 2004/1979). Related to identity is the influence of organizational culture on individual belief patterns. At its core, organizational culture consists of a set of shared basic assumptions that are normatively taught to organizational members and inform them of the proper way to think, feel, and perceive conditions and circumstances within and external to the organization (Schein, 2004). Taken together, influences of identity and culture form a powerful interpretive lens through which members perceive, think, and relate to their environment (Albert and Whetten, 1985; Ashforth and Mael, 1989; Schein, 2004).

Chapter 7 concluded that a major reason that so many Basin governance systems failed was due to an inability to instill into participating individuals a sense of identity that could both transcend the identities and values of members and be 
reconciled and integrated with the values framework of their respective institutions. It further concluded that the reason for the durability of other systems, such as the Pacific Northwest Cooperation Agreement and the Columbia River Compact, is that the parties to those agreements did adopt and internalize the goals and purposes of those arrangements into their cultural and identity frameworks. Consequently, those systems were able to persevere in the face of the same circumstances that caused other systems to collapse.

Chapter 7 went on to offer four hypotheses regarding the influence of values on individual participants. This chapter establishes a theoretical framework within which those hypotheses may be tested. To do so, it draws on the theoretical domains of sociology, social psychology, and psychology. Such an amalgamation is necessary in that no single body of theory provides a complete explanation for neither the process by which the memorandum of agreement establishing the CRBF (and, by extension, other systems) came about nor the reasons for which the CRBF eventually failed.

\section{Empirical Setting and Research Focus}

The theoretical framework presented herein is proposed to be tested using the circumstances surrounding negotiation of the Columbia River Basin Forum memorandum of agreement as its empirical setting. The CRBF offers several advantages for studying the underlying dynamics of regional governance. First, its initiation, development, activation, and demise occurred in a discrete period providing clear start and end points for the entire process. Second, the nature and substance of 
the debate over its creation was well documented by the local press. Third, meetings were open and well recorded, both by a hired facilitator and note-taker and by two news reporters who faithfully attended and reported on almost every meeting. Fourth, the institutional interests and issues at play in the development of the CRBF MOA which became the Forum's operating charter - are consistent with the interests at play in previous regional governance attempts. Fifth, almost all of the participants involved in the CRBF reside locally and are available for interview. Consequently, the CRBF provides a potentially rich empirical setting through which to examine the region's governance history using the theoretical framework introduced above.

In addition to the CRBF records, there is a rich body of literature on the Pacific Northwest's history of development and the major political and social trends affecting the region over time. There is, however, no published work that deals exclusively with the issue of interjurisdictional governance within the Columbia Basin.

\section{Contributions to theory.}

This proposed study approach offers three contributions to theory. The first is the integration of several bodies of theory to explain the CRBF paradox. The historical record alone is insufficient to fully explain why the region has not just failed but actively resisted establishing a governance system with the authority to solve the problems that cause many to think such a system necessary. A complete answer can potentially be found through an integration of: 
- Theories of structuration (Giddens, 1976, 1979, 1984) and social becoming (Sztompka, 1991), as reinforced with theories of organizational culture (Schein, 2004) and social conflict (Giddens, 1979; Pruitt and Kim, 2004).

- Theories of organizational and individual identity (Tajfel and Turner, 2004/1979; Albert and Whetten, 1985; Ashforth and Mael, 1989; Hogg and Terry, 2001).

- Theories of individual decision making, in particular image theory (Beach, 1998; Beach and Connolly, 2005).

Social formation is the product of the "duality" of collective norms and individual choices. Individuals or select groups of individuals act as agents in the development of social structures. Their actions result in social structures - rules and norms - that serve to constrain or enable future behavior. Yet the choices available to these agents are in turn constrained or enabled by those social rules enacted by those that came before them. Thus, agents do not create totally new social systems. They reproduce or transform systems already in existence, remaking them through the "continuity of praxis" (Giddens, 1984, p. 171, emphasis in original; Sztompka, 1991, p. 41). Through praxis, the boundary of social organization is constantly challenged and changed by agents even as the opportunities available for change are shaped by existing rules and norms. Thus, social structure is both the result of agent action and the medium in which such action occurs. Furthermore, structuration theory stresses the importance of history. All social structures are evolutions of the structures they replace and, in turn, set the foundations for the structures yet to come. 
The historical evolution of regional governance and the development of the CRBF is a case study of structuration and social becoming in action. The Northwest has experimented with issues of regional governance since the Columbia River system was first envisioned in the 1920s. The institutions involved have remained relatively constant over this period, although there have been significant periods where some interests' voices were muted by others. ${ }^{160}$

The governance structure preferences for participating institutions have also remained relatively stable over this period. The history of governance in the region demonstrates the following, all consistent with structuration theory:

- There have been repeated initiatives since the 1920 s to establish a regional governance structure in the Northwest.

- Institutions put forward representatives to serve as agents in the public debate over the structure and authority of these governance initiatives.

- These agents work to change, defend, or abolish the structures in existence at the time consistent with their respective institution's interest at the time.

- Institutional interests consist of both material interests and institutional worldview values.

- Each new governance structure has a pedigree that can be traced to previous governance decisions.

\footnotetext{
${ }^{160}$ For example, tribes, harvest interests, and environmental advocates had little voice in regional decision making from the 1920s through the 1960s. This changed with the rise of the tribal sovereignty movement, the Boldt Decision, and the environmental movement in the 1960s/1970s and passage of the Northwest Electric Power and Conservation Act of 1980.
} 
Thus, structuration theory provides a more comprehensive framework for understanding the $\mathrm{CRBF}$ than does interest group theory alone. In fact, the concept of praxis provides the context in which institutional interests played themselves out. But structuration theory still does not fully explain the CRBF paradox. It does not, for example, explain the intensity of belief that agents brought to the MOA development process. Although it asserts that all human beings are knowledgeable agents with the capacity to effect change through their actions, it does not explain how some members of a social group are selected (or accepted) as agents in specific circumstances and others not. And it does not fully explain how institutional values are transmitted relatively consistently - through generations of members over time.

Identity and image theories help fill in these blanks. Indeed, in his 1984 book on structuration, Giddens states that societies are "social systems" with defining features, among which are feelings of "some sort of common identity" (p. 165). He describes social identity as a "marker" in the "virtual time-space of structure" and associates identity with social roles (p. 282). The literature on social identity theory argues that individuals self-categorize themselves into social and organizational groups that either display values the individual already holds or would like to assume. Thus, social groupings become collections of like-valued individuals, albeit with varying degrees of attachment to the values and norms of the group. Those with the strongest attachment integrate the values and goals of the group as part of their personal sense of self. Moreover, identity provides an interpretive lens which defines how members think and perceive of events around them. The organizational 
representatives involved in the $\mathrm{CRBF}$ MOA negotiations approached the discussion with their own sense of what was right, a sense shaped by the social identity of the organization and institutions they represented. Identity therefore helps explain the intensity of belief that individual agents brought to the MOA development process.

But identity theory does not explain how individuals cognitively process and come to accept organizational norms and values as their own. Although there are likely other theories of cognitive psychology that attempt to explain this phenomenon, this study will focus on image theory (Beach and Mitchell, 1987; Beach, 1998; Beach and Connolly, 2005). Image theory explains the process of individual decision making as being grounded in the principles and values of the individual decision maker.

In summary, traditional interest group theory is insufficient to explain the value disputes that underlay the CRBF MOA development. The phenomenon of the MOA process is likewise not fully explainable by structuration, identity, or image theory by themselves. Taken together, however, a more complete explanation of the MOA can be compiled. Conversely, the development of the CRBF MOA offers an empirical vehicle through which elements of each of these bodies of theory can be examined, hopefully adding to the better understanding of each.

A second contribution to theory is the application of identity theory and image theory to better understand the nature of agency.

A third contribution to theory is to potentially offer further development of social conflict theory and the role of identity in conflict settings. The body of 
literature that has evolved since the early 1980s linking social identity with social conflict mostly focuses on violent conflict along international, ethnic, or religious lines. There is recognition of the applicability of identity to organizational and domestic political conflict, but there doesn't appear to be much direct treatment on that particular subject (Ashmore, Jussim, and Wilder, 2001). An exception is the work of Pruitt and Kim's (2004) which offers an integration and synthesis of several interrelated theoretical domains from the social psychology field. These include theories on conflict, strategic choice, inter-group competition, and conflict group mobilization. Fundamental to these theories is social identity and, relevant to the dynamics of Northwest governance issues, its application to organizations through organizational identity theory.

This assertion of Northwest relevance is based on the observation that the debate and development of the CRBF tended to play out along organizational lines. Representatives and leaders from state and federal agencies, business entities, nonprofit organizations, tribal governments, and, in some cases, organizations comprised of a coalition of organizations, were the primary actors (or agents, to put it in the terms of structuration theory) in advocating that the mission, structure, and power of the CRBF be shaped consistent with their respective organizational interests ${ }^{161}$. The upshot of their actions was an MOA that preordained the eventual failure of the CRBF

\footnotetext{
${ }^{161}$ There were also a large number of consultants involved in the effort. Some of these were members of relatively large consulting firms whose interest in the outcome was limited to their firms' contractual obligation to the client. But a significant number of others were self-employed individuals long associated with and whose personal values and beliefs closely aligned with the organizations they represented.
} 
despite the widespread support for a meaningful and substantive governance process. Understanding the processes of identity and how identity encourages or dampens social conflict impulses can thus contribute to a deeper understanding of the reasons why an effective northwest regional governance structure proved so elusive in this particular case, with potentially generalizable lessons to be applied elsewhere.

The remainder of the chapter is organized into two sections. It begins by reviewing the literature regarding theories of structuration, identity, and decision making. In section 2, it argues the need to draw from multiple theories in order to fully explain the region's governance experience. The chapter concludes by identifying the opportunity presented by this model and the CRBF for empirical validation. 


\section{Section 1 \\ Literature Review: Theories to Guide Future Research}

\section{$\underline{\text { Introduction }}$}

The long-running disputes over natural resource use in the Columbia River Basin is highlighted by not just the deep differences over interests but by the intensity of the positions observed in proponents of those interests. Traditional interest-group theory alone cannot explain the paradox of Northwest governance. There is no one theory, or even field of theory, that completely explains the development of governance systems in general or the behaviors and decisions that produced the CRBF MOA in particular. Consequently, this study looks to theories from the fields of sociology, social psychology, and psychology ${ }^{162}$ for a more comprehensive and integrated theoretical framework within which to further explore the reasons behind the rise and demise of regional experiments with governance systems. Specifically, it reviews a relevant sampling of literature from theories of structuration, social identity, and decision making upon which such a framework may be based.

\section{Theories of Social Structuration}

Structuration theory.

Anthony Giddens first addressed structuration in his 1973 book, The Class

Structure of Advance Societies. Known for his interdisciplinary approach to

\footnotetext{
${ }^{162}$ The boundaries between these fields are muddy, at best. Much of the bodies of literature found relevant to this study are themselves syntheses from multiple theoretical fields of study. Examples include structuration (Giddens, 1984), organizational culture (Schein, 2004), and organizational identity (Hatch and Schultz, 2004).
} 
sociology, Giddens interweaves anthropology, linguistics, psychology, philosophy, history, and economics throughout the body of his work. He apparently began his work on structuration around 1969 (Giddens, 1979). ${ }^{163}$

Structuration theory did not originate with Giddens; Jones (1999) cites its general emergence in Europe in the late 1970s. According to Bryant and Jary (1997), Giddens borrowed the term from Piaget and Gurvitch. But Giddens is credited with being "the single most important figure in the debate" over macro and micro influences in society (Bryant and Jary, 1997, p. 4) and with presenting "the most serious attempt to provide one, single, comprehensive, true social theory (Boyne, 1997, p. 72). Although disagreeing with his presentation and conclusions, many of Giddens' critics agree that his treatment of the topic is among - if not the - most influential in the field and it is his work to which most writers react (Held and Thompson, 1989; Bryant and Jary, 1991; Bryant and Jary 1997).

Giddens is credited with the maturation of structuration as serious sociological theory through its sequential, evolutionary treatment in New Rules of Sociological Method (1976), Central Problems of Social Theory (1979), and The Constitution of Society (1984) (Bryant and Jary, 1991). Giddens describes The Constitution of Society as "a summation of [his] previous writings, setting them out in a developed and coherent manner" (Giddens, 1984, preface). As such, and although these three books are reviewed below, it is Constitution that is most heavily relied on for the purposes of this study.

\footnotetext{
${ }^{163}$ Giddens introduces his 1979 book Central Problems in Social Theory as the latest in a ten-year project of studying the legacy of $19^{\text {th }}$ century European social theory.
} 
In New Rules $(1976)$, Giddens presents a critical analysis of $19^{\text {th }}$ century social theory - specifically hermeneutics (or interpretive sociology) and functionalism - and its legacy of application in the $20^{\text {th }}$ century to the fields of sociology, anthropology, and political science. His stated intent was to elaborate upon and begin a reconstruction of the problematic manner in which these prevailing theories dealt with human social activity. He was especially critical of the way the theories treated "action" by individuals within social contexts. His two main arguments were that (1) social theory must treat action as rationalized conduct ordered reflexively by human agents and (2) that it must grasp language as the practical medium whereby reflexive action is made possible.

New Rules (1976) introduced several of Giddens' central tenets of structuration, specifically the concepts of system, structure, agency, institutions, and the duality of structure - described more fully in the discussion of Constitution (1984) below. Giddens (1976) also displays his ambivalence toward empirical research with regard to structuration. He specifically states that this book is "not a guide to practical research" and that he is avoiding specific research proposals. Rather, the book is intended as "an exercise in clarification of logical issues." (p. 8). He provides that clarity by proposing eleven "new rules" to guide future theoretical development, organized under four categories.

In 1979's Central Problems Giddens completes his critique of prevailing theory by addressing structuralism. His confidence in structuration theory apparently grows as he here formally proposes it as a more holistic and complete than are the 
hermeneutic, functionalist, and structuralist approaches upon which he draws and integrates. He does not give language the centrality in Central Problems as he did in New Rules, focusing instead on theories regarding "volunteerism" of the individual and the "determinism" of social groups. He argues that, up until his work, the two were treated as incompatible opposites ${ }^{164}$ unable to address or cope with the questions and problems that one posed to the other. Because of these incompatibilities, Giddens argues that two could not simply be added together; they had to be substantially adjusted.

In Constitution (1984) Giddens states his intent as to put an end to the debate between the school of "functionalists" and "structuralists," with their emphasis on the primacy of social constraints over individual action, and the schools of "humanism" and "hermeneutics" that claimed that the voluntary actions of and meanings held by individuals are the prime explanation for human social conduct. "The basic domain of study of the social sciences, according to the theory of structuration, is neither the experience of the individual actor nor the existence of any form of social totality, but social practices ordered across time and space.” (1984, p. 2).

\section{Critiques of structuration theory.}

Although applauded for his effort to present a grand theory of sociology, Giddens Constitution of Society has his critics. ${ }^{165}$ Some are very positive: Mario Zamora (1985) welcomed the book as "one of the best standard reference works on

\footnotetext{
${ }^{164}$ Giddens used the term "antimonies" to describe this mutual exclusiveness, a word for which this author could find no definition.

${ }^{165}$ Critical reviews of New Rules (1976) and Central Problems (1979) are not presented since Giddens proclaimed Constitution (1984) as the culmination of all of his previous work on structuration. Consequently, the focus here is critiques of his finished product.
} 
Anthony Giddens's [sic] ideas" and recommended it be "in the library of every serious social scientist (p. 568). Others less so: Charles Powers (1988) states that while Constitution is filled with "penetrating insights" (p. 1124) and constructively adds to Giddens' previous discussion of time and space, it falls short of Giddens' stated objective of presenting a complete and comprehensive theory. As such, he sees the book as another step in the progression of Giddens' ideas rather than the end point the author envisioned.

Further critique is found in three anthologies of essays dedicated to Constitution. The tones of the essays range from constructively critical to outright dismissive. The first to be published was Social Theory of Modern Societies: Anthony Giddens and his Critics, edited by Held and Thompson in 1989. The second was Giddens' Theory of Structuration: a Critical Appreciation, edited by Bryant and Jary in 1991. The third, also by Bryant and Jary, was published in 1997 and entitled Anthony Giddens: Critical Assessments. The arguments in those essays can be summarized as follows:

- Giddens arguments are "conflicting and contradictory" and suffer from "ambiguity and vagueness." Consequently, it is questionable if structuration theory is even relevant to understanding the critical functions of society. (Bernstein, 1989).

- Rather than bridging the macro-micro argument, structuration theory "reinstitutes an outer deterministic force" that influences action without being affected by society's actors. In fact, too much autonomy and influence is 
awarded to individuals as Giddens turns "social pattern[s] and distribution" into a "process." (Bauman, 1989, emphasis in original).

- Giddens' "lack of coherence on key questions cast doubt on his work as a whole," especially in his treatment of class and citizenship (Held, 1989).

- Giddens' treatment of time and space is frustratingly limited. His focus on "presence or absence" in time and space fails to account for human ability to reproduce and represent space, especially through symbols and narratives (Gregory, 1989). His formulations on time and space index important issues but do provide enough information to adequately explain a fully worked out position (Urry, 1991).

- Giddens misappropriates elements of his theory, discounting portions that do not align with his overall conclusions (Boyne, 1991; Jary, 1991). He especially misrepresents the work of French social theorists, such as Foucault. (Boyne, 1991).

- Structuration theory is "unhelpful when trying to account for variations in the proportions of volunteerism and determinism" and "degrees of freedom and constraint associated with action" (Archer, 1997).

- Giddens oversimplifies the psychology of individuals (Craib, 1997) and the role of the routine in motivating behavior (Willmott, 1997). It is beyond the scope of this study to address or reconcile the comments of Giddens' critics. What is of interest here is the very limited amount of empirical research that either supports or contradicts Giddens' arguments, a fact lamented by at 
least one team of researchers (Barley and Tolbert, 1997). The critiques cited above and the others found in the edited volumes of Bryant and Jary and Held and Thompson are almost all theoretical in nature. ${ }^{166}$ The only one that addresses empirical issues is Boyne (1991) who critiques Giddens use of Foucault's study of French prisons. One critic (Gregson, 1989) lays the blame for this on Giddens, dismissing structuration theory as a "second order" theory that conceptualizes the general outline of human society but is too abstract and imprecise to generate concepts that directly apply to empirical settings. In essence, Gregson argues, structuration theory as presented by Giddens is inherently non-empirical.

Giddens himself seems ambivalent on the issue. In 1976's New Rules he states his intent specifically as not to present a model for research but rather to address the logic of prevailing theory. Although he devotes a chapter to laying out an empirical approach in 1984's Constitution, noting the importance of ensuring that any theory must be relevant to the world as actually experienced, he subsequently seemed to downplay importance of empirical validation. In a 1989 reply to his critics Giddens states, "Theoretical thinking needs in substantial part to proceed in its own terms and cannot be expected to be linked at every point in empirical considerations" (Giddens, 1989, p. 294). He also argues in Constitution that whereas empirical research is fully appropriate for study of the natural sciences, given nature's "factual" basis, it is an incomplete tool for the study of society since social reality is based on the experiences and interpretations of those living it.

\footnotetext{
${ }^{166}$ Presumably the arguments and positions presented in the essays were based on empirical research conducted by or known to the authors. Such research, if conducted, was not cited.
} 


\section{Social becoming.}

Adding to the work of Giddens, Piotr Sztompka addresses, albeit indirectly, some of the criticisms of Giddens" work by offering a "synthesis of syntheses" to explain what happens as social organizations come into being. His 1991 book Society in Action: the Theory of Social Becoming, like Giddens' Constitution (1984), attempts to bridge the human action vs. group determinism argument. Also like Constitution, Society in Action is an argument grounded in theoretical reasoning rather than empirical observation. Although published after Constitution, and covering much of the same ground, Society in Action is not derived from Giddens' work. Sztompka acknowledges and references structuration theory, but he - as did Giddens - roots his theory in earlier sociological theory. Thus, his conclusions, although consistent with Giddens', appear to have developed in parallel with Giddens' with roots in similar intellectual ground.

Sztompka starts from two broad lines of theoretical development. The first is "agency" which he describes as the active, constructive side of social life by individuals, but with due recognition to constraints posed by the structural framework within which human conduct takes place. The second is historical sociology, which reintroduces the dimension of time and provides the causal mechanisms through which agential creativeness and structural influences merge in the flow of historical process.

Sztompka (1991) summarizes his theory with three insights:

- That society (defined as any social grouping) is humanly constructed.

- That humans are socially shaped 
- That society and humans are both immersed in the flow of historical time Sztompka apparently did not attract the same degree of critical attention as did Giddens; no critiques of his theory of social becoming were found in the course of this review. Sztompka answers and resolves a number of issues raised by Giddens' critics. He is much clearer in his discussion of the interface between individuals and collective society, better explaining praxis and Giddens' duality of individual action and social constraint. He is also clearer in the way he addresses time-space, using his "historical coefficient" to explain society as a constantly dynamic and sequentially evolving series of events over time.

Both Giddens (1984) and Sztompka (1991) recognize the role of formal rules, allocation of resources, and normative social expectations as constituents of structure and their role in the evolution of social systems. For the purposes of creating a framework for future research of regional governance, a closer examination of normative expectations within systems, or organizational culture, is warranted.

Organizational culture.

Edgar Schein started writing on organizational culture in 1968, publishing his first book on the subject in 1985. Organizational Culture and Leadership (1985) was widely accepted and cited within the organization theory community (Shafritz and Ott, 1996). Miner (2005) identifies Schein as being considered by his peers as having developed one of the "essential theories" of organizational behavior - despite its relative lack of empirical support and the view of some that, like Giddens structuration (1984), Schein's theory is inherently non-empirical. Schein's 1985 edition presented 
"the most comprehensive and integrative statement of the organizational culture school" up to that point in time (Shafritz and Ott, 1996, p. 25).

Schein published his second edition in 1992 and the third in 2004. The difference between earlier and later work is that subsequent editions edit the chapters and incorporate more recent case studies while leaving his basic argument and construct intact. Consequently, it is the 2004 publication that is reviewed here.

Schein (2004) maintains that unique cultures can evolve in social units of any size. His focus, however, is at the organization level. He describes organizational culture as a complex psychology-based phenomenon that is difficult to understand but, once understood, clarifies much about a given organization's behavior that might otherwise appear irrational.

Whereas Schein's (2004) concept of culture explains the normative element of social structure (as used in the Giddens (1984) sense), it leaves little room for individual agency. Schein notes that some cultures of the world are grounded in the freedom of the individual while others are centered on the importance of the group. Thus, individual agency can only exist if the culture allows it to - in contradiction of Giddens (1984) and Sztompka (1991). Schein seems to make an exception for organizational leaders, noting that one of the sources of culture is the beliefs and practices of the group leader at the time the group first forms. Once ingrained, it defines all group behavior until such time as the group is threatened, at which point the group will again look to the leader for innovative solutions. In other words, agency is confined to the leader and then only under specific circumstances. 
In this Giddens (1984) and Sztompka (1991) seem to have the better argument. For example, Schein's theory does not cover situations in which individuals belong to multiple organizations and the role that influences from one organization may act as an "external influence" on the behavior of individuals within another organization, thereby contributing to the evolution of the second organization's culture. An example would be a business employee's involvement with an environmental group that leads to promotion and adoption of conservation practices within the business. Schein cannot account for this cultural interplay at the individual level, since such interplay does not represent the "shared group experience" central to his model. Additionally, if behavior is always determined by cultural disposition or in response to external situations, how does one explain behavior deviant to organization cultural norms or social "counter-movements" (Sztompka, 1991)? Schein (2004) does not provide an answer, whereas the theories of structuration (Giddens, 1984) and social becoming (Sztompka, 1991) do. Despite this omission, Schein (1984) offers an elegant, "logically tight and compelling theory" (Miner, 2005, p. 343) that provides clarity to structuration theory's normative component of social "structure."

\section{Intergroup conflict.}

In the main, with the obvious exception of the Indian wars and the tribes' relocation to reservations in the mid 1800s, issues of conflict in the Pacific Northwest played out without widespread violence (Dodds, 1986). The conclusion that the search for a rational and peaceful way to resolve regional disputes is the primary reason for consistent support for some form of Basinwide governance system. A 
theoretical understanding of non-violent conflict is therefore needed. Giddens and Sztompka observe the existence of conflict and explain it through the framework of agency, power, and control. But their discussion of the causes of conflict is frustratingly sparse. Although Giddens' Central Problems (1979) attributes the causes of conflict to competing interests, group identity, and ideology, his $\underline{\text { Constitution }}$ (1984) - self-described as his cumulative summary of structuration - is silent on these issues. Sztompka (1991) does not address the causes of conflict at all.

In the 1980s and 1990s other social and behavioral researchers, picking up on the work of Tajfel and Turner (2004/1979) and others, increasingly emphasized the role of identity as a major source of intergroup conflict. In Social Identity, Intergroup Conflict, and Conflict Resolution (2001), Richard Ashmore, Lee Jussim, and David Wilder collect a set of essays that seek to explain ways in which (1) social identities create and exacerbate intergroup conflicts, (2) intergroup conflict in turn influences social identity, and (3) addressing social identity may help resolve some intergroup conflicts. They note that issues of self and identity occur at multiple levels of conflict. These include disputes among individuals within a social context, among groups within larger social groupings (such as a nation), and among nations. The essays selected focus on real world conflicts among ethnicities, races, religions, and nationstates, and draw contributors from a variety of social sciences such as anthropology, political science, psychology, and sociology. Of use to this study is the authors' conclusion - consistent with Giddens' and Sztompka's "duality of structure" - that 
analysis of intergroup conflict cannot be reduced to either to the individual or group levels; both be taken into account.

Alice Eagly, Reuben Baron, and Lee Hamilton's 2004 book, The Social Psychology of Group Identity and Social Conflict is, at its heart, a tribute to the work of Herbert Kelman renowned for his theoretical and practical contributions to conflict resolution. The contributors to this collection of essays are all students or followers of Kelman's work. The book is organized in three sections. Beginning with several essays that review of the precepts of social psychology, the book then presents case studies of application in various contexts, ranging from health psychology, student access to the internet in schools, and business organizations. The third section is more directly focused on psychological approaches to conflict resolution, discussing case studies from Sri Lanka, the Israeli-Palestinian conflict, and Cyprus.

While underscoring the important role of identity in conflict, the scale and scope of the conflicts in Social Identity, Intergroup Conflict, and Conflict Resolution (2001) and The Social Psychology of Group Identity and Social Conflict (2004) are of, at best, indirect applicability to governance issues in the Northwest. A more generalized and useful discussion is found in Dean Pruitt and Sung Hee Kim's 2004 book, Social Conflict: Escalation, Stalemate, and Settlement ( $3^{\text {rd }}$ edition). The authors integrate and synthesize several interrelated theoretical domains. These include theories on conflict, strategic choice, inter-group competition, conflict group mobilization and social identity. 
Pruitt and Kim wrote their book intending to "produce a readable and integrated synthesis of theory and research on social conflict and its resolution" (p. xvii.) incorporating literature from the social psychology field. They note that conflict has been studied since antiquity, with modern treatment rooted in work by Charles Darwin (with his emphasis on the benefits of biological competition to long term species survival), Sigmund Freud (Individual resolution of internal psychodynamic conflict), and Karl Marx (the inevitable existence of conflict within society). With Darwin, Freud, and Marx providing intellectual inspiration, modern social psychology developed from the great academic interest in the "cauldron of social conflict" surrounding the World War II years (p. xiii).

For the purposes of this study, Pruitt and Kim (2004) offer the most useful synthesis of conflict theory. Their description of not just the sources of conflict, but their discussion of components, strategies, conditions, and stages of conflict resonate with the nature of the conflicts observed in the Columbia Basin.

The literature on structuration, culture, and conflict is summarized in Table B1. This literature offers a theoretical frame for explaining "what" happens as social organizations are formed, sustained and modified over time. The theories discussed also partially explain "why" such changes occur in terms of individual autonomy, structure (to include culture), agency, and the role of conflict in those changes.

But these concepts alone are not sufficient to explain the circumstances regarding Columbia Basin governance in general or the CRBF in particular. They do not, for example, explain why some individuals become accepted as agents of change 
Table B-1.

Theories of Structuration, Social Becoming, Organizational Culture, and Intergroup Conflict

\begin{tabular}{|c|c|c|c|}
\hline \multirow{6}{*}{ 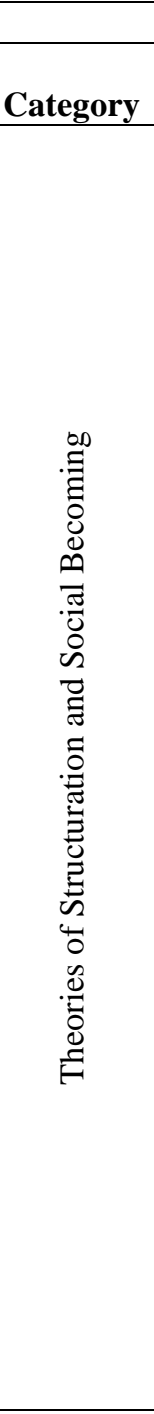 } & \multicolumn{3}{|r|}{ Representative Literature } \\
\hline & Year & $\begin{array}{c}\text { Author(s) / } \\
\text { Editor(s) }\end{array}$ & Title: Relevance \\
\hline & 1976 & Giddens & $\begin{array}{l}\text { New Rules of Sociological Method: Critiques the manner in } \\
\text { which } 19^{\text {th }} \text { century social theory has been incorporated into } \\
20^{\text {th }} \text { century thinking. Introduces structuration theory to } \\
\text { address the problematic manner in which social systems and } \\
\text { structure and individual agency are addressed in prevailing } \\
\text { theoretical thinking. Offers eleven "rules" to guide future } \\
\text { sociological theorizing and research. }\end{array}$ \\
\hline & 1979 & Giddens & $\begin{array}{l}\text { Central Problems in Social Theory: Continues author's } \\
\text { critique of the application of } 19^{\text {th }} \text { century theory to } 20^{\text {th }} \\
\text { century situations. Offers a more rigorous critique of } \\
\text { prevailing thinking and further refines his theory of } \\
\text { structuration. }\end{array}$ \\
\hline & 1984 & Giddens & $\begin{array}{l}\text { The Constitution of Society: Outline of the Theory of } \\
\text { Structuration: The author's most complete and mature } \\
\text { argument for structuration theory. The essence of the theory } \\
\text { is that social structures are products of the irreducible duality } \\
\text { of collective constraint and individual action. Social } \\
\text { structures are created by human agents while simultaneously } \\
\text { constraining their actions. Structure is thus both the product } \\
\text { and medium of social change. Agents do not create social } \\
\text { systems, but remake that which is already made. This } \\
\text { interplay between the individual and collective is constant and } \\
\text { continuous. }\end{array}$ \\
\hline & 1991 & Sztompka & $\begin{array}{l}\text { Society in Action: The Theory of Social Becoming: The } \\
\text { author reaches similar conclusions to those of Giddens and, } \\
\text { like Giddens, seeks the middle ground between collective } \\
\text { determinism and unbridled voluntarism. He presents his work } \\
\text { as a "synthesis of syntheses" emphasizing agency, history, } \\
\text { and praxis. Offers a "triple insight" of social becoming: (1) } \\
\text { society is humanly constructed, (2) humans are socially } \\
\text { shaped and (3) society and humans are both immersed in the } \\
\text { flow of time. }\end{array}$ \\
\hline 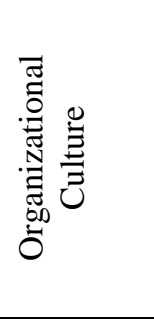 & 2004 & Schein & $\begin{array}{l}\text { Organizational culture and leadership }\left(3^{\text {rd }} \text { ed.) Defines }\right. \\
\text { organizational culture as a pattern of basic assumptions that } \\
\text { was learned by the group over time and is taught to new } \\
\text { members as the correct way to perceive, think, and feel. } \\
\text { Culture's power lies in its psychological effect on group } \\
\text { members, defining what to pay attention to, what things mean, } \\
\text { how to react emotionally to what is going on, and what } \\
\text { actions to take in various situations. }\end{array}$ \\
\hline
\end{tabular}


Table B-1. (Continued)

Theories of Structuration, Social Becoming, Organizational Culture, and Intergroup Conflict

\begin{tabular}{|c|c|c|c|}
\hline \multicolumn{4}{|r|}{ Representative Literature } \\
\hline Category & Year & $\begin{array}{c}\text { Author(s) } / \\
\text { Editor(s) }\end{array}$ & Title: Relevance \\
\hline \multirow{3}{*}{ 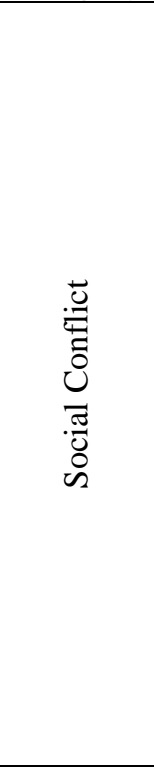 } & 2001 & $\begin{array}{l}\text { Ashmore, } \\
\text { Jussim, and } \\
\text { Wilder }\end{array}$ & $\begin{array}{l}\text { Social Identity, Intergroup Conflict, and Conflict Resolution. } \\
\text { Interdisciplinary collection of essays on social conflict, } \\
\text { centering on the role of identity. Argues that identity } \\
\text { contributes to conflict just as conflict influences future } \\
\text { identity. States applicability to all levels of conflict, while } \\
\text { focusing on case studies of ethnic, racial, religious, and } \\
\text { nationality based conflict. }\end{array}$ \\
\hline & 2004 & $\begin{array}{l}\text { Eagly, } \\
\text { Baron, and } \\
\text { Hamilton }\end{array}$ & $\begin{array}{l}\text { The Social Psychology of Group Identity and Social Conflict. } \\
\text { A collection of case studies from the field of social } \\
\text { psychology focusing on intra- and international scaled } \\
\text { conflict. }\end{array}$ \\
\hline & 2004 & $\begin{array}{l}\text { Pruitt and } \\
\text { Kim }\end{array}$ & $\begin{array}{l}\text { Social Conflict: Escalation, Stalemate, and Settlement }\left(3^{\text {rd }}\right. \\
\text { edition). The authors integrate and synthesize several } \\
\text { interrelated theoretical domains from the social psychology } \\
\text { field. These include theories on conflict, strategic choice, } \\
\text { inter-group competition, conflict group mobilization and } \\
\text { social identity. Fundamental among these is social identity } \\
\text { theory and its application to organizations through } \\
\text { organizational identity theory. }\end{array}$ \\
\hline
\end{tabular}

and others do not, nor explain differences in the degree of passion and commitment that exist among individual organizational members. Finally, neither theory attempts to explain "how" individuals reach decisions as to whether to support or rebel, to follow or lead. Filling out the answers to questions of "why" and "how" is the basis for the following discussions of social identity decision theory.

\section{Theories of Social and Organizational Identity}

Although noting its importance, Giddens only mentioned identity twice in Constitution, and then only briefly. He recognizes "the prevalence, among the members of the society, of feelings that they have some sort of common identity 
however that might be expressed or revealed. Such feelings may be manifest in both practical and discursive consciousness and do not presume a 'value consensus.' Individuals may be aware of belonging to a definite collectivity without agreeing that it is necessarily right and proper"(Giddens, 1984, p. 165, emphasis added.) In this argument, identity serves as a "marker" in the "time-space of structure" (p. 282).

Sztompka (1991) does not discuss identity directly, but argues that the human traits of creativeness, educability, the need for self-realization and self-fulfillment, and the tendency of individuals to put their talents and abilities to use are the cornerstones of agency. But, as will be shown, these traits are shaped by how individual members of society see themselves as individuals and relate to those around them.

$\underline{\text { Seminal theoretical treatments on identity. }}$

Sociologist Charles H. Cooley's defined the self in social terms (Hatch and Schultz, 2004b). Writing in 1902, Cooley's Human Nature and the Social Order sought to reconcile arguments within psychology over what constituted society. $\mathrm{He}$ proposed a concept of "organic synthesis" which envisioned that "society" and "individuals" are not separable phenomena, but are collective and distributive aspects of the same thing. In Cooley's view, individuality and sociality always existed in the human experience side by side - a precursor to Giddens and Sztompka's duality of the social structure. Cooley argued that the individual's very concept of self is made within the context of his or her relationship with others.

In 1934 George H. Mead furthered the concept of the individual's relationship to the social structure. He defined two aspects of self as the "I" and the "me." The "I" 
represents thought, behavior, and feelings unique and internal to the individual. The "me" is derived from the assumptions about the attitudes of others, echoing Cooley's concept of the "looking glass self." The incorporation of the attitudes of others into "me" is the mechanism through which society influences and becomes part of the individual, whereas unique and innovative responses generated by the "I" are the mechanism through which the individual shapes society (Hatch and Schultz, 2004b; Mead, 2004).

Irving Goffman expanded the understanding of the psychological interaction between the individual and society by reasoning that, since the perception of societal judgment greatly influences over the individual; it follows that the individual will actively present him/herself in the most positive light to others in society. ${ }^{167}$ Using the analogy of the interaction of the performance of theatrical actors with their audience, Goffman suggested that identity is an interactive performance with the "actors" ability to manage perception a function of interpersonal skill. In contrast to Cooley and Mead, Goffman argued that identity is communicated by the individual to others through impression management, as opposed to being formed through the opinions of others (Goffman, 2004; Hatch and Schultz, 2004b). The relevance of this insight to organizations is the role that external stakeholders can play in shaping organizational identity, a hypothesis later supported with empirical research by Dutton and Dukerich (Hatch and Schultz, 2004b).

\footnotetext{
${ }^{167}$ Note that Giddens cites and critiques Goffman in Constitution. He states that Goffman's writings "comprise a major contribution to an exploration of the relations between the discursive and practical consciousness in the contexts of encounters" (p. 70).
} 
Henri Tajfel and John Turner published The Social Psychology of Intergroup

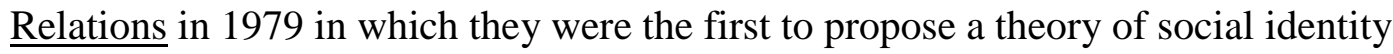
(Hatch and Schultz, 2004b). They reviewed and conducted empirical research that focused on in-group and out-group identification, competitive ethnocentrism, and negative stereotyping among social groups. They observed behaviors that could not be explained by the then-dominant notion that phenomena of group morale, cohesiveness, and cooperation were strictly byproducts of intergroup competition over interests. They concluded that identification with an in-group could operate independently of competition and that, even without competition, "the mere perception of belonging to two distinct groups - that is, social categorization per se - is sufficient to trigger intergroup discrimination favoring the in-group" (Tajfel and Turner, 2004, p. 56). "Social categorization" forms the basis for group definition where individuals define themselves and are defined by others as a group. Individuals in a group "perceive themselves to be members of same social category, share emotional involvement in the common definition of themselves, and achieve a degree of social consensus about the evaluation of their group and their membership in it" (Tajfel and Turner, 2004, p. 59). Social identity consists "of those aspects of an individual's self-image that derive from the social categories to which he perceives himself as belonging" (Tajfel and Turner, 2004, p. 59). Thus, social categorizations provide a system of self-reference that clarifies the individual's place in society.

These categorizations are comparative and consist of three variables. First, the individual must have internalized group membership as some aspect of their self 
concept. Second, the social situation must allow for comparisons to be made between the individual's and other groups. Third, groups do not necessarily compare themselves with every available out-group; to merit comparison other groups must in some manner relevantly intersect with the interests of the in-group along a dimension of shared values. Supportive of Pruitt and Kim's (2001) synthesis of social conflict theory is the distinction made between social and instrumental (or realistic) competition. Social competition ${ }^{168}$ is grounded in the group's sense of identity and is based on social comparison. As such, it needs only those comparisons to evolve. Instrumental or realistic competition is based on self-interest, incompatible group goals, and/or struggle over scarce resources (Tajfel and Turner, 2004; Hatch and Schultz, 2004b).

Independent of the foregoing work in the psychology and social psychology fields was Stuart Albert and David Whetten's Organization Identity published in 1985. Through this work Albert and Whetten are recognized as inaugurating organizational identity as a field of study in the United States. The importance of this paper is manifest by the number of scholars in the field who either reference Albert and Whetten's criteria for organizational identity without comment or make their mark by challenging them all or in part (Hatch and Schultz, 2004b).

Without reference to the rather substantial body of social identity literature existing in the social psychology field at the time they wrote - and working within the field of organizational psychology - Albert and Whetten (1985) claimed that identity had historically been treated as a "loosely coupled set of ideas and concepts" better

${ }^{168}$ Pruitt and Kim prefer to skip the "social competition" term, applying "social identity" in its place. 487 
considered a "framework" as opposed to a theory. They sought to build on the historic literature and define "organizational theory" in a way that passes a rigorous test of theory and that opens clear avenues of empirical research. The authors presented a sequence of researchable questions and hypotheses throughout paper to facilitate the building of a research agenda.

They argued that to truly be part of an organization's identity, any claimed feature must satisfy three criteria. The feature must be seen as the essence of the organization, "the criterion of claimed central character"; the feature must distinguish the organization from others against which it may be compared, "the criterion of claimed distinctiveness"; and the feature must exhibit some degree of sameness or continuity over time; "the criterion of claimed temporal continuity" (p. 265). Despite the enduring quality of certain aspects, organization identity can evolve over time in reaction to such things as loss of an identity-sustaining element or individual or changes to the organization's collective status.

While acknowledging the psychological aspects of individual interpretation of organizational identity, Albert and Whetten (1985) did not really explain how or why that process takes place. Ashforth and Mael (1989) addressed that issue by examining Albert and Whetten's organization identity theory in terms of Tajfel and Turner's (1979) theory of social identity (which they dubbed with the acronym SIT). They noted SIT's social-psychological perspective as to how and why people perceive, join and remain in social groupings. Under SIT, people classify themselves and others into social categories (such as gender, age, race, religion, organization membership, etc.). 
Such categorizations allow individuals to locate themselves in the environment through relational and comparative definition with others resulting in a perception of oneness with a group of like-minded people. Thus, individuals will seek to join one or more social groups in which their perception of the group's values, prestige, and behaviors enhance or reinforce the self-image individuals have or would like to have for themselves. SIT, therefore, defines the relationships among the members of an organization in terms of psychological connectivity as opposed to a mere extension of personal or economic interactions. This connectivity also creates a distinct interpretive lens through which organizations perceive their external environment. The stronger the alignment between the individual's self image and the organizations perceived identity patterns, the greater the degree of identification. Conversely, a weakening of this alignment either through changes in the individual's self image or changes to the organization will weaken the sense of identification and may result in the individual leaving the group altogether.

Taken together, these six theoretical works offer a powerful explanation as to how individuals and social groupings in general (and organizations in particular) interrelate and respond to other social groupings in their external environment. By linking individual self-image (who am I?) to social and organization identity (who are we?) the authors collectively offer a social-psychological construct through which organizational behavior in general and interorganizational conflict in particular can be interpreted and better understood. Thus, either internal changes or the presence of outgroups that are perceived to challenge taken-for-granted assumptions about the central, 
distinctive, and enduring attributes that members most admire in their organizations will generate anxiety and perhaps hostility. In conflict situations, strong identity with group goals and values reinforce belief in the "rightness" of the group's beliefs, exacerbates points of disagreement, and causes trivial differences to take on an importance beyond what the merits would otherwise indicate.

Empirical research on organizational identity theory.

Unlike Giddens' (1984) and Sztompka’s (1991) theoretical work, which apparently inspired little or no empirical study, Albert and Whetten's (1985) theory spawned a significant body of empirical research. These included a seven-year study of the New York/New Jersey Port Authority's response to homeless transients occupying Authority facilities (Dutton and Dukerich,1991); a study of strategic change management at universities (Gioia and Thomas, 1996); a study of responses to the 1992 Business Week rankings of business schools (Elsbach and Kramer, 1996); a study of the management of competing identities within a non-profit firm (GoldenBiddle and Rao, 1997); and a seven-year study of two banks holding differing strategic orientations and how those orientations affected the organizational response to external conditions (Fox-Wolfgramm, Boal, and Hunt, 1998).

These five empirical studies both enhanced and challenged various aspects of Albert and Whetten's (1985) and Ashforth and Mael's (1989) original theories.

Dutton and Dukerich (1991) noted the degree to which perceived organization identity affected issue interpretation and action. Goia and Thomas (1996) found that, under conditions of strategic change, top management perceptions and communication 
of image and identity - especially the desired future identity - are essential to the sense making process for subordinate members and serve as an important link between organizational context and member issue interpretation. Strategic change implies a revision of interpretive schemes by management, members, and stakeholders. Consequently, significant change must be accompanied by alterations in the overall perception of organization identity. Contrary to Albert and Whetten's (1985) conclusion that identity changes were reactive and incidental, Gioia and Thomas found that such change can be deliberately managed and may take place in shorter time periods than originally theory envisioned.

Elsbach and Kramer (1996) found that, in the absence of a generally accepted objective measure of what attributes are considered truly important in business education, individual business schools evolved unique identities and programs. By ranking the schools in a national magazine, Business Week implied that such an objective standard did in fact exist. The rankings therefore presented threats to organization identity by challenging that which was perceived to be "distinct and central" (Albert and Whetten, 1985) ${ }^{169}$ to each school. The authors found that individual members used categorization tactics to reinterpret the findings in ways that affirmed positive perceptions of their school's identity. ${ }^{170}$ Thus rather than distancing

\footnotetext{
${ }^{169}$ The researchers made a point of noting that the rankings did not threaten the physical survival or even the schools' well being. All except one remained among the top-20 in national rankings. What caused the consternation was the relative shifting within the top-20, or the fact that a school did not do as well as they thought they should have. Thus, the threat was more to each school's identity, not legitimacy.

${ }^{170}$ Members would emphasize their school's membership in elite social groups not addressed in the rankings, affirm cherished organizational attributes and identities neglected by the rankings but valued in the business community and select alternate groups of comparison to favorably relate to other schools 
themselves from the organization - as would be predicted under Albert and Whetten's (1985) construct - members distanced themselves from the negative attributes of the rating and emphasized other, unchallenged attributes thereby affirming the intrinsic good of the organization. In effect, members elected to selectively categorize their organization rather than categorize themselves in a different way. This finding strongly supported Ashforth and Mael's (1989) connection between individual and organization identity, reinforcing a similar finding by Dutton and Dukerich (1991).

Golden-Biddle and Rao (1997) studied an organization possessed of dual but contradictory identities at both the member and board of director levels that all considered "central and enduring" (Albert and Whetten, 1985). Members perceived themselves both as a volunteer driven organization and a family of friends. The board of directors perceived themselves as vigilant monitors of organization resources as well as friendly, supportive colleagues. Consequently, some members and directors viewed the strict review of budgets by other directors intrusive and over-bearing. An influential sub-set of directors resolved the conflict by reinforcing the conflicting values at play (accountability and stewardship versus collegiality) to the satisfaction of all. The researchers concluded that the resolution of such conflicts consistent with identity is more important to organization stability than objective merits of given budget proposals.

higher in the rankings. For example, members responded with statements such as "many of our students turned down Harvard to come here," "we are the best among public institutions" and "we are a top regional school 'like' Michigan." 
Finally, Fox-Wolfgramm, Boal, and Hunt (1998) found that organizations' strategic orientations act as interpretive filters resulting in different responses to the same strategic environmental pressure. Their study also reinforced the importance of leadership in managing identity to ensure changes sustain over time.

\section{Integrative treatments.}

In subsequent years, the findings and conclusions of these empirical studies, along with studies from other fields, were theoretically revisited, integrated, and synthesized. In 1994 Dutton, Dukerich, and Harquail presented a model and a revised typology to help explain how images of one's organization shape the strength of the individual's personal identification with the organization. Elegantly melding the theories of Albert and Whetten (1985) and Ashforth and Mael (1989) and building on the work of Dutton and Dukerich (1991), they define organizational identification as "the degree to which a member defines him or her self [sic] by the same attributes that he or she believe define the organization" (p. 239). Borrowing from Albert and Whetten (1985), they labeled the set of beliefs that members collectively share to be distinct, central and enduring about the organization as "collective identity." Supportive of Ashforth and Mael (1989), individuals assess their organizations to determine if the organization will provide a supportive environment and offer opportunities for self-expression. The closer one identifies oneself with the organization, the more personally threatening a negative image (or reinforcing a positive image) can be. 
About ten years after publication of Organization Identity (1985), David

Whetten organized the first of what became a series of three conferences with scholars who were active in identity research and development. The participants met to reflect on what had been learned and to determine if in fact organizational identity warranted a true place as theory. The results of those conferences - both individual papers and transcripts of participant conversations - were collected and published in Identity in Organizations: Building Theory through Conversations (1998), edited by David Whetten and Paul Godfrey. The book is a statement-in-time on the status of organization identity theory at the point it was published, and does not really present a coherent, consensus view beyond Albert and Whetten's three original criteria and the recognition of social identity processes within organizations.

Although Identity in Organizations did not come to closure on a number of questions, it did offer an important advancement. This book appears to be the first to look at the relationship of organization identity to organizational culture. Writing from the perspective of achieving organizational change, and referencing Schein's 1985 book Organizational Culture and Leadership, several conference participants suggest that the difference between the two is one of perspective. Identity is defined within a social - or cultural - context. Thus identity answers the question of "who are we' in relation to larger contexts of meaning and culture. Noting the subjectivity of the work in culture, the difficulty of getting to values and normative beliefs that are often unconscious to those who hold them, and the body of writing describing how difficult changing organizational culture can be, Fiol, Hatch, and Golden-Biddle 
(1998) propose that identity may offer managers a more malleable way to manage organizational change as opposed to challenging culture directly.

Essays in the January 2000 issue of The Academy of Management Review were dedicated exclusively to the topic of organization identity. Brown and Starkey (2000) argued that individuals and organizations are motivated to maintain self-esteem by preserving existing senses of identity. They assert that organizations fail to learn because of ego defenses that maintain the sense of collective self-esteem. Scott and Lane (2000) discuss the degree to which relationships among organizational stakeholders (which include external interests as well as internal organization employees and managers) can shape image and identity. They argued that managing stakeholder relations is a key task of leadership given the profound effect perceptions of the organization by outsiders can have on the workforce. Pratt and Foreman (2000) examined the phenomenon, challenge and benefits of managing multiple organization identities. The major benefit is the capacity to respond to a wider range of conditions than single identity organizations, thus increasing the probability of survival in complex environments. Conversely, multiple identities can lead to internal conflict and ambivalence among members unable to reconcile contradictory images of what the organization is about. Gioia, Schultz, and Corley (2000a) followed up on the conclusions of Gioia and Thomas (1996) and directly challenged Albert and Whetten's (1985) argument concerning the enduring aspect of identity. They argued that the accepted definition of organization identity is too static to apply to the pace of change in contemporary organizations, and does not hold up when studied over time. In a 
companion article, Gioia et al., (2000b) question if the metaphor of individual identity is really applicable to organization identity. They suggest there are important differences between the individual and organizational character. Individual identity is extremely personal and resistant to change. Organization identity is by its nature more removed, varied, and malleable as it is constructed by fluid internal and external interactions. Thus, emphasizing psychological metaphors may be blinding researchers from other avenues of study that allow organization identity to be better dealt with on its own terms.

In the Academy of Management Review's (2000) closing article, three of the earliest theorists and researchers offer their conclusions as to what it all means (Albert, Ashforth, and Dutton, 2000). They maintain that identity and identification are root constructs in organizational phenomena and a subtext of many organizational behaviors. In order to effectively interact with their environment, organizations need an answer to the question "who are we," just as outside entities need an answer to the question "who are they." Thus, the authors maintain the central and distinct aspects of organization identity first hypothesized by Albert and Whetten (1985) and the social identity theory offered by Ashforth and Mael (1989). But they seem to accept the critique that identity may be less permanent than originally thought.

A comprehensive integration of social and organizational identity theories is presented in the 2001 book Social Identity Processes in Organizational Contexts edited by Hogg and Terry. Hogg and Terry and their contributors affirm many of the findings identified above; as such, their work won't be repeated here. Of greater 
relevance to this study is their clear framing of organizational identity as a specialized case of social identity. They state that "organizational contexts provide a near-perfect arena for the operation of social identity processes" (p. 1), and that for "many people their professional and/or organizational identity may be more pervasive and important than ascribed identities based on gender, age, ethnicity, race, or nationality" (p. 2). Noting that "the basic idea of social identity is that a social category (e.g. nationality, political affiliation, organization, work group) within which one falls, and to which one feels one belongs, provides a definition of who one is in terms of the defining characteristics of the category" (p. 3, (emphasis added).

Mary Jo Hatch and Majken Schultz edited and published Organizational Identity: a Reader in 2004 to address the issues of scholars and practitioners looking to identity theory for insights on corporate branding, recruiting, strategy, fostering employee loyalty, and other purposes (Hatch and Schultz, 2004a). The book offers excerpts from a collection of the original sociological and social psychological papers that underlay the current state of theory and more recent papers. Of particular value are the editors' contextual introductions to the book as a whole and to each of its three parts.

\section{$\underline{\text { Identity and Conflict }}$}

The literature reviewed for this section further illustrates the contributions of identity to intergroup conflict (Giddens, 1984; Pruitt and Kim, 2004). The manner in which organizations respond to threats or thwarted aspirations (Pruitt and Kim, 2004) depends on a number of identity-related factors. Organization type (Albert and 
Whetten, 1985); organization orientation and the nature of the change being faced (Fox-Wolfgramm et.al., 1998); the degree of threat perceived (Dutton and Dukerich, 1991; Elsbach and Kramer, 1996); the perceived gap between current identity and desired future identity (Gustafson and Reger, 1995); the number of identities within the organization that are affected (Golden-Biddle and Rao, 1997; Pratt and Foreman, 2000); proactive leadership (Dutton and Dukerich, 1991; Gustafson and Reger, 1995; Gioia and Thomas, 1996; Golden-Biddle and Rao, 1997; Fox-Wolfgramm et al., 1998; Pratt and Foreman, 2000); perceptions of stakeholders (Dutton et al., 1994; Scott and Lane, 2000); and the degree to which an organization is preconditioned to respond to change (Brown and Starkey, 2000) can restrict or facilitate selection and implementation of response actions. Members' sense of identity (Dutton and Dukerich, 1991; Dutton et al., 1994), the organization's strategic orientation (FoxWolfgramm et al., 1998), and management perceptions (Dutton and Dukerich, 1991; Gioia and Thomas, 1996; Golden-Biddle and Rao, 1997; Fox-Wolfgramm et al., 1998), all serve as powerful filters for interpreting what is going on and what is to be done about it. These influences will initially cause culturally familiar routines to be activated in the face of perceived threats while constraining the degree to which other actions are considered acceptable (Dutton and Dukerich, 1991). The organizational response of interest to this study is the determination to accept and support or reject and challenge any given Basin governance system, whether in place or proposed.

What emerges from this set of writings (summarized in Table B-2) is a general endorsement of organization identity as a legitimate theory within the more 
generalized framework of social identity theory. Although some question what is really meant by the enduring aspect of identity (Gioia et al. 2000a and 2000b; Albert, Ashforth, and Dutton, 2000), and although perspectives of identity other than cognitive psychology may deserve exploration (Gioia et al., 2000b), the concept of identity as that which is central and distinctive and the relationship between individual and organization identity is seemingly well supported and accepted.

Thus, understanding the role identity plays in organizational behavior is essential to understanding any given social conflict. It is also essential to understand the role identity plays in individual decision making. By recognizing that identity serves as a major interpretive lens through which organization members perceive their place in the environment and understanding the psychological mechanisms through which individuals process their identity in reaching decisions, greater understanding can be reached regarding the positions taken in public policy discussion and debate.

Table B-2:

Theories of Social and Organizational Identity

\begin{tabular}{|c|c|c|c|}
\hline \multicolumn{4}{|c|}{ Representative Literature } \\
\hline Category & Year & $\begin{array}{c}\text { Author(s) / } \\
\text { Editor(s) }\end{array}$ & Title: Relevance \\
\hline \multirow{4}{*}{ 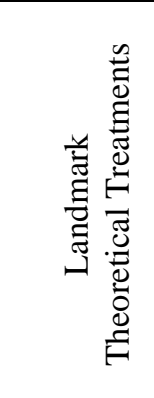 } & 1902 & Cooley & $\begin{array}{l}\text { Society and the Individual: Integrated individual and } \\
\text { social levels of analysis. }\end{array}$ \\
\hline & 1934 & Mead & $\begin{array}{l}\text { Mind, Self, and Society: Distinguishes between the } \\
\text { "I" and "me" in social settings. }\end{array}$ \\
\hline & 1959 & Goffman & $\begin{array}{l}\text { The Presentation of Self in Everyday Life: Introduces } \\
\text { role of audiences in the context of identity and self- } \\
\text { presentation. }\end{array}$ \\
\hline & 1979 & $\begin{array}{l}\text { Tajfel and } \\
\text { Turner }\end{array}$ & $\begin{array}{l}\text { An Integrative Theory of Intergroup Conflict: } \\
\text { Introduced social identity theory into social } \\
\text { psychology }\end{array}$ \\
\hline
\end{tabular}




\begin{tabular}{|c|c|c|c|}
\hline & 1985 & $\begin{array}{l}\text { Albert and } \\
\text { Whetten }\end{array}$ & $\begin{array}{l}\text { Organizational Identity: Introduced organizational } \\
\text { identity; produced parallel to developing literature on } \\
\text { social identity. }\end{array}$ \\
\hline & 1989 & $\begin{array}{l}\text { Ashforth and } \\
\text { Mael }\end{array}$ & $\begin{array}{l}\text { Social Identity Theory and the Organization: } \\
\text { Introduces social identity theory to organizational } \\
\text { studies. }\end{array}$ \\
\hline \multirow{5}{*}{ 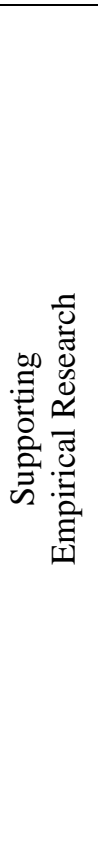 } & 1991 & $\begin{array}{l}\text { Dutton and } \\
\text { Dukerich }\end{array}$ & $\begin{array}{l}\text { Keeping an Eye on the Mirror: Image and Identity in } \\
\text { Organizations: Links organizational theory and image } \\
\text { to strategic choices made in organizational settings. }\end{array}$ \\
\hline & 1996 & $\begin{array}{l}\text { Gioia and } \\
\text { Thomas }\end{array}$ & $\begin{array}{l}\text { Identity, Image, and Issue Interpretation: } \\
\text { Sensemaking during Strategic Change in Academe: } \\
\text { Concluded that identity is more malleable than first } \\
\text { thought; introduced identity and image management } \\
\text { as key leader tasks in times of change. }\end{array}$ \\
\hline & 1996 & $\begin{array}{l}\text { Elsbach and } \\
\text { Kramer }\end{array}$ & $\begin{array}{l}\text { Members' Responses to Organizational Identity } \\
\text { Threats: Encountering and Countering the Business } \\
\text { Week Rankings: Examined how org. members } \\
\text { respond to threats to identity. }\end{array}$ \\
\hline & 1997 & $\begin{array}{l}\text { Golden-Biddle } \\
\text { and Rao }\end{array}$ & $\begin{array}{l}\text { Breaches in the Boardroom: Organizational Identity } \\
\text { and Conflicts of Commitment in a Nonprofit } \\
\text { Organization: Linked individual and organizational } \\
\text { identity with corporate governance. }\end{array}$ \\
\hline & 1998 & $\begin{array}{l}\text { Fox- } \\
\text { Wolfgramm, } \\
\text { Boal, and Hunt }\end{array}$ & $\begin{array}{l}\text { Organizational Adaptation to Institutional Change: A } \\
\text { Comparative Study of First Order Change in } \\
\text { Prospector and Defender Banks: Strategic orientation } \\
\text { impacts response to and duration of imposed } \\
\text { organizational change. }\end{array}$ \\
\hline
\end{tabular}

Table B-2. (Continued)

Theories of Social and Organizational Identity

\begin{tabular}{|c|c|c|c|}
\hline \multicolumn{4}{|c|}{ Representative Literature } \\
\hline Category & Year & $\begin{array}{c}\text { Author(s) / } \\
\text { Editor(s) }\end{array}$ & Title: Relevance \\
\hline \multirow{2}{*}{ 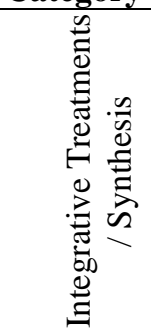 } & 1994 & $\begin{array}{l}\text { Dutton, } \\
\text { Dukerich, and } \\
\text { Harquail }\end{array}$ & $\begin{array}{l}\text { Organizational Images and Member Identification: } \\
\text { Explains how images of one's organization shape the } \\
\text { strength of personal identification with the } \\
\text { organization. }\end{array}$ \\
\hline & 1998 & $\begin{array}{l}\text { Whetten and } \\
\text { Godfrey }\end{array}$ & $\begin{array}{l}\text { Identity in Organizations: Building Theory through } \\
\text { Conversations: Collection of papers, reflections, and } \\
\text { transcripts of discussions between org. identity } \\
\text { theorists and researchers. }\end{array}$ \\
\hline
\end{tabular}




\begin{tabular}{|c|c|l|l|}
\hline 2000 & - & $\begin{array}{l}\text { Academy of Management Review: January issue } \\
\text { dedicated to reflection on empirical organizational } \\
\text { identity research. }\end{array}$ \\
\cline { 2 - 4 } & 2001 & $\begin{array}{l}\text { Hogg and } \\
\text { Terry }\end{array}$ & $\begin{array}{l}\text { Social Identity Processes in Organizational Contexts: } \\
\text { Frames organizational identity as specialized case of } \\
\text { social identity; promotes application of social identity } \\
\text { in organizational analysis. }\end{array}$ \\
\cline { 2 - 4 } & 2004 & $\begin{array}{l}\text { Hatch and } \\
\text { Schultz }\end{array}$ & $\begin{array}{l}\text { Organizational Identity: A Reader: Presents } \\
\text { anthology of central papers on the development of } \\
\text { organizational identity theory. }\end{array}$ \\
\hline
\end{tabular}

\section{Theories of Individual Decision Making}

Although the philosophic nature of decision making has been studied for over 300 years (Connolly and Beach, 1998) its rigorous systematic examination actually began in the 1940s (Beach and Mitchell, 1998). Early attempts (termed as "traditional" or "classical" decision theory) explained decision processes in terms of either statistically-based analyses of probable outcomes or microeconomics-based models of maximum utility. These traditional models, however, did not stand up to empirical scrutiny as to how decisions were observed to actually be made (Mitchell, Rediker, and Beach, 1986; Beach and Mitchell, 1987; Beach, 1990; Beach and Mitchell, 1998).

In response rose alternative schools of thought. Generally termed "naturalistic decision theory" (Beach and Mitchell, 1998, p. 4), they included approaches based on decisions based on pattern recognition from previous experiences and decisions as incremental learning processes (Connolly and Beach, 1998). Leroy Beach, Terry Mitchell, and a group of their colleagues and students viewed these approaches, along with the traditional models, as not so much wrong as incomplete. In response, they 
developed "image theory" as a more holistic theory that incorporates the essential elements of each of the others and, based on their research and observations, better explains how decisions are actually made (Connolly and Beach, 1998). Image theory sees decisions not as mechanistic calculations of optimum outcomes, but rather "guided by the beliefs and values" of the decision maker as held to be relevant to the decision at hand. The analytical assessment of most desired outcome called for under traditional theory does not take place until after available options have been screened for compatibility with those beliefs and values (Beach, 1998, p. x).

This section reviews the formulation of image theory, supporting empirical research, the current state of the theory, and discusses its applicability to this study of Columbia Basin governance. In essence, image theory provides the theoretical "how" of individuals translating personal values and beliefs into policy choices within an organizational context. It also provides empirical methodologies that can be used to empirically examine theoretical components of structuration.

\section{The Formulation of Image Theory:}

"Image Theory" was developed in the mid-1980s in response to observed weaknesses in traditional decision theory and extant critiques of the traditional approach (Connolly and Beach, 1998). It was first presented as a chapter by Mitchell, Rediker, and Beach in Sims and Gioia's The Thinking Organization (1986) and as a journal article by Beach and Mitchell in Acta Psychologica (1987). The theory was 
first given book treatment in Beach's 1990 Image Theory: Decision Making in Personal and Organizational Contexts.

Image theory is presented as a descriptive theory that attempts to explain the way in which individuals makers represent information to themselves as they make decisions and interact with the world around them. Mitchell, Rediker, and Beach (1986) and Beach and Mitchell (1987) presented a relational model that defined the process by which an individual defines his/her current state and plots a course to achieve an anticipated future state through the use of internal mental images. These images were defined as "schemata" that embody the individual's guiding principles, goals, and values. The constitutive elements of such images evolve early in life. These early constructs have a life-long, disproportionate impact on how individuals view and react to the world. Although long lasting, these early-formed images can be shaped through membership in organizations and institutions as individuals assimilate organizational values and norms into some portion of their own self-image. Decisions, in the authors' context, are defined as those of more than routine importance. They contend that their theory accounts for both decisions that an individual makes in a rational, deliberative manner (i.e. traditional decision theory) and those made in a more intuitive manner that is bounded and shaped by internalized values and principles.

Mitchell, Rediker, and Beach (1986) and Beach and Mitchell (1987) initially defined the following as the key elements of image theory: 
- Self Image: Represents personal beliefs, values, ethics, and morals that one intuitively accepts as true. Self-image is constituted of principles, which guide an individual's acceptance or rejection of a goal or course of action.

- Trajectory Image: Represents an individual's agenda for the future. It is constituted through goals, which may be either concrete and specific events or a more abstract desired end-state.

- Action Image: Consists of the plan and tactics envisioned to attain the goals of the trajectory image.

- Projected Image: The projected image consists of events anticipated if the action image (plan) is adopted. Its principle value is that it allows analysis of alternate plans and assessment of plans currently underway.

The four-image construct was revised by 1990. The "projection" and "action" images were combined into a new "strategic" image, and the "self" image was modified as a "values" image ${ }^{171}$ (Beach, 1990). This three-image theoretical construct, although refined over time, remained intact over the subsequent fifteen years of empirical research (Beach, 1996 and 1998; Beach and Connolly, 2005).

\section{Critiques of Image Theory:}

Image theory was not well received when first proposed; Beach (1998) notes the difficulty he and his colleagues initially had in getting the theory published in the

${ }^{171}$ According to Beach (1990), this revision came about in preparation for a presentation to a lay audience for which the presenter combined the "projection" and "action" images into one for purposes of simplification. This in turn caused the authors to reexamine the usefulness of the original constructs theoretical usefulness. Upon reflection, they determined that the components of the projected and action images were so interrelated as to be better consolidated into just one. The author does not explain the shift in terminology from the "self" to the "value" image, leaving the language explaining the two as essentially the same. 
United States. Although published in Sims and Gioia's 1986 The Thinking

Organization, it is worth noting that the book's editors were specifically seeking innovative, avant-garde approaches to understanding organizational social cognition (Sims and Gioia, 1986, introduction). The books editors encouraged contributors to not be bound by traditional or conservative conventions. Beach and his colleagues apparently found little traction in their own right. Beach and Mitchell (1987) thus turned to the Dutch journal Acta Psychologica. Beach's 1990 Image Theory: Decision Making in Personal and Organizational Contexts was published in England by Wiley as the first in an envisioned series on industrial and organizational psychology. ${ }^{172}$

One critic of Beach's 1990 book described it as "intellectually heuristic" (by which the critic meant the theory being useful for research but may be incapable of proof). He further claimed it unconvincing in how it described the manner in which decisions are in fact made, that it ignored relevant literature on the same topic, and that Beach misrepresented the three studies he used in support (Agor, 1992). Another concluded that the key components of the theory are only partially worked out and that a non-associate of the author would have a hard time adopting the books precepts in isolation (Boothroyd, 1991). Both Agor (1992) and Boothroyd (1991) are especially critical of the book's editing and inconsistent use of terms, making it hard to understand. Both also, however, note the book's potential.

These problems for the most part appear to have been overcome with time; no similar critiques of any kind were found for Beach's subsequent publications.

\footnotetext{
${ }^{172}$ Apparently, the envisioned series did not work out as hoped; it is not mentioned on the Wiley website whereas other thematic series are.
} 
Meanwhile, each succeeding publication (Beach 1996, 1998; Beach and Connolly, 2005) incorporated the conclusions of empirical study and became clearer in presentation. Miner's $(2005,2006)$ survey of the opinions of organizational behavioral theorists cites image theory as an "essential" theory of organizational behavior and observes that its major weakness is that it is relatively unknown outside of Beach's circle of colleagues and students.

\section{Empirical Support:}

Beach's 1996 and 1998 books both summarize the results of research conducted and offered proposals for additional study. The 1996 book focuses on research in specific settings. Examples include studies in job search and selection by Stevens and Beach (Beach, 1996); supervision and job satisfaction by Bissell and Beach (Beach, 1996); and audit decisions by Beach and Frederickson (Beach, 1996). The 1998 book focuses on research into the compatibility and profitability tests. Examples include the effect of screening in assessing decision options by Zee, Paluchowski, and Beach (Beach, 1998); the role of imperfect information in prechoice screening by Potter and Beach (Beach, 1998; and problem solving strategies by Christensen-Szalanski (Beach, 1998). Both books use the results of the empirical research presented to reflect upon and refine the theory, such as Weatherly and Beach's (1998) empirical study of organizational culture. They used image theory as a framework to examine the impact of culture on organizational decision making, holding that the role of an organization's culture, goals, and plans on organizational 
decision making is analogous to the role of individual principles, goals, and plans in individual decision making.

In his review of organizational theories, Miner $(2005,2006)$ observes that despite its empirical validity - image theory is not well known outside of Beach and Mitchell's circle of colleagues and students. That may be changing: Ruby Brougham and David Walsh (2007) used image theory to study retirement decisions, comparing image theory's predictive power with a decision model based on goal facilitation and another based on cost/benefit analysis. They found that goal compatibility (image theory's "compatibility" test) held more predictive power than the goal facilitation model and equaled the cost/benefit model.

Beach and Connolly (2005) summarized the state of image theory based on empirical research to date and placed its development within an historical context of decision theory development. The key elements of image theory as presented in the 2005 book and therefore used for the purposes of this study are:

- Image theory is centered on three elements:

- The value image is constituted on individual principles, which serve as self-evident truths that dictate how things should be and how people ought to behave. Principles underscore what the individual and group stand for and form the foundation for decision making.

- The trajectory image provides the goals the individual has selected for the future. 
- The strategic image consists of the plans, tactics, and forecasts selected to achieve one's goals. Plans are implemented through tactics and compared over time against forecasts to judge progress.

- Individuals tend to stay in organizations where the values of the individual and organization are congruent, reinforcing the findings of social identity research (Tajfel and Turner, 1970; Ashforth and Mael, 1989).

The decision theory literature reviewed above is summarized in Table B-3. In essence, image theory sees decisions as based on the beliefs and values of the decision maker as considered relevant to the issues at hand and often made on an intuitive rather than objectively analytical basis (Beach and Mitchell, 1987; Beach 1990, 1996, and 1998; Beach and Connolly, 2005). Image theory does not dismiss the analytical process of traditional decision theory, but rather relegates its use to those situations where two or more decision alternatives have passed the process of value screening. Beach and his colleagues' work provide additional insight to both structuration and identity theory.

Table B-3

Image Theory

\begin{tabular}{|l|c|c|c|}
\hline \multicolumn{2}{|c|}{ Representative Literature } \\
\hline Category & Year & $\begin{array}{c}\text { Author(s) } \\
/ \\
\text { Editor(s) }\end{array}$ & Title: Relevance \\
\hline
\end{tabular}




\begin{tabular}{|c|c|c|c|}
\hline \multirow{3}{*}{ 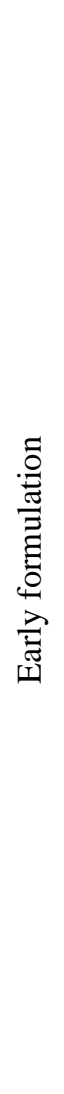 } & 1986 & $\begin{array}{l}\text { Mitchell, } \\
\text { Rediker, } \\
\text { and Beach }\end{array}$ & $\begin{array}{l}\text { Image Theory and Organizational Decision Making: Published } \\
\text { as a chapter in The Thinking Organization (1986) apparently } \\
\text { based on the same manuscript used for the } 1987 \text { Acta } \\
\text { Psychologica article. Critiques traditional decision theories based } \\
\text { on statistical gaming and economic models. Introduces image } \\
\text { theory as more comprehensive alternative, consisting of four } \\
\text { components (self image (principles), trajectory image (plans and } \\
\text { goals), projected image (ordering of events), and action image } \\
\text { (tactics). }\end{array}$ \\
\hline & 1987 & $\begin{array}{l}\text { Beach and } \\
\text { Mitchell }\end{array}$ & $\begin{array}{l}\text { Image Theory: Principles, Goals, and Plans in Decision Making: } \\
\text { Authors present a descriptive theory to explain the way in which } \\
\text { people make individual decisions as they interact with the world } \\
\text { around them. They suggest a decision-making process in which } \\
\text { an individual assesses their current state and then plots a course } \\
\text { to achieve a desired future state. This theory contends with } \\
\text { decisions made in a rational, deliberative manner as well as those } \\
\text { made automatically. Consists of essentially the same content as } \\
\text { the } 1986 \text { chapter in The Thinking Organization. }\end{array}$ \\
\hline & 1990 & Beach & $\begin{array}{l}\text { Image Theory: Decision Making in Personal and Organizational } \\
\text { Contexts. First book-length treatment. Consolidates the four- } \\
\text { image constructed presented in previous articles to three: the } \\
\text { values image (principles), trajectory image (goals), and strategic } \\
\text { image (plans and tactics). Continues critique that economic and } \\
\text { statistics-based decision models are too mechanistic and not } \\
\text { reflective of how decisions are observed to be made. }\end{array}$ \\
\hline \multirow{3}{*}{ 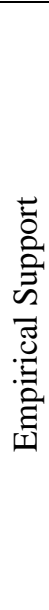 } & 1996 & Beach & $\begin{array}{l}\text { Decision Making in the Workplace: Presents collection of essays } \\
\text { that presents results of empirical research of image theory and its } \\
\text { application in the work place. }\end{array}$ \\
\hline & 1998 & Beach & $\begin{array}{l}\text { Image Theory: Theoretical and Empirical Foundations: Presents } \\
\text { additional empirical results and theoretical extensions. Notes } \\
\text { strong empirical support for theoretical components of } \\
\text { compatibility testing, profitability testing, progress decisions, and } \\
\text { strategy selection. Notes lack of support or research on the } \\
\text { concept of "images." }\end{array}$ \\
\hline & 2007 & $\begin{array}{l}\text { Brougham } \\
\text { and } \\
\text { Walsh }\end{array}$ & $\begin{array}{l}\text { Image Theory, Goal Compatibility, and Retirement Intent. } \\
\text { Empirical study that uses image theory as framework for } \\
\text { understanding retirement decisions. Only research found outside } \\
\text { the coterie of Beach colleagues and students. }\end{array}$ \\
\hline
\end{tabular}

Table B-3. (Continued) Image Theory

\begin{tabular}{|l|c|c|c|}
\hline \multicolumn{2}{|c|}{ Representative Literature } \\
\hline Category & Year & $\begin{array}{c}\text { Author(s) } \\
/ \\
\text { Editor(s) }\end{array}$ & Title: Relevance \\
\hline
\end{tabular}




\begin{tabular}{|l|l|l|l|}
\hline & & $\begin{array}{l}\text { The Psychology of Decision Making (2nd Ed): Provides } \\
\text { summation of evolution of the course of decision making theory } \\
\text { over the years, to include growth of various schools of theoretical } \\
\text { thought. Provides typology of decision theory. Argues that } \\
\text { image theory most comprehensive and allows for holistic nesting } \\
\text { of other theories within the image theory construct. Basic } \\
\text { construct of image theory is unchanged, but component elements } \\
\text { much more clearly defined and discussed. }\end{array}$ \\
\hline
\end{tabular}


Section 2

A Theoretical Framework for Future Research

\section{$\underline{\text { Introduction }}$}

This chapter summarizes the substance of the theories reviewed in Section 1, outlines the reason why an integration of these theories is necessary in order to fully explain the paradox of Northwest regional governance, and presents a framework within which the concluding hypotheses from Chapter 7 may be tested.

\section{$\underline{\text { Summary of Relevant Theories }}$}

\section{Sociology: theories of structuration and social becoming}

Anthony Giddens summarized his work on social structuration in $\underline{\text { The }}$

Constitution of Society, published in 1984. His stated goal was to put an end to the debate between functionalists and humanists over the relationship between the social whole and individuality. Functionalists emphasized the primacy of structural constraints (both formal and normative) imposed over individual members as the dominant explanation for social behavior. Alternatively, advocates of the humanist or hermeneutic school described society as the summation of individual actions. Giddens reconceptualized these oppositions as a coexisting duality of "agency and structure." (p. 162). In his construct, humans are knowledgeable agents within social systems, with the capacity to simultaneously subordinate themselves to social order and engage in autonomous, creative activity (Giddens, 1984). 
Giddens (1984) describes daily life as a flow of intentional actions. Human actors within society have an inherent capacity to understand what they do while they do it and are thus free to accept societal expectations or not. Life is simplified through routinization, in which non-salient decisions are relegated to the rules and normative expectations of those around them. Indeed, routinization is considered vital to psychological mechanisms in that it sustains a sense of trust and ontological security among society members. Salient issues are acted on in a more affirmative manner, providing a capacity for creativity and innovation that can serve to challenge or defend existing social arrangements. The concept of agency thus represents intentions and the capability of people to do the things they intend. "Agency concerns events of which an individual is the perpetrator, in the sense that the individual could, at any phase in a given sequence of conduct, have acted differently. Whatever happened would not have happened if the individual had not intervened" (Giddens, 1984, quote from p. 9).

Under Giddens' (1984) construct, social groups are manifest through systems and structures. Systems are the relationships among and practices of human agents, patterned to the point that they define identifiable social entities (such as groups, organizations, or other social collectivities). Structures are recursively organized sets of rules and resources recognized by members as legitimate properties of the social system and sustained in memory of human agents. As such, these institutionalized features of social systems have structural properties (or rules) that serve to stabilize relationships across time and space, contributing to social order. These rules come in two forms. Normative elements are the non-codified behavioral expectations that 
members hold for themselves and others. Those rules more formally established are termed codes of signification.

"Structuration" is the patterning of social practices in time-space involving the reproduction of situated practices (through rules and alignment of resources).

Structure exists in the practice of social activities by members and is recorded in their memories. It is through these practices and memories that human conduct is oriented, fostering social stability. "The most deeply embedded structural properties, implicated in the reproduction of societal totalities, I call structural principles. Those practices which have the greatest time-space extension within such totalities can be referred to as institutions" Giddens, 1984, p. 17, emphasis in original). He further states that "the most important aspects of structure are rules and resources recursively involved in institutions." (p. 24.) Structuration thus governs the continuity or change of systems, and therefore the reproduction of social systems, with change made more difficult based on the degree of institutionalization that has taken place. Fundamental is the point that agents, systems, and structures are not independent phenomena, but coexist as an irreducible duality. The continuous interaction between system and individual agency means that actors (agents) do not create social systems. They "reproduce or transform them, remaking what is already made in the continuity of praxis" (Giddens, 1984, p. 171, emphasis in original). These human activities are recursive, a product (praxis) of individual ability to monitor the ongoing flow of life and adjust social systems accordingly. 
Piotr Sztompka approached his theory of social becoming (1991) with the same intent as Giddens. He too sought to resolve the long standing sociological debate on the location of "agency" (the capacity for change) between the "macro" of societal structures and the "micro" of the individual. His goal was to "...combine these efforts by introducing a concept of social becoming which attempts to find the middle ground between the rigid determinism of reified totalities and the unbridled voluntarism of free individuals.” (p. 5). Although cognizant of Giddens' work, Sztompka does not build his theory upon Giddens. Rather, he seems to work from similar sources in parallel with Giddens. In so doing, he reinforces and clarifies some of Giddens' conclusions while introducing others of his own.

Sztompka (1991) describes his theory of social becoming as a synthesis of past syntheses. Consistent with Giddens, he treats totalities (social structures and constraints) and individualities (individual creativity) a dualities, arguing that they are "two analytic dimensions of human nature, separable only in imagination." (p. 5).

"The real, not merely conceptual, synthesis of those analytical aspects - individualities and totalities, creativeness and constraints - is due to the historical, processual nature of social life, to its ontological embeddedness in time.” (p. 5).

Also consistent with Giddens is Sztompka's (1991) treatment of agency and praxis, summarized in his diagram presented here as Figure B-1. Sztompka (1991) defines agency as the ultimate cause of events. It is the active, constructive side of social life carried out by individuals but with due recognition of the structural framework within which human conduct takes place. Thus, social structure is both the 
medium for its own continual development and the product of that developmental process. Like Giddens, Sztompka sees agency as carried out by individuals, but notes that multiple individuals can engage in agency collectively for common goals. But Sztompka (1991) expands the concept of agency through introduction of the concept

Figure B-1.

Sztompka's Model of Agency and Praxis

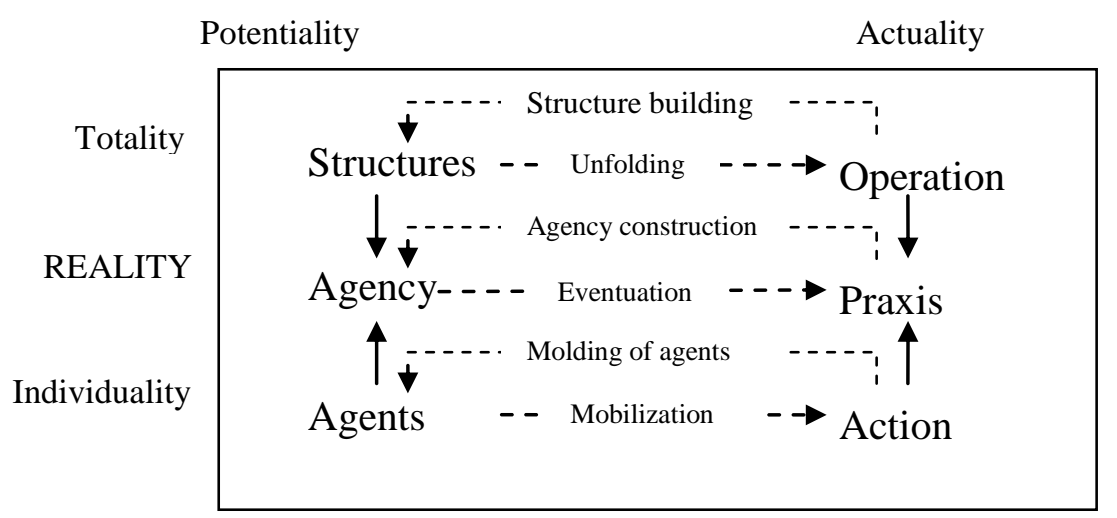

(From Sztompka, 1991, Figure 5.3 (p. 99))

of an agential coefficient active in social construction. This coefficient is defined by six ontological assumptions:

1. Society is a process, undergoing constant change. Society and its members are immersed in the flow of historical time. As such, social systems are not created but evolve from that which came before.

2. Change is, for the most part, produced from within society.

3. The ultimate motor of change is the agential power of human individuals or social collectivities. 
4. The direction, goal, and speed of change are contestable among multiple agents. Direction, goal, and speed thus become the area of conflict and struggle.

5. Action occurs within a context of encountered structures, which agents shape in turn. This results in the dual quality of structures as both shaping and shaped and the dual quality of actors as both producers and products.

6. The interchange of action and structure occurs in time by means of alternating phases of agential creativeness and structural determination.

Sztompka (1991) treatment of praxis is likewise consistent with Giddens, but greatly clarified. Sztompka describes praxis is the context of mediation, defining it as "the actual manifestations of social fabric... where operation and action meet, a dialectic synthesis of what is going on in a society and what people are doing." (p. 96). As such, it "provides the bridge between acting individuals and changing structures" (p. 41). Thus praxis is doubly conditioned from below by individual actions and above by the operation of wider society. "But it is not reducible to either. It is something more than the sum of individual actions, and it is something more than the outcome of ongoing operation. With respect to both levels - individualities and totalities - it is a new emergent quality. Having its own specific ontological quality as reality sui generis, it emanates in two directions, engendering actors' conduct and originating systemic tendencies. It is the true core of social life." (p. 41).

"Praxis" thus provides both the product of social becoming - society - and the medium in which societal changes take place. To Sztompka, "society" is seen as the collection of social groupings in which individuals participate, from local church or 
community groups up through civilization levels (Sztompka, 1991). Accordingly, any social grouping can thus be nested within other groupings, each undergoing its own simultaneous process of structuration / becoming.

Sztompka (1991) is clearer in describing the role of time than is Giddens (1984). He uses historical sociology to explain the causal mechanisms through which agential creativeness and structural influences merge in the flow of historical processes. He introduces the concept of an historical coefficient which, like his agential coefficient, is defined by six ontological assumptions:

1. Social reality is not a steady state but a dynamic process. It occurs rather than exists and is composed of events, not objects.

2. Social change is a confluence of multiple processes with various vectors, partly overlapping, partly convergent, and partly divergent. These vectors may be mutually supportive or destructive.

3. A social grouping undergoing change may be perceived not as an entity but as a fluid set of relations pervaded by both tension and harmony, by conflict and cooperation.

4. The sequence of events within each social process is treated as cumulative. Each phase is culmination of previous phases and sets the stage for the next phase. Future courses of action are delimited by past courses adopted.

5. Social process is constructed by individual or collective human agents through their actions over time. 
6. People do not construct society as they please, but within given structural conditions inherited from the past (constructed by their predecessors). "...there is dialectic of actions and structures, in which actions are partly determined by earlier structures and later structures are produced by earlier actions." (Sztompka, 1991, p. 26).

Finally, Sztompka (1991) offers an enhanced definition of "structure." Whereas Giddens (1984) defined structure as a recursively organized sets of rules and resources, Sztompka offers four-fold typology of structural "levels" identified as normative, ideal, interaction, and opportunity. ${ }^{173}$ The normative level is the network of rules, norms, values, and institutions prescribing the proper expected conduct and proscribing "wrong" conduct. This level is found in systems of laws, mores, and customs and make up a reality of social facts external to any single individual. At the ideal level is the network of ideas, beliefs, images, and convictions about reality. This level clusters in creeds, dogmas, doctrines, and ideologies. Next is the interactional level, consisting of communication networks such as formal channels and lines of access that serve to coordinate the mutually oriented actions of multiple individuals. Finally is the opportunity level. This level is grounded in classes, societal stratification, and prospects for social mobility.

Sztompka (1991) summarizes his theory with three insights:

- That society (defined as any social grouping) is humanly constructed.

- That humans are socially shaped

${ }^{173}$ Giddens' (1984) definition of structure encompasses Sztompka's (1991) normative and ideal levels. 518 
- That society and humans are both immersed in the flow of historical time

As wide-ranging as they are, structuration (Giddens, 1984) and social becoming (Sztompka, 1991) provide only incomplete explanations of the regional governance experience. They explain "what" happened through the role of individual and collective agents in shaping systems and structure, the influence of systems and structure on individuals, and the historical connectivity between structures. To a limited extent, they also explain "why" things happened the way they did in terms of the roles of individual autonomy and freedom and the cognitive consciousness of members in their own social phenomena. But while they note the varying degrees in intensity of commitment held by individuals, they do not explain what motivates some members of a social group to act as change agents while others act just as passionately as agents of the status quo. Nor do they explain "how" individuals process the systems and structures of the social groups in which they are members when rendering individual decisions. Therefore, other theoretical domains must be looked to for a more complete explanation.

Social Psychology: Culture, Identity, and Conflict

\section{Worldviews and culture:}

Giddens' (1984) and Sztompka (1991) assert that social groups are recognizable through organizational patterns and structures of formal rules, norms, customs, and belief systems. Within this construct, the tribal, market-commodity, and environmental worldviews identified in Chapters 3 through 7 represent normative elements of structure. Each provides what Lichatowich et al. (2006) describe as a 
conceptual foundation of principles and assumptions that guide activities. They exist at the broadest possible societal level and, though themselves unwritten, will inspire and guide promulgation of laws, regulations, rituals, and other written and unwritten manifestations of social expectations that serve to guide member behavior. Worldviews may be thought of as "culture" in the anthropologic sense.

Culture also exists at the organizational level. Edgar H. Schein (2004) argues that culture is a complex learning process that occurs within social units holding a shared history. It originates in one of two ways. It may begin through spontaneous interactions within an unstructured group that gradually leads to patterns and norms of behavior as the group becomes better organized over time. In more formal groups, it begins with the values of the organization's founder. In this circumstance, the founder's vision, goals, beliefs, and assumptions as to how things should be are imposed on group members. Initially, the acceptance of this imposition is transactional in nature. It produces compliance but not necessarily buy-in. However, as the group experiences success over time, these values and beliefs become validated and eventually shared within members of the group. "What was originally the founder's individual view of the world leads to shared action, which, if successful, leads to a shared recognition that the founder 'had it right.' The group will then act again on these beliefs and values and, if it continues to be successful, will eventually conclude that it now has the 'correct' way to think, feel, and act" (Schein, 2004, p. 16, emphasis in original). Regardless whether originating through group consensus or an individual founder, this evolved culture provides a shared sense of stability that 
becomes embedded within the group and spans all aspects of group functions. It then leads to patterning of routine behaviors that help members make sense of the world around them. Schein summarizes his definition of culture as:

...a pattern of shared basic assumptions that was learned by the group as it solved its problems of external adaptation and internal integration, and that has worked well enough to be considered valid and, therefore, to be taught to new members as the correct way to perceive, think, and feel in relation to those problems" (Schein, 2004, p. 17).

Schein (2004) maintains that culture can evolve within any size social groupings in which people share significant experiences over time. Such shared experiences lead to learning a shared view of the world and condition future responses to the environment based on those experiences. Over time, the original reason for the behavior may be forgotten, but the behavior continues.

Culture's power is drawn from its psychological effect on group members. "Culture as a set of basic assumptions defines for us what to pay attention to, what things mean, how to react emotionally to what is going on, and what actions to take in various kinds of situations" (p. 32). Culture can evolve within any size social groupings in which people share significant experiences over time. Such shared experiences lead to learning a shared view of the world and condition future responses to the environment based on those experiences. Over time, the original reason for the behavior may be forgotten, but the behavior continues. Therefore, all behaviors result from either the ingrained culture or in reaction to external events.

Culture, then, explains why organizational members behave as they do in carrying out organizational business and complements Giddens' (1984) and 
Sztompka's (1991) concepts of structure. But it does not fully explain personal commitment. To illustrate, envision two proverbial employees. One is only in a business organization "for the job." This individual adheres to organizational expectations, carries out duties assigned, but departs promptly at closing. To this employee, membership in the organization has no intrinsic meaning other than as a source of income. In contrast is the employee who devotes much extra time and effort into organizational goals. This employee always volunteers to organize after-hour social events, puts extra time into getting products completed to the highest quality possible, and actively promotes the organization in external forums. In contrast to the first employee's purely transactional relationship, the second relates to the organization on a personal basis to the degree that membership is integral to the individual's self image. Identity theory explains this difference in ways that, like culture theory, complements structuration theory and provides additional insight into the regional governance experience.

\section{Organizational and Individual Identity:}

Giddens recognizes a role for identity in structuration when he notes "...the prevalence, among the members of the society, of feelings that they have some sort of common identity, however that might be expressed or revealed. Such feelings may be manifest in both practical and discursive consciousness and do not presume a 'value consensus.' Individuals may be aware of belonging to a definite collectivity without agreeing that it is necessarily right and proper" (Giddens, 1984, p. 165, emphasis added.) This, however, is the limit of Giddens' examination as to how identity shapes 
structuration and vice versa. Identity theory merits further discussion given its importance.

Individuals exist within social systems and structures and define their sense of self in relation to the members of the social situation in which they reside. Individual identity is therefore heavily influenced by others (Cooley, 2004/1902; Mead, 2004/1934). In response, individuals will cognitively attempt to in turn influence the perceptions of others in their social group (Goffman, 2004/1959). An individual's drive for self-enhancement and desire to associate with groups of like-minded individuals determine which social groups they do or do not decide to join. Among social groups that people choose to join are organizations (Hogg and Terry, 2001) and people will self-categorize into organizations that share values and worldviews with which they identify or wish to emulate (Tajfel and Turner, 2004/1979; Ashforth and Mael, 1989). This results in organizations tending to evolve into collections of likevalued people. Individual and organizational identity is thus inextricable linked, the degree varying with the level of alignment between individual self-image and the organization's perceived values and behavior patterns (Tajfel and Turner, 2004; Albert and Whetten, 1985; Ashforth and Mael, 1989; Dutton and Dukerich, 1991; Gioia and Thomas, 1996; Elsbach and Kramer, 1996; Fox-Wolfgramm et al., 1998).

Strong psychological bonds may form between individuals and their organizations resulting in individuals adopting attributes of the organization as their own (Dutton et al., 1994). For many people, "their professional and/or organizational identity may be more pervasive and important than ascribed identities based on 
gender, age, ethnicity, race, or nationality" (Hogg and Terry, 2001, p. 2). Not all members of an organization will necessarily share the same intensity of psychological bonding with the group. Often members will recognize and adhere to social expectations without psychologically identifying with them (Giddens, 1984; Albert and Whetten, 1985; Schein, 2004; Ashforth and Mael, 1989). For those who do so identify, perceived threats to the organization become perceived threats to the individual, with the response varying by the nature and degree of the threat (Dutton and Dukerich, 1991; Elsbach and Kramer, 1996; Fox-Wolfgramm et al., 1998).

The combination of individual and organizational identities becomes a powerful lens through which interpretations of other groups within the environment and acceptable response alternatives to intergroup relations are viewed (Tajfel and Turner, 2004; Albert and Whetten, 1985; Ashforth and Mael, 1989; Dutton and Dukerich, 1991, 1994; Elsbach and Kramer, 1996; Fox-Wolfgramm et al., 1998). This interpretive lens shapes the selection of organizational responses to the actions of others. Organization leaders affect perception by explaining what is going on in the environment within the context of the organizational identity lens, thus facilitating member sense-making (Gioia and Thomas, 1996). Consequently, the understanding of observed organizational behavior - such as exhibited during negotiations over the CRBF's MOA - can be greatly informed by the contexts of individual and collective identity of those participating.

An organization's relationship with its environment is iterative and reciprocal (Albert and Whetten (1985); Dutton and Dukerich, 1991; Elsbach and Kramer, 1996; 
Scott and Lane, 2000). Organizational leaders are charged with the formal representation and defense of the organization to the public. Individual members also influence outside perceptions as well through customer service, interaction through professional associations, and other contacts (Scott and Lane, 2000). Organization leaders affect the perception of change by explaining what is going on in the environment within the context of organizational identity thus facilitating member sense-making. These identity mechanisms are not permanently fixed, and may evolve over time (Dutton and Dukerich, 1991; Fox-Wolfgramm et al., 1998; Gioia and Thomas, 1996; Gioia et al., 2000a).

Other significant factors influencing perceptions of the environment include perceptions by outsiders (Cooley, 2004; Mead, 2004; Dutton and Dukerich, 1991; Gioia and Thomas, 1996; Elsbach and Kramer, 1996; Scott and Lane, 2000), the worldview as held by members of the organization (Tajfel and Turner, 2004; Albert and Whetten, 1985; Ashforth and Mael, 1989; Dutton and Dukerich, 1991; Gioia and Thomas, 1996; Elsbach and Kramer, 1996; Fox-Wolfgramm et al., 1998), and the strategic orientation of the organization (Dutton and Dukerich 1991; Fox-Wolfgramm et al., 1998). An organization's relationship with its environment is iterative and reciprocal. Organizations prepare images for public consumption designed to put the organization in the best positive light (Albert and Whetten (1985); Dutton and Dukerich, 1991; Elsbach and Kramer, 1996; Scott and Lane, 2000). Managers acting as representative agents - have a key role in this process, since they are charged 
with the formal representation and defense of the organization to the public (Scott and Lane, 2000).

Outsiders evaluate these images within the context of organization behavior, media coverage, and their personal relationship and identification with the organization and its members. They reflect their interpretation of the images back to the organization (Dutton and Dukerich, 1991; Elsbach and Kramer, 1996; FoxWolfgramm et al., 1998). Individual members will then compare their self-identity and their perceptions of the organization's identity with the perception of the organization as articulated by management and reflected by relevant stakeholders (Goffman, 2004; Dutton and Dukerich, 1991; Dutton et al., 1994; Scott and Lane, 2000). Thus, the organizational perception of environment is a complex interaction among organization members, organization leadership and external stakeholders that is filtered and interpreted through the organization's internal orientation and sense of identity. For Basin governance, this means that those participating in governance negotiations would be expected to represent their views and interests in the best possible light while dismissing or trivializing the alternative messages offered by others.

\section{Conflict:}

The history of events surrounding the structuration of Columbia Basin governance is replete with conflict. Examples include clashes between advocates of public and privately owned electrical power (Ogden, 1949; White, 1995; Brigham, 1998; Pope, 2008); fisheries proponents and river developers (Scheufele, c.1970; 
Blumm, 1981; Robbins, 2004); states and tribes over fishery allocations and other tribal rights (Wilkinson, 2005; Pevar, 2002); turf disputes between federal agencies (McKinley, 1952; Clarke and McCool, 1996); and among just about everybody in the West over water (Wilkinson,1992; Pisani, 2002). These and other regional lines of conflict are recorded in greater detail in Chapters 3 through 7.

On the surface, these regional conflicts could be viewed as struggles among divergent interests over scarce resources. Indeed, up until the late 1970s, resourcebased (or instrumental (Tajfel and Turner, 2004/1979) or divergent interest (Giddens, 1979) or realistic (Coser, 1964; Campbell, 1965; Pruitt and Kim, 2004) competition was considered - at least within social psychology circles - as the dominant reason conflict occurred (Hatch and Schultz, 2004b). But this reasoning did not address observed hostility between groups with no apparent competing interests. This gap was answered when Henri Tajfel and John Turner published their theory of social identity in 1979. Social identity has subsequently assumed a dominant role in conflict analysis by some (Ashmore, Jussim, and Wilder, 2001; Eagly, Baron, and Hamilton, 2004) and a co-equal role with interest-based causes by others (Cox, 1996/1993).

Giddens devotes a chapter to conflict in Central Problems (1979). He defines conflict as the "struggle between actors or collectivities expressed as definite social practices" (p. 131). He notes "two senses of conflict," one being disputes over divergent interests and the other as struggle among groups or actors based on the mere existence of those groups. ${ }^{174}$ He emphasizes the role of ideology in conflict. Writing

\footnotetext{
${ }^{174}$ This second source was the phenomenon under study by Tajfel and Turner at approximately the same time. See section 2 below.
} 
within the context of World War II's Jewish holocaust, he describes ideology as a "belief system." He notes that the promise of science in the age of enlightenment was to end what had been traditions of irrational and unfounded prejudices of unthinking belief. To Giddens, that failed in the face of Nazi ideology in the Germany of the 1930s and '40s thus illustrating the potential for positions of belief to undermine and overwhelm positions of reason.

Giddens did not carry forward this discussion of conflict in Constitution (1984). But he implicitly invokes it through his discussion of critical situations, power, and control. He defines critical situations as those where the "established modes of accustomed life are drastically undermined or shattered" (Giddens, 1984, p. 60). He defines power as "the means of getting things done" (p. 283) and control as the capability of some actors to influence the circumstances of others. By defining agency as the capacity for individuals to act autonomously, he endows them with the power to challenge the status quo of prevailing systems and structures as enforced through the power and control of those in charge. Power and control represent the exercise of agency by some actors as they seek to constrain the agency of others seeking change. The resolution of critical situations, the exercise of power, the imposition of constraint, and agency occur in praxis. Power and constraint represent the exercise of agency by some actors as they seek to restrict the agency of those with whom they disagree. Thus, the capacity for and occurrence of social conflict is inherent in Giddens' theory. 
Sztompka (1991) is more forthright on the subject. He devotes a great deal of discussion to social movements and counter movements. Such movements result in the emergence of new creeds, beliefs, norms, values, tactics, internal structures, and relationships. Any society wishing to grow must foster the conditions for the emergence of social systems that can effectively challenge the status quo. Thus, in Sztompka's construct, conflict appears essential to social evolution. In summary, Giddens and Sztompka observe the existence of conflict and explain it through the framework of praxis and agency. What they don't do is explain the triggering mechanisms that cause conflict to begin.

There are two bodies of theory that do. The first is conflict based on competing group interest. Rational, interest-based conflict of this nature is termed variously as "realistic" (Coser, 1964; Campbell, 1965; Pruitt and Kim, 2004) or “instrumental" (Tajfel and Turner, 2004/1979). Realistic, or instrumental, competition originates with incompatible group goals and manifests in struggles over tangible (such as territory, money, or food) or intangible (such as power, prestige, honor, or a sense of physical security) resources in short supply (Pruitt and Kim, 2004; Tajfel and Turner, 2004/1979; Hatch and Schultz, 2004b). The second source of conflict is social identity. Under this theory, the mere knowledge that another group exists within the salient environmental framework of an in-group can lead to out-group bias and discrimination. Termed "social competition" (Tajfel and Turner, 2004/1979), such conflict is based solely on social comparisons as made by group members (Tajfel and Turner, 2004/1979; Ashforth and Mael, 1989; Ashmore, Jussim, and Wilder, 2001). 
Conflict may arise under conditions of either realistic or social competition. The presence of both, however, can greatly exacerbate the nature of the conflict and make resolution that much more difficult (Ashmore, Jussim, and Wilder, 2001).

Pruitt and Kim (2004) define conflict as a "perceived divergence of interest, a belief that the parties' current aspirations are incompatible" (p. 8, emphasis in original). The central components of realistic conflict are interests, which are defined as "people's feelings about what is basically desirable" (p. 15) and aspirations, defined as "mental representations of the things [a party to the conflict] strives for or believes it must achieve" (Pruitt and Kim, 2004, p. 16). Conflict size (or intensity) is influenced by the salience of any given threat to a group interest or aspiration. Conflict thus arises through the perception of "relative deprivation" that occurs when a party believes that a reasonable interest or aspiration is threatened or has been thwarted.

The manner in which organizations respond to threats or thwarted aspirations depends on a number of identity-related factors. Organization type (Albert and Whetten, 1985); organization orientation Fox-Wolfgramm et al., 1996); the nature of the change being faced (Fox-Wolfgramm et al., 1996); the degree of threat perceived (Dutton and Dukerich, 1991; Elsbach and Kramer, 1996); the perceived gap between current identity and desired future identity (Gustafson and Reger, 1995); the number of identities within the organization that are affected (Golden-Biddle and Rao, 1997; Pratt and Foreman, 2000); proactive leadership (Dutton and Dukerich, 1991; Gustafson and Reger, 1995; Gioia and Thomas, 1996; Golden-Biddle and Rao, 1997; 
Fox-Wolfgramm et al., 1998; Pratt and Foreman, 2000); perceptions of stakeholders (Dutton et al., 1994; Scott and Lane, 2000); and the degree to which an organization is preconditioned to respond to change (Brown and Starkey, 2000) can restrict or facilitate selection and implementation of response actions. Members' sense of identity (Dutton and Dukerich, 1991; Dutton et al., 1994), the organization's strategic orientation (Fox-Wolfgramm et al., 1998), and management perceptions (Dutton and Dukerich, 1991; Gioia and Thomas, 1996; Golden-Biddle and Rao, 1997; FoxWolfgramm et al., 1998), all serve as powerful filters for interpreting what is going on and what is to be done about it. These influences will initially cause culturally familiar routines to be activated in the face of perceived threats while constraining the degree to which other actions are considered acceptable (Dutton and Dukerich, 1991). For the purposes of this study, the organizational response of interest is the determination to accept and support or reject and challenge any given Basin governance system, whether in place or proposed.

Theories of culture, identity, and conflict answer the questions of "why" not addressed under structuration (Giddens, 1984) and social becoming (Sztompka, 1991). The deeply embedded assumptions regarding the correct way to think, feel, and perceive that underlay organizational culture explains why organizational members act the way they do (Schein, 2004). The strong psychological connection that develops in organizational members as they incorporate organizational values and goals as part of their own self-identity (Tajfel and Turner, 2004/1979; Ashforth and Mael, 1989; Dutton et al., 1984) explains why some organizational members hold the degree of 
intensity they do to given positions. Realistic and social competition theories explain the nature of conflict, whether over competing interests or due to the existence of other social groups (Coser, 1964; Campbell, 1965; Tajfel and Turner, 2004/1979; Pruitt and Kim, 2004). Identity theory explains why organizations respond to perceptions of threats or thwarted aspirations the way they do (Pruitt and Kim, 2004, others). Taken together, they greatly help explain the dynamic nature of the region's governance history. But the explanation is still incomplete in that these theories do not explain "how" the influences of culture and identity get translated into individual decision making.

Psychology: image theory and individual decision making

Left unanswered in culture and identity theory is the question of "how" individuals come to make the decisions they do and how organizational values are transferred between individuals and from generation to generation. Decision theory, especially "image theory," more fully answers the "how" questions in exploring the role values and beliefs play in individual decision making.

Giddens (1984) and Sztompka (1991) define agency as the capacity to effect changes to social systems and structures. They argue that individuals exercise agency individually or collectively based on a cognitive understanding of their social environment. Implied is an individual decision making process that leads one to actively challenge, actively defend, or passively acquiesce to the status quo. Consistent with Giddens' (1984) and Sztompka's (1991) concepts of agency, Beach and Mitchell (1998) argue that all decision making occurs at the individual level. 
Once the individual makes up their own mind, the result may be subject to adjustment when presented to and discussed with others. Groups, per se, do not make decisions, but rather serve as "the contexts within which individual members' decisions become consolidated to form a group product" (p. 9). At issue here is how those individual decisions come to be made and the influences in play as those decisions are tested and defended or modified during inter-group and intra-group interactions.

Traditional prescriptive models of decision making are not up to this task. Traditional decision theory, borrowing from economic theory, presumes decision makers engage in a relatively formal analytical process, evaluating the consequences of available actions to maximize utility. Although simple and easy to model, the prescriptive model relies on assumptions not clearly borne out by empirical research and does not fully reflect how decisions are actually made (Mitchell, Rediker, and Beach, 1986). Traditional theory overly simplifies the "messiness" of day-to-day decision making through abstraction. It is rooted in a linear decision tree model, where decision move only in one direction. Individual values, motives and preferences (which may change over time) are dismissed. Time is simplified into "now" (point at which decision is made) and "later" (when result is achieved). There is no continuum over which things can change (Connolly and Beach, 1998).

Beach and Mitchell (1998) argue that, in practice, these formal analytical strategies are seldom used. As a practical matter, formal utility-based models are too time consuming and resource intensive for simple decisions and too "coldly intellectual" (p. 6) for important ones. Furthermore, traditional analytical models 
presume a search for the "best" of a range of plausible options, with "best" being defined as the one that maximizes utility. Consequently, they do not explain situations in which only one option is under consideration. Left unaddressed is the process by which the array of options is first determined and the implication if that process results in only one plausible option. Actual decision making is most often based on doing the "right" thing, even which this "right" option is not in the individual or organization's best interest. They observe that in those cases where a formal analytical decision model is used, decision makers will frequently reject the results the results run counter to their concept of "rightness."

In summary, traditional utility-based theory is prescriptive in that it identifies how decisions should be made, but falls short of accurately describing how decisions are actually made. "In both individual and organizational settings, the problems are the same: decision making is much richer and more subtle than the formal models would suggest, while at the same time it is less thoroughly thought through and less premeditated than the formal models demand" (Mitchell, Rediker, and Beach, 1986, p. 295).

Connolly and Beach (1998) identify other decision making models that have challenged the traditional model and attempted to explain decision making complexity. Descriptive models based on theories of "cognitive situation assessments," "decision through argument," and "decision through exploration" all involve situation assessments, past experience, and causal thinking. "Decision cycle theory" is more incremental, arguing that one's view of a given situation is modified 
through the experience of implemented behavior. Subsequent decisions are based on that experience, with subsequent behavior modified accordingly. Cognitive processes allow for learning that guides and justifies decisions through time. These theories address the "messiness" of actual decision making, but still do not fully address the role of values in shaping the selection of alternatives and ultimate decisions made. As such - like traditional decision theory - they are not so much wrong as incomplete (Connolly and Beach, 1998).

"Image theory" (Mitchell, Rediker, and Beach, 1986; Beach and Mitchell, 1987 and 1998) holistically incorporates the essential elements of these theories (Connolly and Beach, 1998). Image theory assumes decision makers use three "schematic knowledge structures," or "images" to organize and frame their thinking (Beach and Mitchell, 1998, p. 12).

The first of these is the "value image." The value image is composed of "principles." Principles are the imperatives for individual behavior and the behavior of the organization(s) to which the decision maker belongs. They are the decision maker's beliefs, morals, ethics, and social conventions. These "principles" are "self evident truths" that must be respected, thus providing a "rigid criteria" by which the rightness or wrongness of a goal or plan is judged (Beach and Mitchell, 1998, p. 9). As such, they "serve to internally generate candidate goals and plans for possible adoption" as well as criteria against which the goals and plans of others may be evaluated (Beach and Mitchell, 1998, p. 12, emphasis in original). Principles begin to 
be developed in childhood and evolve over the course of one's life. As such, they are inherent to one's self-image and sense of identity. ${ }^{175}$

Principles can run the gamut from specific to general; from the compelling to the trivial; from admirable to abhorrent; from rational to irrational. For example, greed and accumulation of personal power can be as important a principle to some as altruism and charity are to others. Regardless, principles form the foundation upon which all decisions are based. As such, the ultimate legitimacy of decision outcomes is defined by the degree to which the outcomes conform to principles. Goals and strategies not in accordance with principles - whether internally or externally generated - will be deemed unacceptable. More fundamentally, choice alternatives not consistent with the decision maker's principles will be rejected from further consideration regardless of utilitarian value (Beach and Mitchell, 1998; Beach and Connolly, 2005).

The second image is the "trajectory image" consisting of the goals for the future as generated from the decision maker's principles. These goals are not static, however, and extend through time. Goals can be specific or abstract. The more abstract the goal, however, the more difficult the selection of plans and strategies become (Beach and Mitchell, 1998; Beach and Connolly, 2005).

\footnotetext{
${ }^{175}$ In earlier versions of image theory, the authors specifically identify "self-image" as one of four images used in decision making. They describe self-image and its constituent principles as reflecting how one sees oneself and as precepts for the conduct of one's life. They represent personal beliefs, values, ethics, and morals that one intuitively accepts as true. See Mitchell, Rediker, and Beach, 1986, and Beach and Mitchell, 1987. In later versions, the number of images is reduced to three, with the concept of "self-image" apparently subsumed into the "value image" described above. See Beach and Mitchell, 1998.
} 
The third image is the "strategic image" consisting of the plans adopted for achieving the trajectory image's goals. Each plan is an "abstract sequence of potential activities, beginning with goal adoption and ending with goal attainment" (Beach and Mitchell, 1998, p. 13; Beach and Connolly, 2005).

Embedded within the three images are two types of decision. The first is the "adoption decision" which answers whether the goal or strategy is reasonable and achievable. The second decision is termed the "progress decision." This is the decision to proceed with the adopted choice based on whether the desired goal will be achieved. Consequently, the "progress decision" recurs over time as experience grows and new information is acquired (Beach and Mitchell, 1998; Beach and Connolly, 2005).

Both the "adoption" and "progress" decisions are subject to two tests. The first is termed "compatibility testing." Compatibility testing screens candidate goals and plans against the three "images," identified above. This screening depends exclusively on whether the choice presented violates the decision maker's principles. This comparison against principle is not weighted or nuanced in any way - it is solely an “accept or reject” determination, and might well occur subconsciously. In progress decisions a determination of non-compatibility will usually lead to adjustments in the plan rather than automatic withdrawal. The second test is termed "profitability testing." Profitability testing is used when multiple candidates survive compatibility testing. The decision maker will engage in some analytical method or strategy (which 
may be formal or informal, to include traditional decision theory) to select the "best" of the surviving candidates (Beach and Mitchell, 1998; Beach and Connolly, 2005).

Connolly and Beach (2005) amplified on other precepts introduced in early image theory publications. Framing consists of applying relevant elements of the three images to situation at hand. All decisions are made individually; there is no such thing as a "group" decision, per se. Group decisions are agreements reached as each member of the group processes options through their image processes. Agreement is reached at the point when either the option(s) is (are) modified to be congruent with each party's principles, goals, or plans or the individuals involved modify their goals and plans to be consistent with the rest of the group. This modification of options and/or principles, goals, and plans did not occur in the CRBF experience, contributing to its failure.

The basic precepts of image theory are illustrated in Figure B-2. ${ }^{176}$ Individual decision makers frame situations within their experience and knowledge of past and present events and select (often intuitively) those principles (from the values image), goals (from the trajectory image) and plans and tactics (from the strategy image) as applicable to the circumstances at hand. Any given choice is thus subject to the "compatibility test" to determine whether the options at hand violates the decision maker's principles, goals, or plans. If only one option survives this screening, it is adopted. If more than one option survives, it is then subjected to a "profitability" test of varying degrees of formality and consistent with traditional theory to determine

\footnotetext{
${ }^{176}$ This figure first appears in Weatherly and Beach's 1998 essay (presented in Beach, 1998) on the relationship between organizational culture and decision making. Although appearing long after image theory's first formulation, it illustrates the theory as first envisioned very well.
} 
which provides the best outcome (as defined in terms of principles, goals, and values). If no options past these tests, it is possible for the decision maker to redefine and adjust their principles, goals, and plans depending on the criticality of the decision and the situation at hand.

Figure B-2.

Image Theory

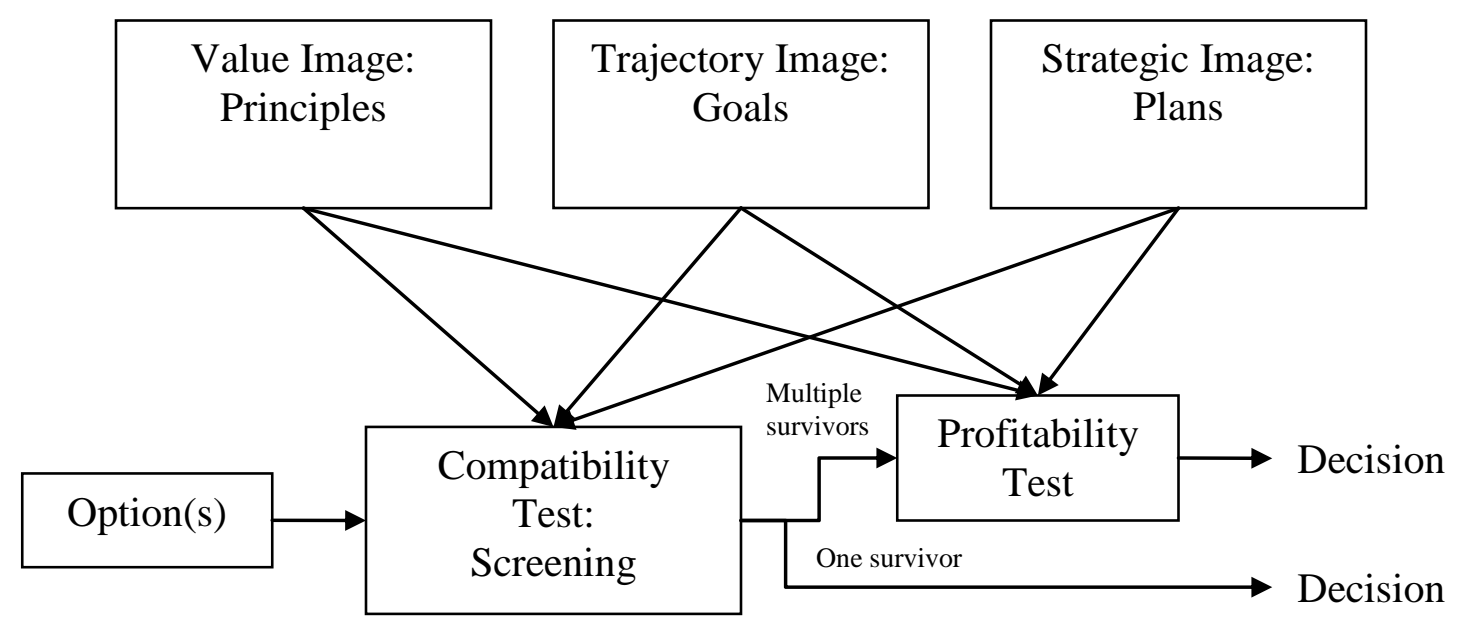

From Weatherly and Beach, 1998, (Adapted from figure 14.1, p. 212)

Weatherly and Beach (1998) use image theory to examine the relationship between organizational culture and the decisions made within that organization. Their intent is to propose a theoretical link between culture and decision making and to test the implications of that link. Citing the work in organizational culture of Schein, Schneider, and Trice and Beyer, ${ }^{177}$ authors define culture as a body of

${ }^{177}$ Schein, E. (1985). Organizational culture and leadership. San Francisco: Jossey-Bass. Schneider, B. (Ed.). (1990). Organizational culture and climate. San Francisco: Jossey-Bass. 
"organizationally relevant beliefs and values that are mutually understood and subscribed to by its members." They summarize the work of these authors in this way: Being grounded in values, culture prescribes what is "true, necessary, and desirable" and thus dictates goals and the strategies considered acceptable. Likewise, it prescribes what is "false, unnecessary, and undesirable" and, thus, "goals and actions that one should not pursue oneself and that one ought to resist when proposed by others" (Weatherly and Beach, quotes from p. 211).

Weatherly and Beach (1998) illustrated both the fundamentals of image theory and the relationship of image theory to culture as shown in Figure B-3. ${ }^{178}$ In their construct, the firmly-held principles of the decision maker's value image are analogous to the culture of the organization. Similarly, the organizational vision and selected strategies are similar to the decision maker's trajectory and strategic images, respectively. Any decision option is subject to a compatibility screening using the constituents of the value, trajectory, and strategic images as screening criteria. Should multiple choice options survive the compatibility test, they are subjected to formal or informal profitability testing, again based on the decision maker's images, to determine which choice represents the best decision. In cases where only one candidate survives compatibility screening, that option becomes the decision with

Trice, H.M. \& Beyer, J.M. (1993). The cultures of work organizations. Englewood Cliffs, NJ: Prentice-Hall.

\footnotetext{
${ }^{178}$ Figure 8-3 is shown as essentially presented by the authors. It is, however, a bit misleading in that it visually suggests a linearity and finality to decisions that is not consistent with the fluidity described in Beach and Mitchell, 1998. What is apparently missing in the diagram are feedback loops from decisions as they get recycled through the process once new information becomes available, decisions are met with unforeseen obstacles, or checks are made to ensure the goals and strategies are on track.
} 
further analysis to be conducted over time as new information comes available

(Weatherly and Beach, 1998).

Figure B-3

An Image Theory Analysis of Organizational Culture ${ }^{179}$

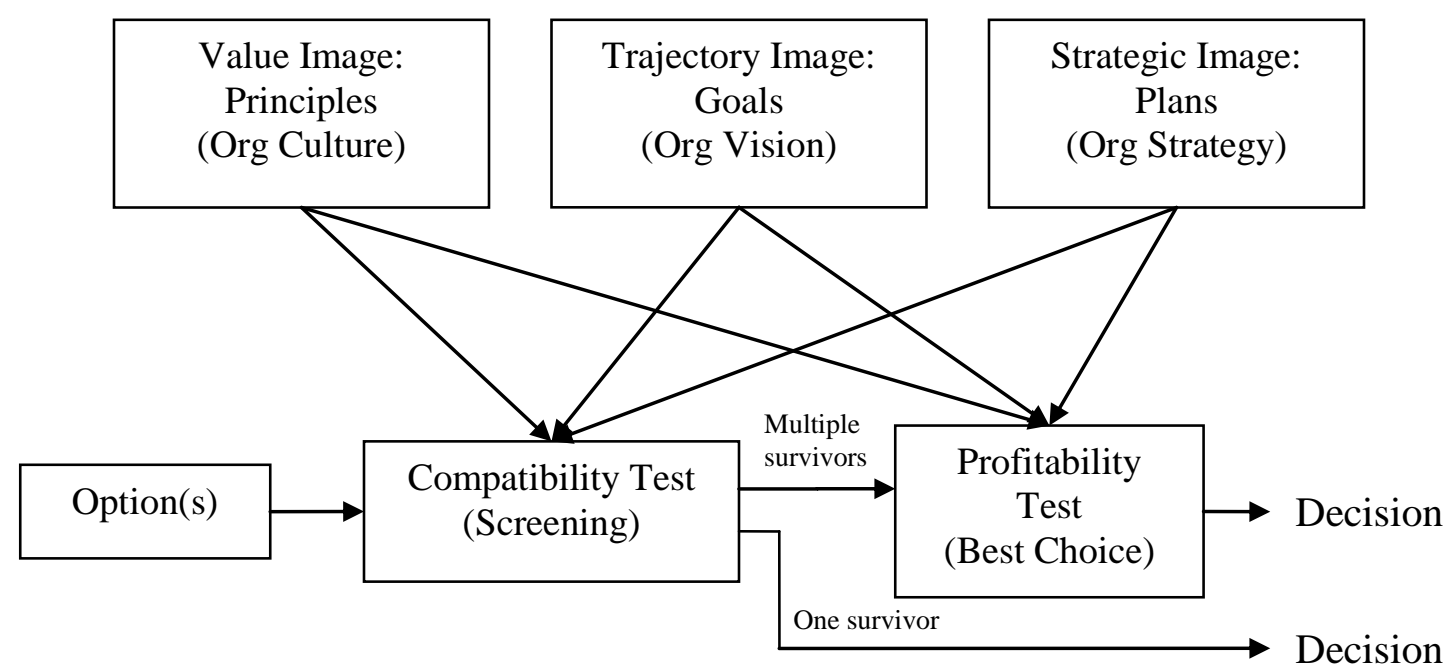

(From Weatherly and Beach (1998), Figure 14.1, p. 212)

Although written from an organizational perspective, this does not violate Beach and Mitchell's (1998) assertion that all decisions are made individually. Rather, it articulates the role that organizational culture plays on those individual decisions. Weatherly and Beach (1998) argue that "potential goals for inclusion in the vision and tactics for inclusion in the strategic plan must not violate the organization's culture, its existing vision, or its existing plans(s)" (p. 213) and that any new ideas

\footnotetext{
${ }^{179}$ Figure B-3 is shown as essentially presented by the authors. It is, however, a bit misleading in that it visually suggests a linearity and finality to decisions that is not consistent with the fluidity described in Beach and Mitchell, 1998. What is apparently missing in the diagram are feedback loops from decisions as they get recycled through the process once new information becomes available, decisions are met with unforeseen obstacles, or checks are made to ensure the goals and strategies are on track.
} 
must be compatible with members' image of themselves as an organization and their goals for the future. Since organizational members share these images, individual decisions will tend to be compatible with member principles even when made in isolation. The implication is that, consistent with Schein (2004), member images and principles will effect member acceptance or rejection of decisions made on the organization's behalf by their leaders. Decisions or ideas that are not compatible with member images risk the leader losing legitimacy in the eyes of those members.

Image theory thus explains "how" values underlying theories of organizational culture and identity are processed into decisions, positions, and actions by individuals. Adding this to the "what" as provided by theories of structuration (Giddens, 1984) and social becoming (Sztompka, 1991), and the "why" provided by theories of culture (Schein, 2004) and identity (Cooley, 2004/1902; Mead, 2004/1934; Goffman, 2004/1959; Tajfel and Turner, 2004/1979; Albert and Whetten, 1985; Ashforth and Mael, 1989) a comprehensive theoretical framework can be offered to explain the evolution of Columbia Basin governance in general and the rise and fall of the CRBF in particular.

\section{Why an Integration of Multiple Theories is Necessary}

There is no single body of theory that adequately addresses the question as to why the CRBF failed. As wide-ranging as they are, structuration (Giddens, 1984) and social becoming (Sztompka, 1991) provide only incomplete theoretical explanations for the regional governance experience. They explain "what" happened through the 
role of individual and collective agents in shaping systems and structure, the influence of systems and structure on individuals, and the historical connectivity between structures. To a limited extent, they also explain "why" things happened the way they did in terms of the roles of individual autonomy and freedom and the cognitive consciousness of members in their own social phenomena. Schein's (2004) theory of organizational culture helps flesh out the concept of structure and helps further explain how normative expectations influence organizational member behavior. But, while acknowledging the varying degrees of intensity in individual commitment, neither Giddens (1984) or Sztompka (1991) explain what motivates some members of a social group to act as change agents while others act just as passionately as agents of the status quo. Nor do they explain "how" individuals process the systems and structures of the social groups in which they are members when rendering individual decisions.

Similarly, theories of interest based conflict, centered on competition over resources or other conflicts of interest (Coser, 1964) do not account for situations where no such conflict of interest exist (Tajfel and Turner, 2004/1979). Theories of individual and group identity help fill in the "why" gaps in the theories of structuration and conflict.

Theories of individual identity (Cooley, 2004/1902; Mead, 2004/1934; Goffman, 2004/1959) explain the concept of individual self within social settings. Social and organizational identity speak to the strong psychological connection that can develop in organizational members as they incorporate organizational values and goals as part of their own self-identity (Tajfel and Turner, 2004/1979; Ashforth and 
Mael, 1989; Dutton et al., 1984) and explain why some organizational members hold the degree of intensity they do to given organizational positions and values (i.e. a system's normative structures). Theories of social competition, grounded in social identity, expand the understanding of the nature of conflict and argue that identitybased competition can either exacerbate conflict over competing interests or lead to conflict in its own right merely based on the existence of other social groups (Tajfel and Turner, 2004/1979; Ashmore, Jussim, and Wilder, 2001; Pruitt and Kim, 2004; Eagly, Baron, and Hamilton, 2004). Identity theory further explains why organizations respond to perceptions of threats or thwarted aspirations the way they do (Albert and Whetten, 1985; Dutton et al., 1994; Fox-Wolfgramm et al., 1996; Dutton and Dukerich, 1991; Gustafson and Reger, 1995; Elsbach and Kramer, 1996; Gioia and Thomas, 1996; Golden-Biddle and Rao, 1997; Scott and Lane, 2000; Pratt and Foreman, 2000; Brown and Starkey, 2000; Pruitt and Kim, 2004). Taken together, they greatly help explain why the interrelationship between the social group and the individual occurs the way it does. But the explanation is still incomplete in that these theories do not explain "how" the influences of system structure, agency, and identity get translated into individual decision making.

Decision theory, especially "image theory," more fully answers the "how" questions in exploring the role values and beliefs play in individual decision making. Giddens (1984) and Sztompka (1991) define agency as the capacity to effect changes to social systems and structures. They argue that individuals exercise agency individually or collectively based on a cognitive understanding of their social 
environment. Implied is an individual decision making process that leads one to actively challenge, actively defend, or passively acquiesce to the status quo.

Consistent with Giddens' (1984) and Sztompka’s (1991) concepts of agency, Beach and Mitchell (1998) argue that all decision making occurs at the individual level. Once the individual makes up their own mind, the result may be subject to adjustment when presented to and discussed with others. Groups, per se, do not make decisions, but rather serve as "the contexts within which individual members' decisions become consolidated to form a group product" (p. 9). At issue here is how those individual decisions come to be made and how the influences of structure and group identity come to play as those decisions are tested and defended or modified during inter-group and intra-group interactions.

Traditional prescriptive models of decision making and more recent naturalistic models are not up to this task. Traditional decision theory, borrowing from economic theory, presumes decision makers engage in a relatively formal analytical process, evaluating the consequences of available actions to maximize utility. Although simple and easy to model, the prescriptive model relies on assumptions not clearly borne out by empirical research and does not fully reflect how decisions are actually made, (Mitchell, Rediker, and Beach, 1986). Furthermore, these structured models are seldom used in practice. They are too time consuming and resource intensive for simple decisions, too "coldly intellectual" (p. 6) for important ones, and assert that actual decision making is often based on doing the "right" thing, even which this "right" option is not in the individual or organization's best interest. 
They observe that in those cases where a formal analytical decision model is used, decision makers will frequently reject the results the results run counter to their concept of "rightness" (Beach and Mitchell, 1998). Similarly, while descriptive models based on theories of "cognitive situation assessments," "decision through argument," "decision through exploration," and "decision cycles" address the "messiness" of actual decision making, they still do not fully address the role of values in shaping the selection of alternatives and ultimate decisions made. As such - like traditional decision theory - they are not so much wrong as incomplete (Connolly and Beach, 1998).

The empirical research on image theory (Beach, 1996, 1998) tends to focus on decision makers situated under relatively passive circumstances. Decision makers are either portrayed as facing problems imposed upon them. The studies of Beach and his colleagues do not report on situations in which the subject is aggressively pursuing a predetermined agenda or outcome.

There is another body of theory, termed "motivated reasoning," that does. Motivated reasoning theory states that motivation to a particular belief or outcome affects reasoning through "reliance on a biased set of cognitive processes: strategies for accessing, constructing, and evaluating beliefs." These processes appear in two major categories: those in which the motive is to arrive at an accurate (or factually correct) conclusion and those in which the motive is to arrive at a particular, directional conclusion (or predetermined outcome). This second case is constrained in that people wishing to arrive at particular conclusion construct justifications that 
would persuade dispassionate observers. These justifications, however, is based on memories of beliefs and rules that support the conclusion and creative combinations of accessed knowledge. The individual or people in question believe the arguments thus construed to be objective and factually based, missing the point that their very process is biased by the goals they are attempting to achieve. This is not cognitive hypocrisy, but rather unconscious decision making based on only a relevant subset of the body of knowledge and beliefs available (Kunda, 1990).

Motivated reasoning has been applied to explain numerous situations, such as perceptions among American Democrats and Republican Party members regarding justifications for and support of the Iraq War (Jacobson, 2010). There are clear parallels between motivated reasoning theory and image theory. Image theory's grounding in the way in which people access those personal principles, goals, and plans relevant to a given situation (Beach, 1998) is remarkably consistent with motivated reasoning's use of belief's and strategies in arriving at desired conclusions. As such, this body of literature will not be further examined here. ${ }^{180}$

Image theory integrates the values underlying identity theory with individual decision making. It also offers insight into the relationship between organizational culture (Schein, 2004) and individual agency (Giddens, 1984; Sztompka, 1991). Weatherly and Beach (1998) illustrate the relationship of image theory to culture as shown in Figure B-2. In this construct, the firmly-held principles of the decision

\footnotetext{
${ }^{180}$ The literature on motivated reasoning theory was identified late in this study effort and is not reviewed here in more detail due to its similarities with image theory and also in the interests of time. A cursory web search revealed that the literature on motivated research is extensive in the psychology and social psychology fields. Its roots appear at least partially grounded in identity theory.
} 
maker's value image are analogous to the culture of the organization and, by extension, other expectations of system structure. Similarly, the organizational vision and selected strategies are similar to the decision maker's trajectory and strategic images, respectively. Any decision option is subject to a compatibility screening against both organizational and individual value, trajectory, and strategic images. Should multiple choice options survive the compatibility test, they are subjected to formal or informal profitability testing, again based again on the organization's and decision maker's images, to determine which choice represents the best decision. In cases where only one candidate survives compatibility screening, that option becomes the decision with further analysis to be conducted over time as new information comes available (Weatherly and Beach, 1998).

Image theory thus explains "how" the values underlying theories of organizational culture and identity are processed into decisions, positions, and actions by individuals. Adding this to the "what" as provided by theories of structuration (Giddens, 1984) and social becoming (Sztompka, 1991), and the "why" provided by theories of culture (Schein, 2004) and identity (Cooley, 2004/1902; Mead, 2004/1934; Goffman, 2004/1959; Tajfel and Turner, 2004/1979; Albert and Whetten, 1985; Ashforth and Mael, 1989) completes the explanation as to "how" agents come make the decisions they do. From this combined set of theories, coupled with observations drawn from the governance history presented in Chapters 3 through 7, a comprehensive theoretical framework can be offered to explain the evolution of Columbia Basin governance in general and the rise and fall of the CRBF in particular. 
In summary, structuration and social becoming theory explain what happens as social organizations emerge and evolve and partially explains why they do so. Social conflict is at least one vehicle through which social evolution occurs in the praxis process. Theories of individual, social, and organizational identity complete the explanation for why agents choose to engage in various issues and the intensity of commitment to social organization values and objectives. Image theory explains how individuals come to accept social values and norms and incorporate them into ones sense of self. These theories provide the building blocks from which a framework can be constructed to guide future research into the region's governance paradox.

\section{$\underline{\text { Research Framework }}$}

\section{A generalized model of governance structuration.}

Figure 8-4 presented the pattern of structuration for Columbia Basin governance systems as found in the historic record. This figure was generalized as shown in Figure 8-5. The discussion which follows discusses the model with respect to the findings of this study on governance and the theories introduced above. This generalized model is not limited to situations of governance. It could, for example, be used to explain the evolution of a local Friday night poker club, a government agency, or any other system. 
Theories of structuration (Giddens, 1984; Sztompka, 1991) hold that all systems and their associated structures exist in the flow of historical time, with any given system having been built on what came before even as it serves as the foundation for what will come later. This point is illustrated in the box in Figure 8-5 entitled "Existing Systems and Structures". Each existing system is comprised of its own set of structures. Structures include the formal and informal rules and expectations guiding social behavior (Giddens, 1984). These include the normative expectations of culture (Schein, 2004) and organizational identity (Albert and Whetten, 1985; Ashforth and Mael, (1989). These structures provide stability to the group over time, allow for routinization of mundane tasks, and provide group members a sense of security (Giddens, 1984; Sztompka, 1991); contribute to an individual's sense of self (Cooley, 2004/1902; Mead, 2004/1934); and provide interpretive lenses that shape how members think about, feel, and perceive other systems and events within their environment (Schein, 2004; Albert and Whetten, 1985; Tajfel and Turner, 2004/1979).

The relationship among systems can be in alliance or in conflict. Conflictual relationships can be due to competition over resources and interests and/or issues of social identity (Giddens, 1979; Tajfel and Turner, 2004; Pruitt and Kim, 2004). These existing relationships also consist of patterns of dominance and subjugation as more powerful systems are able to further their interests at the expense - perceived or actual 
- of others (Giddens, 1984) thus frustrating the aspirations of weaker systems and creating the potential for future conflict (Pruitt and Kim, 2004).

Internally, each system will evolve through time as established systems and structures are either adjusted or defended in response to actions and agency exercised by its members (Giddens, 1984; Sztompka, 1991) and internal movements and counter movements (Sztompka, 1991) - in effect going through its own process of structuration internally. Such internal evolutions occur consistent with member principles (Beach, 1990, 1996, 1998) and organizational values (Schein, 2004) and identity (Albert and Whetten, 1985). This internal structuration is unlikely to rise to the level of attention of other systems unless the other systems' senses of identity and/or interests are challenged (Albert and Whetten, 1985; Fox-Wolfgramm, Boal, and Hunt, 1998; Scott and Lane, 2000).

The stability of the existing arrangement of systems will continue until challenged by situation of sufficient criticality to threaten the status quo (Giddens, 1984) as portrayed in the box labeled "Critical Situation." Critical situations may call the existing patterns of internal and external relationships into question by challenging member identity attachments to the organization (Albert and Whetten, 1985; Elsbach and Kramer, 1996; Fox-Wolfgramm, Boal, and Hunt, 1998) or challenge external relationships by creating opportunities to reopen unresolved differences, create new issues of conflict over resources or interests, or exacerbating conflicts due to identity (Ashmore, Jussim, and Wilder, 2001; Pruitt and Kim, 2004; Eagly, Baron, and Hamilton, 2004). 
Critical situations may or may not result in conflict. For example, the ascendancy of the Republicans to a majority in Congress in 1943 resulted in the defunding of New Deal central planning entities, to include the Pacific Northwest Regional Planning Commission. This occurrence did not result in conflict; the participants to the PNWRPC at the regional and national levels met and voluntarily reformed themselves into the Columbia Basin Inter-Agency Committee (Bessey, 1963; Scheufele, c.1970). Conversely, the hydro-thermal crisis and Bonneville Power Administration's notice of insufficiency in 1976 presented a situation where long suppressed tribal, commercial, and sport fishery concerns over the impact of the hydropower system on regional fisheries resulted in creation of the (now named) Northwest Power and Conservation Council which gave those interests more influence over operational decision making (Blumm, 1982; Hemmingway, 1983; Pope, 2008).

Regardless of whether or not conflict occurs, institutional and other regional leaders will attempt to find resolution. Where conflict does occur, organizational identity and individual principles will serve to reinforce the righteousness of organizational positions and serve as filters through which members interpret the issues and events at hand (Albert and Whetten, 1985; Ashforth and Mael, 1989; Dutton and Dukerich, 1991; Elsbach and Kramer, 1996; Beach, 1998; Ashmore, Jussim, and Wilder, 2001; Pruitt and Kim, 2004; Eagly, Baron, and Hamilton, 2004). Critical situations do not necessarily need to result in conflict between systems; they can serve simply as catalysts for internal change within a system (Dutton and Dukerich, 1991; Goia and Thomas, 1996; Golden-Biddle and Rao; 1997). 
Consequently, although regional leaders may be seeking a rational and objective way to resolve the issues at hand, agents engaging in resolution negotiations come to the negotiation table with a personal suite of principles and values heavily informed by institutional worldview, organizational culture, and social identity (Tajfel and Turner, 2004/1979; Schein, 2004; Beach and Connolly, 2005).

Critical situations affecting relationships among systems, whether involving conflict or not, will lead to calls for rational resolution by system leaders (Hypothesis 1). Organizations will select agents to engage in negotiations to defend organizational values and values and obtain an outcome consistent with those values and interests (Hypothesis 2). Selected agents will enter into these discussions influenced by organizational expectations as well as their own sense of identity, principles, goals, and plans (Hypothesis 3; Beach 1990, 1996, 1998). If the catalytic situation is critical enough to fundamentally threaten the values and interests of the negotiating parties, then the senses of social identity at risk may be altered as may the image goals and plans of individual agents (Goia and Thomas, 1996; Fox-Wolfgramm, Boal, and Hunt, 1998; Scott and Lane, 2000; Beach, 1990, 1996, 1998) ${ }^{181}$ and compromises reached that result in new systems and/or reconstructed patterns of relationships. Over time, as these new systems patterns become established, they will become the foundations for future changes in the face of new critical situations (Giddens, 1984; Sztompka, 1991). If the situations prove to be not of sufficient criticality, the old patterns and systems will likely continue.

\footnotetext{
${ }^{181}$ Alternatively, identity forces can cause interpretations of events that ignore actual threats and foreclose the possibility of resolution (Dutton and Dukerich, 1991; Elsbach and Kramer, 1996).
} 
Figure B-4 illustrates how the bodies of theory discussed above can be combined with the historical record of Columbia Basin governance to help explain the inception, rise, and collapse of the Columbia River Basin Forum focusing on examination of the causes for the structural weaknesses of the CRBF's memorandum of agreement. Structuration, identity, and decision theories combined establish the linkage between group values and interest and individual decisions and actions. This in turn explains the how the institutional representatives selected to negotiate and later execute the CRBF MOA behaved in the way they did to create such a weak organizational structure leading to the system's ultimate failure. The historical record of governance change recounted in Chapters 3 through 7 and illustrated in Figure 8-4 (and generalized in Figure 8-5) provides the social and political context that both provided the background from which the CRBF emerged and shaped the institutions whose agents participated in the CRBF development and operation.

\section{$\underline{\text { Research Approach }}$}

The creation of the CRBF MOA provides a unique opportunity to apply the theoretical concepts identified above against the hypotheses presented in Chapter 8 . The research methodology to test these hypotheses should consist of both inductive and deductive components. The study's unit of analysis would be the organizations represented in the development of CRBF MOA; the unit of observation would be the organizational representatives to MOA development proceedings. The elements of evidence to be obtained by interview will be collected using structured, open ended 
Figure B-4.

Theoretical Framework for Analysis of Governance Structuration

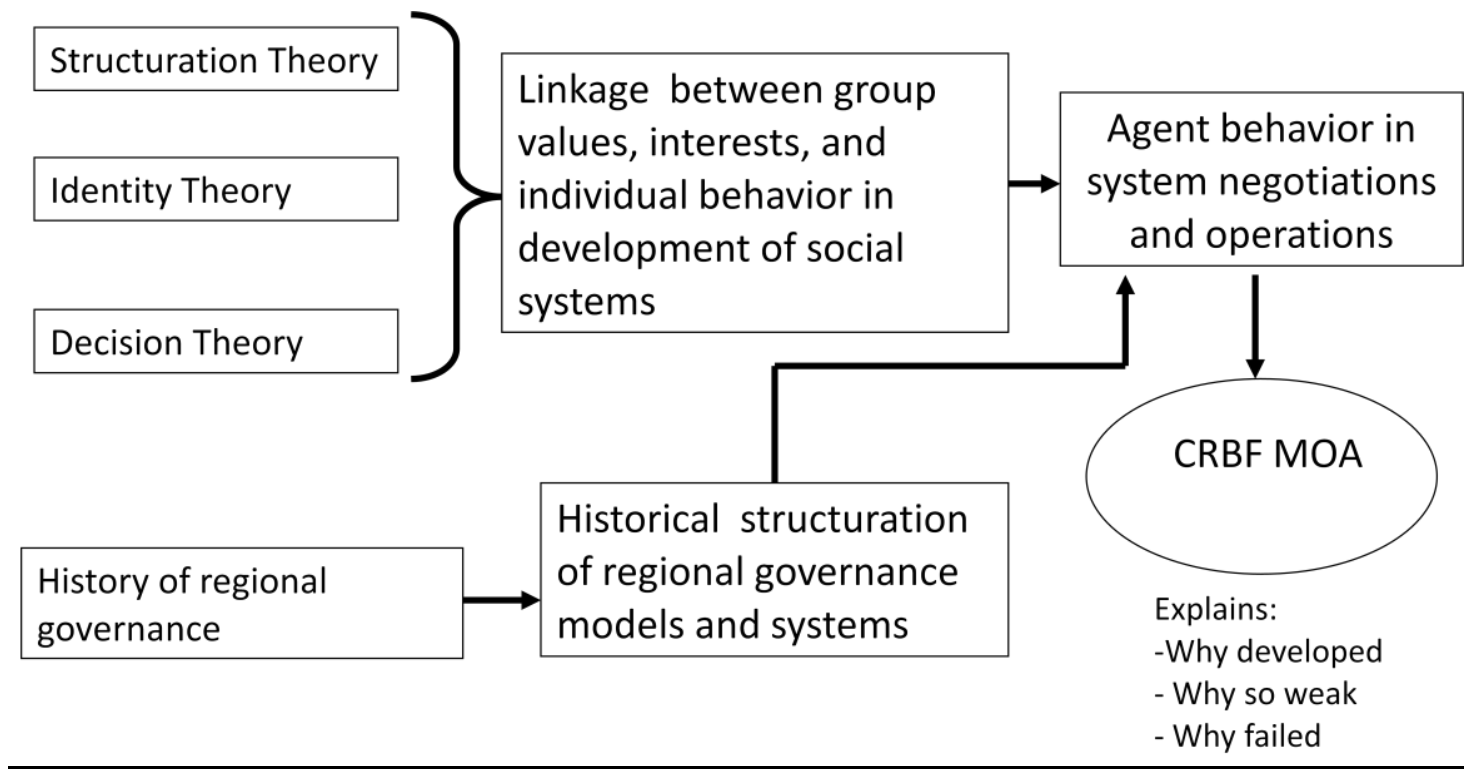

interview questions will be administered as prescribed by Patton (2002). In effect, the questions are used as an interview guide versus a rigidly followed script to allow fullest possible identification of participant values, predispositions, and beliefs. Recommended participants are to be selected from the formally appointed representatives to the $\mathrm{CRBF}$ and close observers, such as the group facilitator and reporters who attended most $\mathrm{CRBF}$ meetings. Basic themes to be explored in the interviews include:

- What did the organization / institution that you represented expect the CRBF to accomplish?

- What did the organization / institution that you represented think it would accomplish? 
- What did you personally expect the CRBF to accomplish?

- What did you personally think it would accomplish?

- What did you / your organization believe to be the salient issues that needed to be addressed by the CRBF?

- To what degree were you free to negotiate those issues within the CRBF?

- To what degree were you restricted from negotiating issues within the CRBF? This effort will, by its nature, rely heavily on qualitative techniques. As such, it faces challenges of validity and generalizability. In qualitative research, validity has been described in terms of trustworthiness (Krefting, 1999) which will be assessed in the eye of the reader. Several authors (Johnson, 1999; Maxwell, 2002; Krefting, 1999) offer frameworks for assessing qualitative work. Others (Schofield, 2002; Lincoln and Guba, 2002) suggest validity is best achieved through careful selection of methodology. Krefting (1999) offers a strategy for achieving validity that consists of credibility, transferability, dependability, and confirmability. But, Maxwell (2002) suggests, the only elements of validity under the direct control of the researcher are descriptive validity and interpretive validity. The upshot, according to Maxwell (2002), is that good qualitative work must be transparent in its articulation of author background, potential biases, and selected methodology. It must also be relentless in its accurate representation of findings. Authenticity and trustworthiness can be enhanced through transparency of method and use of direct quotation evidence to highlight key points. The point is great care must be taken with study and instrument design to ensure the results are supportable and applicable. 
Appendix Summary

This study treats the series of governance systems experienced by the Northwest as regional social organizations that, consistent with Giddens (1984) and Sztompka (1991), have evolved over time within a context of the social and political environments of the day, salient regional issues, and institutional competition. The deeply held beliefs and values underlying the cultures of those institutions (the worldviews), the sense of social identity shared by their members, and the principles held by their members influenced the positions and perceptions of institutional agents participating in the negotiations over those various systems. Consequently, understanding the Columbia River Basin Forum and its predecessors requires an understanding of the values and worldviews of the regional institutions engaged in their creation.

Neither structuration nor social becoming offers a clear empirical roadmap through which their assumptions and conclusions can be tested. Indeed, Giddens' structuration theory has been critiqued as "inherently unempirical" (Gregson, 1989) with Giddens (1984 and 1989) appearing ambiguous (at best) on whether there is even a need for empirical study.

A broader study of Columbia Basin governance should be premised on the grounds that individual decisions and perspectives, as played out in negotiations over the CRBF MOA, were shaped by the social identity and worldviews of the participants and the institutional culture of the organizations they represented. The methodological challenge is how to make this connection. 
REFERENCES:

Theoretical Framework for Future Research

Agor, W.H. (1992). Book review: image theory: decision making in personal and organizational contexts. Journal of Organizational Behavior, 13 (5), 533-534.

Albert, S., Ashforth, B. E., \& Dutton, J. E. (2000, January). Organizational identity and identification: charting new waters and building new bridges. Academy of Management Review, 25 (1), 13-17.

Albert, S., \& Whetten, D. A. (1985). Organization identity. In L. L. Cummings \& B. M. Straw (Eds.), Research in Organizational Behavior, Vol. 7 (pp. 263-295). Greenwich, CT: JAI.

Archer, M. (1997). Morphogenesis versus structuration: on combining structure and action. In C.G.A. Bryant and D. Jary (Eds.), Anthony Giddens: Critical Assessments, (pp. 25-52). New York: Routledge.

Ashforth, B. E., \& Mael, F. (1989). Social identity theory and the organization. Academy of Management Review, 14 (1), 20-29.

Ashmore, R.D., Jussim, L., \& Wilder, D. (Eds.) (2001). Social identity, intergroup conflict, and conflict reduction. New York: Oxford University Press.

Barley, S.R. \& Tolbert, P.S. (1997). Institutionalism and structuration: studying the links between action and institution. Organization Studies, 18 (1), 93-117.

Bauman, Z. (1989). Hermeneutics and modern social theory. In D. Held and J.B. Thompson (Eds.), Social theory of modern societies, Anthony Giddens and his critics, (pp. 34-55). Newcastle, GB: University of Cambridge Press.

Beach, L.R. (1990). Image theory: decision making in personal and organizational contexts. Chichester, UK: John Wiley \& Sons, Ltd.

Beach, L.R. (Ed.) (1996). Decision making in the workplace: a unified perspective. Mahwah, NJ: Lawrence Erlbaum Associates, Inc.

Beach, L.R. (Ed.) (1998). Image theory: theoretical and empirical foundations. Mahwah, NJ: Lawrence Erlbaum Associates, Inc.

Beach, L.R. and Connolly, T. (2005). The psychology of decision making: people in organizations ( $2^{\text {nd }}$ Ed.). Thousand Oaks, CA: Sage Publications. 
Beach, L.R. and Mitchell, T.R. (1987). Image theory: principles, goals, and plans in decision making. Acta Psychologica, 66, 201-220.

Beach, L.R. \& Mitchell, T.R. (1998). The basics of image theory. In L.R. Beach (Ed.), Image Theory: Theoretical and Empirical Foundations, (pp. 3-18). Mahwah, NJ: Erlbaum Associations, Inc.

Bellah, R. N., Madsen, R., Sullivan, W. M., Swidler, A, \& Tipton, S. M. (1996). Habits of the heart: individualism and commitment in American life (updated edition). Berkeley, CA: University of California Press.

Bernstein, R.J. (1989). Social theory as critique. In D. Held and J.B. Thompson (Eds.), Social theory of modern societies, Anthony Giddens and his critics, (pp. 19-33). Newcastle, GB: University of Cambridge Press.

Boothroyd, H. (1991, May). Review: image theory: decision making in personal and organizational contexts. The Journal of the Operational Research Society, 42 (5), 424-425.

Boyne, R. (1997). Power, knowledge, and social theory: the systematic misrepresentation of contemporary French social theory in the work of Anthony Giddens. In C.G.A. Bryant and D. Jary (Eds.), Giddens' Theory of Structuration: A Critical Appreciation, (pp. 52-73). New York: Routledge.

Brougham, R.R., \& Walsh, D.A. (2007). Image theory, goal incompatibility, and retirement intent. International Aging and Human Development, 65 (3), 203 229.

Brown, A. D., \& Starkey, K. (2000, January). Organization learning and identity: a psychodynamic perspective. Academy of Management Review, 25 (1), 102 120.

Bryant, C.G.A. \& Jary, D. (Eds.) (1991). Giddens' theory of structuration: a critical appreciation. New York: Routledge.

Bryant, C.G.A. \& Jary, D. (Eds.) (1997). Anthony Giddens: critical assessments. New York: Routledge.

Campbell, D. T. (1965). Ethnocentric and other altruistic motives. In D. Levine (Ed.), Nebraska symposium on motivation, (pp. 283-301). Lincoln: University of Nebraska Press. 
Connolly, T. \& Beach, L.R. (1998). The theory of image theory: an examination of the central conceptual structure. In L. R. Beach (Ed.), Image Theory: Theoretical and Empirical Foundations. (pp. 249-259). Mahwah, NJ: Lawrence Elbaum Associates.

Cooley, C.H. (2004). Human nature and the social order. Excerpted in Hatch, M.J. and Schultz, M. (Eds.) Organizational identity: a reader, (pp. 16-29). New York: Oxford University Press. (Originally published 1902).

Coser, L.A. (1964). The functions of social conflict $\left(2^{\text {nd }}\right.$ Ed.). New York: Free Press.

Cox, T. H. Jr. (1996). Intergroup conflict. In J.M. Shafritz, and J.S. Ott, (Eds.) Classics of organization theory ( $4^{\text {th }}$ ed.), (pp. 192-202). Orlando, FL: Harcourt Brace College Publishers. (Originally published in 1993.)

Craib, I. (1997). The problem with people. In C.G.A. Bryant and D. Jary (Eds.), Anthony Giddens: Critical Assessments, (pp. 349-358). New York: Routledge.

Douglas, M.T. (1982). Cultural bias. In M.T. Douglas, in the active voice. (pp. 183254). London: Routledge and Kegan Paul.

Dutton, J. E., \& Dukerich, J. M. (1991, September). Keeping an eye on the mirror: image and identity in organizations. Academy of Management Journal, 34 (3), 517-554.

Dutton, J. E., Dukerich, J. M., \& Harquail, C. V. (1994, June). Organizational images and member identification. Administrative Science Quarterly, 39 (2), 239-263.

Eagly, A.H., Baron, R.A., \& Hamilton, V.L. (Eds.) (2004). The social psychology of group identity and social conflict: theory, application, and practice. Washington, DC: American Psychological Association.

Elsbach, K. D., \& Kramer, R. M. (1996, September). Members' responses to organizational identity threats: encountering and countering the Business Week rankings. Administrative Science Quarterly, 41 (3), 442-476.

Fiol, C.M., Hatch, M.J., \& Golden-Biddle, K. (1998). Organizational culture and identity: what's the difference anyway? In D.A. Whetten and P.C. Godfrey (Eds.). Identity in Organizations: Building Theory through Conversations (pp. 56-59). Thousand Oaks, CA: Sage Publications. 
Fox-Wolfgramm, S. J., Boal, K. B., \& Hunt, J. G. (1998, May). Organizational adaptation to institutional change: a comparative study of first order change in prospector and defender banks. Administrative Science Quarterly, 43 (1), 87126.

Giddens, A. (1976). New rules of sociological method: a positive critique of interpretive sociologies. New York: Basic Books, Inc.

Giddens, A. (1979). Central problems in social theory: action, structure, and contradictions in social analysis. Berkeley, CA: University of California Press.

Giddens, A. (1984). The constitution of society: outline of the theory of structuration. Berkeley, CA: University of California Press.

Giddens, A. (1989). A reply to my critics. In D. Held and J.B. Thompson (Eds.), Social Theory of Modern Societies, Anthony Giddens and his Critics, (pp. 249301). Newcastle, GB: University of Cambridge Press.

Gioia, D. A., \& Thomas, J. B. (1996, September). Identity, image, and issue interpretation: sensemaking during strategic change in academe. Administrative Science Quarterly, 41 (3), 370-403.

Gioia, D. A., Schultz, M., \& Corley, K. G. (2000a, January). Organizational identity, image, and adaptive instability. The Academy of Management Review, 25 (1), 63-81.

Gioia, D. A., Schultz, M., \& Corley, K. G. (2000b, January). Where do we go from here? The Academy of Management Review, 25 (1), 145-147.

Goffman, E. (2004). The presentation of self in everyday life. In M.J. Hatch and J. Schultz (Eds.). Organizational Identity: A Reader (pp. 33-55). New York: Oxford University Press. (Originally published 1959.)

Golden-Biddle, K., \& Rao, H. (1997, Nov/Dec). Organizational identity and conflicts of commitment in a non-profit organization. Organization Science, 9 (6), 593611.

Gregory, D. (1989). Presences and absences: Time-space relations and structuration theory. In D. Held and J.B. Thompson (Eds.), Social Theory of Modern Societies, Anthony Giddens and his Critics, (pp. 185-214). Newcastle, GB: University of Cambridge Press. 
Gregson, N. (1989). On the (ir) relevance of structuration theory to empirical research. In D. Held and J.B. Thompson (Eds.). Social Theory of Modern Societies, Anthony Giddens and his Critics, (pp. 235-244). Newcastle, GB: University of Cambridge Press.

Gustafson, L. T., \& Reger, R. K. (1995). Using organization identity to achieve stability and change in high velocity environments. Academy of Management Journal, [Special Volume / Issue: Best Papers Proceedings 1995], 464-471.

Hatch, M.J. \& Schultz, M. (Eds.) (2004). Organizational identity: a Reader. New York: Oxford University Press.

Hatch, M.J. \& Schultz, M. (2004a). Introduction. In M.J. Hatch and J. Schultz (Eds.). Organizational identity: a reader (pp. 1-6). New York: Oxford University Press.

Hatch, M.J. \& Schultz, M. (2004b). Introductions to parts I, II, and III. In M.J. Hatch and J. Schultz (Eds.). Organizational identity: a reader (pp. 9-15, 83-88, and 265-272). New York: Oxford University Press.

Held, D. (1989). Citizenship and autonomy. In D. Held and J.B. Thompson (Eds.), Social theory of modern societies, Anthony Giddens and his critics, (pp. 162184). Newcastle, GB: University of Cambridge Press.

Held, D. \& Thompson, J.B. (Eds.). (1989). Social theory of modern societies: Anthony Giddens and his critics. Newcastle, GB: University of Cambridge Press.

Hogg, M.A. \& Terry, D.J. (Eds.). (2001). Social identity processes in organizational contexts. Ann Arbor, MI: Sheridan Books.

Jacobson, G.C. (2010, Spring). Perception, memory, and partisan polarization on the Iraq War. Political Science Quarterly, 125 (1), 31-56.

Jary, D. (1991). Society as time-traveler: Giddens on historical change, historical materialism, and the nation-state in world society. In C.G.A. Bryant and D. Jary (Eds.), Giddens' Theory of Structuration: A Critical Appreciation, (pp. 116-159). New York: Routledge.

Jones, M. (1999). Structuration theory. In W. Currie and B. Galliers (Eds.). Rethinking Management Information Systems: An Interdisciplinary Perspective (pp. 103-135). New York: Oxford University Press. 
Kemmis, D. (1990). Community and the politics of place. Norman, OK: University of Oklahoma Press.

Kunda, Z. (1990). The case for motivated reasoning. Psychological Bulletin, 108 (3), 480-498.

Mead, G.H. (2004). Mind, self, and society. In Hatch, M.J. and Schultz, M. (Eds.). Organizational Identity: A Reader, (pp. 30-34). New York: Oxford University Press. (Originally published 1934.)

Miner, J.B. (2005). Organizational behavior 2: essential theories of process and structure. New York: M.E. Sharpe, Inc.

Miner, J.B. (2006). Organizational behavior 3: historical origins, theoretical foundations, and the future. New York: M.E. Sharpe, Inc.

Mitchell, T.R., Rediker, K.J., \& Beach, L.R. (1986). Image theory and organizational decision making. In H.P. Sims Jr. and D.A. Goia (Eds.), The Thinking Organization: Dynamics of Organization Social Cognition. (pp. 293-316). San Francisco, CA: Jossey-Bass.

Powers, C.H. (1988, Jun.). Review: the constitution of society by Anthony Giddens. Social Forces, 66 (4), 1124-1125. Published by the University of North Carolina Press.

Pratt, M.G., \& Foreman, P.O. (2000, January). Classifying managerial responses to multiple organizational identities. Academy of Management Review, 25 (1), $18-42$.

Pruitt, D.G. \& Kim, S.H. (2004). Social conflict: escalation, stalemate, and settlement $\left(3^{\text {rd }}\right.$ Ed.). New York: McGraw-Hill.

Sabatier, P.A. \& Jenkins-Smith (Eds.), H.C. (1993). Policy change and learning: an advocacy coalition approach. Boulder, CO: Westview Press.

Scott, S. G., \& Lane, V. R. (January, 2000). A stakeholder approach to organization identity. Academy of Management Review, 25 (1), 43-62.

Schein, E. H. (2004). Organizational culture and leadership ( $3^{\text {rd }}$ Ed.). San Francisco: Jossey-Bass.

Shafritz, J.M. and Ott, J.S. (Eds.) (1996). Classics of organization theory ( $4^{\text {th }}$ Ed.). Orlando, FL: Harcourt Brace College Publishers. 
Sztompka, P. (1991). Society in action: the theory of social becoming. Chicago: University of Chicago Press.

Tajfel, H. \& Turner, J.C. (2004). An integrative theory of intergroup relations. . Excerpted in Hatch, M.J. and Schultz, M. (Eds.) Organizational Identity: A Reader, (pp. 56-65). New York: Oxford University Press. (Originally published 1979).

Urry, J. (1991). Time and space in Giddens' social theory. In C.G.A. Bryant and D. Jary (Eds.), Giddens' Theory of Structuration: A Critical Appreciation, (pp. 160-175). New York: Routledge.

Weatherly, K.A. \& Beach, L.R. (1998). Organizational culture and decision making. In L. R. Beach (Ed.). Image Theory: Theoretical and Empirical Foundations (pp. 211-225). Mahwah, NJ: Lawrence Elbaum Associates.

Whetten, D.A., \& Godfrey, P.C. (Eds.). (1998) Identity in Organizations: Building Theory through Conversations. Thousand Oaks, CA: Sage Publications.

Willmott, H.C. (1997). Unconscious sources of motivation in the theory of the subject: an exploration and critique of Giddens' dualistic models of action and personality. In C.G.A. Bryant and D. Jary (Eds.), Anthony Giddens: Critical Assessments, (pp. 167-184). New York: Routledge.

Zamora, M.D. (1985, Sep.). Book review: the constitution of society by Anthony Giddens. Man, new series, 20 (3), 567-568. Published by the Royal Anthropological Institute of Great Britain and Ireland.

\section{Methodological Approaches}

Babbie, E.R. (2001). Content analysis. In E.R. Babbie, The practice of social research (9 $\left.9^{\text {th }} \mathrm{Ed}\right)$, (pp. 304-315). Belmont, CA: Wadsworth Thomson Learning.

Berg, B. L. (1999). An introduction to content analysis. In B. L. Berg, Qualitative research methods for the social sciences $\left(2^{\text {nd }} E d\right)$. Boston, MA: Allyn and Bacon.

Johnson, R.B. (1999). Examining the validity structure of qualitative research. Appendix A in Milinki, A.K. (Ed.), Cases in Qualitative Research: Research Reports for Discussion and Evaluation (pp. 160-165). Los Angeles: Pyrczak Publishing. 
Krefting, L. (1999). Rigor in qualitative research: the assessment of trustworthiness. Appendix C in Milinki, A.K. (Ed.), Cases in Qualitative Research: Research Reports for Discussion and Evaluation, (pp. 173-181). Los Angeles: Pyrczak Publishing.

Lincoln, Y.S. \& Guba, E.G. (2002). Judging the quality of case study reports. In A. M. Huberman and M. B. Miles (Eds.). The qualitative researcher's companion, (pp. 205-215). Thousand Oaks, CA: Sage Publications.

Maxwell, J.A. (2002). Understanding and validity in qualitative research. In A. M. Huberman and M. B. Miles (Eds.). The qualitative researcher's companion, (pp. 37-64). Thousand Oaks, CA: Sage Publications.

Patton, M.Q. (2002). Qualitative interviewing. M. Q. Patton, Qualitative Research and Evaluative Methods ( ${ }^{\text {rd }}$ Ed.). New York: Sage Publications.

Ritchie, J. \& Spencer, L. (2002). Qualitative data analysis for applied policy research. In Huberman and Miles (eds.) The Qualitative Researcher's Companion (pp. 305-330). Thousand Oaks, CA: Sage Publications.

Schofield, J.W. (2002). Increasing the generalizability of qualitative research. In A. M. Huberman and M. B. Miles (Eds.). The qualitative researcher's companion, (pp. 171-203). Thousand Oaks, CA: Sage Publications. 